\title{
Hidden in Plain Sight: \\ Manager-Employee Social Engagement Strategies
}

\author{
BY \\ MAREE ANNE FOLEY \\ A thesis \\ Doctor of Philosophy in Management
}

submitted to the Victoria University of Wellington

in fulfilment of the requirements for the degree of

Victoria University of Wellington

2014 


\begin{abstract}
Employee engagement occurs at the 'swirling intersection' (Kahn, 1990, p. 719) of the manager-employee relationship; a multidimensional engagement relationship. However, research to date has focused on examining employees' engagement relationships with their role, work or organisation, emphasising linear and transactional aspects of engagement. Interpersonal oriented research has been under-used to explore engagement.
\end{abstract}

In this study, attachment theory is used as a social systems theory to examine the manager-employee interpersonal relationship as a means to understand engagement. Attachment theory research has identified strategic patterns of interaction within close relationships that have been associated with optimising the quality of exploration outside of these relationships. Attachment theory informed workplace research has identified individual differential use of attachment patterns at work with differences in engagement. However, different patterns of attachment in relation to engagement (a potential form of exploration) have yet to be examined within the interpersonal context of the manageremployee relationship. In this study it is proposed that managers and employees might: socially interact with each other when under pressure in unique and strategically patterned ways; and that these interaction patterns might also influence engagement.

This thesis asks: how do managers and employees strategically manage their relationship to optimise their engagement at work? A sequential explanatory mixed methods design study is conducted. Attachment theory methods inform the development of a new concept and measure: manager-employee social engagement strategies. This measure is quantitatively tested in a survey study with managers $(n=200)$ and employees $(n=200)$. The quantitative survey is used to generate qualitative and interpersonal data about manager-employee social engagement strategies and engagement within a series of five qualitatively oriented case studies with manager-employee dyads. 
Quantitative analysis indicates three manager and three employee social engagement strategy measures. These measures each uniquely correlate with perceptions about engagement, such as job and organisation engagement. Qualitative findings from the manager-employee dyads show (when under pressure) that they employ various combinations of social strategies to engage with each other; including a possible fourth strategy. In turn, these strategies are both influenced by, and influence, engagement.

In conjunction with the literature, these findings are formulated into the central contribution of this study: an attachment theory informed framework of manageremployee engagement. This multidimensional framework reconceptualises engagement as a dynamic system and centralises the interpersonal dimension; represented by the manager-employee relationship. This framework specifies simultaneous and multi-directional associations between (a) how managers and employees engage with each other, (b) their perceptions of engagement and attachment, and (c) their engagement.

This research has theoretical and practical implications for the training and coaching of managers and employees. It highlights knowledge currently hidden in plain sight within the engagement field that can be used to change: how we interact with each other when under pressure and stress as a route to changing our perceptions about engagement; and our engagement. This research confirms the relevance of a future research agenda that places the manager-employee relationship at the centre of engagement. 


\section{Acknowledgements}

A lot of living occurs in a family under ordinary circumstances, let alone when a $\mathrm{PhD}$ comes to stay for a few years! Dave, Theo and Flynn, you have been extraordinarily supportive to me and to each other as I have been engaged and immersed in this research. Thank you.

Thank you, Associate Professor Jane Bryson and Dr Geoff Plimmer, my supervisors. I thank you for your wisdom and commitment to this project, your patience with my meanderings down various theoretical and methodological alleys, your expertly placed questions and wonderings, your knowledge of the process and your confidence that I would at some stage emerge with this project somewhere near the finish line.

Thank you Dr Dalice Sim (statistical consultant) Victoria University of Wellington, for your expert advice and review of the statistical findings of this study.

Thank you to Associate Professor Christa Fouche (University of Auckland) and Dr Giles St Burch (University of Auckland) for getting me started on my PhD journey. Thank you to the Victoria School of Management support staff, Sam Farmer, my coaching psychology coach, colleagues and friends.

I gratefully acknowledge the financial support afforded to me via the following scholarships: A Tertiary Education Commission Top Achievers Doctoral Scholarship, a Shirtcliffe Doctoral Fellowship, and a Victoria University of Wellington Doctoral Scholarship. These scholarships enabled me to study full time.

I acknowledge the services of Elite Editing who conducted the final edit of this thesis according to the Proofreading and Editing Policy and Guidelines of Victoria University of Wellington. 


\section{Contents}

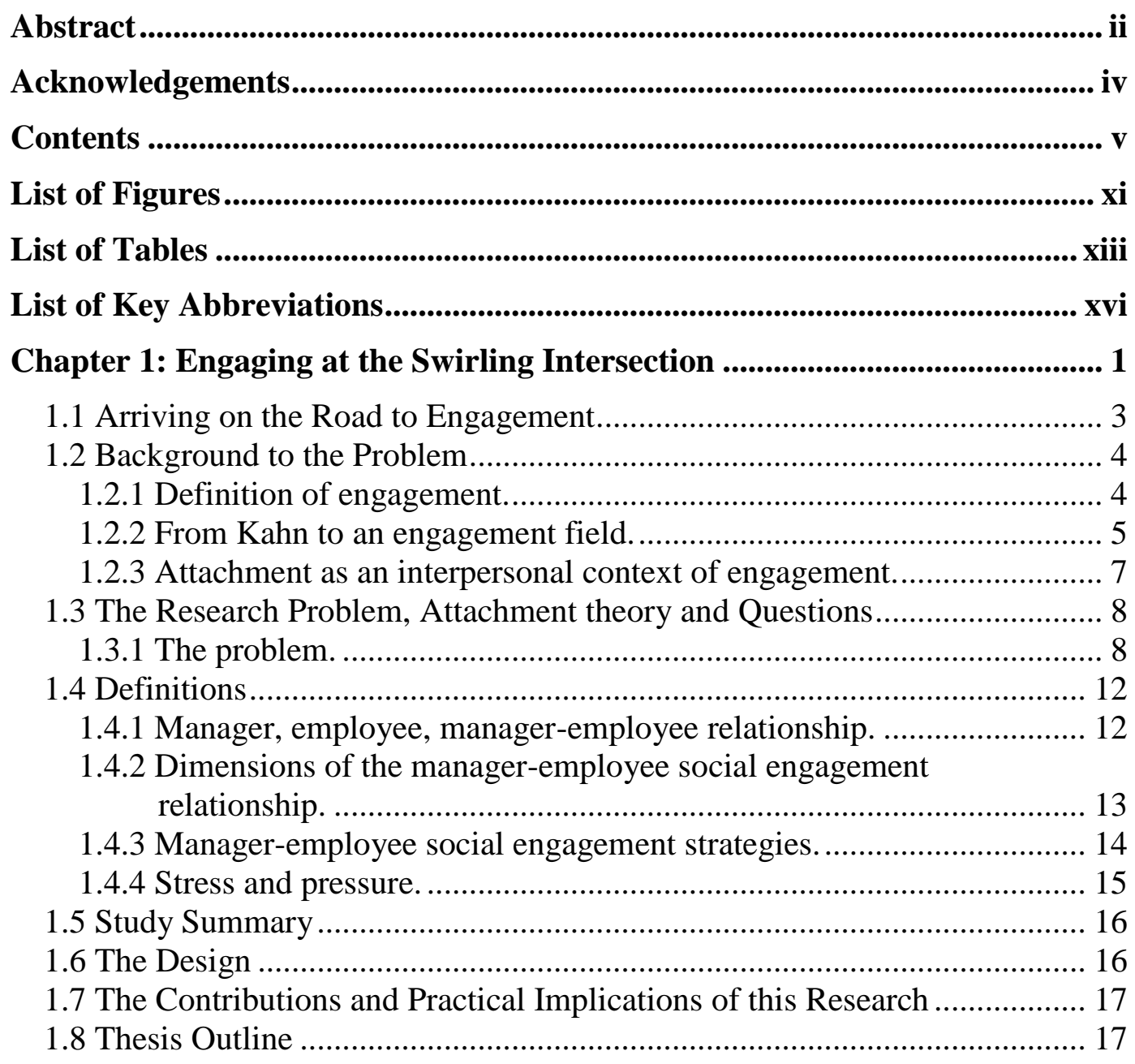

Chapter 2: Engagement, the Manager-Employee Relationship and Attachment Theory ........................................................................................ 19

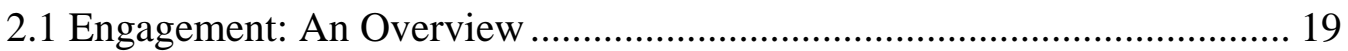

2.1.1 Engagement and context: a multidimensional concept..................... 20

2.1.1.1 Internal dimension. ................................................................... 20

2.1.1.2 Interpersonal dimension.......................................................... 26

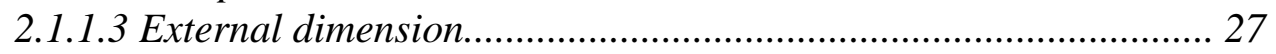

2.2 Engagement and the Manager-Employee Relationship ........................... 28

2.2.1 The manager-employee relationship as a driver of engagement......... 28

2.2.2 Leader-member exchange theory: engagement and the manager-

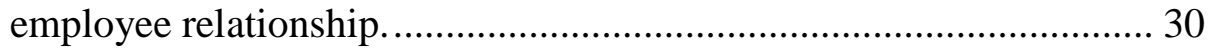

2.2.3 The interpersonal manager-employee relationship and engagement... 32

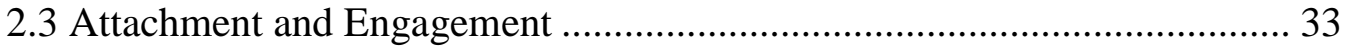

2.3.1 Kahn: attachment and engagement. ............................................... 34

2.3.2 Subsequent descriptions: attachment and engagement. ..................... 35

2.4 Increasing Levels of Engagement .......................................................... 39

2.5 Problem Statement and Research Questions ............................................ 42

2.6 Attachment theory: A Multidimensional Theory ...................................... 43

2.6.1 The internal dimension: the internal working model of the secure base system. 
2.6.2 The interpersonal dimension: secure base use and provision. ............ 44

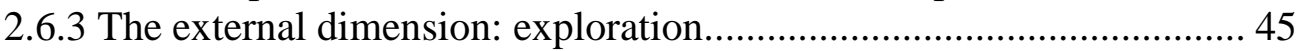

2.6.4 Patterns of attachment.................................................................... 47

2.6.1 Secure base strategies and goal sharing. .......................................... 51

2.7 Engagement: A Multidimensional System............................................. 51

2.8 Manager-Employee Social Engagement Strategies: A Multidimensional

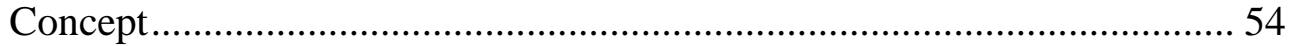

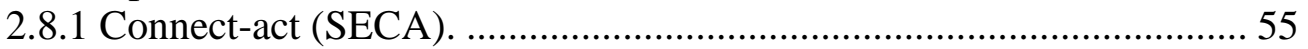

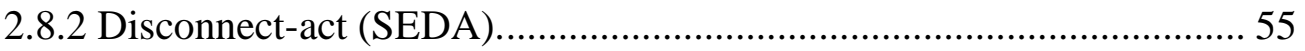

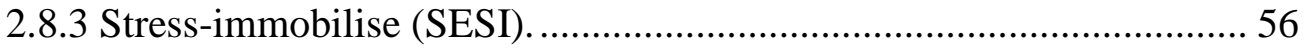

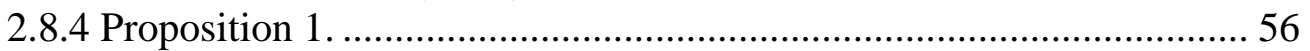

2.8.5 Additional propositions and hypotheses. ...................................... 57

2.8.6 Manager-employee social engagement strategies: pressure and

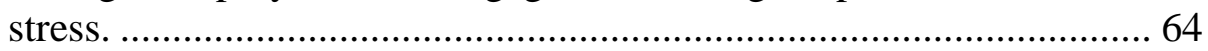

2.8.7 Manager-employee social engagement strategies and organisational

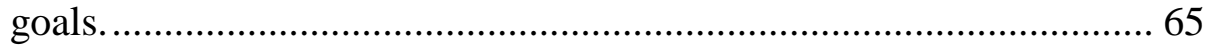

2.8.8 Manager-employee social engagement strategies and engagement..... 66

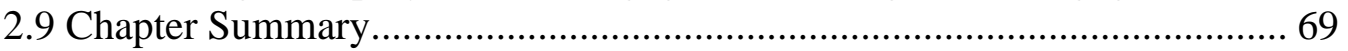

Chapter 3: Methodology ...................................................................................................... 71

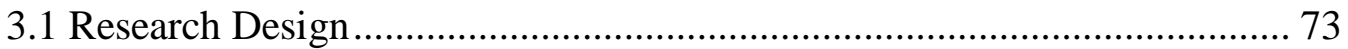

3.2 Manager-Employee Social Engagement Survey.................................... 74

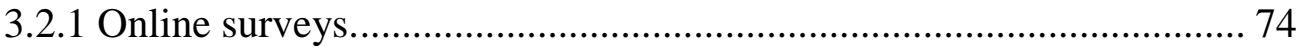

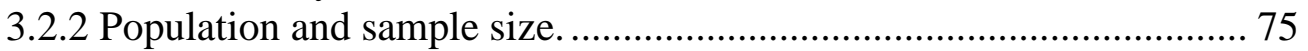

3.2.2.1 Population ............................................................................ 75

3.2.2.2 Sample size ........................................................................... 76

3.2.3 Manager-employee social engagement scale development. ................. 77

3.2.3.1 Scale development step 1: item generation and item review........ 78

3.2.3.2 Scale development step 2: pre-questionnaire administration....... 82

3.2.3.3 Scale development step 3a: survey refinement........................... 82

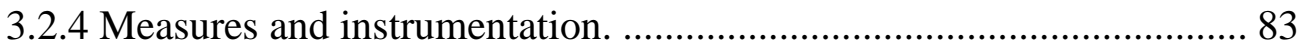

3.2.4.1 Manager-employee social engagement strategies. ..................... 84

3.2.4.2 Perceived organisational support............................................. 84

3.2.4.3 Perceived supervisor support.................................................. 85

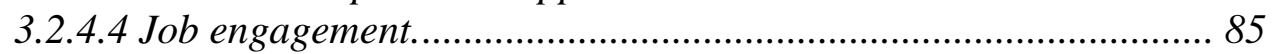

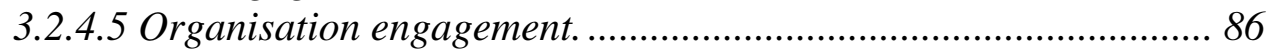

3.2.4.6 Organisational commitment .................................................... 86

3.2.4.7 Intention to quit and turnover. ............................................... 87

3.2.4.8 The relationship questionnaire .............................................. 88

3.2.5 Distributing the survey: scale development step 3b........................ 89

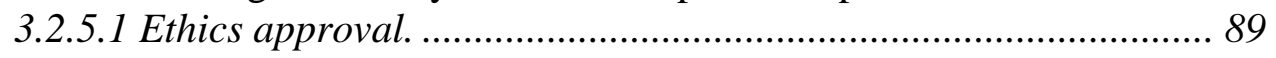

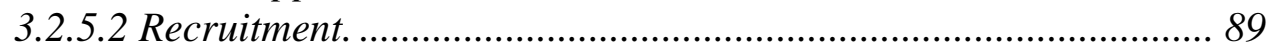

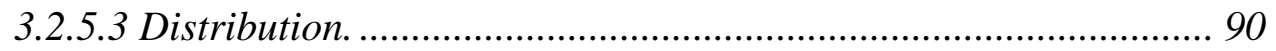

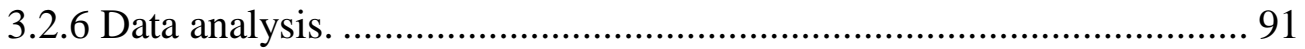

3.2.6.1 Data analysis preparation and sample size. ............................. 92

3.2.6.2 Exploratory factor analysis.................................................... 93

3.2.6.3 Correlation analysis.............................................................. 96

3.2.6.4 Path analysis. ....................................................................... 96

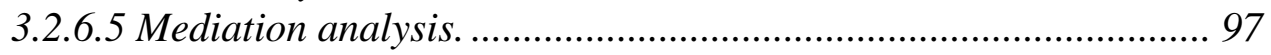

3.3 Intermediary Research Phase ........................................................... 98 


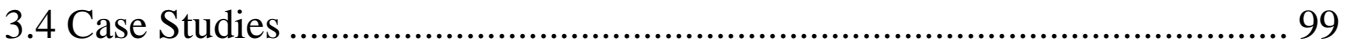

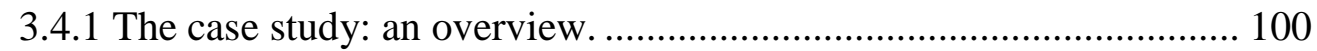

3.4.2 Philosophical underpinnings and rigor. ........................................ 100

3.4.3 Case boundaries, recruitment and sample size.............................. 102

3.4.3.1 Case boundaries.................................................................. 102

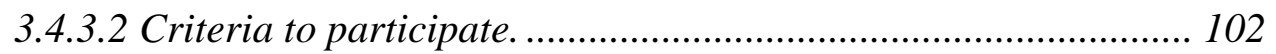

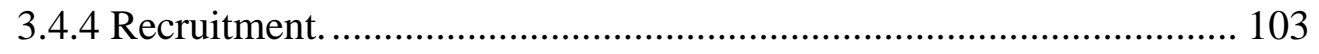

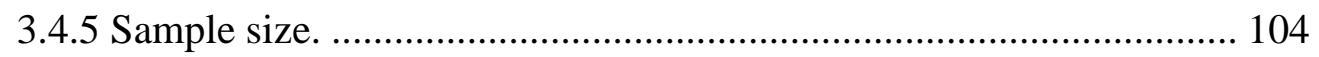

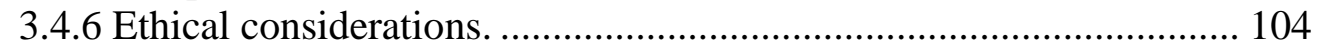

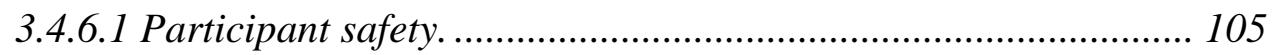

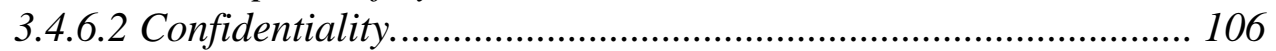

3.4.6.3 Data storage/retention/destruction/future use .......................... 106

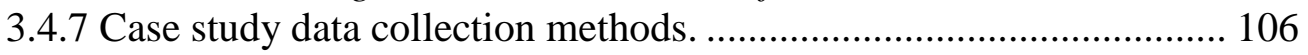

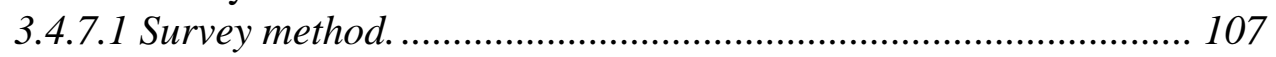

3.4.7.2 In-depth and semi-structured interviews................................. 107

3.4.7.3 Participant document review. ................................................. 108

3.4.8 Case study data collection procedures. .......................................... 109

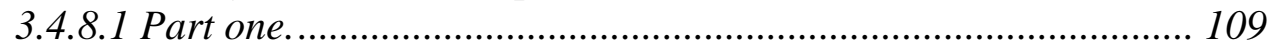

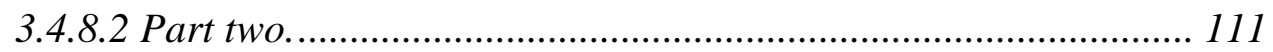

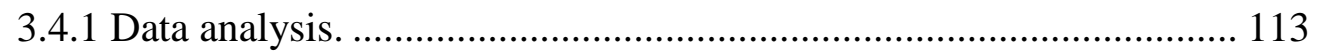

3.4.1.1 Data analysis during data collection. ....................................... 113

3.4.1.2 Thematic analysis.................................................................. 114

3.5 Inter-Case Comparison and Integrative Theoretical Analysis ................. 116

3.5.1 Inter-case comparison and analysis............................................... 116

3.5.1.1 Integrative theoretical analysis............................................ 117

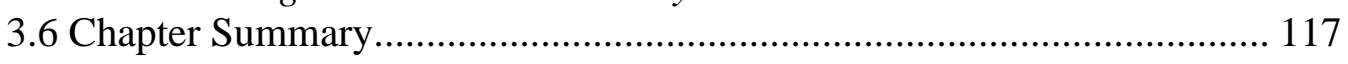

Chapter 4: NZ Manager-Employee Social Engagement Survey Findings .. 119

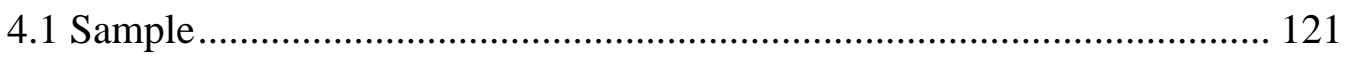

4.2 Scale Development....................................................................... 124

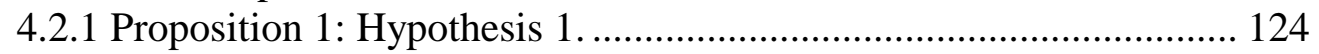

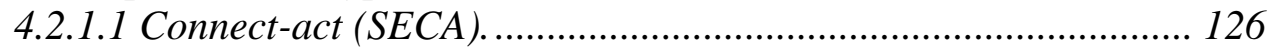

4.2.1.2 Stress-immobilise .................................................................... 131

4.2.1.3 Disconnect-act (SEDA) ........................................................... 133

4.2.1.4 Overview of new manager-employee social engagement scales. 135

4.2.1.5 Hypothesis 1: Summary. .......................................................... 140

4.2.2 Proposition 1: Hypothesis 2.................................................... 142

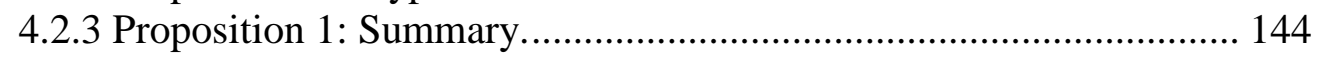

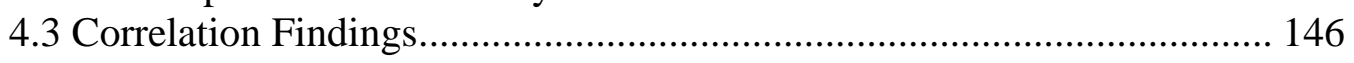

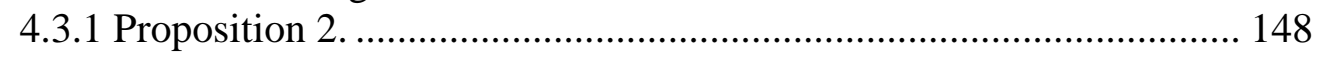

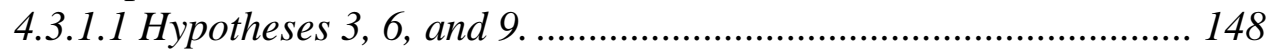

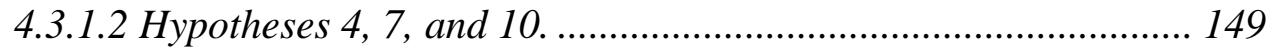

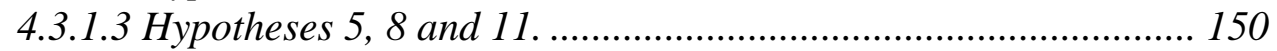

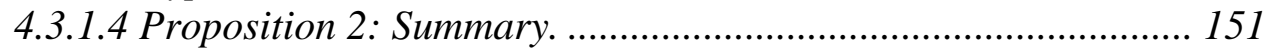

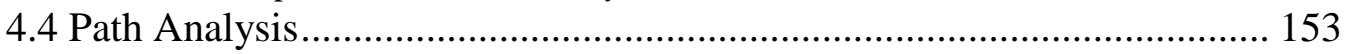

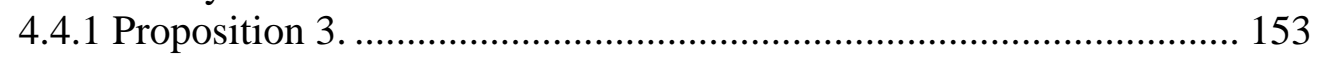

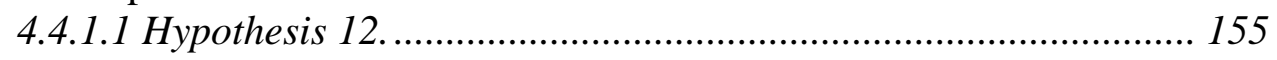

4.4.1.2 Proposition 3: Summary. ........................................................ 159

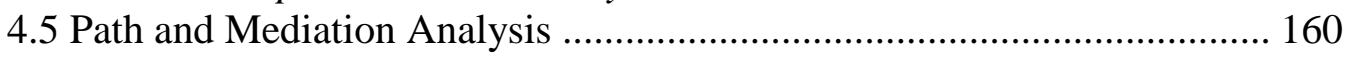

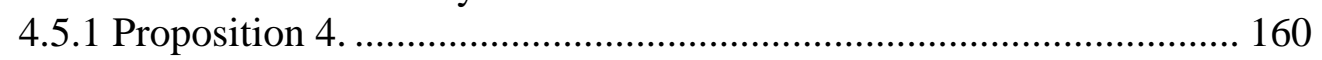




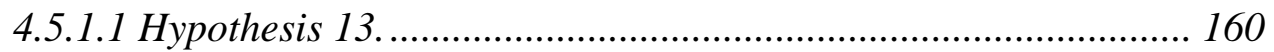

4.5.1.2 Hypothesis 14................................................................. 166

4.5.1.3 Proposition 4: Summary. ......................................................... 173

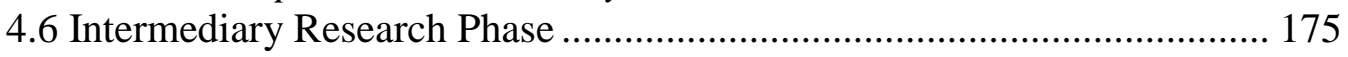

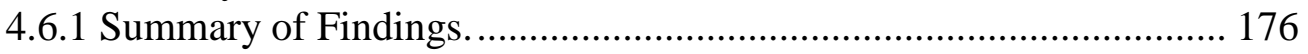

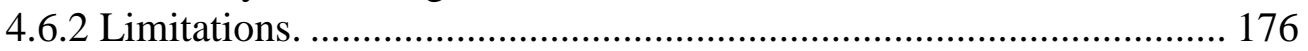

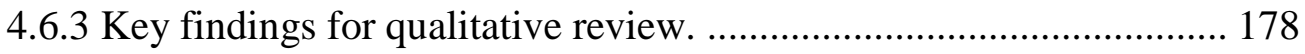

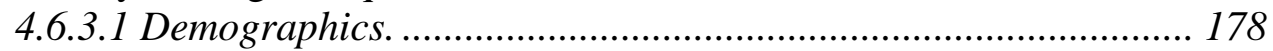

4.6.3.2 Manager-employee social engagement .................................... 180

4.6.3.3 Manager-employee social engagement models of engagement. . 182

4.7 Chapter Summary............................................................................... 183

Chapter 5: MESE Strategy Case Study Findings ........................................... 185

5.1 Introducing the Manager-Employee Dyads ............................................. 185

5.1.1 Case Studies: Part one................................................................. 187

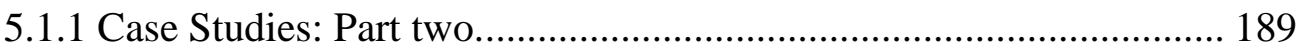

5.1.2 Reporting of findings: Structure. ................................................. 189

5.2 Case Study 1: Hemi and Sione .............................................................. 190

5.2.1 Manager-employee social engagement survey patterns.................... 190

5.2.2 Manager-employee social engagement experiences......................... 191

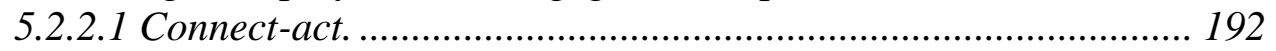

5.2.2.2 Disconnect-act .......................................................................... 192

5.2.2.3 Shifting from disconnect-act to connect-act.............................. 192

5.2.2.4 Stress-immobilise and connect-act (connection). ...................... 192

5.2.2.5 Disconnect-act and stress-immobilise meets connect-act.......... 193

5.2.3 Connect-act and secure attachment................................................. 194

5.2.3.1 Disconnect-act and dismissing-avoidant attachment................. 195

5.2.4 Manager-employee social engagement and engagement

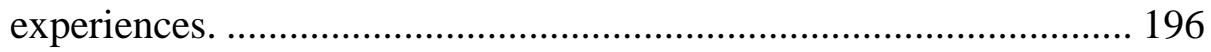

5.2.5 Connect-act and perceived organisational support. ......................... 197

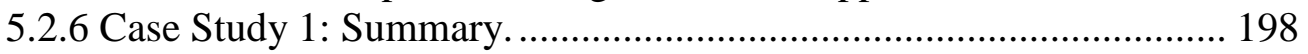

5.3 Case Study 2: Peter and Abby .............................................................. 199

5.3.1 Manager-employee social engagement survey patterns.................... 199

5.3.2 Manager-employee social engagement experiences........................ 200

5.3.2.1 Stress-immobilise and secure attachment .................................. 200

5.3.2.2 Connect-act and secure attachment........................................ 201

5.3.2.3 Stress-immobilise and preoccupied attachment......................... 203

5.3.2.4 From stress-immobilise to connect-act.................................... 204

5.3.3 Peter and Abby: a manager-employee social engagement connectact secure base system. ................................................................ 204

5.3.4 Manager-employee social engagement and engagement

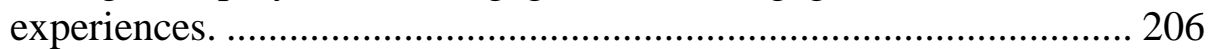

5.3.4.1 Connect-act and perceived organisational support................... 207

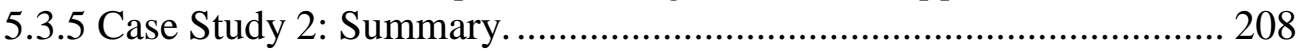

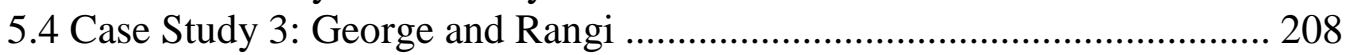

5.4.1 Manager-employee social engagement survey patterns.................... 209

5.4.2 Manager-employee social engagement experiences........................ 210

5.4.2.1 Connect-act and disconnect-act ................................................ 210

5.4.2.2 Connect-act. ........................................................................ 212 
5.4.2.3 A possible fourth manager-employee social engagement strategy.

5.4.3 Manager-employee social engagement and engagement

experiences.

5.4.4 Case Study 3: Summary........................................................... 217

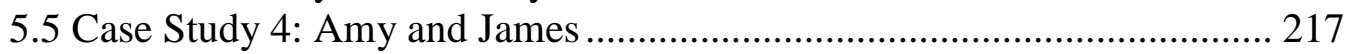

5.5.1 Manager-employee social engagement survey patterns..................... 218

5.5.2 Manager-employee social engagement experiences....................... 219

5.5.2.1 Connect-act and secure attachment........................................ 219

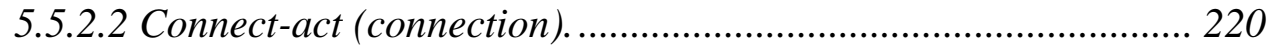

5.5.2.3 Connect-act meets connect-act. ............................................... 221

5.5.3 Manager-employee social engagement and engagement

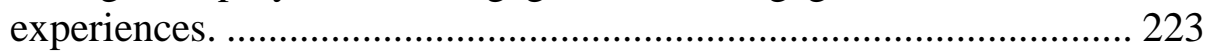

5.5.3.1 Connect-act, connect-act (support received) and perceived organisational support........................................................ 224

5.5.4 Case Study 4: Summary............................................................ 225

5.6 Case Study 5: Donald and Cathy ....................................................... 225

5.6.1 Manager-employee social engagement strategy survey patterns...... 226

5.6.2 Manager-employee social engagement experiences........................ 228

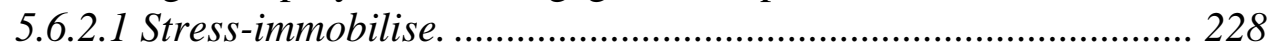

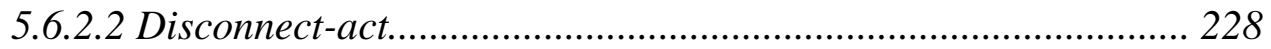

5.6.2.3 Stress-immobilise and fearful-avoidant attachment. ................. 229

5.6.2.4 Disconnect-act and secure attachment. .................................... 230

5.6.3 Manager-employee social engagement and engagement

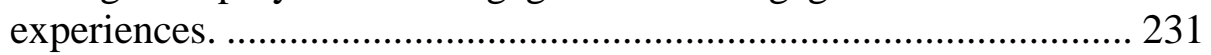

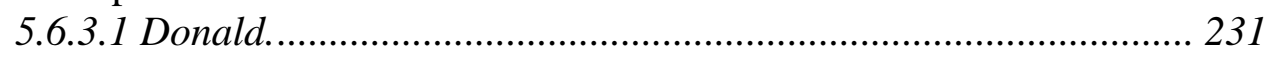

5.6.3.2 Cathy.................................................................................... 232

5.6.3.3 Donald and Cathy: Perceived organisational support.............. 232

5.6.3.4 From connect-act to disconnect-act........................................... 233

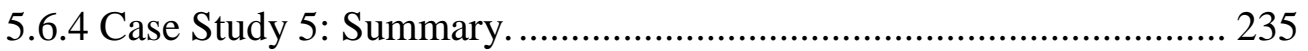

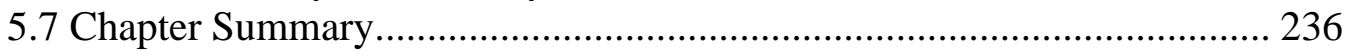

Chapter 6: Discussion ................................................................................ 239

6.1 Inter-Case Comparison of Manager-Employee Social Engagement

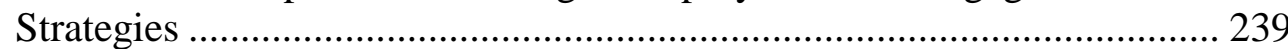

6.1.1 Cross-case descriptions of the manager-employee social

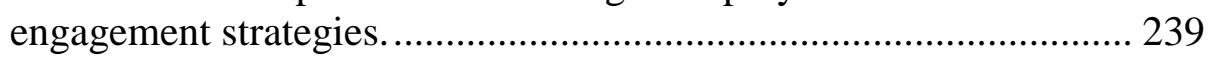

6.1.1.1 Connect-act..................................................................... 241

6.1.1.2 Disconnect-act (SEDA) ...................................................... 244

6.1.1.3 Stress-immobilise (SESI)...................................................... 248

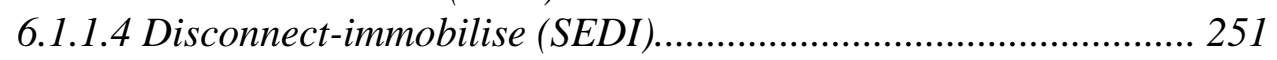

6.1.2 Patterns of MESE strategy use and engagement............................. 254

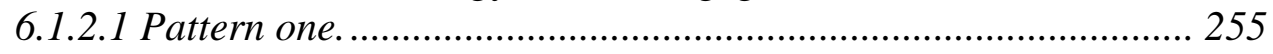

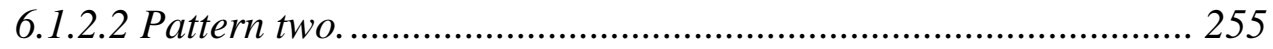

6.1.3 Manager-employee social engagement strategies and dynamic relationships with states of mind about attachment and engagement............................................................................... 256

6.1.3.1 Attachment and the manager-employee social engagement

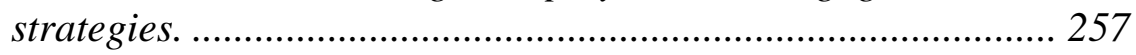

6.1.3.2 Stress-immobilise and the fearful-avoidant attachment............. 258 
6.1.3.3 Manager-employee social engagement strategies, perceived organisational support and attachment. 258

6.1.3.4 Manager-employee social engagement strategies with organisational commitment and the intention to quit/turnover. 260

6.1.4 Summary: inter-case analysis.

6.2 Theoretical Framework: Manager-Employee Engagement ..................... 262

6.2.1 Manager-employee engagement: a multidimensional system. ......... 263

6.2.1.1 Manager-employee social engagement strategies. .................... 266

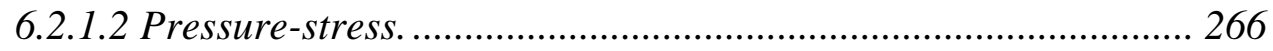

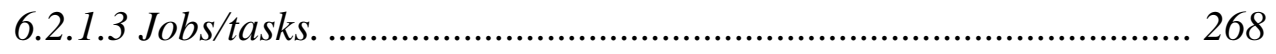

6.2.1.4 Mind states of engagement....................................................... 268

6.2.1.5 Overarching patterns of social engagement and engagement... 269

6.2.1.6 Theoretical framework: a summary..................................... 270

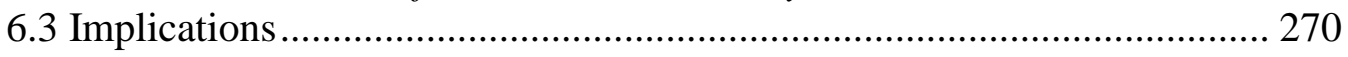

6.3.1 A new explanation for low engagement. ...................................... 270

6.3.2 An alternative route for increasing levels of engagement................. 271

6.3.3 Management training and coaching............................................. 272

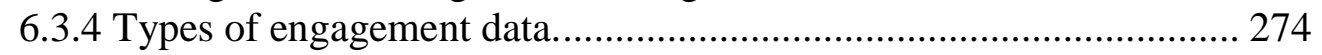

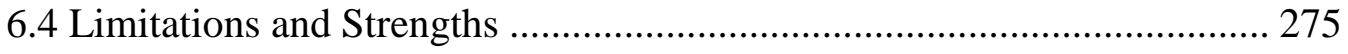

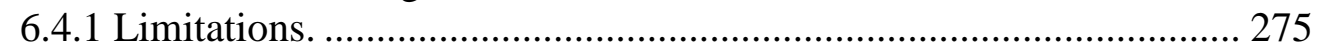

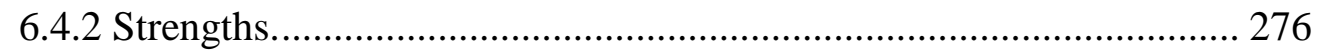

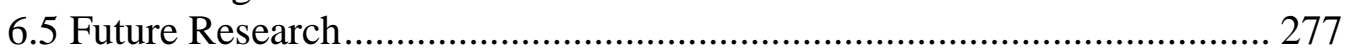

6.5.1 Meso-level engagement research............................................. 278

6.5.2 The manager-employee engagement relationship........................... 278

6.5.3 Keeping stress at bay and pressure in check.................................. 279

6.5.4 Attachment theory and engagement research.............................. 279

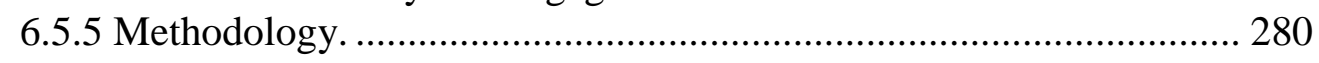

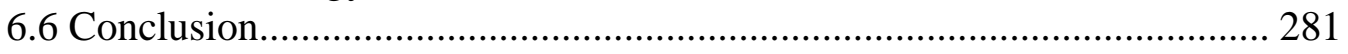

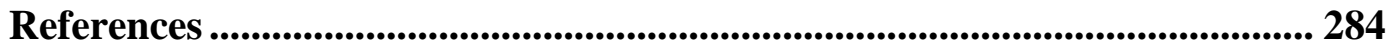

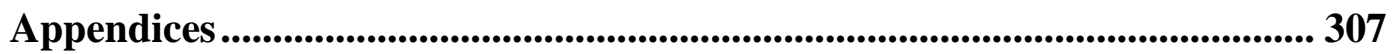




\section{List of Figures}

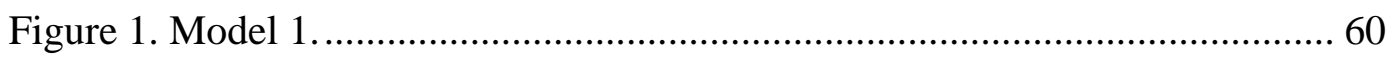

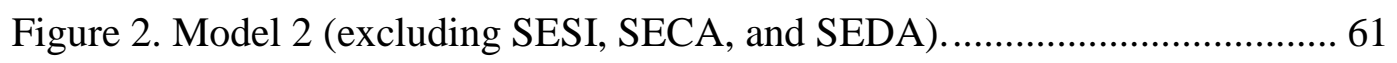

Figure 3. Model 1 A (with SECA and SEDA mediating between JE, OE and

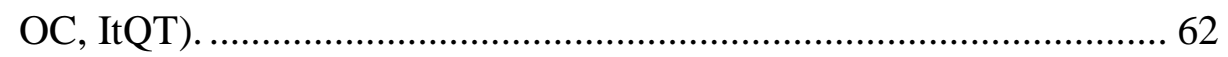

Figure 4. Model 1B. JE and OE mediating between SESI and OC and ItQT...... 63

Figure 5. Summary of the research methodology........................................... 72

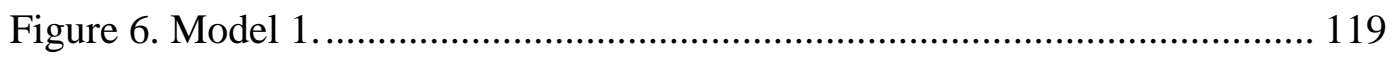

Figure 7. Model 2 (excluding SECA, SEDA, and SESI)............................... 120

Figure 8. Model 1 A (with SECA and SEDA mediating between JE, OE and

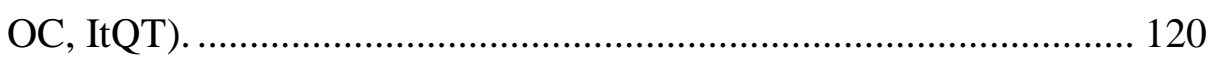

Figure 9. Model 1B. JE and OE mediating between SESI and OC and ItQT.... 120

Figure 10. Manager connect-act scree plot. ..................................................... 126

Figure 11. Employee connect-act scree plot. ................................................... 129

Figure 12. Manager: manager-employee social engagement strategy structure with alpha coefficients. .............................................................. 136

Figure 13. Employee: manager-employee social engagement strategy structure with alpha coefficients.

Figure 14. Model 3 with SESI, SECA and SEDA added in and swapping OC and ItQT with JE and OE.

Figure 15. Model 4. Excluding SESI, SECA and SEDA and swapping OC and ItQT with JE and OE.

Figure 16. Medgraph results: JE, SECA and OC......................................... 162

Figure 17. Medgraph results: JE, SECA, ItQT ............................................. 163

Figure 18. Model 3 Ai additional model testing based on modification indices. 164

Figure 19. Model $3 \mathrm{~A}$ ii additional model testing based on modification indices.

Figure 20. Model 3Aii standardised paths for employee data. .......................... 166

Figure 21. Medgraph results for SESI, JE and OC....................................... 168

Figure 22. Medgraph results for SESI, OE and OC...................................... 169

Figure 23. Model $3 \mathrm{Bi}$ : OC and ItQT mediating between SESI and JE and OE. 170

Figure 24. Model 3Bii. SESI mediating between OC and ItQT and JE and OE. 171

Figure 25. Model 3Bi results for employee data. 
Figure 26. Additional model testing combining Model 3Aii and 3Bi-Model $3 \mathrm{C}$

Figure 27. A theoretical framework of manager-employee engagement. 265 


\section{List of Tables}

Table 1. Individual Attachment Style Behaviours and Levels of Engagement

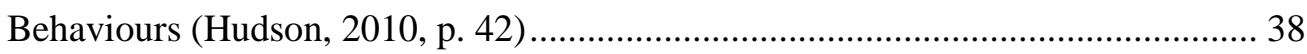

Table 2. Attachment Patterns, Secure Base Use and Secure Base Support............................... 50

Table 3. The Manager-Employee Relationship, Attachment and Engagement: A

multidimensional system of connections............................................................. 53

Table 4. Hypothesised Manager-Employee Social Engagement Strategies: An

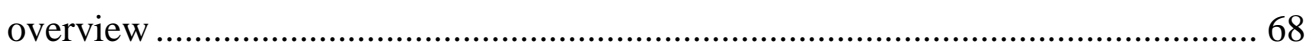

Table 5. Scale Development Process: Manager-Employee Social Engagement

Strategies 77

Table 6. Manager-Employee Social Engagement Strategy Item Development Planner

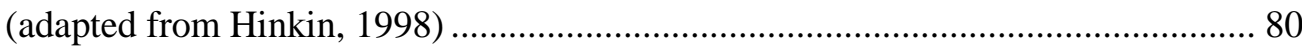

Table 7. Illustrated use of the Tailored Survey Design Method (Dillman et al. 2009) ............... 82

Table 8. Illustrated version of the Tailored Design Scheduling Framework (Dillman

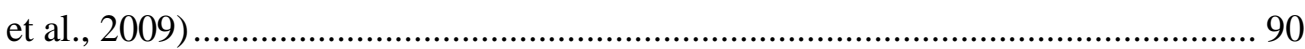

Table 9. Sub-Research Question 1: Hypotheses and Data Analysis Tool Summary .................. 92

Table 10. Computing the RQ Model of Self and Other Dimensions ....................................... 107

Table 11. Summary of Case Study Structure ….......................................................................... 109

Table 12. Part One: Feedback Session Outline ....................................................................... 110

Table 13. Illustrated Interaction with Case Study Participants ................................................ 112

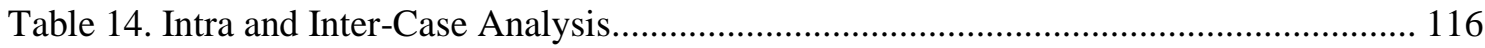

Table 15. Survey Findings Chapter Outline......................................................................... 121

Table 16. Frequencies and Percentages for Demographics ................................................... 122

Table 17. MANOVAs for Variables of Interest by Gender and Ethnicity................................ 122

Table 18. Spearman Correlations between Variables of Interest and Age.............................. 123

Table 19. Manager Connect-Act Eigenvalues and Criterion Values ......................................... 127

Table 20. Manager Connect-Act Pattern Matrix ...................................................................... 127

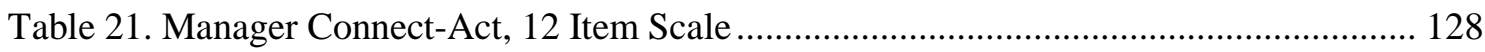

Table 22. Employee Connect-Act Eigenvalues and Criterion Values ...................................... 130

Table 23. Employee Connect-Act Pattern Matrix ........................................................................ 130

Table 24. Employee Connect-Act, 14 Item Scale .................................................................... 131

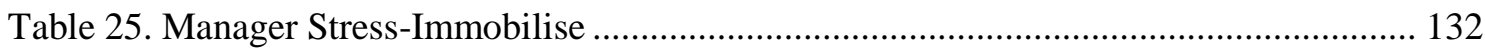

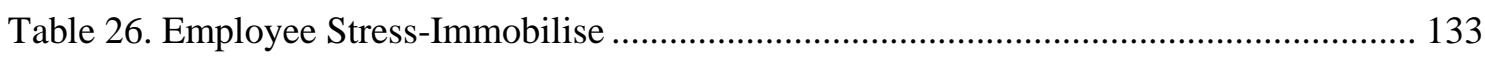

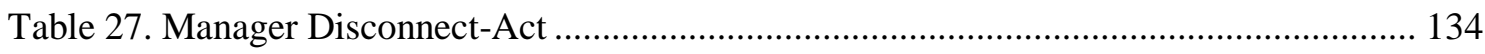

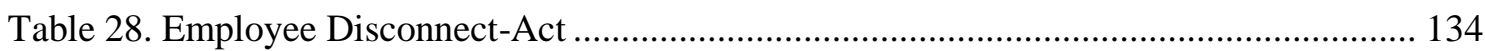


Table 29. Manager and Employee Manager-Employee Social Engagement Scales, Item Numbers, Means and Cronbach's Alpha.

Table 30. Manager Means, Standard Deviations, Reliabilities, and Inter-correlations of Study Variables

Table 31. Employee Means, Standard Deviations, Reliabilities, and Inter-correlations of Study Variables 138

Table 32. Manager and Employee Paired-samples t-tests and eta Squared Statistic 139

Table 33. Manager and Employee Manager-Employee Social Engagement Strategy Scales, Item numbers and Cronbach's Alpha. 140

Table 34. Manager and Employee Manager-Employee Social Engagement Scales 141

Table 35. Relationship Questionnaire Scores, NZ managers and Employees

Comparisons

Table 36. Employee Means, Standard Deviations, and Inter-correlations of the MESE

and RQ Variables

Table 37. Manager Means, Standard Deviations and Inter-correlations of the MESE and RQ Variables

Table 38. Managers and Employees MESE and RQ

Table 39. Manager Means, Standard Deviations, Reliabilities and Inter-correlations of Study Variables

Table 40. Employee Means, Standard Deviations, Reliabilities, and Inter-correlations of Study Variables 147

Table 41. Summary of Significant Associations in Model 1 152

Table 42. Manager and Employee Significant and Non-significant associations and correlation size...

Table 43. Model 1 vs. Model 2 for Manager Data. 155

Table 44. Model 1 vs. Model 2 for Employee Data. 156

Table 45. Model 3 vs. Model 4 for Manager Data. 158

Table 46. Model 3 vs. Model 4 for Employee Data 159

Table 47. Model 1A Criteria Assessment to run Mediation Analysis with the

Manager and Employee Data

Table 48. Model 1A Mediation Results

Table 49. Results from Models 1A, 3Ai and 3Aii for Managers

Table 50. Results from Models 1A, 3Ai and 3Aii for Employees

Table 51. Model 1B Criteria Assessment to run Mediation Analysis with the Manager and Employee Data 167

Table 52. Model 1B: Mediation Results 169

Table 53. Results from Models 1B and 3Bi for Managers 170 


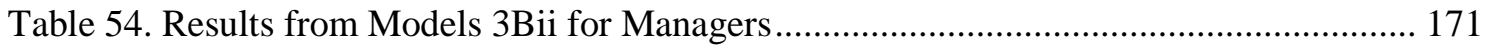

Table 55. Results from Models 1B and 3Bi for Employees ................................................... 171

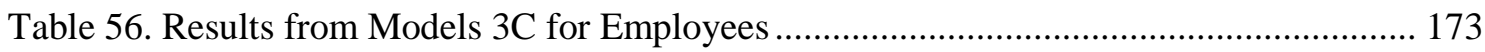

Table 57. Summary of Results from Survey Study Propositions about Sub-Research

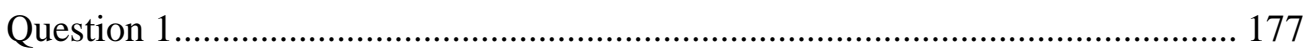

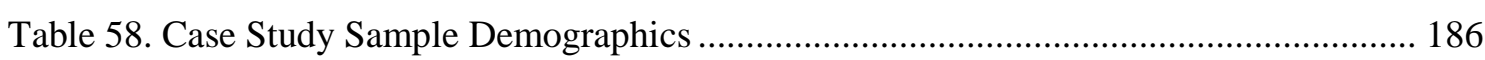

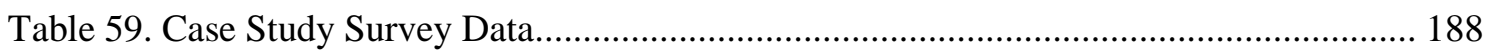

Table 60. Case Study 5 (Donald and Cathy): A Feedback Model of the MESE Survey Results 227

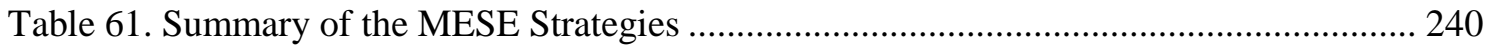

Table 62. Social Engagement Strategy-Engagement Patterns ................................................ 254

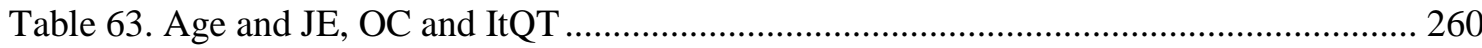




\section{List of Key Abbreviations}

$\begin{array}{ll}\text { CS } & \text { Case Study } \\ \text { CSM } & \text { Case Study Manager } \\ \text { CSE } & \text { Case Study Employee } \\ \text { EFA } & \text { Exploratory Factor Analysis } \\ \text { ItQT } & \text { Intention to Quit Turnover } \\ \text { JE } & \text { Job Engagement } \\ \text { MESE } & \text { Manager-Employee Social Engagement Strategies } \\ \text { NZ } & \text { New Zealand } \\ \text { NZ MESE } & \text { New Zealand Manager-Employee Social Engagement Survey } \\ \text { OC } & \text { Organisational Commitment } \\ \text { OE } & \text { Organisational Engagement } \\ \text { POS } & \text { Perceived Organisational Support } \\ \text { PSS } & \text { Perceived Supervisor Support } \\ \text { RQ } & \text { Relationship Questionnaire } \\ \text { RQDA } & \text { Relationship Questionnaire classification: Dismissing-Avoidant } \\ \text { RQFA } & \text { Relationship Questionnaire classification: Fearful-Avoidant } \\ \text { RQP } & \text { Relationship Questionnaire classification: Preoccupied } \\ \text { RQS } & \text { Relationship Questionnaire classification: Secure } \\ \text { SECA } & \text { Social Engagement Connect-Act } \\ \text { SEDA } & \text { Social Engagement Disconnect-Act } \\ \text { SEDI } & \text { Social Engagement Disconnect-Immobilise } \\ \text { SESI } & \text { Social Engagement Stress-Immobilise } \\ & \end{array}$




\section{Chapter 1: Engaging at the Swirling Intersection}

This study examines the manager-employee relationship as an interpersonal context influencing engagement. The manager-employee relationship has been identified as a driver of engagement (Buckingham \& Coffman, 1999; Gatenby, Alfes, Truss, Rees \& Soane, 2009; MacLeod \& Clarke, 2009); and social context is central to understanding engagement (Alfes, Truss, Soane, Rees \& Gatenby, 2010; Gatenby et al., 2009; Leiter \& Bakker, 2010; Macey \& Schneider, 2008; Shuck \& Wollard, 2010). Emphasising a complex interplay between organisational contexts and engagement, Kahn (1990) proposed that engagement is influenced by 'the swirling intersection' (p. 719) of individual, interpersonal and organisational factors. However, in contrast to research that focuses on interpersonal factors, knowledge development about engagement typically favours a focus on individual and organisational factors.

To examine the manager-employee relationship in association with engagement, I drew on attachment theory (Ainsworth, Blehar, Waters \& Wall, 1978; Ainsworth \& Wittig, 1969; Bowlby, 1969; Cassidy \& Shaver, 2008; Crowell et al., 2002; Mikulincer \& Shaver, 2007). Attachment theory is an interpersonal theory that examines interpersonal strategic variations of help seeking use and help provision that occurs between persons; and that function to optimise exploratory behaviour, such as playing and working.

At the outset of this study I developed an attachment theory informed theoretical framework of engagement. Engagement was defined as 'employment ... in task behaviours' (Kahn, 1990, p. 700). The individual context of engagement was represented by individual workers multidimensional perceptions of their engagement relationships. The interpersonal context was represented by a new concept and measure, developed and tested in this study: manager-employee social engagement strategies. Based on this framework, this study asked: How do managers and employees strategically manage their relationship to optimise their engagement at work?

I addressed this question by employing a sequential explanatory mixed method design (Creswell \& Plano Clark, 2007; Tashakkori \& Creswell, 2007). Consistent with attachment theory, the design was informed by methods of 
examining interpersonal relationships (Ainsworth et al., 1978; Crowell \& Feldman, 1991; Crowell et al., 2002) which I adapted to examine social engagement strategic variations within the interpersonal context of the manageremployee relationship.

The design included a survey study and manager-employee dyad case studies. The primary purpose of the quantitative survey was to generate qualitative and interpersonal data about manager-employee social engagement strategies and engagement. To this end, an online survey was developed and administered to managers and employees in New Zealand across sectors. Data from this survey was used to begin the validation process of the new manager-employee social engagement measures; and to examine relationships between the new measures of social engagement and measures of engagement. Individual quantitative data about social engagement strategies and engagement was then qualitatively explored and analysed within the interpersonal context of the manager-employee dyad case studies.

Study findings highlight multi-directional associations between: (a) differences in interpersonal engagement strategies; (b) perceptions of engagement and attachment; and (c) engagement behaviour. These findings, in conjunction with the literature, culminate in the central contribution of this study: an attachment theory informed framework of manager-employee engagement. In this framework, the interpersonal context of engagement is central to understanding the intersection of individual, interpersonal and organisational influences on engagement. As a result this study contributes a new explanation for understanding engagement and provides an alternative route for increasing levels of engagement.

In the remainder of this chapter, I introduce how I arrived at this research topic. I then provide a back ground to the study which includes defining engagement, introducing the engagement literature and attachment theory. I then present the research problem and elaborate on the research question. Next, key definitions are provided including a definition of: manager-employee social engagement strategies. The research design is outlined, followed by an overview of the contributions of this study to the engagement literature. Finally, I outline a chapter summary of this thesis. 


\subsection{Arriving on the Road to Engagement}

I found myself on the road to engagement by surprise. I set out with two related interests. First, I was interested in applying attachment theory to further understand aspects of interaction in workplace relationships (that were both in and out of awareness), as a route to understanding organisational behaviour. Second, I wanted to use attachment theory as an interpersonal organisational theory to further understand a current business issue.

First, attachment theory has been most commonly used to understand infant and child-parent relationships but has also been used to explore workplace relationships pertaining to leadership and leader-follower relations (Game, 2011; Harms, 2011; Hazen \& Shaver, 1990; Mikulincer \& Shaver, 2007; Neustadt, Chamorro-Premuzic \& Furnham, 2006). This research had extended the scope of attachment theory to understanding workplace behaviour in terms of personality traits and styles, and had done so using attachment as an individual level construct. However, examples of the application of attachment theory as a systems theory to describe, explain and study interpersonal relationships at work in terms of a 'secure base system' (Bowlby, 1973, p. 182), were not found in the literature.

Second, in looking for a current business issue within which to apply attachment theory, the MacLeod and Clarke's (2009) review (commissioned by the United Kingdom (UK) government) on employee engagement caught my full attention. Based on qualitative interviews with multiple stakeholders across the UK, engagement was described as a 'two-way adult relationship between leaders and managers and employees where challenges can be met and goals achieved' (MacLeod \& Clarke, 2009, pp. 3-4). However, engagement research that centred on the two-way relationship; in contrast to the separate contributions of managers and employees seemed sparse.

In addition, attachment as a concept was frequently used to characterise engagement by emphasising the strength of employees' relationships with their job or organisation (John Robertson and Associates (JRA) 2009; Kahn, 1990; Nokia Siemens Networks, 2008). However, it was not used to describe or research different qualities of social engagement between managers and employees. As a result of these initial understandings I focused my study on the interpersonal 
context where possible social engagement strategies within the manager-employee relationship and engagement, intersect.

\subsection{Background to the Problem}

\subsubsection{Definition of engagement.}

Kahn (1990) introduced a number of foundational ideas about engagement. He defined personal engagement and personal disengagement as follows (with my italics added):

Personal engagement is the simultaneous employment ... in task behaviors that promote connections to work and to others... and active, full role performance ... Personal disengagement ... is the simultaneous withdrawal... in behaviors that promote a lack of connections, physical, cognitive and emotional absence, and passive, incomplete role performances. (Kahn, 1990, pp. 700-701)

Kahn's (1990) emphasis on engagement as task behaviours has been further referred to as engagement behaviour: behaviour that is 'evident to others in the display of personal initiative, adaptability, efforts and persistence directed toward organizational goals' (Macey, Schnedier, Barbera \& Young, 2009, p. 7).

Kahn (1990) simultaneously conceptualised engagement and its context. He proposed that the experience of personal engagement-disengagement occurred within a 'dynamic and multidimensional relationship' (Kahn, 1990, p. 692) between (a) an employee and their organisation and (b) the representative of the organisation, the manager. The dynamic nature of the relationship included the interplay between roles, tasks and interactions, with each other (and others) at work. The multidimensional nature included: the physical (one's personal relationship with the tasks done in association to one's work and/or organisation); the cognitive (one's personal mind state towards organisational commitment and job satisfaction); and the emotional (described as relationship-based connections with others, such as the interpersonal manager-employee relationship).

Further reflecting on a connection between engagement and the experience of work, Kahn (1990) asserted: 'conscious and unconscious phenomena' (p. 693) concerning the meaningfulness of one's work, a sense of personal safety at work and one's own sense of being personally available to do the job, in turn influenced the experience of engagement. As such, he advocated that experiences of engagement be understood within the context of work. In keeping with this view, 
he advocated that engagement research should avoid 'context-free sweeps' ( $\mathrm{p}$. 693) about engagement.

\subsubsection{From Kahn to an engagement field.}

Kahn's (1990) seminal conceptual work on engagement is a cornerstone in the field. However, his work remained relatively unexplored for nearly a decade before the concept of engagement resurfaced as a business case (Buckingham \& Coffman, 1999). Since 1999, engagement has evolved into a 'hot topic' in popular literature, and an increasingly popular issue in academia.

For example, a Google search using the key phrase 'employee engagement', resulted in 1,200,000 hits (5 January 2011), reflecting its popular currency, commercial interests and public opinion status. It has also been identified by some as an organisational goal and a top management issue (Czarnowsky, 2008; States, 2008; The Ken Blanchard Companies, 2009). Consequently, organisations have invested millions of dollars in programmes to increase engagement (Hudson, 2010; States, 2008).

Academia has primarily conceptualised engagement as a multidimensional and/or multilayered concept (Alfes et al., 2010; Gourlay et al., 2012; Saks, 2006). For example, drawing on job-demands resources theory, work engagement has been described as the 'relationship of the employee with his or her work' (Shaufeli \& Bakker, 2010, p. 10). Work engagement is:

A positive, fulfilling, work-related state of mind that is characterized by vigor, dedication, and absorption... [and it is] a more persistent and pervasive affective-cognitive state that is not focused on any particular object, event, individual, or behaviour. (Schaufeli, Salanova, Gonzalez-Roma, \& Bakker, 2002, p. 74)

Similarly, Saks (2006) used social exchange theory (Cropanzano \& Mitchell, 2005) to further understandings about engagement. Based on the premise that employees exchange their engagement for resources from their employee; and that employees often hold multiple roles, especially in regard to their job and their organisation, Saks (2006) conceptualised two different but related types of engagement: job and organization engagement. Job engagement represented workers psychological presence in their job; and organisation engagement represented workers psychological presence within their organisation. In addition, engagement has been conceptualised as a multi-levelled concept that 
includes (a) emotional engagement that involves displaying emotional attachment to varying aspects of the job, and (b) transactional engagement that involves doing what is required and being motivated by rewards (Gourlay et al., 2012).

Engagement has also been conceptualised as a: 'two-way relationship between leaders and managers and employees where challenges can be met and goals achieved' (MacLeod \& Clarke, 2009, pp. 3-4); whereby 'the organisation must work to develop and nurture engagement, which requires a two-way relationship between employer and employee' (Robinson, Perryman, \& Hayday, 2004 , p. 1). Further supporting this relational view of engagement as an extension of the individual, Leiter and Bakker (2010) stated:

\footnotetext{
Although work engagement is a personal experience of individual employees, it does not occur in isolation. A thorough consideration of sources, experiences and consequences of engagement go beyond the individual to consider the social dynamics among individuals as well as larger institutional dynamics reflecting an organizations' culture. (p.5)
}

Consistent with this view is the notion of social engagement; a dimension of the Intellectual, Social, Affective Engagement Scale (Soane, Truss, Alfes, Shantz, Rees \& Gatenby, 2012). Social engagement represents 'the relationship between individuals and their work colleagues' (Gatenby et al., 2009, p. 24). It includes the 'extent to which one is socially connected with the working environment and shares common values with colleagues' (Soane et al., 2012, p. 532). It involves participating in 'constructive dialogue' (Alfes et al., 2010, p. 6) and 'actively taking opportunities to discuss work-related improvements with others at work' (Alfes et al., 2010, p. 5). Using a multi-context framework, this concept conceptualises social engagement as an interpersonal context of engagement, but it is currently operationalised as an individual survey measure.

Overall, these engagement concepts (and their respective measures as delineated in Chapter 2) largely capture the individual context of engagement, but, these concepts and the theories that underpin them, such as job demands resources and social exchange theory, also acknowledge the interpersonal context of engagement (Alfes et al., 2010; Gatenby et al., 2009; Leiter \& Bakker, 2010; Macey \& Schneider, 2008; Shuck \& Wollard, 2010). Yet, there has been a paucity of research that includes the interpersonal context as a research context. To elaborate, I examine the use of attachment in the engagement literature. 


\subsubsection{Attachment as an interpersonal context of engagement.}

The use of attachment in the engagement provides another example of the interpersonal context being acknowledged, but not directly researched as a context. For example, as elaborated on in Chapter 2, attachment is used to denote employees relationships with their organisation. Furthermore, Kahn $(1995,1996$, 1998) used the attachment theory informed concept of the secure base to explore connections between individual's engagement and their relationship with their organisation. More recently, Hudson (2010) used attachment theory to examine a connection between interpersonal relationships at work and work engagement. However, in this study interpersonal relationships were studied from the perspective of the individual; they were not studied within an interpersonal context. As shown in Chapter 2, this approach to studying relationships is not uncommon within the engagement literature; and is not uncommon in the attachment theory informed workplace literature.

This is surprising because, longitudinal attachment theory research (Cassidy \& Shaver, 2008; Grossmann et al., 2005) emphasises the significance of early relationship experience sequences, entailing: exploration (such as playing), experiencing stress of some sort followed by help seeking on the part of the child and caregiving in response on the part of the parent. These sequences of interaction represent the secure base system. This system is 'central to the logic and coherence of attachment theory and to its status as an organizational construct' (Waters \& Cummings, 2000, p. 3).

Furthermore, the secure base system, originally developed to address interpersonal dynamics within parent-infant relationships, has developed as a lifespan theory (Bowlby, 1988). For example, adult attachment research findings have shown that adults in close relationships, use different strategies of relating as a way to meet the goals of the relationship (Cassidy \& Shaver, 2008; Crowell et al., 2002; Grossmann, Grossmann \& Waters, 2005; Mikulincer \& Shaver, 2007), especially when they are under pressure.

This system describes and explains: (a) how close interpersonal relationships function together when under pressure, such as during times of conflict, anxiety or uncertainty; and (b) how different strategies of functioning in 
relationships, when under pressure, affect levels of exploration, such as play and work (Ainsworth et al., 1978; Bowlby, 1969; Hazen \& Shaver, 1990). Over time, these relationship strategies become mentalised as internal working models of oneself in relationship to others; and of others in relation to ourselves, especially during times of stress. These mental models are malleable and function at varying levels of awareness within and between individuals (Cassidy \& Shaver, 2008; Grossmann et al., 2005; Mikulincer \& Shaver, 2007).

The attachment theory informed workplace research has tended to underplay the secure base system as an interpersonal system of interactions. Instead, workplace attachment theory research has adopted a trait/personality theory approach to understand interpersonal relationships at work (Neustadt et al., 2011). For example, attachment theory has been used to examine aspects of leadership and leader-follower relations (Hardy \& Barkham, 1994; Hazen \& Shaver, 1990; Kahn, 1995, 1996, 1998; Keller, 2003; Mikulincer \& Shaver, 2007; Neustadt, Chamorro-Premuzic \& Furnham, 2006, 2011). Game (2011) and Harms (2011) provide general overviews of this body of research. Empirical studies show associations between individual level factors, such as trust and employee perceived qualities of a leader and varying attachment styles of leaders and followers. Further illustrating this research trend, Pang Tze Lin (2009) reviewed eleven attachment theory informed leader-follower relationship studies. Each study conceptualized a relationship between managers and employees, but researched the individual experiences of the relationship within the individual context of engagement.

Overall, while attachment as a concept is evident in the engagement literature, and in the workplace literature to explore leader-follower relationships, there is a dearth of available research that uses attachment theory as a systems theory to describe and explain interpersonal relationships at work in terms of a 'secure base system' (Bowlby, 1973, p. 182).

\subsection{The Research Problem, Attachment theory and Questions}

\subsubsection{The problem.}

Surprisingly, increases in knowledge about engagement and programmes to enhance it have not generally equated to growth in reported levels of 
engagement. Czarnowsky (2008) observed a 'discrepancy between the perceived importance of engagement and the level of engagement that exists in organizations today' (p. 4). For example, commercially derived data (dating from the late 1990s and early 2000s by the Gallup Organisation) estimated nearly 70 per cent of the global workforce was disengaged (Wagner \& Harter, 2006). Saks (2006), referencing only United States of America businesses, estimated that low engagement could be producing an annual ' $\$ 300$ billion loss in productivity’ ( $p$. 600 ), indicating that a disengaged workforce risks revenue losses. More recent figures report a similar trend. For the period 2008 to 2010, Aon Hewitt's measure of the overall global average employee engagement score dropped from 59 per cent to 56 per cent (Aon Hewitt, 2011).

Using Kahn's (1990) description of the interplay between contexts and engagement, I argue that one possible under-explored reason for low engagement is that knowledge generation about interpersonal factors is patchy. I also show in Chapter 2 that features concerning individual perceptions of engagement are used synonymously to describe engagement; that is, doing the tasks of the job, which in turn are then used to infer organisational outcomes. This anomaly is problematic regarding efforts to increase engagement, because it: (a) supports assumptions that knowledge about one dimension (such as individual drivers of engagement) equates to change in engagement; and (b) underplays interpersonal conversations that bridge the drivers of engagement and engagement as behaviour.

Similarly, attachment has not yet been conceptualised or operationalised as an interpersonal dimension of engagement. Instead, constructs such as role attachment (Kahn, 1990) and organisational attachment (Lin, 2010) explore and explain individuals' quantities of attachment directed towards the job or organisation. Attachment theory has also been applied to describe an association between the experience of secure base relationships at work and engagement (Kahn, 1995, 1996). More recently, a study showed an association between individual attachment styles and levels of work engagement (Hudson, 2010). Less common is the use of attachment theory (Ainsworth \& Wittig, 1969; Bowlby, 1969) as a systems theory to explore and explain qualities and patterns of interaction to understand engagement experiences and behaviour. 
In sum, theoretical connections between engagement, the manageremployee relationship and attachment are currently under-used to explore engagement. While there is support for the notion of engagement to be viewed as a multidimensional construct, research has focused on contextual dimensions other than the interpersonal dimension of engagement. Similarly, the notion of attachment has been rarely used to examine the interpersonal manager-employee relationship in association with engagement. As a result, we know little about how the manager-employee interpersonal relationship, as a social context (that includes past and current attachment relationships), influences interactions at work and engagement. Consequently, understanding of the interpersonal dimension of the manager-employee relationship is not readily available to be: (a) theoretically integrated to further understandings about the simultaneous interplay of the dimensions of engagement; or (b) practically integrated into organisational practices and programmes aimed at increasing levels of engagement.

\subsubsection{An attachment theory lens on this problem.}

At the outset of the study a number of relevant theories to engagement (in conjunction with attachment theory) were explored. Such as: social exchange theory (Cropanzano \& Mitchell, 2005); leader-member exchange (LMX) theory (Dansereau, Graen \& Haga, 1975; Graen \& Cashman, 1975; Liden \& Graen, 1980; Liden \& Maslyn, 1998); and employee-organisation relationship theory (Coyle-Shapiro, Shore, Taylor \& Tetrick, 2004; Shore, Coyle-Shapiro \& Tetrick, 2012). Also examined was research into the psychological contract (CoyleShapiro \& Kessler, 2000; Cullinane \& Dundon, 2006); and the study of interpersonal relationships (Ferris et al., 2009). While these theories are relevant to engagement, they have not typically featured in engagement research, with the exception of social exchange theory and LMX theory.

For example, Saks (2006) used social exchange theory to examine employees' exchange of job and organisational engagement in return for socioeconomic resources from the organisation. Interpersonal exchanges were not examined in association with engagement. Following this work (and further described in Chapter 2), a small body of LMX and engagement research emerged (Agarwal, Datta, Blake-Beard \& Bhargava, 2012; Lee, 2012; Reed, 2011). 
However, LMX theory was not used to research the leader-member relationship as a unit of analysis. Instead, individual-level data was sought from which inferences were made about the quality of this relationship.

In sum, these theories are relevant to theorising about the manageremployee relationship but they do not provide a method in which to research the manager-employee relationship within an interpersonal context. In contrast, attachment theory, while not commonly used within organisational research provides a systems theory of relationships in conjunction with research methods designed for use within an interpersonal context.

Therefore, in this study I use attachment theory to examine the interpersonal context of engagement. In addition, I draw on attachment theory informed methodologies to construct a method in this study that creates a pathway to researching the manager-employee relationship within an interpersonal context of engagement. Of note, the interpersonal context involves an array of workplace relationships including worker-client; worker-customer, and peer relationships. However, I focus on the manager-employee relationship so as to specifically further interpersonal based understandings related to the manager-employee relationship as a driver of engagement.

Attachment theory provides a theory from which to address key features of Kahn's description of engagement and its multidimensional context. As such, in this study attachment theory was used to explore interpersonal factors. For example, the secure base system was used to conceptualise and operationalise 'the notion of patterned interactions' (Johnson, 2008, p. 811) between managers and employees in association with their engagement. In addition, the concept of internal working models of the secure base system was useful in exploring individual conscious and unconscious factors of engagement (Kahn, 1990).

Attachment theory also provides structured observation methods, designed to observe the workings of the secure base system within interpersonal contexts such as parent-child relationships (Ainsworth et al., 1978) and adult-adult relationships (Crowell et al., 2002). Drawing on these methods, I designed and developed a survey that: (a) aimed to tap internal elements of the secure base system; and (b) in turn, provided a platform for manager and employee dyads to talk together about their respective secure base experiences at work, in association 
with their engagement. Overall, this approach enabled aspects of the interpersonal context of engagement to be viewed within the manager-employee relationship.

Using attachment theory to view the interpersonal context of the manageremployee relationship in association with engagement I questioned if managers and employees: (a) might socially interact with each other when under pressure in unique and patterned ways, reflecting the hypothesised secure base system; and (b) whether these interaction patterns might also be influencing levels of engagement.

\subsubsection{The questions.}

Using an attachment theory lens from which to view the problem outlined above, my primary research question became:

How do managers and employees strategically manage their relationship to optimise their engagement at work?

The following sub-questions focused the investigation:

1. What is the association (if any) between: the different ways that managers and employees engage with each other about their job, when they are under pressure; their states of mind about engagement; and their states of mind about antecedents and outcomes of engagement?

2. What can be understood from managers and employees who work together about their experiences of engagement in association with their relationship?

\subsection{Definitions}

\subsubsection{Manager, employee, manager-employee relationship.}

Based on the New Zealand Ministry of Business, Innovation and Employment's (MBIE) (2013) definition of an employee, this study used the term to refer to anyone under a contract of service, who holds neither a managerial position, nor is responsible for the work of others in the organisation. The term 'manager' refers to an employee who holds a managerial position and who is responsible for the work of others in the organisation.

The manager-employee relationship exists within the complex interplay of an overarching employee-organisation relationship that includes the domains of 
justice, industrial relations, the law, economic perspectives and social exchange (Coyle-Shapiro et al., 2004; Shore et al., 2012).

The empirical unit of this study is: the manager-employee social engagement relationship. This relationship resides within and across each of these domains. This relationship refers to a two-way interpersonal social relationship between managers and employees characterised by task-related conversations (Kahn, 1998; MacLeod \& Clarke, 2009; Tjosvold, Hui \& Law, 1998) that function to meet organisational goals. Drawing on attachment theory, it was assumed that within the interpersonal context, managers and employees might typically activate different aspects of the secure base system. This idea is elaborated on in Chapter 2.

\subsubsection{Dimensions of the manager-employee social engagement relationship.}

In this study, I use the following terms to distinguish multi-dimensional contexts of engagement from engagement. For this purpose I refer to the following dimensions: the internal dimension reflects individual influences; the external dimension represents organisational influences; and the interpersonal dimension represents day-to-day interactions. Engagement is used to refer to doing the tasks of the job.

First, the internal dimension represents the 'psychological experience of work and work contexts' (Kahn, 1990, p. 695) and includes states of mind/perceptions relating to engagement. In turn, these mind states include 'subtexts of emotional connections and disconnections running alongside our task-related conversations' (Khan, 1998, p. 40); [that] 'shape how people think, feel, and act at work' (Khan, 1998, p. 71), and attachment, specifically regarding the secure base system of relationships.

Of note, the manager-employee relationship comprises a broad array of facets, which have also been characterised as dimensions such as trust, support, affect and loyalty (Ferris et al., 2009). In this study, I classified these varying facets as features of the internal dimension because these variables (while diverse in their subject matter) are structurally similar. That is, they are each typically measured in ways designed to tap employees' perceptions. 
Second, the external dimension refers to 'the objective properties of jobs, roles, and work contexts' (Kahn, 1999, p. 693) oriented towards meeting organisational goals. In this study, workplace pressure and stress (defined below) was also recognised as a feature of the external dimension.

The third dimension is the interpersonal dimension. Drawing on the notion of social engagement (Alfes et al., 2010; Gatenby et al., 2009), this dimension includes, 'the relationship between individuals and their work colleagues' (Gatenby et al., 2009, p. 24). It focuses on 'interpersonal interactions' (Kahn, 1990, p. 707) and 'task-related conversations and work with one another' (Kahn, 1998, p. 40) such as participating in 'constructive dialogue' (Alfes et al., 2010, p. 6 ) and 'actively taking opportunities to discuss work-related improvements with others at work' (Alfes et al., 2010, p. 5). It also represents interaction strategies (further delineated on below) that relate to experiences of the secure base system.

Social engagement with peers at work (Gatenby et al., 2009; Schaufeli \& Bakker, 2010) is relevant to the thesis, but general collegial relationships remained outside the scope of this study. This study specifically focuses on the strategies that managers and employees use within their interpersonal relationship to manage their experiences of factors in the internal and external dimensions of engagement.

\subsubsection{Manager-employee social engagement strategies.}

I have developed the construct of manager-employee social engagement strategies for the purposes of this study and define these as:

Strategically patterned secure base use and support oriented interactions that occur between managers and employees at times of stress and that may temporarily interrupt engagement behaviour. These interactions aim to decrease stress to remobilise engagement behaviours oriented towards the organisation's goals.

This definition draws on engagement and attachment theory research. It draws on the concept of social engagement (Alfes et al., 2010; Gatenby et al., 2009; Soane et al., 2012) (which focused on the amount or frequency of social engagement) and it captures the notion of relationship goal-oriented 'strategic variations' (Mikulincer, 1998, p. 420). These strategies refer to discrete and coherent patterns of experiencing and behaving that occur within the secure base use system (Crowell et al., 2002). Drawing on attachment theory, I hypothesise 
that these strategies are variously associated with engagement (see Chapter 2) and I conceptualise three qualitatively distinct social engagement strategies with unique patterns of engagement states of mind. Conceptualising engagement as varying social strategies complements the commonly used continuum approach used in engagement research, such as the continuum of high to low engagement.

\subsubsection{Stress and pressure.}

Pressure and stress can manifest across internal, interpersonal and external dimensions of manager-employee relationship. In this study I focus on pressure and stress as: (a) an external dimension of organisational life; and (b) as a primer to activating the secure base interpersonal system at work.

First, the following World Health Organization definition captures stress and pressure as an aspect of organisational life:

Pressure at the workplace is unavoidable due to the demands of the contemporary work environment. Pressure perceived as acceptable by an individual may even keep workers alert, motivated, able to work and learn, depending on the available resources and personal characteristics. However, when that pressure becomes excessive or otherwise unmanageable it leads to stress. Stress can damage your workers' health and your business performance. (Leka, Griffiths \& Cox, 2003, pp. 3-4)

Second, attachment theory connects experiences of pressure and stress with variations in interpersonal behaviour and exploratory behaviour, such as working (Hazen \& Shaver, 1990). In response to pressure, interpersonal attachment behaviours are observed as a sequence of 'support seeking, support availability, distress relief' (Mikulincer, Shaver, Sapir-Lavid \& Avihou-Kanza, 2009, p. 623). This interpersonal exchange aims to regulate stress so exploration (such as working) can resume.

Accordingly, attachment theory-informed workplace research examines an association between individual level attachment styles and: (a) work stress (Ronen \& Mikulincer, 2009); (b) burnout (Pines, 2004); and (c) work strain (Schirmer \& Lopez, 2001). However, associations between the experience of working under pressure, the secure base system of interpersonal relationships and engagement as an organisational behaviour have been under-researched. This study uses attachment theory to explore the interpersonal manager-employee relationship as a 
social engagement relationship that functions within the rubric of external workplace pressure, to meet organisational goals.

\subsection{Study Summary}

This study examines the interpersonal manager-employee relationship as a mediator between manager and employees internal perceptions about engagement and their engagement behaviour. To date, engagement research has focused on the internal and the external dimensions of engagement; and attachment theory informed workplace research has focused on the internal dimension. While both fields of study acknowledge the importance of the workplace relationships to understanding engagement (Hudson, 2010; MacLeod \& Clarke), research that aims to bridge the internal, interpersonal and external dimensions of engagement has been under developed. This research endeavours to address the interplay between the three dimensions of engagement as way to understand low levels of engagement. To this end, a mixed methods study was designed that enabled social and statistical data to be collected and analysed across each dimension, within the one study.

\subsection{The Design}

To tap the multidimensional contexts of engagement the research questions were examined using a sequential explanatory mixed method design (Creswell \& Plano Clark, 2007; Tashakkori \& Creswell, 2007): sub-question one was examined using a quantitatively oriented survey study; sub-question two was examined via exploratory oriented case studies with manager-employee dyads.

First, as there was no known measure of manager-employee social engagement strategy, a new survey was constructed: the New Zealand ManagerEmployee Social Engagement Survey (NZ MESE Survey). This survey was distributed online to a sample of New Zealand managers ( $=200)$ and employees $(\mathrm{N}=200)$. Findings yielded a reliable and valid set of manager-employee social engagement scales. A statistical association was shown between these strategies and unique patterns of engagement states of mind, and statistical nuances were highlighted for further exploration in the case studies. 
Second, the case studies were conducted with manager-employee dyads. Because there were no known engagement studies that examined the experience of managers and employees regarding their use of social engagement strategies and their engagement, a new approach to researching the manager-employee dyad in the workplace was developed. This included an adapted version of the online NZ MESE Survey, and semi-structured individual and dyad interviews. In these studies, the managers and employees indicated that (when they felt under pressure) they used various combinations of social engagement strategies with each other to optimise their capacity to maintain engagement with both their jobs and organisations.

\subsection{The Contributions and Practical Implications of this Research}

Based on the literature and findings of this study I developed a theoretical framework of manager-employee engagement. This reveals social engagementrelated knowledge, currently hidden in plain sight, such as manager-employee social engagement strategies. The case studies showed the practical potential for this framework to be used by managers and employees as a guide to adapt the ways they interact to improve their engagement. Findings from this study offer a new way to understand and potentially increase engagement levels.

This framework extends Kahn's (1990) view of the simultaneous interplay between engagement and its context and it builds on his initial use of the secure base construct to explore differences in engagement (Kahn, 1995, 1996, 1998). It also extends the notion of social engagement (Alfes et al., 2010; Gatenby et al., 2009) towards qualitatively diverse interpersonal social engagement secure base strategies. These strategies statistically correlated with states of mind about engagement and socially connected with variations in engagement behaviour. Finally, the inclusion of an interpersonal approach to the study of the manageremployee relationship extended the trait/personality based approach to exploring workplace relationships.

\subsection{Thesis Outline}

This thesis is divided into six chapters. 
Chapter One overviews the empirical domain of interest to the present study: an attachment theory-informed examination of the manager-employee relationship as a social engagement relationship.

Chapter Two describes engagement as a multidimensional construct and highlights the interpersonal dimension. While central in the literature, this is the least explored in comparison to internal and external dimensions. In turn, an attachment theory framework of engagement is introduced that informs this study of the manager-employee relationship as an interpersonal dimension of engagement.

Chapter Three provides an audit trail of the mixed methods sequential explanatory design (Creswell \& Plano Clark, 2007; Tashakkori \& Creswell, 2007) used in this study. I outline the research processes, ethical considerations and analyses used to conduct the survey study and the case studies.

Chapter Four presents the statistical survey data to address the first subresearch question. Three primary manager, manager-employee social engagement strategy scales and three primary employee, manager-employee social engagement strategy scales are tested and shown to be reliable and valid. Next, these newly validated scales are shown to be associated with unique patterns of engagement states of mind. Consistent with the design, an intermediary analysis was conducted between the two primary research phases. The results of this analysis are reported at the end of the chapter.

Chapter Five addresses the second sub-research question. The manageremployee social engagement strategy variables are used as a springboard from which to explore the interpersonal dimension of engagement within each manager-employee dyad case study. Five studies are reported, which show how, when and at times why, managers and employees used a number of social engagement strategies. These simultaneously pertained to secure base use and provision of support, with differing effects on their engagement states of mind and behaviour.

Chapter Six presents an inter-case comparison and analysis culminating in this study's contribution: a theoretical framework of manager-employee engagement. I conclude by outlining the implications of this study for understanding and increasing levels of engagement. I identify the strengths and limitations of the study and close with suggestions for future research. 


\section{Chapter 2: Engagement, the Manager-Employee Relationship and Attachment Theory}

Studying connections between engagement, the interpersonal manageremployee relationship and attachment may provide new insights into how levels of engagement can be increased. This is because engagement frequently occurs within the day-to-day social context of interpersonal relationships at work, including the manager-employee relationship. However, these connections are hidden in plain sight within the engagement literature. This chapter highlights the missing connections. It demonstrates that the literature has acknowledged engagement's multidimensional nature, but under studied the manager-employee interpersonal relationship. This chapter highlights potential connections between: (a) the manager-employee relationship as a central driver of engagement; and (b) the use of attachment as an interpersonal construct to explore and explain engagement. Finally, an attachment theory-informed framework is developed for understanding and investigating the manager-employee relationship as an engagement context.

\subsection{Engagement: An Overview}

Engagement is a primary issue for managers. For example, in a survey of 1,800 corporate managers, 58 per cent noted that 'creating an engaged workforce' (The Ken Blanchard Companies, 2009, p. 5) was a top management issue.

Similarly, a survey conducted by the Society for Human Resource Management in 2011, found that 99 per cent of human resource leaders they surveyed considered their primary challenge was achieving an increase in employee engagement levels.

Engagement matters to managers because the extent of employee engagement influences organisational bottom-line results, including productivity, profitability and employee retention (Bates, 2004; Baumruk, 2004; Buckingham \& Coffman, 1999; Harter, Schmidt, Killham \& Agrawal, 2009; Richman, 2006). An engaged and productive workforce is positively related to competitive advantage for businesses (Wellins, Bernthal, \& Phelps, 2005). A disengaged workforce risks revenue losses (Saks, 2006). 
Moreover, while managers have been focused on ways to increase engagement, academia has examined the validity of engagement as a construct (Little \& Little, 2006; Newman \& Harrison, 2008). This emphasis has resulted in the development of domain specific concepts, such as work engagement (Schaufeli et al., 2002) and job and organisation engagement (Saks, 2006). In addition, academic interest in engagement has expanded, as evidenced by an ever increasing number of engagement literature reviews (e.g. Albrecht, 2010; Bakker \& Leiter, 2010; Kular, Gatenby, Rees, Soane, \& Truss, 2008; Kumar \& Swetha, 2011; Macey \& Schneider, 2008; Shuck, 2011; Shuck \& Wollard, 2010; Simpson, 2009). This development highlights engagement's interest for both the commercial and academic sectors.

\subsubsection{Engagement and context: a multidimensional concept.}

As introduced in Chapter 1, for the purposes of this study I adapted Kahn's (1990) multidimensional approach to engagement. I did this to highlight the interpersonal context of engagement. I outline three dimensions (internal, external and interpersonal) below. This multidimensional approach to engagement contexts illustrates that much of the engagement literature is concerned with internal and external dimensions. In contrast, the interpersonal dimension has been acknowledged but under-examined.

\subsubsection{Internal dimension.}

Elements of this dimension were first described by Kahn as the 'psychological experiences of work and work contexts' (Kahn, 1990, p. 694). Further, these experiences include: physical (for example, one's personal relationship with the tasks performed in association with one's work or organisational goals); cognitive (one's personal mind state towards organisational commitment and job satisfaction, etc.) and emotional (described as relationshipbased connections with others, such as the interpersonal manager-employee relationship) factors. Building on this work, Kahn developed the notion of psychological presence to describe 'the experiential state accompanying the behaviours of personally engaged role performance' (Kahn, 1992, p. 331). 
Building on Kahn (1990) work engagement (Leiter \& Bakker, 2010; Schaufeli et al., 2002; Schaufeli \& Bakker, 2004) (defined in Chapter 1) is a foundational concept within engagement research. It is comprised of three dimensions: vigor (high levels of energy and mental resilience); dedication (being highly involved in one's work while also experiencing a sense of significance, enthusiasm, and challenge regarding ones work); and absorption (the experience of concentrating and being engrossed in work) (Schaufeli et al., 2002). The measure of work engagement is the Utrecht Work Engagement Scale (UWES); a 17 item self-report survey designed to measure a workers psychological state of mind with regard to vigor, dedication and absorption (Schaufeli et al., 2002).

Furthermore, variations in work engagement have also been associated with life outside of work. For example, a study of 159 employees (over a four week period) showed that work engagement was influenced by what workers did in their non-work time. For example, higher levels of work engagement were maintained when workers disengaged completely from work in their non-work time (Sonnentag, Mojza, Binnewies \& Scholl, 2008).

In addition to work engagement research, engagement research has captured experiences of work and its context in a plethora of ways. For example, capturing experiences of work, the notion of psychological engagement (May, Gilson \& Harter, 2004) was constructed using Kahn's (1990) definition of personal engagement. However, this research conceptualises the conditions of engagement (meaningfulness, safety and availability) as states of mind only.

Other examples include the concepts of job and organisation engagement (Saks, 2006), which tap into individual experiences of the job and organisation (Saks, 2006). Saks (2006) drew on social exchange theory to explain an employee-employer exchange relationship whereby employees exchange job and organisation engagement for economic and socio-emotional resources. Saks (2006) proposed that job engagement represented the degree to which an individual attended to and was absorbed in the performance of their job. Organisation engagement referred to the degree to which an individual attended to and was absorbed in the performance of their organisation.

The literature is also replete with examples that capture engagementrelated experiences, such as perceptions concerning commitment to an organisation, work satisfaction and the intention to stay in the organisation 
(Buckingham \& Coffman, 1999). Descriptions refer to engagement as 'an individual's sense of purpose and focused energy' (Macey et al., 2009, p.7) and a willingness to exert discretionary effort (Macey et al., 2009). Similarly, engagement has been defined as the degree to which employees are 'satisfied with their jobs, feel valued, and experience collaboration and trust' (Catteeuw, Flynn \& Vonderhorst, 2007, p. 152).

Academia has also tested the validity of engagement as an organisational construct. Discriminant validity has been established between work engagement and a number of closely related concepts such as: burnout, job involvement, job satisfaction, organisational commitment and workaholism (Schaufeli \& Bakker, 2010, p. 18 - 19). In addition, job engagement and organisation engagement has been distinguished from perceived organisational support, perceived supervisor support, organisational commitment, and the intention to quit/turnover (Saks, 2006). For example, Saks (2006, p. 601) differentiated organisation commitment from engagement by asserting that commitment 'refers to a person's attitude and attachment towards their organization. Engagement is not an attitude; it is the degree to which an individual is attentive and absorbed in the performance of their roles'.

Furthermore, engagement related concepts have been described and tested as antecedent and outcome variables of engagement. The concepts of perceived organisational support (POS) and perceived supervisor support (PSS) are typically understood to be antecedent factors to engagement (Saks, 2006; Shuck, 2011). Definitions of perceived organisational support are underpinned by social exchange theory and include references to employees' 'global beliefs concerning the extent to which the organisation values their contributions and cares about their wellbeing' (Eisenberger, Huntington, Hutchinson \& Sowa, 1986, p. 500). Organisational support theory asserts that in return for a high level of support, employees' discretionary effort increases to help their organisation reach its goals (Aselage \& Eisenberger, 2003). Perceived organisational support has been found to have a significant effect on organisational commitment (Rhoades \& Eisenberger, 2002; Riggle, Edmondson \& Hansen, 2009). Similar to perceived organisational support, perceived supervisor support refers to 'a general indication concerning a supervisor's positive valuation of the employees' contributions and 
care about the employee's wellbeing' (Rhoades, Eisenberger \& Armeli, 2001, p. 828) (also see Kotte \& Sharafinski, 1988).

Organisational commitment (OC) and the intention to quit/turnover (ItQT) are typically considered as outcomes of engagement (Juhdi, Pa'Wan \& Hansaram, 2013; Saks, 2006; Shuck et al., 2011). Organisational commitment refers to an individual's psychological state regarding the degree to which he or she identifies with, and is involved in, a particular organisation. Organisational commitment is typically characterised by three factors: (a) acceptance of the organisation's goals and values; (b) discretionary effort to work on behalf of the organisation; and (c) level of motivation to remain in the organisation (Porter, Steers, Mowday \& Boulian, 1974). Similarly, Meyer and Allen (1997) referred to three components of commitment that tapped: (a) affective (employees' identification to, involvement with and attachment to the organisation); (b) continuance (links with the cost that employees associate with leaving the organisation); and (c) normative commitment (level of employee obligation to remain in an organisation). Work engagement has been found to be an empirically distinct construct from organisational commitment (Hallberg \& Schaufeli, 2006; Leiter \& Bakker, 2010).

The intention to quit/turnover (Colarelli, 1984) in an organisation has been identified as a final step in voluntary turnover (Lambert, Hogan \& Barton, 2001; Steel \& Lounsbury, 2009; Steel \& Ovalle, 1984). It has been variously defined as the willingness of employees to leave an organisation and their intention to search for a new job (Benson, 2006; Mobley, Horner \& Hollingsworth, 1978; Tett \& Meyer, 1993).

Similarly, intention to quit/turnover refers to an employee's perception of the likelihood that they will stay or leave their organisation, which includes a combination of decision making and attitudes towards one's job (Sager, Griffeth \& Hom, 1998). Intention to quit/turnover is a conscious process of the employee, where the intent to leave is a predictor of actual turnover behaviour (Chiu, Lin, Tsai \& Hsiao, 2005; Tett \& Meyer, 1993).

Next, statistical models of engagement have been generated and tested that comprise an array of antecedent, mediating and outcome engagement-related variables (see Simpson, 2009; Shuck, 2010 \& 2011, for an overview). The variables tap employees' states of mind in relation to engagement and engagement-related variables. For example, Saks (2006) found that employees 
with higher levels of perceived organisational support were more likely to reciprocate with higher levels of job and organisation engagement. Employees who perceived higher positive job characteristics were more likely to indicate higher levels of job engagement, and employees with higher levels of perceived procedural justice were more likely to indicate higher levels of organisation engagement. In this model, the antecedent constructs of perceived supervisor support and perceived organisational support will be further explored, as they specifically pertain to the social orientation of this thesis.

Saks (2006) found:

1. Perceived organisational support was distinct from and positively related to job engagement and organisation engagement, and perceived organisational support predicted job engagement and organisation engagement.

2. A non-significant relationship between perceived supervisor support and job engagement and organisation engagement.

3. Job engagement was positively associated with organisation commitment and negatively associated with the intention to quit/turnover.

4. Organisation engagement was positively associated with organisation commitment and negatively associated with the intention to quit/turnover.

Of note Saks (2006) also found that job characteristics (as an antecedent) predicted job engagement, and procedural justice (as an antecedent) predicted organisation engagement. Furthermore, job engagement and organisation engagement predicted job satisfaction and organisational citizenship behaviour (as outcome factors).

Similar to Saks (2006), studies have repeatedly shown an association between high levels of engagement and low levels of intending to quit/turnover (De Lange, De Witte \& Notelaers, 2008; Schaufeli \& Bakker, 2004; Shuck, 2011; Vance, 2006). In addition, affective commitment has been associated with higher levels of job performance and discretionary effort in comparison with normative and continuance commitment (Meyer \& Allen, 1997). Organisational commitment has been associated with higher levels of discretionary effort and job performance and lower levels of turnover and absenteeism (Mowday, Porter \& Steers, 1982). 
Shuck (2010) studied the statistical relationships among job fit, affective commitment, psychological climate, discretionary effort, intention to turnover and employee engagement. The findings showed a significant positive relationship between job fit, affective commitment, psychological climate and employee engagement. In addition, employee engagement and affective commitment predicted intention to turnover.

Juhdi et al. (2013) conducted a study concerning human resource practices and their effects on intention to quit/turnover, organisational commitment (Marsden, Kalleberg \& Cook, 1993) and organisation engagement. In contrast to job engagement and organisational engagement as mediating variables to organisational commitment and the intention to quit/turnover, this study found that organisational commitment and organisational engagement acted as partial mediators between human resource practices and intention to quit/turnover (Judhi et al., 2013).

Moreover, variables that tap into individual perceptions about social relationships at work are embedded within these statistical models (May et al., 2004; Saks, 2006; Rich, LePine \& Crawford, 2010). For example, Saks (2006) was interested in social exchange between managers and employees and engagement. May et al. (2004) referred to social relationships as satisfaction with co-worker relations. Accordingly, they collected satisfaction oriented perceptions based data in contrast to studying social relationships by researching 'actual work interactions' (Kahn, 1990, p. 705).

In summary, descriptions and definitions of engagement typically represent the internal context of engagement as they tap into experiences of engagement via people's states of mind with regard to engagement. In turn, these experiences are typically assessed using attitudinal data collected from self-report surveys (e.g. Buckingham \& Coffman, 1999; Juhdi et al., 2013; Saks, 2006; Schaufeli et al., 2002; Shuck, Reio \& Rocco, 2011). The nature of this survey data generally reflects employees' experiences concerning their work (Schaufeli et al., 2002), as well as their willingness to exert discretionary effort (Macey et al., 2009; Saks, 2006). Overall, the associations between the internal dimension oriented variables tell us that these states of mind are related. However, they do not inform how these variables interact within the interpersonal context of the manager-employee relationship. 


\subsubsection{Interpersonal dimension.}

For Kahn (1998), the internal and external contexts of engagement were interconnected with the interpersonal dimension, because 'organizations have tasks; tasks require linkages; linkages require work relationships' (p. 40). He observed that these interpersonal linkages comprised:

Subtexts of emotional connections and disconnections running alongside our task-related conversations and work with one another. What may appear on the surface as cognitive and rational may be a manifestation of these emotional subtexts. (Kahn, 1998, p. 40)

Three psychological conditions that influenced workers' experiences of themselves in their roles at work and the effect of this on their engagementdisengagement are: meaningfulness, safety and availability (Kahn, 1990). These conditions were defined in ways that matched features of the internal dimension, but Kahn also described them in interpersonal terms. For example, meaningfulness included an experience of a positive relationship between embracing one's role at work, role performance and 'rewarding interpersonal interactions with co-workers and clients' (Kahn, 1990, p. 703-707).

Meaningful interpersonal interactions at work comprise: 'dignity, selfappreciation, sense of value, and the inclusion of personal as well as professional elements' (Kahn, 1990, p.705). Safety included interpersonal relationships and related to the degree that social relationships at work were experienced as trusting, supportive and open, which in turn influenced decisions along the engagementdisengagement continuum (Kahn, 1990, p. 708-713). Availability was described as personal availability (the internal dimension). However, this availability had implications for the workers' engagement with their tasks, roles and interactions. Kahn (1990) found that 'personal engagement was connected to higher levels of psychological availability' (p. 714).

Such workplace relationships help to achieve organisational goals (Buckingham \& Coffman, 1999; Gatenby, Rees, Soane \& Truss, 2008, MacLeod $\&$ Clarke, 2009; Robinson et al., 2004). For example, the notion of social engagement specifically captures the interpersonal dimension; it refers to purposeful dialogue between individuals and their colleagues about 'work-related improvements with others at work' (Alfes et al., 2010, p. 5).

Recently, the definition of social engagement has been extended to include 'the extent to which one is socially connected with the working environment and 
shares common values with colleagues' (Soane et al., 2012, p. 532). Social connection includes: participating in 'constructive dialogue with those around them about their work or how to improve working, methods or skills' (Alfes et al., 2010, p. 6); and 'actively taking opportunities to discuss work-related improvements with others at work' (Alfes et al., 2010, p. 5). This concept refers to the relationship between people at work, but it has predominantly been measured using a survey method, tapping individual perceptions of the relationship in contrast to interpersonal interactions. This point is further illustrated below in section 2.2 in an examination of the connection between: (a) engagement and the manager-employee relationship; and (b) engagement and attachment.

\subsubsection{External dimension.}

Kahn (1990) describes this dimension as comprising the organisational context with features such as job characteristics, role descriptions and leader characteristics at work. The external context also includes changes in organisational structure. For example, in the latter part of the twentieth century, many organisations balanced multiple tensions between: cost-cutting while not compromising on business growth; downsizing staff numbers while sustaining productivity; and increasing the capacity to adapt to increasingly rapid market changes (Handy, 1994; 1989). In an endeavour to resolve these tensions, Kahn observed that organisations were increasingly using structures that depended 'less on tightly linked superior-subordinate units and more on the autonomy and independence of employee and business units' (Kahn, 2002, p. 239).

In turn, this change in the external structure of the manager-employee relationship had placed the employee in a situation that Kahn described as a 'paradox of self-reliance' (Kahn, 2002, p. 239): whereby employees are: (a) expected to work more autonomously with less support; and (b) 'required to venture forth into the unknown... without the sense of a safety net below' (Kahn, 1996, p. 161). Kahn argued the diminished organisational secure base in conjunction with increased demand for autonomous workplace behaviour, negatively affected their engagement at work (Kahn, 1996). Drawing on this overview and a multidimensional lens on engagement contexts, the focus now 
turns to examining the manager-employee relationship as a context of engagement.

\subsection{Engagement and the Manager-Employee Relationship}

The manager-employee relationship is important for understanding engagement (Alfes et al., 2010; Gatenby et al., 2009; Hughes, 2009; Kahn, 1990; Leiter \& Bakker, 2010; MacLeod \& Clarke, 2009). The following statements illustrate this point: 'There's no magic bullet to employee engagement; it's simply about improving the relationship between manager and managed' (Hughes, 2009, p. 84). In turn, this relationship provides a platform from which 'challenges can be met and goals achieved' (MacLeod \& Clarke, 2009, pp. 3-4), which in turn benefits the organisation (Buckingham \& Coffman, 1999; Harter et al., 2009; Robinson et al., 2004).

This relationship has commonly been researched as an internal and or external dimension, resulting in knowledge about individual workers and their external contexts. Based on this knowledge, inferences about the relationship between managers and employees, in association with engagement, have been made. However, knowledge about the interpersonal relationship as an engagement dimension is under-examined. To demonstrate this, I examine the manageremployee relationship as: (a) a driver of engagement; (b) as a construct represented in models of engagement; (c) through the lens of leader-member exchange theory; and (d) as an interpersonal relationship associated with engagement.

\subsubsection{The manager-employee relationship as a driver of engagement.}

The relationship between managers and employees has been identified as a driver of engagement (Agarwal et al., 2012; Buckingham \& Coffman, 1999; Macey \& Schneider, 2008; Robinson et al., 2004). Buckingham and Coffman (1999) state:

The talented employee may join a company because of its charismatic leaders, its generous benefits, and its world-class training programs, but how long that employee stays and how productive he is while he is there is determined by his relationship with his immediate supervisor. (p. 1) 
While acknowledged as an interpersonal relationship, knowledge of this engagement driver emphasises internal and external dimensions. For example, the Gallup Organisation has anchored engagement research around their measure of engagement, the Q12. This measure taps the internal dimension, that is:

'employee perceptions of the quality of people-related management practices in their business units... the actionable issues for measurement' (Harter et al., 2009, p. 8).

In emphasising the external dimension, research concerning this relationship has typically focused on what managers can do to develop employee engagement. For example, drivers include encouraging employees to be involved in decision making about aspects of their job and providing employees with job development opportunities (see Corporate Leadership Council 2004; MacLeod \& Clarke, 2009; Robertson-Smith \& Markwick, 2009; Scherbaum, Putka, Naidoo \& Youssefina, 2010).

Further, Gatenby et al. (2009) provided examples of manager behaviours that inhibit engagement:

\begin{abstract}
Reactive decision making that does not pick up problems before it is too late; inconsistent management style based on the attitudes of individual managers, which leads to perceptions of unfairness; low levels of advocacy which carry the risk of creating a downward spiral of employee resentment and disengagement; lack of fluidity in communications and knowledge-sharing due to rigid communication channels or cultural norms; poor work-life balance due to a long-hours culture; and low perceptions of senior management visibility and quality of downward communication. (Gatenby et al., 2009, p. 5)
\end{abstract}

In addition, the literature smoothly connects the internal and external dimensions. For example, manager-initiated interactions are considered to facilitate employee focused drivers of engagement that emphasise employee experiences of their work, including: employees experiencing a sense of belonging to the business; feeling that they are valued and involved in a business and experiencing a supportive work-life culture; and experiencing meaning at work (Alfes et al., 2010; Robinson et al., 2004; Saks, 2006; Towers Perrin, 2006). Similarly, other drivers associated with this relationship have been described as including 'employee voice, being able to feed your views upwards; senior management communication and vision; supportive work environment; personjob fit; and line management style' (Alfes et al., 2010, p. 55). 


\subsubsection{Leader-member exchange theory: engagement and the manager- employee relationship.}

In addition to generating a statistical model of engagement, Saks (2006) suggested 'engaged employees were more likely to have a high-quality relationship with their employer, which in turn lead to more positive attitudes, intentions, and behaviors' (Saks, 2006, p. 613). Following this work, a small body of leader-member exchange (LMX) theory and engagement research has emerged (Agarwal et al., 2012; Lee, 2012; and Reed, 2011). LMX theory conceptually concerns the dyadic interaction relationship between managers and employees, yet leader-member exchange as a variable taps the internal dimension concerning employees' perceptions and experiences of their immediate supervisors (Graen \& Cashman, 1975; Liden \& Graen, 1980).

To elaborate, LMX theory (Dansereau et al., 1975; Graen \& Cashman, 1975; Liden \& Graen, 1980; Liden \& Maslyn, 1998) provides a relational lens from which to view the manager-employee relationship and engagement. The theory explores and explains a process of mutual influence between leaders and their members/subordinates. The theory assumes that leaders and members have limited personal and organisational resources, such as time and energy, and as a result, are selective in their use and distribution of these resources. This selective process affects the quality of the exchange relationship between leaders and members and is the basis for an emerging body of engagement research.

Applying this theory to examine engagement, Reed (2011) examined the effect of leader efficacy on workgroup performance. Reed surveyed employees using measures of emotional and rational commitment to measure leader-member exchange, and the engagement survey and analysis tool (Corporate Leadership Council, 2004) to measure engagement. Based on this employee-only data, inferences were made about the manager-employee relationship: 'Examining LMX within the context of engagement provides business leaders with a better understanding of how and why leadership relationships impact employee performance' (Reed, 2011, p. 5).

In a different study, Agarwal et al. (2012) examined the relationships between leader-member exchange, innovative work behaviour, intention to quit and work engagement. All the variables tapped states of mind, best represented by 
the internal dimension. They used the nine-item Utrecht Work Engagement Scale (UWES) (Schaufeli, Bakker \& Salanova, 2006) to measure work engagement and the LMX seven-item scale (Graen \& Cashman, 1975; Liden \& Graen, 1980) to measure leader-member exchange. Similar to Reed (2011), individual and internal data was collected (this time from managers only), giving the following conclusion: 'quality of exchanges between employees and immediate supervisors influence engagement levels' (Agarwal et al., 2012, p. 221).

Also drawing on LMX theory, Lee (2012) examined the association between antecedents and outcomes of engagement, measured using variables that captured managers' and employees' states of mind regarding these concepts. The antecedent variables included core self-evaluations (self-perceived worthiness and capability) and the psychological climate (which included customer orientation, internal service, managerial practice, as well as information and communication). Outcome factors included job satisfaction, organisational commitment, intrinsic rewards and leader-member exchange. Data was collected from managers and employees as individuals, but not as dyads. Significant statistical relationships were found between core self-evaluations and work engagement, work engagement and leader-member exchange and leader-member exchange and organisational commitment. Lee (2012) also found that the leader-member exchange variable mediated the relationship between engagement, job satisfaction and organisational commitment. Based on individual statistical data with unmatched pairs, Lee (2012) concluded that the exchange relationship between engaged hotel employees and their supervisors was 'an explanatory factor for the direct relationship with engagement' (p. 157).

In summary, each of these studies makes inferences about the manageremployee relationship based on statistical data concerning the internal dimension. Of note, this situation reflects a trend in leader-member exchange research where the relationship is theorised but data collection is largely focused on the attributes of individuals within the dyad, not the dyad itself (Harms, 2011; Martin, Epitropaki, Thomas \& Topakas, 2010). 


\subsubsection{The interpersonal manager-employee relationship and engagement.}

The interpersonal relationship between immediate managers and their employees has been acknowledged within research about: (a) social engagement (Alfes et al., 2010; Gatenby et al., 2009) (described above) and face-to-face feedback (Watson Wyatt, 2008-2009); (b) work engagement, where this relationship is considered as a resource to support engagement (Leiter \& Bakker, 2010; Schaufeli et al., 2002); and (c) embedded as a focus within a range of methodologies used to examine engagement.

First, Alfes et al. (2010) suggested that organisations might under-use workplace relationships as a resource to support engagement. For example, in a survey study of 2,000 working adults in the UK, social engagement scores were lower than scores for intellectual engagement (thinking about the job) and affective engagement (feeling positive about the job). That is, scores for social engagement were the lowest for both the extent and frequency of 'constructive dialogue... about their work or how to improve working methods or skills' (Alfes et al., 2010, p. 6). Further supporting this suggestion, a Watson Wyatt Survey (2008-2009) found that engaged employees have frequent work-related discussions with their immediate manager in comparison to colleagues with medium to low engagement levels (Watson Wyatt Survey (2008-2009, p. 81). Forty-three per cent of engaged employees received face-to-face weekly feedback compared with 18 per cent of employees with low engagement. Similarly, a lack of face-to-face time between managers and employees was used to explain low engagement (Hughes, 2009).

Second, work engagement (Schaufeli et al., 2002) research specifically focuses on the 'relationship of the employee with his or her work' (Schaufeli \& Bakker, 2010, p. 10), which includes 'social dynamics among individuals as well as larger institutional dynamics reflecting an organization's culture' (Leiter \& Bakker, 2010, p. 5). In this body of research supervisor and co-worker support has been revealed as a resource to balance job demands, which in turn influences work engagement (Leiter \& Bakker, 2010). Further elaborating on the role of interpersonal interactions at work Leiter and Bakker (2010) stated: 'employee interactions with customers, clients, students or patients. It is in these interactions 
that the energy, dedication, absorption, or efficacy that lie at the heart of work engagement, turn into action' (p. 5).

Third, engagement studies have used a range of methodological approaches to examine social aspects of engagement, such as ethnographic studies (Kahn, 1990, 1996, 1998), case studies (Alfes et al., 2010; Gatenby et al., 2009; MacLeod \& Clarke, 2009) and the survey approach (for example, Gatenby et al., 2009; Hudson, 2010; Saks, 2006; Shuck, 2010). Each of these studies has emphasised the importance of: (a) interpersonal interactions (Hudson, 2010; Kahn, 1990); (b) social engagement (Alfes et al., 2010; Gatenby et al., 2009; Soane et al., 2012); (c) employee relationships with supervisors (Saks 2006) and the role of supportive management within the psychological climate (Shuck, 2010); and (d) the social context (Shuck \& Wollard, 2010) to understanding engagement. However, each study researches this relationship using a preponderance of internal related data in contrast to interpersonal data.

To conclude, knowledge about the relationship between managers and employees in association with engagement has largely been generated about managers or employees. In contrast, qualitative details regarding relationships, such as day-to-day interactions, are sparse. As a result, we know much less about the association between engagement and interpersonal relationships than we do about employees' internal engagement relationships with their work and/or their organisation.

To further examine this issue, I explore the notion of attachment. Attachment has been frequently used as a concept within the engagement literature, and has been used to describe leader-follower relationships in the organisational literature (Game, 2011; Keller, 2003; Mikulincer \& Shaver, 2007; Richards \& Hackett, 2012). In addition, attachment theory describes and explains goal-oriented, interpersonal relationships (Crowell \& Waters, 2005).

\subsection{Attachment and Engagement}

The notion of attachment is embedded within definitions of engagement to describe quantities of employees' emotional experience at work regarding their role and/or organisation. This contributes to understandings about the internal dimension of engagement, but it under-uses the capacity of attachment theory to 
shed light on the internal unconscious, and interpersonal dimensions of engagement. To elaborate, I will explore: (a) Kahn's (1995, 1996, 1998, 2002) use of attachment to explore engagement; and (b) the engagement literature more generally.

\subsubsection{Kahn: attachment and engagement.}

Kahn used the notion of attachment to describe internal and external aspects of engagement, and to infer the interpersonal dimension. Kahn (1998) asserted that 'on the surface people form connections with one another on the basis of their tasks and roles' (p. 70) to meet organisational goals. However, Kahn (1998) also stated 'under the surface it is more complicated' (p. 70), because workplace relationships are 'shaped by underlying relational systems' (p. 39). He further described these underlying systems as 'emotional attachments and detachments' (Kahn, 1998, p. 70), which in turn influenced engagement. For example, he described workplace relationships as varying, depending on the strength of the attachment relationship:

Strong attachments contain emotional weight; members are bound to others through experiences of feeling themselves joined, seen and felt, known, and not alone in the context of their work lives. Weak attachments (and their extreme form, detachments) contain little emotional weight; members are superficially connected, if at all. (Kahn, 1998, p. 39)

Kahn also used attachment theory (Bowlby, 1973, 1980) to conceptualise workplace relationships as secure base relationships (Kahn, 1996, 1998), from which employees choose to engage-disengage (Kahn 1995, 1996). As noted above, he described the organisation-employee relationship as changing from a relationship characterised by predictability and security to one that now existed within a 'paradox of self-reliance' (Kahn, 2002). This paradox is characterised by employees experiencing 'insecurity, chaos, and unpredictability' (Kahn, 1998, p. 42) and further reporting experiences of being 'lost, confused, frightened, anxious, or threatened' (Kahn, 1998, p.42).

Bowlby (1988) asserted that the secure base phenomenon was relevant across the lifespan. Consistent with this idea, Kahn (1996) stated that 'secure base relationships... involve skills of asking for caregiving when appropriate and receiving it when offered... people can learn to ask for what they need from 
others' (p. 176). Further, Kahn (1998) directly linked experiences of the secure base at work and engagement:

Organization members may experience anxiety and still remain adults, by requesting and accepting emotional and other types of support in appropriate, temporary ways without becoming infantalized. Doing so may help them remain effectively engaged. ( p. 42)

Furthermore, Kahn used attachment to describe caregiving relationships at work (Kahn, 1993, 1998). Kahn (1998) empirically identified descriptions of caregiving in the workplace that were generated from the clinical case study method, further delineating features of anchoring relationships. For example, caregiving behaviours included accessibility, inquiry, attention, validation, empathy, support, compassion and consistency. Finally, for Kahn, workplace caregiving remained 'part of, rather than separate from, work interactions' (Kahn, 1998, p. 43).

Kahn redefined secure base relationships between children and their parents as anchoring the relationships between adults at work:

Anchoring relationships are those in which co-workers, teammates, or managers and employees create a temporary space for appropriate relational work to occur. Other sorts of tasks (e.g., directing, managing, working alongside, collaborating, and coaching) are temporarily held aside, while people provide bounded, limited support for one another. Organization members may anchor and be anchored, across situations and relationships, and may form a variety of different anchoring relationships with multiple people. (Kahn, 1998, p. 42)

Surprisingly (based on the observation that it is not typically cited), this research from Kahn $(1996,1998,2002)$ sits outside the engagement literature. As such, his work on attachment, workplace relationships, and engagement has been under-used to further understand links between interpersonal workplace relationships and engagement.

\subsubsection{Subsequent descriptions: attachment and engagement.}

Attachment has been used to capture engagement in terms of: (a) quantifying employees' relationships as strong or weak with their organisations and with members of the organisation; and (b) personal patterns of attachment and engagement (Hudson, 2010). However, attachment theory as an interpersonal theory has not been used to develop understandings about the interpersonal dimension of engagement.

First, attachment has been used within descriptions of engagement to capture elements of organisational attachment: 'an individual's psychological and 
behavioural involvement in a social group or unit of which he or she is a member' (Tsui, Egan \& O’Reilly, 1992, p. 556). For example, engagement has been described as (with my italics):

An emotional attachment to the organisation, pride and a willingness to be an advocate of the organisation, a rational understanding of the organisation's strategic goals, values, and how employees fit and motivation and willingness to invest discretionary effort to go above and beyond. (Nokia Siemens Networks, 2008)

John Robertson and Associates (JRA) (2009) stated that engagement referred to:

The extent to which an employee feels emotionally attached to their organisation, the cognitions that underpin that sense of attachment, and the resultant willingness of the employee to go the extra mile in order to help the organisation succeed. (JRA, 2009, p. 1)

References to emotional engagement also include 'displaying an emotional attachment to one or more aspects of their work' (Gourlay et al., 2012, p. 3). This type of engagement was further compared to transactional engagement:

Happy to exhibit the behaviour of engagement, do what is required or expected as long as promised rewards such as promotion or training are forthcoming, but not committed to the job or the organisation and willing to leave if a better offer appears elsewhere. (Gourlay et al., 2012, p. 3)

Attachment is used here to distinguish between 'people doing the job because it's the one they have and people who express an emotional bond to their work, colleagues or the company they work for' (Gourlay et al., 2012, p. 3). Findings from survey and interview data showed that employees who scored higher for emotional engagement, in contrast to transactional engagement, also performed better overall on measures such as wellbeing, task performance and levels of citizenship behaviour (Gourlay et al. 2012). However, as the study was correlation based, it was not possible to ascertain directionality.

Similarly, 'engaged employees have a sense of personal attachment to their work and organisation' (MacLeod \& Clarke, 2009, p. 7). In addition, the Boeing Company defined employee engagement as 'an individual's personal attachment to his or her work on both an intellectual and emotional level' (Savolainen, 2005, p. 1). Sonnentag et al. (2008) used the notion of psychological detachment to describe a process of disengaging from work: 'leaving ones work behind when returning home from work' (p. 260). Finally, Lin (2010) proposed the use of attachment theory to understand work engagement as a form of organisational attachment. However, in this study, attachment was not assessed and attachment theory did not inform the findings' discussion. Overall, these 
examples show that attachment is typically used to delineate the internal dimension of engagement.

Second, attachment theory has been used to examine adult attachment styles and engagement in employees who share the same work environment (Hudson, 2010). Hudson drew on Kahn's (2003) notion that organisations can experience trauma. Organisational trauma can affect work teams and individuals, who in turn might also experience trauma or stress at work. In turn, Kahn proposed this might activate personal attachment experiences as represented by their attachment style.

As background to the Hudson (2010) study, survey-based attachment theory research with adults had identified different attachment styles (Bartholomew \& Horowitz, 1991; Hazen \& Shaver, 1987). Building on Hazen and Shaver's (1987) survey model, in conjunction with the concept of the internal working model (Bowlby, 1969), Bartholomew and Horowitz (1991) proposed that adult attachment styles could be determined by asking questions relating to experiences of: (a) self and other; and (b) anxiety and avoidance. As a result, four different styles of responding to stress in a close relationship were identified.

These styles were based on the interaction of: (a) anxiety and avoidance; and (b) positive and/ or negative views of self and others. The secure style was characterised by a positive view of self and others, with low anxiety about being in the relationship at times of stress and low avoidance of their partner at times of stress. The preoccupied style was characterised by a negative view of self and positive view of others, with high anxiety and low avoidance, when under stress. The dismissing-avoidant style was identified by a positive view of self and negative view of others, with low anxiety but high avoidance of their partner when under stress. The fearful-avoidant style was characterised by a negative view of self and others, with high anxiety about being in the relationship and high avoidance of the relationship when under stress (Bartholomew, 1990; Bartholomew \& Horowitz, 1991).

Hudson (2010) proposed 'individual attachment styles may have an impact on workplace engagement' (p. 41). Table 1 illustrates these hypothesised connections. To test this association, Hudson (2010) used the measure of work engagement (Schaufeli et al., 2006) and the workplace attachment questionnaire (Misciagna, 2005) (adapted from Bartholomew \& Horowitz, 1991). 
Table 1

Individual Attachment Style Behaviours and Levels of Engagement Behaviours (Hudson, 2010, p. 42)

\begin{tabular}{|c|c|c|c|}
\hline \multicolumn{4}{|c|}{ Attachment behaviours } \\
\hline Secure & Preoccupied & Dismissing & Fearful \\
\hline $\begin{array}{l}\text { Objective stance } \\
\text { regarding any } \\
\text { particular } \\
\text { event/relationship } \\
\text { Shows empathy and } \\
\text { provides greater } \\
\text { discretionary effort } \\
\text { Views organisation } \\
\text { as available to help } \\
\text { when distressed } \\
\text { Free to pursue } \\
\text { creativity and } \\
\text { innovation } \\
\text { Helpful to peers and } \\
\text { co-workers }\end{array}$ & $\begin{array}{l}\text { Consistently needs } \\
\text { reassurance and } \\
\text { direction } \\
\text { Less confident in } \\
\text { making decisions } \\
\text { Helpful to others } \\
\text { at the expense of } \\
\text { their own work } \\
\text { Less likely to } \\
\text { volunteer or } \\
\text { initiate projects } \\
\text { Less likely to be } \\
\text { creative }\end{array}$ & $\begin{array}{l}\text { Viewed by others as } \\
\text { being self-important, } \\
\text { and controlling } \\
\text { Capable of } \\
\text { exceptional work but } \\
\text { avoids close } \\
\text { workplace } \\
\text { relationships } \\
\text { Most likely to } \\
\text { automatically reject } \\
\text { any organisational } \\
\text { change } \\
\text { Negative view of } \\
\text { organisation as being } \\
\text { helpful or supportive }\end{array}$ & $\begin{array}{l}\text { Feelings of } \\
\text { unworthiness } \\
\text { Avoids close } \\
\text { involvements that } \\
\text { could lead to } \\
\text { rejection } \\
\text { Likely to abandon } \\
\text { organisation at the } \\
\text { slightest hint of } \\
\text { organisational } \\
\text { disruption or } \\
\text { trauma } \\
\text { View of } \\
\text { organisation as } \\
\text { untrustworthy }\end{array}$ \\
\hline \multicolumn{4}{|c|}{ Engagement behaviours } \\
\hline Engaged & $\begin{array}{l}\text { Engaged to not } \\
\text { engaged }\end{array}$ & $\begin{array}{l}\text { Not engaged to } \\
\text { actively disengaged }\end{array}$ & $\begin{array}{l}\text { Actively } \\
\text { disengaged }\end{array}$ \\
\hline $\begin{array}{l}\text { Curious about the } \\
\text { organisation and } \\
\text { their place in it } \\
\text { Performs at } \\
\text { constantly high } \\
\text { levels } \\
\text { Drives innovation } \\
\text { Meets and exceeds } \\
\text { the expectations of } \\
\text { their role within the } \\
\text { organisation }\end{array}$ & $\begin{array}{l}\text { Must be told what } \\
\text { to do so they can } \\
\text { do it } \\
\text { Feel contributions } \\
\text { are overlooked } \\
\text { Emotions override } \\
\text { productive work } \\
\text { habits and } \\
\text { relationships with } \\
\text { managers and co- } \\
\text { workers } \\
\text { Minimises own } \\
\text { abilities }\end{array}$ & $\begin{array}{l}\text { Concentrates on tasks } \\
\text { rather than goals and } \\
\text { outcomes } \\
\text { Feels full potential is } \\
\text { not being used } \\
\text { Contributions are } \\
\text { overlooked } \\
\text { Undermines engaged } \\
\text { employees' } \\
\text { accomplishments }\end{array}$ & $\begin{array}{l}\text { Consistently acts } \\
\text { out their } \\
\text { unhappiness with } \\
\text { organisations } \\
\text { Ignores engaged } \\
\text { employees } \\
\text { Concentrates on } \\
\text { tasks rather than } \\
\text { organisational } \\
\text { goals or outcomes }\end{array}$ \\
\hline
\end{tabular}

Findings showed a significant statistical correlation between different attachment styles and work engagement. Viewing this study with a multidimensional lens highlights that it collected state of mind (internal dimension) data. It did not collect data concerning the external or interpersonal dimensions. However, similar to other studies cited above, as a research output, this study provided descriptions of engagement and attachment behaviour.

For example, employees with a secure attachment style displayed 'a significant difference in their level of engagement from those individuals with a dismissing and fearful attachment style' (Hudson, 2010, p. 62). Employees with a preoccupied style scored the second highest engagement levels. Based on these 
inferences about engagement behaviour, Hudson (2010) stated that the findings 'might be useful for organizations as a guide to the development of more effective programmes for increasing the level of employee engagement' (p. 63).

In addition, attachment theory informed workplace research has studied engagement related concepts such as organisation commitment and the intention to quit/turnover. For example, higher levels of organisational commitment have been associated with secure attachment and lower levels with ambivalent (preoccupied) and avoidant (dismissing-avoidant) attachment categories (Mikulincer \& Shaver, 2007). Also, higher levels of intention to quit/turnover have been associated with avoidant attachment but not ambivalent attachment, and lower levels of intention to quit/turnover associated with secure attachment (Mikulincer \& Shaver, 2007).

Overall, conceptualising and researching engagement as a multidimensional construct within a social context that includes the manageremployee interpersonal relationship is undoubtedly challenging. The above studies, and especially those of Hudson (2010) and Kahn (1996, 1998) highlight the potential of attachment theory as a base from which to explore connections between internal states of mind about engagement, external engagement behaviour and interpersonal relationships at work.

\subsection{Increasing Levels of Engagement}

Throughout the past decade, low levels of engagement have been reported globally (BlessingWhite, 2008; AonHewitt, 2011; Richman, 2006). In this thesis reasons for low engagement are highlighted using a multidimensional lens and these reasons come into view when reports of low engagement are juxtaposed with ever growing knowledge about engagement, and efforts to increase engagement levels. This lens highlights the simultaneous influence of the dimensions, specifically the effect of social factors on personal experiences and task behaviours. In so doing it highlights three possible under explored reasons for low engagement.

First, knowledge generation about the internal and external dimensions of engagement has been favoured over knowledge generation about interpersonal factors. For example, the contribution of the internal dimension to low 
engagement includes the influence of conscious and unconscious phenomena on how workers interact with their roles, tasks and fellow workers (Kahn, 1990). More recently, Hudson (2010) proposed that employees' attachment styles influence their levels of engagement. Contributing factors from the external dimension have included: (a) contexts external to the employee, such as the global recession (Martin \& Schmidt, 2010); (b) programmes oriented towards a small percentage of high potential staff, 'at most, 10 percent of an organization's workforce' (Cross, Gray, Gerbasi \& Assimakopoulos, 2012, p. 2), and/or an overemphasis on individual rewards, (Cross et al., 2012); and (c) an assumption that high potential staff are always engaged staff (Martin \& Schmidt, 2010).

Second, features concerning the internal dimension are used synonymously to describe features of the external dimension. For example, data pertaining to engagement states of mind are commonly collected using the selfreport survey method: the Q12 (Buckingham \& Coffman, 1999), work engagement (Schaufeli et al., 2002) and job and organisation engagement (Saks, 2006). In turn, this data is then commonly described as engagement behaviour, using expressions such as 'levels of engagement' (e.g. Buckingham \& Coffman, 1999; Hudson, 2010). Then, data originally related to engagement states of mind, but described as engagement behaviour, are directly associated with organisational outcomes (May et al., 2004), such as 'flourishing high performing organisations' (Catteeuw et al., 2007, p. 152). This anomaly is problematic regarding efforts to increase engagement, because it functions in a way that underplays the social context within which engagement occurs.

Third, there is a tendency to assume knowledge about one dimension (such as internal drivers of engagement) equates to change in another dimension, such as external observable engagement behaviour. The following statements illustrate this point: 'Since we know the UK drivers of employee engagement, organisations can begin taking immediate actions to push employee engagement higher' (Wiley, 2010, p. 4); 'If certain specific conditions are appropriately altered, employee engagement will follow' (Macey \& Schneider, 2008, p. 23); 'Certain conditions' (drivers, such as job satisfaction) result in 'a high performing company' (Catteeuw et al., 2007, p. 152); and 'managers influence the job commitment and satisfaction of employees ... If leaders are not held accountable for employee 
motivation or commitment then employees are lacking in direction and may be left to flounder' (WorldatWork, May, 2010).

These anomalies within the literature are evident in programmes designed to increase levels of engagement behaviour (Hudson, 2010; States, 2008). For example, engagement programmes have included talent development programmes (Martin \& Schmidt, 2010) and key driver-analysis strategies (Scherbaum et al., 2010). These programmes primarily focus on changing factors in the external dimension, such as adding talent to increase engagement, thereby increasing positive organisational outcomes. MacLeod and Clarke (2009) estimated that 75 per cent of engagement programmes fitted this genre, where increasing engagement behaviour was viewed as 'a set of activities or targets... an add-on' (p. 72) to what workers should be doing. Only 25 per cent of programmes were underpinned by a view that 'employees are an integral part of developing and delivering the overall business strategy' (MacLeod \& Clarke, 2009, p. 73).

Exceptions to this trend include an engagement intervention programme developed by Cross et al. (2012) that assessed: (a) states of mind pertaining to engagement; and (b) informal person-to-person networks that exist across levels within an organisation. These are called 'organizational network analysis (ONA)' (Cross et al., 2012, p. 2). This intervention explicitly includes the interpersonal dimension. In addition, academic-commercial collaborations, such as the Employee Engagement Consortium in the UK (Alfes et al., 2010; Gatenby et al., 2009), the Voice Project in Australia (Langford, 2010), and the MacLeod and Clarke (2009) report, offer a picture of engagement that highlights the increasingly complex multidimensional picture of engagement. This picture includes Kahn's original ideas pertaining to the internal dimension of employee experience, the external dimension of the work context, social engagement and the business level relationship between individual engagement and business outcomes.

Overall, day-to-day interpersonal conversations that bridge the internal and external dimensions of engagement have been under-explored. This is a problem for furthering understanding about how to increase engagement because between the internal and external dimensions are processes that are 'for the most part social not statistical in nature' (House, Rosseau \& Thomas-Hunt, 1995, p. 85). That is, 'micro and macro processes cannot be treated separately and then 
added up to understand behavior in, or behavior of, organisations' (House et al., 1995, p. 73). This suggests that meso-level understandings about engagement might contribute another perspective to how engagement works in practice, because a meso-level lens analyses the 'intersections of actions in context' (Keyton, Ford \& Smith, 2008, p. 384).

\subsection{Problem Statement and Research Questions}

In sum, theoretical connections between engagement, the manageremployee relationship and attachment are currently under-used to explore engagement. While there is support for the notion of engagement to be viewed as a multidimensional construct, research has focused on the internal and external dimensions and under-examined the interpersonal dimension of engagement. Similarly, the notion of attachment has been used to describe features of the internal and external dimensions, but rarely used to examine the interpersonal manager-employee relationship in association with engagement. As a result, we know little about how the manager-employee interpersonal relationship, as a social context (that includes past and current attachment relationships), influences interactions at work and engagement. Consequently, understanding of the interpersonal dimension of the manager-employee relationship is not readily available to be: (a) theoretically integrated to further understandings about the simultaneous interplay of the dimensions of engagement; or (b) practically integrated into practices and programmes aimed at increasing levels of engagement.

This thesis argues that underplaying the interpersonal dimension of engagement may be contributing to an overarching problem in the field, where two decades of increased knowledge about engagement have not resulted in increased engagement levels. To examine this argument, this thesis asks the following research question and two sub-questions:

How do managers and employees strategically manage their relationship to optimise their engagement at work?

Sub-question one

What is the association (if any) between: the different ways that managers and employees engage with each other about their job, when they are 
under pressure; their states of mind about engagement; and their states of mind about antecedents and outcomes of engagement?

Sub-question two

What can be understood from managers and employees who work together, about their experiences of engagement in association with their relationship?

To empirically examine these questions, an attachment theory informed framework was developed to explore the interpersonal dimension of engagement, in association with features that represented the internal and external dimensions of engagement. Within this framework the manager-employee engagement relationship is the focal unit of analysis. This approach builds on the current understandings of the manager-employee relationship as a driver of engagement. It also fits with calls from within organisational science to research the relationship as a unit of study (Coyle-Shapiro \& Conway, 2004; Coyle-Shapiro \& Shore, 2007; Cropanzano \& Mitchell, 2005; Cunliffe \& Eriksen, 2011; Dachler \& Hosking, 1995; Ferris et al., 2009; Liden, Sparrowe, \& Wayne, 1997). I will now provide an overview of attachment theory and then outline a multidimensional framework for examining the connection between engagement, the manageremployee relationship and attachment.

\subsection{Attachment theory: A Multidimensional Theory}

Attachment theory explores how people in close relationships (across their life spans) draw on each other to regulate distress so they are able to resume dayto-day activities. Attachment theory is a multidimensional theory. The internal dimension is comprised of representations (based on experiences over time) of the secure base system. These representations are commonly referred to internal working models of the secure base system. The interpersonal dimension is characterised by strategic ways of seeking help and providing help to others as way to regulate experiences of pressure and or stress. The external dimension is represented by environmental pressure that can be variously experienced as stressful during exploration (such as playing and or working). 


\subsubsection{The internal dimension: the internal working model of the secure base system.}

Attachment theory asserts that internal cognitive representations of experiences of help, support, and exploration of new things in earlier relationships, collectively form a representation of an interpersonal secure base system (Bowlby, 1969, 1988).

Bowlby (1969) hypothesised internal working models of actual experiences of the secure base system. These models, first developed in infancy traverse the lifespan and concern anticipated sequences of secure base use, provision, and exploration at times of pressure and stress. These models include a person's expectations and beliefs about 'the availability of others, and in turn, the self as worthy or unworthy of care, [which] provides a basic context for subsequent transactions with the environment, most particularly social relationships' (Sroufe, 1988, p. 18). In turn, these expectations and beliefs consist of 'rules that guide responses to stress and shape the ways people manage distress and cope with stressful events' (Mikulincer, 1998, p. 420).

Furthermore, longitudinal studies found continuity in internal working models (states of mind) about attachment over a 20 year period (Crowell \& Waters, 2005). However, where change did occur, this was associated with changes in the 'caregiving environment' (Crowell \& Water, 2005, p. 231), such as a parental death and or serious illness in the parent and or child. Therefore, working models about attachment are strong predictors of qualities of exploration, however, this logic only holds when states of mind and exploration are viewed within the interpersonal secure base system.

\subsubsection{The interpersonal dimension: secure base use and provision.}

The internal representations of attachment influence the interpersonal experiences of the secure base system. Therefore, attachment theory explores people's current interpersonal relationships in conjunction with their representations of their childhood experiences of this system. This is because attachment theory is interested in how cognitive representations of early secure base system experiences are: (a) shaped into unconscious beliefs and expectations about how interpersonal relationships work across the lifespan to get a job done, 
be that job, playing together or working together; and (b) adapted over time across different relationships. Building on the Bowlby-Ainsworth tradition, Crowell et al., (2002) refer to the secure base system in adults using the following terms: secure base use; and secure base support.

Secure base use entails four types of interactions: signalling the need for help, maintaining the signal as needed, proximity seeking and sustaining contact (Crowell et al., 1998). How these interactions manifest in interpersonal relationships are guided by people's conscious and unconscious responses to the following questions: 'Based on my expectations of other persons at times of need for help and support, how do I cue a significant other that I need their help or support?'; 'How available do I think the other person will be?'; and 'What kind of relief/renewed sense of direction do I expect will arise from my cueing and receiving a response from a significant other?' (adapted from Mikulincer et al., 2009).

Secure base support includes: recognition of the signal for help; attention to interpreting the optimal support action to offer; and timely responsiveness. As above, interactions in response to being cued for help are guided by people's personal answers to the following questions: 'Based on my expectations of myself when someone with whom I am in a key caring relationship cues that they need help/support, how do I initially respond to this cue?'; 'In what ways will I make myself available or not?'; and 'What do I expect will be the outcome of my response to the other person?' (adapted from Mikulincer et al., 2009).

\subsubsection{The external dimension: exploration.}

Secure base use and provision are directly connected with exploration. Exploration entails activities and actions, such as learning about oneself and others, in conjunction with learning about how things in the world work. Exploration was originally used to describe childhood behaviours such as play and curiosity (Bowlby, 1969). In adults, exploration involves curiosity (Mikulincer, 1997), leisure activities (Carnelly \& Ruscher, 2000), a new learning environment (Aspelmeier \& Kerns, 2003), and work (Hazen \& Shaver, 1990). Building on Hazen and Shaver (1990), it is also possible that engagement at work 
(with one's work and workplace relationships) might also be a form of exploration.

It is important to distinguish between internal states of mind (that representations about secure base use and provision), the interpersonal context, and exploration: 'The representation may serve as a relatively enduring guide to behavior, feelings, and cognitions in close relationships, but it offers no guarantee that any particular relationship will exactly map onto it' (Crowell et al., 2003, p. 691). This is because the quality of the interpersonal relationship within which the secure base behaviour occurs, is considered to be a primary mediating experience between states of mind and exploration. This notion was first observed by Ainsworth et al., (1978) who noticed qualitative differences in relationships between a toddler and their parent. Specifically differences were noted in the ways the secure base system was used by toddlers to seek support; and how it was used by their parents to provide support; which in turn resulted in qualitatively different exploratory outcomes for the toddler and their parent.

Next, experiences of pressure are thought to activate the secure base system. For example, while playing/working within the exploratory system, experiences of pressure will inevitably activate the need for secure base use (e.g. seeking help); with secure base provision in response (Grossmann, Grossmann, \& Zimmermann, 1999).

Attachment theory asserts a stress-attachment connection to understand differences in exploration. Adult responses to pressure are influenced by patterned sequences of thoughts about the secure base system generally as well as current secure base relationships. In turn, these working models of the secure base system influence the way a person seeks help when needed and responds to others who seek help from them (Mikulincer et al., 2009). The stress-attachment connection asserts that at times of stress, adults are likely to seek help from others and/or offer help to others. This is part of an interpersonal strategy to reduce the effects of stress to resume exploration. In addition, attachment theory asserts that when the process of pressure or stress, support seeking, support provision and stress regulation is viewed in sequence, patterns of stress-attachment are revealed (Ainsworth, Bell, \& Stayton, 1971; Ainsworth et al., 1978; George \& Solomon, 1999). 


\subsubsection{Patterns of attachment.}

Attachment theory asserts that these stress-attachment connections are characterised by unique patterns of interpersonal help seeking and help provision behaviour. These patterns were originally labelled as: secure, ambivalent and avoidant (Ainsworth et al., 1978), with a fourth pattern later identified as disorganised (Main, Kaplan \& Cassidy, 1985; Main \& Solomon, 1990). Each pattern informs how the dyad typically works together to regulate experiences of stress, and is further described as strategic variations of regulation (Mikulincer, 1998).

The secure strategy is characterised by confident and timely help provision in response to cues for support seeking; over time, establishing a confidence in the relationship that distress will be regulated. In turn, exploration was freely engaged in due to confidence in the secure base system should it be activated.

The anxious-ambivalent strategy is characterised by a heightened response to stress, with little use of the secure base use system, combined with unreliable help provision. In this strategy, stress remains high and exploration is not freely engaged in, due to uncertainty that the secure base system will regulate distress.

In contrast, the avoidant strategy is characterised by a muting of the stress experience. Minimal use of the secure base system ensures a quality of secure base provision that was task focused, but emotionally low key. Essentially, this strategy self regulates, in contrast to drawing on the relationship in the secure strategy, as a way to return to exploration.

Finally, the disorganised strategy was identified by Main and Solomon (1990) using data that had been initially categorised as 'unclassifiable' by Ainsworth and her colleagues (Ainsworth et al., 1978). This strategy is characterised by a heightened response to stress, with little use of the secure base use system; combined with little help provision on the part of the parent. For example the parent might be frightened themselves by the child's secure base use, or be frightening to the child as a response to their cues for support. In this strategy, there is no resolution to relationship distress. It is called disorganised, as the external view of the behaviour does not make sense. However, the strategies that children learn in order to protect themselves in their caregiving relationship are highly organised. Exploration can be excessive or totally restricted, with 
neither option providing regulation from the initial distress (Main \& Solomon, 1990).

Furthermore, attachment theory and the notion of attachment patterns of behaviour evolved from observational studies (Bowlby, 1969; Ainsworth et al., 1978). Based on these studies, adult attachment theory advanced and has focused on developing understandings about patterned states of mind about attachment. As a result three methodologies emerged: (a) a survey-based approach (Hazen \& Shaver, 1987; Bartholomew \& Horowitz, 1991) (as cited above); (b) a narrativebased approach (Main, 2000; Main et al., 1985); and (c) an observational approach (Crowell et al., 2002).

The survey based approach emphasises self reports of adult attachment styles and has been used as an extension of personality/trait theory. Attachment theory-workplace informed research has favoured this approach (Harms, 2011; Hudson, 2010; Neustadt et al., 2011). For example it has been used as a personality like classification system (Hudson, 2010). It has also been used as a continuum of psychometric constructs such as anxiety-avoidance (Mikulincer \& Shaver, 2007) where: high anxiety reflects the preoccupied pattern; high avoidance the avoidant pattern; and low anxiety and avoidance, the secure pattern (Bartholomew \& Horowitz, 1991).

In contrast, the narrative-interview approach emphasises adult's states of mind concerning engagement. This approach examines the interpersonal secure base system, in contrast to developing knowledge about personality-like attachment styles. For example, using narratives from adults about their recollected experiences of being parented, four distinct states of mind are identified: autonomous; dismissing; preoccupied; and unresolved (Main et al., 1985). Each mind state is identified by mapping how past experiences were remembered, in contrast to what happened.

First, in the autonomous state of mind, past experiences of being parented are recalled in a balanced way, with positive and negative experiences, and a ready supply of examples to support the recollected experiences. Second, in the dismissing state of mind recollections of experiences of being parented are talked about in generally highly positive ways. However, recalling examples is challenging and there is a tendency to dismiss earlier experiences as being of little influence on their current relationships. Third, in the preoccupied state of mind, 
experiences of being parented are talked about in emotionally charged ways. Recollections are very clear, as if they occurred yesterday. Examples are plentiful but they are characterised by negative, lengthy and entangled stories that both devalue and other times idealise their parents. Fourth, in the unresolved state of mind, experiences are recalled in ways that reflect all of the above characteristics but lack coherence, are confusing to follow and often contain experiences of being frequently afraid of one or both parents.

Research has shown that adult attachment states of mind influence current interpersonal relationships in relatively predictable ways (Grossmann et al., 2005). For example, mind states in adults predicted patterns of relating between parents and their children in the secure base system and, in turn, predicted children's attachment behaviour in these relationships (Grossmann \& Grossmann, 1991; van Ijzendoorn, 1995). That is, how past events were recalled and talked about in the present by adults, was a better predictor of attachment experiences in current relationships (such as with their partners and or children), when compared with a case history of events.

For example, irrespective of past experiences, a current autonomous mind state in a parent was correlated with children showing secure attachment behaviour; the preoccupied mind state in a parent was correlated with their children having ambivalent attachment behaviour; the dismissing mind state was correlated with children with avoidant attachment behaviour; and the unresolved mind state was correlated with children with disorganised attachment behaviour. More recently, these states of mind-attachment and behaviour pairings have been reconceptualised as secure base scripts which have been accessed using narrative and observational methods (Crowell \& Waters, 2005; Crowell et al., 2002; Waters $\&$ Waters, 2006). Table 2 outlines the three most common attachment patterns and attachment states of mind in relation to the varying secure base scripts about secure base use and provision. 
Table 2

Attachment Patterns, Secure Base Use and Secure Base Support.

\begin{tabular}{|c|c|c|}
\hline $\begin{array}{l}\text { Attachment pattern } \\
\text { Attachment state of } \\
\text { mind }\end{array}$ & Secure base use & Secure base support \\
\hline $\begin{array}{l}\text { Secure } \\
\text { Balanced }\end{array}$ & $\begin{array}{l}\text { Confident in their capacity } \\
\text { to cue for help, and } \\
\text { maintain the cue until help } \\
\text { is provided. } \\
\text { Acknowledge distress } \\
\text { without being } \\
\text { overwhelmed. } \\
\text { Flexible and constructive } \\
\text { under stress. } \\
\text { Being helped provides } \\
\text { relief and an easy transition } \\
\text { back into exploration. }\end{array}$ & $\begin{array}{l}\text { Confident in their capacity } \\
\text { to be available when } \\
\text { needed. } \\
\text { Not overwhelmed by } \\
\text { another's need for } \\
\text { emotional proximity. } \\
\text { Stay with the support until } \\
\text { the other person is ready to } \\
\text { resume exploration. }\end{array}$ \\
\hline $\begin{array}{l}\text { Avoidant } \\
\text { Dismissing }\end{array}$ & $\begin{array}{l}\text { Tend to self-regulate stress } \\
\text { before cuing for help. } \\
\text { Self-reliance precedes help } \\
\text { seeking. } \\
\text { Focus on need for support } \\
\text { for a task and dismiss } \\
\text { emotional needs. }\end{array}$ & $\begin{array}{l}\text { Provide support but } \\
\text { minimise emotional } \\
\text { support. } \\
\text { Support is practical and task } \\
\text { focused. } \\
\text { Preference for supporting } \\
\text { just enough to see the other } \\
\text { person get back to } \\
\text { exploration. }\end{array}$ \\
\hline $\begin{array}{l}\text { Anxious-ambivalent } \\
\text { Preoccupied }\end{array}$ & $\begin{array}{l}\text { Tend to regulate stress by } \\
\text { hyper-activating their need } \\
\text { for others. } \\
\text { Anxiety increases due to } \\
\text { belief about the uncertainty } \\
\text { of others' availability to } \\
\text { match their needs. } \\
\text { Exploration is returned to } \\
\text { with a wariness regarding } \\
\text { venturing too far away in } \\
\text { case help is not available } \\
\text { when needed. }\end{array}$ & $\begin{array}{l}\text { Responding to the } \\
\text { emotional needs of others } \\
\text { can be stressful and raise } \\
\text { self-doubt about one's } \\
\text { availability to respond or } \\
\text { not. } \\
\text { Resolution occurs via an } \\
\text { expiration of emotional } \\
\text { need in contrast to a } \\
\text { cooperative problem solving } \\
\text { experience. } \\
\text { Dance between hyper- } \\
\text { activated availability and } \\
\text { passive unavailability. }\end{array}$ \\
\hline
\end{tabular}

Adapted from: Ainsworth et al.(1978); Crowell \& Waters (2005); Main \& Solomon (1990); Mikulincer (1998); and Mikulincer et al.(2009). 


\subsubsection{Secure base strategies and goal sharing.}

In addition to the continuum approach to viewing attachment patterns, this theory asserts that varying secure base scripts (Crowell et al., 2002) influences the capacity to collaborate on shared goals. In the early days of attachment theory research it was assumed that optimal collaboration was akin to a 'Fred-and Ginger model of dyadic synchrony' (Tronick \& Beeghly, 2011, p. 111), characterised by enduring positivity between the partners and low levels of conflict. However, recent infant-parent research has not found support for this assumption (Cohn \& Tronick, 1989; Tronick, 1989). Instead, the new findings have found that:

The typical interaction is messy. It moves from matching (coordinated, synchronous) states of shared meanings and intentionality to mismatched (miscoordinated, dys-synchronous) states and back to matching intentional states via an active, shared reparatory process. (Tronick \& Beeghly, 2011, p. 112)

By implication, the notion of messy goal oriented patterned secure base use and provision when under pressure or stress could in part explain patterned variations in exploratory behaviour, such as engagement. Therefore, drawing on attachment theory to view the manager-employee relationship in association with engagement, it is possible that managers and employees may employ different patterns of interpersonal secure base use and provision at work; and these in turn may be associated with variations in: a) mind states pertaining to attachment (the internal working model) and engagement; b) responses to experiences of pressure at work; and c) exploratory behaviour such as engagement. To explore this idea further I now develop an attachment theory framework of engagement as a multidimensional system centred on manager-employee social engagement strategies.

\subsection{Engagement: A Multidimensional System}

The secure base phenomenon provides a theoretical base from which to explore the manager-employee relationship as an interpersonal context of engagement. Cited above, the secure base system crosses contexts; and engagement is influenced by the interplay of multiple contexts. As such, the manager-employee interpersonal relationship is explored as part of a multidimensional system of engagement contexts, including the internal and 
external contexts of engagement. The key features of this system are illustrated in Table 3.

Within this hypothesised system, the external context was represented by:

(a) stress in the work context, experienced while doing one's job; and (b)

organisational factors, such as organisational structure and the effects of the economic climate.

Next, the interpersonal dimension was represented by secure base use and provision strategies (Crowell et al., 2002) as a shared regulation system (Tronick, 1989) (an extension of the concept of social engagement). A new construct was developed to capture this dimension: manager-employee social engagement strategies. This construct is described below in section 2.8 and traverses dimensions. As interpersonal dimension it focuses on the interactions entailed in secure base use and provision; as an internal dimension it represents internal working models of the secure base system; and as an external dimension, it acknowledges experiences of pressure as primer experiences for the activation of the secure base system.

The internal dimension was represented by states of mind pertaining to engagement and attachment. First, to represent engagement, I chose the concepts of job engagement (Saks, 2006) and organisation engagement (Saks, 2006). Academic engagement research typically uses the concept of work engagement (Schaufeli \& Bakker, 2003) (see Shuck, 2010) with the UWES measure of work engagement. However, in this study I used the concepts and measures of job engagement (Saks, 2006) and organisation engagement (Saks, 2006) as a way to capture two aspects of the internal multidimensional nature of engagement. My rationale for this decision was pragmatic and directly related to methodological issues, of which I elaborate on in Chapter 3 (Section 3.2.4). 
Table 3

The Manager-Employee Relationship, Attachment and Engagement: A multidimensional system of connections.

\begin{tabular}{|c|c|c|}
\hline Dimensions & $\begin{array}{l}\text { Engagement as a } \\
\text { multidimensional system }\end{array}$ & $\begin{array}{l}\text { The Manager-Employee relationship as a } \\
\text { multidimensional secure base system }\end{array}$ \\
\hline \multirow[t]{2}{*}{ External } & $\begin{array}{l}\text { Organisational structures. } \\
\text { The organisational secure base } \\
\text { construct (Kahn, 1998). }\end{array}$ & $\begin{array}{l}\text { Pressure that is experienced during the process of } \\
\text { exploration and activates the internal and } \\
\text { interpersonal dimensions. }\end{array}$ \\
\hline & & $\begin{array}{l}\text { When under increasing pressure, historical and } \\
\text { current attachment patterns within relationships } \\
\text { affect the quality of the manager-employee } \\
\text { relationship which in turn influences exploration, a } \\
\text { possible form of engagement. }\end{array}$ \\
\hline \multirow[t]{2}{*}{ Internal } & $\begin{array}{l}\text { States of mind about engagement, } \\
\text { such as JE and OE; antecedents } \\
\text { (POS and PSS); and outcomes } \\
\text { (OC and ItQT). }\end{array}$ & $\begin{array}{l}\text { States of mind about the secure base system } \\
\text { reflected in patterns of secure base use and support } \\
\text { affect levels of engagement. }\end{array}$ \\
\hline & $\begin{array}{l}\text { 'Underlying systems of emotional } \\
\text { attachments and detachments' } \\
\text { (Kahn, 1998, p. 70). }\end{array}$ & $\begin{array}{l}\text { Secure base scripts (Crowell et al., 2002) affect the } \\
\text { capacity to collaborate on shared goals. }\end{array}$ \\
\hline \multirow[t]{3}{*}{ Interpersonal } & $\begin{array}{l}\text { Social engagement: Purposeful } \\
\text { conversations at work about the } \\
\text { tasks and goals of the organisation } \\
\text { (Alfes et al., 2010; Gatenby et al., } \\
\text { 2010; Soane et al., 2012). }\end{array}$ & $\begin{array}{l}\text { Secure base use and secure base support work in } \\
\text { tandem through the sequence of strategic } \\
\text { interactions oriented towards reducing } \\
\text { stress/pressure to provide a pathway for exploration } \\
\text { such as engagement. }\end{array}$ \\
\hline & & $\begin{array}{l}\text { Pattern of secure base use and support affects the } \\
\text { capacity to sustain a balance between social } \\
\text { engagement and getting a job (such as engagement) } \\
\text { done (Crowell et al., 2002). }\end{array}$ \\
\hline & & Manager-employee social engagement strategies. \\
\hline
\end{tabular}

To further represent the internal dimension, I chose a selection of antecedent and outcome variables of engagement. My choice of these variables, were in large part informed by my choice to use the measures of job engagement and organisation engagement. As such I selected measures from the Saks (2006) study that were shown to be significantly associated with job and organisation engagement; and that had also been used in other engagement studies. As a result, perceived organisational support, and perceived supervisor support represented antecedents; and organisational commitment and the intention to quit/turnover, represented outcome variables. 
Moreover, states of mind about attachment, also represented 'underlying systems of emotional attachments and detachments' (Kahn, 1998, p. 70) pertaining to engagement. To this end, attachment states of mind were represented by the survey based attachment Relationship Questionnaire (Bartholomew \& Horowitz, 1991)(see section 3.2.4.8). In addition, the newly constructed concept of manager-employee social engagement strategies (described below and in section 2.8) also represented the internal context. Of note and elaborated on in Chapter 3, this new concept was operationalised as a survey, capturing the internal dimension and in turn the survey was also used as a tool within the interpersonal context of the manager-employee dyad relationship interviews.

Finally, the loose and messy connections between the dimensions function together as a system of engagement. For example, internal mind states of attachment, could affect interpersonal use and provision of secure base strategies at work; and these in turn might influence managers' and employees' capacity to maintain the exploratory system, such as engagement. Conceptualising engagement and its contexts in this way provides a clear view of the interpersonal context of engagement, which in turn provides an opportunity to further understanding about the influences of the multidimensional contexts on engagement.

In addition, this hypothesised system was underpinned by the following assumptions. First, reflecting Tronick and Beeghly's (2011) view of social engagement, engagement as a shared goal between managers and employees will be messy, and at times more dys-synchronous than synchronous. Second, the amount and frequency of social engagement may also be influenced by varying social engagement strategies. Third, these strategies might contribute to varying levels of engagement behaviour.

\subsection{Manager-Employee Social Engagement Strategies: A Multidimensional Concept}

Engagement, the manager-employee relationship and attachment converge within the multidimensional concept of manager-employee social engagement strategies. Reflecting the multidimensional contexts of engagement as a system, these strategies include: 
1. Internal states of mind pertaining to attachment.

2. Interpersonal patterned secure base use and support interactions that occur between managers and employees at times of stress and that may temporarily interrupt exploratory behaviour, such as engagement.

3. Interpersonal strategies that aim to affect the experience of the external dimension by decreasing stress to remobilise exploratory behaviour towards organisational goals.

Based on the criteria established by Law, Chi-Sum and Mobley (1998) for developing multidimensional constructs, I developed the concept of manageremployee social engagement strategies as a latent concept. The higher-order factor of manager-employee social engagement (MESE) strategies, underpinned the components of each unique but related strategy: (a) connect-act; (b) disconnectact; and (c) stress-immobilise. I now describe these hypothesised strategies. In Chapter 3, I outline the operationalisation and scale development process for each newly hypothesised strategy.

\subsubsection{Connect-act (SECA).}

This strategy is connected with secure attachment (Bartholomew \& Horowitz 1991) and corresponding secure base use and provision (Crowell et al., 2002). For example, workers who used this strategy would likely fit the following description, 'shows empathy and provides greater discretionary effort; and views organization as available to help when distressed' (Hudson, 2010, p. 42). In attachment terms these observations are underpinned by a strategy that entails, when under pressure: cueing for help by acknowledging the stress while also being able to focus on task oriented solutions. This is because there is confidence in the availability of the secure base use and support systems when under pressure. Connecting with others around the stress, with a focus on problem solving supports engagement.

\subsubsection{Disconnect-act (SEDA).}

This strategy is connected with dismissing-avoidant attachment (Bartholomew \& Horowitz, 1991), with corresponding secure base use and provision (Crowell et al., 2002). For example, managers and employees using this 
strategy might be described as 'capable of exceptional work but avoids close workplace relationships; [and has a] negative view of the organization as being helpful or supportive' (Hudson, 2010, p. 42). In attachment terms these observations are underpinned by a strategy that entails disconnecting from others at times of stress, avoiding secure base use, while becoming increasingly task focused as a way to manage stress, enabling return to exploration. This strategy has been associated with a lack of confidence in secure base support systems availability in times of pressure, balanced with a confidence in self-support when under pressure.

\subsubsection{Stress-immobilise (SESI).}

This strategy is connected with preoccupied attachment (Bartholomew \& Horowitz, 1991) and corresponding secure base use and secure base support (Crowell et al., 2002). For example, use of this strategy might include a tendency to experience or show high levels of stress at work and needing a lot of 'reassurance and direction' (Hudson, 2010, p. 42). In attachment terms, these observations might be underpinned by a strategy that entails experiencing high levels of stress and cueing others about this, but not being able to make use of the offered help effectively. This is because of an anxiety that others will be unreliable. In turn, this preoccupying uncertainty might immobilise efforts, or reduce the capacity to use help when offered. This may culminate in being somewhat immobilised to get on with one's job.

\subsubsection{Proposition 1.}

Proposition 1: The three theorised manager-employee social engagement strategies will be reliable and associated with a pre-validated survey measure of adult attachment.

As these strategies are theoretically informed, it is anticipated that they will each uniquely relate to the established attachment classifications of secure (connect-act), dismissing-avoidant (disconnect-act); and preoccupied (stressimmobilise).

Hypothesis 1: Manager-employee social engagement strategies can be represented by three related but unique strategies: connect-act; disconnectact; and stress-immobilise. 
Hypothesis 2: Manager-employee social engagement strategies will correlate with the Relationship Questionnaire (RQ) attachment categories. Specifically: (a) connect-act will be positively correlated with secure; (b) disconnect-act will be positively correlated with dismissing-avoidant; and

(c) stress-immobilise will be positively correlated with preoccupied.

\subsubsection{Additional propositions and hypotheses.}

Next, associations between the new concepts and existing engagement concepts are considered. The purpose of this step was to ascertain associations within the internal context as a step towards examining the interpersonal context of engagement. As such, the following propositions and hypotheses were made about the associations between: (a) the three manager-employee social engagement strategies; and (b) the internal dimension of engagement, represented by engagement concepts, and antecedent and outcome concepts of engagement.

Proposition 2: There will be an association between the manager-employee social engagement strategies and engagement related concepts.

Reflecting the reviewed literature above, associations between the three manager-employee social engagement strategies and the following engagement, antecedents and outcomes of engagement were hypothesised: perceived organisational support, perceived supervisor support, job engagement, organisation engagement, organisational commitment and intention to quit/turnover.

First, regarding the connect-act and engagement related concepts. The use of the connect-act strategy was characterised by confidence and certainty in secure base use and provision. As such, it was expected that use of this strategy would be positively associated with perceived organisational support and perceived supervisor support. This is because this strategy is underpinned by a generally positive view of self and others as potentially helpful at times of stress and pressure (Bartholomew \& Horowitz, 1991). It was also anticipated that the use of this strategy, when under pressure would be positively associated with job engagement and organisation engagement. Regarding organisational outcomes, given the capacity to draw on the interpersonal dimension as part of functioning in the external dimension, such as getting the job done, it would be expected that use 
of this strategy would be positively associated with organisation commitment and negatively associated with intention to quit/turnover. Furthermore, higher levels of job engagement and organisation engagement have been associated with higher levels of organisational commitment and lower levels of intention to quit/turnover (Saks, 2006).

Hypothesis 3: Connect-act will be positively associated to perceived organisational support and perceived supervisor support.

Hypothesis 4: Connect-act will be positively associated to job engagement and organisation engagement.

Hypothesis 5: Connect-act will be positively associated to organisational commitment and will be negatively associated to intention to quit/turnover.

Second, regarding the disconnect-act strategy and engagement related concepts. Use of this strategy was characterised by a self confidence to work through issues of concern with minimal use of the interpersonal dimension of the secure base system at times of pressure. In turn, use of this strategy was characterised by a reduced confidence in an organisation's capacity to be helpful and/or supportive, and it is assumed that this reduced confidence in others may also transfer to supervisors. Hence, it was anticipated that the use of disconnectact strategy might be negatively associated with perceived organisational support and perceived supervisor support. This is because this strategy is underpinned by a generally positive view of self and negative view of others as being potentially helpful at times of stress and pressure (Bartholomew \& Horowitz, 1991).

It was also expected that the use of this strategy when under pressure would be positively associated with job engagement because under stress focus turns towards the task. However, it was expected that use of this strategy would be negatively associated with organisation engagement because of the associated negative view of others as helpful at times of stress. Regarding organisational outcomes, given the capacity to stay on task in the absence of working alongside others, a limited reliance on and confidence in the organisation would be expected, suggesting this strategy would be positively associated with organisational commitment and negatively associated with intention to quit/turnover.

Hypothesis 6: Disconnect-act will be negatively associated to perceived organisational support and perceived supervisor support. 
Hypothesis 7: Disconnect-act will be positively associated to job engagement and negatively associated to organisation engagement.

Hypothesis 8: Disconnect-act will be positively associated to organisational commitment and negatively associated to intention to quit/turnover.

Third, concerning the stress-immobilise strategy and engagement related concepts. Use of this strategy was characterised by a lack of self confidence to work through issues of concern with increased use of the interpersonal dimension of the secure base system at times of pressure. It was expected that use of this strategy would be positively associated with perceived organisational support and perceived supervisor support. This is because this strategy is underpinned by a generally positive view of others as potentially helpful (albeit they might be experienced as unreliably unhelpful) (Bartholomew \& Horowitz, 1991). However, it was also expected that the capacity to use this potential support for getting on with the job might be compromised because of the tension between exploration and the possibility of unavailable support.

Consequently, it was predicted that using this strategy when under pressure would be negatively associated with job engagement and organisation engagement. Further, as low job engagement and organisation engagement have been associated with lower levels of organisational commitment and higher levels of intention to quit/turnover (Saks, 2006), it was expected that this strategy would also be negatively associated with organisational commitment and positively associated with intention to quit/turnover.

Hypothesis 9: Stress-immobilise and will be positively associated to perceived organisational support and perceived supervisor support.

Hypothesis 10: Stress-immobilise will be negatively associated to job engagement and organisation engagement.

Hypothesis 11: Stress-immobilise will be negatively associated to organisational commitment and positively associated to intention to quit/turnover.

In sum, hypotheses one through to eleven address the expected associations between the manager-employee social engagement variables (connect-act; disconnect-act; and stress-immobilise) and job engagement and organisation engagement, as well as perceived organisational support and 
perceived supervisor support, and the outcome variables of organisational commitment and the intention to quit/turnover.

Next, to examine the potential contribution of the new concepts to understanding engagement, a new model was constructed: Model 1 (Figure 1).

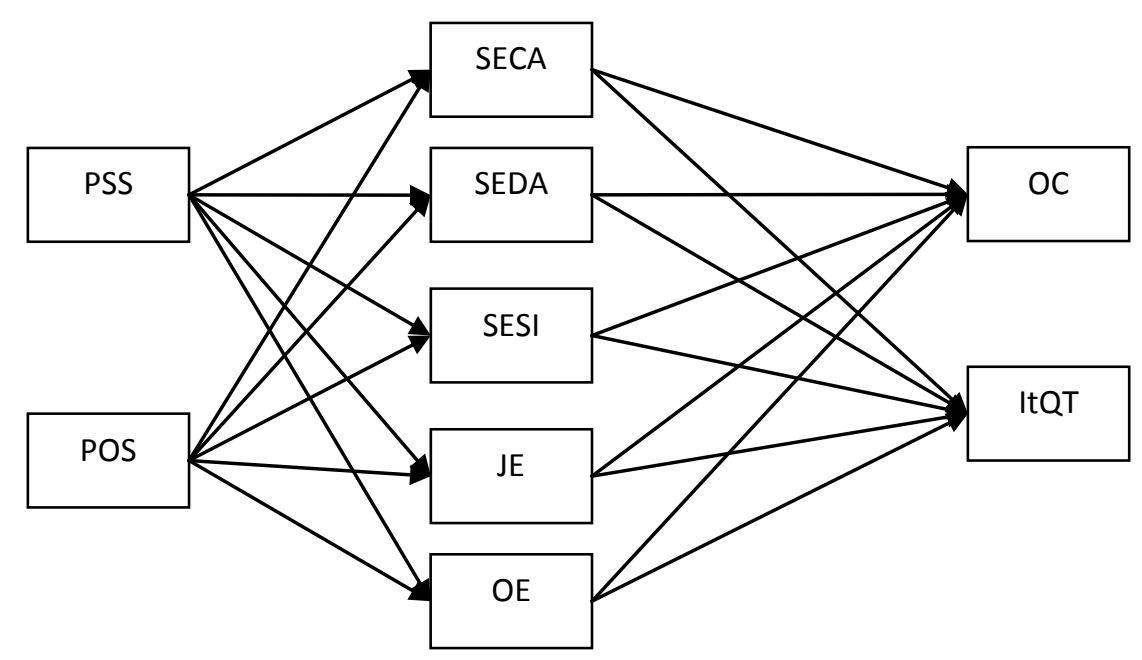

Notes: Perceived Organisational Support (POS), Perceived Supervisor Support (PSS), Job Engagement (JE), Organisation Engagement (OE), Social Engagement Connect-Act (SECA), Social Engagement Disconnect-Act (SEDA), Social Engagement Stress-Immobilise (SESI), Organisational Commitment (OC) and Intention to Quit/Turnover (ItQT).

Figure 1. Model 1.

Model 1 includes concepts typically seen in engagement models that represent the internal dimension: (a) job engagement and organisation engagement represent states of mind pertaining to levels of engagement; (b) perceived organisational support and perceived supervisor support represent antecedents of engagement; and (c) organisational commitment and the intention to quit/turnover represent outcomes of engagement. These variables were chosen because they are commonly used as concepts in models of engagement (Judhi et al., 2013; Saks, 2006; Shuck et al., 2011). In addition, Model 1 also includes the internal and interpersonal concept of manager-employee social engagement strategies.

In contrast, Model 2 (Figure 2) is an example of a typical engagement model that draws predominantly on concepts and data pertaining to the internal dimension of engagement. 


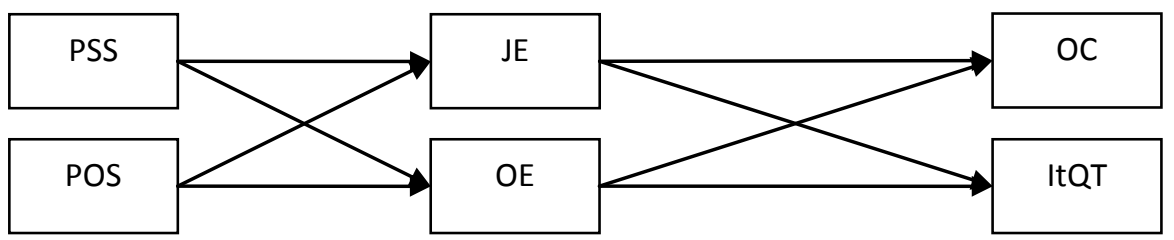

Figure 2. Model 2 (excluding SESI, SECA, and SEDA).

Looking at these models, it is anticipated that Model 1 will have stronger predictive and explanatory power than Mode1 2. This is because Model 1 explicitly includes perceptions of the manager-employee relationship, a driver of engagement; and Model 2 does not.

Proposition 3: Model 1 will better predict engagement and engagementrelated outcomes than Mode1 2.

Hypothesis 12: Perceived organisational support, perceived supervisor support, stress-immobilise, connect-act and disconnect-act with job engagement and organisation engagement will better predict organisational commitment and intention to quit/turnover, than perceived organisational support, perceived supervisor support, job engagement and organisation engagement alone.

Proposition 4: Within Model 1, connect-act and disconnect-act will work differently from stress-immobilise in relation to engagement.

Based on understandings about the secure base system and the proposed use of secure base systems in the workplace-Proposition 4-relates to the possibility that the connect-act and disconnect-act strategies might interact differently as social engagement strategies in relation with job engagement and organisation engagement when compared with stress-immobilise. This is because both the connect-act and disconnect-act strategies result in the capacity to explore when under pressure, which may equate with the capacity to sustain engagement with one's job and organisation. However, use of the stress-immobilise strategy when under pressure is likely to result in reduced exploration which in turn could negatively affect the capacity to engage with the job and/or the organisation.

To elaborate, in Model 1A (Figure 3), connect-act and disconnect-act are situated as possible mediators between job engagement and organisation engagement, and between organisational commitment and intention to quit/turnover. This is because for both of these strategies, stress at work is most 
likely to occur during the process of exploration. That is, while engaging with the work/job/organisation without underlying concerns regarding support, as might be the situation when the stress-immobilise strategy is in use. This is because, connect-act and disconnect-act secure base strategies are based on a confidence that in the presence of pressure, (a) others will be readily available to offer support (connect-act), or (b) one's own capacity to cope and get on with the job, even when under a lot of pressure, as in the case of the disconnect-act strategy.

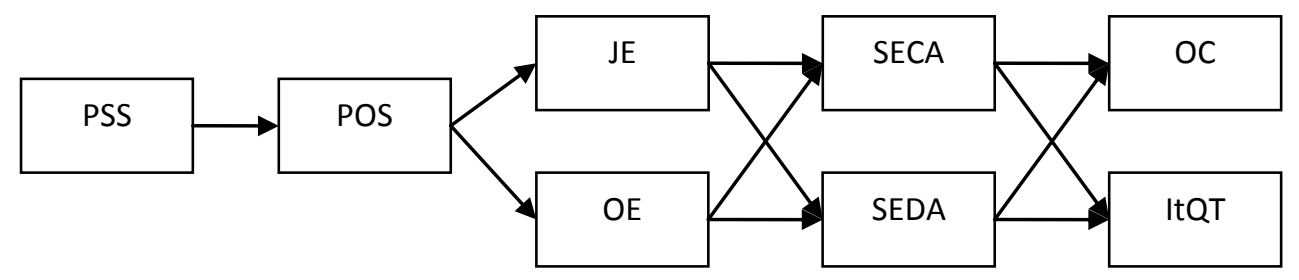

Figure 3. Model 1 A (with SECA and SEDA mediating between JE, OE and OC, ItQT).

Moreover, because connect-act and disconnect-act strategies promote exploration, it is anticipated that these two strategies will mediate between job engagement and organisation on the one hand, and organisational outcomes on the other. This is because of the positively reinforcing sequence of interactions between (a) doing one's job and feeling inevitable pressure, and (b) feeling able to cue for help (positive view of self) and receive help (positive view of others) to resume work (connect-act). It also includes feeling able to self manage pressure (positive view of self and negative view of others to be helpful) (disconnect-act), followed by resuming work. Based on these assertions, it is hypothesised that levels of organisational commitment would remain high and intention to quit/turnover would be low.

In contrast, in Model 1B (Figure 4) job engagement and organisation engagement were identified as mediators between stress-immobilise, and organisational commitment and intention to quit/turnover. This is because for people most likely to use this social engagement strategy, stress at work is likely to be activated from a combination of doing the job while also being worried about a potential lack of available support if required. Uncertainty with regard to perceived organisational support may activate the stress-immobilise strategy 
which in effect reduces exploration. As a result this may also be reflected in decreased engagement.

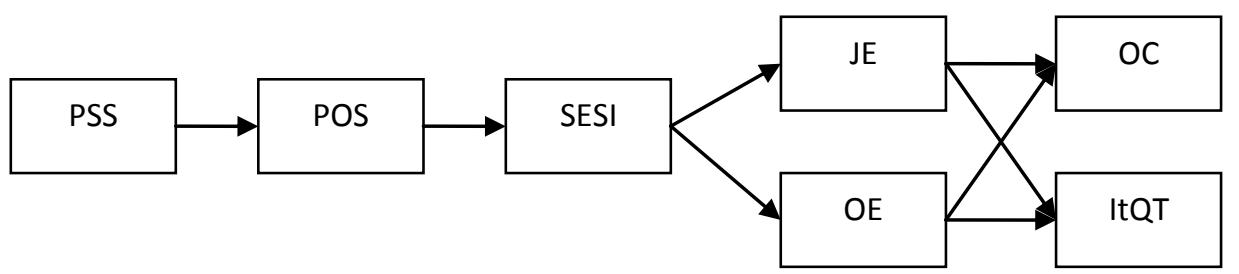

Figure 4. Model 1B. JE and OE mediating between SESI and OC and ItQT.

As cited above, low job engagement and organisational engagement have been associated with lower levels of organisational commitment and higher levels of intention to quit/turnover. Therefore, as the experience of exploration when using a stress-immobilise strategy is likely to activate the secure base system, it is anticipated that job engagement and organisation engagement would mediate between stress-immobilise and organisational commitment and intention to quit/turnover. This is because of a negatively reinforcing sequence whereby doing one's job (exploration) activates the secure base system. In turn, this typically raises feelings of uncertainty about being able to cue for help. As a result, the workers are stuck between needing help and not being sure how to get help so as to reduce their anxiety. These experiences may function to reinforce a negative view of one's efficacy to effect change and results. This could (understandably) increase the intention to quit/turn overt and decrease organisational commitment.

Furthermore, in Model 1A and Model 1B, the perceived supervisor support variable is situated as an exogenous variable leading to perceived organisational support (now represented as an endogenous variable). The rationale for this change is as follows. As stated above, Saks (2006) did not find an association between perceived supervisor support and job engagement and organisation engagement. However, Eisenberger, Stinglhamber, Vandenberghe, Sucharski and Rhoades (2002) suggested that perceived supervisor support leads to perceived organisational support because supervisors are frequently identified as representing the organisation. As such, in this hypothesised model, perceived 
organisational support is situated as a mediating variable between perceived supervisor support and stress-immobilise.

Hypothesis 13: Connect-act and disconnect-act will mediate between job engagement and organisation engagement, and the outcome variables of organisational commitment and intention to quit/turnover; and perceived organisational support will mediate between perceived supervisor support, and job engagement and organisation engagement.

Hypothesis 14: Job engagement and organisation engagement will mediate between stress-immobilise and the outcome variables of organisational commitment and intention to quit/turnover; and perceived organisational support will mediate between perceived supervisor support and stressimmobilise.

In summary, the models above illustrate the internal context of engagement. They are tested in this study by specifically addressing sub question one. However, this study also aims to capture the interpersonal context of engagement. To support this aim, the external context is viewed in conjunction with the internal context of engagement providing a pathway to the interpersonal context (which is specifically examined by addressing sub question two in the manager-employee dyad case studies). The external context is represented by here in two ways: (a) pressure and stress; and (b) organisational goals.

\subsubsection{Manager-employee social engagement strategies: pressure and stress.}

I defined the concepts of pressure and stress in Chapter 1. As described above, each strategy reflects understandings within attachment theory about how the following secure base system elements are connected: (a) pressure and stress; (b) within-person internal working models of relationships at times of pressure; and (c) between-persons interpersonal sequences of help seeking and help provision strategies and exploratory behaviour (such as play and work) (Cassidy \& Shaver, 2008).

I now elaborate on how the experiences of pressure and stress (Ganster \& Rosen, 2013) might relate to further understanding the manager-employee social engagement strategies. Traditional views of stress at work have emphasised stressors external to the worker, such as work load and conditions. Recent research highlights a complex interplay between psychological and physiological 
processes and worker health outcomes (Ganster \& Rosen, 2013). Similarly, attachment theory research has also studied the complex interplay between attachment experiences, stress and physiology (Porges, 2011). In addition, attachment theory has directly studied factors experienced within the interpersonal relationship as a way to understand the role of stress on exploratory behaviour (Kobak, Cassidy, Lyons-Ruth, \& Ziv, 2006; Lyons-Ruth \& Jacobvitz, 2008).

Connections between stressors and or buffers of stress, secure base use and provision within the manager-employee relationship and engagement, has to my knowledge been under-examined. In this study it was anticipated that use of each manager-employee social engagement strategy might highlight unique ways of experiencing pressure and stress at work, combined with unique responses concerning interpersonal relationships and engagement. For example:

1. The use of connect-act might be associated with experiences of pressure mostly being located in the external dimension and buffered against by activating internal and interpersonal resources.

2. The use of disconnect-act might be associated with experiences of pressure mostly being located in the external dimension and buffered against by activating internal resources and deactivating interpersonal resources.

3. The use of stress-immobilise might be associated with experiences of pressure mostly being located in the external and internal dimension with limited capacity to reliably use the interpersonal dimension to help buffer the stress.

\subsubsection{Manager-employee social engagement strategies and organisational goals.}

Over the past decade, as cited above, increasing engagement has become an organisational goal for many organisations. This study acknowledges engagement as an organisational goal because it represents an aspect of the external context of engagement; irrespective of whether or not this is a shared goal between employees and their organisations.

In this study I focus on the interplay between the contexts of engagement. For example, the interpersonal secure base system is an open-goal-oriented 
'messy' system (Tronick \& Beeghly, 2011). In turn, messy patterned sequences of synchrony and dys-synchronous interaction might better represent how managers and employees socially engage on a day-to-day basis as part of the working towards the goals of the organisation. As such, the use of different social engagement strategies within the manager-employee relationship might influence the experience and outcome of goal sharing, such as engagement.

In turn in this study, it was anticipated that use of each manager-employee social engagement strategy might highlight unique ways of experiencing organisational goals, combined with variations in engagement. For example:

1. The use of connect-act might be associated with experiences of connecting with the organisational goal in an internal and interpersonal way as a precursor to working towards the goal.

2. The use of disconnect-act might be associated with experiences of disconnecting from the social aspects of the goal when under pressure, but fully engaging at an internal and behavioural way so as to work towards the goals of the organisation.

3. The use of stress-immobilise might be associated with experiences of increased internal pressure and stress when faced with external goals as the new goals might heighten awareness of a workers limited capacity (when under pressure) to reliably use the interpersonal dimension to support the experience of working together towards a shared goal.

In sum, the core logic of the hypotheses above indicates that variations in interpersonal secure base behaviour between managers and employees are likely to be influenced by external contexts and internal variations in perceptions about attachment and engagement. As such, the focus now turns to engagement (Kahn, 1990).

\subsubsection{Manager-employee social engagement strategies and engagement.}

Continuing with the attachment theory lens, Hazen and Shaver (1990) asserted that work is a form of exploration. In turn, it is possible to consider exploration as an expression of engagement: that which is observable by others as part of working towards organisational goals (Macey \& Schneider, 2008). It is 
also possible that variable use of interpersonal manager-employee social engagement strategies combined with unique experiences of pressure at work in relation to working towards organisational goals might affect exploration; engagement.

For example, because the connect-act and the disconnect-act strategies function to directly support exploration, it is expected that use of these strategies will correspond with reports (from the manager-employee dyads) of high levels of engagement. On the other hand, use of the stress-immobilise strategy will more likely be associated with reports of lower levels of engagement. While these associations between mind states of attachment and engagement are logical, I do not assume that this logic captures the capacity for variability within the secure base system, because this is an open system of relationships and open to change.

In summary, Table 4 summarises the dimensions of each manageremployee social engagement strategy. It illustrates how each strategy relates to the secure base phenomenon and the stress-attachment connection (Ainsworth et al., 1978; Bowlby, 1969, 1988) and interpersonal patterns of secure base use and support (Ainsworth et al., 1978; Crowell et al., 2002). It also shows how each strategy relates to general adult attachment representations of attachment (Bartholomew \& Horowitz, 1991). These include states of mind about the role of self and others regarding helping and being helped, at times of stress.

In addition, Table 4 describes the hypothesised patterns of states of mind pertaining to job and organisation, and engagement-related concepts (perceived organisational support, perceived supervisor support, organisational commitment, and intention to quit/turnover) for each proposed strategy. It also alerts to how each strategy variously connects with the external dimension such as organisational goals and engagement behaviour. 
Table 4

Hypothesised Manager-Employee Social Engagement Strategies: An overview

\begin{tabular}{|c|c|c|c|}
\hline $\begin{array}{l}\text { MESE } \\
\text { Strategy }\end{array}$ & External & Internal & Interpersonal \\
\hline $\begin{array}{l}\text { Connect- } \\
\text { Act }\end{array}$ & $\begin{array}{l}\text { Goal sharing } \\
\text { Pressure-Stress } \\
\text { Engagement } \\
\text { behaviour } \\
\text { Organisation } \\
\text { specific } \\
\text { strengths } \\
\text { and challenges }\end{array}$ & $\begin{array}{l}\text { General attachment representation } \\
\text { (Bartholomew \& Horowitz, 1991): } \\
\text { Secure: Positive view of self and } \\
\text { positive view of others } \\
\text { Secure base script (Crowell et al., } \\
\text { 2002). Confident in their capacity to } \\
\text { cue for help (respond to cue for help) } \\
\text { and maintain the cue (help) until a } \\
\text { connection is made. Help via } \\
\text { connection with others frequently } \\
\text { relieves distress and supports } \\
\text { creative and flexible solutions. } \\
\text { Mind state towards engagement. } \\
\text { Higher JE and OE; Higher PSS and } \\
\text { POS; Higher OC and Lower ItQT }\end{array}$ & $\begin{array}{l}\text { Secure base use: } \\
\text { Timely and confident help seeking, } \\
\text { stress is acknowledged without } \\
\text { being overwhelmed by it while also } \\
\text { being able to think creatively and } \\
\text { flexibly within the conversation. } \\
\text { Being helped, provides relief and an } \\
\text { easy transition back into exploration } \\
\text { Secure base provision: } \\
\text { Confident in their capacity to } \\
\text { respond to cues for help in a timely } \\
\text { way, that connects with the persons } \\
\text { experience of distress and then } \\
\text { offers creative and flexible solutions } \\
\text { Exploration: } \\
\text { Balance between exploration of the } \\
\text { internal, interpersonal and external } \\
\text { dimensions. }\end{array}$ \\
\hline $\begin{array}{l}\text { Disconnect- } \\
\text { Act }\end{array}$ & $\begin{array}{l}\text { Goal sharing } \\
\text { Pressure-Stress } \\
\text { Engagement } \\
\text { behaviour } \\
\text { Organisation } \\
\text { specific } \\
\text { strengths } \\
\text { and challenges }\end{array}$ & $\begin{array}{l}\text { General attachment representation } \\
\text { (Bartholomew \& Horowitz, 1991) } \\
\text { Dismissing-Avoidant: Negative view } \\
\text { of self and positive view of others } \\
\text { Secure base script (Crowell et al., } \\
\text { 2002). Self-regulate the stress, and } \\
\text { minimise the experience of stress then } \\
\text { cue for task focused help. When } \\
\text { providing help to others, minimise the } \\
\text { distress by focusing on something } \\
\text { practical that will get the person back } \\
\text { into exploration. } \\
\text { Mind state towards engagement. } \\
\text { Higher JE and lower OE; Lower PSS } \\
\text { and POS; Higher OC and lower ItQT }\end{array}$ & $\begin{array}{l}\text { Secure base use: } \\
\begin{array}{l}\text { Self-regulate then seek help with a } \\
\text { task. }\end{array} \\
\text { Secure base provision: } \\
\text { Self-regulate by providing just } \\
\text { enough practical and task focused } \\
\text { support to get the person back to } \\
\text { exploration. } \\
\text { Exploration: } \\
\text { Favours exploration of the internal } \\
\text { and external dimensions. }\end{array}$ \\
\hline $\begin{array}{l}\text { Stress- } \\
\text { Immobilise }\end{array}$ & $\begin{array}{l}\text { Goal sharing } \\
\text { Pressure-Stress } \\
\text { Engagement } \\
\text { behaviour } \\
\text { Organisation } \\
\text { specific } \\
\text { strengths and } \\
\text { challenges }\end{array}$ & $\begin{array}{l}\text { General attachment } \\
\text { representation (Bartholomew \& } \\
\text { Horowitz, 1991) } \\
\text { Preoccupied: Negative view of self } \\
\text { and positive view of others } \\
\text { Secure base script (Crowell et al., } \\
\text { 2002). Regulate stress by maintaining } \\
\text { stress cue to manage the anxiety } \\
\text { about the uncertainty of others' } \\
\text { availability to relieve the stress. } \\
\text { Responding to stress/distress in } \\
\text { others raises self-doubt about one's } \\
\text { availability to respond or not; the } \\
\text { focus stays on the stress with less } \\
\text { cooperative problem solving } \\
\text { experiences. } \\
\text { Mind state towards engagement. } \\
\text { Lower JE and OE; Higher PSS and } \\
\text { POS; Lower OC and Higher ItQT }\end{array}$ & $\begin{array}{l}\text { Secure base use: } \\
\text { High stress with anxiety about the } \\
\text { type of help offered; stress } \\
\text { minimally reduced to help and } \\
\text { exploration retuned to but } \\
\text { cautiously. } \\
\text { Secure base provision: } \\
\text { Others stress/distress raises self- } \\
\text { doubt about one's availability, } \\
\text { which leads to fluctuations in } \\
\text { availability; and when available the } \\
\text { focus stays on the stress with less } \\
\text { emphasis on support to return to } \\
\text { exploration. } \\
\text { Exploration: } \\
\text { Favours exploration of the internal } \\
\text { and interpersonal dimensions. }\end{array}$ \\
\hline
\end{tabular}




\subsection{Chapter Summary}

This chapter introduced the concept of engagement and reviewed the intersection between the manager-employee relationship and the concept of attachment in the engagement literature. As a result, the research problem was highlighted, the research questions were outlined, and a framework and new model for understanding MESE strategies as part of an engagement system was developed. The next chapter (Chapter 3) describes how I tested the models. Chapter 4 and 5 present the results of the model testing process. I return to the theoretical framework in Chapter 6 where it provides an analytical framework from which to discuss the study's research findings. 


\section{Chapter 3: Methodology}

This chapter describes the mixed methods sequential explanatory design (Ivankova, Cresswell \& Stick, 2006; Teddlie \& Tashakkori, 2009) I used to test the research propositions, hypotheses (outlined in Chapter 2) and the overarching research question of this study: How do managers and employees strategically manage their relationship to optimise their engagement at work? To this end I conducted two inter-related studies with managers and employees in New Zealand: an online survey; and a series of five manager-employee dyad case studies.

At the outset, the primary purpose of the quantitative survey was to generate qualitative and interpersonal data about manager-employee social engagement strategies and engagement. To this end, individual level quantitative data from the survey was used to: (a) test the reliability of the new manageremployee social engagement strategy measures, and the hypothesised models concerning concepts specific to the internal context of engagement; and (b) inform the structure of the interpersonal and qualitatively oriented case studies. In turn, this quantitative data was used within the interpersonal context of the case studies where it functioned as a springboard for conversation between the manageremployee dyads about their experiences of social engagement strategies and engagement.

The overarching methodology and research process across the whole study is summarised in Figure 5. Of note, Figure 5 includes two commonly used mixed method terms: QUAN (quantitative) and qual (qualitative). The use of uppercase signifies that method has been given priority status in the research process; the use of lowercase letters signifies a supporting role. In sequential explanatory designs (such as that used here) the quantitative component of study is usually given the dominant status (QUAN) over the smaller preceding qualitative (qual) component and is denoted as follows: QUAN $\rightarrow$ qual (Ivankova et al., 2006; Morgan, 1998). 

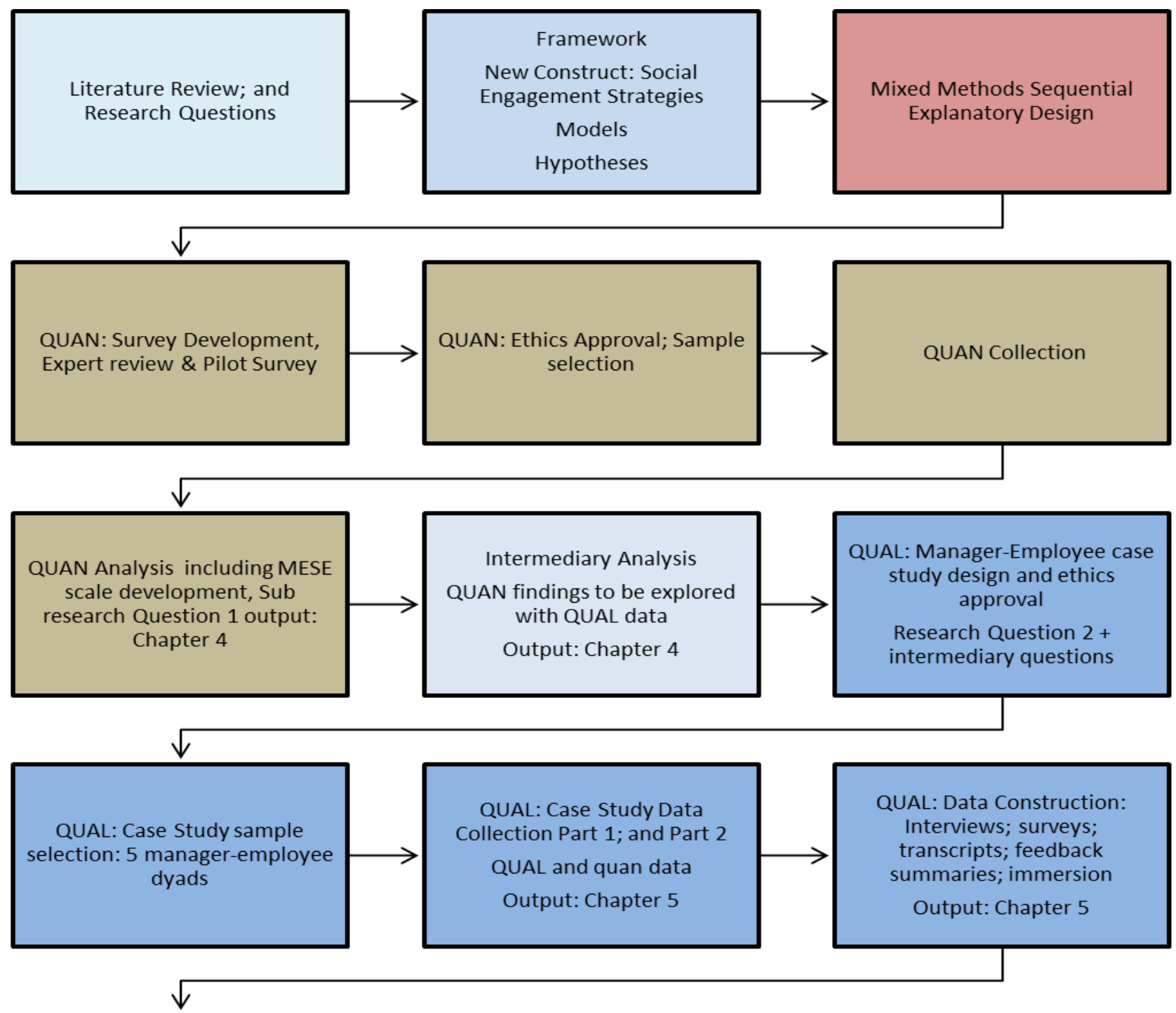

QUAL and quan data analysis

Manager-Employee Dyad Case Studies Sub-Research Question 2

Output: Chapter 5
Inter-case thematic analysis inductive sub-themes + subthemes related to the framework

Output: Chapter 6
In what ways does the Qual data contribute to the QUAN findings + research questions? Immersion and Reflection Output: Chapter 6

Contribution, Implications and Conclusion Output: Chapter 6

Figure 5. Summary of the research methodology. 


\subsection{Research Design}

Mixed methods research entails mixing qualitative and quantitative approaches of data collection and analysis within the same study (Creswell \& Plano Clark, 2007; Dunning, Williams, Abonyi \& Crooks, 2008). It involves: (a) collecting, analysing and then selecting key quantitative findings to be qualitatively explored; and (b) collecting and analysing qualitative data to explain the quantitative findings. The goal is to add depth to quantitatively generated data (Creswell \& Plano Clark, 2007). This approach supported the overarching goal of this study which was to examine the associations between states of mind about engagement, the interpersonal context of the manager-employee relationship and engagement.

This approach was pragmatic (Betzner, 2008; Cresswell \& Plano Clark, 2007; Johnson \& Onwuegbuzie, 2004). Pragmatism involves the process of mixing research approaches 'in ways that offer the best opportunities for answering important research questions' (Johnson \& Onwuegbuzie, 2004, p.16) and helps to construct a research design that is 'useful, practical and accurate' (Patton, 2002a, p. 271).

As such, this design matched my research questions (that needed to be quantitatively and qualitatively examined) as it enabled me to address these questions within a multidimensional research framework. In addition the structure of the questions suggested use of a non-experimental explanatory research design (Pedhazur \& Scmelkin, 1991). Non-experimental research investigates what is there in contrast to manipulating the independent variable(s). It is used to show relationships between variables, but is limited in showing cause and effect. The mixed methods explanatory design offered the potential for the qualitative findings to complement the representativeness and generalisability of quantitative findings (Greene \& Caracelli, 2003; Morse, 1991).

In conjunction with pragmatism, this approach drew on existing engagement research methods. Quantitative studies have provided a plethora of models of engagement that highlight relationships between internal dimension factors (e.g. Bakker \& Leiter, 2010; May et al., 2004; Saks, 2006; and Shuck et al., 2011). Qualitative approaches have provided a window into manager and employees experiences of engagement and in turn have contributed a plethora of 
organisational influences on engagement (Kahn, 1990, 1993, 1996, 1998;

MacLeod \& Clarke, 2009). In addition, qualitative interview/public consultation based studies have emerged that have integrated survey and interview based data. These studies provide a new direction for engagement research (e.g. Alfes et al., 2010; Gatenby et al., 2009; MacLeod \& Clarke, 2009) and my study follows this path where I use a survey-interview approach under the umbrella of mixed methods design.

The design of this study also drew on attachment theory methods to create a methodological window from which to view the manager-employee relationship as an interpersonal context of engagement. First, attachment theory informed the operationalisation process of the concept: manager-employee social engagement strategies (see section 3.2.3). Second, attachment theory informed methods of observing the secure base system (Ainsworth et al., 1978; Crowell et al., 2002) were adapted for use in the dyad interviews in the case studies (see section 3.4.7.2).

\subsection{Manager-Employee Social Engagement Survey}

A manager-employee engagement (NZ MESE) survey was developed to generate data from which to test sub-research question one. This section begins by reporting the online survey method and then describes the population and sample size. Next I detail the process used regarding scale development for the manager-employee social engagement variables; the remaining variables are then described. I outline the procedures followed to conduct the internet-based survey. Finally, I describe how the data was analysed.

\subsubsection{Online surveys.}

An internet-based self-report survey was developed and distributed via the Qualtrics $^{\mathrm{TM}}$ research suite. Online surveys have become increasingly popular as a mode of data collection. Academia and business favour this approach as it saves time and costs, compared with mail-based surveys. It also enables access to a larger population, increasing the potential generalisability of findings (Dillman, Smyth \& Christian, 2009; Kiesler \& Sproull, 1986). 
Conversely, limitations of this approach include biased sampling and technical issues. Biased sampling occurs due to the participant pool including only those with internet access (Kiesler \& Sproull, 1986; Lockhart \& Russo, 1996). Technical issues, such as the survey design, the survey programme, software compatibility issues and user competence, can affect response rates (Dillman, Tortora \& Bowker, 1999). In turn, low response rates increase the possibility of sampling and coverage errors, measurement errors and non-response errors. Sampling and coverage errors can result in under-representative populations (Dillman et al., 1999). Measurement errors can result in inaccurate answers and non-response errors from people whose contribution would most likely alter the overall distribution of responses. Taking these limitations into account, Schonlau, Fricker and Elliott (2001) suggested the response rate could be anywhere from six to 68 per cent, whereas Crawford, Couper and Lamias (2001) estimated a response rate, up to 30 per cent.

In this study, the sample was potentially biased, as the survey required using an internet-based survey link. However, given the target sample, it was assumed that many managers and employees had access to the internet either within their organisation or via a professional association. To counter coverage and sampling errors, the survey was neither industry nor sector specific.

\subsubsection{Population and sample size.}

\subsubsection{Population.}

The questionnaire was administered to a sample of managers and employees in New Zealand. Two hundred managers completed the manager survey, and two hundred employees completed the employee survey. The majority of managers were aged $40-49$ years $(66$, or $33 \%)$ or $50-59$ years $(60$, or $30 \%)$. The employees were more dispersed in age, with the largest group being 50-59 years $(58$, or $29 \%)$. A slight majority of the managers were male (102, or 52\%), while the majority of the employees were female (144, or $72 \%)$. The most common ethnic group for both groups was 'New Zealand European'. Frequencies and percentages for participant demographics are presented in Chapter 4, Table 16. 
Survey participants represented a heterogeneous sample of organisations (government, private and non-profit) and industries (education, health, banking, retail, professional services and social services). The rationale to access a broad sample across organisational types and industries, in contrast to an industry specific sample, was based on: (a) the empirical focus of the study, the manageremployee interpersonal relationship; and (b) the overarching goal of the study, which was to develop a general picture of this interpersonal relationship in relation to engagement, as a precursor to focusing on nuances within industry specific contexts.

\subsubsection{Sample size.}

An estimated sample size was calculated to generate inferences about the population from the survey data (Hinkle, Wiersma \& Jurs, 2003). Based on my data analysis plan, I conducted two sample size estimations.

First, as part of the scale development process I planned to conduct exploratory factor analysis. My three hypothesised manager-employee social engagement variables comprised 42 questions. To run factor analysis, an optimal subject item ratio of five to 10 cases per item had been suggested (Comrey \& Lee, 1992; Gorsuch, 1983). However, in practice this optimal ratio seemed less common. For example, Costello and Osborne (2005), in a study of 1,700 studies using exploratory factor analysis, found that: 25 per cent of studies used a 2:1 but $<5: 1$ subject to item ratio; 22 per cent of papers used a 5:1 to <10:1 ratio; and 15.4 per cent used a 10:1<20:1 ratio. Based on a 5:1 ratio a sample size of 210 would be adequate.

Second, to run the correlation and path analysis I had 10 variables: three hypothesised manager-employee social engagement variables, the Relationship Questionnaire and six engagement-related variables, with an initial total of 78 questions. Similar to that above, a sample size of 5:1 or more was recommended. Based on a 5:1 ratio, a sample size of 390 would be adequate.

In summary, a sample size of 400 manager and employee participants was sought. I return to the issue of sample size later in this section when I discuss data analysis. 


\subsubsection{Manager-employee social engagement scale development.}

I developed a manager-employee social engagement scale because there was no known instrument to measure this construct. Consistent with Hinkin (1998), scale development standards of validity (content, construct and criterion) were addressed via a six-step scale development process: 1 . item generation; 2 . questionnaire administration; 3. initial item reduction; 4. confirmatory factor analysis; 5. convergent/discriminant validity; and 6. Replication (Table 5).

Table 5

Scale Development Process: Manager-Employee Social Engagement Strategies

\begin{tabular}{|c|c|c|}
\hline Step & Scale development steps & Scale development tasks \\
\hline 1 & $\begin{array}{l}\text { Item generation } \\
\text { Content validity }\end{array}$ & $\begin{array}{l}\text { Utilised Hinkin's (1998) guidelines for developing } \\
\text { survey items in conjunction with the literature to } \\
\text { deductively generate items }\end{array}$ \\
\hline 2 & $\begin{array}{l}\text { Item review } \\
\text { Item reduction (round 1) } \\
\text { Content Validity }\end{array}$ & $\begin{array}{l}\text { Expert panel of attachment theory specialists examined } \\
\text { the items; informal reviews with attachment specialist } \\
\text { colleagues; and a pre-test was run in a private sector } \\
\text { professional service to test the questions for suitability to } \\
\text { the workplace context }\end{array}$ \\
\hline $3 b$ & $\begin{array}{l}\text { Questionnaire refinement } \\
\text { (Construct Validity) }\end{array}$ & $\begin{array}{l}\text { Keeping questions simple, focused and short while } \\
\text { maintaining theoretical coherence to the secure base } \\
\text { system }\end{array}$ \\
\hline $4 a$ & $\begin{array}{l}\text { EFA (Principle components } \\
\text { analysis) } \\
\text { Item reduction (round 2) } \\
\text { Construct validity }\end{array}$ & $\begin{array}{l}\text { 1. EFA with oblique rotation was conducted with (a) } \\
42 \text { manager items; and (b) the } 42 \text { employee items. } \\
\text { 2. A series of } 6 \text { separate analyses were conducted: } \\
\text { Manager SESI (14 items), Manager SECA (14 } \\
\text { items), Manager SEDA (14 items), Employee SESI } \\
\text { (14 items), Employee SECA (14 items) and } \\
\text { Employee SEDA (14items) }\end{array}$ \\
\hline $4 b$ & $\begin{array}{l}\text { Alpha coefficient of each } \\
\text { scale Reliability }\end{array}$ & $\begin{array}{l}\text { The alpha coefficient of each scale was tested. Each } \\
\text { scale had an alpha coefficient of } 0.70 \text { or above }\end{array}$ \\
\hline 5 & $\begin{array}{l}\text { Criterion related validity } \\
\text { Convergent and } \\
\text { discriminant validity }\end{array}$ & $\begin{array}{l}\text { Compared scores on the RQ } \\
\text { (Bartholomew \& Horowitz, 1991) with scores from the } \\
\text { MESE } \rightarrow \text { related but distinct construct (see Chapter 4.2) }\end{array}$ \\
\hline 6 & $\begin{array}{l}\text { Replication } \\
\text { Reliability: Split-half } \\
\text { reliability }\end{array}$ & $\begin{array}{l}\text { Manager and Employee samples analysed separately } \rightarrow \\
\text { similar but unique findings regarding the MESE variable } \\
\text { for each sample group }\end{array}$ \\
\hline
\end{tabular}

Following Step 6, another round of item reduction was conducted reentering the process between Step 3 and 4 (Hinkin, 1998) (Table 5). Of note, at Step 4 in this study, I used exploratory factor analysis instead of conducting 
confirmatory factor analysis. This decision is discussed below. Step 1 through to Step 4a and b: item generation, scale development, and scale reliability are described below; and Steps 5 and 6 are addressed in Chapter 4, via an ongoing process of validity testing.

\subsubsection{Scale development step 1: item generation and item review.}

Items were generated using a deductive process (Hinkin, 1998). The manager-employee social engagement strategy definitions, and the framework provided in Chapter 2, informed the item generation process. To guide this process, measures of adult attachment were reviewed, including the adult secure base script research (Crowell et al., 2002), the adult projective inventory (George $\&$ West, 2001), the love and work questionnaire (Hazen \& Shaver, 1990), the workplace attachment questionnaire (WAQ) (Misciagna, 2005) and the attachment at work survey (Neustadt et al. 2006, 2011). In addition, commentaries regarding adult measures of attachment were reviewed (Cassidy \& Shaver, 2008; Crowell \& Treboux, 1995; Crowell \& Waters, 2005; Mikulincer \& Shaver, 2007).

Consistent with attachment theory, I specifically drew on the work of Crowell et al. (2002) who had adapted findings from parent-child secure base script studies (Waters \& Waters, 2006) to develop an observational measure of secure base behaviour in adult partnerships (in contrast to individual interviews or surveys). Crowell et al. (2002) acknowledged that in comparison to infants, adult secure base behaviour is: 'relatively intermittent, can be subtle, involves many contexts, and is often verbal. In turn, these aspects make naturalistic observations difficult (p. 680)'. As a result of this methodological challenge, they used observations of problem-solving interactions within dyads as a priming prompt to activate the secure base system. In turn, they assessed the observations using the Secure Base Scoring System of secure base use and provision (Crowell et al., 2002).

For the purposes of my study, I adapted the observational method outlined by Crowell et al. (2002) into a survey that created a platform for interpersonal interaction between the dyads. Instead of using a direct problem-solving prompt, I used a more generic experience of feeling under pressure at work and doing one's work. As such the survey that I designed enquired about engagement-based 
interactions between a manager and an employee, such as seeking support and providing support, to meet organisational goals. At the outset, the empirical context was changed from adult romantic partners to goal directed conversations that were likely to occur between a manager and an employee.

Building on the observations of Crowell et al. (2002) regarding differences between infant and adult attachment, I do not assume that the manager-employee relationship is necessarily reciprocal; nor do I assume the relationship matches a non-reciprocal parent-child relationship. To elaborate, infant-parent studies assume a non-reciprocal relationship where the infant seeks help but does not provide secure base support. In contrast, adult couples' attachment theory research has assumed that secure base behaviour in close adult relationships is reciprocal. Furthermore attachment theory informed workplace research has commonly referred to leader-follower relationships as analogous to parent-child relationships (Popper \& Mayseless, 2003). However, in this study I assume that interactions within the manager-employee relationship may temporarily reflect a range of secure base specific roles, which may or may not be reciprocal.

Therefore, I focused on the following role based relationships: (a) help seeking (secure base use) in response to pressure was viewed in relation to employees seeking support from managers; with managers seeking support from senior colleagues; and (b) help provision (secure base provision) was illustrated by managers providing support to employees; and employees providing support to their peers.

Next, for the survey to function as a prompt within the dyad interviews, new questions were formulated regarding the secure base subsystems (secure base use, secure base provision and exploration) that may be evident during day-to-day interactions between managers and employees. The questions included activators of the inferred secure base system, such as pressure/stress at work; and workplace conflict. These questions in part tapped unconscious features of interpersonal help seeking and help provision.

Two sets of questions were constructed to represent the manageremployee social engagement strategy construct: A set of questions for employees (Appendix A); and a set for managers (Appendix B). Each set contained 14 core questions about secure base use, secure base, and exploration (that is doing the job). Each core question included three possible answers that were structured as 
Likert scale based questions (creating a total of 42 items). Each item theoretically correlated with one of the newly formulated manager-employee social engagement variables, in accordance with its corresponding attachment strategy: (a) connect-act (SECA) related to secure-balanced (14 items); (b) disconnect-act (SEDA) related to dismissing-avoidant (14 items); and (c) stress-immobilisation (SESI) related to ambivalent-preoccupied (14 items). An illustration of the item generation process is provided in Table 6 .

Table 6

Manager-Employee Social Engagement Strategy Item Development Planner (adapted from Hinkin, 1998)

\begin{tabular}{|c|c|c|c|}
\hline $\begin{array}{l}\text { Secure base system } \\
\text { characteristics within } \\
\text { the MESE strategies }\end{array}$ & $\begin{array}{l}\text { Prompting } \\
\text { examples }\end{array}$ & $\begin{array}{l}\text { Internal working } \\
\text { model of self and } \\
\text { others at work; } \\
\text { and of work } \\
\text { represented by a } \\
\text { focus on }\end{array}$ & Initial MESE items \\
\hline $\begin{array}{l}\text { Workplace of } \\
\text { stress/pressure/conflict }\end{array}$ & $\begin{array}{l}\text { When } \\
\text { you/others are } \\
\text { under pressure } \\
\text { at work }\end{array}$ & $\begin{array}{l}\text { SESI: Self + } \\
\text { others } \\
\text { SECA: Self } \\
\text { +others +task } \\
\text { SEDA: Self +task }\end{array}$ & $\begin{array}{l}\text { E-SESI:1-13 } \\
\text { E-SECA:1-13 } \\
\text { E-SEDA:1-13 } \\
\text { M-SESI:1-13 } \\
\text { M-SECA:1-13 } \\
\text { M-SEDA:1-13 }\end{array}$ \\
\hline Secure base use & $\begin{array}{l}\text { What kind of } \\
\text { support do you } \\
\text { prefer? }\end{array}$ & $\begin{array}{l}\text { SESI: Self + } \\
\text { others } \\
\text { SECA: Self + } \\
\text { others +task } \\
\text { SEDA: Self +task }\end{array}$ & $\begin{array}{l}\text { E-SESI: } 1,3,7,10,13 \\
\text { E-SECA: } 1,3,7,10,13 \\
\text { E-SEDA: } 1 \\
3,7,10,13 \\
\text { M-SESI: } 1,3,6,10,13 \\
\text { M-SECA: } \\
\text { 1,3,6,10,13 } \\
\text { M-SEDA: } \\
\text { 1,3,6,10,13 }\end{array}$ \\
\hline $\begin{array}{l}\text { Secure } \\
\text { base provision }\end{array}$ & $\begin{array}{l}\text { What kind of } \\
\text { help do you } \\
\text { prefer to offer? }\end{array}$ & $\begin{array}{l}\text { SESI: Self + } \\
\text { others } \\
\text { SECA: Self + } \\
\text { others + task } \\
\text { SEDA: Self +task }\end{array}$ & $\begin{array}{l}\text { E-SESI: } 2,6,9,11 \\
\text { E-SECA: } 2,6,9,11 \\
\text { E-SEDA: } 2,6,9,11 \\
\text { M-SESI: } 2,5,7,9,11 \\
\text { M-SECA: } 2,5,7,9,11 \\
\text { M-SEDA: } 2,5,7,9,11\end{array}$ \\
\hline $\begin{array}{l}\text { Exploration } \\
\text { Doing the job }\end{array}$ & $\begin{array}{l}\text { How do you go } \\
\text { about doing } \\
\text { your job? }\end{array}$ & $\begin{array}{l}\text { SESI: Self + } \\
\text { others } \\
\text { SECA: Self + } \\
\text { others + task } \\
\text { SEDA: Self +task }\end{array}$ & $\begin{array}{l}\text { E-SESI: } 4,5,8,12,14 \\
\text { E-SECA: } 4,5, \\
8,12,14 \\
\text { E-SEDA: } 4, \\
5,8,12,14 \\
\text { M-SESI: } 4,8,12,14 \\
\text { M-SECA:4,8,12,14 } \\
\text { M-SEDA: } 4,8,12,14\end{array}$ \\
\hline
\end{tabular}

Note. E=Employee; $\mathrm{M}=$ Manager; SECA = connect-act; SEDA = disconnect-act; and SESI = stress-immobilise. 
Furthermore, two separate surveys were constructed. These aimed to capture in part the different roles managers and employees might hold within the secure base system at work. In turn it was anticipated that these unique roles might form a base for a conversation about secure base interactions in the manager-employee dyad case studies. As a result, each item set while similar, was uniquely oriented towards assumed primary roles in the manager-employee relationship: the manager (secure base provision); the employee (secure base use).

For the manager and employee surveys, 7 of the 14 items were identical (items 4 and 8 pertaining to conflict; and items 10, 11, 12, 13, and 14 pertaining to the secure base relationship more generally with the organisation). Next, items 1 , 2, 3, 6, 7 and 9 were the same questions pertaining to secure base use and provision, but were worded in role specific ways. For example, the manager item 6 asked: when you are under pressure, what might colleagues senior to you notice about how you seek support?; and the employee item 7 asked: When you are under pressure what might your manager notice about how you seek support. Finally, item 5 was different for managers and employees. For managers, this question was used to ask another question about their secure base provision, this time to senior colleagues under pressure. For employees, item 5 tapped a question about the effect of pressure on the part of their manager and the influence or this on their engagement: When your manager is under pressure, how do you go about doing your job.

The proposed manager-employee social engagement scales were designed as self-report questions, similar to other engagement-related scales, such as the work engagement (Schaufeli et al., 2002), job engagement and organisation engagement (Saks, 2006) and social engagement (Alfes, et al., 2010; Gatenby et al., 2009) scales. However, instead of asking questions about experiences of work, the job and or the organisation, or about how often they interact with colleagues, the manager-employee social engagement questions asked respondents about what they do, or prefer to do in their relationships at work in different workplace situations. These questions were not a substitute for observing workplace behaviour, but they were intended as a step towards researching engagement behaviour in conjunction with states of mind pertaining to engagement.

Next, an international panel of subject matter experts in attachment theory reviewed the items. The panel consisted of New Zealand and international 
colleagues, who represented a range of disciplines, including psychiatry, psychology and social work. The review process occurred over several months with minor but meaningful changes made to the items. For example, the wording of items was refined to reflect, as closely as possible, day-to-day workplace interactions, while also trying to capture what might represent an interpersonal secure base system in the workplace.

\subsubsection{Scale development step 2: pre-questionnaire administration.}

Before being administered, the questions were pre-tested with a sample of managers and employees in a medium sized private sector professional services company.

\subsubsection{Scale development step 3a: survey refinement.}

This step entailed a pre-distribution survey review. To reduce measurement errors, I used the tailored design method (Dillman et al., 2009). This method comprised four primary tasks (Table 7) and was aimed at ensuring the survey was participant and context specific.

Table 7

Illustrated use of the Tailored Survey Design Method (Dillman et al. 2009)

\begin{tabular}{|c|c|c|c|}
\hline Task & Purpose of the task & Action in this study & Output \\
\hline $\begin{array}{l}\text { 1. Survey the } \\
\text { content to be } \\
\text { reviewed by } \\
\text { colleagues }\end{array}$ & $\begin{array}{l}\text { Collaboration with } \\
\text { experts in the field } \\
\text { and in survey } \\
\text { development }\end{array}$ & $\begin{array}{l}\text { Send the proposed } \\
\text { questions to the } \\
\text { experts for review }\end{array}$ & Feedback from experts \\
\hline $\begin{array}{l}\text { 2. } \\
\text { Conduct } \\
\text { interviews to } \\
\text { evaluate survey } \\
\text { design etc., } \\
\text { question } \\
\text { wording }\end{array}$ & $\begin{array}{l}\text { To test the utility of } \\
\text { the questions and } \\
\text { consider potential } \\
\text { experience of the } \\
\text { survey by } \\
\text { participants }\end{array}$ & $\begin{array}{l}\text { Invite staff from a } \\
\text { medium sized } \\
\text { organisation to } \\
\text { review the entire } \\
\text { survey }\end{array}$ & $\begin{array}{l}\text { Editing of the survey and } \\
\text { decisions made regarding } \\
\text { the OC variable }\end{array}$ \\
\hline $\begin{array}{l}\text { 3. Conduct a pilot } \\
\text { study }\end{array}$ & $\begin{array}{l}\text { A run-through to } \\
\text { mirror the } \\
\text { procedures to be } \\
\text { used in the full study } \\
\text { and to catch any } \\
\text { glitches }\end{array}$ & $\begin{array}{l}\text { Invite colleagues to } \\
\text { do a run-through of } \\
\text { the survey via } \\
\text { Qualtrics }\end{array}$ & $\begin{array}{l}\text { Five staff in a private } \\
\text { sector organisation } \\
\text { having trialled the survey } \\
\text { accessing it via a link to } \\
\text { Qualtrics }\end{array}$ \\
\hline $\begin{array}{l}\text { 4. Conduct a final } \\
\text { check }\end{array}$ & $\begin{array}{l}\text { A further check with } \\
\text { a fresh pair of eyes } \\
\text { to check for missing } \\
\text { information and } \\
\text { errors }\end{array}$ & $\begin{array}{l}\text { Editing by a } \\
\text { colleague and my } \\
\text { supervisors }\end{array}$ & Final edit \\
\hline
\end{tabular}


In this study, the survey content and survey design (Tasks 1 and 2) were reviewed by my supervisors and other staff at the Victoria University of Wellington, School of Management. Task 3 involved conducting a pre-survey pilot study with a small number of managers and employees in a private sector company, who were sent an electronic link of the survey. They reviewed the survey regarding both question clarity and layout, and ease of access and use of the electronic link to the survey via Qualtrics ${ }^{\mathrm{TM}}$. Finally, Step 4 involved another edit, including an edit by a colleague who had not seen the survey during its development process.

\subsubsection{Measures and instrumentation.}

This section details the instruments used to measure each research variable: the manager-employee social engagement variables; antecedent variables of perceived supervisor support and perceived organisational support; engagement variables of job engagement and organisation engagement; and two outcome variables, intention to quit/turnover and organisation commitment. The Relationship Questionnaire (an attachment measure), while not directly related to the engagement-related constructs in this study, was included to test the concurrent validity of the manager employee social engagement strategy variables. The constructs underpinning the variables are elucidated below, with a full summary of items listed in Appendix C.

As cited in Chapter 2, the rationale for the choice of engagement, and antecedent and outcome measures of engagement was pragmatic. First, using the multidimensional context frame of this study, survey based measures of engagement such as the measure of work engagement (UWES), and job and organisation engagement (Saks, 2006), captured aspects of the internal context. Second, in the early stages of survey development I shared these three measures with colleagues. I asked for their opinions about which questions they would be most at ease answering in an online survey. There was unanimous support for the job and organisation measures; and each person expressed a lack of ease concerning some of the wording in the work engagement measure, specifically those to pertaining to the dimension of vigor. These opinions possibly reflect cultural differences of expression between the Dutch and New Zealand 
Europeans. Third, as I balanced item breadth with survey length, I faced a tradeoff. At this junction, I decided to use job engagement (five items) and organisation engagement (six items) with a total of 11 items, in contrast to capturing one aspect of engagement with the UWES (which has 17 items).

\subsubsection{Manager-employee social engagement strategies.}

The manager manager-employee social engagement and employee manager-employee social engagement consisted of 14 core questions (with a combined total of 42 items). Each question provided three possible responses. Each response option described an aspect of the secure base system and represented one of the three hypothesised manager-employee social engagement strategies: stress-immobilise; connect-act; and disconnect-act. Participants were invited to rate their responses on a five-point Likert-type scale, with anchors (1) 'not like me' to (5), 'most like me'.

\subsubsection{Perceived organisational support.}

The validated eight-item short version of the original perceived organisational support 36-item measure (Eisenberger et al., 1986), with a sevenpoint Likert-type scale including the anchors (1) 'strongly disagree' to (7) 'strongly agree', was used to measure perceived organisational support. As suggested by Rhoades and Eisenberger (2002), both facets of the perceived organisational support definition (i.e. valuation of employees' contribution and care about employees' wellbeing) were represented in the perceived organisational support short version questionnaire with a Cronbach's alpha reliability of $\alpha=0.90$ (Eisenberger, Cummings, Armeli, Stephen \& Lynch, 1997).

In the present study, the employee sample of the perceived organisational support (eight-item short version) had a Cronbach's alpha reliability coefficient of $\alpha=0.50$, with the corrected data inter-item correlations ranging from 0.06 to 0.35 . Removing any of the eight items would not have increased the alpha. In contrast, the manager sample alpha score was $\alpha=0.75$, with the corrected data inter-item correlations ranging from 0.25 to 0.68 . There was no significant benefit to removing the second item (0.25). Also given the strength of previous studies regarding this variable (Rhoades \& Eisenberger, 2002), I decided to keep the same 
item set for the perceived organisational support variable across the manager and employee sample.

\subsubsection{Perceived supervisor support.}

The validated eight-item perceived supervisor support short version eightitem (Eisenberger et al., 2002), with a seven-point Likert-type scale, (1) 'strongly disagree' to (7) 'strongly agree', was used to measure perceived supervisor support. Previously, Rhoades et al. (2001) had adapted items from the perceived organisational support survey $(8,9,25$ and 27 , with factor loadings of $0.74,0.83$, 0.82 and 0.76 respectively) (Eisenberger et al., 1986), to create a four-item scale to measure perceived supervisor support. The adaptation involved replacing the word 'organisation' with 'supervisor'.

For example, 'my organisation cares about my opinions' was changed to 'my supervisor cares about my opinions'; and 'my organisation strongly considers my goals and values' was changed to 'my supervisor strongly considers my goals and values'. Consistent with Eisenberger et al. (2002), I measured perceived supervisor support with the same eight items used to measure perceived organisational support, and as per the above modification, the word 'organisation' was replaced with 'supervisor'. Cronbach's alpha reliability coefficient for the eight-item perceived supervisor support measure $\alpha=0.88$ (Eisenberger et al., 2002).

In the present study, the employee sample of the perceived supervisor support (eight items) had a Cronbach's alpha reliability coefficient of $\alpha=0.77$, with the data inter-item correlations ranging from 0.39 to 0.58 . In the manager sample, the perceived supervisor support scale had a Cronbach's alpha reliability coefficient of $\alpha=0.84$, with the data inter-item correlations ranging from 0.52 to 0.64 .

\subsubsection{Job engagement.}

Job engagement was measured using the five-item scale, using a five-point Likert-type scale (1) 'strongly disagree' to (5) 'strongly agree' (Saks, 2006). Coefficient alpha scores for this scale were $\alpha=0.82$ (Saks, 2006). In the present study, within the employee sample, initial alpha reliabilities for the five-item 
measure were: $\alpha=0.57$, with the data inter-item correlations ranging from 0.43 to 0.58 . In the manager sample, $\alpha=0.62$, with the data inter-item correlations ranging from 0.02 to 0.60 . To sustain alpha scores above 0.70 , item 4 ' $\mathrm{My}$ mind often wanders and I think of other things when doing my job' was removed from the manager and employee job engagement question set. This resulted in an employee four-item job engagement scale $(\alpha=0.77)$, with corrected item-to-total correlations ranging from 0.69 to 0.55 , and a manager four-item job engagement scale $(\alpha=0.81$ ), with corrected item-to-total correlations ranging from 0.63 to 0.46 .

\subsubsection{Organisation engagement.}

Organisation engagement was measured using the six-item scale, using a five-point Likert-type scale (1) 'strongly disagree' to (5) 'strongly agree' (Saks, 2006). Coefficient alpha scores for this scale were $\alpha=0.90$ (Saks, 2006). In the present study, to sustain alphas above 0.70 , item 3 , 'I am really not into the "goings-on" in this organisation' was removed from both the employee and manager organisation engagement item set, resulting in (a) an employee organisation engagement five-item scale ( $\alpha=0.92)$, with corrected item-to-total correlations ranging from 0.84 to 0.71 ; and (b) a manager organisation engagement five-item scale $(\alpha=0.90)$, with corrected item-to-total correlations ranging from 0.82 to 0.68 .

\subsubsection{Organisational commitment.}

Organisational commitment was measured using a six-item measure with a four-point Likert-type scale (1) 'strongly disagree' to (4) 'strongly agree' (Marsden et al., 1993). Coefficient alpha scores for this scale were $\alpha=0.74$ (Marsden et al., 1993).

This measure of organisational commitment was chosen because it contributed to parsimony within the survey, while tapping into the three core components of the 15-item organisational commitment questionnaire (OCQ) (Mowday et al., 1982, p. 221): (a) the willingness to engage in discretionary effort on behalf of the organisation (item 1); (b) the belief and acceptance of organisational values and goals (items 2, 4 and 5); and (c) the intent to stay in the organisation (items 3 and 6). 
In the present study, data inter-item correlations ranged from 0.23 to 0.55 in the employee sample for the organisational commitment scale, with an initial alpha coefficient of $\alpha=0.68$. However, removing item 2, 'I feel very little loyalty to this organisation', increased the alpha to $\alpha=0.72$. As such, a five-item scale of organisational commitment ( $\alpha=0.72$ ), with corrected item-to-total correlations ranging from 0.37 to 0.59 was used in the employee sample. The manager organisational commitment scale used the original full item resulting in a manager organisational commitment six-item scale $(\alpha=0.73)$, with data inter-item correlations ranging from 0.29 to 0.67 .

\subsubsection{Intention to quit and turnover.}

Intention to quit/turnover was measured using a three-item measure with a five-point Likert-type scale (1) 'strongly disagree' to (5) 'strongly agree' (Colarelli, 1984). This scale measured an employee's future intentions to leave an organisation. Colarelli (1984) reported an alpha of 0.75. In two subsequent studies using this measure, Saks and Ashforth (1997) reported a coefficient of 0.86, and Saks (2006) demonstrated a coefficient alpha of 0.82 .

In the present study with the employee sample, the three-item scale demonstrated an alpha $\alpha=0.48$, with the data inter-item correlations ranging from 0.16 to 0.43 . In the manager sample, it demonstrated an alpha of $\alpha=0.68$, with the data inter-item correlations ranging from 0.27 to 0.64 . These internal reliability outcomes were unexpected. My first response was to check if I had made a coding error by inadvertently not programming the reverse codings for this item, but no error was found. Next, the recommended three items per variable rule of thumb was traded for a two-item intention to quit/turnover scale, with greater, albeit less than optimal, internal reliability. So, I removed the third item, 'If I have my own way, I will be working for this organisation one year from now', from both sample groups. This resulted in a two-item intention to quit/turnover scale, whereby: (a) the employee intention to quit/turnover scale alpha increased to $\alpha=0.64$, with data inter-item correlations ranging from 0.29 to 0.67 ; and (b) the manager ItQT scale alpha increased to 0.87 , with inter-item correlations ranging from 0.27 to 0.64 . 


\subsubsection{The relationship questionnaire.}

The Relationship Questionnaire (Bartholomew \& Horowitz, 1991) is a self-report instrument designed to assess adult attachment in adult close relationships. This questionnaire builds on Hazen and Shaver (1997), who developed the first survey-based attached questionnaire. The function of relationship questionnaire in the survey was to test the concurrent validity of the manager-employee social engagement variables. This data output is in contrast to interview-based attachment assessments with adults that aim to assess mental representations of the internal working model regarding an adult's relationship with their parent/s (George, Kaplan \& Main, 1985).

The Relationship Questionnaire consists of four short paragraphs (items), one for each of the following four attachment strategies: secure, preoccupied, fearful and dismissing. For example, the item that most closely corresponds to adult attachment security is 'It is easy for me to become emotionally close to others. I am comfortable depending on others and having others depend on me. I don't worry about being alone or having others not accept me'. Using a sevenpoint Likert scale (1) from 'not at all like me' to (7) 'very much like me', participants were asked to: (a) mark the item that best described them, or was the closest best description of them in close relationships; then (b) rate each question according to the extent to which each description corresponded to their relationship style generally. This use of the questionnaire as a categorical and continuous measure is recommended by its originators (Bartholomew \& Horowitz, 1991).

Validation of this questionnaire occurred via concurrent interviews (Bartholomew \& Horowitz 1991). Since that time, the Relationship Questionnaire has been commonly used as a measure of attachment in adult attachment research with its validation reviewed (Crowell \& Treboux, 1995; Crowell et al., 2008). More recently, it has been used in workplace research (Hudson, 2010). Finally, unlike the other measures above, the Relationship Questionnaire was not originally developed for use in the workplace. However, the questions concerning non-work close relationships were deemed general enough to be appropriate in a workplace survey. This assumption was also tested in the case studies. 


\subsubsection{Distributing the survey: scale development step $3 \mathrm{~b}$.}

\subsubsection{Ethics approval.}

Prior to administering the survey, ethics approval was sought and gained from Victoria University of Wellington Human Ethics Committee. The survey was anonymous, recording only a participant's responses. Respondent tracking capacities in the Qualtrics ${ }^{\mathrm{TM}}$ programme were turned off to offer extra reassurance to participants of their anonymity, and that neither they nor their organisation were electronically identifiable. A participant information sheet was embedded into the Qualtrics ${ }^{\mathrm{TM}}$ survey. The survey study ethics application and approval documentation, including consent forms and participation information sheets are available on request (See Appendix D, Manager survey; Appendix E, Employee survey; and Appendix F for the Information Sheet).

\subsubsection{Recruitment.}

Following ethics approval, details about the survey were provided to organisations whose staff or members may have been especially interested in participating, to increase the likelihood of responses from people who were familiar with engagement. For example, my supervisors suggested that the Human Resources Institute of New Zealand (HRINZ) may be especially interested in the study because engagement had been a growing area of interest for their members. Second and directly related to this starting point, I attended a national HRINZ conference. At this conference I met a number of people who expressed interest in the study. For example, staff from the New Zealand Institute of Management and the New Zealand Chamber of Commerce expressed interest in the study, on behalf of their organisations. As a result, I sent invitations to participate in the study, to these organisations.

Each organisation had an opportunity to preview the survey and make inquiries about the study before agreeing to distribute the survey link to their members and/or employees. Potential participants were then made aware of the survey by their employer and/or their professional association via an invitation to participate. Recruitment strategies included invitations to participate via direct email, advertising in general organisational newsletters, and the use of 
snowballing. Snowballing is a non-probability sampling technique that involves respondents identifying other potential respondents for the study (Vogt, 1999).

\subsubsection{Distribution.}

The tailored design scheduling framework (Dillman et al., 2009) provided a map to track the multi-pronged sampling process (Table 8).

Table 8

Illustrated version of the Tailored Design Scheduling Framework (Dillman et al., 2009)

\begin{tabular}{|c|c|c|}
\hline Timeframe & Action & Output \\
\hline Week 1 & $\begin{array}{l}\text { Survey launched } \\
\text { across industries, } \\
\text { organisations and } \\
\text { professional } \\
\text { membership bodies }\end{array}$ & $\begin{array}{l}\text { Results as they arrive into Qualtrics } \\
\text { within both surveys checked and } \\
\text { participant numbers tracked }\end{array}$ \\
\hline $\begin{array}{l}\text { Three days after } \\
\text { initial survey } \\
\text { email }\end{array}$ & $\begin{array}{l}\text { Follow-up reminder } \\
\text { Correspondence with } \\
\text { contact people who } \\
\text { had sent the survey } \\
\text { out on my behalf }\end{array}$ & $\begin{array}{l}\text { Follow up: reminders sent to participants } \\
\text { who received a direct email invitation to } \\
\text { participate }\end{array}$ \\
\hline $\begin{array}{l}\text { One week after } \\
\text { initial survey } \\
\text { email }\end{array}$ & $\begin{array}{l}\text { Follow-up reminder } \\
\text { Ongoing liaison with } \\
\text { contact people } \\
\text { representing potential } \\
\text { participants }\end{array}$ & $\begin{array}{l}\text { Follow up: reminders sent to participants } \\
\text { who received a direct email invitation to } \\
\text { participate }\end{array}$ \\
\hline $\begin{array}{l}\text { Two weeks after } \\
\text { initial survey } \\
\text { email }\end{array}$ & Follow-up reminder & $\begin{array}{l}\text { Follow up: reminders sent to participants } \\
\text { who received a direct email invitation to } \\
\text { participate }\end{array}$ \\
\hline $\begin{array}{l}\text { Conclusion of the } \\
\text { survey }\end{array}$ & Thank you email & $\begin{array}{l}\text { Follow up: written three-page summary of } \\
\text { results to all known participating } \\
\text { organisations }\end{array}$ \\
\hline Data Storage & $\begin{array}{l}\text { Protection of } \\
\text { participants' privacy }\end{array}$ & $\begin{array}{l}\text { Data downloaded into SPSS, password } \\
\text { protected on the university computer } \\
\text { system. } \\
\text { Hard copy data stored in a locked cabinet } \\
\text { on campus; stored for } 3 \text { years post study } \\
\text { completion in accordance with human } \\
\text { ethics procedures }\end{array}$ \\
\hline
\end{tabular}

The survey was distributed to managers and employees who worked for

New Zealand based organisations including public, private and non-governmental 
organisations (NGOs). These included Victoria University of Wellington, The Wellington City Council, Porirua Chamber of Commerce and The Salvation Army (New Zealand). New Zealand based professional associations such as those related to management, human resources and business, also participated. These organisations included: The New Zealand Human Resources Institute of New Zealand (HRINZ) and the New Zealand Institute of Management. The survey link remained open for ten weeks.

Regarding the non-response error, follow-up notifications with invitations to participate were planned with the participating organisations, such as HRINZ. Given the diversity in distribution strategies, the anonymous nature of the survey and the purposeful disabling of identification links with the Qualtrics ${ }^{\mathrm{TM}}$ programme, estimating the response rate was not possible for the study. Data collection continued until the sample reached 200 completed surveys from managers and 200 from employees.

Of note, this survey was conducted very soon after the Christchurch earthquake of February 2011. Many New Zealand businesses and professional organisations were affected. I am grateful to the people who, while facing the deaths of staff, colleagues and friends, along with the loss of buildings and premises, found time to support this study.

The remainder of the scale development steps are reported in Chapter 4.

\subsubsection{Data analysis.}

To test the first sub-research, and its respective propositions and hypotheses, this question was operationalised as: what is the association (if any) between: (a) manager-employee social engagement strategies; (b) job engagement and organisation engagement; and (c) antecedents of engagement (perceived organisational support and perceived supervisor support) and outcomes of engagement (organisational commitment and intention to quit/turnover)? To test this question I conducted descriptive data analysis, exploratory factor analysis, mediation analysis and path analysis (Table 9). Each method provided a unique view of the survey data. They also provided triangulated data useful for identifying similarities and differences within and between each data set. 
Table 9

Sub-Research Question 1: Hypotheses and Data Analysis Tool Summary

\begin{tabular}{lll}
\hline Proposition & \multicolumn{1}{c}{ Hypothesis } & \multicolumn{1}{c}{ Data analysis } \\
\hline 1 & 1 & Exploratory factor analysis \\
1 & 2 & Descriptive and correlation analysis \\
2 & $3,4,5$ & Correlation analysis \\
& $6,7,8$ & Correlation analysis \\
3 & $9,10,11$ & Correlation analysis \\
4 & 12 & Path analysis \\
& 13,14 & Path analysis and mediation analysis \\
\hline
\end{tabular}

Before describing each form of data analysis I outline how I prepared the data for analysis.

\subsubsection{Data analysis preparation and sample size.}

The survey responses were exported from Qualtrics to SPSS (Statistical Package for Social Sciences) version 17. The data was transferred, checked for missing data and cleaned (Pallant, 2011). Data cleaning included identifying and deleting: (a) zero data, where the link to the survey had been opened but the participant did not continue (managers $\mathrm{N}=25$; employees $\mathrm{N}=8$ ); and (b) incomplete data, where most of the questions were not answered throughout the survey (managers: $\mathrm{N}=10$; employees, $\mathrm{N}=9$ ). Data sets were considered complete where there was less than five per cent of missing values from each participant entry. In line with Pallant (2011), I managed the missing data by using the SPSS missing value analysis option to exclude cases pairwise, which only excluded data from a case when data was missing for that particular analysis. Throughout this time a codebook was developed and the item codes were input into SPSS (Pallant, 2011).

Next, pertaining to sample size, during initial explorations of the data the manager and employee data sets yielded unique data. As a result, I kept the data sets separate: a manager data set $(n=200)$ and an employee data set $(n=200)$. In doing this, the participant: item ratios also changed. For the factor analysis, this changed from an anticipated 10:1 ratio, to an adequate 5:1 ratio. For the other analyses the original 5:1 ratio dropped to under a 3:1 ratio.

This unfolding sample size also changed an initial plan to randomly split the data set of 400 to conduct exploratory factor analysis with one set; and then 
use the other set to test the hypotheses, estimating the effect size (Dahl, Grotle, Benth \& Natvig, 2008). Random data splitting validates a new construct, and a model containing the new construct within the same study: 'Data splitting is the act of portioning available data into two portions, usually for cross-validatory purposes. One portion of the data is used to develop a predictive model and the other to evaluate the model's performance' (Picard \& Berk, 1990, p. 140).

However, given a new sample size of 200, it was not possible to further split each set to a sample size of 100 cases for factor analysis, and 100 cases for the correlation and path analysis. In summary, the data analysis plan was conducted with (a) the manager data set $(n=200)$ and then with (b) the employee data set $(n=200)$.

Further, the analytical tools used below come under the umbrella of parametric tests. They assume that the data to be tested is interval data collected independently across samples normally distributed, showing homogeneity of variance (Field, 2009). The assumption of normally distributed data was tested using a two-pronged process: (a) visual checking using histograms and probability-probability plots; and (b) checking the values for skewness and kurtosis. The assumption for homogeneity of variance was tested using Levene's test (Field, 2009, p. 150).

\subsubsection{Exploratory factor analysis.}

Exploratory factor analysis (EFA) was used to test hypothesis one by assessing the internal structure of the 42 manager-employee social engagement items. Using SPSS version 17, principal components analysis with an oblimin rotation was selected. I acknowledge the ongoing debates concerning the similarities and differences between factor analysis and principal components analysis (Costello \& Osborne, 2005). Both analyses have been used previously in engagement research (Gonzalez-Roma, Schaufeli, Bakker \& Lloret, 2006; May et al., 2004; Saks, 2006; Wefald \& Downey, 2009).

In this study I use the generic term of exploratory factor analysis to describe the overall method of analysis that I used to generate empirical summaries about each newly constructed manager-employee social engagement variable that provided information about (a) how the different items loaded on 
newly identified components, and (b) possible composite scales for each manageremployee social engagement strategy item set. I hoped that these summaries would add further understandings about the theorised manager-employee social engagement constructs. Kerlinger and Lee (2000) identified four features of factor analysis: data preparation, correlation, factor rotation and factor extraction.

\subsection{Data preparation.}

In conjunction with establishing adequate sample size as described above, exploratory factor analysis was conducted with a manager data set of $n=200$ and an employee sample data of $n=200$. The data sets were screened for outliers, and sample adequacy size was estimated. No outliers were found. Skewness scores were used to test the assumption of normal distribution. Skewness scores fell within a range of (+/-1 to $+/-2)$ and were considered acceptable, indicating the data was suitable for parametric statistical analyses.

\subsection{Correlation.}

The factorability of the data was checked by reviewing the inter-item correlations; any items with coefficients less than 0.30 were removed before further analysis. The Kaiser-Meyer-Olkin (KMO) measure of sampling adequacy was evaluated. The KMO statistic indicates the 'degree to which it is likely that the common factors explain the observed correlations among the variables' (Leong \& Austin, 2006, p. 250). A KMO index of less than 0.50 indicates correlations between the variables are not accounted for by common factors; a KMO statistic of 0.80 is 'meritorious' (Leong \& Austin, 2006, p. 250); and a $\mathrm{KMO}$ index of 0.60 is recommended as a minimum value from which to proceed with exploratory factor analysis (Tabachnick \& Fidell, 2007).

Next, items with communality under 0.40 were examined regarding their relationship to (a) other similar factors, or (b) whether they represented a different factor (Costello \& Osborne, 2005). Items with communality of 0.30 or below were mostly removed as a way to reliably reduce the item number while increasing the total variance explained (Pallant, 2011). This cut-off mark was guided by Tabachnick and Fidell (2007). They suggested 0.32 as the minimum loading of an item, equating to an approximate 10 per cent overlap of variance 
with other items in that component. Items that cross-loaded across components at 0.32 or higher on two or more components were also dropped. Items with adequate to strong loadings of 0.50 or higher within each component were retained. Components with fewer than three items were considered unstable and were not retained.

\subsection{Factor rotation.}

Factor analysis was run with an oblique (oblimin) rotation because the theorised components within the manager-employee social engagement scales were assumed to correlate with each other. Pairwise data exclusion was used to ensure cases with missing data remained in the sample (stopping further sample size reduction).

\subsection{Factor extraction.}

The process of deciding how many factors to retain entailed a threepronged approach: the Kaiser criterion, the scree test, and parallel analysis (Watkins, 2000). Parallel analysis was conducted using MonteCarloPA.exe, sourced from Pallant (2011). For this calculation, the following data was used: (a) the number of variables (items) to be analysed $(n=14)$; (b) the number of participants in the sample $(\mathrm{n}=200)$; and (c) the number of replications. I specified 100, based on the recommendation from Pallant (2011).

\subsection{Cronbach's alpha.}

The reliability of each new manager-employee social engagement scale was tested using Cronbach's alpha (Cronbach, 1951). Consistent with recommendations by Nunnally (1978), an alpha score of 0.70 or above was established as a set goal for each variable under examination. Further, corrected item-to-total correlations of less than 0.30 were considered weak in terms of item analysis and (exceptions are discussed below) were mostly removed (de Vaus, 2002, p. 184). The alpha outputs are sample specific and do not generalise beyond the sample. However, Field (2009) suggested that results can be generalised 'if analysis using different samples reveals the same factor structure' (Field, 2009, p. 637). My results are cautiously generalisable to managers and employees across 
industries, as I conducted the same analysis across two different samples, with similar results.

\subsection{Reporting Exploratory Factor Analysis Results.}

These results are reported in Chapter 4, following the guidelines proposed by Cabrera-Nguyen (2010).

\subsubsection{Correlation analysis.}

Hypothesis two was tested using descriptive and correlation analysis. Hypotheses three through to eleven were tested using correlation analysis.

Pearson correlation (the Pearson $r$ ) was conducted to measure the degree of linear association between the variables. The value of the correlation coefficient varies between +1 and -1 , with values closer to 1 indicating a stronger association between the variables. The positive or minus indicates the direction of the relationship. All variables were normally distributed (Bobko, 2001).

\subsubsection{Path analysis.}

Path analysis was conducted using SPSS/AMOS to address hypotheses 12, 13 and 14. Path analysis 'allows examination of a set of relationships between one or more IVs, either continuous or discrete, and one or more dependent variables (DV), either continuous or discrete' (Ullman, 2007, p. 676). Of note, in this study the independent variables (IV) are generally referred to as antecedents of engagement, and the dependent variables (DV) as outcomes of engagement.

Path analysis is based on linear equations and is used to identify the comparative strengths of direct and indirect relationships among a set of variables. Each path between variables is represented by a series of hypotheses and can never be statistically tested for directionality. However, path analysis makes explicit the imperfect nature of measures, as it specifies unexplained variance. Further, in contrast to a unitary test, path analysis uses multiple tests to evaluate model fit, for example, chi square, comparative fit index (CFI), and root mean squared error of approximation (RMSEA).

First, the chi square test indicates the amount of difference between expected and observed covariance matrices. A chi square value close to zero with 
a probability level greater than 0.05 indicates little difference between the expected and observed covariance matrices (Pallant, 2011).

Second, the comparative fit index (CFI) is equal to the discrepancy function adjusted for sample size. CFI ranges from 0 to 1 , with an acceptable model fit indicated by a CFI value of 0.90 or greater (Hu \& Bentler, 1998).

Third, the root mean square error of approximation (RMSEA) estimates the lack of fit in a model and compares this with a perfect fit in the model (Tabachnick \& Fidell, 2007). RMSEA values range from 0 to 1, with an acceptable model fit indicated by an RMSEA value of 0.06 or less (Hu \& Bentler, 1998).

\subsubsection{Mediation analysis.}

To test hypotheses 13 and 14, mediation analysis was conducted using Medgraph (Jose, 2013). Mediation refers to the covariance relationships among three variables: an independent; mediating; and dependent variable. A 'mediating variable accounts for a significant amount of shared variance between the IV and DV' (Jose, 2013, downloaded from Victoria University of Wellington site). Medgraph uses correlation matrix and regression output data to perform the Sobel test. Three necessary conditions must be met to establish mediation (Baron \& Kenny, 1986):

1. The independent variables (perceived organisational support and perceived supervisor support) must be related to the mediators (job engagement, organisation engagement, connect-act, disconnect-act and stress immobilise).

2. The mediators (job engagement, organisation engagement, connect-act, disconnect-act and stress immobilise), must be related to the dependent variables (organisational commitment and intention to quit/turnover).

3. A significant relationship between the independent variable(s) and the dependent variables must be reduced, indicating partial mediation or no longer significant indicating full mediation when controlling for the mediators. 
Consistent with Jose (2013), mediating and moderating variables were differentiated: 'A mediator is a variable that changes in relation to the other two variables, and a moderator is a variable that does not necessarily change in relation to the IV' (Jose, 2013). Drawing on Baron and Kenny (1986), I was interested in manager-employee social engagement as a mediating variable. I primarily wanted to know about the extent to which the manager-employee social engagement variables might account for differences in the other variables of interest, rather than the moderating influence the manager-employee social engagement variables might have on the strength of a relationship between the other variables of interest. Finally, mediation analysis is commonly conducted with concurrent data (as in this study). However, as Jose (2013) cautions, the use of concurrent data, in the absence of longitudinal data, limits the capacity to infer mediating relationships with any certainty. Taking this into account, the mediation findings with the concurrent data are further examined in the case studies.

\subsection{Intermediary Research Phase}

This research phase occurred between the survey and the case studies. The aim of this phase was to identify significant survey findings that would inform the case studies (Cresswell \& Plano Clark, 2007). This phase spanned several months, resulting in key quantitative findings from the survey study being identified for qualitative exploration in the case studies. Then, in conjunction with the reviewed literature, the key findings informed a series of questions that aimed to empirically connect the two studies:

1. Given the use of concurrent data in the survey analysis, what findings, such as those related to the correlation, mediation and path analysis, can be further explored using qualitative data?

2. Is it possible to match the ways that managers and employees talk about their relationship when under pressure with the hypothesised manager-employee social engagement strategies?

3. Are there any noticeable differences between what participants report regarding their mind state in relation to engagement (i.e. their survey results) and: (a) how they describe how they interact with others at 
work; and (b) what they actually do at work, that is their engagement behaviour?

4. If there are differences, what information from the participants' experiences of engaging with their work and with each other might explain these differences?

These questions clarified the purpose of the case studies. However, clarity sat juxtaposed with a 'tolerance for ambiguity' (Colaizzi, 1978, p. 61). The support of my supervisors at this time served as a relational secure base from which to explore the case study design.

In addition, to counter potential threats to validity, instrument development and use was rigorous, and the case study participants were specifically chosen according to their potential to help explain the survey findings. In conjunction, the design of the case studies was reviewed via 'writing and rewriting' (van Manen, 1990, p.7) the case study ethics application. During this time, a series of design-oriented conversations occurred between me, my supervisors and the Victoria University Ethics Committee concerning participant safety. In response, adjustments were made to the design. Human ethics approval was granted by the Victoria University of Wellington Human Ethics Committee in November 2011.

\subsection{Case Studies}

Case studies with manager-employee dyads were conducted to address the second sub-research question. As there was no known study that had researched attachment theory-informed social engagement strategies within the manageremployee relationship, a new approach was developed. This approach involved sampling five dyads of managers and employees who worked together. Each dyad represented one case and provided unique case study data. The participants' experiences of the manager-employee social engagement strategies, in association with their engagement, constituted the primary unit of analysis for each case study. The case studies collected survey and interview data about the association of manager-employee social engagement strategies with engagement, and provided methodological data from which to explore the process of researching the manager-employee relationship as a unit of analysis. 
This section provides a brief overview of the case study as a method. Next, the philosophical underpinnings of this study and issues of rigor are described. Case selection and sample size is delineated, followed by the ethical considerations that guided my practice as a researcher within each case. The recruitment process is described, along with the data collection structure of each case. Finally, data analysis methods and processes are outlined, highlighting the iterative process of data construction, data analysis and methodology.

\subsubsection{The case study: an overview.}

A case study is an empirical inquiry that collects, organises and analyses contextualised social data about phenomena (Eisenhardt \& Graebner, 2007; Hartley, 2004), by investigating it within 'its real life context' (Yin, 2009, p. 13). In addition, the case study emphasises both content and the 'process of inquiry' (Stake, 2000, p. 436). In this study, content and process data was used to further develop the proposed theoretical framework, where fresh interpretations were made in support of existing, albeit under-used, theory (Hussey \& Hussey, 1997; Ragin, 1992; Stake, 2005; Yin, 2009) (see Chapter 6).

Moreover, a multi-case design was selected for this study because 'different cases often emphasise complementary aspects of a phenomenon. By piecing together the individual patterns, the research can draw a more complete theoretical picture' (Eisenhardt, 1991, p. 620). In this study a multiple-case strategy enabled me to conduct intra and inter-case analysis with the manageremployee dyad data, revealing commonalities and variances across the cases. Finally, the case studies complemented the survey study because survey findings were generalisable to the sample, and the case study findings were 'generalisable to theoretical propositions' (Yin, 2009, p. 15).

\subsubsection{Philosophical underpinnings and rigor.}

An interpretive-functionalist (Gioia \& Pitre, 1990) lens underpinned these case studies. A functionalist lens informed the statistics generated from the surveys conducted by the case study participants. In conjunction, understandings about the statistical data were sought via phenomenology, an interpretive approach. 
Phenomenology has been described as the study of: 'things as they appear to consciousness, as they seem when they are in mind. This includes: perceptions, sensations, feelings, memories... expectations, ideas - whatever occupies the mental stage' (Stern, 2004, p. 8). In turn, regarding the use of this approach in organisational science, Sanders (1982) advocated that phenomenology was useful for revealing 'the deeper structures of what is believed to be commonplace' ( $p$. 258). Both of these descriptions fitted well with the goal of the case studies, which was to consider how the participants related (if at all) their everyday experiences as managers and employees working together with their experiences of engagement.

In terms of applying this methodological framework, van Manen (1990) described phenomenological research as an iterative process of data collection and analysis that entails (a) 'writing-entering and traversing the space of the text' (van Manen, 2002, p. 7), and (b) engaging with 'the dynamic interplay among six research activities' (van Manen, 2002, p. 30). These activities include:

1. turning to the nature of the lived experience

2. investigating experience as we live it rather than as we conceptualise it

3. reflecting on the essential themes which characterise the phenomenon

4. describing the phenomenon through the art of writing and rewriting

5. maintaining a strong and oriented relation to the phenomenon

6. balancing the research context by considering parts and wholes.

(van Manen, 1990, pp. 30-32)

In practice, the phenomenologically oriented processes of data construction and analysis overlapped with: (a) the case study procedures; (b) thematic analysis; and (c) theory focused analysis. In turn, research rigor strategies were structured into the process of conducting case studies to generate findings with ecological validity, confirmability and transferability (Lincoln \& Guba, 1985).

First, ecological validity refers to the associations between the 'theoretical parameters of the work' (Schmuckler, 2001, p. 432), the real-world phenomena under study, and the investigation of these phenomena in experimental/research settings (Schmuckler, 2001). The mixed methods design increased the potential 
ecological validity of the findings. Second, confirmability refers to the findings, analysis and conclusions being directly connected to the research question/problem, methodology, methods and data collected (Lincoln \& Guba, 1985). In this study, the intermediary analysis and final theoretical analysis phase were especially oriented to making data informed conclusions. Third, transferability refers to providing clear, coherent and data that is as rich as possible for a reader regarding the decision trail from beginning to end of the project, akin to 'auditing' and 'leaving a trail' (Padgett, 1998, p. 101). Overall, attending to these issues involved keeping in mind the triadic ecological associations between: (a) theory (e.g. engagement and attachment theory); (b) the phenomena (manager-employee social engagement strategies); and (c) the research strategy and design (multi-case studies with manager-employee dyads).

\subsubsection{Case boundaries, recruitment and sample size.}

\subsubsection{Case boundaries.}

While it is necessary to delineate the boundaries of a case, these are 'never quite as solid' (Miles \& Huberman, 1994, p. 27) as theoretically proposed. In this study, I drew a boundary around the unit of analysis: the manager-employee relationship. This theoretically informed and socially constructed boundary guided a process of non-probability sampling and purposive case selection (Eisenhardt, 1989; Patton, 2002b) with managers and employees who worked in New Zealand.

\subsubsection{Criteria to participate.}

The criteria to participate constituted the second boundary. Establishing the criteria was informed by: (a) interpersonal theory: relationships need time to form (Ferris et al., 2009); (b) attachment theory: normative patterns were under review, in contrast to actively including dyads, which may be more likely to use disorganised social engagement strategies (Cassidy \& Shaver, 2008); (c) social engagement at work: talking with each other about how to improve work outcomes (Gatenby et al., 2009); and (d) the intent of the study: self reflection in relationship with others, in contrast to trouble shooting or relational repair work. 
As a result, the population for each case consisted of a manager with one of their direct reports who met the following criteria:

1. they currently work directly together and had done so for at least the last six months

2. each person was happy enough with their own style of interacting with others at work

3. each person was interested in exploring person-to-person interactive based communication skills unique to the job they do and the organisation they work in

4. each person agreed to voluntarily participate

5. each person agreed to keep the identity of each other confidential

6. the dyad had clearance, where necessary, from their organisation to participate.

\subsubsection{Recruitment.}

Potential participants were recruited by (a) contacting those who had expressed interest in participating as a result of the survey, and (b) responding to requests to participate from people who had heard about the study through other means, for example conference presentations.

An information sheet (Appendix G) was made available to all potential participants. Information was provided about the study: the criteria to participate, participation details, confidentiality, storage of data, potential benefits to the participant from participation, potential risks, right to withdraw from participation and ethics approval, as well as information about the researcher and an invitation to make any further enquiries.

Upon agreement to participate, each participant in the dyad was asked to email the researcher stating their participation was voluntary, copying the other dyad participant into the email. As part of the consent process, additional organisational requirements and approvals were attended to at this stage of the process (See Appendix H for the consent form for part one).

Assessment of the criteria that participants were 'happy enough with their own style of interacting with others at work' was made during the pre- 
participation dyad interview. During these interviews, I reiterated to potential participants that the case studies were not about trouble shooting and were not designed on a 360 type model of assessment. I noted that each potential participant expressed curiosity in their own interaction patterns at work; and expressed regard for their participating colleague. I also noted that all of the participants: (a) talked freely with each other about current shared projects; and (b) where challenges were raised, these pertained to issues about their work that were centred outside of the relationship.

\subsubsection{Sample size.}

Regarding adequate sample size within purposive sampling, Padgett (1998) advised 'to become saturated with information about a specific topic' (p. 52). Further, Hart (2005) recommended 15 cases, with the caveat: there is 'never any assurance that subjects will be representative of their category' (p. 345). Five case studies were conducted providing ample data from which to explore the research question/s. Each case consisted of a manager-employee dyad, with the gender mix of the dyads being random. Each case represented a diverse range of industries: two cases from the government financial sector, two cases from the not-for-profit social services sector, and one case from the private sector, which provided professional services. The sample is further described in Chapter 5. The case studies were conducted over a five-month period from November 2011 through to March 2012.

\subsubsection{Ethical considerations.}

A second human ethics application was made for the case studies and Human Ethics approval was granted by the Victoria University of Wellington Human Ethics Committee in November 2011. While the ethical issues are outlined below, as with the survey study ethics application, the case study application and approval documentation, including consent forms and participation information sheets, are available on request.

Three primary ethical issues considered in the case study design entailed: ensuring participant safety, confidentiality and data storage. 


\subsubsection{Participant safety.}

A multifaceted approach contributed to participant safety.

First, a clearly delineated selection criteria contributed to creating a safe working space by greatly reducing the likelihood that dyads experiencing current serious conflict would opt to participate.

Second, participants were not asked to rate or judge each other's behaviour or performance. Participation was about self reflection, and was guided by the following overarching question: how might I communicate/interact better with this other person so I/we do better work? This focus was deliberately intended to be differentiated from a typical 360 degree feedback structure.

Third, voluntary self-selection, a structured approach to establishing ground rules, and an iterative process of consent to share data throughout each step of the study, also contributed to the safety.

Fourth, safe withdrawal options were developed. For example, the most likely place within the study where uncertainty/wishing to withdraw might have occurred was between receiving individual survey feedback and engaging in the first dyad interview. Taking this into account, a two-part design created a natural exit point between Parts One and Two. That is, participants could participate in Part One, and opt to not participate in Part Two. They could opt out of the study based on their comfort levels and time commitments, with minimal risk to their manager-employee relationship.

Fifth, the two-part design also created an iterative participant-focused informed consent process. Participants were given general information about the process of study, and information about themselves as participants based on information gained from their Part One responses. Next, based on this information, participants were invited to complete Part Two. Consent to participate included a consent to carry forward their information (adapted as necessary) to Part Two of the study. This process included a series of email exchanges, a Part Two information sheet, and individual and dyad interviews.

Sixth, ensuring participant safety was especially considered in Part Two of the case study, due to the possibility of the following situations occurring: (a) a breach of confidentiality from one of the participants; (b) (while unlikely given the selection criteria) participation having triggered memories that increased the 
stress levels of the participant and affected their work and/or relationship in the case study dyad; and (c) participation that had uncovered negative issues in the manager-employee relationship that pre-existed the study, but remained unaddressed.

Seventh, to protect participants from these potential risks and/or similar, a process step at the beginning of Part Two was introduced. This included the researcher meeting with the dyad to talk about the interview process and to talk about these possible risks, and to hear about any potential organisation specific risks. In this session, these issues were discussed, ground rules established and a separate participant consent and agreement form was signed. In addition, there was scope for the researcher - with the participants - to devise a plan, specific to the dyad, regarding what action would be taken, and by whom, if any risk factors arose.

\subsubsection{Confidentiality.}

All information provided by participants was treated confidentially with participants' real names not used in any research report, any presentation of the findings or publication of the research. Participants' identities and that of their organisation were further protected by their information being identifiable only by code and/or pseudonym.

\subsubsection{Data storage/retention/destruction/future use.}

All data was stored in a locked cabinet on the Victoria University of Wellington campus. Data held on digital file was password protected with consent form/s stored separately from participant data. At the end of this study, audio files of individual interviews will be returned to participants and/or deleted by the researcher as per the request of the participant; and dyad interview recordings will be deleted. All other data will be destroyed after three years from the time of the case studies.

\subsubsection{Case study data collection methods.}

Data collection methods included: survey, in-depth interviews and participant document review. 


\subsubsection{Survey method.}

The variables from Phase 1 were used in the case study surveys, with the exception of the perceived supervisor support variable. This variable was removed as it involved the supervisor being rated by the employee.

\subsection{The relationship questionnaire.}

Further, the function of the relationship questionnaire changed in the case studies. In the survey study, the relationship questionnaire was used to establish concurrent validity with the manager-employee social engagement variables. In the case studies, this variable was used to further understandings about the qualities of manager-employee social engagement strategies, and the experience of these strategies with others. The items remained unchanged, but the analysis of the variable was extended to include its capacity to compute scores pertaining to two dimensions of the internal working model: a model of self and a model of others (Griffin \& Bartholomew, 1994a, 1994b). Table 10 illustrates how these scores were computed.

Table 10

Computing the RQ Model of Self and Other Dimensions

Model of self-dimension score $(M S)$
(Secure + Dismissing) $-($ Preoccupied + Fearful $)=($ Item 1 + Item 2) -
(Item 3 + Item 4)
Model of others dimension score $(M O)$
(Secure + Preoccupied $)-($ Dismissing + Fearful $)=($ Item 1 + Item 3) -
$($ Item 2 + Item 4)

\subsubsection{In-depth and semi-structured interviews.}

In-depth and semi-structured interviews were used. Taylor and Bogdan (1984) define in-depth interviews as 'repeated face-to-face encounters between the researcher and informants directed towards understanding informants' perspectives on their lives, experiences or situations as expressed in their own words' (p. 77). The researcher is oriented towards the participants' experiences of the phenomenon, in contrast to directing the participants to address the research question/s. Semi-structured interviews enable the focus of the interview to float in 
the space between the research purpose and the human encounter within an interview (See Appendix I- Individual manager feedback session outline; and Appendix J - Individual employee feedback session outline).

In these interviews the quantitative survey data was primarily developed as a springboard for a qualitatively oriented examination of social engagement strategies. However, the MESE survey itself provided a measure of manageremployee social engagement strategies that was further developed, tested and refined within the case studies. In turn, the NZ MESE survey data, in conjunction with each participant's individual survey data, provided a base from which to explore the secure base system within the interpersonal context of a research interview.

Of note, the surveys were used not to construct a diagnosis as might occur in a clinical interview. Instead they were used as a platform for the manageremployee dyads to focus their conversation together on their respective secure base experiences at work, in association with their engagement. Overall, this approach, enabled observations of the interpersonal context to occur within the research context of the manager-employee dyad case studies.

Furthermore, in this study, engagement specific data was available for review in the case studies through self-report descriptions corroborated within the dyad interviews. I did not use psychometric measures, such as the measure of organisational citizenship behaviour (Lee \& Allen, 2002) as a possible measure of engagement behaviour. This was because I considered this measure (and similar measures) as tapping the internal dimension of perceptions as evidenced by perceptions based survey items such as: 'willingly gives one's time and assists others with their duties' (Lee \& Allen, 2002). Similarly, while it is typical to refer to levels of engagement based on internal data (as illustrated above), in this study I refer to engagement based on corroborated narrative reports about doing the tasks/job at hand; data sourced from the manager-employee dyad case studies.

\subsubsection{Participant document review.}

Following each interview, the transcription and interview summary was made available to participants for review. This process reflected the phenomenological underpinnings of the case design, where data collection and 
analysis overlap. As a result, data was constructed using a collaborative process between the researcher and the researched of 'writing and re-writing' (van Manen, 1990, p. 7), further described below.

\subsubsection{Case study data collection procedures.}

Each study began with a preparation interview. Participating dyads met with the researcher to ask any questions regarding the study, talk through the steps of the programme, sign consents and create a timetable to fit around their schedules. The studies were then conducted in two parts, illustrated in Table 11 below ${ }^{1}$.

Table 11

Summary of Case Study Structure

\begin{tabular}{|c|c|}
\hline Time & Tools and Measures \\
\hline $\begin{array}{l}\text { Part One } \\
\text { Week One }\end{array}$ & $\begin{array}{l}\text { Online survey: Confidential MESE survey. Conducted individually by each } \\
\text { manager and employee in the dyad. The questionnaire is confidential between } \\
\text { the individual participant and the researcher }\end{array}$ \\
\hline $\begin{array}{l}\text { Week Two } \\
\text { and Three }\end{array}$ & $\begin{array}{l}\text { Individual feedback sessions } \\
\text { Digitally recorded. Data is confidential between the researcher and individual } \\
\text { participant }\end{array}$ \\
\hline $\begin{array}{l}\text { Part Two } \\
\text { Week One }\end{array}$ & $\begin{array}{l}\text { Manager and Employee dyad feedback session } \\
\text { Digitally recorded. The data is confidential to the dyad and researcher }\end{array}$ \\
\hline Week Three & $\begin{array}{l}\text { Manager and Employee dyad follow-up session } \\
\text { Digitally recorded. The data is confidential to the researcher and the individual } \\
\text { participant }\end{array}$ \\
\hline
\end{tabular}

\subsubsection{Part one.}

This required approximately two and a half hours of each participant's time. Each member of the dyad individually completed the online survey and then participated in an individual interview. Participation was voluntary and data treated as confidential. Part One was comprised of four steps and concluded with each person in the dyad being invited to consider participating in Part Two.

\footnotetext{
${ }^{1}$ Throughout the case studies, if participants requested follow-up coaching, I had planned to direct them to the New Zealand Coaching Psychology Group (NZCPSIG).
} 


\subsection{Step 1: Introduction to the researcher and the programme.}

Managers and employees were invited to meet with me separately first if they chose and then to meet with me as a manager-employee dyad to: address any further questions regarding the study; sign consent forms; arrange the delivery time frame for the online survey; assign the dyad with an identification code; and create an interview timetable.

\subsection{Step 2: Online survey.}

Each participant conducted an online survey (10-15 minutes long), administered from the Qualtrics ${ }^{\mathrm{TM}}$ suite. Survey results were confidential and were made available to each individual participant in writing.

\subsection{Step 3: Individual feedback session.}

A one hour, audio-recorded feedback session entailed working through survey findings, identifying and exploring the participant's social engagement strategies when under stress, inviting participants to identify areas of the survey for further exploration and exploring future scenarios in the day-to-day relationship with the other person in the dyad, where they might consider or adapt their current social engagement strategy to support better work outcomes. An illustrated session outline is provided in Table 12.

Table 12

Part One: Feedback Session Outline

\begin{tabular}{ll}
\hline \multicolumn{1}{c}{ Time } & \multicolumn{1}{c}{ Focus } \\
\hline 5 mins & Session overview-add any goals \\
15 mins & Survey Findings and discussion \\
20 mins & Explore semi-structured questions \\
15 mins & a) Identify social engagement strategy: strengths and challenges \\
& b) Identify specific workplace situations where the participant could \\
& practice adapted social engagement strategies \\
& c) Develop a plan for on the job social engagement strategy practice \\
5 mins & What's next; written feedback; timeframe \\
\end{tabular}

\subsection{Step 4: Data review and invitation to participate in Part Two.}

Following the session, a full transcript of the interview was made and a summary written. Both of these were made available to participants. The 
summary included an invitation to participants to (a) review the documents and make any changes as necessary and (b) consider participating in Part Two as a manager-employee dyad. Participant information sheets for Part Two were available upon request.

\subsubsection{Part two.}

Part Two required a maximum of three hours of each participant's time and entailed each member of the dyad participating in one or two shared interviews (as decided by the participants) at their work, or if preferred by them, at Victoria University of Wellington. The processes involved in Part Two were:

\subsection{Step 1: preparing for the dyad session(s).}

First, I met with each individual participant in the dyad to clarify and obtain verbal consent to use their information from Part One in Part Two of the study. Only information agreed upon with the participants was used. Next, I met with each dyad to talk about the interview process, to establish ground rules and to review details in the consent form (See Appendix K).

Based on the individual data agreed to, I then wrote a dyad summary that included a summary of each person's survey scores and the key themes from the stage one interview concerning social engagement strategies at work. The summary was confidential and available to only the participants in the dyad and my supervisors.

\subsection{Step 2: Manager-employee dyad feedback session.}

This audio-recorded session explored how the social engagement strategies of participants in the dyad influenced how they went about getting their work done (see Appendix L).

\subsection{Step 3: Written review.}

The audio-recording was transcribed and a summary made available to the dyad as a confidential document, along with an invitation to amend or comment if necessary. 


\subsection{Step 4: Manager-employee dyad second session.}

This session was included in the design as an extra session should the dyad wish to continue further exploration of social engagement strategies and their associations with job and organisation engagement (Appendix $\mathbf{M}$ ).

In summary, Part One involved five dyad preparation interviews, 10 surveys, and 10 audio-recorded individual interviews. Part Two involved eight individual interviews and four audio-recorded dyad interviews. In total, 27 interviews were conducted, 14 of which were digitally recorded. The type and amount of data that was collected and constructed is illustrated in Table 13.

Table 13

Illustrated Interaction with Case Study Participants

\begin{tabular}{|c|c|c|c|c|c|}
\hline $\begin{array}{c}\text { Case } \\
\text { number, } \\
\text { purpose } \\
\text { and } \\
\text { output }\end{array}$ & $\begin{array}{l}\frac{\text { Part 1: }}{\underline{\text { Step 1. }}} \\
\text { Manager- } \\
\text { Employee } \\
\text { dyad } \\
\text { preparation } \\
\text { interviews }\end{array}$ & $\frac{\text { Step 2: }}{\text { Survey }}$ & $\begin{array}{l}\text { Step 3: } \\
\text { Individual } \\
\text { feedback } \\
\text { interviews } \\
\text { (audio } \\
\text { recorded) }\end{array}$ & $\begin{array}{l}\text { Part 2: } \\
\text { Step 1. } \\
\text { Preparation } \\
\text { for Part } 2 \\
\text { Individual } \\
\text { interviews }\end{array}$ & $\begin{array}{l}\frac{\text { Step 2: }}{\text { Dyad }} \\
\text { interviews } \\
\text { (audio } \\
\text { recorded) }\end{array}$ \\
\hline $\mathrm{CS} 1$ & Interview & $\begin{array}{l}\text { CS1M + } \\
\text { CS1E }\end{array}$ & $\begin{array}{l}\text { CS1M + } \\
\text { CS1E }\end{array}$ & $\begin{array}{l}\text { CS1M + } \\
\text { CS1E }\end{array}$ & $\begin{array}{l}\text { CS1M + } \\
\text { CS1E }\end{array}$ \\
\hline $\mathrm{CS} 2$ & Interview & $\begin{array}{l}\text { CS2M + } \\
\text { CS2E }\end{array}$ & $\begin{array}{l}\text { CS2M + } \\
\text { CS2E }\end{array}$ & $\begin{array}{l}\text { CS2M + } \\
\text { CS2E }\end{array}$ & $\begin{array}{l}\text { CS2M + } \\
\text { CS2E }\end{array}$ \\
\hline CS3 & Interview & $\begin{array}{l}\text { CS3M + } \\
\text { CS3E }\end{array}$ & $\begin{array}{l}\text { CS3M + } \\
\text { CS3E }\end{array}$ & $\begin{array}{l}\text { CS3M + } \\
\text { CS3E }\end{array}$ & $\begin{array}{l}\text { CS3M + } \\
\text { CS3E }\end{array}$ \\
\hline CS4 & Interview & $\begin{array}{l}\text { CS4M + } \\
\text { CS4E }\end{array}$ & $\begin{array}{l}\text { CS4M + } \\
\text { CS4E }\end{array}$ & $\begin{array}{l}\text { CS4M + } \\
\text { CS4E }\end{array}$ & $\begin{array}{l}\text { CS4M + } \\
\text { CS4E }\end{array}$ \\
\hline CS5 & Interview & $\begin{array}{l}\text { CS5M + } \\
\text { CS5E }\end{array}$ & $\begin{array}{l}\text { CS5M + } \\
\text { CS5E }\end{array}$ & $\mathrm{X}$ & $\mathrm{X}$ \\
\hline Purpose & $\begin{array}{l}\text { Information } \\
\text { sharing; } \\
\text { information } \\
\text { sheets (Part 1) }\end{array}$ & $\begin{array}{l}\text { QUAN data } \\
\text { collection }\end{array}$ & $\begin{array}{l}\text { QUAL data } \\
\text { collection }\end{array}$ & $\begin{array}{l}\text { Information } \\
\text { sharing; } \\
\text { Information } \\
\text { sheets (Part } \\
\text { 2) }\end{array}$ & $\begin{array}{l}\text { QUAL } \\
\text { data } \\
\text { collection }\end{array}$ \\
\hline Output & $\begin{array}{l}\text { Relationship } \\
\text { building } \\
\text { signed } \\
\text { consent forms } \\
\text { (Part 1) }\end{array}$ & $\begin{array}{l}10 \text { individual } \\
\text { surveys } \\
\text { (Which } \\
\text { included } 5 \\
\text { matched } \\
\text { surveys). } \\
10 \text { data } \\
\text { feedback } \\
\text { summaries }\end{array}$ & $\begin{array}{l}10 \text { interview } \\
\text { audio } \\
\text { recordings } \\
\text { Step 4: } \\
10 \text { transcripts } \\
10 \text { feedback } \\
\text { summaries for } \\
\text { each } \\
\text { participant }\end{array}$ & $\begin{array}{l}\text { Relationship } \\
\text { building } \\
\text { signed } \\
\text { consent } \\
\text { forms } \\
\text { (Part 2) } \\
\text { Dyad } \\
\text { summaries }\end{array}$ & $\begin{array}{l}\text { Step 3: } \\
4 \text { transcripts } \\
4 \text { feedback } \\
\text { summaries } \\
\text { for each } \\
\text { dyad }\end{array}$ \\
\hline
\end{tabular}

Notes. CS: Case Study; M: Manager; E: Employee; NGO: Non-government organisation; NZ: New Zealand. 


\subsubsection{Data analysis.}

I conducted an intra-case analysis, an inter-case comparison and analysis and a final integrative theoretical analysis, which included merging findings from both the survey and case studies. The data analysis process pertaining to the intracase analysis is described below and the inter-case analysis is described in the next section.

\subsubsection{Data analysis during data collection.}

Case study data was collected and constructed via an online survey in conjunction with an interactive interpretive process in collaboration with the participants. Throughout this phenomenological process, the experiences and perspectives of the participants were translated into data. However, in exploring the relationships between meaning, experience and narrative, Stern (2004) identified a 'problematic relationship between a lived experience (a present moment) and it's later linguistic (re) construction' (p. 144). He further stated that 'something is gained and something is lost when experience is put into words' (Stern, 2004, p. 144). This researcher quandary was in part lessened via prolonged engagement and researcher reflexivity.

This was a time of prolonged engagement (Padgett, 1998, p. 94) with participants and the case study process. It entailed engaging in interviews, constructing transcripts and written summaries, feedback and follow-up interviews. Member checking (Padgett, 1998, p. 100), for example inviting participants to comment on their data as it was being constructed, was an integral part of the data collection process.

As a researcher, I engaged in systematised reflexivity (Lather, 1986, pp. 450-452) via note-taking, practice supervision and academic supervision. Reflexivity contributes to rigor as it attends to researcher bias and influence in terms of data generation and interpretation (Buckner, 2005, p. 59) (see Redmond, 2004, for an overview). Supervision supports the practice of reflexivity by ensuring my awareness of my pre-understandings, biases and blind spots (Koch, 1996, pp. 241-243).

In addition, the cases were theoretically collective, but the feedback process within each case was unique and tailored to suit each dyad. Every 
interaction point offered an opportunity to reflect on the dance between theorymethod-and being in relation to the phenomenon with the participants. The research-oriented conversations were social, non-linear and participant led. For example, while the design had clearly marked parameters around workplace relationships, participants seamlessly weaved their narratives across the entirety of their lives, which included work and non-work relationships. During this time, in conjunction with supervision, I drew on my professional background as a psychotherapist and as a coach to trust the unfolding collection and analysis process of research based conversations.

\subsubsection{Thematic analysis.}

Thematic analysis was conducted over the course of several months. The case study data was analysed in relation to the research questions and the intermediary analysis questions and involved 'reflecting on the essential themes which characterise the phenomenon... [and]... bringing into nearness that which tends to be obscure, that which tends to evade the intelligibility of our natural attitude of everyday life' (van Manen, 1990, pp. 30-32).

To provide a structure to the reflective process of seeking patterns and themes in the data, the procedural steps advocated by Colaizzi (1978) were followed:

1. reading all of the participants' descriptions

2. extracting significant statements pertaining directly to the research questions

3. creating formulated meanings

4. collating the formulated meanings into clusters of themes, checking back to the original descriptions for validation and noting discrepancies

5. writing an exhaustive description of key features of the phenomenon

6. identifying fundamental structures of the phenomenon 7. returning to the selected participants and checking the formulations for validation (pp. 59-61). 
I used the work of Colaizzi (1978) in an iterative way. For example, task seven from the list above included a cyclical process of working through the other tasks. I integrated this task with the iterative feedback and review process with participants. In addition, the analysis focused on describing, as best as possible, what was there to be seen, before actively synthesising the data.

This process was important for my responsibility as a researcher to the participants and to the research community. It was my job to provide descriptive data as close as possible to the lived experience shared in the interviews. Concerning this task, Colaizzi (1978) advised researchers to have 'tolerance for ambiguity' (p. 61). As a researcher, I experienced tensions between sustaining the uniqueness of each participant's contributions and each dyad's contributions, while simultaneously losing these in a search for what was common across the interviews. To preserve the data, while listening for common themes across the cases, Chapter 5 presents the data from each case, with the inter-case comparison findings presented at the beginning of Chapter 6 .

Finally, to increase the validity of findings and their interpretation, I was actively engaged in a process of peer debriefing (Spall, 1998). This included regular academic supervision and coaching psychology supervision sessions with a NZ registered coaching psychologist. Professional connections with colleagues, subject matter experts in attachment theory, were maintained via my work at an executive level with The World Association of Infant Mental Health. Similarly, connections with subject matter experts in organisational behaviour were maintained via my work at an executive level within the NZ Coaching Psychology Special Interest Group Committee.

I also presented my research at academic peer reviewed conferences across a range of disciplines, including: The NZ Psychology Society Conference, 2011 (Queenstown, NZ; Best Student Paper Award); The Australian Association of Infant Mental Health, Perth, Australia, 2011; The World Association of Infant Mental Health Congress (WAIMH), 2012 (Cape Town, South Africa); and the International Federation of Scholarly Associations of Management (IFSAM), 2012 (Limerick, Ireland). Each presentation provided an opportunity to participate in conversation and inquiry about engagement across a diverse range of disciplines. 


\subsection{Inter-Case Comparison and Integrative Theoretical Analysis}

An inter-case comparison and theoretical analysis was conducted using an analysis process characterised by triangulation. Triangulation (Padgett, 1998) was used to view the phenomena from a number of vantage points. This benefits qualitative inquiry; 'each method implies a different line of action towards reality and hence each will reveal different aspects of it' (Denzin, 1989, p. 235). In addition, it was beneficial in maintaining a social lens on the interactions between the quantitative and qualitative aspects of the phenomena. Table 14 illustrates the overlapping analysis process of the intra and inter-case study analysis.

Table 14

Intra and Inter-Case Analysis

\begin{tabular}{lll}
\hline \multicolumn{1}{c}{ Focus of the analysis } & \multicolumn{1}{c}{$\begin{array}{c}\text { Rigor } \\
\text { strategies }\end{array}$} & \multicolumn{1}{c}{ Output } \\
\hline $\begin{array}{l}\text { Linear survey data analysis and non-linear } \\
\text { phenomenologically oriented collaborative } \\
\text { data construction }\end{array}$ & $\begin{array}{l}\text { Prolonged } \\
\text { engagement; } \\
\text { member } \\
\text { checking; } \\
\text { Reflexivity }\end{array}$ & $\begin{array}{l}\text { Audio recordings, transcripts, } \\
\text { survey findings, written } \\
\text { summaries and feedback } \\
\text { (Chapter 5) }\end{array}$ \\
\hline $\begin{array}{l}\text { Case study methodological review process: } \\
\begin{array}{l}\text { Adapting to meet and suit the participants, } \\
\text { during the case study data collection and } \\
\text { early data construction stages }\end{array}\end{array}$ & $\begin{array}{l}\text { Prolonged } \\
\text { engagement }\end{array}$ & $\begin{array}{l}\text { Each case highlighted unique } \\
\text { methodological data (Chapter 5) }\end{array}$ \\
\hline $\begin{array}{l}\text { Thematic analysis: Participant data and } \\
\text { methodological data. }\end{array}$ & $\begin{array}{l}\text { Prolonged } \\
\text { engagement }\end{array}$ & $\begin{array}{l}\text { Linear and non-linear } \\
\text { engagement themes that exist in } \\
\text { rhenomenological thematic analysis in } \\
\text { conjunction with descriptive statistics; and } \\
\text { methodological analysis of the case study } \\
\text { process }\end{array}$ \\
$\begin{array}{l}\text { Chapter 5) } \\
\text { Linear and non-linear } \\
\text { methodological themes that } \\
\text { exist in relation with each other } \\
\text { (Chapter 5) }\end{array}$ \\
$\begin{array}{l}\text { Inter-case comparison } \\
\begin{array}{l}\text { Theoretical analysis of the framework and } \\
\text { the model of engagement }\end{array}\end{array}$ & $\begin{array}{l}\text { Chapter 6: Discussion and } \\
\text { conclusion }\end{array}$ \\
\hline
\end{tabular}

\subsubsection{Inter-case comparison and analysis.}

The focus of the inter-case analysis was the second sub-research question. As such, the analysis process was anchored in the phenomenological approach to stay as close as possible to the participants' experiences. In conjunction, the survey findings and the guiding questions from the intermediary analysis, were 
also used to guide this analysis. Following the inter-case analysis, the focus shifted into an integrative theoretical analysis.

\subsubsection{Integrative theoretical analysis.}

The goal of the integrative theoretical analysis was to answer the overarching research question. This analysis involved reviewing the data across both studies, resulting in inferences being made about the empirical unit of analysis: manager-employee social engagement strategies. At best, these inferences were valid, that is: 'meaningful and accurate conclusions from all the data in the study' (Cresswell \& Plano Clark, 2007, p. 146). Regarding this analytical process, Lambdin (2012) stated:

The making of scientific inferences is always a qualitative process. It is something we must do ourselves. It can be helped by mathematics, but it cannot be replaced by mathematics. Math does not do the reasoning for us. The hard work will always take place between our ears. (p. 84)

Finally, this analysis drew on an interplay between interpretivism and functionalism, which included a pragmatic focus on addressing the research questions using statistics while 'writing-entering and traversing the space of the text' (van Manen, 2002, p. 7) as a pathway to maintaining a 'strong and oriented relation to the phenomenon' (van Manen, 1990, p. 30). The output of this analysis is reported in Chapter 6.

\subsection{Chapter Summary}

This chapter has outlined the methodological (mixed method study), philosophical (functionalist-interpretive) and contextual (NZ managers and employees across industries) foundations for the empirical study. The practical steps concerning data collection and analyses have been detailed, establishing an audit trail. The research phases and their respective findings, analyses and interpretations will now be outlined in the following three chapters. Chapter 4 provides the findings from the statistical analysis of the survey data and concludes by identifying core findings to be further examined in the case studies. Chapter 5 describes each case study and Chapter 6 provides findings from the inter-case analysis. 


\section{Chapter 4: NZ Manager-Employee Social Engagement Survey Findings}

This chapter reports the findings from Phase 1 of the study. Managers and employees from NZ organisations participated in the online manager-employee engagement survey. The survey aimed to address the first sub-research question:

What is the association (if any) between: the different ways that managers and employees engage with each other about their job, when they are under pressure; their states of mind about engagement; and their states of mind about antecedents and outcomes of engagement?

To statistically answer this question I created a series of engagement models (Chapter 2: Figure 1, 2, 3 and 4) and then operationalised these in Chapter 3. These models are now re-presented below for easy reference as (Figure 6, 7, 8, and 9).

1. Model 1 (Figure 6)

2. Model 2 (Figure 7)

3. Model 1A (Figure 8)

4. $\quad$ Model 1B (Figure 9)

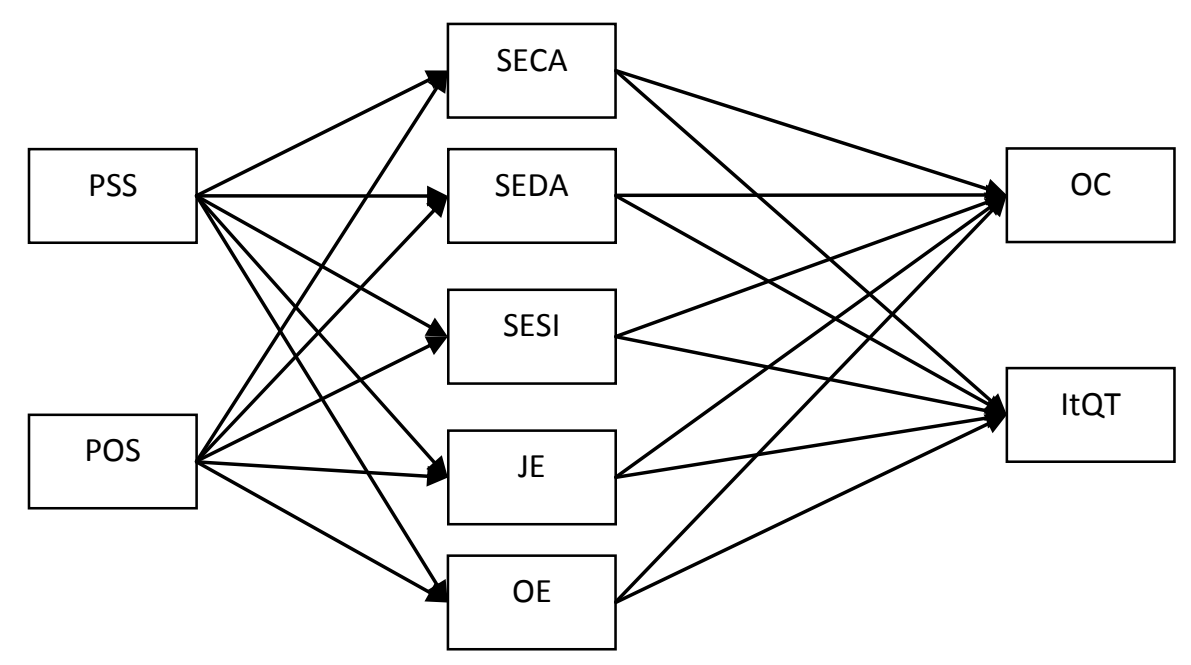

Figure 6. Model 1. 


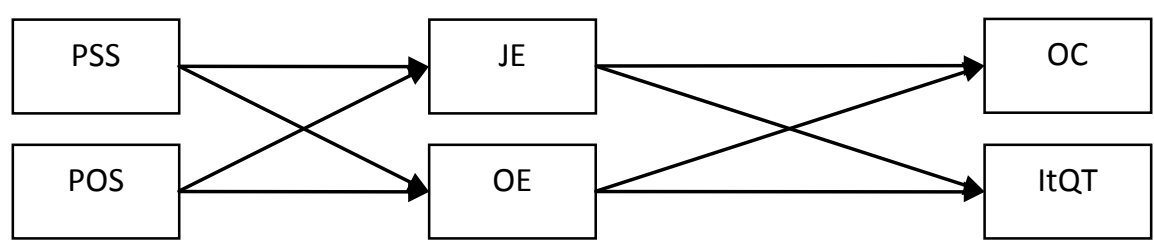

Figure 7. Model 2 (excluding SECA, SEDA, and SESI).

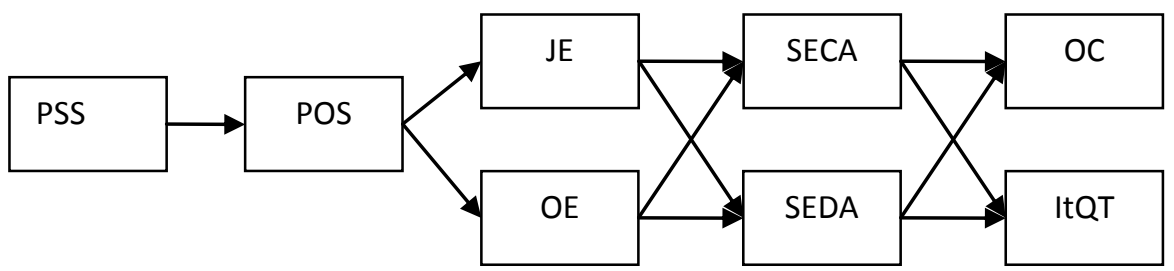

Figure 8. Model 1 A (with SECA and SEDA mediating between JE, OE and OC, ItQT).

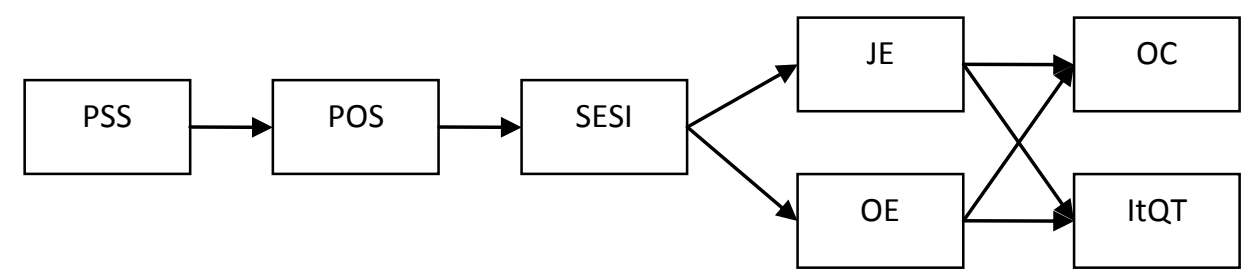

Figure 9. Model 1B. JE and OE mediating between SESI and OC and ItQT.

Data from the surveys were analysed as two separate datasets: a manager dataset and an employee dataset (as discussed in Chapter 3, Section 2). At the outset, this chapter presents a demographic picture of the sample. Next, findings pertaining to each research proposition $(1,2,3$, and 4) and their respective hypotheses are reported, with similarities and differences between the manager and employee datasets highlighted. Consistent with the mixed methods sequential explanatory design, the chapter concludes with an intermediary analysis of the survey findings, where key findings are identified for qualitative review in the manager-employee case studies. Table 15 provides a chapter outline. 
Table 15

Survey Findings Chapter Outline

\begin{tabular}{|c|c|c|c|}
\hline Section & Proposition & Hypothesis & Findings \\
\hline 4.1 Sample & $\mathrm{X}$ & $\mathrm{X}$ & $\begin{array}{l}\text { Demographic picture of the } \\
\text { sample }\end{array}$ \\
\hline 4.2 Scale Development & 1 & 1 & EFA: MESE Scales \\
\hline 4.2 Scale Development & 1 & 2 & $\begin{array}{l}\text { Descriptive and correlation } \\
\text { analysis: MESE scale convergent } \\
\text { validity }\end{array}$ \\
\hline 4.3 Correlation Findings & 2 & $3,6,9$ & $\begin{array}{l}\text { Correlation analysis: } \\
\text { scales with POS and PSS }\end{array}$ \\
\hline 4.3 Correlation Findings & 2 & $4,7,10$ & $\begin{array}{l}\text { Correlation analysis: MESE } \\
\text { scales with JE and OE }\end{array}$ \\
\hline 4.3 Correlation Findings & 2 & $5,8,11$ & $\begin{array}{l}\text { Correlation analysis: } \\
\text { scales with OC and ItQT }\end{array}$ \\
\hline 4.4 Path Analysis & 3 & 12 & $\begin{array}{l}\text { Path analysis with MESE scales } \\
\text { and PSS, POS, JE, OE, OC and } \\
\text { ItQT }\end{array}$ \\
\hline $\begin{array}{l}\text { 4.5 Path Analysis and } \\
\text { Mediation Analysis }\end{array}$ & 4 & 13,14 & $\begin{array}{l}\text { Mediation analysis and path } \\
\text { analysis with MESE scales and } \\
\text { PSS, POS, JE, OE, OC and ItQT }\end{array}$ \\
\hline $\begin{array}{l}\text { 4.6 Intermediary Research } \\
\text { findings } \\
\text { 4.7 Chapter Summary }\end{array}$ & & & $\begin{array}{l}\text { Key quantitative findings for } \\
\text { social review in Study } 2\end{array}$ \\
\hline
\end{tabular}

\subsection{Sample}

The sample consisted of 200 (non-paired) completed surveys from managers and 200 completed surveys from employees. Participant demographics have been described (Chapter 3). Frequencies and percentages for participant demographics pertaining to age, gender and ethnicity are presented in Table 16.

Exploratory multivariate analyses of variance (MANOVAs) were conducted to see if gender and ethnicity were related to the nine variables of interest:

1. The manager data: perceived supervisor support, perceived organisational support, manager connect-act, disconnect-act, stress-immobilise, job engagement, organisation engagement, intention to quit/turnover, and organisational commitment.

2. The employee data: perceived supervisor support, perceived organisational support, employee connect-act, disconnect-act, stress-immobilise, job engagement, organisation engagement, intention to quit/turnover, and organisational commitment. 
Table 16

Frequencies and Percentages for Demographics

\begin{tabular}{lrrrr}
\hline \multicolumn{1}{c}{ Demographic } & \multicolumn{2}{c}{ Manager } & \multicolumn{2}{c}{ Employee } \\
\cline { 2 - 5 } Age & $N$ & $\%$ & $n$ & $\%$ \\
$21-29$ & 2 & 1 & 36 & 18 \\
$30-39$ & 31 & 16 & 42 & 21 \\
$40-49$ & 66 & 33 & 51 & 26 \\
$50-59$ & 60 & 30 & 58 & 29 \\
$60-69$ & 37 & 19 & 11 & 6 \\
$70-79$ & 4 & 2 & 2 & 1 \\
Gender & & & & \\
Female & 96 & 48 & 144 & 72 \\
Male & 102 & 52 & 56 & 28 \\
Ethnicity & & & & \\
Maori & 9 & 5 & 12 & 6 \\
NZ European & 172 & 86 & 155 & 78 \\
Pacific Islander & 1 & 1 & 4 & 2 \\
Asian & 1 & 1 & 7 & 4 \\
Other European & 18 & 9 & 19 & 10 \\
Other & 9 & 5 & 19 & 10 \\
\hline
\end{tabular}

The MANOVA was selected for the demographic features of ethnicity and gender because these variables were nominal. In the manager sample, results of the MANOVA by gender was not significant, $F(9,152)=1.91, \mathrm{p}=0.054$, and results of the MANOVA by ethnicity was also not significant, $F(9,765)=1.10, p$ $=0.304$. In the employee data, results of the MANOVA by gender was not significant, $F(9,126)=1.18, p=0.316$, and results of the MANOVA by ethnicity was also not significant, $F(9,630)=0.86, p=0.732$. This suggests that gender and ethnicity are not related to the variables of interest for managers or employees. Results of the MANOVAs are presented in Table 17.

Table 17

MANOVAs for Variables of Interest by Gender and Ethnicity

\begin{tabular}{llccc}
\hline \multicolumn{1}{c}{ Dataset } & \multicolumn{1}{c}{ Group } & $F$ & $d f$ & $P$ \\
\hline Manager & Gender & 1.91 & 9,152 & .054 \\
Manager & Ethnicity & 1.10 & 9,765 & .304 \\
Employee & Gender & 1.18 & 9,126 & .316 \\
Employee & Ethnicity & 0.86 & 9,630 & .732 \\
\hline
\end{tabular}


Exploratory Spearman correlations were also conducted on the variables of interest with age for both managers and employees. Spearman correlations were conducted because age was an ordinal variable.

For the managers, results of the correlations showed that age was significantly (small) negatively correlated with job engagement $\left(r_{s}=-0.13, p<\right.$ $0.05)$ and intention to quit/turnover $\left(r_{s}=-0.21, p<0.01\right)$. This suggests, in this manager sample that as age increases, job engagement and intention to quit/turnover scores tend to decrease. For the employees, results also show a significant (small) positive correlation between age and organisational commitment scores $\left(r_{s}=0.13, p<0.05\right)$ (see Section 4.2 for a description of effect size). This suggests, in this employee sample that as age increases, organisation commitment scores tend to increase. Results of the correlations are presented in Table 18.

Table 18

Spearman Correlations between Variables of Interest and Age

\begin{tabular}{lcc}
\hline $\begin{array}{c}\text { Variable of } \\
\text { interest }\end{array}$ & Age (Manager) & Age (Employee) \\
\hline PSS & -.10 & .03 \\
POS & -.04 & .01 \\
SESI & -.11 & -.02 \\
SECA & .02 & -.02 \\
SEDA & .00 & .00 \\
JE & $-.13^{*}$ & .03 \\
OE & .02 & .05 \\
ItQT & $-.21^{* *}$ & -.03 \\
OC & .09 & $.13^{*}$ \\
\hline Note. ${ }^{*} p<0.05 . * * p<0.01$. &
\end{tabular}

Data was collected about industry type. I asked: in which industry are you currently employed? Responses were categorised as follows: education; government/public service; health and community services; professional, scientific and technical services; Iwi (Maori tribal) Trusts; and other. However, the open question was ambiguous in terms of job and industry. For example, grouped responses under the umbrella of education included: health educator, early childhood teacher, administrator and tertiary education lecturer. Responses under professional included: policy analysts, human resource (HR) managers, accountants and coaches. Given the overall goal of the study, in conjunction with 
a poorly asked question on my part, I decided this data lacked sufficient specificity to be meaningful and was not further analysed.

\subsection{Scale Development}

\subsubsection{Proposition 1: Hypothesis 1.}

Proposition 1: The three theorised manager-employee social engagement strategies will be reliable and associated with a pre-validated survey measure of adult attachment.

Hypothesis 1: Manager-employee social engagement strategies can be represented by three related but unique strategies: connect-act; disconnect-act; and stress-immobilise.

Hypothesis 1 was examined by following Steps $4 \mathrm{a}$ and $4 \mathrm{~b}$ in the scale development process, previously outlined in Table 5. An initial examination of the factorability of (a) the 42 manager items, and (b) the 42 employee items was conducted. Neither data set met all of the conditions to run factor analysis.

First, the 42 items from the manager survey dataset indicated items correlated from 0.00 to 0.63 , and therefore did not meet the criteria for all items to correlate 0.30 or above. Similarly, communalities ranged from 0.15 to 0.59 , and therefore did not meet the criteria to be 0.30 or above. However, the KaiserMeyer-Olkin (KMO) index was 0.73 adequate. The scree plot and initial eigenvalues indicated a potential three-component structure. The first component explained 39 per cent of the variance, the second 26 per cent, and the third component 11 per cent of the variance, with the three components explaining 77 per cent of the cumulative variance (See Appendix $\mathrm{N}$ for the scree plot and item component matrix).

Second, the 42 items from the employee dataset showed that items correlated from 0.002 to 0.70 , therefore not meeting the criteria for items to correlate 0.30 or above. However, the other conditions were met and supported factorability: the KMO index was 0.81 and communalities were all above 0.30 , ranging from 0.33 to 0.67 . In contrast to the manager data set, initial eigenvalues indicated a potential six factor structure, where the first factor explained 20 per cent of the variance, the second factor 12 per cent, the third factor eight per cent, 
the fourth factor five per cent, the fifth factor four per cent, and the sixth factor, four per cent, explaining 53 per cent of the cumulative variance. Further examination of the six factors highlighted: two connect-act factors; two disconnect-act factors; and stress-immobilise factors (See Appendix $\mathrm{O}$ for the scree plot and item component matrix). Although the overall statistical picture was promising, this picture was underpinned by compromised factorability in the 42 items sets.

Next, I explored the possibility of conducting factor analysis calculations with each 14 item scale: (a) manager connect-act; disconnect-act; and stressimmobilise; and (b) employee connect-act; disconnect-act; and stress-immobilise. Each 14 item scale met the conditions to run exploratory factor analysis. Next, an initial exploratory reliability test with each of the six 14 item scales showed each scale had an alpha coefficient of 0.70 or above.

Moreover, attachment theory research had repeatedly validated the three normative secure base strategies that underpinned this study. In addition, across narrative and survey method oriented research, the derivatives of attachment theory had been well established (Cassidy \& Shaver, 2008). The expert review process confirmed that the items representing each strategy appeared representative of the normative secure base strategies.

As a result, I decided to conduct six separate calculations: three employee calculations and three manager calculations. To provide an audit trail of the process, I first report in full the factor analysis results and the internal reliability of the manager connect-act variable and the employee connect-act variable. Other factor analysis results (which followed the same process for the connect-act variable) regarding the manager disconnect-act and stress-immobilise; and the employee disconnect-act and stress-immobilise calculations, are summarised below. The respective scree plots and pattern matrices are in Appendix $\mathrm{P}$ (Manager SESI and SEDA) and Appendix Q (Employee SESI and SEDA); and Table 34 (at the end of this section concerning hypothesis 1) summarises each new scale and subscale. 


\subsubsection{Connect-act (SECA).}

\subsection{Manager connect-act.}

An initial examination suggested adequate factorability. All items correlated at least 0.30 with at least one other item, the highest correlation being 0.56 . The KMO index was 0.80 and communalities were all above 0.30 , ranging from 0.32 to 0.74 . Based on these indicators, exploratory factor analysis was conducted with all 14 items.

The initial eigenvalues indicated a potential three-factor structure, where the first factor explained 29 per cent of the variance, the second factor 14 per cent, and a third factor 11 per cent of the variance, with a cumulative 54 per cent explanation of variance. The scree plot, as shown in Figure 10, also indicated a three-factor structure (with a possible four-factor structure).

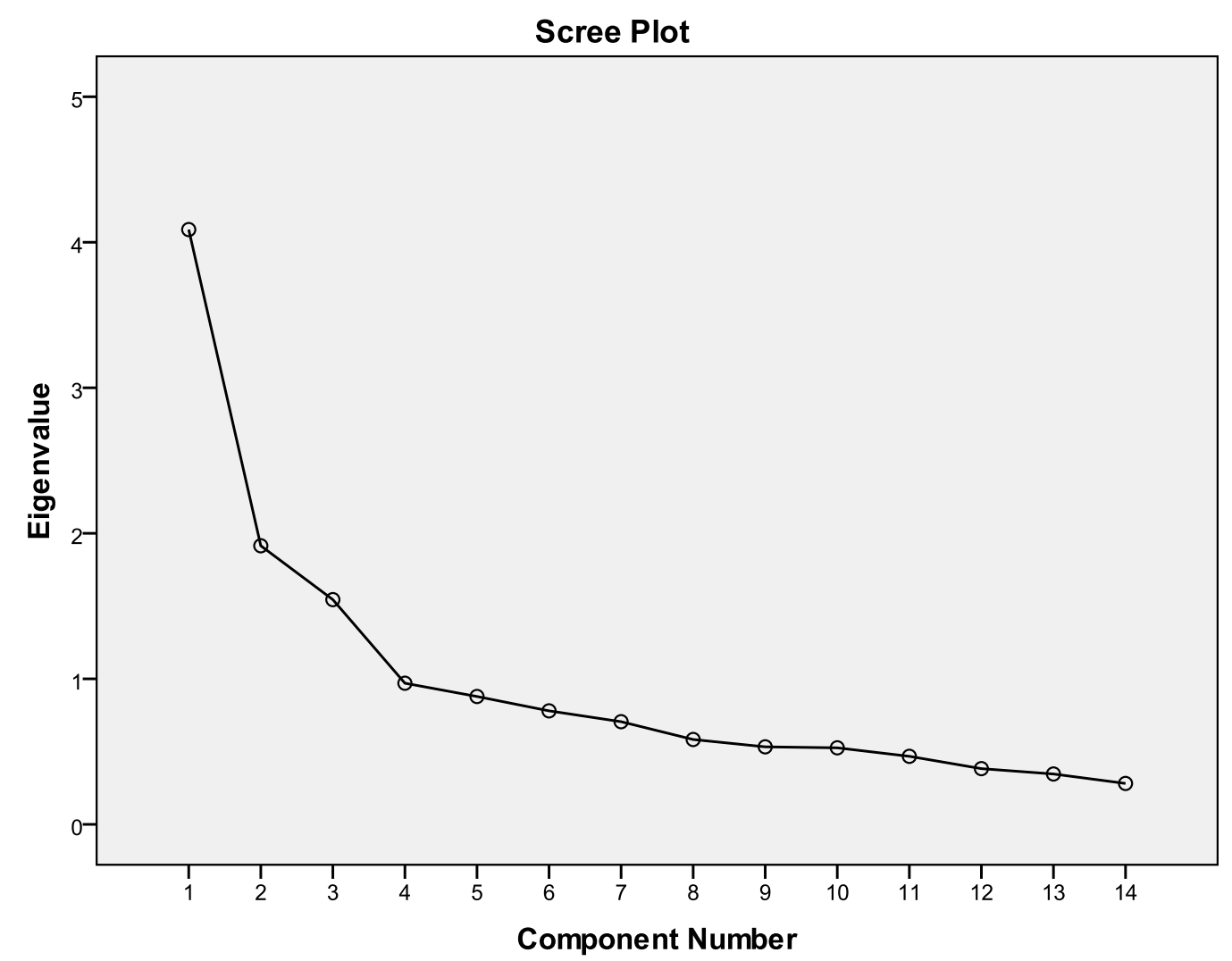

Figure 10. Manager connect-act scree plot. 
Eigenvalues, in comparison to the criterion values generated from the parallel analysis, also indicated a three-factor structure (Table 19).

Table 19

Manager Connect-Act Eigenvalues and Criterion Values

\begin{tabular}{lcccc}
\hline & $\begin{array}{c}\text { Component } \\
\text { number }\end{array}$ & Actual eigenvalue & $\begin{array}{c}\text { Criterion value from } \\
\text { parallel analysis }\end{array}$ & Decision \\
\hline Manager & 1 & 4.087 & 1.4699 & Accept \\
SECA & 2 & 1.914 & 1.3540 & Accept \\
& 3 & 1.544 & 1.2631 & Accept \\
\hline
\end{tabular}

Next, the pattern matrix indicated a three-component structure, and the structure matrix indicated acceptable inter-item correlations, except for item 10 (Table 20). However, item 10 was initially retained and placed in component 3, because of its better fit with the component 3 items, and due to its slightly higher loading on this component compared to component 1 . The correlation matrix indicated a weak positive correlation between the three components; 0.217 between component 1 and 2; 0.215 between component 1 and 3; and 0.217 between component 2 and 3 .

Table 20

Manager Connect-Act Pattern Matrix

\begin{tabular}{|c|c|c|c|}
\hline MESE Item & & Component & \\
\hline & 1 & 2 & 3 \\
\hline & Support received & Connection & Secure base use \\
\hline Q1: Secure base seeking & & & .750 \\
\hline Q2: Support received & .666 & & .282 \\
\hline Q3: Support seeking frequency & & -.145 & .725 \\
\hline Q4: Conflict response & -.205 & .750 & .125 \\
\hline Q5: Support to others & .256 & .721 & -.194 \\
\hline Q6: support seeking behaviour & & .257 & .542 \\
\hline Q7: Expected support & .728 & .178 & \\
\hline Q8: Preferred conflict response & & .764 & \\
\hline Q9: Support to others & & .721 & \\
\hline Q10: Support organisation & .336 & & .407 \\
\hline Q11: Organisation response & .872 & & \\
\hline Q12: Doing the job & .735 & & -.117 \\
\hline Q13: Stress behaviour & & .102 & .559 \\
\hline Q14: Goal sharing & 668 & & \\
\hline
\end{tabular}

Note. Major loadings for each item are in bold. Extraction method: Principal component analysis; Rotation method: Oblimin with Kaiser normalization (rotation in 6 iterations).

Cronbach's alpha for the total 14 -item scale was $\alpha=0.79$. The corrected item-to-total correlations ranged from 0.59 to 0.29 , resulting in item $3(0.29)$ and item $13(0.30)$, both from component 3 , being removed. The internal reliability of 
the remaining 12 items was recalculated resulting in a manager connect-act 12 item measure with an alpha coefficient of $\alpha=0.80$, with corrected item-to-total correlations ranging from 0.75 to $0.32(\mathrm{M}=3.79, \mathrm{SD}=0.49)$.

The 12 item connect-act scale included three sub-component scales:

1. Connect-act (support) (SECA-support): A five-item scale, $\alpha=0.81$ (corrected item-to-total correlations 0.72 to 0.50$)(\mathrm{M}=3.84, \mathrm{SD}=0.69)$.

2. Connect-act (connection) (SECA- connection): A four-item scale, $\alpha=0.75$ (corrected item-to-total correlations ranging from 0.60 to 0.52 $(\mathrm{M}=4.05, \mathrm{SD}=0.59)$.

3. Connect-act (secure base use) (SECA-secure base use): A threeitem scale, $\alpha=0.55$ (corrected item-to-total correlations 0.41 to 0.31 $(\mathrm{M}=3.46, \mathrm{SD}=0.71)$.

No substantial increases in alpha for any of the scales could have been achieved by removing any items. Finally, composite scores were created for each of the three factors, based on the mean of the items that had their primary loadings on each factor. Higher scores indicated greater use and/or identification of communication strategy. Skewness scores were all within an acceptable range: connect-act (-0.296); connect-act (support) (-0.700); connect-act (connection) ($1.131)$ and connect-act (secure base use) (-0.187). Finally, Cronbach's alpha for component 3 , connect-act (secure base use) was below 0.70 . This component was retained at this stage of the study because the component represented a theoretically coherent cluster. This decision was further explored using the data from the case studies (Chapter 5). Key findings are summarised in Table 21.

Table 21

Manager Connect-Act, 12 Item Scale

\begin{tabular}{|c|c|c|c|c|c|c|}
\hline $\begin{array}{c}\text { Connect- } \\
\text { Act }\end{array}$ & $N$ & Eigenvalue & $\begin{array}{c}\% \text { of } \\
\text { Variance }\end{array}$ & $\begin{array}{c}\text { Cumulative } \\
\%\end{array}$ & $M(S D)$ & $\alpha$ \\
\hline Support & 5 & 4.087 & $29 \%$ & $19 \%$ & 3.84 (0.69) & .81 \\
\hline Connection & 4 & 1.914 & $14 \%$ & $33 \%$ & $4.05(0.59)$ & .75 \\
\hline $\begin{array}{c}\text { Secure base } \\
\text { use }\end{array}$ & 3 & 1.544 & $11 \%$ & $54 \%$ & $3.46(0.71)$ & .55 \\
\hline
\end{tabular}




\subsection{Employee Connect-Act.}

An initial examination of the employee connect-act variable suggested adequate factorability: all 14 items correlated at least 0.30 , with at least one other item; the KMO measure of sampling adequacy was 0.85 ; and communalities were all above 0.30 , ranging from 0.41 to 0.69 , confirming shared common variance between the items. Based on these indicators, factor analysis was conducted with all 14 items. Initial eigenvalues showed that the first factor explained 39 per cent of the variance, the second factor 14 per cent of the variance and a third factor nine per cent of the variance, with a cumulative 62 per cent explanation of variance, indicating a potential three-factor structure. However, the scree plot, as shown in Figure 11, indicated a two-factor structure.

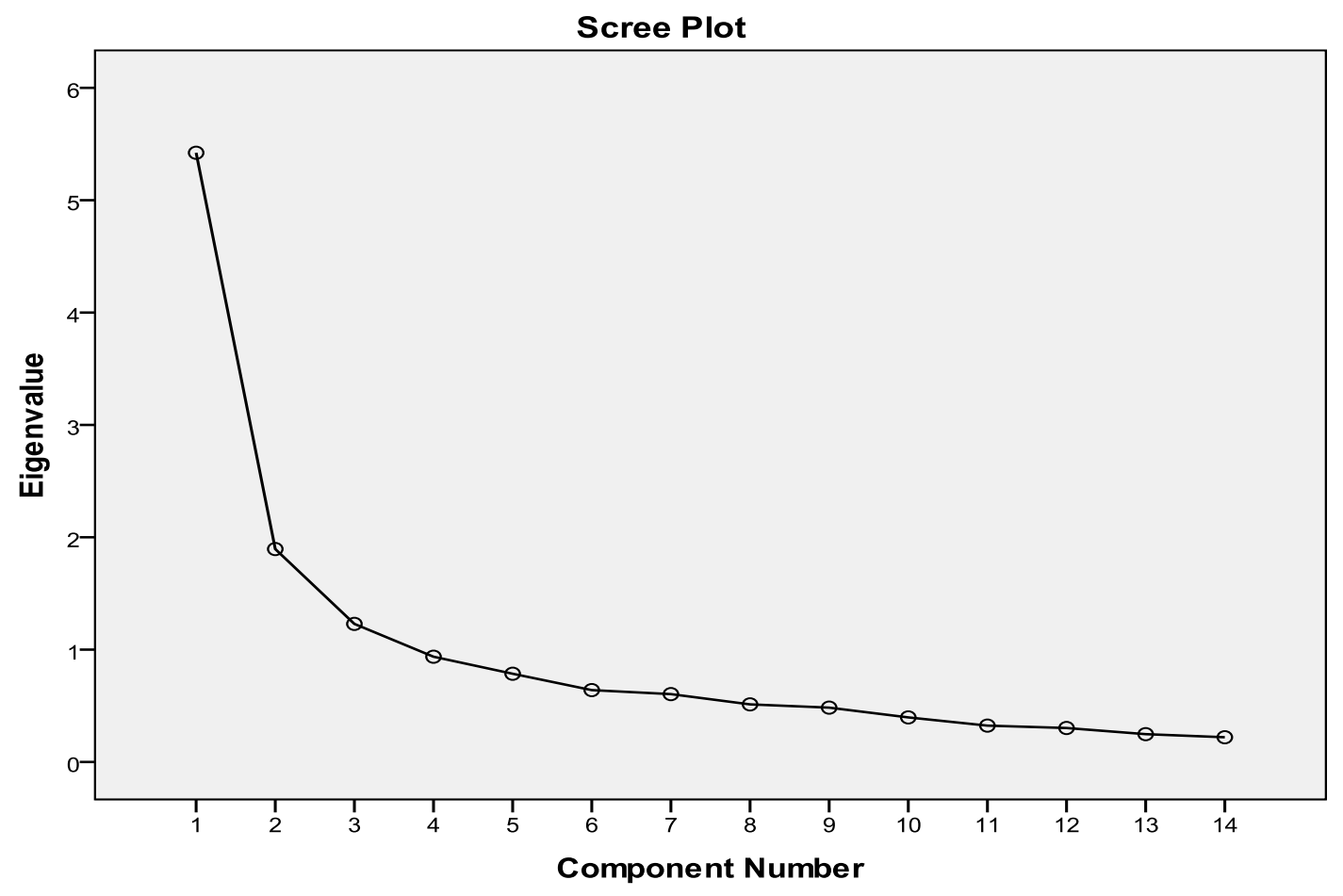

Figure 11. Employee connect-act scree plot.

Eigenvalues were then compared with the criterion values generated from the parallel analysis. The first two eigenvalues values were higher than the criterion value, and the third component was slightly less, indicating the likelihood of a two-component structure (Table 22). 
Table 22

Employee Connect-Act Eigenvalues and Criterion Values

\begin{tabular}{lcrcc}
\hline & $\begin{array}{c}\text { Component } \\
\text { number }\end{array}$ & $\begin{array}{c}\text { Actual } \\
\text { eigenvalue }\end{array}$ & $\begin{array}{c}\text { Criterion value from } \\
\text { parallel analysis }\end{array}$ & Decision \\
\hline Employee & 1 & 5.422 & 1.4669 & Accept \\
SECA & 2 & 1.895 & 1.3540 & Accept \\
& 3 & 1.229 & 1.2632 & Reject \\
\hline
\end{tabular}

Next, the pattern matrix (Table 23) and structure matrix indicated a threecomponent structure. As shown in Table 23, item 10 was highly correlated across component $1(0.38)$ and component $3(0.42)$. Next, item 10 was placed as a best fit item in component 3 with the expectation that this item would be removed if necessary in the process of establishing internal consistency. The internal reliability of the 14 items was calculated, resulting in an employee connect-act 14item measure with an alpha coefficient of $\alpha=0.88$ and with corrected item-tototal correlations ranging from 0.36 to $0.67(M=3.51, S D=0.61)$.

Table 23

Employee Connect-Act Pattern Matrix

\begin{tabular}{llll}
\hline MESE Item & Component & & \\
& 1 & 2 & 3 \\
& Support & Connection & Secure base \\
& Received & & Use \\
1: Secure base seeking & .062 & .133 & $\mathbf{. 7 2 5}$ \\
2: Support received & .757 & -.138 & .170 \\
3: Support seeking frequency & .105 & -.128 & $\mathbf{. 6 0 4}$ \\
4: Conflict response & -.008 & $\mathbf{. 8 4 3}$ & -.086 \\
5: Support to others & $\mathbf{. 5 9 5}$ & .096 & .168 \\
5: Expected support & .034 & .135 & $\mathbf{. 7 7 6}$ \\
7: Support seeking behaviour & $\mathbf{. 8 3 9}$ & -.096 & .090 \\
3: Preferred conflict response & .067 & $\mathbf{. 8 2 9}$ & -.094 \\
9: Support to others & .053 & $\mathbf{. 7 2 5}$ & .108 \\
10: Support organisation & .382 & .195 &. $\mathbf{4 2 0}$ \\
11: Organisation response & $\mathbf{. 8 2 4}$ & .000 & .017 \\
12: Doing the job & $\mathbf{. 7 1 6}$ & .350 & -.292 \\
13: Stress behaviour & -.072 & $\mathbf{. 5 8 2}$ & .280 \\
14: Goal sharing & $\mathbf{. 7 7 4}$ & -.016 & -.013 \\
\hline
\end{tabular}

Note. Major loadings for each item are in bold. Extraction method: Principal component analysis; Rotation method: Oblimin with Kaiser normalization (rotation in 6 iterations).

The employee connect-act sub-component scales included:

1. Connect-act (support) (SECA-support): A six-item scale, $\alpha=0.87$ (corrected item-to-total correlations 0.57 to 0.77$)(M=3.63, S D=0.78)$; 
2. Connect-act (connection) (SECA-connection): A four-item scale, $\alpha$ $=0.77$ (corrected item-to-total correlations ranging from 0.40 to 0.67 ) $(\mathrm{M}=3.78, \mathrm{SD}=0.64)$; and

3. Connect-act (secure base use) (SECA-secure base use): A fouritem scale, $\alpha=0.73$ (corrected item-to-total correlations ranging from 0.38 to 0.61$)(\mathrm{M}=3.13, \mathrm{SD}=0.80)$.

Removing any of the items would not have increased the alpha for any of the scales. Skewness scores were all within an acceptable range: connect-act (0.332); connect-act (support) (-0.531); connect-act (connection) (-0.397); and connect-act (secure base use) (-0.465). Key findings are summarised in Table 24.

Table 24

Employee Connect-Act, 14 Item Scale

\begin{tabular}{|c|c|c|c|c|c|c|}
\hline Connect-Act & $n$ & Eigenvalue & $\begin{array}{c}\% \text { of } \\
\text { Variance }\end{array}$ & $\begin{array}{c}\text { Cumulative } \\
\%\end{array}$ & $'(S D)$ & $\alpha$ \\
\hline Support & 4 & 5.422 & $39 \%$ & $39 \%$ & $\begin{array}{l}3.63 \\
.78)\end{array}$ & .87 \\
\hline Connection & 4 & 1.895 & $14 \%$ & $53 \%$ & $\begin{array}{l}3.78 \\
0.64)\end{array}$ & .77 \\
\hline Secure base use & 6 & 1.229 & $9 \%$ & $62 \%$ & $\begin{array}{l}3.13 \\
0.80) \\
\end{array}$ & .73 \\
\hline
\end{tabular}

Note. Extraction method: PCA with oblimin rotation.

\subsubsection{Stress-immobilise.}

\subsection{Manager stress-immobilise.}

EFA resulted in a manager stress-immobilise, 12 -item scale $(\alpha=0.80)$, with corrected item-to-total correlations ranging from 0.30 to $0.73,(\mathrm{M}=2.25, \mathrm{SD}=$ 0.55). Based on the scree plot (Appendix P), eigenvalues and criterion values, a two-component scale was indicated, accounting for $44 \%$ of the variance.

Consistent with the pattern matrix (Appendix P):

1. Component 1: Stress-Immobilise (Conflict) was represented by a four-item scale $(\alpha=0.82)$ with corrected item-to-total correlations ranging from 0.45 to $0.73(\mathrm{M}=2.10, \mathrm{SD}=0.69)$. 
2. Component 2: Stress-immobilise (Support) was represented by a three-item scale $(\alpha=0.64)$ with item-to-total correlations ranging from 0.32 to $0.48(\mathrm{M}=2.44, \mathrm{SD}=0.61)$.

Skewness scores were all within an acceptable range: Stress-immobilise (0.371); stress-immobilise (Conflict) (-0.490); and stress-immobilise (Support) (0.141). The findings are summarised in Table 25.

Table 25

Manager Stress-Immobilise

\begin{tabular}{ccccccc}
\hline $\begin{array}{c}\text { Stress- } \\
\text { Immobilise }\end{array}$ & $N$ & Eigenvalue & $\begin{array}{c}\% \text { of } \\
\text { Variance }\end{array}$ & $\begin{array}{c}\text { Cumulative } \\
\%\end{array}$ & $M(S D)$ & $\alpha$ \\
\hline Conflict & 4 & 4.099 & $29 \%$ & $29 \%$ & $\begin{array}{l}2.10 \\
(0.69)\end{array}$ & .82 \\
Support & 3 & 2.165 & $15 \%$ & $44 \%$ & $\begin{array}{l}2.44 \\
(0.61)\end{array}$ & .64 \\
\hline
\end{tabular}

Note. Extraction method: PCA with oblimin rotation.

\subsection{Employee stress-immobilise.}

Results indicated an employee stress-immobilise, 10 item scale $(\alpha=0.85)$ $(\mathrm{M}=2.31, \mathrm{SD}=0.67)$ with corrected item-to-total correlations ranging from 0.45 to 0.64. Based on the scree plot (Appendix P), eigenvalues and criterion values, a two-component scale was indicated, accounting for $50 \%$ of the variance.

Consistent with the pattern matrix (Appendix P):

1. Component 1: Stress-immobilise (Conflict) was represented by a seven-item scale $(\alpha=0.84)$ with corrected item-to-total correlations ranging from 0.54 to 0.65$)(\mathrm{M}=2.41, \mathrm{SD}=0.78)$.

2. Component 2: Stress-immobilise (Support) was represented by a three-item scale ( $\alpha=0.70$ ) with item-to-total correlations ranging from 0.49 to 0.51$)(\mathrm{M}=2.11, \mathrm{SD}=0.68)$.

Skewness scores were all within an acceptable range: Stress-immobilise (0.841), stress-immobilise (conflict) (-0.547) and stress-immobilise (support) (0.494). Findings are summarised in Table 26. 
Table 26

Employee Stress-Immobilise

\begin{tabular}{ccccccc}
\hline $\begin{array}{c}\text { Stress- } \\
\text { Immobilise }\end{array}$ & $N$ & Eigenvalue & $\begin{array}{c}\% \text { of } \\
\text { Variance }\end{array}$ & $\begin{array}{c}\text { Cumulative } \\
\%\end{array}$ & $M(S D)$ & $\alpha$ \\
\hline Conflict & 7 & 4.099 & $32 \%$ & $32 \%$ & $\begin{array}{l}2.41 \\
(0.78)\end{array}$ & .84 \\
Support & 3 & 2.165 & $18 \%$ & $50 \%$ & $\begin{array}{l}2.11 \\
(0.68)\end{array}$ & .70 \\
\hline
\end{tabular}

Note. Extraction method: PCA with oblimin rotation.

\subsubsection{Disconnect-act (SEDA).}

\subsection{Manager disconnect-act.}

Results indicated a manager disconnect-act, 11 -item scale $(\alpha=0.79)$ with corrected item-to-total correlations, ranging from 0.33 to $0.52(\mathrm{M}=3.46, \mathrm{SD}=$ 0.55). Based on the scree plot (Appendix Q), eigenvalues and criterion values, a three-component scale was indicated accounting for 49 per cent of the variance. Consistent with the pattern matrix (Appendix Q):

1. Component 1: Disconnection (SEDA-Disconnection) was represented by a four-item scale $(\alpha=0.60)$ with corrected item-to-total correlations ranging from 0.33 to $0.43(\mathrm{M}=3.33, \mathrm{SD}=0.67)$.

2. Component 2: Support (SEDA-Support) was represented by a three-item scale $(\alpha=0.75)$ with item-to-total correlations ranging from 0.53 to $0.68(\mathrm{M}=3.54, \mathrm{SD}=0.82)$.

3. Component 3: Conflict (SEDA-Conflict) was represented by a four-item scale $(\alpha=0.68)$ with item-to-total correlations ranging from 0.38 to $0.63(\mathrm{M}=3.57, \mathrm{SD}=0.69)$.

Skewness scores were all within an acceptable range: Disconnect-act (0.094), disconnect-act (disconnection) (-0.094), disconnect-act (support) (-0.741) and disconnect-act (conflict) (-0.648). Table 27 provides a summary of findings. 
Table 27

Manager Disconnect-Act

\begin{tabular}{|c|c|c|c|c|c|c|}
\hline $\begin{array}{c}\text { Disconnect- } \\
\text { Act }\end{array}$ & $n$ & Eigenvalue & $\begin{array}{c}\% \text { of } \\
\text { Variance }\end{array}$ & $\begin{array}{c}\text { Cumulative } \\
\%\end{array}$ & $M(S D)$ & $\alpha$ \\
\hline Disconnection & 4 & 3.665 & $26 \%$ & $26 \%$ & $\begin{array}{c}3.33 \\
(0.67)\end{array}$ & .60 \\
\hline Support & 3 & 1.889 & $13 \%$ & $39 \%$ & $\begin{array}{c}3.54 \\
(0.82)\end{array}$ & .75 \\
\hline Conflict & 4 & 1.375 & $10 \%$ & $49 \%$ & $\begin{array}{c}3.57 \\
(0.69)\end{array}$ & .68 \\
\hline
\end{tabular}

Note. Extraction method: PCA with oblimin rotation.

\subsection{Employee disconnect-act.}

Results showed a 11-item employee disconnect-act scale $(\alpha=0.73)$, with corrected item-to-total correlations ranging from 0.33 to $0.52(\mathrm{M}=3.60, \mathrm{SD}=$ 0.51). Based on the scree plot (Appendix Q), eigenvalues and criterion values, a two-component scale was indicated, accounting for 39 per cent of the variance. Consistent with the pattern matrix (Appendix Q):

1. Component 1: Disconnection (SEDA-Disconnection) was represented by an eight-item scale $(\alpha=0.78)$ with corrected item-to-total correlations ranging from 0.39 to $0.60(\mathrm{M}=3.52, \mathrm{SD}=0.57)$.

2. Component 2: Support (SEDA-Support) was represented by a three-item scale $(\alpha=0.69)$ with item-to-total correlations ranging from 0.40 to $0.60(\mathrm{M}=3.62, \mathrm{SD}=0.83)$.

Skewness scores were all within an acceptable range: Disconnect-act (0.510), disconnect-act (disconnection) (-0.552) and disconnect-act (support) (0.956). Table 28 summarises these key findings.

Table 28

Employee Disconnect-Act

\begin{tabular}{|c|c|c|c|c|c|c|}
\hline $\begin{array}{c}\text { Disconnect- } \\
\text { Act }\end{array}$ & $n$ & Eigenvalue & $\begin{array}{c}\% \text { of } \\
\text { Variance }\end{array}$ & $\begin{array}{c}\text { Cumulative } \\
\%\end{array}$ & $M(S D)$ & $\alpha$ \\
\hline Disconnection & 8 & 3.473 & $25 \%$ & $25 \%$ & $\begin{array}{c}3.52 \\
(0.57)\end{array}$ & .78 \\
\hline Support & 3 & 1.965 & $14 \%$ & $39 \%$ & $\begin{array}{c}3.62 \\
(0.83)\end{array}$ & .69 \\
\hline
\end{tabular}

Note. Extraction method: PCA with oblimin rotation. 


\subsubsection{Overview of new manager-employee social engagement scales.}

Table 29 provides a summary of the new manager and employee scales, component scales, and shows the item numbers that were retained in each scale. (The items are listed in full in Appendix A and B.)

Table 29

Manager and Employee MESE Scales, Item Numbers, Means and Cronbach's Alpha

\begin{tabular}{lrlrrr}
\hline \begin{tabular}{l} 
Manager MESE \\
\multicolumn{1}{c}{ scales }
\end{tabular} & \multicolumn{1}{c}{ Items } & items & & $S D$ & $\alpha$ \\
\hline SESI & 12 & $1,2,3,4,5,7,8,9,10,11,12,14$ & 2.25 & 0.55 & .80 \\
SESI-Conflict & 7 & $2,4,7,8,11,12,14$ & 2.10 & 0.69 & .82 \\
SESI-Support & 5 & $1,3,5,9,10$ & 2.44 & 0.61 & .64 \\
SECA & 12 & $1,2,4,5,6,7,8,9,10,11,12,14$ & 3.79 & 0.49 & .80 \\
SECA-Support & 5 & $2,7,11,12,14$ & 3.84 & 0.69 & .81 \\
SECA-Connection & 4 & $4,5,8,9$ & 4.05 & 0.59 & .75 \\
SECA-Secure base use & 3 & $1,6,10$ & 3.46 & 0.71 & .55 \\
SEDA & 11 & $1,2,4,5,7,8,9,10,11,12,13$ & 3.46 & 0.55 & .78 \\
SEDA-Disconnection & 4 & $10,11,12,13$ & 3.33 & 0.67 & .60 \\
SEDA-Support & 3 & $1,2,7$ & 3.54 & 0.82 & .75 \\
SEDA-Conflict & 4 & $4,5,8,9$ & 3.57 & 0.69 & .68 \\
\hline Employee MESE scales & & & & & \\
\hline SESI & 10 & $2,4,5,7,8,10,11,12,13,14$ & 2.11 & 0.67 & .85 \\
SESI-Conflict & 7 & $2,4,7,8,11,12,14$ & 2.41 & 0.78 & .84 \\
SESI-Support & 3 & $5,10,13$ & 2.11 & 0.68 & .70 \\
SECA & 14 & $1,2,3,4,5,6,7,8,9,10,11,12,13,14$ & 3.51 & 8.54 & .88 \\
SECA-Support & 6 & $2,5,7,11,12,14$ & 3.63 & 0.78 & .87 \\
SECA-Connection & 4 & $4,8,9,13$ & 3.78 & 0.64 & .77 \\
SECA-Secure base use & 4 & $1,3,6,10$ & 3.13 & 0.80 & .73 \\
SEDA & 11 & $1,2,4,5,6,7,8,9,10,12,13$ & 3.60 & 0.51 & .73 \\
SEDA-Disconnection & 8 & $4,5,6,8,9,10,12,13$ & 3.52 & 0.57 & .78 \\
SEDA-Support & 3 & $1,2,7$ & 3.62 & 0.83 & .69 \\
\hline
\end{tabular}

Both datasets confirmed hypothesis 1 in a similar but unique way and are illustrated below in Figure 12 and Figure 13. Figure 12 illustrates the manager scales where manager-employee social engagement was represented by three components, each with their own unique sub-component structure:

1. Stress-immobilise comprised two sub-components: SESI-Conflict and SESI-Support.

2. Connect-act was comprised of three sub-components: SECAsupport received, SECA-Connection, and SECA-Secure base use.

3. Disconnect-act also indicated a three-component structure: SEDADisconnection, SEDA-Support, and SEDA-Conflict. 

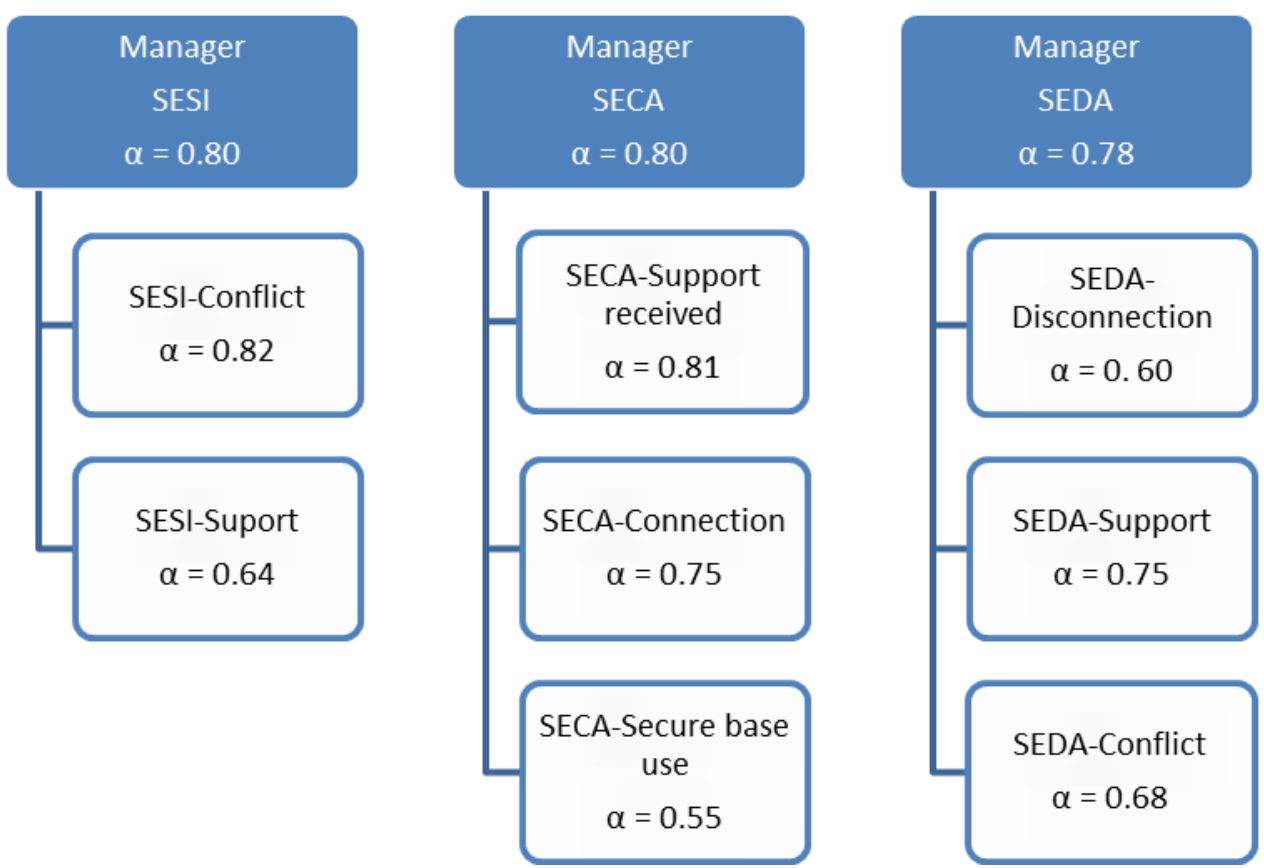

Figure 12. Manager: manager-employee social engagement strategy structure with alpha coefficients.

Figure 13 illustrates the employee scales. As above, manager-employee social engagement was represented by three components, each with their own unique sub-component structure:

1. Stress-immobilise comprised two sub-components: SESI-Conflict and SESI Support.

2. Connect-act was comprised of three sub-components: SECASupport received, SECA-Connection, and SECA-Secure base use.

3. Disconnect-act indicated a two-component structure: SEDADisconnection and SEDA-Support. 


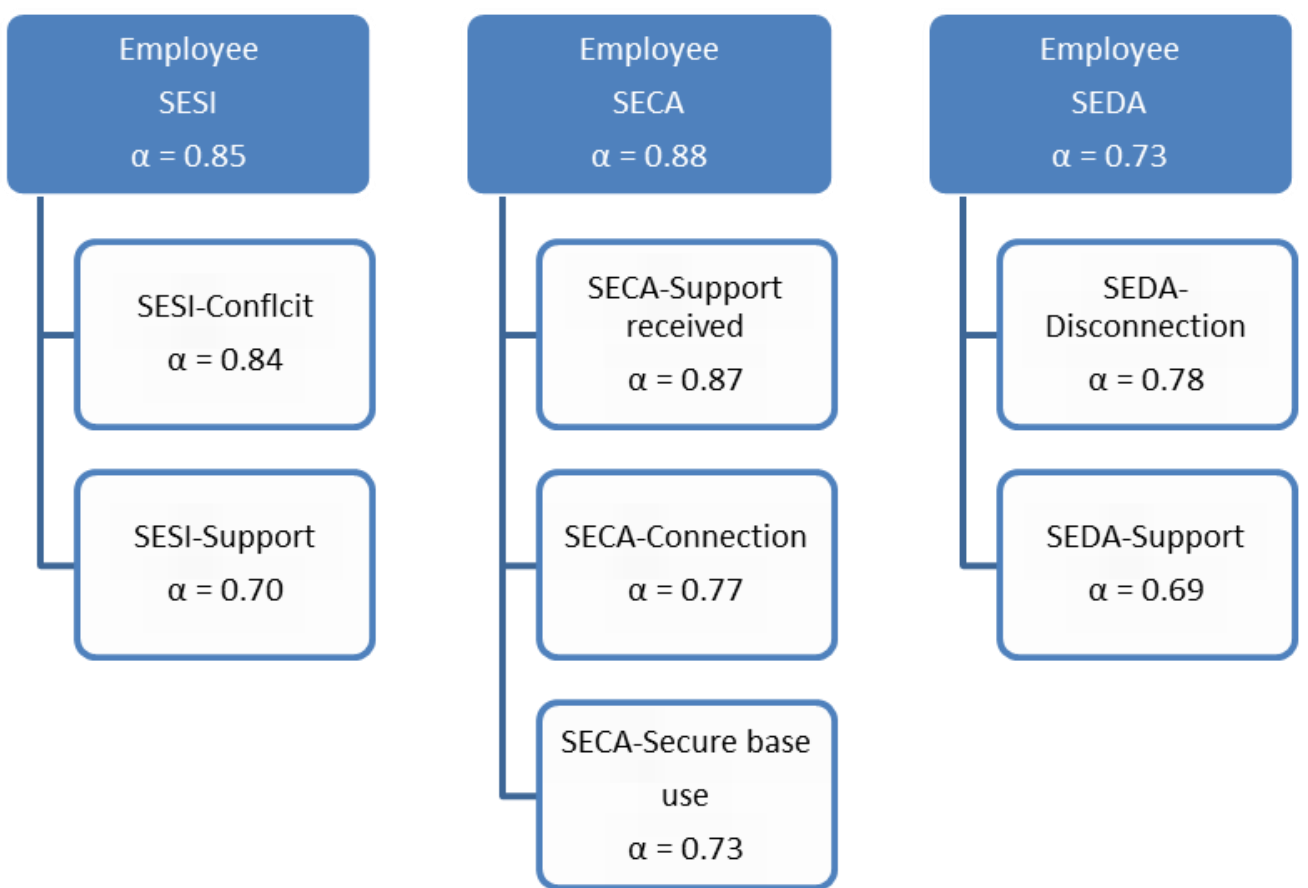

Figure 13. Employee: manager-employee social engagement strategy structure with alpha coefficients.

Next, the relationship between the manager-employee social engagement strategy scales (and their respective sub-components) was investigated, using the Pearson product-moment correlation coefficient. Preliminary analyses were conducted to ensure the assumptions of normality, linearity and homoscedasticity were not violated. Correlation results were evaluated using Cohen's (1988) effect size evaluation criteria: small effects ( $r=0.00$ to 0.28$)$, medium effects ( $r=0.28$ to 0.49$)$ and large effects $(r=>0.49)$. Based on an assumption that the new scales would be related but unique - that is measuring different social engagement strategies - it was anticipated that the correlations between the scales would be small.

Table 30 (manager data) and Table 31 (employee data) report the correlations pertaining to the three core social engagement strategy scales. Correlations for the sub-components were also computed. A full set of findings is provided in Appendix R.

First, Table 30 shows a significant difference between manager stressimmobilise and connect-act $(\mathrm{r}=-0.278, \mathrm{p}<0.05)$, connect-act and disconnect-act $(\mathrm{r}=-0.231, \mathrm{p}<0.01)$; however, both of these correlations were small $(0.28$ or below). A non-significant relationship was indicated between stress-immobilise and disconnect-act. These findings indicate that the three manager, manager- 
employee social engagement strategy variables are related but unique, that is measuring a unique strategy.

Table 30

Manager Means, Standard Deviations, Reliabilities, and Inter-correlations of Study Variables

\begin{tabular}{lllccc}
\hline \multicolumn{1}{c}{ Variable } & $M$ & $S D$ & SESI & SECA & SEDA \\
\hline 1. SESI & 2.25 & 0.55 & $(0.80)$ & & \\
2. SECA & 2.10 & 0.69 & $-.28 * *$ & $(0.82)$ & \\
3. SEDA & 3.46 & 0.55 & .13 & $-.23 * *$ & $(0.78)$ \\
\hline Notes. $* p<0.05 ; * * p<0.01 ; * * *$ & $p<0.001 ;$ and reliabilities are in parentheses.
\end{tabular}

Second, Table 31 shows a significant difference was shown between employee stress-immobilise and connect-act $(r=-0.605$, $\mathrm{p}<0.01)$, stressimmobilise and connect-act $(\mathrm{r}=-0.157, \mathrm{p}<0.05)$. A non-significant relationship was indicated between connect-act and disconnect-act. The significant relationship between stress-immobilise and disconnect-act was, as expected, small (and with the non-significant relationship between connect-act and disconnectact). These findings indicate that the disconnect-act employee variable is related but unique to stress-immobilise and connect-act. However, the significant inverse association between stress-immobilise and connect-act was large. Statistically, this could be interpreted to mean that the higher the scores for stress-immobilise the lower the scores for connect-act and vice versa.

Table 31

Employee Means, Standard Deviations, Reliabilities, and Inter-correlations of Study Variables

\begin{tabular}{llllcc}
\hline Variable & $M$ & $S D$ & SESI & SECA & SEDA \\
\hline 1. SESI & 2.11 & 0.67 & $(0.85)$ & $(0.88)$ & \\
2. SECA & 3.51 & 0.61 & $-.61 * *$ & -.12 & $(0.73)$ \\
3. SEDA & 3.60 & 0.51 & $-.16^{*}$ & & \\
\hline Notes. ${ }^{*} p<0.05 ; * *$ & $p<0.01 ; * * *$ & $p<0.001 ;$ and reliabilities are in parentheses.
\end{tabular}

Next, given the gender distribution differences across the manager and employee samples, gender was considered a possible factor contributing to sample differences. However, results of the MANOVAs suggested that gender was not related to the new variables.

Multi-collinearity across the new variables and their sub-components was examined. Multi-collinearity is indicated when variables correlate very highly, 
suggesting they are measuring the same construct. Green (1991) suggested when correlations are greater than 0.90 between variables they should either be removed or combined. Two correlations were found to be greater than 0.90: manager stress-immobilise and stress-immobilise (conflict) $(r=0.905, p<0.01)$; and employee stress-immobilise and stress-immobilise (conflict) $(r=0.964, p<0.01)$. For the purposes of the correlation analysis, stress-immobilise (conflict) was combined with stress-immobilise. However, for the purposes of examining the social data in the case studies, both scales stress-immobilise and stress-immobilise (conflict) were calculated and examined.

Further, variables with correlations above 0.75 were noted and observed throughout the data analysis process. In the employee data, these were: connectact and connect-act (support) $(r=0.898, p<0.01)$, connect-act and connect-act (secure base use) $(r=0.825, p<0.01)$ and disconnect-act and disconnect-act (disconnection) $(r=0.851, p<0.01)$. Similarly, from the manager data: connectact and connect-act (support) $(r=0.752, p<0.01)$, connect-act and connect-act (secure base use) $(r=0.766, p<0.01)$ and disconnect-act and disconnect-act (disconnection) $(r=0.796, p<0.01)$.

A paired-samples t-test was conducted to evaluate the differences in means. Both datasets revealed significant differences in the means of each pair. Effect sizes for the paired-samples t-test were calculated using the eta squared statistic (ES) (Pallant, 2011). Interpretation guidelines proposed by Cohen (1988) were used: (a) $0.01=$ small effect; (b) $0.06=$ a moderate effect; and (c) $0.14=a$ large effect. Effect size for each mean pair from both the employee and manager data was large. Findings are reported in Table 32.

Table 32

Manager and Employee Paired-samples t-tests and eta Squared Statistic

\begin{tabular}{lcccc}
\hline Manager variables compared & $\mathrm{t}$ value & $D f$ & $P$ & $E S$ \\
\hline SESI \& SECA & 24.60 & 179 & .000 & .95 \\
SECA \& SEDA & 10.42 & 179 & .000 & .79 \\
SEDA \& SESI & -19.08 & 176 & .000 & .93 \\
\hline Employee variables compared & & & & \\
\hline SESI \& SECA & 23.40 & 156 & .000 & .94 \\
SECA \& SEDA & 11.06 & 158 & .000 & .81 \\
SEDA \& SESI & -22.77 & 161 & .000 & .95 \\
\hline
\end{tabular}




\subsubsection{Hypothesis 1: Summary.}

Hypothesis 1 was confirmed. Results showed that manager-employee social engagement as a construct can be represented by three related but unique scales: connect-act, disconnect-act and stress-immobilise. In addition, two similar but unique solutions were found pertaining to the manager dataset and the employee dataset. For example, the manager disconnect-act variable indicated a three-component structure, whereas the employee disconnect-act variable indicated a two-component structure.

Table 33 provides a summary of the six core manager-employee social engagement scales.

Table 33

Manager and Employee Manager-Employee Social Engagement Strategy Scales, Item numbers and Cronbach's Alpha

\begin{tabular}{llcc}
\hline Role & Scale & $\begin{array}{c}\text { Nof } \\
\text { items }\end{array}$ & $\alpha$ \\
\hline Manager & SESI & 12 & .80 \\
& SECA & 12 & .80 \\
Employee & SEDA & 11 & .78 \\
& SESI & 10 & .85 \\
& SECA & 14 & .88 \\
& SEDA & 11 & .73 \\
\hline
\end{tabular}

Concerning analysis, composite scores were created for each manageremployee social engagement scale, based on the mean of the items within each scale. Higher scores indicated greater use and/or identification of use of a particular social engagement strategy. Table 34 provides a summary of findings from scale development process.

Regarding the process of scale development, these findings were carried through into Step 5: establishing convergent and discriminant validity of the new scales. Step 5 is described immediately below as part of testing hypothesis 2 . Step 6 , establishing reliability through replication, was attended to throughout the overall statistical analysis process, with the analysis being conducted with two separate data sets. 
Table 34

Manager and Employee Manager-Employee Social Engagement Scales

\begin{tabular}{|c|c|c|c|}
\hline $\begin{array}{l}\text { Scale name and } \\
\text { Acronym }\end{array}$ & $\begin{array}{l}\text { Manager } \\
\text { Items }\end{array}$ & Employee Items & Description \\
\hline $\begin{array}{l}\text { Stress-immobilise } \\
\text { SESI }\end{array}$ & $\begin{array}{l}1,2,3,4,5,7,8,9 \\
10,11,12,14\end{array}$ & $\begin{array}{l}2,4,5,7,8,10,11 \\
12,13,14\end{array}$ & $\begin{array}{l}\text { Inconsistent secure base use and } \\
\text { provision, with frequent reported } \\
\text { experiences of conflict. }\end{array}$ \\
\hline SESI-Conflict & $2,4,7,8,11,12,14$ & $2,4,7,8,11,12,14$ & $\begin{array}{l}\text { Inconsistent support provision to others } \\
\text { with high levels of conflict and reduced } \\
\text { outputs. }\end{array}$ \\
\hline SESI Support & $1,3,5,9,10$ & $5,10,13$ & $\begin{array}{l}\text { Increased support seeking with } \\
\text { inconsistent support provision to others. }\end{array}$ \\
\hline $\begin{array}{l}\text { Connect-Act } \\
\text { SECA }\end{array}$ & $\begin{array}{l}1,2,4,5,6,7,8,9 \\
10,11,12,14\end{array}$ & $\begin{array}{l}1,2,3,4,5,6,7,8 \\
9,10,11,12,13 \\
14\end{array}$ & $\begin{array}{l}\text { Task and emotion support seeking and } \\
\text { provision. }\end{array}$ \\
\hline SECA-Support & $2,7,11,12,14$ & $2,5,7,11,12,14$ & $\begin{array}{l}\text { Reliable task and emotion oriented } \\
\text { support offered and received generally, } \\
\text { and during conflict, with sustained } \\
\text { productivity. }\end{array}$ \\
\hline SECA-Connection & $4,5,8,9$ & $4,8,9,13$ & $\begin{array}{l}\text { Stays connected with others in times of } \\
\text { conflict and remains a reliable support to } \\
\text { others. }\end{array}$ \\
\hline $\begin{array}{l}\text { SECA-secure base } \\
\text { use }\end{array}$ & $1,6,10$ & $1,3,6,10$ & Task and emotional support seeking. \\
\hline $\begin{array}{l}\text { Disconnect-act } \\
\text { SEDA }\end{array}$ & $\begin{array}{l}1,2,4,5,7,8,9,10 \\
11,12,13\end{array}$ & $\begin{array}{l}1,2,4,5,6,7,8,9 \\
10,12,13\end{array}$ & $\begin{array}{l}\text { Task oriented support seeking and } \\
\text { provision. }\end{array}$ \\
\hline $\begin{array}{l}\text { SEDA- } \\
\text { Disconnection }\end{array}$ & $10,11,12,13$ & $\mathrm{X}$ & $\begin{array}{l}\text { Task oriented support seeking with } \\
\text { reduced contact with others and } \\
\text { sustained productivity. }\end{array}$ \\
\hline SEDA- Support & $1,2,7$ & $\mathrm{X}$ & $\begin{array}{l}\text { Task oriented support seeking and } \\
\text { experience } \\
\text { of support received. }\end{array}$ \\
\hline SEDA-Conflict & $4,5,8,9$ & $\mathrm{X}$ & $\begin{array}{l}\text { Avoid and or fact focused approach to } \\
\text { conflict with task focused support to } \\
\text { others. }\end{array}$ \\
\hline $\begin{array}{l}\text { SEDA- } \\
\text { Disconnection }\end{array}$ & $\mathrm{X}$ & $\begin{array}{l}4,5,6,8,9,10,12 \\
13\end{array}$ & $\begin{array}{l}\text { Avoid/ and or fact focused approach to } \\
\text { conflict with: task focused support to } \\
\text { others; minimal support seeking for self; } \\
\text { reduced contact with others; and } \\
\text { sustained productivity. }\end{array}$ \\
\hline SEDA-Support & $\mathrm{X}$ & $1,2,7$ & $\begin{array}{l}\text { Task oriented support seeking and } \\
\text { experience of support received. }\end{array}$ \\
\hline
\end{tabular}




\subsubsection{Proposition 1: Hypothesis 2.}

Manager-employee social engagement strategies will correlate with the Relationship Questionnaire (RQ) attachment categories. Hypothesis 2: Specifically: (a) connect-act will be positively correlated with secure; (b) disconnect-act will be positively correlated with dismissing-avoidant and (c) stress-immobilise will be positively correlated with preoccupied.

This hypothesis was tested using descriptive and correlational analysis. It was confirmed in the employee dataset, where connect-act, disconnect-act and stress-immobilise correlated as expected with the previously validated RQ (Bartholomew \& Horowitz, 1991), and partially confirmed in the manager dataset, where connect-act and disconnect-act correlated as expected, but not stressimmobilise.

Described in Chapter 3, responses for the categorical RQ measure, across international samples, were typically weighted, with sample percentages approximating as follows: (a) Secure (RQS), 60 per cent; (b) DismissingAvoidant (RQDA) and Fearful-Avoidant (RQFA), 30 per cent; and (c) Preoccupied (RQS), 10 per cent. Findings from the NZ manager and employee surveys followed a similar trend, for example, 66 per cent of managers and 55 per cent of employees noted secure (RQS) as a best descriptor. Comparative findings between the Bartholomew and Horowitz (1991) studies and the NZ manager and employee samples are presented in Table 35.

Table 35

Relationship Questionnaire Scores, NZ managers and Employees Comparisons

\begin{tabular}{lccccc}
\hline \multicolumn{1}{c}{ Study } & $\begin{array}{c}\text { Valid } \\
\text { Sample } \\
N\end{array}$ & $\begin{array}{c}\text { Secure } \\
\text { RQS }\end{array}$ & $\begin{array}{c}\text { Preoccupied } \\
\text { RQP }\end{array}$ & $\begin{array}{c}\text { Dismissing } \\
\text { Avoidant } \\
\text { RQDA }\end{array}$ & $\begin{array}{c}\text { Fearful } \\
\text { Avoidant } \\
\text { RQFA }\end{array}$ \\
\hline $\begin{array}{l}\text { Bartholomew \& } \\
\text { Horowitz (1991) } \\
\text { Study 1 }\end{array}$ & 81 & $47 \%$ & $14 \%$ & $18 \%$ & $21 \%$ \\
\hline $\begin{array}{l}\text { Bartholomew \& } \\
\begin{array}{l}\text { Horowitz (1991) } \\
\text { Study 2 }\end{array}\end{array}$ & 69 & $57 \%$ & $10 \%$ & $18 \%$ & $15 \%$ \\
\hline NZ managers & 200 & $66 \%$ & $4 \%$ & $27 \%$ & $5 \%$ \\
\hline NZ employees & 200 & $55 \%$ & $6 \%$ & $27 \%$ & $12 \%$ \\
\hline
\end{tabular}

Tables 36 and 37 present the correlation matrix for the Relationship Questionnaire and connect-act, disconnect-act and stress-immobilise for the employee and manager samples respectively. The employee data (Table 36) 
showed significant (of medium effect) and positive associations between stressimmobilise and preoccupied (RQP), connect-act and secure (RQS), and disconnect-act and dismissing-avoidant (RQDA). The associations of interest are in bold type. These employee findings supported Hypothesis 2.

Table 36

Employee Means, Standard Deviations, and Inter-correlations of the MESE and $R Q$ Variables

\begin{tabular}{|c|c|c|c|c|c|c|}
\hline Variable & $M$ & $S D$ & RQS & RQDA & RQFA & RQP \\
\hline $\begin{array}{ll}\text { 1. } & \text { RQS }\end{array}$ & 4.82 & 1.50 & & & & \\
\hline 2. RQDA & 4.06 & 1.58 & $-.29^{* *}$ & & & \\
\hline 3. RQFA & 3.09 & 1.58 & $-.41^{* *}$ & $.15^{*}$ & & \\
\hline 4. RQP & 2.74 & 1.36 & -.08 & $-.29^{* *}$ & $.20^{* *}$ & \\
\hline 5. SESI & 2.11 & 0.67 & $.26^{* *}$ & -.07 & $.27^{* *}$ & $.37^{* *}$ \\
\hline 6. SECA & 3.51 & 0.61 & $.45^{* *}$ & $-.20^{* *}$ & $-.20^{* *}$ & .05 \\
\hline 7. SEDA & 3.60 & 0.51 & -.13 & $.46^{* * *}$ & .11 & $-.25^{* *}$ \\
\hline
\end{tabular}

The manager sample showed a similar trend, albeit not so clear-cut, with each of the pairs of interest (Table 37). A significant (of medium effect) and positive association was indicated between connect-act and secure; a significant (of small effect) and positive association was shown between disconnect-act and dismissing-avoidant; and a significant (of medium effect) and positive association was shown between stress-immobilise and preoccupied. However, and this was not expected, stress-immobilise was also shown to be more highly associated (significant large positive association with fearful-avoidant $(r=0.524, p<0.01)$. This finding is further discussed in Section 4.6. As above, the associations of interest are in bold type. These manager findings partially supported Hypothesis 2.

Table 37

Manager Means, Standard Deviations and Inter-correlations of the MESE and $R Q$ Variables

\begin{tabular}{|c|c|c|c|c|c|c|}
\hline Variable & $M$ & $S D$ & RQS & RQDA & RQFA & RQP \\
\hline 1. RQS & 4.84 & 1.47 & & & & \\
\hline 2. RQDA & 4.28 & 1.50 & $-.22 * *$ & & & \\
\hline 3. RQFA & 2.62 & 1.40 & $-.29 * *$ & $.28 * *$ & & \\
\hline 4. RQP & 2.27 & 1.10 & .05 & -.03 & $.28 * *$ & \\
\hline 5. SESI & 2.25 & 0.55 & $-.28 * *$ & $.19 * *$ & $.52 * *$ & $.47 * *$ \\
\hline 6. SECA & 3.25 & 0.42 & $.41 * *$ & -.12 & $-.32 * *$ & $-.15^{*}$ \\
\hline 7. SEDA & 3.46 & 0.55 & -.15 & $.19 * *$ & $.16^{*}$ & -.14 \\
\hline
\end{tabular}


Finally, correlation analysis revealed an expected pattern of positive and negative correlations between the Relationship Questionnaire attachment category items and the manager-employee social engagement variables, and these are summarised in Table 38.

Table 38

Managers and Employees MESE and RQ

\begin{tabular}{|c|c|c|c|c|c|c|}
\hline \multirow[t]{2}{*}{ RQ } & \multicolumn{2}{|c|}{ SESI } & \multicolumn{2}{|c|}{ SECA } & \multicolumn{2}{|c|}{ SEDA } \\
\hline & $\mathrm{M}$ & $\mathrm{E}$ & $\mathrm{M}$ & $\mathrm{E}$ & $\mathrm{M}$ & $\mathrm{E}$ \\
\hline RQ Secure & $-* *$ & $+* *$ & $+* *$ & $+* *$ & $-*$ & - \\
\hline RQ Preoccupied & $+* *$ & $+* *$ & $-*$ & - & $-*$ & $-* *$ \\
\hline $\begin{array}{l}\text { RQ Dismissing- } \\
\text { avoidant }\end{array}$ & $-* *$ & - & & $-* *$ & $+* *$ & $+*$ \\
\hline $\begin{array}{l}\text { RQ Fearful- } \\
\text { avoidant }\end{array}$ & $* *$ & $+* *$ & $-* *$ & $-* *$ & $+*$ & + \\
\hline
\end{tabular}
0.001 .

The overall pattern confirmed Hypothesis 2, as shown by the associations highlighted in darker green. Further, the associations highlighted in lighter green (while not hypothesised) are a good fit with the underpinning theory, and are therefore unsurprising. The associations marked in red were unexpected. These findings are further examined in the case studies. For example, the manager in case study 5 provided descriptions that captured experiences at work of an association between fearful-avoidant and use of a stress-immobilise.

\subsubsection{Proposition 1: Summary.}

Hypothesis 1 was confirmed across both datasets, and Hypothesis 2 was confirmed with the employee data; it was partially confirmed in the manager data, where two of three expected correlations were found. These findings empirically support proposition one and provide empirical evidence in support of manageremployee social engagement as a reliable and valid, three-dimensional construct.

Concerning the dimensionality of manager-employee social engagement, the three main manager-employee social engagement scales showed acceptable internal consistency with Cronbach's alpha reliabilities across both datasets, ranging from 0.73 to 0.88 . The means between the manager-employee social engagement scores were significant. Correlations between the scales ranged from 
0.13 to -0.28 in the manager dataset, and from -0.04 to -0.61 in the employee data, suggesting an absence of multi-collinearity across the three core manageremployee social engagement scales. In addition, the three manager-employee social engagement scales appear to covary with the score from the Relationship Questionnaire.

Regarding convergent validity, it appears as if the manager-employee social engagement scales are tapping into aspects of the inferred attachment system. Regarding discriminant validity, the scales were related, but correlated in a way suggesting they were measuring a different construct. These findings, in conjunction with the earlier scale development processes (outlined in Chapter 3), provide a first step in the open and never-ending process (Schwab, 1980) of validating manager-employee social engagement strategies as a construct.

Finally, the manager MESE scales and the employee MESE scales were similar, but, not the same. To make preliminary sense of these findings I reviewed the items that were omitted from each data set during the scale development process. I noted that the items removed from the manager scale were clustered around secure base use. However, in the employee scales, the items removed were not clustered around secure base use and instead related to experiences of secure base use and provision.

For example, regarding the SESI scale: item 6 (secure base use) was removed from both scales; items 1 (secure base use) and 9 (secure base provision) from the employee scale; and item 13 (secure base use) from the manager scale. In the SECA scale, items were removed from the manager scale only (items 3 and 13 - secure base use). From the SEDA scale: item 3 and 14 was removed from both scales; item 6 was removed the manager scale; and item 11 (secure base provision) from the employee scale.

Drawing on the secure base system lens, one way to interpret these findings is to suggest that managers may be predominantly providing support to others, but not accessing, to the same degree, secure base support for themselves. These statistics may be indicating an imbalance in the overall workings of secure base system at work, for managers. This preliminary explanation could in part also explain the differences in reliability between: (a) the employee secure base use scale, with an alpha score of 0.73; and (b) the manager secure base use sub scale which had a low alpha coefficient $(\alpha=0.55)$. 
In conjunction with reviewing the items removed, only the manager SEDA scale indicated a conflict sub-scale (items 4, 5, 8 and 9). Items 4 and 8 relate directly to workplace conflict; and items 5 related to experiences of secure base provision. This manager subscale may indicate that managing workplace conflict combined with secure base provision may be more of an issue for managers than for employees.

\subsection{Correlation Findings}

Next, to address the remaining propositions and their respective hypotheses, zero order correlational coefficients between the variables of interest were examined for meaningfulness, according to effect size standards (Cohen, 1988). Throughout the correlation analysis, the size of the correlation was evaluated using Cohen's (1988) evaluation criteria: small (s) $(r=0.10$, to 0.29$)$, medium (m) ( $r=0.30$, to 0.49$)$ and (l) large ( $r=0.50$, to 1.0$)$. Table 39 (manager) and Table 40 (employee), present the mean, standard deviation and intercorrelation values of the study variables: perceived supervisor support; perceived organisational support; connect-act; disconnect-act; stress-immobilise; job engagement; organisation engagement; intention to quit/turnover; and organisational commitment.

Correlations between the sub-components of connect-act, disconnect-act, and stress-immobilise were conducted; results are provided in Appendix S. The manager-employee social engagement sub-components were not included in the statistical analyses below. Instead, the manager-employee social engagement subcomponents were examined in the survey data of the dyad case studies, with the findings from this examination reported in Chapter 5. This decision was made because it was statistically possible to test the hypothesised models using the three core manager-employee social engagement scales. Connect-act, disconnect-act, and stress-immobilise each provided reliable measures from which to test the propositions and hypotheses. Using the three core manager-employee social engagement scales also helped to keep the number of variables in the study manageable. 
Table 39

Manager Means, Standard Deviations, Reliabilities and Inter-correlations of Study Variables

\begin{tabular}{|c|c|c|c|c|c|c|c|c|c|c|c|}
\hline Variable & $M$ & $S D$ & POS & PSS & SECA & SEDA & SESI & JE & $\mathrm{OE}$ & $\mathrm{OC}$ & ItQT \\
\hline 1. POS & 4.89 & 0.36 & $(0.75)$ & & & & & & & & \\
\hline 2. PSS & 5.00 & 0.32 & $0.44 * * *$ & $(0.84)$ & & & & & & & \\
\hline 3. SECA & 3.25 & 0.42 & $-0.16^{*}$ & -0.12 & $(0.80)$ & & & & & & \\
\hline 4. SEDA & 3.46 & 0.55 & $0.18 *$ & 0.06 & $-0.23 * *$ & $(0.78)$ & & & & & \\
\hline 5. SESI & 2.25 & 0.55 & $0.21 * *$ & $0.18 *$ & $-0.28 * * *$ & 0.13 & $(0.80)$ & & & & \\
\hline 6. JE & 3.89 & 0.62 & 0.003 & 0.06 & $0.23 * *$ & -0.03 & $-0.20 * *$ & $(0.81)$ & & & \\
\hline 7. $\mathrm{OE}$ & 3.82 & 0.72 & 0.002 & -0.02 & $0.34 * * *$ & $-0.17 *$ & $-0.38 * * *$ & $0.54 * * *$ & $(0.83)$ & & \\
\hline 8. OC & 2.64 & 0.35 & -0.02 & $-0.14 *$ & $0.37 * * *$ & -0.13 & $-0.33 * * *$ & $0.29 * * *$ & $0.64 * * *$ & $(0.73)$ & \\
\hline 9. ItQT & 2.25 & 1.12 & $0.15^{*}$ & $0.19 * *$ & $-0.44 * * *$ & 0.05 & $0.55 * * *$ & $-.26 * * *$ & $-0.58 * * *$ & $-0.55 * * *$ & $(0.87)$ \\
\hline
\end{tabular}

Notes. $* p<0.05 ; * * p<0.01 ; * * * p<0.001$; and reliabilities are in parentheses.

Table 40

Employee Means, Standard Deviations, Reliabilities, and Inter-correlations of Study Variables

\begin{tabular}{|c|c|c|c|c|c|c|c|c|c|c|c|}
\hline Variable & $\mathrm{M}$ & SD & POS & PSS & SECA & SEDA & SESI & $\mathrm{JE}$ & $\mathrm{OE}$ & $\mathrm{OC}$ & ItQT \\
\hline 1. POS & 4.43 & 0.41 & $(0.50)$ & & & & & & & & \\
\hline 2. PSS & 4.66 & 0.34 & $0.48 * * *$ & $(0.77)$ & & & & & & & \\
\hline 3. SECA & 3.51 & 0.61 & -0.09 & -0.09 & $(0.88)$ & & & & & & \\
\hline 4. SEDA & 3.60 & 0.51 & 0.15 & 0.06 & -0.12 & $(0.73)$ & & & & & \\
\hline 5. SESI & 2.31 & 0.67 & $0.27 * * *$ & $0.24 * *$ & $-0.60 * * *$ & $-0.16^{*}$ & $(0.85)$ & & & & \\
\hline 6. JE & 3.69 & 0.70 & -0.009 & 0.003 & $0.28 * * *$ & -0.05 & $-0.24 * *$ & $(0.77)$ & & & \\
\hline 7. $\mathrm{OE}$ & 3.32 & 0.82 & -0.04 & -0.004 & $0.47 * * *$ & $-0.17 *$ & $-0.29 * * *$ & $0.63 * * *$ & $(0.92)$ & & \\
\hline 8. OC & 2.58 & 0.46 & -0.06 & -0.09 & $0.55^{* * *}$ & $0.17 *$ & $-0.43 * * *$ & $0.32 * * *$ & $0.67 * * *$ & $(0.72)$ & \\
\hline 9. ItQT & 2.41 & 0.94 & 0.11 & 0.08 & $-0.19 *$ & -0.02 & $0.25^{* *}$ & $-.33 * * *$ & $-0.41 * * *$ & $0.31 * * *$ & $(0.64)$ \\
\hline
\end{tabular}

Notes. $* p<0.05 ; * * p<0.01 ; * * * p<0.001$; and reliabilities are in parentheses. 


\subsubsection{Proposition 2.}

Proposition 2: There will be an association between the manageremployee social engagement strategies and engagement related concepts.

The results are presented to capture similarities and differences between: (a) the manager and employee data sets; and (b) the three new scales in relation to each other, and the other variables of interest, within each data set. As such the results are presented as they pertain to the manager data set, and then the employee data set. Also, hypotheses 3, 6, and 9 are grouped together as they each relate to perceived organisational support and perceived supervisor support. Results for hypotheses 4, 7,10 are grouped together as they relate to job and organisation engagement; and results for hypotheses 5,8 and 11 are grouped as they relate to organisational commitment and intention to quit/turnover.

\subsubsection{Hypotheses 3, 6, and 9.}

Hypothesis 3. Connect-act will be positively associated to perceived organisational support and perceived supervisor support.

In the manager data, the association between connect-act and perceived organisational support was significantly negatively associated $(r=-0.16, p<$ $0.05)$, with a non-significant negative relationship between connect-act and perceived supervisor support $(r=-0.12)$. In the employee data the association between connect-act and perceived organisational support $(r=-0.09)$, and connect-act and perceived supervisor support $(r=-0.09)$ was not significant.

Hypothesis 6. Disconnect-act will be negatively associated to perceived organisational support and perceived supervisor support.

In the manager data, the association between disconnect-act and perceived organisational support was significantly (small) positively related ( $r=0.18, p<$ 0.05). However disconnect-act was not significantly related to PSS ( $r=0.06)$. In the employee data the association between disconnect-act and perceived organisational support $(r=0.15)$ and disconnect-act and perceived supervisor support $(r=0.06)$, was not significant. 
Hypothesis 9. Stress-immobilise and will be positively associated to perceived organisational support and perceived supervisor support.

In the manager data (and as expected), stress-immobilise was significantly (small) positively related to both perceived organisational support $(r=0.21, p<$ $0.01)$ and perceived supervisor support $(r=0.18, \mathrm{p}<0.05)$. A similar trend was revealed in the employee data where stress-immobilise was significantly (small) positively related to both perceived organisational support $(r=0.27, p<0.001)$ and perceived supervisor support $(r=0.24, \mathrm{p}<0.01)$.

\subsubsection{Hypotheses 4, 7, and 10.}

Hypothesis 4. Connect-act will be positively associated to job engagement and organisation engagement.

The manager data showed a significant (small) positive relationship between connect-act and job engagement $(r=0.23, p<0.01)$, and a significant (medium) positive relationship between connect-act and organisation engagement $(r=0.37, p<0.001)$. Similarly, in the employee data, a significant (small) positive relationship was shown between connect-act and job engagement $(r=0.28, p<$ 0.001 ) and a significant (medium) positive relationship between connect-act and organisation engagement $(r=0.47 \mathrm{p}<0.001)$.

Hypothesis 7. Disconnect-act will be positively associated to job engagement and negatively associated to organisation engagement.

In the manager data there was a significant negative relationship between disconnect-act and organisation engagement $(r=-0.17, \mathrm{p}<0.05)$. The hypothesised positive relationship between disconnect-act and job engagement was not confirmed. Instead, the data showed there was no significant relationship between disconnect-act and job engagement $(r=-0.03)$. In the employee data the negative relationship between disconnect-act and organisation engagement was significant $(\mathrm{r}=-0.17, \mathrm{p}<0.05)$. The hypothesised positive relationship between disconnect-act and job engagement was not significant $(r=-0.05)$. 
Hypothesis 10. Stress-immobilise will be negatively associated to job engagement and organisation engagement.

In the manager data there was a significant negative relationship between stress-immobilise and job engagement $(r=-0.20, p<0.01)$ and there was also a significant negative relationship between stress-immobilise and organisation engagement $(r=-0.38, p<0.001)$. In the employee data there was a significant (small) negative relationship between stress-immobilise and job engagement $(r=-$ $0.24, \mathrm{p}<0.01$ ), and there was also a significant negative relationship between stress-immobilise and organisation engagement $(r=-0.29, p<0.0001)$.

\subsubsection{Hypotheses 5, 8 and 11.}

Hypothesis 5.Connect-act will be positively associated to organisational commitment and will be negatively associated to intention to quit/turnover.

Connect-act was significantly positively related to organisational commitment (across both data sets) and significantly negatively related to intention to quit/turnover in the employee data. In the manager data there was a significant (medium) positive relationship between connect-act and organisational commitment, $r=0.37, p<0.001$, and a significant (medium) negative relationship between connect-act and intention to quit/turnover, $r=-0.44, p<0.001$. Similarly, in the employee data there was a significant (large) positive relationship between connect-act and organisational commitment $(r=0.55, p<0.001)$ and a significant (small) negative relationship between connect-act and intention to quit/turnover $(r$ $=-0.186, \mathrm{p}<0.05)$.

Hypothesis 8. Disconnect-act will be positively associated to organisational commitment and negatively associated to intention to quit/turnover.

In the manager data, disconnect-act was not significantly related to organisational commitment ( $r=-0.13$ ), and was not significantly related to intention to quit/turnover $(r=0.05)$. However, in the employee data disconnectact was significantly (small) and positively related to organisational commitment $(r=0.17, p<0.05)$, but not related to intention to quit/turnover $(r=-0.02)$. 


\section{Hypothesis 11. Stress-immobilise will be negatively associated to organisational commitment and positively associated to intention to quit/turnover.}

In the manager data there was a significant (medium) negative relationship between stress-immobilise and organisational commitment, $r=-0.33, p<0.001$, and a significant (large) positive relationship between stress-immobilise and intention to quit/turnover, $r=0.55, p<0.001$. Similarly, in the employee data there was a significant (medium) negative relationship between stress-immobilise and organisational commitment, $r=-0.43, p<0.001$, and a significant (small) positive relationship between stress-immobilise and intention to quit/turnover, $r=$ $0.25, p<0.01$. Noted here is the reduced effect size when compared to the manager data regarding stress-immobilise and intention to quit/turnover.

\subsubsection{Proposition 2: Summary.}

Proposition 2 related to associations within Model 1 between the manageremployee social engagement strategy, engagement and antecedent and outcome measures of engagement. Key findings are summarised in Table 41.

Many correlations were confirmed as hypothesised, but the following findings were not confirmed. First, the manager data set showed that connect-act was negatively associated to perceived organisational support. In addition, disconnect- act was positively associated to perceived organisational support but not associated to organisational commitment nor intention to quit/turnover. Second, in the employee data: connect-act was not positively associated to perceived organisational support or perceived supervisor support; and disconnectact was not negatively associated to perceived organisational support or perceived supervisor support.

At face value, these findings did not make immediate theoretical sense. Connect-act was theoretically associated with greater levels of perceived organisational support; and disconnect-act with lesser levels of perceived organisational support. However, the manager findings especially, offer a fresh lens on these theorised associations.

For example, it is possible that the manager findings are suggesting that under pressure, managers who use the connect-act strategy may primarily seek support in the interpersonal context with colleagues and staff; and as a secondary 
source seek organisational support in terms of external resourcing. As a result, they may not typically turn to their organisations (as a first port of call) when under pressure. If this is so, this may in part account for the negative association between use of the connect-act strategy and perceived organisational support.

On the other hand, managers who use the disconnect-act strategy when under pressure may primarily seek support from the external context with a focus on external resourcing to relieve the work pressure; and as a secondary source, seek interpersonal connection and support as a resource. As such, under pressure, managers who use this strategy may more typically turn to their organisations. If this is so, this may in part account for the positive association between use of the disconnect-act strategy and perceived organisational support.

Table 41

Summary of Significant Associations in Model 1

\begin{tabular}{|c|c|c|}
\hline \multicolumn{3}{|l|}{ Managers } \\
\hline Hypothesis & $\begin{array}{l}\text { Confirmed/ } \\
\text { Non } \\
\text { Confirmed }\end{array}$ & Finding \\
\hline 3 & $\mathrm{NC}$ & SECA was negatively associated to POS \\
\hline 4 & $\mathrm{C}$ & SECA was positively associated to JE and OE \\
\hline 5 & $\mathrm{C}$ & $\begin{array}{l}\text { SECA was positively associated to OC and } \\
\text { negatively associated to ItQT }\end{array}$ \\
\hline 6 & $\mathrm{NC}$ & SEDA was positively associated to POS \\
\hline 7 & $\mathrm{C}$ & SEDA was negatively associated to $\mathrm{OE}$ \\
\hline 8 & $\mathrm{NC}$ & SEDA was not associated to OC nor ItQT \\
\hline 9 & $\mathrm{C}$ & SESI was positively associated to POS and PSS \\
\hline 10 & $\mathrm{C}$ & SESI was negatively associated to JE and OE \\
\hline 11 & $\mathrm{C}$ & $\begin{array}{l}\text { SESI was negatively associated to } \mathrm{OC} \text { and } \\
\text { positively associated to ItQT }\end{array}$ \\
\hline \multicolumn{3}{|l|}{ Employees } \\
\hline 3 & $\mathrm{NC}$ & SECA was not associated with POS or PSS \\
\hline 4 & $\mathrm{C}$ & SECA was positively associated to JE and OE \\
\hline 5 & $\mathrm{C}$ & $\begin{array}{l}\text { SECA was positively associated to OC and } \\
\text { negatively associated to ItQT }\end{array}$ \\
\hline 6 & $\mathrm{NC}$ & SEDA was not associated with POS or PSS \\
\hline 7 & $\mathrm{C}$ & SEDA was negatively associated to $\mathrm{OE}$ \\
\hline 8 & $\mathrm{C}$ & SEDA was positively associated to $\mathrm{OC}$ \\
\hline 9 & $\mathrm{C}$ & SESI was positively associated to POS and PSS \\
\hline 10 & $\mathrm{C}$ & SESI was negatively associated to JE and OE \\
\hline 11 & $\mathrm{C}$ & $\begin{array}{l}\text { SESI was negatively associated to OC and } \\
\text { positively associated to ItQT }\end{array}$ \\
\hline
\end{tabular}


Table 42 illustrates the direction and significance of each of the correlations reported above.

Table 42

Illustrated Associations between the Variables of Interest

\begin{tabular}{ccccccc}
\hline Manager & POS & PSS & JE & OE & OC & ItQT \\
\hline SESI & $+S s$ & $+S s$ & $-S s$ & $-S m$ & $-S m$ & + Sl \\
SECA & $-S s$ & $-N S$ & + Ss & + Sm & + Sm & - Sm \\
SEDA & $+S s$ & $+N S$ & $-N S$ & $-S s$ & $-\mathrm{NS}$ & $+\mathrm{NS}$ \\
\hline Employee & POS & PSS & JE & OE & OC & ItQT \\
\hline SESI & $+S s$ & $+S s$ & $-S s$ & $-S s$ & $-S m$ & + Sm \\
SECA & $-N S$ & $-N S$ & $+\mathrm{Ss}$ & $+\mathrm{Sm}$ & $+\mathrm{S} 1$ & $-\mathrm{Ss}$ \\
SEDA & $+N S$ & $+N S$ & $-N S$ & $-S s$ & $+\mathrm{Ss}$ & $-\mathrm{NS}$ \\
\hline
\end{tabular}

Note. (-) negative; (+) positive (+), (S) significant, (NS) non-significant, small (s) medium (m), or large.

Of note, each correlation is identified as negative (-) or positive (+), significant (S) or non-significant (NS), with the size of the correlation shown as small (s), medium (m) or large (1).

\subsection{Path Analysis}

\subsubsection{Proposition 3.}

Proposition 3: Model 1 will better predict engagement and engagementrelated outcomes than Mode1 2.

The focus now shifts from examining associations within Model 1 to testing Model 1 in association with Model 2. Path analysis was used to compare Model 1 (Figure 8) and Model 2 (Figure 9) statistically. As age co-varied significantly (albeit of small effect) in the manager data with job engagement and organisational commitment, and in the employee data with organisational commitment, age was tested at the outset as a covariant in Model 1. First, age with job engagement and intention to quit/turnover were added into Model 1 (managers) and second, age with organisational commitment was added to Model 1 (employees). As a result, age did not improve the models and was a poorer fit, compared to the original Model 1 test (Manager Model 1: $\chi^{2}(19)=377.18, \mathrm{p}<$ $0.001, \mathrm{CFI}=0.43, \mathrm{TLI}=-0.27, \mathrm{RMSEA}=0.32$, and Employee Model $1: \chi^{2}(20)=$ 
369.21, $\mathrm{p}<0.001, \mathrm{CFI}=0.35, \mathrm{TLI}=-0.36, \mathrm{RMSEA}=0.32$. Based on this finding age was not further tested as a covariate.

Path analysis involved model testing and model generation. Path analysis was conducted using SPSS/AMOS (analysis of a moment structures). Good model fit was assessed and path analysis was used to gain more understanding about the fit. All variables were observed variables. As Model 1 could be nested within Model 2, Model 1 was examined first. A chi square difference test was conducted between the models to see if there was a statistically significant difference between the models with and without connect-act, disconnect-act and stressimmobilise.

The assumptions of path analysis, a simplified version of structural equation modelling, are similar to those of multivariate techniques: linearity, normality, avoidance of multi-collinearity and homoscedasticity. Normal probability plots of residuals and scatter diagrams of residuals versus predicted residuals were checked for outliers, normality, linearity, homoscadasticity and independence of residuals, and the Mahalanobis distance was calculated. No violations of normality, linearity or homoscedasticity of residuals were observed. Finally, based on Tabachnick and Fidell (2007), the critical value on which to interpret the Mahalanobis score with seven independent (predictor) variables, was 24.32. None of the values exceeded the chi square criterion, so I concluded there were no multivariate outliers.

Regarding multi-collinearity, correlations between the variables are shown above (Tables 39 and 40). All correlations were 0.70 or below, indicating no multi-collinearity among the variables. Collinearity statistics were also tested with a suggested cut-off point for determining the presence of multi-collinearity to be a tolerance value of less than 0.10 or a VIF (variance inflation factor) value above 0.10 (Pallant, 2011, p. 158). Tolerance values were less than 0.10 and VIF values above 0.10 , further indicating no violation of the assumption of multi-collinearity.

Regarding sample size, Bentler and Chou (1987) estimated a ratio of 5:1. That is, five cases per parameter. Kenny (2012) suggested 200 cases. In this study, Model 1 had 20 parameters, therefore a sample size of 200 was adequate to conduct path analysis. 


\subsubsection{Hypothesis 12.}

Hypothesis 12. Perceived organisational support, perceived supervisor support, stress-immobilise, connect-act and disconnect-act with job engagement and organisation engagement will better predict organisational commitment and intention to quit/turnover, than perceived organisational support, perceived supervisor support, job engagement and organisation engagement alone.

In brief, results showed neither Model 1 nor Model 2 fit well overall; however in both datasets Model 1, which included the MESE variables, was shown to better fit the data than Model 2.

\subsection{Manager dataset: Models 1 and 2.}

Running Model 1 using the manager dataset showed a poor fit: $\chi^{2}(14)=$ $145.44, p<0.001, \mathrm{CFI}=0.66, \mathrm{TLI}=0.15, \mathrm{RMSEA}=0.22$. Modification indices (a set of numbers that suggest ways to improve the model) were examined to improve the model fit. Modification indices suggested that job engagement and organisation engagement should be the dependent variables of the model, and not organisational commitment and intention to quit/turnover. Running Model 2 using the manager data also showed a poor fit, $\chi^{2}(5)=83.04, p<0.001, \mathrm{CFI}=0.71$, $\mathrm{TLI}=0.18, \mathrm{RMSEA}=0.28$. Modification indices were also examined to improve the model fit. Again, modification indices suggest job engagement and organisation engagement should be the dependent variables of the model, and not organisational commitment and intention to quit/turnover.

A chi square difference test was conducted between the models. The results of the difference test were significant, $\chi^{2}(9)=62.40, p<0.001$. This suggests that the model significantly changes when adding connect-act, disconnect-act and stress-immobilise. Results of the model testing for Model 1 and 2 are presented in Table 43.

Table 43

Model 1 vs. Model 2 for Manager Data

\begin{tabular}{lcccccc}
\hline \multicolumn{1}{c}{ Model } & $\chi^{2}$ & $d f$ & $P$ & CFI & TLI & RMSEA \\
\hline 1 & 145.44 & 14 & .001 & 0.66 & 0.15 & 0.22 \\
2 & 83.04 & 5 & .001 & 0.71 & 0.18 & 0.28 \\
Difference & 62.40 & 9 & .001 & - & - & - \\
\hline
\end{tabular}




\subsection{Employee dataset: Models 1 and 2.}

Running Model 1 using the employee dataset showed a poor fit, $\chi^{2}(14)=$ 230.27, $p<0.001, \mathrm{CFI}=0.48, \mathrm{TLI}=-0.31, \mathrm{RMSEA}=0.28$. Modification indices were examined to improve the model fit. Modification indices suggested that job engagement and organisation engagement should be the dependent variables of the model, and not organisational commitment and intention to quit/turnover.

Running Model 2 using the employee data showed a poor fit, $\chi^{2}(5)=$ 101.57, $p<0.001, \mathrm{CFI}=0.61, \mathrm{TLI}=-0.08, \mathrm{RMSEA}=0.32$. Modification indices were also examined to improve the model fit. Again, modification indices suggested job engagement and organisation engagement should be the dependent variables of the model, and not organisational commitment and intention to quit/turnover. Exploratory models will be conducted to test this.

A chi square difference test was conducted between the models. The results of the difference test were significant, $\chi^{2}(9)=128.70, p<0.001$. This suggests that the model significantly changes when adding in connect-act, disconnect-act and stress-immobilise. As above, neither model indicated a good fit. However, as there was a significant chi square difference, it can be concluded that the base line Model 1 fits the data better than the nested comparison model, Model 2 (Table 44).

Table 44

Model 1 vs. Model 2 for Employee Data

\begin{tabular}{lcccccc}
\hline \multicolumn{1}{c}{ Model } & $\chi^{2}$ & $d f$ & $P$ & CFI & TLI & RMSEA \\
\hline 1 & 145.44 & 14 & .001 & 0.66 & 0.15 & 0.22 \\
2 & 101.57 & 5 & .001 & 0.61 & -0.08 & 0.32 \\
Difference & 128.70 & 9 & .001 & - & - & - \\
\hline
\end{tabular}

\subsection{Model 1 and Model 2 summary.}

Using interpretation recommendations from Bryant and Satorra (2012), while neither model indicated a good fit, the significant chi square indicates that the base line model, Model 1, fits the data better than the nested comparison model, Model 2.

At this point in the analysis, model testing shifted to model generating (JÖreskog, 1993). Model generating is indicated (as in this study) when an initial 
poor model fit to the sample data is found. Model generation included a sequential process of modifying the original model/s. This process was informed by the statistical feedback on previous poorly fitting models and by the theoretical framework.

The main statistical feedback worth exploring was identifying the potential source of the poor fits: Both manager and employee data suggested that job engagement and organisation engagement should be the dependent variables. So, two new models were developed: Model 3, Figure 14, and Model 4, Figure 15). The new models were run and then compared using the same chi square difference test.

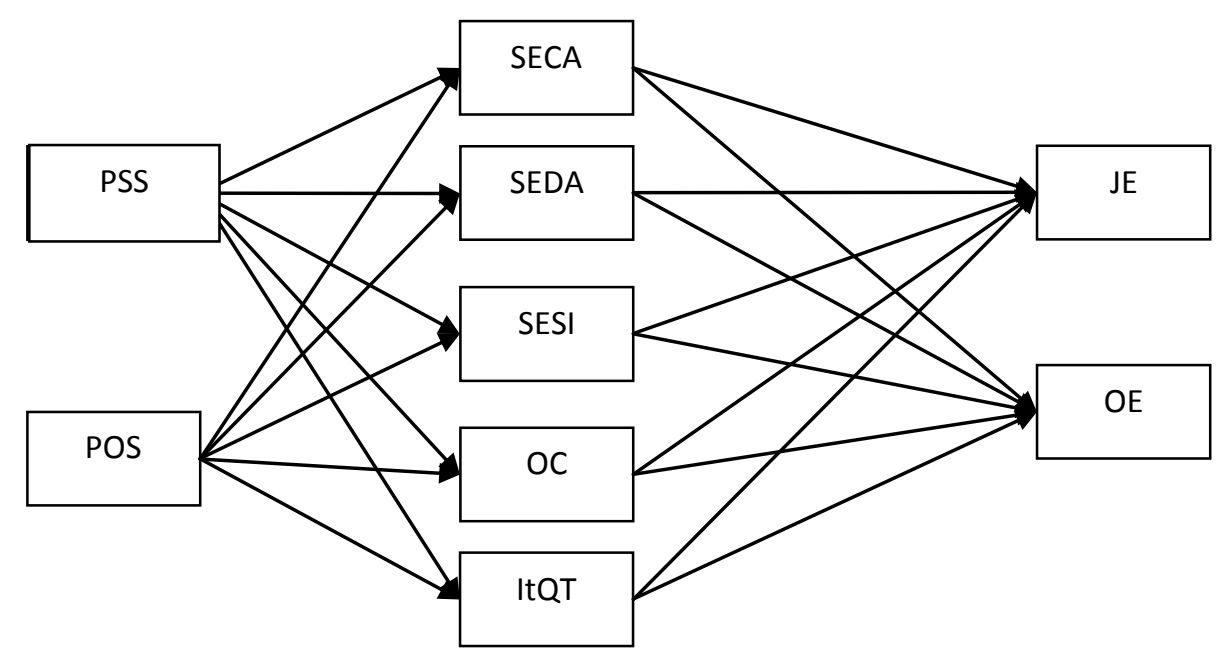

Figure 14. Model 3 with SESI, SECA and SEDA added in and swapping OC and ItQT with JE and OE.

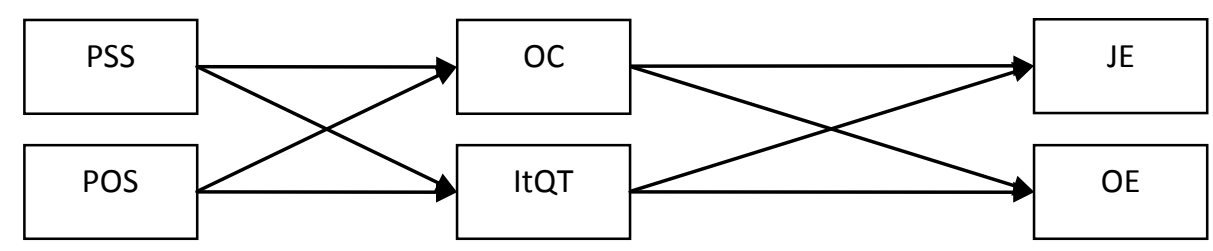

Figure 15. Model 4. Excluding SESI, SECA and SEDA and swapping OC and ItQT with JE and OE. 


\subsection{Manager data: Model 3 versus Model 4.}

Running Model 3 using the manager dataset showed a poor fit, $\chi^{2}(14)=$ $145.44, p<0.001, \mathrm{CFI}=0.66, \mathrm{TLI}=0.15, \mathrm{RMSEA}=0.22$. Modification indices were examined for improving the model fit. The modification indices now suggested that organisational commitment and intention to quit/turnover should be the dependent variables, and thus no good model could be found in the current structure.

Running Model 4 using the manager data also showed a poor fit, $\chi^{2}(5)=$ 72.92, $p<0.001, \mathrm{CFI}=0.74, \mathrm{TLI}=0.28, \mathrm{RMSEA}=0.27$. Modification indices were also examined to improve the model fit. The modification indices again suggested that organisational commitment and intention to quit/turnover should be the dependent variables, and thus no good model could be found in the current structure.

A chi square difference test was conducted between the models. The results of the difference test were significant, $\chi^{2}(9)=72.52, p<0.001$. This suggests that the model significantly changes when adding in connect-act, disconnect-act and stress-immobilise. As with Models 1 and 2, while neither model indicated a good fit, with a significant chi square difference, it can be concluded that overall, Model 3 fits the data better than the nested comparison model, Model 4. Results of the model testing for Models 3 and 4 are presented in Table 45.

Table 45

Model 3 vs. Model 4 for Manager Data

\begin{tabular}{lcccccc}
\hline \multicolumn{1}{c}{ Model } & $\chi^{2}$ & $d f$ & $P$ & CFI & TLI & RMSEA \\
\hline 3 & 183.94 & 14 & .001 & 0.56 & -0.10 & 0.25 \\
4 & 72.92 & 5 & .001 & 0.74 & 0.28 & 0.27 \\
Difference & 72.52 & 9 & .001 & - & - & - \\
\hline
\end{tabular}

\subsection{Employee data: Model 3 versus Model 4.}

Running Model 3 using the employee dataset showed a poor fit, $\chi^{2}(14)=$ 174.01, $p<0.001, \mathrm{CFI}=0.61, \mathrm{TLI}=0.03, \mathrm{RMSEA}=0.25$. Modification indices were examined for improving the model fit. The modification indices now suggested that organisational commitment and intention to quit/turnover should be 
the dependent variables, and thus no good model could be found in the current structure.

Running Model 4 using the employee data also showed a poor fit, $\chi^{2}(5)=$ 20.15, $p=0.001, \mathrm{CFI}=0.94, \mathrm{TLI}=0.83, \mathrm{RMSEA}=0.13$. Although this was a large improvement, it was still a poorly fitting model. Modification indices were examined. As previously, these suggested that organisational commitment and intention to quit/turnover should be the dependent variables, and thus no good model could be found in the current structure. Results of the model testing for Models 3 and 4 are presented in Table 46.

Table 46

Model 3 vs. Model 4 for Employee Data

\begin{tabular}{lcccccc}
\hline \multicolumn{1}{c}{ Model } & $\chi^{2}$ & $d f$ & $P$ & CFI & TLI & RMSEA \\
\hline 3 & 174.01 & 14 & .001 & 0.61 & 0.03 & 0.25 \\
4 & 20.15 & 5 & .001 & 0.94 & 0.83 & 0.13 \\
Difference & 153.86 & 9 & .001 & - & - & - \\
\hline
\end{tabular}

4.4.1.1.6 Models 3 and 4 summary.

A chi square difference test was conducted between the models. The results of the difference test were significant, $\chi^{2}(9)=153.86, p<0.001$. This suggests that the model significantly changes when adding in connect-act, disconnect-act and stress-immobilise. As with Models 1 and 2, while neither model indicated a good fit, as there was a significant chi square difference, it can be concluded that overall, Model 3 fits the data better than the nested comparison model, Model 4.

\subsubsection{Proposition 3: Summary.}

The results lend partial support to Proposition 3:

1. With the manager data, in the absence of a good fit of any of the models tested, models that included connect-act, disconnect-act and stressimmobilise fitted the data better.

2. In the employee data, in the absence of a good fit of any of the models tested, the models that included connect-act, disconnect-act and stressimmobilise fitted the data better overall. 
3. In both sets of data, path analysis suggested that job engagement and organisation engagement should be the dependent variables. In response, Models 3 and 4 were generated and tested, with findings again showing no goodness of fit. However these findings raise questions regarding job engagement and organisation engagement as being best represented as independent (antecedent) or dependent (outcome) variables in models of engagement. These findings are further examined by testing Proposition 4 .

\subsection{Path and Mediation Analysis}

\subsubsection{Proposition 4.}

Within Model 1, connect-act and disconnect-act will work differently from stress-immobilise in relation to engagement.

Models 1A (Figure 8) and 1B (Figure 9) were developed to test the proposed differences within the manager-employee social engagement strategies. In Model 1A, connect-act and disconnect-act, with perceived organisational support, perceived organisational support, job engagement and organisation engagement, are identified as independent variables with organisational commitment and intention to quit/turnover as dependent variables. In Model 1B, stress-immobilise with perceived organisational support, perceived organisational support, job engagement and organisation engagement, are identified as independent variables with organisational commitment and intention to quit/turnover as dependent variables. Model 1A is tested, followed by model 1B, using mediation and path analysis.

\subsubsection{Hypothesis 13.}

Connect-act and disconnect-act will mediate between job engagement and organisation engagement, and the outcome variables of organisational commitment and intention to quit/turnover; and perceived organisational support will mediate between perceived supervisor support, and job engagement and organisation engagement.

Before conducting mediation analysis, the pre-analysis criteria of Baron and Kenny (1986) (delineated in Chapter 3, section 3.2.6.5) was determined (Table 47). Mediation analysis was conducted only with the variable sets that met 
the criteria. Further, regarding the interpretation of Medgraph outputs, Jose (2013) recommends the following criteria:

\begin{abstract}
Null mediation occurs when the Sobel's z-value (see next paragraph) is NS. Full mediation occurs when the Sobel's z-value is significant, and the beta weight for the basic relationship (IV to DV) becomes NS in the second regression. Partial mediation occurs when the Sobel's z-value is significant, and the beta weight for the basic relationship (IV to DV) remains significant. (http://pavlov.psyc.vuw.ac.nz/paul-jose/medgraph)
\end{abstract}

Table 47

Model 1A Criteria Assessment to run Mediation Analysis with the Manager and Employee Data

\begin{tabular}{|c|c|c|c|c|c|c|}
\hline \multirow[t]{2}{*}{$\begin{array}{c}\text { Hypothesised IV } \rightarrow \mathrm{MV} \rightarrow \mathrm{DV} \\
\text { Linear association }\end{array}$} & \multicolumn{2}{|c|}{$\begin{array}{c}\text { IV is related to the } \\
\text { MV }\end{array}$} & \multicolumn{2}{|c|}{$\begin{array}{l}\text { MV is related to } \\
\text { the DV }\end{array}$} & \multicolumn{2}{|c|}{$\begin{array}{c}\text { Criteria } \\
\text { met } \rightarrow \text { Test }\end{array}$} \\
\hline & $\mathrm{M}$ & $\mathrm{E}$ & $\mathrm{M}$ & $\mathrm{E}$ & $\mathrm{M}$ & $E$ \\
\hline $\mathrm{PSS} \rightarrow \mathrm{POS} \rightarrow \mathrm{JE}$ & $\checkmark$ & $\checkmark$ & $\mathrm{X}$ & $\mathrm{X}$ & $\mathrm{X}$ & $\mathrm{X}$ \\
\hline $\mathrm{PSS} \rightarrow \mathrm{POS} \rightarrow \mathrm{OE}$ & $\checkmark$ & $\checkmark$ & $\mathrm{X}$ & $X$ & $X$ & $\mathrm{X}$ \\
\hline $\mathrm{POS} \rightarrow \mathrm{JE} \rightarrow \mathrm{SECA}$ & $\mathrm{X}$ & $\mathrm{X}$ & $\checkmark$ & $\checkmark$ & $X$ & $\mathrm{X}$ \\
\hline $\mathrm{POS} \rightarrow \mathrm{JE} \rightarrow \mathrm{SEDA}$ & $X$ & $\mathrm{X}$ & $\mathrm{X}$ & $X$ & $X$ & $\mathrm{X}$ \\
\hline $\mathrm{POS} \rightarrow \mathrm{OE} \rightarrow \mathrm{SECA}$ & $X$ & $\mathrm{X}$ & $\checkmark$ & $\checkmark$ & $X$ & $\mathrm{X}$ \\
\hline $\mathrm{POS} \rightarrow \mathrm{OE} \rightarrow \mathrm{SEDA}$ & $X$ & $X$ & $\checkmark$ & $\checkmark$ & $X$ & $X$ \\
\hline $\mathrm{JE} \rightarrow \mathrm{SECA} \rightarrow \mathrm{OC}$ & $\checkmark$ & $\checkmark$ & $\checkmark$ & $\checkmark$ & $\checkmark$ & $\checkmark$ \\
\hline $\mathrm{JE} \rightarrow \mathrm{SEDA} \rightarrow \mathrm{OC}$ & $\mathrm{X}$ & $\mathrm{X}$ & $\mathrm{X}$ & $\checkmark$ & $X$ & $\mathrm{X}$ \\
\hline $\mathrm{JE} \rightarrow \mathrm{SECA} \rightarrow \mathrm{ItQT}$ & $\checkmark$ & $\checkmark$ & $\checkmark$ & $\checkmark$ & $\checkmark$ & $\checkmark$ \\
\hline $\mathrm{JE} \rightarrow \mathrm{SEDA} \rightarrow \mathrm{ItQT}$ & $\mathrm{X}$ & $\mathrm{X}$ & $\mathrm{X}$ & $\mathrm{X}$ & $\mathrm{X}$ & $\mathrm{X}$ \\
\hline $\mathrm{OE} \rightarrow \mathrm{SECA} \rightarrow \mathrm{OC}$ & $\checkmark$ & $\checkmark$ & $\checkmark$ & $\checkmark$ & $\checkmark$ & $\checkmark$ \\
\hline $\mathrm{OE} \rightarrow \mathrm{SEDA} \rightarrow \mathrm{OC}$ & $\checkmark$ & $\checkmark$ & $\mathrm{X}$ & $\checkmark$ & $X$ & $\checkmark$ \\
\hline $\mathrm{OE} \rightarrow \mathrm{SECA} \rightarrow \mathrm{ItQT}$ & $\checkmark$ & $\checkmark$ & $\checkmark$ & $\checkmark$ & $\checkmark$ & $\checkmark$ \\
\hline $\mathrm{OE} \rightarrow \mathrm{SEDA} \rightarrow \mathrm{ItQT}$ & $\checkmark$ & $\mathrm{X}$ & $\mathrm{X}$ & $X$ & $\mathrm{X}$ & $\mathrm{X}$ \\
\hline
\end{tabular}

Note. $\mathrm{M}=$ manager; $\mathrm{E}=$ employee.

Results of the Medgraph analyses (Jose, 2013) are summarised below, in Table 48. Two examples are provided to illustrate the analysis process.

Figure 16 illustrates the Medgraph output with the manager sample. It was hypothesised that the relationship between job engagement and organisation commitment would be mediated by connect-act. The relationship between job engagement and organisation commitment was partially mediated by connect-act. The standardised regression coefficient between job engagement and organisation commitment decreased when controlling for connect-act. The other conditions of mediation were also met: job engagement was a significant predictor of organisational commitment and connect-act, and connect-act was a significant predictor of organisational commitment, while controlling for job engagement (Sobel z-value 2.63, $p=0.008$, total 0.288 , direct 0.215 , indirect effect 0.073 , indirect to total ratio $=0.253$ ). 
JE

$.288^{* * *}$

OC

Independent Variable

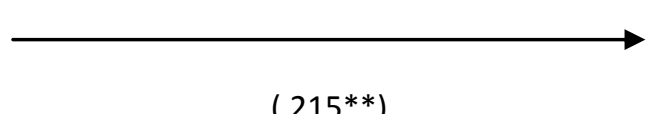

Outcome Variable

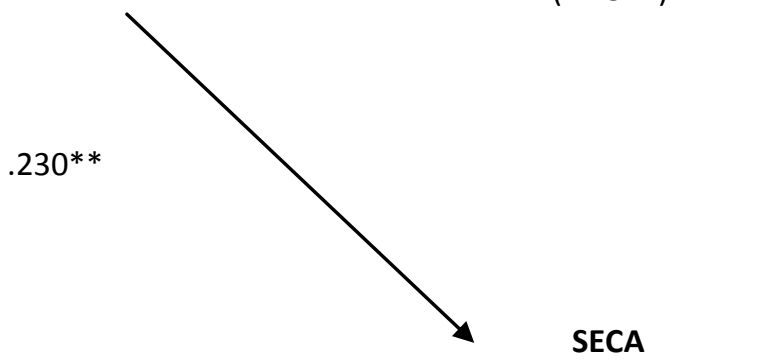

Mediating Variable

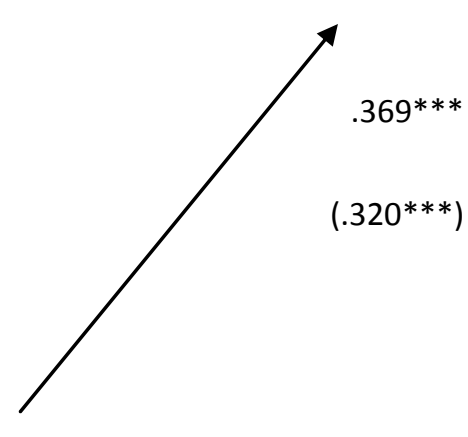

Note: Standardised regression coefficients for the relationship between JE and OC as mediated by SECA. The standardised regression coefficient between JE and OC controlling for SECA is in parentheses. ${ }^{*} \mathrm{p}<0.05$.

Figure 16. Medgraph results: JE, SECA and OC.

In another example from the manager dataset, it was hypothesised that the relationship between job engagement and intention to quit/turnover would be mediated by connect-act. The relationship between job engagement and intention to quit/turnover was fully mediated by connect-act. The standardised regression coefficient between job engagement and intention to quit/turnover decreased substantially when controlling for connect-act. The other conditions of mediation were also met: job engagement was a significant predictor of intention to quit/turnover and connect-act, and connect-act was a significant predictor of intention to quit/turnover, while controlling for job engagement (Sobel z-value $2.23, p=0.03$, total -0.163 , direct -0.089 , indirect effect 0.074 , indirect to total ratio $=0.454($ Figure 17$)$. 


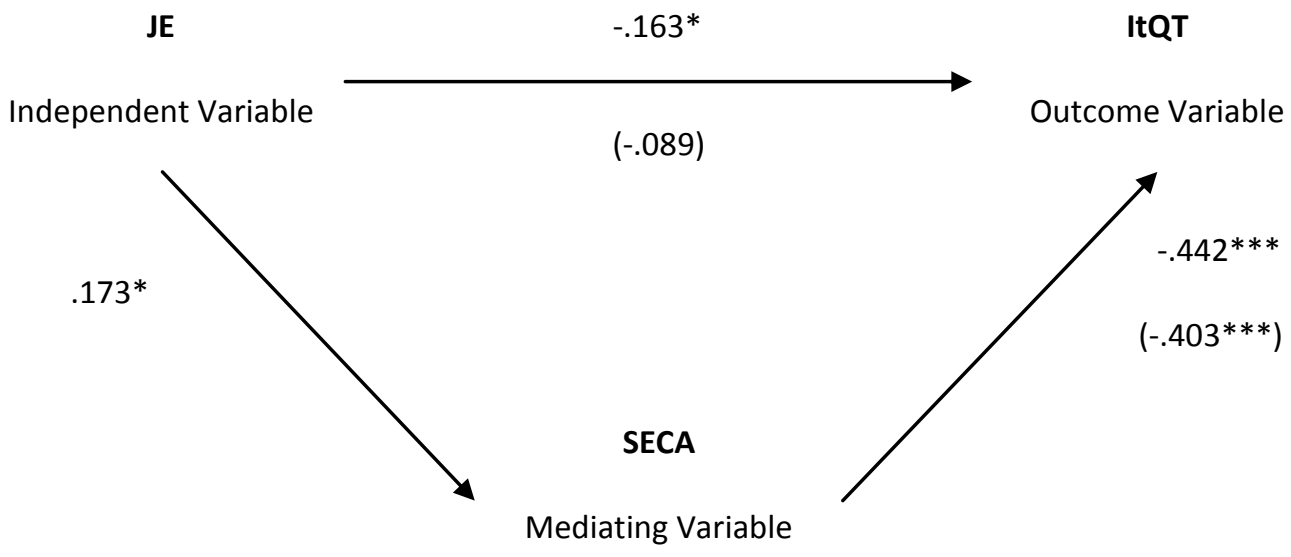

Note: Standardised regression coefficients for the relationship between JE and ItQT was mediated by SECA. The standardised regression coefficient between JE and ItQT controlling for SECA is in parentheses. ${ }^{*} \mathrm{p}<0.05$.

Figure 17. Medgraph results: JE, SECA, ItQT

The remainder of the findings are summarised in Table 48.

Table 48

Model 1A Mediation Results

\begin{tabular}{|l|c|c|}
\hline \multirow{2}{*}{$\begin{array}{c}\text { Hypothesised } \mathrm{IV} \rightarrow \mathrm{MV} \rightarrow \mathrm{DV} \\
\text { Linear association }\end{array}$} & Manager mediation & Employee mediation \\
\cline { 2 - 3 } & $\mathrm{F}=$ Full mediation; $\mathrm{P}=$ Partial mediation; $\mathrm{N}=$ No mediation \\
\hline $\mathrm{JE} \rightarrow \mathrm{SECA} \rightarrow \mathrm{OC}$ & $\mathrm{P}$ & $\mathrm{P}$ \\
\hline $\mathrm{JE} \rightarrow \mathrm{SECA} \rightarrow \mathrm{ItQT}$ & $\mathrm{F}$ & $\mathrm{P}$ \\
\hline $\mathrm{OE} \rightarrow \mathrm{SECA} \rightarrow \mathrm{OC}$ & $\mathrm{P}$ & $\mathrm{N}$ \\
\hline $\mathrm{OE} \rightarrow \mathrm{SEDA} \rightarrow \mathrm{OC}$ & - & $\mathrm{N}$ \\
\hline $\mathrm{OE} \rightarrow \mathrm{SECA} \rightarrow \mathrm{ItQT}$ & $\mathrm{P}$ & \\
\hline
\end{tabular}

Mediation findings from the employee data show connect-act acts as a mediator between: job engagement and organisational commitment; and organisation engagement and organisational commitment. In the manager data connect-act acts as a mediator between: job engagement and organisational commitment; job engagement and intention to quit/turnover; organisation engagement and organisational commitment; and organisation engagement and intention to quit/turnover. Related to this finding, 'under standard assumptions, the $\mathrm{X} \rightarrow \mathrm{M} \rightarrow \mathrm{Y}$ mediation model is statistically indistinguishable from a $\mathrm{Y} \rightarrow \mathrm{M} \rightarrow \mathrm{X}$ model' (Mathieu, DeShon \& Bergh, 2008, p. 212). This is an important consideration in light of the initial path analysis indications above, which 
indicated job engagement and organisation engagement as dependent variables.

Following this argument, connect-act might also be a mediator between: (a) organisational commitment and intention to quit/turnover as independent variables; and (b) job engagement and organisation engagement as dependent variables.

Keeping this possibility in mind, hypothesis 13 was further tested using path analysis to understand more about the fit pertaining to Model 1A. As above, path analysis was conducted using model testing, followed by a process of model generating (JÖreskog, 1993). For reporting purposes, results are first reported on the manager data, followed by the employee data.

\subsection{Model 1A: Manager data.}

Regarding Model 1A, results of the model showed a poor fit for managers, $\chi^{2}(16)=203.17, p<0.001, \mathrm{CFI}=0.49, \mathrm{TLI}=0.10, \mathrm{RMSEA}=0.25$. Examination of modification indices suggested that job engagement and organisation engagement should be the dependent variables again.

Next, two additional models, based on Model 3, were examined using job engagement and organisation engagement as the dependent variables: Model 3Ai (Figure 18) and 3Aii (Figure 19) were tested. Results of Model 3Ai still showed a poor model fit, $\chi^{2}(16)=203.69, p<0.001, \mathrm{CFI}=0.48, \mathrm{TLI}=0.10, \mathrm{RMSEA}=$ 0.25 . Results of Model 3Aii also showed a poor model fit, $\chi^{2}(16)=77.58, p<$ $0.001, \mathrm{CFI}=0.83, \mathrm{TLI}=0.70, \mathrm{RMSEA}=0.14$. This model showed much improvement over Model 3Ai, but still did not achieve a good fit. Modification indices showed no usable solutions to the model fit. Table 49 shows the results of Models 1A, 3Ai, and 3Aii.

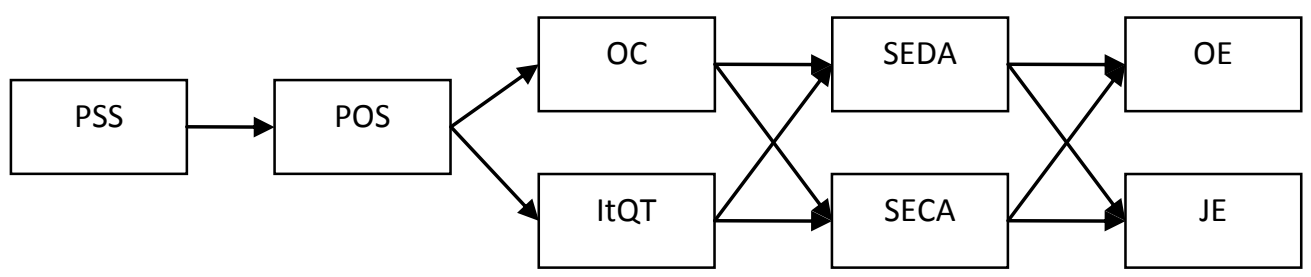

Figure 18. Model 3 Ai additional model testing based on modification indices. 


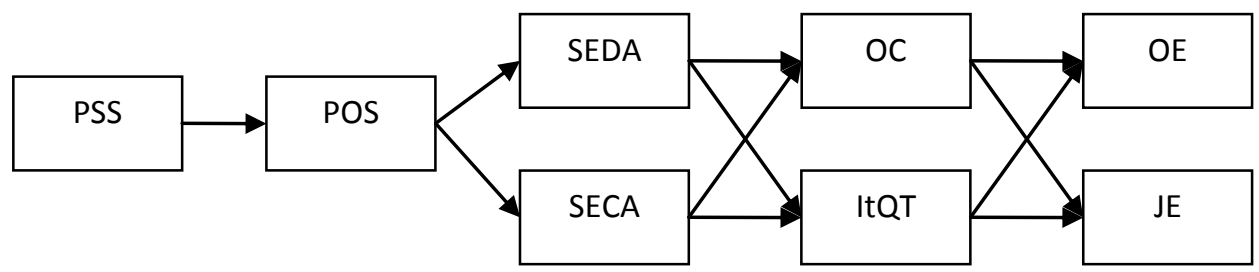

Figure 19. Model 3 A ii additional model testing based on modification indices.

Table 49

Results from Models 1A, 3Ai and 3Aii for Managers

\begin{tabular}{lcccccc}
\hline \multicolumn{1}{c}{ Model } & $\chi^{2}$ & $D f$ & $P$ & CFI & TLI & RMSEA \\
\hline 1A & 203.17 & 16 & .001 & 0.49 & 0.10 & 0.25 \\
3Ai & 203.69 & 16 & .001 & 0.48 & 0.10 & 0.25 \\
3Aii & 77.58 & 16 & .001 & 0.83 & 0.70 & 0.14 \\
\hline
\end{tabular}

\subsection{Model 1 A: employee data.}

Results of the Model 1A showed a poor fit for employees as well, $\chi 2$ (16) $=197.21, \mathrm{p}<0.001, \mathrm{CFI}=0.49, \mathrm{TLI}=0.10, \mathrm{RMSEA}=0.24$. Examination of modification indices suggested that job engagement and organisation engagement should be the dependent variables. Again, the two additional models (3Ai and 3Aii) were examined using job engagement and organisation engagement as the dependent variables. Results of Model 3Ai still showed a poor model fit, $\chi 2(16)=$ 118.67, $\mathrm{p}<0.001, \mathrm{CFI}=0.71, \mathrm{TLI}=0.49, \mathrm{RMSEA}=0.18$. Results of Model 3Aii finally had a good model fit, $\chi 2(16)=22.60, p=0.099, \mathrm{CFI}=0.98, \mathrm{TLI}=0.96$, RMSEA $=0.05$. Table 50 shows the results of Models $1 \mathrm{~A}, 3 \mathrm{Ai}$ and 3Aii.

Table 50

Results from Models 1A, 3Ai and 3Aii for Employees

\begin{tabular}{lcccccc}
\hline \multicolumn{1}{c}{ Model } & $\chi^{2}$ & $d f$ & $P$ & CFI & TLI & RMSEA \\
\hline 1A & 197.21 & 16 & .001 & 0.49 & 0.10 & 0.25 \\
3Ai & 118.67 & 16 & .001 & 0.71 & 0.49 & 0.18 \\
3Aii & 22.60 & 16 & .099 & 0.98 & 0.96 & 0.05 \\
\hline
\end{tabular}

Figure 20 shows the results of Model 3Aii's standardised paths for the employee data. 


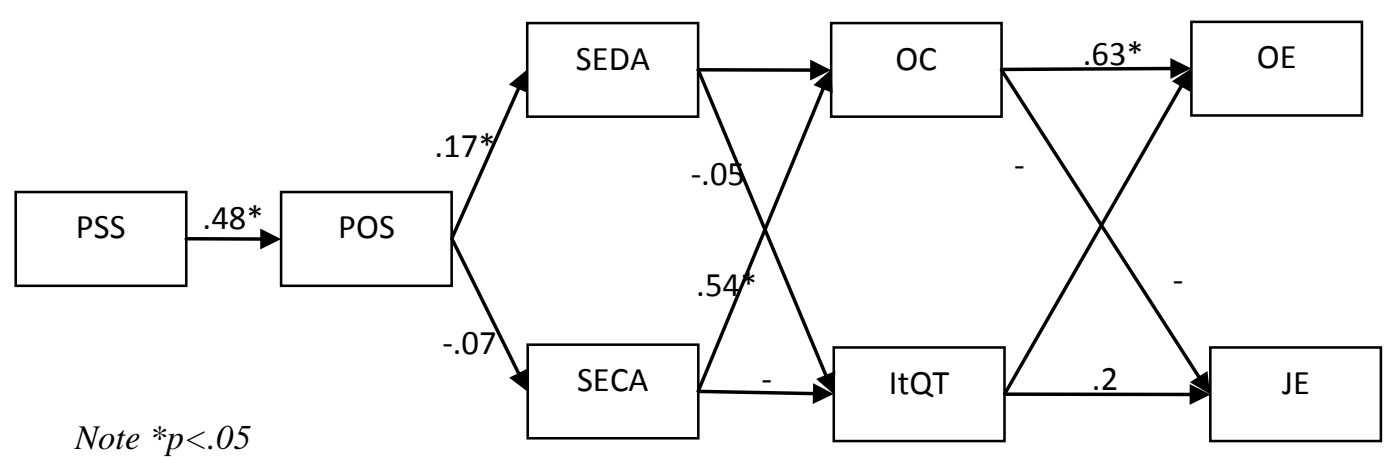

Figure 20. Model 3Aii standardised paths for employee data.

In summary, Hypothesis 13 was partially confirmed. First, across both datasets, connect-act mediated: between job engagement and organisational commitment; and organisation engagement and organisational commitment. Plus the manager data showed that connect-act also mediated between job engagement and intention to quit/turnover; and organisation engagement and intention to quit/turnover. No mediating association with disconnect-act were found. Also the hypothesised mediation association, where perceived organisational support would mediate between perceived supervisor support and job engagement and organisation engagement, was not able to be tested as the variables did not meet the pre-assessment criteria. Further, no well-fitting model was found in the manager data during model generation. However, Model 3 Aii was found to be a good fit for the employee data. In this model organisation engagement and job engagement were positioned as dependent variables instead of, as hypothesised, independent variables. Finally, the good fitting model (3Aii) does not change the fact that hypothesis 13 was not confirmed. However it does create a wider window from which to view to the case study data.

\subsubsection{Hypothesis 14.}

Job engagement and organisation engagement will mediate between stress-immobilise and the outcome variables of organisational commitment and intention to quit/turnover; and perceived organisational support will mediate between perceived supervisor support and stress-immobilise.

This hypothesis tested Model 1B and was partially confirmed. As above, the variables were checked (Baron \& Kenny, 1986) before conducting mediation 
analysis. All of the hypothesised mediating relationships met the criteria to conduct mediation analysis (Table 51). Mediation analysis was conducted only with the variable sets that met the criteria.

Table 51

Model 1B Criteria Assessment to run Mediation Analysis with the Manager and Employee Data

\begin{tabular}{|l|c|c|c|c|c|c|}
\hline \multirow{2}{*}{$\begin{array}{c}\text { Hypothesised IV } \rightarrow \text { MV } \rightarrow \text { DV } \\
\text { Linear association }\end{array}$} & \multicolumn{2}{|c|}{$\begin{array}{c}\text { IV is related to the } \\
\text { MV }\end{array}$} & \multicolumn{2}{c|}{$\begin{array}{c}\text { MV is related to } \\
\text { the DV }\end{array}$} & \multicolumn{2}{c|}{$\begin{array}{c}\text { Criteria } \\
\text { met } \rightarrow \text { Test }\end{array}$} \\
\cline { 2 - 7 } & M & E & M & E & M & E \\
\hline PSS $\rightarrow$ POS $\rightarrow$ SESI & $\checkmark$ & $\checkmark$ & $\checkmark$ & $\checkmark$ & $\checkmark$ & $\checkmark$ \\
\hline POS $\rightarrow$ SESI $\rightarrow$ JE & $\checkmark$ & $\checkmark$ & $\checkmark$ & $\checkmark$ & $\checkmark$ & $\checkmark$ \\
\hline POS $\rightarrow$ SESI $\rightarrow$ OE & $\checkmark$ & $\checkmark$ & $\checkmark$ & $\checkmark$ & $\checkmark$ & $\checkmark$ \\
\hline SESI $\rightarrow \mathrm{JE} \rightarrow$ OC & $\checkmark$ & $\checkmark$ & $\checkmark$ & $\checkmark$ & $\checkmark$ & $\checkmark$ \\
\hline SESI $\rightarrow \mathrm{IE} \rightarrow \mathrm{ItQT}$ & $\checkmark$ & $\checkmark$ & $\checkmark$ & $\checkmark$ & $\checkmark$ & $\checkmark$ \\
\hline SESI $\rightarrow$ OE $\rightarrow$ OC & $\checkmark$ & $\checkmark$ & $\checkmark$ & $\checkmark$ & $\checkmark$ & $\checkmark$ \\
\hline SESI $\rightarrow$ OE $\rightarrow$ ItQT & $\checkmark$ & $\checkmark$ & $\checkmark$ & $\checkmark$ & $\checkmark$ & $\checkmark$ \\
\hline
\end{tabular}

Note. $\mathrm{M}=$ Manager; $\mathrm{E}=$ Employee.

Also as above, two Medgraph examples are provided to illustrate the analytical process: Manager SESI $\rightarrow$ JE $\rightarrow$ OC (Figure 21), and manager SESI $\rightarrow$ $\mathrm{OE} \rightarrow$ OC (Figure 18).

Manager: SESI $\rightarrow J E \rightarrow O C$ (Figure 21): The relationship between stressimmobilise and organisational commitment was partially mediated by job engagement. As Figure 21 illustrates, the standardised regression coefficient between stress-immobilise and organisational commitment decreased substantially when controlling for job engagement. The other conditions of mediation were also met: stress-immobilise was a significant predictor of organisational commitment and job engagement, and job engagement was a significant predictor of organisational commitment, while controlling for stress-immobilise (Sobel zvalue $-2.43, p=0.014$, total -0.325 , direct -0.278 , indirect effect -0.047 , indirect to total ratio $=0.145$ ). 


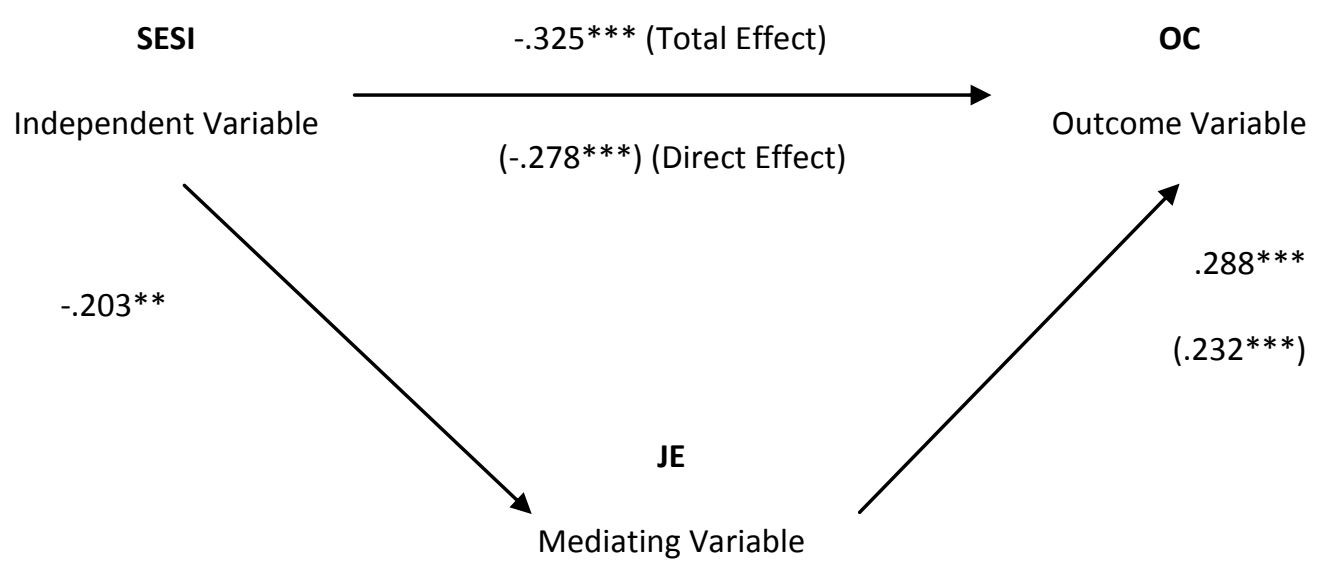

Note: Standardised regression coefficients for the relationship between SESI and OC as mediated by JE. The standardised regression coefficient between SESI and OC controlling for JE is in parentheses. *p<.05.

Figure 21. Medgraph results for SESI, JE and OC.

Manager: SESI $\rightarrow O E \rightarrow O C$ (Figure 22): The relationship between stressimmobilise and organisation commitment was fully mediated by organisation engagement. As Figure 18 illustrates, the standardised regression coefficient between stress-immobilise and organisation commitment decreased substantially when controlling for organisation engagement. The other conditions of mediation were also met: stress-immobilise was a significant predictor of organisation commitment and organisation engagement, and organisation engagement was a significant predictor of organisation commitment, while controlling for stressimmobilise (Sobel z-value $-4.81 \mathrm{p}=0.004$, total -0.325 , direct -0.097 , indirect effect -0.228 , indirect to total ratio $=0.702$ ). 
SESI

$-.325 * * *$

OC

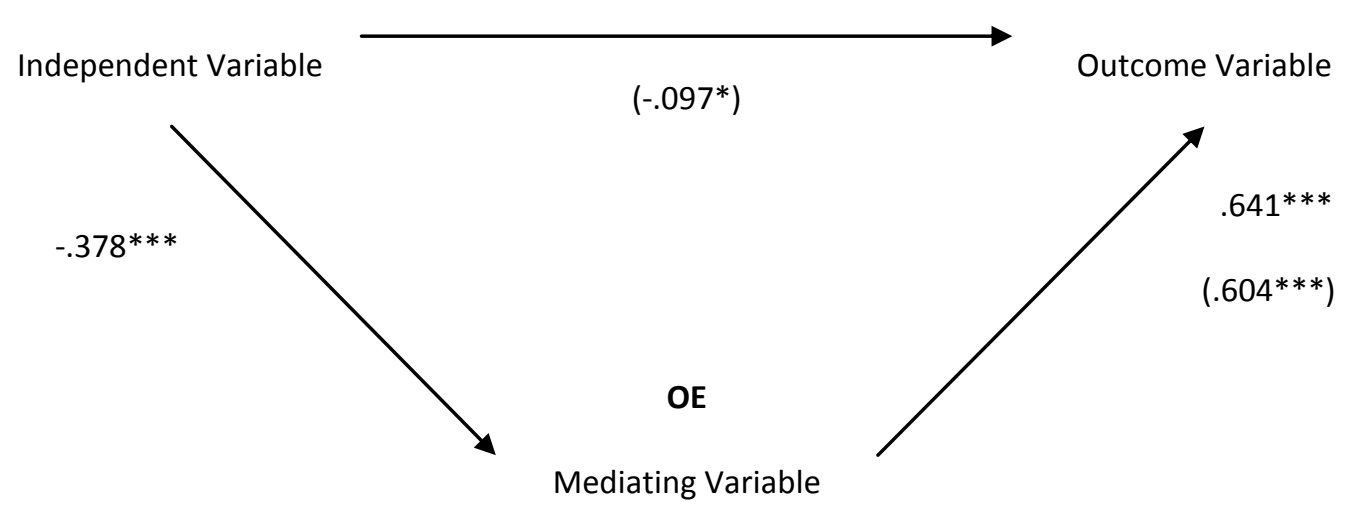

Note: Standardised regression coefficients for the relationship between SESI and OC as mediated by OE. The standardised regression coefficient between SESI and OC controlling for OE is in parentheses. $* p<0.05$.

Figure 22. Medgraph results for SESI, OE and OC.

The Medgraph analyses are summarised below in Table 52. Mediation findings from the manager data confirmed all but two of the hypothesised associations. Perceived organisational support as a mediator between perceived supervisor support and stress-immobilise, and job engagement as a mediator between stress-immobilise and intention to quit/turnover, were not significant. Mediation findings from the employee data confirmed all the hypothesised associations.

Table 52

Model 1B: Mediation Results

\begin{tabular}{|c|c|c|}
\hline \multirow{2}{*}{$\begin{array}{c}\text { Hypothesised } \\
\mathrm{IV} \rightarrow \mathrm{MV} \rightarrow \mathrm{DV} \\
\text { Linear association }\end{array}$} & Manager Mediation & Employee Mediation \\
\hline & \multicolumn{2}{|c|}{$\mathrm{F}=$ Full mediation; $\mathrm{P}=$ Partial mediation; $\mathrm{N}=$ No mediation } \\
\hline $\mathrm{PSS} \rightarrow \mathrm{POS} \rightarrow \mathrm{SESI}$ & $\mathrm{N}$ & $\mathrm{P}$ \\
\hline $\mathrm{POS} \rightarrow \mathrm{SESI} \rightarrow \mathrm{JE}$ & $\mathrm{P}$ & $\mathrm{P}$ \\
\hline $\mathrm{POS} \rightarrow \mathrm{SESI} \rightarrow \mathrm{OE}$ & $\mathrm{P}$ & $\mathrm{P}$ \\
\hline $\mathrm{SESI} \rightarrow \mathrm{JE} \rightarrow \mathrm{OC}$ & $\mathrm{P}$ & $\mathrm{P}$ \\
\hline $\mathrm{SESI} \rightarrow \mathrm{JE} \rightarrow \mathrm{ItQT}$ & $\mathrm{N}$ & $\mathrm{P}$ \\
\hline $\mathrm{SESI} \rightarrow \mathrm{OE} \rightarrow \mathrm{OC}$ & $\mathrm{F}$ & $\mathrm{P}$ \\
\hline $\mathrm{SESI} \rightarrow \mathrm{OE} \rightarrow \mathrm{ItQT}$ & $\mathrm{P}$ & $\mathrm{P}$ \\
\hline
\end{tabular}

Next, good model fit was analysed and path analysis was used to understand more about the fit of Model 1B. As above, path analysis was conducted using model testing, followed by a process of model generating 
(JÖreskog, 1993). For reporting purposes, results from the manager data are followed by the employee data.

\subsection{Model 1B: Manager data.}

Results of the model showed a poor fit for managers, $\chi^{2}(12)=109.75$, p < $0.001, \mathrm{CFI}=0.74, \mathrm{TLI}=0.54, \mathrm{RMSEA}=0.20$. As previously, modification indices suggested that job engagement and organisation engagement should be the dependent variables. In turn, an additional model was run that used job engagement and organisation engagement as the dependent variables, and organisational commitment and intention to quit/turnover as the mediator variables: Model 3Bi (Figure 23).

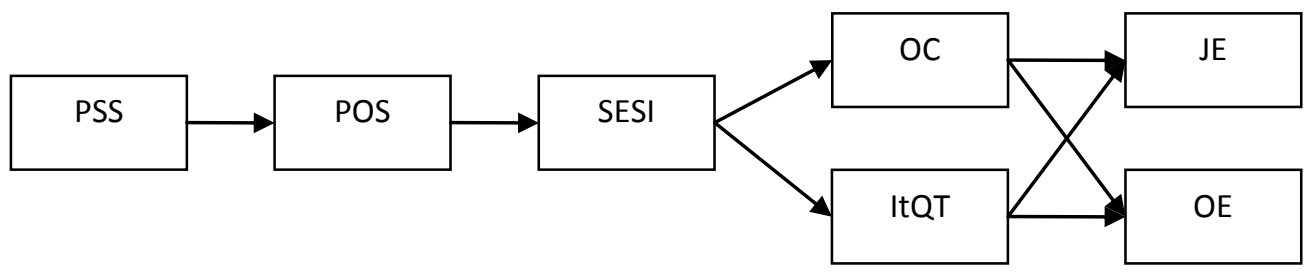

Figure 23. Model 3 Bi: OC and ItQT mediating between SESI and JE and OE.

The results of the model also showed inadequate model fit, $\chi^{2}(12)=$ 62.42, $p<0.001, \mathrm{CFI}=0.87, \mathrm{TLI}=0.76, \mathrm{RMSEA}=0.15$. As before, modification indices suggested that and organisational commitment and intention to quit/turnover be the dependent variables and a good model fit could not be found. Results for Model 1B and 3Bi for managers is presented in Table 53.

Table 53

Results from Models $1 B$ and $3 B$ i for managers

\begin{tabular}{lcccccc}
\hline \multicolumn{1}{c}{ Model } & $\chi^{2}$ & $d f$ & $P$ & CFI & TLI & RMSEA \\
\hline 1B & 109.75 & 12 & .001 & 0.74 & 0.54 & 0.20 \\
3Bi & 62.42 & 12 & .001 & 0.87 & 0.76 & 0.15 \\
\hline
\end{tabular}

To continue the search for an appropriate model for managers, Model 3Bii was tested (Figure 24). However, a good model fit still could not be found, $\chi^{2}$ (13) $=183.69, p<0.001, \mathrm{CFI}=0.54, \mathrm{TLI}=0.26, \mathrm{RMSEA}=0.26$. Results of the Model 3Bii for managers are presented in Table 54. 


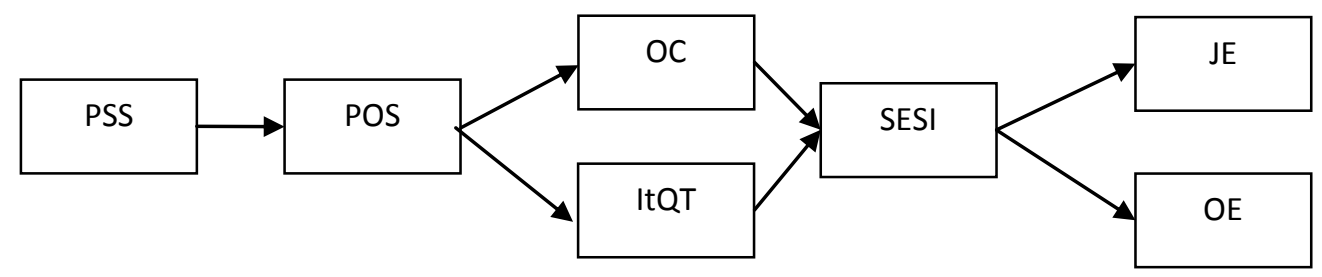

Figure 24. Model 3Bii. SESI mediating between OC and ItQT and JE and OE.

Table 54

Results from Models 3Bii for Managers

\begin{tabular}{ccccccc}
\hline Model & $\chi^{2}$ & $d f$ & $P$ & CFI & TLI & RMSEA \\
\hline 3Bii & 183.69 & 13 & .001 & 0.54 & 0.26 & 0.26 \\
\hline
\end{tabular}

\subsection{Model 1B: employee data.}

The results showed a poor model fit, $\chi 2(12)=113.03, \mathrm{p}<0.001, \mathrm{CFI}=$ $0.70, \mathrm{TLI}=0.48, \mathrm{RMSEA}=0.21$. Like the previous models, modification indices suggested that job engagement and organisation engagement should be the dependent variables. Therefore, Model 3Bi was also run for the employee data. This model resulted in a good model fit, $\chi 2(12)=20.77, \mathrm{p}=0.054$, CFI $=0.97$, $\mathrm{TLI}=0.96$, RMSEA $=0.06$. Table 55 shows the model fit for Model $1 \mathrm{~B}$ and $3 \mathrm{Bi}$ for employee data. Figure 25 shows the standardised path weights for model 3Bi for the employee data.

Table 55

Results from Models $1 B$ and 3Bi for Employees

\begin{tabular}{lcccccc}
\hline \multicolumn{1}{c}{ Model } & $\chi^{2}$ & $D f$ & $P$ & CFI & TLI & RMSEA \\
\hline 1B & 113.03 & 12 & .001 & 0.70 & 0.48 & 0.21 \\
3Bi & 20.77 & 12 & .054 & 0.97 & 0.96 & 0.06
\end{tabular}




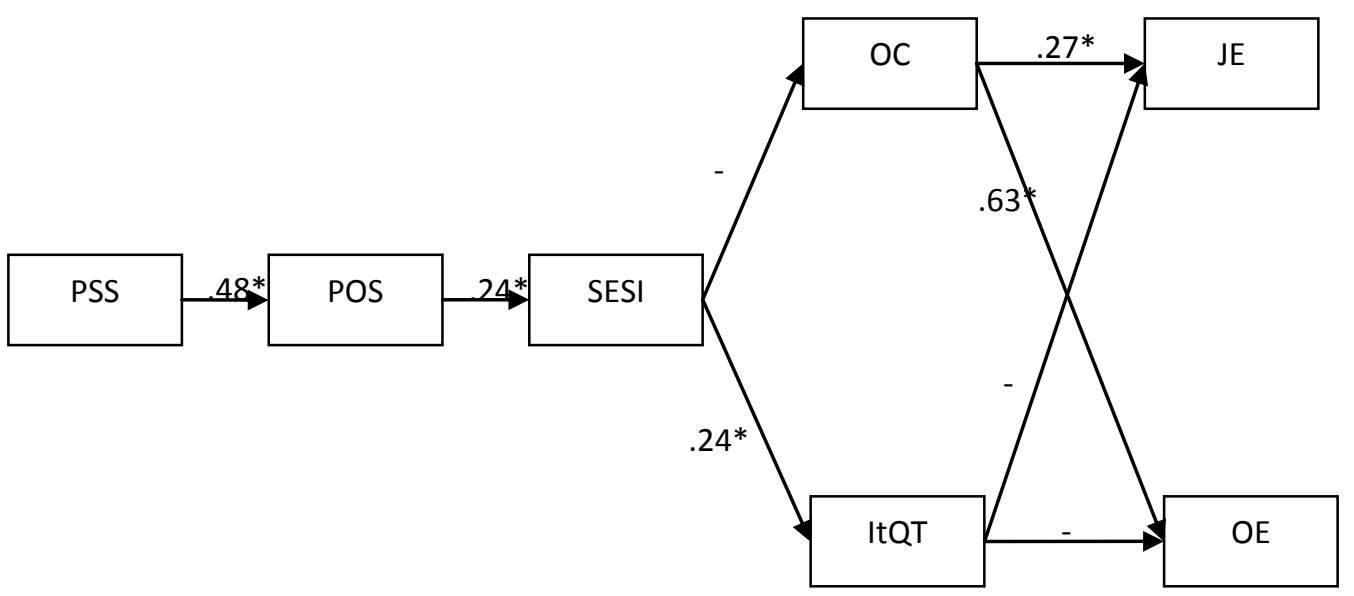

Figure 25. Model 3Bi results for employee data.

It is notable that, to date - as shown in Chapter 2-most linear models of engagement, such as Saks (2006) position job engagement and organisation engagement as mediator variables/predictor. However, in this data the employee good fit models (3Aii and 3Bi) show job engagement and organisation engagement as outcome variables. Finally, as Models 3Aii and 3Bi showed a good fit for employees, these two models were combined to create Model 3C (Figure 26).

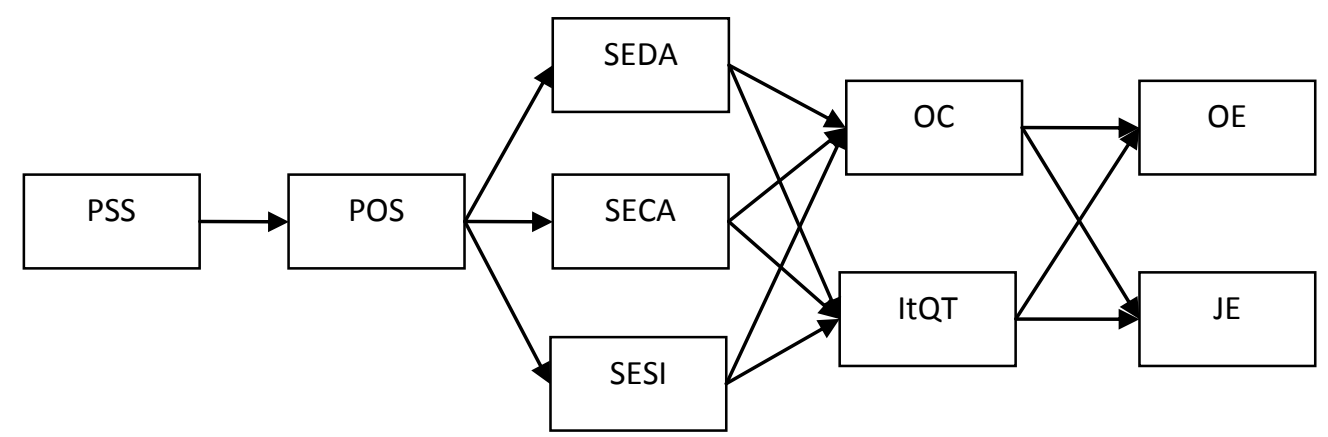

Figure 26. Additional model testing combining Model 3Aii and 3Bi-Model 3C.

The results did not show a good model fit, $\chi^{2}(21)=116.92, p<.001$, CFI $=0.79, \mathrm{TLI}=0.64, \mathrm{RMSEA}=0.15$. Results of model $3 \mathrm{C}$ for employees are presented in Table 56. 
Table 56

Results from Models 3 C for Employees

\begin{tabular}{ccccccc}
\hline Model & $\chi^{2}$ & $D f$ & $P$ & CFI & TLI & RMSEA \\
\hline $3 \mathrm{C}$ & 116.92 & 21 & .001 & 0.79 & 0.64 & 0.15 \\
\hline
\end{tabular}

In summary, hypothesis 14 was partially confirmed. First, findings from the manager data confirmed all but two of the hypothesised associations and, as above, no well-fitting model was found in the manager dataset. Findings from the employee data confirmed all the hypothesised associations and also, as above, a well-fitting model (Model $3 \mathrm{Bi}$ ) was found whereby job engagement and organisation engagement were positioned as outcome variables instead of, as hypothesised, predictor variables.

\subsubsection{Proposition 4: Summary.}

The manager and employee data showed a poor fit for Model 1. Model 1 was based on the theory presented in Chapter 2 that proposed in each model perceived supervisor support would influence perceived organisational support as antecedent measures of engagement. Furthermore, in Model 1A, connect-act and disconnect act would be mediators between job and organisation engagement; and organisational commitment and the intention to quit as outcomes of engagement. In contrast in Model 1B, job and organisation engagement were proposed as mediators between stress-immobilise and organisational commitment and the intention to quit as outcomes of engagement.

As these models showed poor fit model generation ensued based on findings from engagement studies that did not find support for the Saks (2006) model. For example, Shuck (2010) had found engagement and affective commitment as predictors of intention to turnover. More recently, Judhi et al. (2013) found organisational engagement and organisational commitment as mediators of human resources practices and the intention to quit/turnover.

As a result of model generation, in the employee data, two good fit models were found (Model 3Aii and 3Bi). In these pathways, as proposed, perceived supervisor support influenced perceived organisational support in both good fit models (Model 3Aii and Model 3Bi) which in turn in influenced manageremployee social engagement strategies. However, not proposed: (a) social 
engagement strategies influenced organisational commitment and the intention to quit/turnover (that is, an employees' intention to be in a working relationship with the organisation); and (b) organisational commitment and the intention to quit/turn over mediated between these strategies and states of mind about engagement, as outcome measures.

In addition, when the two well-fitting employee models (one with connectact and disconnect-act as independent variables; and one with stress-immobilise as an independent variable) were tested as one model, the model fit was poor. This suggests that in the employee data, connect-act and disconnect-act work differently in relation to the antecedent, engagement and outcome variables, from stress-immobilise.

These good-fit models add support to Eisenberger et al. (2002) who found that perceived supervisor support influences perceived organisational support (because supervisors are frequently identified as representing the organisation). In the employee data, as hypothesised, perceived organisational support mediated between perceived supervisor support and the stress-immobilise strategy, however, findings also showed that perceived organisational support mediated between perceived supervisor support and the connect-act, and disconnect-act strategies. This new pathway could be suggesting that for some employees their overall relationship with their supervisor, affects how they view their organisation which in turn influences their use of social engagement strategies.

Overall, the goodness of fit models indicate that perceptions of the manager-employee relationship influence other internal experiences related to employees' intention to be in a working relationship with the organisation (their organisational commitment and their intention to quit/turnover) and these in turn might be influencing attitudes about engagement. By implication, these findings could be suggesting that a focus on employee perceptions of their supervisor and their organisation may be a critical port of entry to understanding the interplay between variable use of social engagement strategies, states of mind about engagement, and engagement. However, these possible meanings about the data need to be further explored in future research.

Turning now to the manager data, while inclusion of the social engagement strategies strengthened the models, the overall pathways were not a good-fit with the data. These findings suggest that other factors, specific to 
managers need to be further considered. To begin this exploration, I take into account three interrelated findings. First, a possible imbalance between managers activating secure base provision and secure base use strategies (as indicated in the scale development process. Second, based on the correlation findings pertaining to social engagement strategy preferences and perceived organisational and supervisor support, variable use of social engagement strategies may influence the source of support which is primarily sought: such as external organisational factors or interpersonal relationships. Third, mediation findings showed use of the secure-act strategy (partially and fully) mediated between job and organisation engagement, and organisational commitment and the intention to quit/turnover; and job and organisation engagement (partially and fully) mediated between use of the stress-immobilise strategy and organisational commitment and the intention to quit/turnover.

Collectively, these findings could be suggesting that for some managers, focusing specifically on variations in social engagement secure base use strategies may be a critical port of entry to understanding: (a) their unique role as agents of increasing engagement in their organisations; and (b) their experiences of engagement, and possibly their engagement. Keeping these possibilities in mind, these pathways will be furthered explored in the manager-employee dyad case studies.

\subsection{Intermediary Research Phase}

Consistent with sequential explanatory mixed methods design (Creswell \& Plano Clark, 2007) an intermediary research phase was implemented following the survey study and before conducting the manager-employee dyad case studies. This phase was important because, as Armstrong (2007) stated, 'no one has shown that the applications of tests of significance improve decision making or advance scientific knowledge' (p. 335). As such the findings above, while of interest, cannot be used directly to inform managers and employees about their day-to-day endeavours to maintain and or increase engagement. Therefore, to increase the ecological validity (Schmuckler, 2001) of the survey study findings they were: (a) summarised to answer the first sub-research question; (b) examined in light of the 
limitations of the survey study; and then (c) examined to address the intermediary research phase guiding questions (outlined in Chapter 3, Section 4).

\subsubsection{Summary of Findings.}

Statistical results from the survey study were used to answer the first research sub-question. A summary of the findings pertaining to addressing subresearch question 1 are presented in Table 57.

Findings showed that the manager-employee social engagement scales were reliable and uniquely statistically significant contributors to mind states of engagement and engagement related factors. Overall, the above findings extend current linear models of engagement by: (a) adding different qualities of social engagement via the manager-employee social engagement strategy scales to the picture of engagement; and (b) providing two new engagement paths to consider for employees, situating job engagement and organisation engagement as outcome variables, and organisational commitment and intention to quit/turnover, and the manager-employee social engagement variables as antecedents. These findings extend existing models of engagement that predominantly show job engagement and organisation engagement as mediating variables between antecedent and outcome factors (Saks, 2006; Shuck et al., 2011).

\subsubsection{Limitations.}

The above results should be considered in light of their limitations: crosssectional data, snowballing, self-report data and non-relational data. First, similar to many engagement studies (e.g. May et al., 2004; Reed, 2011; Rothbard, 2001; Saks, 2006; Schaufeli \& Bakker, 2004) cross-sectional, concurrent data were used. Cross-sectional data can be used to identify associations between measures, but not the direction of the association. Optimally, longitudinal data are required to make assertions regarding the direction of the association between measures. 
Table 57

Summary of results from survey study propositions about sub-research question 1

\begin{tabular}{l} 
Proposition \\
\hline P1: There will be an \\
association between \\
MESEs and the RQ \\
P2: There will be an \\
association between the \\
manager-employee \\
social engagement \\
strategies and \\
engagement related \\
concepts.
\end{tabular}

P3: Model 1 will better predict engagement and engagement-related outcomes than Mode1 2.

Managers and employees: Finding

The MESE strategies were associated to the RQ classifications:

SECA to RQS

SEDA to RQDA

SESI to RQP

Managers only:

SESI with most highly associated to RQAF.

Managers and employees:

SECA was positively associated to JE, OE, and OC and negatively associated to ITQT

SEDA was negatively associated to OE

SESI was positively associated to POS, PSS and ItQT, and negatively associated to JE, OE and OC. Managers only: SECA was negatively associated to POS and SEDA was positively associated to POS. Employees only: SEDA was positively associated to OC.

Managers and employees:

Neither model was a good fit but Model 1 fitted the data better overall than Model 2.

Both models indicated JE and OE as the DV, not the IV.

P4: Within Model 1, connect-act and disconnect-act will work differently from stressimmobilise in relation to engagement.

Managers:

SECA mediated between: JE and OC; JE and ItQT;

OE and OC; OE and ItQT.

Employees:

SECA mediated between JE and OC; OE and OC.

Employees only:

A good fitting model with JE and OE were the DV's: $\mathrm{PSS} \rightarrow \mathrm{POS} \rightarrow($ SEDA \& SECA $) \rightarrow(\mathrm{OC} \& \mathrm{ItQT})$ $\rightarrow(\mathrm{JE} \& \mathrm{OE})$.

Managers \& Employees:

SESI mediated between: POS and JE; and POS and OE.

JE mediated between SESI and OC

OE mediated between SESI \& OC; and SESI \& ItQT

Employees only:

POS mediated between PSS \& SESI

JE mediated between SESI \& ItQT.

Employees only:

A good fitting model with JE and OE were the DV's: $\mathrm{PSS} \rightarrow \mathrm{POS} \rightarrow(\mathrm{SESI}) \rightarrow(\mathrm{OC} \& \mathrm{ItQT}) \rightarrow(\mathrm{JE} \&$ $\mathrm{OE})$. 
Second, the use of a snowballing sampling approach ensures difficulty in generalising these findings beyond the $\mathrm{NZ}$ manager and employee population. Third, all measures in the study were self-report measures of mind states pertaining to engagement, in contrast to observations of engagement behaviour. Fourth, the survey data, while indicative of relationships, is individual level data and not interpersonal data. In summary, all of these collection methods are vulnerable to issues of method bias, and as such limit the scope of conclusions that can be made regarding the results.

Further, the analytical tools used have limitations on the scope of conclusions. Correlation and path analysis results indicate an association between the manager-employee social engagement strategy measures and other engagement related measures, but do not indicate causal relationships between the measures. While each analytical tool aims to progressively construct more complex linear statistical models; but none are tests of causality. In addition, measurement errors can occur within surveys from several sources: systematic and/or random errors. Path analysis was conducted to account for random measurement errors possible in the inferential, correlation and mediation analysis. As a result, findings regarding the manager-employee social engagement variables further support the engagement literature placing the manager-employee relationship as a central driver of engagement, but they do not explain why MESE is associated with engagement.

\subsubsection{Key findings for qualitative review.}

The mixed methods design of this study presented an opportunity to address some of these limitations. As such, in preparation for Phase 2 of the study (the manager-employee dyad case studies), the intermediary analysis questions described in Chapter 3 (Section 4) were addressed. Three major findings pertaining to: (a) demographics; (b) manager-employee social engagement as strategy as a measure; and (c) models of engagement, were identified.

\subsubsection{Demographics.}

Demographic data is often underplayed in engagement studies, as evidenced by the limited number of studies that describe and analyse this data in 
association with their engagement findings. However, demographic data is a potentially untapped source of engagement data that could explain engagement states of mind. To illustrate, in the NZ MESE study manager data, age was significantly negatively (small) correlated with JE $\left(r_{s}=-0.13, p<0.05\right)$ and intention to quit/turnover $\left(r_{s}=-0.21, p<0.01\right)$, indicating that as the age of managers increases, job engagement and intention to quit/turnover scores decrease. In the employee sample, results also showed a significant positive (small) correlation between age and organisational commitment scores $\left(r_{s}=0.13\right.$, $p<0.05$ ), suggesting that as the age of employees increases, organisational scores increase as well.

Further, gender and ethnicity were non significant co-variants to the variables of interest. However, these findings need to be considered in conjunction with the overall demographic of the sample, where there was: (a) a gender imbalance in the employee data, with the majority of participants being female; and (b) an ethnicity bias across both data sets, with the majority of participants being NZ Europeans. Therefore the non significant finding for gender and ethnicity may reflect NZ Europeans but not necessarily other ethnic groups such as Maori or Pacific Islander.

Comparing this sample with other engagement studies highlights an understudied research space between demographics and the analysis of engagement data. For example, the Saks (2006) study $(\mathrm{N}=109$, average age 34 with $60 \%$ percent female participants) did not report the effect of demographic factors in association with the variables of interest. Judhi et al. (2013) reported a sample size of 457 respondents, of which 55 per cent were female, and 46 per cent aged between 21 and 30 years. This study was conducted in Malaysia, but ethnicity data was not reported and demographic analysis with the variables of interest was not reported. In the Reed (2011) study $(N=523)$, the cultural demographic was described as diverse but was not specified. Finally, the Shuck (2010) study (N= 283) comprised 53 per cent female and 33 per cent male, with most participants aged between 20 and 59 years. This study further analysed the demographic data with similar findings reported to the NZ MESE study sample. For example, Shuck (2010) reported that the Wilk's lambda criterion indicated: (a) age to be a significant covariant to the intention to quit variable, with the younger participants (aged 20-29) scoring lower means on this variable than those in the 30 to 39 and 
40 to 49 age groups; with (b) no significant group differences between ethnicity and gender.

Much remains to be learnt about the role of demographics in association with engagement. For example, it seems counter-intuitive to not explore a possible relationship between ethnicity and engagement, even though these factors appear to be statistically non significant. Further, it is possible to assume the association between ethnicity and engagement might be better understood via a mixture of methods, rather than the survey method alone. As such, in the manager-employee dyad case studies, demographic data pertaining to age, ethnicity and gender was analysed using both survey and qualitative data.

\subsubsection{Manager-employee social engagement.}

The findings above show an association between states of mind about attachment generally and states of mind pertaining to the secure base system in workplace relationships. This suggests that understandings about the individual use of manager-employee social engagement strategies and engagement states of mind can be drawn from these findings. Doing this extends the current application of attachment theory workplace research from: (a) a personality-oriented focus on the two-dimensional model of attachment (Game, 2011; Harms, 2011) and/or a global categorical approach, such as that used by Hudson (2010); to (b) one that examines states of mind pertaining to the secure base system within workplace relationships.

For example, it is possible to consider that managers and employees variously use the manager-employee social engagement strategies across different parts of the secure base system (help seeking, help provision and exploration). For example, they might favour a connect-act strategy for secure base use and a disconnect-act strategy for providing support to others.

This possibility is further highlighted by reviewing the manager-employee social engagement scales (stress-immobilise, connect-act and disconnect-act) in conjunction with the Relationship Questionnaire. For example, in the manager data, as expected there was an association between: stress-immobilise and preoccupied. However, a significant association was also indicated between stress-immobilise and fearful-avoidant; and stress-immobilise and dismissing- 
avoidant. In the employee data, as expected there was a significant association between: stress-immobilise and preoccupied. However, significant associations were also found between stress-immobilise and secure and stress-immobilise and fearful-avoidant. These unexpected differences could point to a greater degree of adaptability in workplace relationships (than identified in previous research) across (a) the two dimensions of attachment: anxiety and avoidance (Bartholomew \& Horowitz, 1991; Griffin \& Bartholomew, 1994a, 1994b); (b) the use of categorical attachment patterns (a categorical approach); and as already suggested, secure base use and provision.

Moreover, a small significant difference was shown in the manager data between (a) stress-immobilise and connect-act; and (b) connect-act and disconnect-act. In the employee data, a small and significant difference was shown between stress-immobilise and disconnect-act, with a large significant inverse association between stress-immobilise and connect-act. These associations are examined in Chapter 5 and Chapter 6, based on the data available across the case studies.

In addition, across both data sets, stress-immobilise and stress-immobilise (conflict) statistically indicated they were likely measuring the same construct. This finding will be further examined in light of the social data pertaining to the secure base system, where theoretically stress-immobilise captures the whole system and stress-immobilise (conflict) taps secure base provision in the presence of conflict; and stress-immobilise (secure base use) primarily taps the secure use when under pressure. Social data from case study 5 was specifically used to explore this finding further.

In summary, the statistical data indicates the possibility of variable strategic use but does not show how and when participants might variously use the different manager-employee social engagement strategies, and/or the manageremployee social engagement components within each strategy or across strategies. An examination of how and when participants used different manager-employee social engagement strategies was conducted using data from the manageremployee dyad case studies. 


\subsubsection{Manager-employee social engagement models of engagement.}

The inclusion of the manager-employee social engagement variables in the engagement models highlighted a new statistical picture of engagement: both manager and employee models showed a better fit with the inclusion of manageremployee social engagement variables. Current models of engagement typically represent the extent to which workers perceive they are engaged (Judhi et al., 2013; Lee, 2012; Saks, 2006; Yalabik, Popaitoon, Chowne \& Rayton, 2013) Alfes et al. (2010) also differentiates between the extent and frequency of engagement. The manager-employee social engagement models of engagement add factors pertaining to states of mind in relation to qualities of interaction when under pressure, to the existing picture of extent and frequency of engagement.

For example, Table 42 illustrates that each manager-employee social engagement strategy formed a unique pattern of significant and non significant statistical associations with the engagement-related variables. These findings add to the current picture of the internal dimension of engagement. They suggest different qualities of social engagement are connected with different mind states of engagement. In turn, these findings can be used to explore the interpersonal and external dimensions of engagement. Such, these findings will be further examined in the case studies, where patterns in the statistical data can be viewed and examined along with the social data pertaining to interpersonal exchanges and descriptions of engagement.

Unexpected findings between perceived organisational support, job engagement, and organisation engagement were noted and discussed in brief above. Previous studies have confirmed a significant and positive association between perceived organisational support and: (a) work engagement (Leiter \& Bakker, 2010); and (b) job engagement and organisation engagement (Biwas \& Bhatnagar, 2013; Saks, 2006). However, the findings in the NZ MESE survey did not show a significant association between perceived organisational support, job engagement and organisation engagement.

Overall, these findings guided the analysis of the case study data, in contrast to the design. The case studies were designed to address the overarching question within an interpersonal context, guided by sub-research Question 2: what can be understood from managers and employees who work together about their 
experiences of engagement in association with their relationship? The case studies focused on the participants' experiences of the phenomenon under study and provided a qualitative lens through which to understand these key statistical findings.

\subsection{Chapter Summary}

This chapter presented the findings concerning (a) manager-employee social engagement as a new scale and (b) the statistical relationships between manager-employee social engagement and the other variables of interest. The scale development findings suggested that manager-employee social engagement was a measurable variable represented by three primary scales: stress-immobilise, connect-act and disconnect-act. In turn, each manager-employee social engagement scale showed a unique pattern of statistical relationships with the other variables of interest. The results suggested that states of mind concerning the quality of social engagement might be influencing engagement states of mind, and in turn possibly engagement behaviour. Further, while there were problems with model fit in the manager data, the overall statistical picture indicated that stress-immobilise, connect-act and disconnect-act with job engagement and organisation engagement was a better predictor of organisational commitment and intention to quit/turnover, than job engagement and organisation engagement alone. Next, Chapter 5 draws on these statistical results by using the manageremployee social engagement survey with manager-employee dyad case studies, within which the manager-employee social engagement strategy variable and its respective scales were used as a springboard to explore the interpersonal context of engagement. 


\section{Chapter 5: MESE Strategy Case Study Findings}

Five manager-employee dyad case studies were conducted between November 2011 and May 2012. Each case addressed the primary research question and the second sub-research question. This chapter outlines the manageremployee social engagement strategies that each case participant and each case dyad used and examines these in relation to engagement states of mind and behaviour. The manager-employee social engagement and engagement framework (Chapter 2, Section 7) and the intermediary analysis (Chapter 4, Section 4) provided a structure from which to present each case.

I begin by providing an overview of the cases. Next, findings from each case are presented, moving from Case Study 1(CS1) through to Case study 5 (CS5). This sequence reflects industry clusters across the cases. Case study 1 and 2 were conducted in two similar community service, Non Government Organisations (NGOs); case study 3 and 4, in a government agency; and case study 5 , in a private sector professional services firm. The chapter concludes with a chapter summary.

\subsection{Introducing the Manager-Employee Dyads}

Case study participants represented a diverse range of industries: NGOs, the government sector and the private sector. Participants included four male and one female employee, and four male and one female manager. Participant ages ranged from 30 to 65 years. One participant identified as Maori, seven as NZ European, and two as Samoan (See Table 58).

The anonymity of participants was assured via the use of pseudonyms and participant codes. The pseudonyms were chosen to reflect each participant's ethnicity. For example, the employee who identified as Samoan in Case Study 1 is referred to as Sione (CS1E) and the manager, who identified as Māori, is referred to as Hemi (CS1M). The pseudonyms are used to report participant data within each of their respective case studies, and codes are used to refer to the participant data across the case studies and in the discussion. 


\section{Table 58}

Case Study Sample Demographics

\begin{tabular}{|c|c|c|c|c|c|c|c|c|}
\hline Case & Age & Gender & Ethnicity & Type of organisation & Type of work & Contact frequency & $\begin{array}{c}\text { Time worked } \\
\text { together }\end{array}$ & Pseudonym \\
\hline CS1E & 38 & $\mathrm{M}$ & Samoan & $\mathrm{NGO}$ & Social Work & 20 hours per week & 2 years & Sione \\
\hline CS1M & 45 & M & Maori & NGO & Social Work & 20 hours per week & 2 years & Hemi \\
\hline CS2E & 50 & $\mathrm{~F}$ & NZ European & NGO & $\begin{array}{l}\text { Frontline Social } \\
\text { Service work }\end{array}$ & Daily: 4 days per week & 8 months & Abby \\
\hline CS2M & 65 & M & NZ European & NGO & $\begin{array}{l}\text { Frontline Social } \\
\text { Service work }\end{array}$ & Daily: 4 days per week & 8 months & Peter \\
\hline CS3E & 30 & M & Samoan & Government & Info Tech & Mostly daily & 3.5 years & Rangi \\
\hline CS3M & 40 & M & NZ European & Government & Info Tech & Mostly daily & 3.5 years & George \\
\hline CS4E & 52 & M & NZ European & Government & Economics & Daily & 6 years & James \\
\hline CS4M & 35 & $\mathrm{~F}$ & NZ European & Government & Economics & Daily & 6 years & Amy \\
\hline CS5E & 36 & F & NZ European & $\begin{array}{l}\text { Private: Professional } \\
\text { Services }\end{array}$ & Accounting & Mostly daily & 10 years & Cathy \\
\hline CS5M & 46 & M & NZ European & $\begin{array}{l}\text { Private: Professional } \\
\text { Services }\end{array}$ & Accounting & Mostly daily & 10 years & Donald \\
\hline
\end{tabular}

Notes. Case Study (CS); Manager (M); Employee (E); Non Governmental Organisation (NGO); New Zealand (NZ). 
The focal context for each case was the social engagement relationship between a manager and employee as they worked towards organisational goals under work conditions of stress/pressure. In each case, this unique focal context was influenced by a shared national and global context: a global recession. Across cases and industries, participants talked about the effect of the global recession on job choice:

Jobs don't come easy ... People are saying 'I want to quit, but I'm going to be here' ... but they realise they're not going anywhere ... jobs aren't that easy to get, they're downsizing everywhere, we're in a recession. (CS4M)

The recession had also affected job demands:

'Front line social work has had an increasing demand for emergency housing and food bank services'. (CS2M)

Further, the recession had affected job demands and organisational culture: Job security in the private sector is tenuous and it's been tough downsizing loyal staff, and then asking those remaining to do more work, with less resources and support. $(\mathrm{CS} 5 \mathrm{M})$

\subsubsection{Case Studies: Part one.}

As described in Chapter 3, the case studies were conducted in two parts. Part one involved each participant completing an adapted version (as detailed in Chapter 3) of the manager-employee social engagement survey and then participating in an individual interview. In this interview each participant explored their individual survey scores in relation to the NZ MESE study findings. For example in case study 1 , the first individual interview was conducted with Sione (CS1E) within which only his individual survey scores (and not Hemi's) were examined in relation to the NZ MESE employee survey scores. In the next interview with Hemi, only Hemi's individual survey scores were examined in relation to the NZ MESE manager survey scores. Table 59 presents an overview of the case study participant survey information alongside the NZ MESE survey study means for managers and employees. 
Table 59

Case Study Survey Data

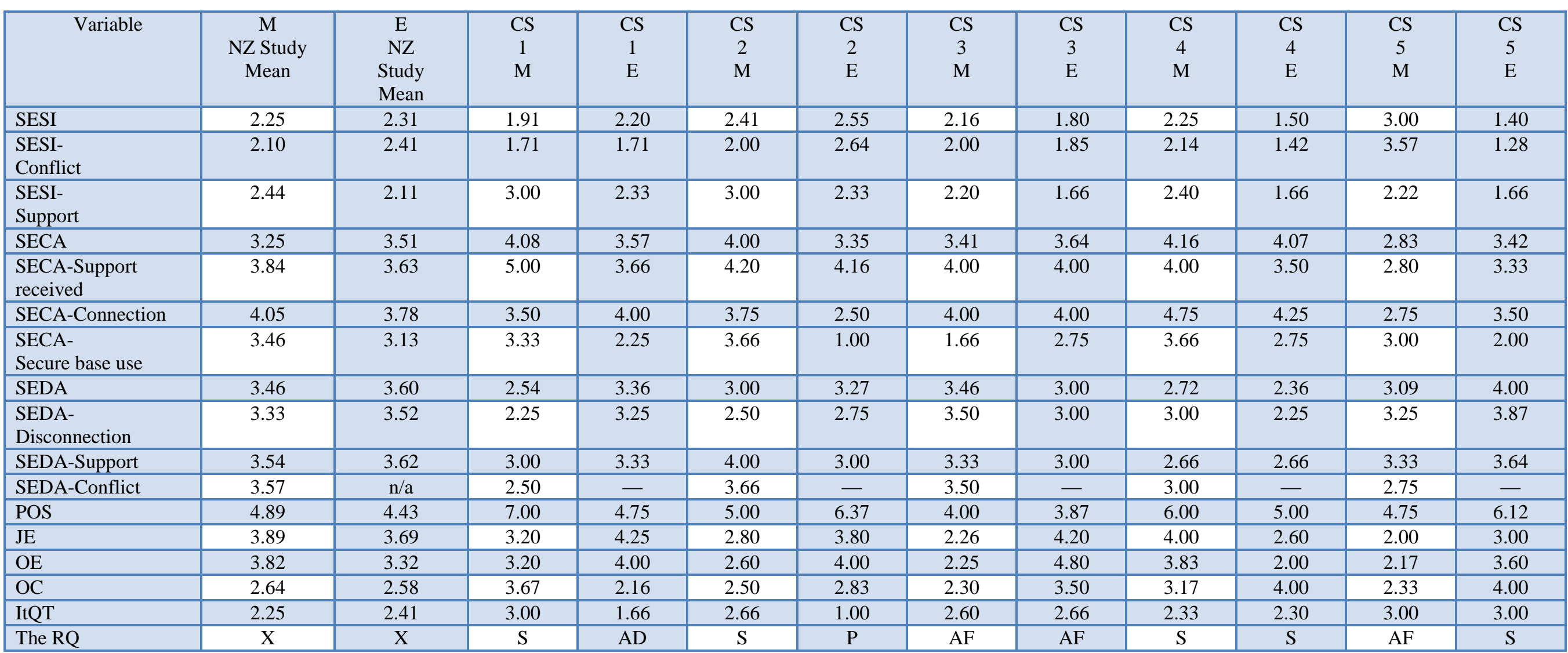

Notes. Manager (M); Employee (E); Case Study (CS). The RQ score is provided as a category rather than a mean. 


\subsubsection{Case Studies: Part two.}

Part two of the case studies involved manager-employee dyad interviews. In preparation for these interviews, each participant reviewed and then consented to share with the other person in the dyad (a) their survey findings, and (b) a summary of their individual interview. Data from the other cases were not included. For example, in case study 1 , the shared data for examination in the dyad interview included survey findings from Sione and Hemi, and Sione and Hemi's individual interview summaries. In the interviews, the shared data was used as a springboard to explore experiences of interaction within the dyad, in conjunction with their engagement behaviour.

\subsubsection{Reporting of findings: Structure.}

Each case study is presented using the same structure where I:

1. Introduce the manager-employee dyad.

2. Provide an overview of their survey scores.

3. Present individual and dyadic experiences of the manager-employee social engagement strategies used in that case.

4. Show connections where possible between the manager-employee social engagement strategies, states of mind about attachment and engagement, and engagement behaviour.

Across the cases, social data pertaining to the associations between manager-employee social engagement and the relationship questionnaire, manager-employee social engagement and perceived organisational support, and job engagement and organisation engagement was readily available; social data concerning the association between the manager-employee social engagement strategies, organisational commitment and the intention to quit/turnover was least available. As such, each case addresses the second sub-research question, based on the data available from that case, concluding with its unique contribution to addressing the research questions. Of note, the individual and dyad interview data for case study 1, 2, 4 and 5 (case study 3 has only individual level data) is presented in combination, to best represent a unique case-by-case view of the 
connections between the manager-employee social engagement strategies and engagement.

\subsection{Case Study 1: Hemi and Sione}

Hemi (CS1M: manager) and Sione (CS1E: employee) worked together in a community social service NGO providing services such as: emergency housing, budgeting and community counselling. Hemi, 45 years of age and Maori, had been a manager for a number of years and was currently a senior manager at Francis House $^{2}$. He managed a staff of paid employees and volunteers, as well as multiple stakeholder relationships with the Ministry of Social Development, Ministry of Justice and a variety of local government and NGOs. Sione, 38 years of age and Samoan, was a social worker and had been an employee at Francis House for three years, within which time he had worked closely with Hemi on a number of shared team projects. For this dyad, as evident in their descriptions below, an awareness of culture was central to their experiences at home and at work.

The direct effects of the economic recession within this organisation included a spike in client demand for housing and food bank services and in the number of referrals related to domestic violence. Staff had been experiencing added stress as they endeavoured to balance organisational and stakeholder goals with clients who were increasingly stressed. For example, Sione talked about added external pressure arising from client demands and from organisational stakeholder requests to use organisational processes that were a poor match for meeting client needs:

It's about government agencies telling us how to run our houses; it doesn't work that way. We're providing a service, because we have a goal in mind, but all they want us to do is a little bit. But we're not about just this little bit, we're about the holistic person. It's stressful realigning with what we're about all the time. (Sione)

\subsubsection{Manager-employee social engagement survey patterns.}

Hemi identified connect-act as his primary manager-employee social engagement strategy, with a relationship questionnaire categorical rating of secure and higher levels of organisational commitment. This pattern of scores was consistent with scores from the NZ MESE survey findings, where connect-act was

\footnotetext{
${ }^{2}$ A pseudonym for the organisation.
} 
highly associated with secure (RQS) and higher levels of organisational commitment. However, he also scored above the mean for perceived organisational support and intention to quit/turnover, and lower than average means for organisation engagement and job engagement. When grouped together, these scores mirror a similar score pattern found in regard to disconnect-act (see Table 42). Collectively, these scores indicate a stated preference for connect-act strategies, with the possibility of disconnect-act as a secondary strategy.

Sione's scores also indicated the possibility of a combined use of connectact and disconnect-act strategies. Sione identified connect-act as his primary strategy; consistent with this he scored above the mean for job engagement and organisation engagement, and below the mean for intention to quit/turnover. However, he also identified a relationship questionnaire categorical rating of dismissing-avoidant which was associated with disconnect-act and not connectact. In addition, he scored above the mean for perceived organisational support and below the mean for organisational commitment. Similar to Hemi, these scores indicate an overall stated preference for connect-act strategies with the possibility of disconnect-act as a secondary strategy.

Further, this case provided data from which to examine the following issues from the intermediary analysis: (a) demographics with regard to ethnicity; and (b) the hypothesised association between connect-act and higher levels of perceived organisational support. These statistical findings will now be examined with the social data provided by Hemi and Sione pertaining to: (a) their manageremployee social engagement experiences, including descriptions of the strategies and of the associations between these strategies and the relationship questionnaire; and (b) manager-employee social engagement strategies and engagement-related strategies.

\subsubsection{Manager-employee social engagement experiences.}

Hemi described his interactions at work in ways that elaborated on the connect-act, and disconnect-act strategies. Sione described his experiences in ways that elaborated upon a mixed strategy. This included the use of disconnectact and stress-immobilise strategies, that had been adapted over time to connectact strategies, as a result of interactions with Hemi at work, and his wife at home. 


\subsubsection{Connect-act.}

Reflecting Hemi's overall use of this strategy he said:

I think culturally as Maori sometimes I think we talk too much, and not enough action, but I understand the importance of working through something together so we can get the job done. (Hemi)

If we're going to manage people we need to have feelings. It's about building good relationships with people. I'd rather build a relationship with someone first, before I give them a task to do, because I need to know how they tick and what works for them, and what doesn't work for them. (Hemi)

When you connect with people about what's happening at home it gives you a better understanding of what's happening at work. I learnt that very, very quickly, to find common ground. (Hemi)

Whanaungatanga is everything. It's not just work, it's home, school, play; it's the whole thing. (Hemi)

\subsubsection{Disconnect-act.}

Reflecting this strategy, Hemi said that when he got really stressed, the job could override his relationships with staff:

Just focusing on the job we can forget to turn behind us and look at the devastation we sometimes cause to others when we're trying to get the job done. (Hemi)

\subsubsection{Shifting from disconnect-act to connect-act.}

In turn, Hemi described how he would catch himself at these times and focus on relationship repair with the staff, to bring things back into a connect-act oriented working relationship:

Sometimes we leave our feelings at the door. We've got to go back out and say, 'Oh I've left my feelings at the door, I need to go back', and you know it is about being able to say, 'Hey, I didn't really like the way I spoke to you yesterday'. (Hemi)

I make mistakes, too. It's about me putting them right. We can be focused too much on getting the job done. (Hemi)

\subsubsection{Stress-immobilise and connect-act (connection).}

Hemi scored above the mean for the stress-immobilise strategy (support), which captured support seeking, and he scored above the mean for the connect-act (support) strategy. He also scored below the mean for connect-act (connection). Together these scores, in conjunction with his overall connect-act strategy, indicated a possible mixed strategy for secure base use and provision, especially at times of conflict. Hemi (and Sione, when talking about his experience of Hemi 
as a manager, see below), described that the stress-immobilise strategy was more reflective of his past, and use of the connect-act strategy reflected his present experience as a manager with staff. For example, Hemi said: 'Do I like dealing with conflict? No'.

However, over time he had learnt to manage his dislike of conflict as a manager. He talked about how he now placed his relationship with staff over his personal dislike of conflict by:

Dealing with conflict straight away, soon as I hear about it or see it. 'We need to talk'. (Hemi)

Hemi also described how he dealt with conflict while supporting others:

For me it is about relationship, but not waiting 'til conflict comes. I think you've got to master the art of seeing when conflict's ready to come, and that's a hard thing to do. (Hemi)

I think there's a balance. People know that you're going to deal with conflict, and they know that you're going to support them. (Hemi)

Further reflecting a connection between the connect-act strategy and an autonomous state of mind about attachment, Hemi also seamlessly talked about his family of origin without any prompting:

I also think that being available to your staff at all times... like my father, always had the office open, the same thing for me. Even if I'm busy doing something, I will make the time to sit down, to talk. They can come in and out when they want to, and that we're able to talk, and sometimes that's only a thirty second conversation. (Hemi)

\subsubsection{Disconnect-act and stress-immobilise meets connect-act.}

Like Hemi, Sione described how over time he had changed the way he related to people when under pressure. For example, describing experiences that best fit in the disconnect-act strategy he said:

When I am stressed sometimes it comes out pretty sharp, pretty blunt, it's not sugar coated. I think it's very effective, but it's not. (Sione)

In conjunction, at these times, at work he was likely to tell himself:

Nah, I'm fine, I'm fine, just do your job. (Sione)

Then when he got home from work, he told himself:

I realise yeah, I've let it get to me. (Sione)

I'm not fine. It manifested itself at home, but it was there the whole time at work. I don't think I've taken it on here at work but when things aren't good at home, I then realise I had shut it off at work. (Sione)

Then it's like, well how did that get from here to there sort of thing, you know? (Sione) 
In addition, reflecting his higher score for stress-immobilise (support), he described sometimes responding to high levels of pressure at work with high stress, with compromised concentration on job combined with an inability to make optimal use of support to get back into work:

When I am at work and get really stressed, I am so overwhelmed with feeling it; it's hard to think about anything else. (Sione)

We've got a strategy for stuff, but then, when I get really stressed, that goes out the window, too. (Sione)

He then described a change from the combined use of disconnect-act and stress-immobilise strategies to ones that he described that reflected connect-act strategies. He described these changes as a result of his interactions with his wife and with Hemi; like Hemi, he seamlessly introduced aspects of his family life into his work oriented conversations.

Regarding his relationship with Hemi, he described how he helped Hemi align with connect-act strategies, and that this had shaped his engagement behaviour as an employee. Sione talked about the quality of help he received at these times in ways that reflected his higher scores for connect-act (support received). He described how his interactions with Hemi, at these times, were pivotal in helping resume his typically high engagement behaviour:

With just a little bit of his time, I am good to go and get back to my work. (Sione) He also talked about how his interactions with his wife at home helped him at work: Laura my wife ... I've got friends that I text, too, who keep me accountable to that. I've got a support network, who are there for me. (Sione)

Further, Sione illustrated receiving this quality of help from Hemi and Laura. In turn, this helped him reconnect with others and the job at work (connectact (connection)):

I'm focused on the person and the task, and so I might talk about it. This is what's going on. This is how I'm thinking about it, and how I want to deal with it. (Sione)

An examination of the relationship questionnaire score in conjunction with their manager-employee social engagement scores provides insight into the different interactive pathways that Hemi and Sione took when under increasing pressure and stress.

\subsubsection{Connect-act and secure attachment.}

Hemi's manager-employee social engagement and relationship questionnaire scores made sense to him as he spontaneously referred to his parents 
saying his dad's style fitted the description for the connect-act strategy, whereas his mum more commonly used a disconnect-act strategy:

My parents were busy people, but they always had time for us. If we had something that was on our minds, we would talk about it with our parents. My mother was very 'yes or no, let's get it done and carry on with it', but my father would listen, input and then leave the decision for us. 'This is what I think'. 'You've got to make a decision'. (Hemi)

Hemi talked about how he had especially tried to develop his father's approach in his own relationships with his family and at work:

I want to empower people to do what they feel is right, if they get it wrong, that's okay. I want to see people grow in who they are 'It's all good to make mistakes'. 'No one's going to come down on you'. (Hemi)

However, he was aware that when he got very stressed at work he was likely to draw more on his mum's approach:

One of the things I constantly work on and watch is my patience; I can reach [the end of] my patience with things. That's normally what brings on my stress. I'm normally a patient guy, but when people don't do what I'm asking them to do, then I tell them straight; more my mother's style, yes or no. I'm trying to work on this cos staff may be a little bit afraid to approach me. So there's some development things around there for me. (Hemi)

\subsubsection{Disconnect-act and dismissing-avoidant attachment.}

Similarly, Sione's manager-employee social engagement and relationship questionnaire scores made sense to him:

There's Sione in there, all right, and I recognise my cultural side and also that I'm married to a palagi ${ }^{3}$. (Sione)

He talked about getting into trouble with the law when he was growing up. He did community service (a sentencing option for persons convicted of crimes) and then made a fresh start. He used the language of delivery to describe the changes in his mode of communicating with others when under stress. He said he was now committed to using connect-act strategies, but acknowledged that he was still working on being consistent with this, as he balanced his Samoan family's approach to stress while he was growing up, with how he wanted to be as a husband and dad in his Samoan-Palagi family:

I think there's my upbringing and my culture [Samoan] and my home, being married to my lovely wife Laura. When I was growing up what dad says is what's gonna happen and that's the way it is, but after 14 years of marriage I'm still learning to talk and listen differently. I can find myself getting into the cultural side being like dad, then it's

\footnotetext{
${ }^{3}$ Palagi is a Samoan term for a person of European descent. Laura, Sione's wife, is a New Zealand European.
} 
understanding what its about and being able to slow things right down and have a look at it. The right delivery is so important for me. (Sione)

Sione described how he used his awareness of this to transition from using the disconnect-act strategy to one that entailed accessing more emotions at the time he was experiencing them at work, instead of later:

The stuff that's there [at work], often, you wait too late for it to be accessed so you can then go and get some help, rather than saying okay and acknowledging [the stressful stuff while at work] and getting help while I am there. (Sione)

It would be good to think about that a bit, [to] recognise the stress at that time and acknowledge stuff prior to letting it out [later at home]. (Sione)

Hemi and Sione managed their relationship strategically, to optimise their engagement, using interactions characterised as a connect-act and secure base use strategy for Sione, combined with a connect-act secure base provision strategy for Hemi. However, when under increased pressure, Hemi demonstrated that he sometimes unintentionally interacted with staff in ways that reflected the disconnect-act strategy (a strategy he linked to his relationship with his mother). In conjunction, he described how his overall secure relationships (RQS) appeared to function as a driver, anchoring him to the connect-act strategies. Similarly, under pressure, Sione described the intentional influence of his dismissingavoidant (RQDA) classification, linked to his childhood experiences of help and support, expressed in his current relationships in ways characteristic of a combined disconnect-act and stress-immobilise strategy. However, Sione also demonstrated he was able to draw on Hemi's connect-act secure base provision to align himself with his conscious current day connect-act interaction choices.

\subsubsection{Manager-employee social engagement and engagement experiences.}

Hemi explained that his overall job engagement and organisation engagement scores were lower than they had been, and his intention to quit score was also higher than it had been, because he was ready to leave his job and do something different: 'I'm at that stage, to go and run my own business' (Hemi).

As such, Hemi's engagement state of mind scores reflected his current work plans, and not his engagement behaviour, of which both he and Sione provided plentiful examples demonstrating high levels of engagement behaviour. In contrast, Sione's use of the connect-act interactions were reflected in his 
engagement states of mind scores, which indicated high levels of job engagement, organisation engagement, organisational commitment and low intention to quit/turnover.

\subsubsection{Connect-act and perceived organisational support.}

While the hypothesised positive association between higher levels of perceived organisational support and connect-act was statistically unconfirmed, Sione and Hemi's survey data and social data seemed to show a positive connection between higher perceived organisational support and connect-act type strategies. For example, Hemi described his positive experience of perceived organisational support as being connected to his experience of role clarity. In turn, he connected this with helping him sustain connect-act type secure base provisions to staff, assisting them to do their jobs better:

Coming here, there's lots of support mechanisms, lots of good management, good understanding, I know my role [but] the role is not the same as the relationship. (Hemi)

I'm a manager, that's a role and what I do in that role with staff is all about, about whanaungatanga. It's about respect while we work together to get the job done. (Hemi)

He further described the support he received within his organisation as person and relationship specific:

If I'm under stress I would talk to my manager and that's really to talk about the situation, to try and get them resolved... like "Am I on the right track?" or "am I just shooting off somewhere?"... so I can move back on with my task. I want to get a resolution around why I'm feeling this way so I can get back on and get the job done. (Hemi)

These descriptions were in stark contrast to his first experiences of perceived organisational support as a new manager in a different organisation, where he described low levels of perceived organisational support alongside selfdescriptions that did not reflect his connect-act descriptions:

In the beginning as a manager I was stressed, lost. I didn't know how to engage with people. You would have found a very stressed out Hemi in the first six months of my time. (Hemi)

I used to get sick quite regularly. Migraines. Still went to work though. It was very, very tough, and you had no one you could call on. That was the other thing, there was no - you get your manager up here, but they didn't really care. They're just "Oh! too hard for me. Go and sort your own thing. Don't bring that to me". (Hemi)

Similarly, Sione described his experience of higher levels perceived organisational support in relation to his use of secure base use strategies that fitted the emerging understanding of connect-act strategies: 
I like to get some reassurance about the direction I'm heading in. It's just bringing the idea to life. It's going from being able to talk, to doing it. Okay, cool. Now I know the direction I'm wanting to head in. There's a lot of everyone's saying, 'Look, you're not on your own'. (Sione)

Hemi is like 'Vicks Formula 44' with just a little bit of his time I am good to go and get back to my work. (Sione)

He also described his experience of perceived organisational support in his organisation in a person and relationship specific way, and he linked this support directly to doing his job better:

It's good to have my senior manager. I am able to say, I'm not sure about this, what do you think? [When I do this] I can get back to work and focus. (Sione)

In summary, Sione's interactions with Hemi using connect-act strategies seemed to contribute towards: (a) his engagement states of mind, summarised as higher levels of job engagement, organisation engagement, organisational commitment and lower levels of intention to quit/turnover; and (b) his engagement behaviour at work. Further, descriptions about their experiences of working together to sustain engagement captured a seamless interplay between unconscious and conscious elements, day-to-day purposeful interactions about how to get the job done and how they maintained their engagement behaviour during times of stress and pressure. For example, their descriptions of whanaungatanga, culture and family of origin experiences of the secure base system, combined with their current relationship, demonstrated the positive effect of social reparation at work to repair interactive errors (Tronick \& Beeghly, 2011, p. 112) when under pressure. Collectively, they formed a strategy that successfully maintained high levels of self-reported and observed levels of engagement behaviour in each of them.

\subsubsection{Case Study 1: Summary.}

Hemi and Sione used a mix of disconnect-act and stress-immobilise strategies when under pressure. However, as a response to increasing pressure Hemi was drawn back to connect-act type secure base provision strategies, which Sione used as a way to support sustained levels of engagement behaviour. In addition, culture was an inseparable aspect of their engagement experiences with each other and their approaches to work. 


\subsection{Case Study 2: Peter and Abby}

Peter (CS2: manager) and Abby (CS2: employee) worked together in a community social service NGO, providing services such as: emergency housing, budgeting and community counselling. Peter, 65 years of age, was the managing director of the Emmaus Centre ${ }^{4}$. Peter, a manager for over 20 years, had recently joined the Emmaus team, which comprised both employed and volunteer staff. The centre had multiple stakeholders, including the Ministry of Social Development, the Ministry of Justice and various local government organisations. Abby, 50 years of age, a community service worker, had been an employee at the Emmaus Centre for eight months, during which time she had worked closely with Peter on a number of team projects.

At the time of the study, the Emmaus Centre had been greatly affected by the recession. The demand for housing and food bank services had increased considerably, as had the number of referrals related to domestic violence. Also, the centre had been through a major building upgrade. The increased demand for services, combined with a challenging physical work environment, had been disruptive to the team's cohesion:

When I first came here they had just finished a big building project. The staff had stuck through the most appalling working conditions, so the thing that needed doing when I got here was the re-focusing of roles and what people were doing. It was out of balance. (Peter)

\subsubsection{Manager-employee social engagement survey patterns.}

Peter identified connect-act as his primary strategy, with a relationship questionnaire categorical rating of secure (RQS). Of note, findings from the NZ MESE survey highlighted a significant and positive association between connectact and RQ secure. However, his engagement state of mind scores matched a statistical pattern more associated with the stress-immobilise strategy, with scores above the mean for perceived organisational support and intention to quit/turnover and below the mean for organisational commitment, organisation engagement and job engagement.

4 A pseudonym for the organisation 
In contrast, Abby's scores indicated a preference for using a stressimmobilise strategy, alongside a general attachment style classification of preoccupation (RQP), with higher scores for perceived organisational support. However, Abby scored above the mean for job engagement, organisation engagement, and organisation commitment and lower means for intention to quit/turnover; a pattern of scores better matched with connect-act.

These survey findings will now be examined with the social data provided by Peter and Abby concerning their manager-employee social engagement experiences, and their manager-employee social engagement and engagementrelated experiences. This case also provides data from which to examine aspects of the intermediary analysis concerning: (a) the stress-immobilise strategy and its components; (b) higher levels of perceived organisational support in association with the use of connect-act strategies; and (c) demographic data pertaining to negative associations between manager age and job engagement and intention to quit/turnover; and positive associations between employee age and organisational commitment.

\subsubsection{Manager-employee social engagement experiences.}

Both Peter and Abby described changes in their use of the manageremployee social engagement strategies over time; from using the stressimmobilise strategy to primary use of the connect-act strategy. While the global change in strategy is similar within this case, the stories and their approaches to this change over time are unique.

\subsubsection{Stress-immobilise and secure attachment.}

Peter described his secure relationship questionnaire score as a reflection of his current relationships at work and at home; with his earlier years being described in ways that reflected experiences of stress-immobilise:

When I was a kid, mum and dad were loving to us, but they were unhappy and eventually broke up, so it was a very fragile sort of relationship. There was lots of tension and it never got sorted. It was hard to do other stuff. (Peter)

This preoccupation was combined with not having any efficacy to change that situation:

In a family as a child, you don't have authority to do anything, really, and when you try and exert it, it's hard and it has other consequences. (Peter) 
He described how these early experiences of conflict affected his experiences with staff when he first became a manager, where he was most likely to use stress-immobilise strategies. For example, he discussed being preoccupied with how to manage workplace conflict: 'I was very uncomfortable with that' (Peter):

I would get very anxious about was leading, particularly in governing meetings. I don't know why they scared me but I found them very stressful and I was so relieved when they finished. That was a very big area of growth ... not to be afraid of leading a group. I think it was the fear of conflict ... actually, wanting to please people. I'm more comfortable with conflict now, and people's anger. (Peter)

\subsubsection{Connect-act and secure attachment.}

Peter then discussed how he had over time changed his interaction style as a manager from stress-immobilise to connect-act: 'I didn't start out as a good manager, but I have become better' (Peter). Peter attributed this change to a combination of his training as a manager in conjunction with some counselling, and time. This data provided support not only for his high connect-act score (support received), but also showed how his experience had created a window from which to reflect on experiences in his past, in a way that actively benefitted his practice as a manager.

\subsection{Connect-act (support received).}

For example, regarding training he said:

I attended a social service management course which were in blocks of about 15 people and it went for about two or three years. We met several times a year and worked on projects. (Peter)

The counselling I've done helped me to see it's important that people express anger and express different ideas and it's not necessarily a threat. (Peter)

I was the oldest son, so I think fear of conflict was about fear of things breaking up and feeling you had to hold things together and you're responsible and all that. (Peter)

Making these connections helped me at work. I had been getting caught into traps of blaming or getting scared or not getting information or [only] hearing one side of a story and so on. (Peter)

Peter also talked about change occurring over a period of time, alongside self reflection:

I think that's the result of all that time. (Peter) 
I'm just grateful for the years of training. It has happened over the years and is still happening. (Peter)

I've got blind spots so what I don't see I don't see, I don't know, but I think the groups that I've led over the years tend to have responded okay. (Peter)

\subsection{Connect-act (connection).}

Peter then described how his experiences of receiving connect-act support helped him to stay connected and work focused in the presence of conflict at work:

I still feel the stress come if there's conflict in the staff, if people are unhappy or start arguing, or if staff aren't talking to each other. That's the old Peter thinking he has to hold the family together. I now think, 'Oh well, you're big people, it's a workplace'. I have grown a bit there of not feeling this personal responsibility to make sure everyone's happy. Some people won't be some days. (Peter)

Peter described that he has not always been able to maintain connection with others at times of conflict:

I've sometimes thought I might be scared to do this but in a couple of years' time what would I wish I'd done? I suppose that's helped me to develop courage, I suppose, to do something which naturally I would shrink from; because it's the right thing to do and it's what I want to live with later on. And I suppose I've learnt that people actually appreciate that. They still have nice Peter around, but actually Peter who does make some demands and expects some things. And we see some things, we see results, which people like to see; results from networking. (Peter)

He also talked about how this capacity has grown and continues to grow over his time as a manager:

I like people to like me and I don't like conflict and to actually be directive or to make hard decisions or unpopular decisions has been quite a step. I've had to work at that aspect of it...I suppose I developed a self-confidence to sit where there's conflict and not be so affected by it. (Peter)

\subsection{Connect-act.}

In turn, Peter provided a number of examples that characterised his overall use of the connect-act strategy:

I always try to be task focused and aware of people's needs. (Peter)

He did this by taking time to get to know the staff and working with the goals of multiple stakeholders:

If you take time to know people then your authority is easy to use. I don't make many executive decisions but you can, at the end of the day you can say, 'Well, I've heard everyone and this is what we're gonna do'. (Peter) 
He also took time to build a bridge between his role as a manager with staff and with the organisations' stakeholders:

So I had to set roles and then people talked about how they fitted into that. But then we had to perform ... meeting our contracts with our funders. There's all those things in the mix. (Peter)

With the people who have contracts with $\mathrm{CYFS}^{5}$ or whatever. I sat down and showed them the contract and this is what we have to do. And so people were clear. We've got to meet that. I said, 'This is the contract. This is what you're doing'. I think that was helpful. It was helpful for me to be able to add that task- focus thing so there's the warm part about working together for a job description that really fits and then there's a task focus thing so that at the end of the year that's what we've got to do. (Peter)

Overall, Peter described changes in how he provided a secure base for staff. These descriptions illustrate his capacity to adapt his use of manageremployee social engagement strategies over time to increase his capacity to provide conditions for staff that were most likely to increase their engagement.

\subsubsection{Stress-immobilise and preoccupied attachment.}

Similar to Peter, Abby made personal sense of her survey findings. She described a change in herself over time, where she had consciously decided to interact with others at work when under stress in a different way. In the past, Abby had typically used stress-immobilise strategies when she was under pressure at work. However, she now typically used the connect-act (connection) strategy. She described how this change of social engagement strategy had helped her work better. Abby had made this change as a result of reflecting on her experiences of growing up, and seeing how some of these experiences had negatively influenced her current work relationships:

More recently, I had a breakdown and so I had to rebuild myself. In rebuilding myself, I picked out the things I liked and left the other stuff behind. (Abby)

Referring to her relationship questionnaire score of preoccupation, she said that when she was growing up she was preoccupied with trying to get her parents' attention:

Growing up, my older brother was the glory child and so support went to him. It was difficult for me to gain any support or get noticed. (Abby)

\footnotetext{
${ }^{5}$ New Zealand Child Youth and Family Services
} 
She described how her experience of this had influenced her interactions at work: prior to her breakdown she was prone to seek support via emotional attention seeking at work:

People know things that come from their past and they hook into that. I can go a bit better than not just running away into my introverted self. It's like, 'Oh! I don't have to do that; I don't have to survive that way anymore', and just push it out a little bit. (Abby)

\subsubsection{From stress-immobilise to connect-act.}

Abby's descriptions provided a window from which to view how she had responded differently to pressure at work, and in turn increased her capacity to stay engaged with the job. She described how she had changed, from letting her stress-induced emotions guide her behaviour at work, to cognitively managing her feelings of stress at work. In turn, she discussed how these changes had increased her capacity to connect with others in a way where she both sought support and made use of the support available to help her do a better job:

I think the one thing is that I'm trying to do better is that if it gets to that point of being stressed that I just need to reflect and use the resources that are around me rather than come into myself to do it all. (Abby)

There are people that I would go to without question and I think I would be more likely to seek that person before I even thought to go inward. (Abby)

There is a huge heap of people resources here. Being within this environment with other people that obviously care; they're genuine ... most of the time there are people around who I could go to. (Abby)

I think I'm getting to the point that it can be anywhere at all. I have learnt what stress is for me. I feel it in my shoulders. So I try not to get it high. I listen to my body and think, 'Oh! Okay. Something's happening'. (Abby)

Abby's descriptions of her prior use of the stress-immobilise strategy and her current use of the connect-act highlighted her own progress:

It just amazes me. You know this is a survey and you just go through it but there's all this information in it. It's good for me to see the movement of myself the growth of myself. (Abby)

It also highlighted that the workplace had been the primary place of interpersonal change for her, and that she took this back to her family life.

\subsubsection{Peter and Abby: a manager-employee social engagement connect- act secure base system.}

Peter and Abby described their workplace interactions in ways that reflected a connect-act strategy of secure base use and provision, with high levels 
of high engagement behaviour. The example below highlights the secure base system as an interpersonal system. It includes:

1. Peter's development as a manager over time, which enabled him to offer a quality of secure base provision to Abby.

2. This supported Abby's personal development at work, which included her capacity to sustain her personal change goals at work, supported by her increased capacity to use the support on offer.

3. As a result of these interactional changes, Abby's (self-reported, and observed by Peter) levels of engagement behaviour increased.

To illustrate, when Abby first joined the team, Peter took the time to get to know her and adapt his management style to optimise her capacity to maintain high levels of engagement behaviour:

When Abby joined the team I didn't know her. I had to sit and think and say how does Abby operate and not put you in a box of how other people operate and then expect the same because that won't work. My observation of Abby, she is a creative person who probably doesn't go in straight lines which I find quite frustrating 'cause I'm a straight line person. She has an enormous creativity and the ability to do things so beautifully well. But not in a straight line. (Peter)

Illustrating his capacity to adapt as a manager he said:

I've got to restrain my fear that nothing's happening. I've got to trust that it will happen on time and [that] it will be done well, it's not easy. (Peter)

With Abby I just say to her, 'How's that going?' I am learning about how she works and I am setting her free to do her stuff. I let you know that I value how you work and I feel secure that, like everyone else, we all want a result [and] there's got to be a result. (Peter)

In response, Abby also illustrated her capacity to adapt to her new work outputs and to her relationship with Peter in regard to these:

I know I have to be prepared and that I will get the things done. I know I've done it and it's just remembering; not being in Peter's office every day saying I've done this look at me. I don't need to do that anymore. But I do need to remind myself that you're interested and want to know, it's good. I haven't had a workplace where someone's just said, this is something I think you can do well, 1 just go and do it. It works well. It gives me more passion to do it well. (Abby)

Further illustrating the influence of Peter's connect-act interaction strategies on Abby's interaction style and her productivity:

Peter's a good manager 'cos if it's all too much there's no pressure to say 'What's the problem?' So you can deal with it in your own way. If I had to go into the emotional stuff too much at work the whole thing would just be like a pack of cards and just fall apart. (Abby)

She also talked about how Peter had structured a daily team de-brief time, which helped to keep her focused on her work: 
Peter makes sure we get our no-contact time as a team each day. We close the door and we just sit down with staff and we laugh and stuff. So, in the middle of the day you can debrief or you can just be yourself before you pick it up again. So that works really well. You wonder how it would but it does. (Abby)

This example highlights the dynamism of the secure base system, where secure base provision, in contrast to the more typical starting point of secure base use, seemed to be a port of entry into an interaction system that functioned to support engagement behaviour. This was Peter's tailored management approach to Abby, which began with the provision of support structures, in contrast to waiting for Abby to seek support.

Overall, Peter and Abby strategically managed their relationship to optimise their engagement, by use of interactions characterised as a connect-act (secure base provision) strategy for Peter, combined with use of a connect-act (secure base use strategies) for Abby. For both Abby and Peter, change in their preferred manager-employee social engagement strategies of use and provision had occurred over time; this change had affected their capacity to: (a) engage at work as Abby showed; and (b) support high levels of engagement behaviour in an employee, as shown by Peter.

\subsubsection{Manager-employee social engagement and engagement experiences.}

While Peter described using connect-act strategies, his engagement-related scores (lower job engagement, organisation engagement, and organisation commitment, with higher scores for intention to quit/turnover and perceived organisational support) were statistically better matched with stress-immobilise. Peter explained that these engagement scores reflected his life stage, as he was actively preparing for retirement and was beginning to transfer his interests from work to other things. His manager-employee social engagement related scores reflected his personal development journey as a manager.

For Abby, her engagement-related scores (higher job engagement, organisation engagement, organisation commitment and lower intention to quit/turnover reflected her current use of connect-act strategies, with her mixed manager-employee social engagement scores also reflecting her personal development as an employee with a concern for how she related to her manager. 


\subsubsection{Connect-act and perceived organisational support.}

Peter and Abby both scored above the mean for perceived organisational support. While neither participant spoke directly of their organisation in relation to perceived organisational support, similar to case study 1 , they described their experiences of support in ways that were characteristic of connect-act secure base use and provision, in comparison to stress-immobilise. For example, organisational support was described in person and relationship specific terms and was discussed in direct correlation to helping them do their jobs better. Of Peter, Abby said he helped to create a supportive work environment by taking the time to get to know staff. This helped her feel more valued and supported at work:

He's really good at working out what people's strengths are and going with those. (Abby)

You feel valued that someone's taking the time to do that; that they understand what makes you tick. It's working well because he does that with everybody. He sits down and he takes time with people. It's not just a hello and into his office, it's actual time. (Abby)

He's always open to suggestions. If he didn't think it was wise he would say, 'Look, we'll think about that', or something. I haven't had that yet, but he is open to suggestions that make the workplace work better. (Abby)

In turn, Peter's descriptions of his own support style were congruent with Abby's experiences:

I sat down with the people and said, 'This is what we're going to do and, I would like you to think about working in this area. What do you think of this job description?' The staff didn't have the authority to do that but they had the authority to talk about the area they were expert in and I just helped match them up. Then our first staff appraisal was to go back over those job descriptions we'd set and said: 'How are those working?' (Peter)

Peter and Abby provided further social data that illustrated a positive association between using connect-act strategies and high levels of perceived organisational support. They both provided examples that supported the hypothesised, but unconfirmed association, between higher levels of connect-act (with higher levels of job engagement and organisation engagement) and perceived organisational support. Peter stated:

There's a lot of give and take here. Almost everyone works more hours than what they're paid but they're also free to go and do [personal] things that need doing. We do a lot of debriefing just by sitting down; like I knock on the person's desk and say, 'Come into the office' and sit down with them and just say, 'How did that go?' or 'What happened there?' (Peter)

Similarly, Abby talked about the support she experienced from the team and how this support helped her stay engaged throughout a lengthy and complicated interview: 
The other week I had a client who came in and initially it was just for food. I took them in to do the interview and it was about heaps more. I was in the interview for two hours. My manager rang on the internal phone to make sure I was alright and I could see the staff walking up and down outside the door making sure that I was alright. You know that it's a secure environment to be in. It shows the caring environment within the workplace, you know that support's there. (Abby)

Finally, Abby discussed the open-plan team environment:

You can hear people and you know you could yell across the room, 'is everything alright?' It's something thing that I've never experienced before. I always felt like everyone was listening to me but here I don't feel like that. (Abby)

In summary, Abby attributed a large part of her capacity to sustain her high levels of engagement to her experiences within her employee-manager relationship with Peter. In turn, this changed her experience of work and created a change in her engagement states of mind, summarised as higher levels of job engagement, organisation engagement, organisational commitment and lower levels of intention to quit/turnover. As in case study 1, Peter and Abby described their experiences of working together in ways characterised by a seamless interplay between unconscious and conscious elements, day-to-day purposeful interactions about how to get the job done, and how they maintained their engagement behaviour during times of stress and pressure.

\subsubsection{Case Study 2: Summary.}

Case study 2 outlined the primary use of connect-act strategies in the manager-employee relationship as a contributor to sustaining high levels of engagement behaviour, even when under pressure. In addition, this case illustrates the centrality, and adaptability, of the manager-employee social engagement interactions as a factor in understanding engagement behaviour over time. They provide insights into: (a) the restorative capacity of positive workplace relationships to a person's personal development; and (b) the adaptive capacity of social engagement strategies at work to increase one's own engagement and those of one's team.

\subsection{Case Study 3: George and Rangi}

George (CS3M: manager) and Rangi (CS3E: employee) worked together at a senior level in a NZ government organisation, providing information technology (IT) expertise. George, 40 years of age and a senior manager, had been 
in this role for three years. His job involved directly managing a staff of 15 highly skilled information technologists. Rangi, 30 years of age, had been an IT technician in the organisation for six years, and had recently taken on a training role across the whole organisation. George and Rangi had worked closely together on a number of projects over the past three years. They both acknowledged that they worked in an externally high pressured environment, and had experienced unique personal responses to this stress.

Referring to changes over time in his job, Rangi said:

We used to be sort of jack-of-all-trades, so we could actually fit into different projects, but now I'm quite specialised. It's quite difficult for me to jump into someone else's project and pick it up because it's so specialised. So that's made it even more isolated and quite difficult to offload stuff. Plus the fact that I think we've all got our own workloads. It's a risk in regard to having all the expertise in certain individuals. (Rangi)

Further, Rangi described how he and George were working together to increase staff capacity:

I don't like offloading work to other people. I don't want to be one of those guys that passes on work all the time. But I've been told I need to do that, so I'm working quite closely with George with hiring new people. (Rangi)

\subsubsection{Manager-employee social engagement survey patterns.}

George identified connect-act as his primary strategy, with lower levels of perceived organisational support; however, his score for connect-act (secure base use) was well below the mean. His other engagement state of mind scores matched a statistical pattern more associated with the stress-immobilise strategy, with scores below the mean job engagement, organisation engagement and organisational commitment, with higher levels of intention to quit/turnover, giving a general attachment style classification of fearful-avoidant.

In contrast, Rangi's scores indicated a preference for using connect-act strategies, with higher scores for job engagement, organisation engagement and organisational commitment and lower scores for perceived organisational support. Similar to George, Rangi identified most with a general attachment style classification of fearful-avoidant and had scores above the mean for intention to quit/turnover; this reflected a NZ MESE survey pattern that better matched with the stress-immobilise strategy.

Further, the general attachment classification of fearful-avoidant was acknowledged by George as a fair reflection of himself in close relationships, but 
he did not elaborate further on this. Similarly, Rangi's relationship questionnaire score was also fearful-avoidant. He also acknowledged it was a true for him, but he did not elaborate. Across the five case studies, George and Rangi were the only participants who did not spontaneously link their relationships at work with other important relationships in their life. As the interviews were work focused it was outside the scope of the interviews to prompt participants to reflect on relationships outside work.

These survey findings will now be examined with the social data provided by George and Rangi concerning their manager-employee social engagement strategy experiences, and their engagement-related experiences. This case also provided data from which to examine: (a) the statistical picture of lower levels of perceived organisational support in association with the use of connect-act strategies; and (b) the qualitatively different experience of pressure and stress and the effect of this on internal engagement states of mind, day-to-day interactions and engagement behaviour.

This was the only case where a participant did not agree to proceed from Part 1 of the case study to Part 2 (Rangi chose not to continue in the study). As a result, this case study drew on: (a) survey data from Rangi and George, in association with the NZ MESE survey findings; and (b) Rangi's individual interview data and George's individual interview data.

\subsubsection{Manager-employee social engagement experiences.}

\subsubsection{Connect-act and disconnect-act.}

George's survey scores represented a mixed strategy, where he used connect-act strategies for secure base provision to others, and disconnect-act strategies for secure base use. For example, in the interview George immediately noticed an anomaly in his connect-act scores (namely his lower score for connectact (secure base use), his higher scores for disconnect-act (disconnection), and his below the mean scores for job engagement and organisation engagement).

George asked what the difference was between the two scores connect-act (secure base use), and disconnect-act (disconnection). In response, the following descriptions were provided by me: 
1. Connect-act (secure base use): I am confident to ask for information/resources and talk about stresses at work with my manager so that I can do my work better.

2. Disconnect-act (disconnection): I am confident to ask for information about my job, but if I am feeling very stressed, I am less likely to ask for any help at all.

George acknowledged that the disconnect-act (disconnection) best described him. He became teary eyed with shaking hands at this point in the conversation. George's astute observations of his data took him to an internal experience, where his capacity to sustain exploration/engagement in the interview appeared secondary to his efforts at self-preservation. In response, my role as an interviewer also shifted from a shared interview goal of exploration, to one of secure base provision. I reassured him that he was in charge of the exploration of his survey material, and we could stop the interview at any time.

George said he was keen to continue with the interview. He said a big challenge at work for him was how he seemed to get himself from connect-act to disconnect-act (disconnection):

I think it's more about asking for it. I'm happy to take it if anybody offers, but it's just asking for it in the first place, rather than expecting it to be there or waiting 'til somebody offers. (George)

I can't think of any examples off the top of my head, but I certainly recognise that and it's something that I need to be thinking about working with my team; making sure that I am sharing stuff and getting other people involved and stuff. Not trying to do it all myself. (George)

These experiences highlighted that, under the umbrella of the disconnectact strategy, stress is experienced but not shared in the same way as in the connect-act strategy. George showed that his behaviour at work regarding secure base use was distressing for him. Highlighting disconnection is not the same as not experiencing stress or distress. For George, distress was experienced, and his tendency to disconnect from others at these very times left him on his own to manage his distress.

George also showed that stress regulation occurred by anchoring onto an external factor or task. For example, in contrast to the previous participants in case study 1 and 2, who made sense of their current experiences via impromptu reflections of their family of origin, George focused on non-specified external factors in his life that contributed to his experience of a loss of connection with 
others at the times he most needed it at work. He questioned whether his shift from connect-act to disconnect-act was an 'external... or an internal one' (George). He further used his capacity to think (reflecting a protective strength in the use of the distancing-action strategy), providing some relief from his overwhelming emotion and focusing on a task:

Okay, so the main thing is for me to think about where I can practise asking for help. (George)

In response to the cue from George to be solution focused, we talked about with whom in his organisation he might practice this. He said:

Probably with peers. I can see how practicing that would help. (George)

As the conversation was solution (task) focused, George increased his exploratory thinking:

I think being aware that I don't ask for support easily is one. Just kind of trying to keep that in mind helps. Recognise it early enough as well. (George)

This example provides a window into a possible connection between: (a) the use of distancing-action strategies as a way to self manage overwhelming emotion; and b) engagement. George showed that using this strategy at this particular time enabled him to contain his overwhelming emotions at work.

In contrast, at the end of the interview when George appeared less stressed, he demonstrated his preferred use of connect-act combined with relaxed exploratory conversation when we talked about mountain biking. The discussion was animated, as we talked about good local trails, how to find the right line to take in downhill sections, as well as the inevitable crashes and how to avoid them.

\subsubsection{Connect-act.}

Rangi described that he typically functioned at work using connect-act strategies that kept him focused on his work even when stressed:

I find, when we do hit a wall situation where something goes wrong, I actually do quite well. That's because I know the job and I know what to do. I know which elements need to be kicked in and who needs to be kicked. (Rangi)

Even if I do go outside and the problem doesn't get solved I don't get too stressed about it. It's within my control. I've been in it for so long [and] I'm pretty confident that we'll get things sorted. I am confident doing the job. (Rangi)

Rangi talked about being most engaged with his job when his work focused on his technical skills: 
I'm here (pointing to SECA) most of the time. I am technical guy. (Rangi)

However, if the job shifted to include more personal issues, this affected his performance, and his engagement shifted from being focused on the job to being focused on self-management:

Having to deal with people and their personal issues, and having to front for the group ... It's not really my cup of tea. (Rangi)

He also talked about changes in his job that increased his people contact time; this had had a negative effect on his sense of security at work, and on his engagement:

So for me some of the strategies would be [to] do smaller good things more frequently, get comfortable and just build on it and get bigger and bigger, rather than, 'Oh! By the way, you're making a presentation for 300 people'. The funny thing is, I play in a couple of bands and I'm happy to stand in front of thousands of people and play because I know what I'm doing. But when I open my mouth in presentations, it's slightly different! (Rangi)

\subsubsection{A possible fourth manager-employee social engagement strategy.}

In this case, both George and Rangi provided data that indicated a possible fourth MESE strategy, characterised by: (a) the following pattern of scores: fearful-avoidant and low perceived organisational support (from George and Rangi's data) and low connect-act (secure base use) and high disconnect-act (disconnection) (from George's data); and (b) descriptions where job pressure at work was experienced as increasingly more stressful, due to aspects of their internal working models of the secure base interactional system.

In this case, both George and Rangi identified experiences at work they experienced as stressful; as a consequence, this influenced their capacity to sustain their ordinarily high levels of confidence and competence in their job tasks, and their engagement behaviour. For George, a current increase in workload was additionally stressful because of his personal experience when he needed to enlist necessary support from others. For Rangi, a recent extension in his role from an IT specialist to a trainer within the organisation had stretched him beyond his professional comfort zone. In addition, his personal experience of increased stress when faced with uncertainty had resulted in him having panic attacks at work. However, his relationship with George enabled him to talk about his experiences and to seek his support regarding this matter. 
Both George and Rangi described personal factors that contributed to shifting the experience from pressure at work to one of high stress. Both described elements of their internal attachment states of mind that affected their usual interactional competencies.

For George, pressure became stress when he needed to ask for support. For example, George showed distress in the interview as he described his struggle to make use of support:

It's hard to ask for it and it's hard also sometimes when people recognise that I need to ask for help. (George)

For Rangi, he described a process which seemed to take him from connect-act to stress-immobilise, to fearful-avoidant:

It's the other things that start to stress me which are not really related to my job. It's more a personal thing than anything else. (Rangi)

The few times that I've been here (pointing to RQFA) overshadows my sense of security. (Rangi)

He further described a process that involved experiencing an increasingly negative view of himself and his own expertise, combined with a positive view of others' expertise:

I worry about what they will think about me. What's their perception of me, my presentation? You get in a room with highly educated people. (Rangi)

The following example illustrates how unexpected increased job demands negatively affected his typical high levels of engagement. In response to the increased demand, he described a shift from: (a) functioning within his typical connect-act strategies; to (b) finding he was unable to focus on his work or engage as he ordinarily would with others or the work.

Rangi explained that as a result of his expertise, his job had been expanded (without warning) to include making staff presentations about IT:

I have been pulled up to do small presentations. If it's something I know, that's fine, and if it's off the cuff, it's really good. But if I had to prepare for it, it can get quite daunting. (Rangi)

Rangi described how he experienced this external unexpected change in his job. He described being caught off-guard. He struggled to perform the new tasks of the job to his own expected level of competence. His view of himself became increasingly negative; as did his view of others. He did not make use of his preferred connect-act strategy. Instead, he described being paradoxically alone and afraid in the presence of others: 
They assume because they are highly educated in other areas ... they ask you 20,000 questions about something that's not relevant, and it starts getting into a pissing contest. Even though I don't know what the answers are, or I never will know I get even more worried especially when you start rambling on and then you get to when you're finished and then there's complete silence, and everyone's looking at you, and you think, 'Oh, well! What do I do now?' (Rangi)

It's daunting. I've had a couple of panic attacks at work and they're not nice. I was doing a talk and the meeting was pretty much over, but I had a panic attack. It was daunting. I knew I was gone because I didn't think. And normally when you're a bit nervous you can continue, you can start rambling and you're fine, but when you can't think, the feelings are physical ... your body starts shaking and I can't think. (Rangi)

Rangi went on to describe that he had sought George's support. It was observed that while the experience was daunting, the secure base use and provision focused on the cognitive aspects:

I've talked to George. We talked about thinking about it as a series of steps. (Rangi)

Generally it's step one or step two that we have to act to try and divert the momentum. (Rangi)

Just doing it and re-running it through, and not getting from here [pointing to SECA] and then into here [pointing to SESI]. (Rangi)

Of note, as with George, although the solution strategy was rational and made sense, its actual efficacy was doubted by Rangi, as the daunting emotion remained, potentially disrupting the execution of the rational plan:

It's daunting, I don't really know how not to make that happen. (Rangi)

It probably requires attending more to what at the time seems pretty minor ... get a hold of it before it starts and before it's too late. (Rangi)

But if you're not used to it at work, it can be quite daunting (pointing to the RQFA quadrant). (Rangi)

While seemingly counter-intuitive, this example shows that seeking help at times when pressure was experienced as stress and distress can itself be experienced as stressful. To access the help located in the external and interpersonal dimensions, George and Rangi showed they self-regulated their distress, and selectively used the secure base for tasks and practical solutions.

\subsubsection{Manager-employee social engagement and engagement experiences.}

As this case did not proceed to Part Two of the case study, understandings about the survey scores were based only on individual level data. However, this case illustrated how the internal dimension concerning mind states towards 
attachment (in this case fearful-avoidant) seemed to influence use of the interpersonal secure base system, which affected engagement behaviour.

First, reflecting an overall connect-act strategy and high scores for job engagement and organisation engagement, Rangi described experiences of support from George (and his team) that helped maintain his engagement behaviour during a very busy period. Of note, Rangi did not provide examples regarding his generic experience of support in the organisation. Instead, he provided examples that were person specific. For example he said:

Having a good rapport with my immediate manager is pretty key. (Rangi)

Towards the end of last year I was working at the weekend for about 12 weeks; it was just part of the job. I was in a trench and I needed to get out of it. But I'd always talk to George. We had weekly updates, more so than now. George was there basically to get everyone else off my back and make sure I just continued doing jobs. (Rangi)

Rangi also talked positively about the support he received from his team:

There are a couple of senior people in our team. We know that we've got each other's back. I mean we don't cover each other in regards of capability, but we know that later on they could step up and do it. But then again, we are quite distant in some relationships, and I'm not sure why that is. (Rangi)

On the surface, this qualitative data of support based experiences did not match Rangi's lower score for perceived organisational support. However, Rangi's connect-act component score for connect-act (secure base use) was below the mean. This score was reflected in Rangi's descriptions as he talked about not needing much support overall; when he did, it was specific to work-flow management and seeking extra technical backup:

I'm technical so it's pretty straightforward. It's like maths, it's either right or wrong, so you fall back to the basics. For most of the technical issues here the buck stops with me, so if I can't get support I have to go outside. It's rare that I'll need to turn to a peer and [when I do] I'll be straight to George and say I'll need to call these people in. (Rangi)

The only time that I ever really go to the manager for support is to get help to prioritise stuff. (Rangi)

This qualitative material reflects a disconnect-act approach to secure base use. It is also consistent with Rangi's task focused secure base use of George in regard to his panic attacks. In contrast to the connect-act secure base examples in case study 1 and case study 2, Rangi seemed comfortable with this strategy. There was no evidence from Rangi that he experienced this task focused support seeking, and task focused support provision by George, as anything other than supportive. As such, he seemed to neither seek out, nor expect the qualitative 
support characteristic of a connect-act strategy from George. However, in contrast to case study 1 and 2, this disconnect-act secure base use and provision was not transformative in terms of changing the experience of stress and re-mobilising engagement, as illustrated in case study 1 and 2. For example, in regard to Rangi's experience of panic attacks, he felt supported by George in regard to solutions, but was not reassured about their usefulness.

Overall, Rangi's relationship with George was useful in maintaining high levels of engagement when he was under external pressure at work, but was less effective when Rangi was personally stressed with compromised engagement behaviours, as illustrated above.

\subsubsection{Case Study 3: Summary.}

Case study 3 outlined a mixed connect-act and disconnect-act strategy. These strategies were reported to be useful in sustaining high levels of engagement behaviour, even when under pressure. However, when unique internal responses to external workplace pressure were activated, this dyad demonstrated a possible fourth manager-employee social engagement strategy: this was characterised by mind states of low perceived organisational support and fearful-avoidant attachment; and temporarily immobilised engagement behaviour. This possible fourth manager-employee social engagement strategy is revisited in case study 5 .

\subsection{Case Study 4: Amy and James}

Amy (CS4M: manager) and James (CS4E: employee) worked together in a NZ government department and both indicated a preference for connect-act strategies. Amy, 35 years of age, was a senior manager in her department and had been in this role for five years. Her current job involved managing a highly skilled staff, which included accountants and economists. James, 52 years of age, had been a senior economist in the organisation for 10 years. Amy and James had worked closely together on a number of projects over the past six years.

Like the previous organisations, this organisation had been incredibly stretched during tough economic times. For this organisation, the pressure had 
been immense due to its advisory role to government regarding economic and social policy:

We've had a lot of change going on. The organisation [from time to time] has been through immense stress ... particularly senior management. (Amy)

\subsubsection{Manager-employee social engagement survey patterns.}

Amy identified connect-act as her primary strategy, with scores for job engagement, organisation engagement and organisational commitment above the mean and a general attachment style classification of secure. However, she scored above the mean for perceived organisational support and intention to quit/turnover, which is consistent with the NZ MESE survey, connect-act pattern of scores.

Similarly, James' scores indicated a preference for the use of connect-act strategy with a general attachment style classification of secure, and score above the mean for organisational commitment and below the mean for intention to quit/turnover. He also scored below the mean job engagement and organisation engagement and above the mean for perceived organisational support, possibly indicating disconnect-act as a secondary strategy.

This case was the only case where both participants:

1. Indicated the primary use of connect-act strategies in relationship with each other to optimise their engagement at work.

2. Identified the secure category (RQS) as the best descriptor of themselves in close attachment relationships.

3. Recorded scores above the mean, for organisational commitment. As a result, this case provided a unique window from which to view an interplay of associations between shared connect-act qualitative experiences of pressure and stress, and the effect of this on internal engagement states of mind, day-to-day interactions and engagement behaviour. In addition, this case provided data from which to examine aspects of the intermediary analysis concerning: (a) the statistical picture of lower levels of perceived organisational support in association with the use of connect-act strategies; and (b) demographic data pertaining to employee age and organisational commitment. Following a similar format to the previous cases, these survey findings are examined below with the 
social data provided by Amy and James concerning their MESE and engagementrelated experiences.

\subsubsection{Manager-employee social engagement experiences.}

Amy and James both provided examples that qualitatively supported their survey finding scores pertaining to a positive association between connect-act strategies and secure; characterised by: (a) task and emotional oriented secure base use and provision; (b) a positive view of self and others; and (c) the capacity to sustain engagement behaviour under pressure. These connections were accompanied by spontaneous reports of positive experiences of care in their family of origin, and an acknowledgement that their capacity to sustain connectact strategies at work was not an automatic transfer of experiences, but had developed over the course of their working lives.

\subsubsection{Connect-act and secure attachment.}

Both Amy and James spontaneously connected their confidence and capacity at work to focus on others' experiences at work, in conjunction with doing the work, with their respective experiences of support from their own family and friends. Amy said:

Just last night, I had a phone call from a good friend's mum to say that he was incredibly stressed at work, so of course I went round and saw him. He had to get to such a low point until he could ask for help ... and I thought, I just naturally have a support network around me that I don't think I'll ever get there. Maybe it's because I have the confidence and I like to talk and I have close friends that I readily confide in. (Amy)

I love my work but it doesn't define me, it's more about my family and networks. I have confidence, so I'm not going to get too upset or stressed about it if I'm not performing to the expectation that I have. (Amy)

Similarly James said:

I try to put things in perspective ... is it life or death? Is it affecting the most important things; my wife and my family, well no, it's a job. I've gotta get the job done, it will be stressful but at the end of the day the only thing I can do is say, ok, do this bit; and I'll get this bit done ... doing nothing is often not the way out. (James)

I've got my family relationships, so if you're confident on that perhaps that helps because often what happens in the family relationship is not worlds apart from what happens in the business relationship. (James)

I can credit my father for my patience because he'd have an enormous amount of patience putting up with five children. So, hopefully, I've got that. (James) 
Second, similar to CS1 and CS2, Amy and James acknowledged that the connection between positive workplace relationships and sustained engagement behaviours at work developed over time. For example, Amy discussed learning about herself in the role of a manager, and how these learnings underpinned her current capacity to be relationally adaptive in her own style in response to others when under pressure:

It's a luxury to be able to spend an hour just talking about yourself, about improving those relationships or communication and better understanding other people, because it's so important when you're working with a group of really smart people. As a manager I always want to know that I'm getting the most out of them, or creating an environment that best suits them and any insight into people is extremely valuable to me. (Amy)

When I was first in leadership positions, or section head positions I was a lot focused on doing a good job, and I think just as you mature and you get more experience, you start to realise that people are more than the work that they do and so I take that more into consideration. I like to think that I do take people into consideration, but at the end of the day I know what I want to achieve and what I want my team to achieve. (Amy)

James also acknowledged changes in his approach to work over time:

In the past you just carry on, but I guess resources cannot be moved unless you communicate. We've gone through quite a bit of stress in recent years through projects that we were involved in, and I guess being older, more senior than I used to be. I can feel more comfortable communicating about what's needed ... but that doesn't mean I'm running to them. (James)

Next, examples of secure attachment and connect-act highlighted how this combination of variables seemed to function to keep high pressure situations from being experienced as overly stressful. For example, James said:

We're in an environment of very talented people. It'd be great to have those abilities but in a practical sense you don't and I guess being confident or happy in what you do really does matter because otherwise you'd get really stressed. (James)

So if you're in a stressful time, 'cause there will be stress in a job... If it's acknowledged, if there's someone to discuss the issues with, then you're likely to be low on the stress barometer. (James)

Even though times are tough and there's lots on, and there's pressure around, I'm aware of that, yet still focused on you how the staff are getting along, and this helps me adapt what I do as a manager so we are achieving the outcome and getting the job done. (Amy)

Amy and James also provided examples that illuminated the connect-act (connection) component. (Examples of connect-act (support received) are provided below, as they relate directly to examining the association between connection-act and POS).

\subsubsection{Connect-act (connection).}

I want to show my team that I'm not just interested in the job, but in them too. (Amy) 
As a manager, at the end of the day, you've got a responsibility. There's an organisation here that pays the salary. You're always wanting to be as supportive as possible, but there's an expectation back the other way. I believe in that fairness, it's not all one way. (Amy)

Emphasising secure base provision to encourage collaboration as a way to minimise her workplace stress Amy stated:

I sit with the team and say we've got so much work on that I just want to be clear that the number one priority is $\mathrm{x}$. I try to do that in a group setting so that everyone has the same message and it's what we should all be working towards as a priority. (Amy)

\subsubsection{Connect-act meets connect-act.}

Further, this case provided a window from which to view the interactions of Amy and James anchored in an interplay of connect-act strategies and secure attachment, where they both linked high-quality supportive relationships in their team with high levels of sustained engagement throughout a relatively lengthy stressful period:

I'm thinking about James and the system development that we did. It was really stressful, and he didn't show a lot of stress. I could tell though he was stressed even though he wasn't explicitly telling me. He is amazing and, in these circumstances, is very task focused. (Amy)

I think I could work more with you than I do but I'm also conscious you've got a lot of things happening as well. Sometimes I feel that if I have to keep coming to you to get help then I'll start to feel not so good, but I don't feel any barriers for me to wander across and ask you a question. (James)

James provided further descriptions of his use of the connect-act strategy, as evidenced by his acknowledgement of stress and emotions as way to prioritise tasks to sustain engagement behaviour:

I just try and put things into that spectrum of life and death ... often there's a lot of emotion going on when in reality, if they can get rid of the emotion they'll get through an issue. So I guess I try and take the emotion out and just do the job. (James)

This example was differentiated from a disconnect-act strategy (for example, CS3M), characterised by an under-acknowledgement of stress and emotion as a way to sustain engagement.

Further, Amy and James' positive view of themselves as workers, in conjunction with their positive view of others, was reflected in their awareness of their complementary value to each other:

Where I have a weakness, that's James's strength. I've always seen the two of us working so well together. I know James doesn't think he can sometimes see new opportunities or the way of doing things differently, but that's what I really enjoy doing. We complement 
each other really well ... we're not in conflict because our working styles are different. (Amy)

That does work well because, I may want to be able to see change and I don't always necessarily see it, but I will see it if you explain it. As an economist you do want to do things better than the way you did it before. So if someone has a skill or can see that sort of thing, that's really great. I don't reject or object to someone coming up with the ideas as my ability is to get something done, I can put your objective into a plan and do it. (James)

Exactly ... I know James will be able to put his finger on exactly what an issue is and work out how to resolve it and then work with every single person to sort it out. At the end of the day our objectives are the same. We just do different things to achieve the same outcome. (Amy)

Another example illustrates the effect of connect-act strategies on Amy and James' capacities to help each other keep high levels of stress at bay during a lengthy high pressured period at work. They talked about a recent situation in their team which involved an 'unengaged team member' (Amy), who used questioning as a way to avoid doing the job:

This person, he questioned a lot. I don't have a problem with questioning but it was questioning where he should have known the answers. It showed that he wasn't invested in what we were doing ... unengaged ... He didn't go and look for information himself. He would question when James and I [were] in meetings. Anyone else who wanted to put something on the table knew they were going to get questioned by him, and not in a useful way. The flow of the meetings was stopped. The questions were basically undermining what we were trying to do at the time. (Amy)

He was always interacting with someone, but the outcome of the interaction wasn't helping getting the job done. (Amy)

James elaborated further when he said:

No one likes conflict, but we certainly had a staff member who introduced conflict. He was a disruptive influence. (James)

In response to this situation, Amy and James talked about how they (and

the team) began adapting their usual interaction styles by restricting their usual

breadth of emotional expression, as a way to manage the increasing pressure:

I was willing to be supportive to an extent, but [at the same time] I expect they will take ownership and responsibility of their work. I understand we all have our ups and downs but [this situation] was extremely difficult to deal with because I had [to] move into being more demanding. I'd been supportive but [this was not effective] and this person's oneway world view was impacting on the rest of the team. (Amy)

There's fifteen of us or so. I started to realise he was impacting on me. I wasn't managing from my natural style which is about enthusiasm and encouragement and creating an environment where people want to work together rather than through me. When I realised that, I felt obligated to be more demanding and expect this person to take some personal responsibility. I had to kind of change tack, which was not easy for me. It used to take a lot of my head-space. (Amy)

It worked in my head-space too. (James) 
It used to take a lot of our time. (Amy)

There would be nobody in the team who would raise the issue that they were having to do extra work because that person wasn't pulling their weight. That really surprised me.

(Amy)

I was surprised too. It was a difficult situation. They didn't want to rock the boat because he looked like he was getting on with so many people, when in reality I imagine it was just a pure veneer. You know, he behaved as if he was getting on with everybody and I guess others were thinking well, he must be getting on with that person, so it's okay. (James)

It meant in the end going through a formal process and he left. (Amy)

\subsubsection{Manager-employee social engagement and engagement experiences.}

The above findings lend qualitative support to Amy's statistical data: higher scores for job engagement, organisational engagement, organisational commitment, perceived organisational support and connect-act. However, the statistical association between James' connect-act scores and his lower scores in job engagement and organisation engagement were not qualitatively supported. James made sense of his job engagement and organisation engagement statistics by saying:

I looked at [it] and thought, 'Well it's not where I get my most enjoyment from'. I'm happy to come to work here, but I've got a family; I've got another life thanks. (James)

If you'd asked me these questions maybe a couple of years ago when I was on a specific project (we were developing a new software) I would have scored higher. (James)

However, James provided a number of descriptions (supported by Amy) that indicated an interplay between connect-act strategies and high levels of engagement behaviour. For example, James said:

We have quite a few stressful situations throughout the year when we're trying to release information, [and] information isn't quite coming into the right buckets at the right times. But I don't think I've gone mad in the office, yet. I just push it through. We've got a good team. (James)

\section{Consistent with this self-perception, Amy said:}

I know you're incredibly busy in your role and I can see you; you've always got an immense amount of work on your table at any one go and I think you must be stressed, but I never see it. (Amy)

I'm sometimes surprised at the amount of stuff that I throw at James. I don't know that you've ever come back to me and said 'listen, I just haven't got the space to do this', and I think it's partly because we agree that it can be passed on to someone else, but I don't know how much of that actually ends up happening. I am amazed by your ability to take on all the stuff that I throw at you. (Amy) 
In response James said:

I think I would feel confident to come back and go 'no more, I'm full', but sometimes I don't understand where full is, so I've got to keep an eye on that. (James)

In addition, James's pattern of scores fitted the MESE survey findings, where employee age was positively correlated with organisational commitment. James spoke highly of his organisation, and of his positive relationship over time with the organisation. However, he was also clear that his life was not only about work:

If we're honest, we work to earn money to live, and I don't come here to live. This organisation has tried over recent times to encourage work/life balance and I guess they've had some success with me. (James)

\subsubsection{Connect-act, connect-act (support received) and perceived organisational support.}

Both Amy and James provided examples that demonstrated a positive connection between: (a) the use of connect-act strategies, especially connect-act (support received); (b) positive experiences of perceived organisational support within their team and from senior management; and (c) doing a good job. For example, Amy talked about the support she received from her senior management team while she navigated her way through a performance management issue with a staff member (further discussed below). Referring to her experience of support (connect-act- support received), she said:

I learnt an awful lot, and I learnt you know benefit of hindsight — do it quicker, and do it faster, and the support that I got in terms of from HR, and in terms of the senior management, they were like, 'We're behind you one hundred percent, just keep going'. (Amy)

She also referred to the support she received from her team:

I knew at that stage that what had pushed me through the process was the team. I work with an amazing team. It's a credit to them. They acknowledge it (the staff issue), but we get on and we got the job done so, which is most important thing for New Zealanders I guess. So yeah, [we're] pretty proud of what we've been through. (Amy)

For James, he talked about his experience of perceived organisational support in terms of (a) knowledge that support was there, and (b) that he knew how to access it as required:

I've been in this organisation a long time, so I guess there's a comfort level, and I sort of know many of the senior management, so [am] less reluctant to hold back, I guess. (James) 
In this manager-employee relationship, there was a clear distinction in work roles, but there was also a shared supportive relationship. For example, during the difficult situation above regarding a staff member, Amy felt supported by James's capacity to stay engaged and James was supported by Amy's management of the situation:

I like the fact that we can be quite honest with each other. I don't think it's ever got to the stage where it's too much but I'd never want it to get to that stage either, so I think that we both tell each other. I think I told you once I was going to throttle him and you probably kept me away from him for a week. I like the fact that we can have those honest conversations and we're looking out for each other. (Amy)

In turn, this mutual experience of support was used to begin the process of rebuilding the team to its high level of task and emotional oriented interactions, with high productivity levels:

Even though no one was said anything this situation had been stressing people out and it had been creating a negative atmosphere. The team is much more collaborative and engaged now, and so much more willing to share and help each other because that negativity's gone. (Amy)

We both noticed the team's developments since his departure. The team are now willing to take on things and to discuss things and build a team again. Him leaving has destressed the team a fair bit. (James)

We have so much more time now. (Amy)

When that person left we were putting together some boxes to put their stuff in. There was this jubilant sort of atmosphere, everyone wanted to help out. (Amy)

\subsubsection{Case Study 4: Summary.}

This dyad demonstrated a shared use of connect-act strategies with secure attachment. The case demonstrated a mutually supportive and mutually stressregulating pattern of secure base use and provision within the dyad. Attributes of this shared strategy were identified as contributors to sustaining high levels of engagement behaviour amid an increasingly pressured workplace environment. James's data also highlighted the difference between scores concerning engagement states of mind, such as job engagement and organisation engagement and engagement behaviour at work.

\subsection{Case Study 5: Donald and Cathy}

Donald (CS5M: manager) and Cathy (CS5E: employee) worked together in a private sector accounting firm. Donald, 46 years of age and a founding 
partner of the firm, had increasingly taken on managerial roles over the past 20 years as the firm had grown into a medium sized organisation with 30 plus staff. Cathy, 36 years of age, a senior associate, had been in the firm for over ten years, throughout which time she and Donald had worked together on a number of projects. The firm was weathering the recession, but as a result was undergoing a major restructure, entailing changes in staff numbers and roles, and internal work management systems.

\subsubsection{Manager-employee social engagement strategy survey patterns.}

Donald identified stress-immobilise as his primary manager-employee social engagement strategy, with scores for job engagement, organisation engagement and organisational commitment below the mean, a general attachment style classification of fearful-dismissing, and higher levels of intention to quit/turnover. However, inconsistent with the stress-immobilise pattern of scores, he scored below the mean for perceived organisational support.

Cathy's scores indicated a preference for the use of disconnect-act strategy with scores above the mean for perceived organisational support and below the mean for job engagement. However, inconsistent with a disconnect-act pattern of scores, her other scores reflected a connect-act, where she indicated a general attachment style classification of secure attachment, scoring above the mean for organisation engagement and organisational commitment and above the mean for intention to quit/turnover. In summary, her survey indicated the possible use of a mixed disconnect-act and connect-act strategy.

As with the previous cases, these survey findings are examined below with the social data provided by Donald and Cathy concerning: (a) their manageremployee social engagement strategy experiences, including descriptions of the strategies, and of the associations between these and their general attachment scores; and (b) the strategies in association with engagement-related experiences. However, this material is presented slightly differently due to an adaptation in the feedback process. Drawing on emerging insights from the other cases, a feedback model for Cathy and Donald regarding their shared survey data was developed for use in dyad interview (Table 60). 
This model captured the survey data presented above in a way that created a shared map and language for conversation in the dyad interview. The survey feedback model was designed to use a simple green, amber and red traffic light colour coded system. A quadrant with the following representational colours was used:

1. Green for connect-act, the strategy most likely to be associated with increased levels of engagement.

2. Amber and Orange for disconnect-act and stress-immobilise respectively as the strategies which were most likely to be associated with mixed levels of engagement.

3. Red for a possible fourth manager-employee social engagement strategy most likely to be associated with decreased levels of engagement.

Table 60

Case Study 5 (Donald and Cathy): A Feedback Model of the MESE Survey Results

\begin{tabular}{|c|c|}
\hline $\begin{array}{l}\text { Manager SECA: RQS, } \uparrow \mathrm{JE}, \uparrow \mathrm{OE}, \uparrow \mathrm{TC} \text {, } \\
\downarrow \text { ItQT, } \downarrow \text { POS }\end{array}$ & $\begin{array}{l}\text { Manager SESI: RQP, } \downarrow \text { JE, } \downarrow \text { OE, } \\
\downarrow \mathrm{OC}, \uparrow \mathrm{ItQT}, \uparrow \mathrm{POS} \\
\text { Donald: } \downarrow \text { JE, } \downarrow \mathrm{OE}, \downarrow \mathrm{OC}, \uparrow \mathrm{ItQT}(\downarrow \\
\text { POS) }\end{array}$ \\
\hline $\begin{array}{l}\text { Employee SECA: RQS, } \uparrow \mathrm{JE}, \uparrow \mathrm{OE}, \uparrow \mathrm{OC} \text {, } \\
\downarrow \text { ItQT, } \\
\text { NS: POS } \\
\text { Cathy: RQS, } \uparrow \mathrm{OE}, \uparrow \mathrm{OC}\end{array}$ & $\begin{array}{l}\text { Employee SESI: RQP, } \downarrow \text { JE, } \downarrow \text { OE, } \\
\downarrow \text { OC, } \uparrow \text { ItQT, } \uparrow \text { POS }\end{array}$ \\
\hline $\begin{array}{l}\text { Manager SEDA: RQDA, } \downarrow \text { OE, } \uparrow \text { POS } \\
\text { NS: JE, OC, ItQT }\end{array}$ & $\begin{array}{l}\text { Manager: RQFA } \\
\text { Donald: RQFA }\end{array}$ \\
\hline $\begin{array}{l}\text { Employee SEDA: RQDA, } \downarrow \text { OE, } \uparrow \mathrm{OC}, \\
\text { NS: +POS, -JE, +ItQT } \\
\text { Cathy: NS but: } \uparrow \mathrm{POS}, \downarrow \mathrm{JE}, \uparrow \mathrm{ItQT}\end{array}$ & Employee RQFA \\
\hline
\end{tabular}

Note. $\uparrow=$ significant and positively associated with MESE variable; $\downarrow$ = significant and negatively associated with MESE variable.

To show how Table 60 was used throughout the dyad interview in this case, the connect-act strategy and associated variables are highlighted in green, as these strategies were most highly associated with the organisational outcomes of increased job engagement, organisation engagement, organisational commitment and decreased intention to quit/turnover. Stress-immobilise and disconnect-act were coloured orange and amber respectively, to represent a need to get ready to stop and take stock if increased engagement was the goal because: (a) stress- 
immobilise and associated variables are least likely to affect an increase in engagement; and (b) disconnect-act and associated variables showed mixed results in regard to increased engagement. The bottom right hand quadrant is highlighted red. It represents the fearful-dismissing attachment classification. From the emerging case data (CS3M, CS3E and CS5M), it indicates the strategy least likely to be associated with high levels of engagement.

\subsubsection{Manager-employee social engagement experiences.}

Donald described his interactions at work in ways that elaborated on the stress -immobilise strategy, and Cathy described her experiences in ways that elaborated upon disconnect-act (disconnection) and disconnect-act (support).

\subsubsection{Stress-immobilise.}

Donald described his experience of stress of at work as follows:

Even though I work hard and others would say I am successful at what I do, I often find that I get worried that I am not doing a good-enough job. If I get more stressed, I know what I should do, like go and talk to someone, or think about what I can do to help fix the problem, but instead I plummet down into this awful space. In fact, I am ashamed to admit it ... I end up feeling really bad about myself and lonely. When I think like this I also don't believe anyone or anything can help-I feel trapped in my own self. A terrible place to be as a manager. (Donald)

Further elaborating, Donald reflected on his experience of stress at work and the impact this was having on his work:

The other partners seem more comfortable in that amber box (SEDA) than me. I find it harder to keep a lid on how I feel and there's no space to talk about that anymore. It's now seen as a sort of weakness as if I am not managing my own caseload. It makes me worried that maybe I am not managing like I should be. (Donald)

\subsubsection{Disconnect-act.}

In contrast, Cathy provided examples which represented the disconnect-act strategy, characterised by a task focused approach to manage stress. First, illustrating use of the disconnect-act (disconnection) strategy, underpinned by a positive view of self and a negative view of others, Cathy said:

When things get stressful within projects I find it tricky not fix the problem myself. I get someone to do a piece of work and it comes back to me and it's not quite what I wanted, I'll just fix it myself rather than going back and sitting down with whoever it is and saying actually, this bit here's really good. (Cathy) 


\section{And further elaborating:}

The time you would have to spend to bringing somebody up to speed, I often calculate being much larger than it is and so therefore you think it's just faster to do it myself. (Cathy)

Second, illustrating use of the disconnect-act (support) strategy (also underpinned by a positive view of self and a negative view of others), Cathy said:

When you're already stressed you don't actually need to talk about one more stressful thing. Other peoples stress can rub off on you if you're already feeling stress cause I feel like I don't have the capacity to deal with that on top of all my own stuff. I just want to focus on addressing this particular issue and so practical support is what I find works first best for me in a lot of situations. (Cathy)

Next, as with the other cases, this case provided support for the emerging idea that the relationship questionnaire score gives a window into how people at work are likely to adapt their manager-employee social engagement strategies in response to stress and or conflict as a way to maintain capacity to do their job.

\subsubsection{Stress-immobilise and fearful-avoidant attachment.}

Using the quadrant, Donald provided some insight into the association between stress-immobilise and fearful-avoidant attachment. He described the association in progressive steps, from his use of connect-act strategies (when not stressed) to stress-immobilisation (when stress increased combined with an increasingly negative view of self), to the fearful-avoidant red box where his description matched a negative view of self and of others:

When I am not stressed, I work mostly from that green box, then, when I get more stressed, I go the orange box (SESI), then if the stress really kicks in, I am catapulted into the red box. (Donald)

Donald said that while growing up, things were mostly good in his family, but when they were not, the family functioned differently:

Instead of getting closer and working together everyone just scattered like flies. No one really talked about the hard stuff. We would all just sort of re-surface when it was calm, as if nothing had happened. (Donald)

Donald said he felt like this a lot in his family, but that this was not true of his family now. Of his wife and kids he said:

They haul me out of my rabbit hole. They provide perspective. At the end of the day, am I going to be able to go home and hang out with my family and have a nice time? And the answer is yes, so I have the family anchor as well. (Donald) 


\subsubsection{Disconnect-act and secure attachment.}

Cathy described that as a result of organisational cultural changes, she had found herself using disconnect-act strategies and had increasingly sought emotional support outside her workplace from her partner and family. She described that she had become more socially distant in her relationships at work, as a way to get through the ever increasing work load:

It's not like it used to be when we could follow a project all the way through ... Now we seem to do bits of this and bits of that. It's not about working on a shared project anymore it's about churning our work and not as satisfying as it used to be. (Cathy)

However, similar to CS4M, Cathy described that her security anchors outside work were both historical — that is her family of origin — and current:

I've got a couple of external reference points when I'm really, really stressed. For me I always go back to my brother, who committed suicide ... and it's like, well, is it as bad as that? No. Okay, it's not an issue and for me - and my other reference are my husband and daughter, they really help me to focus on what's important and I find those two; one a really, really positive thing and one a really, really negative thing and I find that the combination of those two things if I'm feeling really stressed actually just help to kind of put things in perspective and there's almost nothing that is more important than those two things for me. (Cathy)

While these anchors helped her keep things in perspective overall, using

the quadrant as a base she described the flow-on effect of disconnect-act type strategies on the relationships that staff were developing with clients:

Looking at our culture, there could be a need to think about some strategies to make sure that we meet with our clients in the green box. I think that we are prone to meet people from that amber box (SEDA) where we have negative images of others. With a lot of our work we're coming in to fix something, or someone's made a mistake. I find it quite hard to not think, "oh, for goodness sake you idiots. Why did you do it like that? Why didn't you do it like that or why are you going down that path when actually the path. (Cathy)

Cathy used the quadrant to structure her ongoing reflections, including a personal change in her approach at work to social engagement that was a better personal match for her (i.e. RQ secure and connect-act):

I am wondering now if a better way of doing it is to acknowledge that somebody's made a mistake and what actually matters is the situation that you've got in front of you and helping your client fix it. I think that can be really hard to kind of get your head around if you are standing in the amber box, but much easier from the green box. (Cathy)

These descriptions of the manager-employee social engagement strategies are further elaborated below in regard to Donald and Cathy's (a) experiences of 
engagement and (b) the effect of the dynamic use of stress-immobilise and disconnect-act strategies between Donald and Cathy.

\subsubsection{Manager-employee social engagement and engagement experiences.}

\subsubsection{Donald.}

Donald provided a wealth of supporting social data to understand his statistical data: lower scores for job engagement, organisation engagement, organisational commitment and perceived organisational support with higher scores for stress-immobilise, intention to quit/turnover and fearful-avoidant attachment. He also used the coloured quadrant to tell his story, beginning with his experiences in the orange stress-immobilise quadrant:

I was worried that I hadn't got a contract for a project and I got really stressed about it. But I did, but I couldn't immediately find it, and I really freaked out about that. I was distancing myself. I was trying to sort it all out myself without again asking for help. I didn't tell anybody because I felt bad and I thought that they would think I was a nincompoop for not having the contract. (Donald)

Then, as his stress increased, he described his experience in the red quadrant:

When I am there I can't think straight and I can't solve simple problems. This makes me more stressed. It doesn't help to talk to people cos I am afraid they will think badly of me and it doesn't help to avoid them cos I am clearly not sorting things out myself very well. (Donald)

Next, using the quadrant as a tool for himself at work, he described how it had helped him go from amber to green, instead of from amber to red:

After our first session I am using it more and more. I am trying to be more conscious of times when I'm in that really stressful situation and I feel like I could slip over from green to amber. (Donald)

We were doing a big project and the budget was blowing out. Instead of going into my shell I did quite a lot of stuff with another staff member to work out how we could minimise the blow out. We did a lot of work together to support each other. It was stressful but working together solving the problem helped me feel less stressed and this helped me think more clearly. If I had behaved in the way I did about the contract I would have got fearful, isolated and distracted ... and then a problem that was fixable would have got so big and then possibly far less fixable. (Donald)

I find I have a greater clarity of thinking if I concentrate on getting into that green box. If I don't my negative self image can skew my thinking about myself and others. (Donald) 
I can see now that this isn't just about breaking a task down, it's about staying in the green box and not letting it stay too much in the amber. Amber is ok if there's no stress, but if I get really stressed I have to react quickly and head into that green box. The amber box is not a good place for me to be when I am under pressure. (Donald)

Moreover, this reported change in the quality of his social engagement strategy was matched with descriptions of increased engagement behaviour and a decreased intention to quit:

It's been a very positive experience. I am so much more productive. I feel genuinely different about being at work, more positive all round, and have even been thinking that I do actually want to keep working here. (Donald)

\subsubsection{Cathy.}

Cathy's social data complemented her mixed statistical data, which indicated a preference for the use of disconnect-act strategies with higher levels of organisational engagement, organisational commitment and the intention to quit/turnover, and lower levels of job engagement. Although she scored below the mean for job engagement, there was not any social data that supported this statistic:

I'm quite aware that other people are busy, too, and other people have lives, as well, and I don't want to feel like I'm letting the team down by not being able to do what I'm supposed to be doing, regardless of whether what I'm supposed to be doing is actually a reasonable expectation or not. That side of it doesn't really come into it for me. I just kind of think it's my job to do it, and so I just have to do it. (Cathy)

\subsubsection{Donald and Cathy: Perceived organisational support.}

Donald talked about support: of himself as a recipient of support from his fellow partners, and as a provider of support to staff. His low score for perceived organisational support reflected his experience of a change in the way the partners interacted with each other:

As partners we used to look out for each other much more. As the pressure to keep the firm afloat has increased we seem to be working more in our isolated pockets, kind of protecting our own patch of interest in the firm. We don't take the time we used to just to check in with each other. (Donald)

Using the quadrant he said:

We used to be in that green box most of the time. Now when we meet it's all about the business. We talk to each other, get a job done, but we rarely address how we are doing really, there is a disconnection between what we do and how we are doing. We work much more together from that orange box (pointing to SEDA). We work hard, but have stopped supporting each other like we used to. (Donald) 
Donald described the flow-on effect of how he and his partners now supported each other, and how they supported employees:

We are accountants, but at the end of the day the firm is about people; we used to be a firm that was focused as much on supporting our staff as we were on working for clients. (Donald)

We used to be much more supportive to juniors now we expect them to work independently with new jobs they've never done before, we don't support them any more when it really matters. (Donald)

We are much more comfortable talking about work stress but we hardly talk about stress between us based on how we are working together. Even when that's causing more stress than the work itself. (Donald)

This view was confirmed by Cathy who described the firm in its early days as being: A really supportive workplace; a strong family focus; flexibility to be supportive at different times of your life; [being] ... in it together having a bit of a joke about it reduces the stress at the time. (Cathy)

Although the breadth of support in the organisation had changed, Cathy described the type of support now on offer, which was technical support focused, as still a good match for her. As illustrated above in her disconnect-act (disconnection) comments, this type of support fitted the way she managed her own stress and other people's stress at work. It also matched her score for perceived organisational support, which was above the mean. In conjunction, and reflecting her secure attachment category, she did not seek emotional support at work; instead seeking this from her family and friends, as illustrated above.

However for Donald, the organisational cultural change towards disconnect-act strategies was not a good match for him; this was also reflected in his perceived organisational support score below the mean.

\subsubsection{From connect-act to disconnect-act.}

Donald and Cathy demonstrated a connection between increased pressure at work, increased use of disconnect-act strategies and a decline in levels of engagement behaviour. An example came from a dyadic conversation between Donald and Cathy concerning the change evolving in organisational culture, characterised as a shift from connect-act to disconnect-act strategies, with a drop in staff engagement. Once again, they used the coloured quadrant to reflect together on a shared experience at work they had both been part of, pertaining to the changes in organisational support. As cited above, their support culture had shifted from the provision of extra support across the organisation at times of high 
workload, to social fun team-building events, such as a quiz nights, to 'boost morale' (Donald). However, Donald said this type of focus on team-building had coexisted with a reduction in overall work support:

Support to staff when they actually need it has dwindled ... but we continue to load them up with projects, with tight deadlines, and just expect them to come through with no extra support and no complaining. (Donald)

Elaborating further, Cathy said:

We had a new person working on a project. Looking back he was not ready to do this piece of work on his own. He started off with a big task and then as the weeks went on it got smaller and smaller and smaller ... and he failed to be able to deliver on the simplest things. I see now it was overwhelming starting a new job, being given a piece of work that he'd never done before. (Cathy)

He had no idea what he was doing, I reckon he had gotten himself in the red box and to be honest I was probably in there in the amber box, thinking negatively about him because he wasn't working well, and feeling bad that I wasn't do a better job at helping him. (Donald)

And I was here in the orange box ... and I still have a really negative image of him in my own head and I see now it's not necessarily all his issue. (Cathy)

We would have been much better to give him a chance to get comfortable in a smaller piece of work ... so he gets some runs on the board and we get confidence that he knows where he's at and what he's comfortable doing. (Cathy)

I am wondering now if a better way of doing it is to acknowledge that yeah, somebody's made a mistake. What actually matters is the situation that you've got in front of you and helping your client fix it ... or staff ... that can be really hard to kind of get your head around if you are standing in the amber box, but much easier from the green box. (Cathy)

In addition, this dyad provided examples that occurred between their individual interviews and their dyad interview. For example, they both talked about how they had begun to use the quadrant to implement changes in the way they engaged with staff socially, especially relating to increasing the provision of support:

I was talking to one of the staff. They need more guidance, so I'm going to check in with them at the day tomorrow about this piece of work which we talked about this morning to see how well it's going. So hopefully, that will mean that if I haven't briefed them well or they haven't got it, or whatever, then we've got the opportunity to adjust it. (Donald)

That's quite interesting that you say that because I've done that too. I've got a high pressure project on at the moment. Rather than give a piece of work and say come back to me in two weeks when you've done it all, we have put in place much more regular catchups so that you can see that they're getting along fine and that they've got what they need to deliver to me what I need. (Cathy)

These examples illustrated that under stress it was possible to shift from using disconnect-act to connect-act strategies, and that this shift increased engagement behaviour. 
Finally, Donald and Cathy drew on insights from each other to begin making manager-employee social engagement strategy changes as a way to attain a better match for them personally and for overall staff engagement:

I think that's probably a good approach that we need to take across the firm all the time. (Donald)

Yes, particularly with new people and some of our junior people. I think that's probably good for them too, so they don't beaver away on something and then hand it up and find out that that's not actually what was needed at all. That puts them in a really crappy place and it's not very fair on them. (Cathy)

In addition, they talked about and how they might use it to support each other to 'work with each other in the green' (Donald):

I'd certainly like to work on this. It fits in getting other people to be involved in work. (Cathy)

If you just take the orange approach and you don"t deal with any underlying issues, the next time that you and that person find yourself in that relationship, in that situation or a stressful situation, you're likely to distance from each other even further. (Cathy)

\subsubsection{Case Study 5: Summary.}

Case study 5 showed a mixed stress-immobilise and disconnect-act strategy. In conjunction, this case illustrated the interplay between adaptive personal strategies in response to a changing organisational culture, characterised by both participants as a shift from connect-act to disconnect-act strategies. In turn, in this case Donald provided social data that supported the findings from case study 3 regarding an association between a possible strategy described as: disconnect-immobilise and experienced as the simultaneous disconnection from others and immobilisation to maintain job engagement.

Donald also provided social data in which to consider the stressimmobilise strategy and its sub component stress-immobilise (conflict). Donald showed that conflict for him was largely experienced as a private internal experience (in contrast to an interpersonal conflict) and that this internal conflict: (a) affected how he perceived himself as not being able to seek help from others because he would look incompetent; and (b) interrupted his capacity to engage with others and his job. However, Donald also showed how adaptations in manager-employee social engagement strategy from stress-immobilise towards the connect-act strategy increased his self-reported engagement behaviour. In addition, the shared adaptation of both Donald (from stress-immobilise to 
connect-act) and Cathy (from disconnect-act to connect-act) within their interactions with other staff, resulted in self-reported increases in engagement states of mind and engagement behaviour.

\subsection{Chapter Summary}

This chapter considered the question: what can be understood from managers and employees who work together about their experiences of engagement in association with their relationship? Each case showed how managers and employees used a number of manager-employee social engagement strategies simultaneously pertaining to secure base use and provision of support, with differing effects on their engagement states of mind and engagement behaviour. Also, each case illustrated the effect of pressure and stress on the individual participants and on the dyad in relation to: (a) the use of manageremployee social engagement strategies; and (b) the effect of these strategies on engagement behaviour. While these findings do not suggest causality, they do suggest that understandings about the individual use of manager-employee social engagement strategies and use of the strategies in workplace relationships — such as the manager-employee relationship — can be drawn from these findings.

For example, each case showed how diverse secure base experiences (across the strategies) within workplace relationships occur during the course of actually doing one's work (engagement behaviour); and that these seem to influence states of mind pertaining to engagement. Further, each case showed how states of mind pertaining to MESE strategies (as demonstrated in the survey data) were associated with participants' reported interactions and descriptions of efforts to: (a) maintain engagement when under pressure; and (b) re-establish levels of engagement when under stress.

Moreover, understanding about how participants used different manageremployee social engagement strategies was extended by viewing these scores and relationship questionnaire scores in conjunction with participants' descriptions of how these scores made sense to them (in light of their personal stories). In turn, understanding about when participants used different manager-employee social engagement strategies was extended by viewing their strategy scores in conjunction with their relationship questionnaire scores, and experiences of 
pressure and stress. For example, case study 1, 2, 4 and 5 explicitly highlighted the influence of life history on the use of social engagement strategies used under pressure and stress; case study 3 implicitly showed this.

In summary, this chapter provided five distinct case-based examples organised similarly to enable inter-case comparison. In turn, each case highlighted differences between: (a) data about the phenomena of social engagement strategies; and (b) data that captured something of the lived experiences of the phenomena. To further understand the survey and the case study data, Chapter 6 reports on and discusses findings from an inter-case comparison. 


\section{Chapter 6: Discussion}

This chapter reports the results from the inter-case comparison and analysis and then contributes a theoretical framework of manager-employee engagement to the engagement literature. The implications of this framework for organisations, their managers and employees endeavouring to implement changes in employee engagement are considered. The research limitations and strengths are outlined and suggested areas for future research are delineated. The chapter ends with a concluding statement.

\subsection{Inter-Case Comparison of Manager-Employee Social Engagement Strategies}

Descriptive data from across the cases was analysed regarding the uses of and the experiences of each manager-employee social engagement strategy in relation to engagement. Three key sets of findings emerged: cross-case descriptions of the varying manager-employee social engagement strategies; patterns of manager-employee social engagement strategy use and job and organisation engagement; and where data permitted, social data pictures relating to the other variables of interest (attachment, perceived organisational support, organisational commitment and intention to quit/turnover).

\subsubsection{Cross-case descriptions of the manager-employee social engagement strategies.}

Themes and sub-themes were grouped together that best represented the quality of each manager-employee social engagement strategy and its association with engagement. Overall, the density of data for this analysis was weighted towards descriptions that characterised the connect-act strategy, reflecting the sampling bias of the cases. However, taking this bias into account, descriptive data was available pertaining to each theorised manager-employee social engagement strategy, including a possible fourth manager-employee social engagement strategy.

Table 61 summarises the survey and cross-case social data pertaining to the manager-employee social engagement strategies. Then I provide the inter-case findings for each of the strategies moving from the most commonly described 
strategy (connect-act) and the most consistently related to higher levels of

engagement, to the least common but most disruptive pattern of engagement

(disconnect-immobilise).

Table 61

Summary of the MESE Strategies

\begin{tabular}{|c|c|c|c|}
\hline MESE strategy & $\begin{array}{l}\text { Statistical association } \\
\text { with JE and OE }\end{array}$ & $\begin{array}{l}\text { Experiences of } \\
\text { MESE strategy } \\
\text { (Social data) }\end{array}$ & $\begin{array}{c}\text { Descriptions of } \\
\text { engagement } \\
\text { experiences and } \\
\text { behaviour. }\end{array}$ \\
\hline Connect-act & Higher JE and OE & $\begin{array}{l}\text { A dynamic interplay } \\
\text { between the external, } \\
\text { internal and } \\
\text { interpersonal } \\
\text { dimensions with the } \\
\text { interpersonal dimension } \\
\text { actively employed to } \\
\text { reduce the experience } \\
\text { of stress, and to inform } \\
\text { action as a way to } \\
\text { sustain engagement } \\
\text { behaviour }\end{array}$ & $\begin{array}{l}\text { High levels of } \\
\text { engagement }\end{array}$ \\
\hline Disconnect-act & $\begin{array}{l}\text { Lower OE and no } \\
\text { significant change in JE }\end{array}$ & $\begin{array}{l}\text { Underplay the } \\
\text { experience of stress and } \\
\text { interpersonal } \\
\text { relationships and } \\
\text { emphasise action in the } \\
\text { external dimension }\end{array}$ & Mixed engagement \\
\hline Stress-immobilise & Lower JE and OE & $\begin{array}{l}\text { Stress is communicated } \\
\text { but the interpersonal } \\
\text { dimension is under- } \\
\text { used to relieve the } \\
\text { stress. Stress remains } \\
\text { which can immobilise } \\
\text { attempts to return to } \\
\text { exploration. } \\
\text { Experiences described } \\
\text { as: } \\
\text { Lonely and anxious } \\
\text { about being } \\
\text { professionally exposed } \\
\text { as incompetent at work. }\end{array}$ & Mixed engagement \\
\hline Disconnect-immobilise & $\begin{array}{l}\text { No statistical data } \\
\text { available as not } \\
\text { assessed in the MESE } \\
\text { survey }\end{array}$ & $\begin{array}{l}\text { Daunted and isolated } \\
\text { Too overwhelmed to } \\
\text { connect or engage. The } \\
\text { primary focus is self } \\
\text { managing the internal } \\
\text { dimension as a way to } \\
\text { be available to connect } \\
\text { and act. } \\
\text { Disconnected and } \\
\text { Immobilised }\end{array}$ & Low engagement \\
\hline
\end{tabular}




\subsubsection{Connect-act.}

When under pressure, this strategy involved connecting with others around the experience of pressure and the task at hand to maintain engagement. This strategy can be characterised by the following sequence of interactions:

1. Actively connecting with others about the issue at hand as a way to relieve pressure by having the experience of pressure acknowledged; followed by a collaborative effort to problem solve.

2. Returning to the job or task at hand with a fresh purpose.

The experience of connection was variously described in ways that directly related to sharing the experience of the problem, in conjunction with solving the problem, 'with just a little bit of his time I am good to go and get back to work' (CS1E). Connection provided a clearer picture of the problem to inform the way forward. Action occurred following connection, which entailed a fresh capacity to draw dynamically on external, internal and interpersonal dimensions simultaneously to reduce stress and maintain engagement.

\subsection{External dimension.}

Features of the external dimension were described in terms that reflected a positive view of self and others. For example, goal sharing was marked by 'finding the common ground' $(\mathrm{CS} 1 \mathrm{M})$, and by establishing role clarity in association with organisational goals (CS1M, CS2M and CS4M). Organisational stress was described in ways that were publically recognisable, such as the global financial crisis (CS4M), working in a construction site (CS2M), and the increasing demand for services (CS1M). Job tasks were discussed in ways that directly included the interpersonal dimension, such as: interpersonal communication with staff (CS1M, CS2M, CS4M and CS4E); establishing clear and connected boundaries with the staff $(\mathrm{CS} 1 \mathrm{M})$; and taking time to get to know them (CS1M, CS2M and CS4M). Finally, issues to do with roles at work were also included in the interpersonal dimension, where the role of the manager was differentiated from the relationship with staff (CS1M), and where getting a job done included purposeful interpersonal collaboration (CS1E, CS2M, CS2E, CS4E and CS4M). 


\subsection{Internal dimension.}

The positive view of self and of others was also reflected in the internal dimension, where the secure attachment classification was most associated with this strategy (CS1M, CS2M, CS4M, CS4E and CS5E). This mind state of attachment indicator was reflected in descriptions that included confident and active interpersonal secure base use at times of pressure or conflict. This selfconfidence was matched with a confidence in others to be supportive. CS4M and CS4E especially illustrated this confidence in the secure base system. Also, reflecting the use of secure strategies, this dimension highlighted a seamless flexible dance between thinking and experiencing emotions associated with both secure base use and provision, which in turn supported a return to exploration (e.g. CS1, CS2 and CS4).

Use of connect-act was also characterised by acknowledging that development, as a worker who consistently used connect-act strategies when under pressure, took time (CS1M, CS2M and CS2E, CS4M, CS5M and CS5E). This includes training over a long period of time (CS2E) and self reflection (CS1M, CS1E, CS2M, CS2E, CS4M, CS4E, CS5M, and CS5E). Finally, it included a mind state described as 'mistakes can be mended' (CS1).

Concerning mind states about engagement, based on the NZ MESE survey data, the connect-act strategy provided a unique statistical picture with engagement and engagement-related variables. For managers, there was a positive and significant association between connect-act and secure attachment; and connect-act and job engagement, organisation engagement and organisation commitment, and a negative significant association with intention to quit/turnover and perceived organisational support. While the social data supported the overall statistical picture, it did not support the negative association between connect-act and perceived organisational support. Instead, descriptions consistently indicated a positive association between connect-act and perceived organisational support.

\subsection{Interpersonal dimension.}

Reflecting the internal dimension, this strategy was used to reduce the pressure using the interpersonal dimension as a way to actively cue another about the experience of pressure at work (CS2E, CS3E and CS4M). Secure base use was 
confidently sought out with an expectation that the quality of help provided would reduce the pressure where, as illustrated by CS1E, the process was not necessarily lengthy. In response, secure base provision was prompt and maintained until the other person was ready to get back into work. This was also the case whereby conflict was managed in conjunction with supporting staff work through the conflict (CS1M, CS2M, and CS4M).

In turn, interpersonal interactions during secure base and provision provided experiences of interactive reparation that included the flexible use of thoughts and emotions as sources of information to guide a collaborative problem solving process. These experiences were described in collaborative terms such as 'lifting together to get the task done' (CS1M).

These descriptions provided a different view of what Kahn (2002) observed as the 'paradox of self-reliance' (p. 239). Descriptions that matched Kahn's observations fitted the disconnect-act strategy outlined below. In contrast, the connect-act strategy paradoxically reached self-reliance using connection; with the experience of connect-act based self-reliance being described in qualitatively different ways to that of the disconnect-act strategy.

Essentially, the connect-act strategy highlighted anchoring relationships supported self-reliance as a way of sustaining levels of engagement behaviour when under pressure. For example, participants CS4E and CS4M described their experiences of autonomy using a process of shared stress regulation. In addition, case study 1 provided rich examples of the interactive process of 'rupture and repair' (Tronick \& Beeghly, 2011), that kept engagement high, with similar reparative processes being described in case study 4 and 5. The interpersonal relationship between these participants co-created a buffer to the stress, resulting in high levels of engagement being maintained.

\subsection{A dynamic interplay between the dimensions.}

Use of this strategy highlighted a dynamic flow between the dimensions, where the interpersonal and internal dimensions supported features of the external dimension, such as levels of engagement behaviour. Use of this strategy reflected Kahn's (1990) observations that greater amounts of personal engagement were associated with a dynamic interplay between the employment of actions, 
cognitions and emotions, as well as relationships between an individual and their role at work, the tasks they did and their interactions with others at work.

Similarly, use of the connect-act strategy described employees in the Hudson (2010) study who were empathic, showed increased discretionary effort and who considered their organisation to be 'available to help when distressed' ( $p$. 42). They were also most likely to show higher levels of engagement and also be classified in attachment terms as secure.

In addition, these findings suggested a positive contagion effect of the connect-act strategy in interpersonal relationships that 'hold[s] the potential for social contagion in which employees not only respond similarly to their shared work environment but also influence one another's experience of engagement' (Schaufeli \& Bakker, 2010, p. 5).

\subsubsection{Disconnect-act (SEDA).}

Use of this strategy involved disconnecting from the experience of pressure by being 'civil' (CSE5) to others while being self-reliant and focusing on the job as a way to maintain engagement. This strategy was characterised by the following sequence of interactions:

1. Actively self managing ones experience of pressure before connecting with others about the issue at hand.

2. Keeping pressure at bay by seeking help about tasks and solutions.

3. Return to exploration with new ideas regarding the task at hand, while continuing to self manage an ongoing experience of pressure.

The experience of disconnection was variously described as working alone to get the task done (CS5M) and overestimating the time it takes to connect with others (CS5E). In addition, CS5E described how she responded to other people's stress when she was already stressed, by increasing her focus on the tasks and reducing her contact with others. In turn, action entailed a capacity to draw dynamically on external and internal dimensions while underplaying the emotional experiences of stress in the interpersonal dimension, as a way to maintain engagement. 


\subsection{External dimension.}

Features of the external dimension were described in terms that reflected a positive view of self and a negative view of others. For example, goal sharing was marked by a tendency to fix the problem alone rather than by working with others (CS5E), and working alone with 'negative image[s] of others' (CS5E).

Organisational stress was described in clear and coherent ways as in the connectact descriptions. However, the personal effect of this on day-to-day work was under-acknowledged (CS1E). Descriptions about job tasks emphasised transactional matters, as illustrated in CS5 where staff were loaded up with projects that had tight deadlines, and were given 'no extra support' (CS5M). Similarly, issues to do with roles at work were also described in transactional ways (CS5).

\subsection{Internal dimension.}

The positive view of self and negative view of others was also reflected in the internal dimension, where the dismissing-avoidant attachment classification was most associated with this (CS1E). This mind state of attachment indicator was reflected in secure base use, which was used less than in the connect-act strategy; the use made of it was qualitatively different. For example, secure base use was preceded with self monitoring and regulation of the experience of pressure, with secure base use being reserved for task and practically oriented needs (CS3M and CS5E). In turn, help provision was expected in terms of practical solutions (CS3E and CS3M).

This strategy was underpinned with ideas such as it was better and faster to get down and do the job oneself. This was combined with a positive view of self, based on a self-confidence to manage under pressure that coexisted with a negative view of others. This was based on the belief that including others at such a time was less efficient in getting the job done. Descriptions also included focus on the cognitive (thinking about the job) and physical (doing the job) dimensions, with the social interpersonal dimension, under-used.

Based on the NZ MESE survey data, the disconnect-act strategy provided a unique statistical picture of states of mind concerning engagement and related variables. For managers, there was a negative and significant association between 
disconnect-act and organisation engagement, and a positive significant association with perceived organisational support, and dismissing-avoidant attachment; for employees, a negative significant association between disconnect-act and organisation engagement, and a positive significant relationship between perceived organisational support and organisation commitment.

While Hudson associated the avoidant attachment style with a 'negative view of the organization as being helpful or supportive' (Hudson, 2010, p. 42), the findings from the NZ MESE survey indicated higher levels of perceived organisational support and organisational commitment. Hudson (2010) identified avoidant attachment with 'not engaged to actively disengaged' (p. 42) behaviours. Similarly, the NZ MESE survey findings found lower levels of organisational engagement for managers and employees and lower levels of job engagement for managers; and the social data supported the overall statistical picture. In contrast, the social data seemed to indicate a positive association with connect-act and job engagement behaviour (CS1E and CS5E) and descriptions indicated a negative association between disconnect-act and perceived organisational support (CS5M). The social data did not provide evidence in support of a positive association between disconnect-act and perceived organisational support.

\subsection{Interpersonal dimension.}

Reflecting the internal dimension, this strategy was used to reduce pressure to maintain engagement, by minimally cueing others about the experience of pressure at work (CS3M and CS5E) and focusing on getting the job done. As a result, task focused secure base use was sought out, and/or asking for help when needed was avoided altogether (CS3E, CS3M, CS5M and CS5E). In addition, CS3M highlighted that not asking for help did not equate to a lack of stress: 'It's hard to be seen to need help' (CS3M). In conjunction, task focused secure base provision was evident in disconnect-act secure base provision (CS5M).

The interpersonal dimension during secure base and provision provided solution focused interactions that included the flexible use of thoughts and actions, while omitting sharing the experience of pressure as part of the problem solving process (as with the connect-act strategy). As such, the disconnection 
aspect of this strategy was not related to the relationship itself, but to the experience of stress in the relationship. This was especially highlighted in case study 3 , where the interpersonal relationship was actively connected to the task at hand, but not the experience of the stress/distress and the task in tandem, as in the connect-act strategy.

Regarding the paradox of self-reliance (Kahn, 2002), the disconnect-act strategy seemed to fit comfortably with this paradox. However, comfort with the strategy did not necessarily equate with better engagement outcomes. For example, as demonstrated in the next section, this strategy — while individually effective was-less effective than the connect-act strategy in supporting engagement in others. Similarly, an 'anchoring relationship' was characterised by task focused secure base provision, as noted in case study 3. Anchoring relationships are emotionally distanced, as a strategy to be self-reliant with sustained engagement.

\subsection{A dynamic interplay between the dimensions.}

Use of this strategy highlighted a dynamic flow between the internal and external dimensions, where the interpersonal dimension pertaining to the experience of pressure was underplayed in terms of its association with engagement. The disconnect-act strategy highlighted an interplay between selfconfidence in being able to draw on one's own resources at times of pressure, and a capacity to dynamically draw on cognitions and physical engagement dimensions while underplaying the interpersonal dimension. (Attending to this can be experienced as an additional pressure). Unlike the connect-act strategy above, where the interpersonal relationship seemed to function as a buffer to stress, the disconnect-act strategy predominantly drew on external and internal resources to seek support and provide support to others to maintain engagement. The overall effectiveness of this strategy to maintain engagement was less effective than that of connect-act strategy, but more effective than the stressimmobilise strategy. 


\subsubsection{Stress-immobilise (SESI).}

When under pressure, use of this strategy was characterised by experiencing, and at times communicating with others about this experience, as way to maintain engagement. Use of this strategy was characterised by the following sequence of interaction:

1. Experiencing high levels of stress at work.

2. Under-use of the secure base use system resulting in being immobilised with ongoing stress.

3. Limited capacity to focus on doing the job.

The experience of stress at these times was connected with negative views of self, such as worries about not doing a good job and what others thought about them (CS5M). The negative view of self, seemed to interrupt the process of actively cuing others about the experience of stress, resulting in feeling ashamed and lonely at work (CS5M). However, in contrast to the connect-act and disconnect-act strategies that resulted in action, the stress-immobilise strategy was characterised by immobilised action and reduced engagement (CS5M and CS2E in the past).

\subsection{External dimension.}

Features of the external dimension were described in terms that reflected a negative view of self and positive view of others. For example, goal sharing was marked by experiences of isolation and self preoccupation about one's competence (CS5M). Organisational stress was described in ways indicating being deeply personally affected, and in contrast to the connect-act and disconnect-act strategies, this stress effect was largely private. Concerning tasks and roles, there were little data to allow comment about these. However, it was of interest that this omission was juxtaposed with conversations indicating self preoccupation at these times, in contrast to considerations about tasks and roles.

\subsection{Internal dimension.}

The negative view of self and positive view of others, including the organisation, reflected the preoccupied attachment classification most associated with this strategy (CS2E historically and CS5M currently). Both C2E and CS5M 
identified historical childhood experiences of experiencing stress, combined with not being able to access secure base support reliably.

Under pressure, they experienced worry and uncertainty about their capacity to do the job at hand, in conjunction with experiencing worries about what others at work might think about them because of this (CS2E and CS5M). Stress and conflict at work prompted a preoccupation with oneself: largely in terms of one's competence as a worker, which in turn promoted a tendency to work alone with compromised work outputs. Further, doing the task when under pressure did not bring relief from experiencing pressure. As well, when this strategy was used to maintain engagement, thinking and active problem solving was under-used, making it a less effective strategy in contrast to connect-act and disconnect-act.

The NZ MESE survey data for managers and employees provided a unique statistical picture about mind states, which was largely supported by available social data (albeit minimal): a positive significant association between stress-immobilise, preoccupied attachment, intention to quit/turnover and perceived organisational support, and a negative significant association with job engagement, organisation engagement and organisational commitment. Further, Hudson (2010) associated the preoccupied style of attachment with being 'engaged to not engaged'. However, the findings here suggest lower levels of engagement a result of using this strategy.

\subsection{Interpersonal dimension.}

Reflecting the internal dimension (characterised by a negative view of self and positive view others when under pressure) this strategy was least effective at reducing pressure within the interpersonal context. To elaborate, interpersonal relationships were under-used to support engagement. Instead, they were used to acknowledge the experience of stress. Central to this strategy is an internal working model of the secure base system that expects uncertainty: uncertainty regarding secure base use, secure base provision and the capacity to do the job (CS2E and CS5M). In turn, interpersonal interaction during secure base use and provision were not focused on purposeful conversations at work about the tasks and goals of the organisation (Alfes et al., 2010; Gatenby et al., 2009; Soane et al., 
2012). Overall, use of the secure base system was characterised primarily by doubt about one's own competence. This was reflected in interactions with others at work oriented to either avoid conversations about work, such as 'going into my shell' (CS5M), or to interact with others, not about the shared work goals, but to be reassured about one's competence to do the job. In turn, this self-doubt functioned to minimise the use of initiative and creativity, as observed by Hudson (2010); it also made sense of why people who use this strategy 'consistently need reassurance and direction', while being 'less confident in making decisions' (Hudson, 2010, p. 42).

Further, use of this strategy at work was challenging as the very nature of work (akin to exploration) was likely to elicit a need for support. Use of this strategy involved a reduction in exploratory behaviour as a way to manage the internal expectations of support being unreliable. CS2E described her experience of this and described the efforts she had made to reduce the use of this strategy in a bid to do her job.

The experience of Kahn's (2002) 'paradox of self-reliance' appeared to compromise the capacity to sustain engagement. The perceived loss of others' availability when required to conduct a task functioned to increase stress, triggering preoccupied use of the secure base system, as illustrated in CS2E and CS5M. In turn, the stress-immobilise strategy highlighted anchoring relationships as unreliably available, which had the effect of immobilising efforts to engage in exploration.

\subsection{A dynamic interplay between the dimensions.}

Use of this strategy highlighted under-use of the external and interpersonal dimensions in favour of the internal dimension. The stress-immobilise strategy juggled a conflict in the internal dimension, whereby a lack of self-confidence was juxtaposed with an expectation that other people's support would be unreliable and ineffective. Unlike the disconnect-act strategy, where self-reliance reduces pressure which supports engagement, use of self-reliance in the stressimmobilise strategy did not support engagement behaviour. 


\subsubsection{Disconnect-immobilise (SEDI).}

When under pressure, use of this strategy was characterised by disconnecting from others and endeavouring to publically continue with one's job while feeling daunted, overwhelmed and not able to think clearly (CS3E and CS5M). Use of this strategy was characterised by the following sequence of interaction:

1. Acute and crippling internal experience of stress.

2. A disconnect from others to self manage distress in an endeavour to function at work.

3. Help not sought from others about the distress.

4. Engagement endeavoured but temporarily immobilised.

5. Overtime, the internal stress abated marking a return to use of other strategies.

The experience of disconnection occurred in response to immobilising fear (albeit temporary) that arose while attending to relatively typical job demands for the respective professions. Experiences were described in terms of being daunted, freaked out, overwhelmed, panicked and not knowing how to stop the feelings of fear (CS3E, CS3M and CS5M). Amid efforts to maintain engagement, engagement was immobilised. Engagement with the job at these times was secondary to managing the internal and private experience of fear.

In this study, this possible fourth strategy arose from the case study data. As such, there are not any NZ MESE survey statistics to draw on. However, a common feature of this strategy was an experience of fear. Attachment theory research identified fear as a core feature of an 'unresolved state of mind' about attachment (Main, 2000; Main et al., 1985; Waters \& Valenzuela1999).

\subsection{External dimension.}

Features of the external dimension were described in terms that reflected a negative view of self and others. For example, organisational pressure was described in terms that directly connected back to the overwhelming experience of personal stress. In turn, the job tasks at these times were talked about rationally, in the presence of crippling fear (CS3E). 


\subsection{Internal dimension.}

The negative view of self and of others, including the organisation, reflected the fearful-avoidant attachment classification most associated with this strategy (CS3E, CS3M and CS5M). This mind state of attachment indicator was congruent with descriptions of a loss of self-confidence at work, self-doubt, loss of connection and not knowing how to connect with others at work when overwhelmed by such feelings, with a sense of isolation from others.

In addition, overwhelming feelings interrupted thinking, and action highlighted an immobilised capacity to think and act:

I can't think straight and I can't solve simple problems ... this makes me more stressed ... it doesn't help to talk to people 'cos I am afraid they will think badly of me and it doesn't help to avoid them 'cos I am clearly not sorting things out myself very well. $(\mathrm{CS} 5 \mathrm{M})$

In turn, the fear was a response to the internal dimension, in contrast to external frightening events such as experiencing an earthquake at work. This seemed to increase feelings of shame that arose in response to these experiences of overwhelming anxiety and stress at work. In addition, these workers usually experienced themselves as highly engaged and high levels performers.

While these experiences were temporary (and low engagement was at these times also temporary), the effect of these experiences endured. For example as CS3E stated, although the experience was in the past, it remained 'daunting ... I don't really know how not to make that happen'. Similarly, CS5M stated he became fearful, isolated and distracted.

Concerning mind states about engagement, of the participants that reported these experiences, they each indicated the fearful-avoidant attachment classification. In addition, the two managers and the one employee each indicated low organisational commitment, perceived organisational support and high intention to quit/turnover. The two managers also scored below the mean for job engagement and organisation engagement.

\subsection{Interpersonal dimension.}

Reflecting an immobilised system under pressure, this strategy was used to reduce distress using the internal dimension to actively distance themselves from others to self manage feelings of overwhelming distress (CS3E, CS3M and 
CS5M). When the secure base system was used, it was for task management (CS3E) issues. The distress was not shared and there was an overall 'loss of a connection with others and not being able to control the loss' (CS3M). There were no examples of secure base provision, but it can be inferred it would typically be very task focused (amid great efforts to self manage experiences of fear). In addition, CS3M, CS3E and CS5M all described as much as possible avoiding interpersonal interaction with others at work when they were caught in this strategy. This was summed up as 'get me out of here' (CS3E).

Use of this possible strategy describes employees in the Hudson (2010) study who also identified with a fearful-avoidant attachment style, and who were found to consistently act out their unhappiness, ignored engaged employees and/or concentrated on tasks rather than organisational goals. Further, Hudson (2010) described this classification as 'actively disengaged'. The findings help to understand the connection between these observations and the interpersonal experience of engagement. For example, CS3E, CS3M and CS5M described being so overwhelmed at these times that their focus was solely on the selfpreservation of confidence and doing all they could to stop their poor performance being observed by others. This situation added to the experience of distress for these usually highly competent and engaged workers (CS3M, CS3E and CS5M).

These descriptions seemed to capture a strategy where distress was experienced to such a magnitude that the usual secure base system of help seeking, provision, stress reduction and getting back to work appeared abandoned. Instead, they favoured a personal strategy that involved help seeking and provision within oneself as self protective strategy.

\subsection{A dynamic interplay between the dimensions.}

Use of this strategy highlighted an acute awareness of the internal dimension, with a limited capacity to draw on the external and/or interpersonal resources for help, resulting in a temporary decline in engagement behaviour. For the participants in this study, such behaviours were the result of the dynamic interplay between the internal and interpersonal dimensions. In summary, personal efforts were directed towards self-preservation, with engagement and social engagement a secondary endeavour, as described especially by CS3E and 
CS5M. However, when not overwhelmed with stress, these participants used alternative strategies that were frequently in use, such as connect-act (CS3M, CS3E and CS5M), with self-reported higher levels of engagement.

\subsubsection{Patterns of MESE strategy use and engagement.}

Two overarching patterns of social engagement strategy and engagement were identified in the survey findings and the case studies. These are illustrated in Table 62. For example, findings pertaining to Proposition 4 generated an employee good fit model by positioning organisation engagement and job engagement as outcome variables instead of, as hypothesised, predictor variables. Further, when the two better-fitting models, one with connect-act and disconnectact as independent variables and one with stress-immobilise as a independent variable, were tested as one model, the model fit was poor. The statistical findings indicated that connect-act and disconnect-act worked differently from stressimmobilise in relation to the antecedent, engagement and outcome variables.

Similarly, the social-oriented case study data showed that the connect-act and disconnect-act strategies were most associated with sustained levels of engagement behaviour; with the stress-immobilise and disconnect-act strategies being consistently linked with a lowering of engagement behaviour when under pressure. In addition, the case studies contributed a view of the interpersonal dimension that helped explain variations in engagement behaviour based on the strategies used in the dyad, in contrast to viewing the individual manager or employee.

Table 62

Social engagement strategy-engagement patterns

\begin{tabular}{|c|c|c|}
\hline $\begin{array}{l}\text { Social engagement -engagement } \\
\text { patterns }\end{array}$ & MESE strategies & $\mathrm{JE}$ and $\mathrm{OE}$ \\
\hline $\begin{array}{l}\text { 1: Strategic use of social } \\
\text { engagement affecting engagement }\end{array}$ & $\begin{array}{l}\text { Connect-act } \\
\text { Disconnect-act }\end{array}$ & $\begin{array}{l}\mathrm{JE} \uparrow \mathrm{OE} \uparrow \\
\mathrm{OE} \downarrow \mathrm{JE}-\end{array}$ \\
\hline $\begin{array}{l}\text { 2: Strategic use of engagement } \\
\text { affecting social engagement }\end{array}$ & $\begin{array}{l}\text { Stress-immobilise } \\
\text { Disconnect-Immobilise }\end{array}$ & $\begin{array}{l}\mathrm{JE} \downarrow \\
\mathrm{JE} \downarrow \\
\end{array}$ \\
\hline
\end{tabular}




\subsubsection{Pattern one.}

This pattern illustrated the strategic use of social engagement to support the maintenance of engagement behaviour (connect-act and disconnect-act). For managers and employees, use of the connect-act strategy when under pressure saw a significant and positive effect on engagement, with levels of engagement more likely to be maintained. For example, the optimal dyadic strategy for maintaining higher levels of engagement was best illustrated in case study 4, where connectact plus connect-act equalled high engagement. Further, in dyads where at least one person used the connect-act strategy when under pressure, the other person (irrespective of their preferred manager-employee social engagement strategies) also seemed to manage work pressure in a way that resulted in engagement levels being maintained. This was illustrated in case study 1 and 2 .

In addition, managers and employees who used the disconnect-act strategy statistically indicated a non significant negative effect on job engagement and a negative significant effect on organisation engagement. However, their social data showed use of this strategy was frequently associated with personal levels of increased job engagement behaviour. This strategy was frequently used in varying ways in all of the cases (CS1, CS2, CS3, CS4 and CS5). However, in contrast to the connect-act strategy, it was less effective at supporting engagement behaviour in others who were under pressure.

\subsubsection{Pattern two.}

This pattern illustrated the strategic use of engagement behaviour to maintain social engagement (stress-immobilise and disconnect-immobilise). In contrast to Pattern 1, this pattern illustrated the strategic lowering of engagement behaviour in conjunction with efforts to use the secure base use system to reduce the experience of pressure and increase engagement. Not surprisingly, managers and employees who used this overarching pattern indicated lower levels of engagement behaviour when under pressure.

CS3E, CS3M and CS5M each described their experiences of this disconnect-immobilise strategy, which entailed not being able to cue for and access support when needed. As a result of not being able to draw on interactions to maintain engagement, they described reducing aspects of their typically high 
job engagement to manage stress. In attachment theory terms, in the absence of support from others, stress was self-managed by reducing exploration. In engagement terms, engagement was temporarily reduced to best maintain a social connection with others at work.

CS5M illustrated: (a) personal shame-like experiences that emerged as a result of using this pattern; and (b) the temporary nature of this pattern. CS5M used pattern two, but was helped back to pattern one strategies by CS5E, who used pattern one strategies when under pressure. Similarly, in case study 3 both members of the dyad shared: (a) personal shame-like experiences when they interacted in these ways; and (b) demonstrated the temporary nature of this pattern in their overall relationship. However, unlike CS5M, who used CS5E as a pattern one anchor relationship, this was not the situation for CS3E or CS3M. Both participants in the case study 3 dyad used this disconnect-immobilise strategy, albeit temporarily, and reported that maintaining high engagement levels was challenging.

Further, CS3E, CS3M and CS5M each highlighted the difference between stress and pressure, as differentiated by the World Health Organization (Leka et al., 2003). Under pressure they were often able to sustain pattern one strategies, but when pressure was experienced as stress, pattern two strategies were activated. Overall, the manager-employee social engagement strategies and the two overarching patterns highlight the dynamic and multidimensional nature of the interplay between context and engagement.

\subsubsection{Manager-employee social engagement strategies and dynamic relationships with states of mind about attachment and engagement.}

Managers and employees drew on multiple social engagement strategies at times of pressure, in ways that influenced their engagement behaviour and that of others. The dynamic relationship between the manager-employee social engagement strategies and job engagement and organisation engagement was further understood by examining: (a) attachment styles (the RQ scores) as an aspect of the internal dimension to help make sense of how the external and interpersonal dimensions are experienced; (b) manager-employee social engagement strategies and perceived organisational support; and (c) the 
interaction between manager-employee social engagement strategies, organisation commitment and the intention to quit/turnover.

\subsubsection{Attachment and the manager-employee social engagement strategies.}

The association between the relationship questionnaire scores and manager-employee social engagement strategy scores showed how the internal dimension interacted with the interpersonal and external dimensions. For example, scores from the relationship questionnaire were a consistent indicator of a manager's or employee's likely secure base use behaviour in response to pressure at work. In turn, this consistently correlated with levels of engagement behaviour. Further, the relationship questionnaire score assisted in understanding the use of manager-employee social engagement strategies at the dyad level. Viewing the relationship questionnaire score in conjunction with the manageremployee social engagement scores across the dyad was a better indicator of whether or not engagement behaviour would be maintained when under pressure than: (a) using the manager-employee social engagement scores with the engagement state of mind scores, such as job engagement and organisation engagement; or (b) using the engagement state of mind scores alone.

Moreover, throughout the study the original statistical function of the relationship questionnaire scores unexpectedly shifted. At the outset, these scores were used as a statistical measure to cross-check the validity of the manageremployee social engagement measures. However, in the case studies the relationship questionnaire scores were of interest to many participants. For example, participants with a categorical score of secure, dismissing and/or preoccupied spontaneously discussed their partners and families without any prompting, as they each made personal sense of their survey scores in association with their experiences of others at work. However, those fearful-avoidant score did not, with CS5M being the exception. Overall, the relationship questionnaire score was a useful tool for exploring the dynamic relationship between the dimensions of engagement in an organisational setting. 


\subsubsection{Stress-immobilise and the fearful-avoidant attachment.}

The NZ MESE survey findings highlighted an unexpected statistical association between stress-immobilise and fearful-avoidant attachment. Of the ten case study participants, statistical and social data from CS5M showed an association between the use of stress-immobilise strategies and the fearfulavoidant attachment. CS5M used stress-immobilise strategies when he experienced increased personal stress combined with the stress of managing others. In turn, this manager identified for himself that using the stress-immobilise strategy to manage stress was a high risk manoeuvre, as it placed him at higher risk to use the disconnect-immobilise strategy. This was a strategy that had a negative impact on his social engagement relationships at work and his engagement.

\subsubsection{Manager-employee social engagement strategies, perceived organisational support and attachment.}

When the statistical data regarding perceived organisational support (discussed in Chapter 4) was viewed in the context of interpersonal manageremployee relationships, another critical factor arose: states of mind (conscious and unconscious) about attachment (measured using the relationship questionnaire) seems to influence engagement.

To recap, statistical findings for managers in the NZ MESE study indicated a significant negative association between connect-act and perceived organisational support; and a significant positive association between disconnectact and perceived organisational support. In Chapter 4, I proposed that these findings might suggest that manager's variable use of social engagement strategies influences where they initially seek support (such as from interpersonal relationships or external organisational sources). In conjunction, the scale development process indicated that secure base use may be under-utilised by managers given their assumed role of conflict management and help provision with employees.

I viewed these findings and possible initial possible understandings in the light of the case studies data pertaining to organisational support, the relationship 
questionnaire and the manager-employee social engagement measures. Two overarching findings seemed to support the original hypothesis, in contrast to the NZ MESE survey findings regarding a negative association between manager perceived organisational support and connect-act:

1. In the case study sample, seven participants scored above the mean for perceived organisational support. Of these seven, five participants scored above the mean for the connect-act strategy and perceived organisational support.

2. Three participants scored below the mean for perceived organisational support and these same three participants each most identified with the fearful-avoidant (CS3E, CS3M, CS5M) classification. Two of these participants also scored above the mean for connect-act (CS3E and CS3M).

These findings highlight that irrespective of the manager-employee social engagement strategy preferred on a day-to-day basis, when participants felt increasingly under pressure, the relationship questionnaire score in conjunction with the manager-employee social engagement score seemed to better indicate how support would be accessed than their perceived organisational support score alone.

To elaborate, in the case studies, higher perceived organisational support was associated with the secure attachment (RQS). For example, of the five participants who identified secure attachment as a best descriptor, all of these participants also scored above the mean for perceived organisational support. Four out of five (CS1M, CS2M, CS4M and CS4E) also scored above the mean for connect-act, with CS1M, CS2M and CS4M also scoring above the mean for connect-act (support received); and CS4E above the mean for connect-act (connection). In addition, the social data provided by CS5E described a similar pattern when she was under extra pressure at work. CS5E typically used a MESE disconnect-act strategy at work. However, as pressure at work for her increased, consistent with her secure attachment score, she actively sought out and used the organisational support available, reflected in her high perceived organisational support score.

Next, low perceived organisational support was associated with the fearful-dismissing attachment. In turn, this was associated with constrained 
support seeking at times when needed. That is, support was not sought at all or was sought only to manage the physical and perhaps the cognitive aspects of stress. Support seeking regarding the 'daunting' (CS3E) emotional aspects was not reported. For example, CS3E and CS3M typically used MESE connect-act strategies, but under increasing pressure, evidence of their fearful-dismissing attachment scores seemed to be reflected in their difficulties to enlist the necessary support at these times, resulting in low perceived organisational support. Similarly, the interpersonal support seeking behaviour of CS5M, when under increasing pressure, also seemed to be influenced by his fearful-dismissing score with a corresponding low perceived organisational support. However, reflecting the dynamic nature of these social systems, CS5M demonstrated that when he actively and purposefully used connect-act strategies to seek help, his experience of support was qualitatively different and increasingly positive.

\subsubsection{Manager-employee social engagement strategies with organisational commitment and the intention to quit/turnover.}

In the NZ MESE survey data, age was significantly positively correlated with job engagement and intention to quit/turnover in the manager data and organisational commitment in the employee data, but this correlation did not affect the statistical outcomes of the tested models. However, age was revisited as a potential covariate in the case studies. Table 63 summarises the NZ MESE manager and employee survey data, plus the age of each case study participant and their respective survey scores for job engagement, organisation engagement, organisational commitment and intention to quit/turnover.

Table 63

Age and $J E, O C$ and ItQT

\begin{tabular}{|l|c|c|c|c|c|c|c|c|c|c|c|c|}
\hline Variable & M & E & CS & CS & CS & CS & CS & CS & CS & CS & CS & CS \\
& NZ & NZ & 1 & 1 & 2 & 2 & 3 & 3 & 4 & 4 & 5 & 5 \\
& $\begin{array}{l}\text { Study } \\
\text { Mean }\end{array}$ & $\begin{array}{c}\text { Study } \\
\text { Mean }\end{array}$ & $\mathrm{M}$ & $\mathrm{E}$ & $\mathrm{M}$ & $\mathrm{E}$ & $\mathrm{M}$ & $\mathrm{E}$ & $\mathrm{M}$ & $\mathrm{E}$ & $\mathrm{M}$ & $\mathrm{E}$ \\
& & & 45 & 38 & 65 & 50 & 40 & 30 & 35 & 52 & 46 & 36 \\
\hline Age & 3.89 & 3.69 & 3.20 & 4.25 & 2.80 & 3.80 & 2.26 & 4.20 & 4.00 & 2.60 & 2.00 & 3.00 \\
\hline OE & 3.82 & 3.32 & 3.20 & 4.00 & 2.60 & 4.00 & 2.25 & 4.80 & 3.83 & 2.00 & 2.17 & 3.60 \\
\hline OC & 2.64 & 2.58 & 3.67 & 2.16 & 2.50 & 2.83 & 2.30 & 3.50 & 3.17 & 4.00 & 2.33 & 4.00 \\
\hline ItQT & 2.25 & 2.41 & 3.00 & 1.66 & 2.66 & 1.00 & 2.60 & 2.66 & 2.33 & 2.30 & 3.00 & 3.00 \\
\hline
\end{tabular}

Notes. Manager (M); Employee (E); Case Study (CS). 
In the manager data, age was significantly negatively correlated with job engagement and intention to quit/turnover. In the case studies, this statistical trend was observed, but each case could be uniquely explained. For example, CS2M, aged 65 years, was readying himself for retirement. CS5M also indicated lower job engagement and higher intention to quit/turnover; however, this was directly associated with use of the disconnect-immobilise strategy. He reported increases in job engagement and decreases in intention to quit/turnover when he made more frequent use of the connect-act strategy.

In the employee data, age was significantly positively correlated with organisational commitment. This trend was observed in CS2E, aged 50 years, and CS4E, aged 52 years. Of note, both of these workers also scored lower on intention to quit/turnover. Using the secure base system to explain these findings, both CS2E and CS4E used connect-act strategies when under pressure at work, and both of these workers had managers who also frequently drew on connect-act strategies. Further, looking at the sub-component scores, both CS2E and CS4E scored above the mean for connect-act (connection), and below the mean for use of disconnect-act strategies. Collectively, this picture reflects features consistent with Pattern 1, with connect-act an optimal strategy within this pattern most likely to result in higher levels of job engagement and organisation engagement.

The NZ MESE survey study from both data sets showed connect-act as a mediator between job engagement and organisational commitment, and organisation engagement and organisational commitment; in the manager data set connect-act mediated between job engagement and intention to quit/turnover, and organisation engagement and intention to quit/turnover. Stress-immobilise was shown to be a mediator between perceived organisational support and job engagement and organisation engagement, while also mediating between job engagement and organisation engagement, and organisation engagement and intention to quit/turnover. Overall, organisational commitment and intention to quit/turnover seemed to be predictor variables rather than outcome variables.

Not surprisingly, the case study data further complicated this picture. The case study data did not confirm any lines of directionality between the varying states of mind pertaining to engagement. Instead they support the idea proposed by Kahn (1990), and further supported by Sonnentag (2003) that intra-individual 
differences in engagement occurred on any given day at work in conjunction with workers' levels of engagement.

The findings here also add an alternative explanation for individual differences. Instead of a personality or trait-based explanation, these findings show how the secure base system (Crowell et al., 2002) can explain differences in engagement at an individual and a dyadic level. That is the operation of the secure base system when under pressure variously affects secure base use, secure base provision and the capacity to maintain engagement. It affects the dynamism of a multidimensional engagement system.

\subsubsection{Summary: inter-case analysis.}

The findings above extend current understandings about the interplay between the internal, external and interpersonal contexts of engagement. For example, these empirical findings show how managers and employees (a) strategically use their interpersonal relationship in ways that influence their engagement, and (b) strategically adapt their engagement to influence their relationship.

\subsection{Theoretical Framework: Manager-Employee Engagement}

Building on the reviewed literature and the framework outlined in Chapter 2 , I now draw on the findings above to develop a 'dynamic process model' of engagement (Kahn, 1990, p. 717). I outline a theoretical framework of manageremployee engagement that highlights engagement as a dynamic and multidimensional system, within which social engagement strategies are central. It is based on a hypothesised model of engagement as an open and socially situated system. The framework explains varying levels of engagement and demonstrates how changes in social engagement strategies at work might also change levels of engagement. It aims to capture something of a meso-level view of engagement by emphasising 'the incremental effects of the interaction between variables at the various levels of analysis' (House et al., 1995, p. 85). As such it is designed to complement 'the deceptive tidiness of individual, group, and organization' (Rousseau \& House, 1994, p. 16) boundaries. 


\subsubsection{Manager-employee engagement: a multidimensional system.}

The relationship between managers and employees is a multidimensional organisational system comprised of three core dimensions: external, internal and interpersonal (previously defined in Chapter 2 and elaborated in Chapter 5). Within this hypothesised system, the manager-employee relationship is conceptualised as an engagement relationship that includes (at least) three factors:

1. An employee's experience of the interplay between the internal, external and interpersonal dimensions of engagement, which includes their states of mind concerning attachment and engagement, and their engagement behaviour directed towards their work, other employees and the goals of the organisation.

2. A manager as the representative of the organisation and their experience of the interplay between the internal, external and interpersonal dimensions of engagement, which includes their states of mind concerning attachment and engagement and their engagement behaviour directed towards their work, other employees and the goals of the organisation.

3. The dynamic interplay of the dimensions of engagement, including experiences and engagement behaviour that unfolds between a manager and an employee in regard to each other, the job and the organisation.

In this framework (illustrated in Figure 27), the interpersonal dimension, represented by the manager-employee social engagement strategies, acts like an anchor from which to view and understand the interplay between the internal (states of mind) and the external (the job/task) dimensions. In tandem, the influence and the effect of pressure and stress on managers and employees (which, as we saw in the case studies) can be situated in and across every dimension. Similarly, the two overarching patterns of social engagement strategies in association with engagement can also be represented in and across each dimension.

Further, the framework is purposefully coloured. Building on the use of a coloured quadrant in case study 5 , this framework is similarly coloured. For example, the intersection of manager connect-act with employee connect-act (as in CS4) showed optimal outcomes for maintaining high engagement. This segment is coloured green to depict the optimal set of dimensions most likely 
associated with high engagement. On the other hand, the intersection of manager disconnect-immobilise with disconnect-immobilise, albeit temporary, was associated with high levels of personal self-regulation, combined with lower levels of engagement. This segment is coloured red. The light amber segment represents the stress-immobilise strategy and its related features, and the dark amber segment represents the disconnect-act strategy and associated features. Further, we saw in case study 1,2 and 5 the dynamic capacity of the strategies when viewed within the context of a relationship. In these cases, the use of connect-act strategies (green segment) by one member of the dyad, was effective in drawing the other member back from other colours (including the red segment) towards experiences of work and relationships more characteristic of the connectact experience; this importantly included the highest levels of sustained engagement behaviour when under pressure.

Overall, this framework provides a map to track an endless possibility of sequential interactions between employees' and managers':

1. states of mind pertaining to engagement-related constructs

2. interpersonal experiences of the secure base system within the manageremployee relationship

3. engagement behaviour.

The remainder of this section elaborates on the key features mentioned above. 


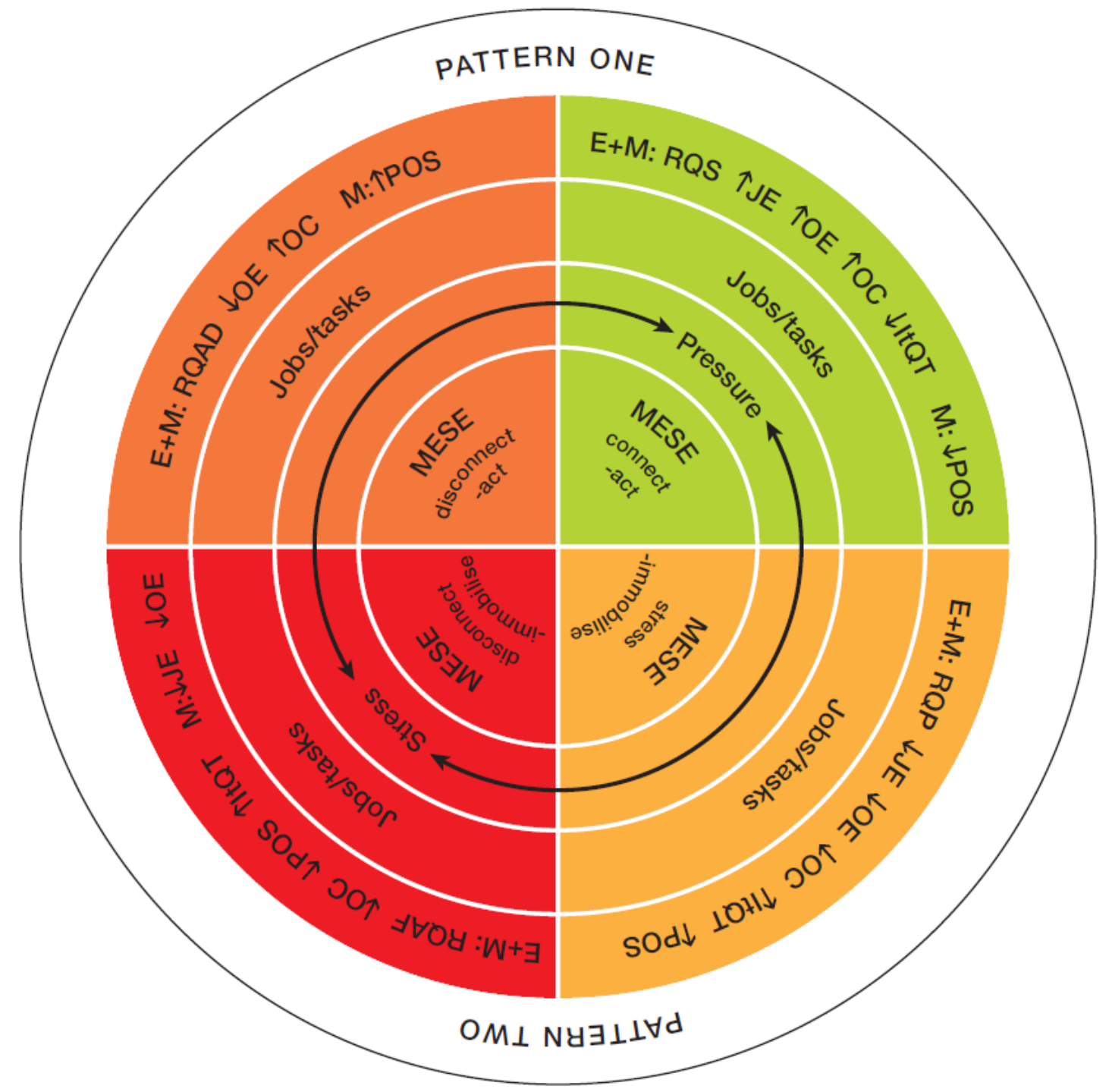

Notes: $\mathrm{E}=$ employee; $\mathrm{M}=$ manager; $\uparrow=$ above the NZ MESE survey mean; $\downarrow$ below the NZ MESE survey mean

Figure 27. A theoretical framework of manager-employee engagement. 


\subsubsection{Manager-employee social engagement strategies.}

The multidimensional manager-employee social engagement strategies are situated at the hub of the framework as way to reflect the unique individual and dyadic interplay of internal, external and interpersonal dimensions. For example, in the case studies, internal dimension survey findings from CS1M and CS4E indicate lower engagement. However, there is no other evidence to support these findings. In fact, the evidence representing data from the external and interpersonal dimensions indicates that these workers actually behaved in ways at work consistent with high levels of engagement.

Further, the multidimensional secure base system is central to the logic and coherence of the manager-employee social engagement strategy concept. As such, the ecological validity of manager-employee social engagement scores can be increased by collecting data from managers and employees that concerns: (a) their states of mind pertaining to engagement; (b) examples from themselves and in relationship with each other about their engagement behaviour; and (c) how their states of mind about engagement and their levels of engagement behaviour change over time in response to experiences of stress and pressure.

\subsubsection{Pressure-stress.}

Manager's and employee's responses to pressure and stress are situated as an intermediary influence (with the external tasks required to do ones job) between manager-employee social engagement strategies and mind states pertaining to engagement (such as job engagement and organisation engagement). For example, across the five case studies (CS4 being the exception), as stress increased participants were increasingly likely to shift from the use of connect-act as a primary strategy, to using the disconnect-act and or stress-immobilise strategies. Four out of five of the cases (CS1, CS2, CS3 and CS5) identify the most common alternative strategy to connect-act when under pressure as the disconnect-act strategy. In turn, this strategy is statistically associated with lower levels of organisation engagement, and non significant associations with job engagement. 
These findings elaborate on the World Health Organisation (WHO) description of workplace pressure and stress, provided in Chapter 1. Work pressure is described as 'unavoidable due to the demands of the contemporary work environment' (Leka et al., 2003, p. 3) and is considered a potential motivator to getting a job done. The case studies provide a plethora of examples of managers and employees experiencing workplace pressure (CS1M, CS2E, CS2M, CS4E, CS4M and CS5E). These findings extend this broad and largely external view of pressure, to include an association between: (a) the capacity to maintain engagement with the job when under pressure; and (b) the secure base system of interpersonal relationships.

Moreover, "when that pressure becomes excessive or otherwise unmanageable it leads to stress. Stress can damage your workers' health and your business performance' (Leka et al., 2003, p. 4). This transition from pressure to stress, with a negative effect on organisational behaviour and health, is illustrated by CS3E, CS3M and CS5E. Each describe their experiences of moving from pressure to stress and the negative effect this had on their engagement and their self-esteem at work.

Further, attending to experiences of pressure and stress in conjunction with engagement, using the attachment theory informed model of secure base use and provision (Crowell et al., 2002) extends the current use of attachment theoryinformed workplace research in two ways. First, it builds on a trait approach by including interpersonal factors that have been shown to be related to engagement behaviour. Consistent with Tronick and Beeghly (2011), this framework shows that patterns of interaction between social engagement (manager-employee social engagement strategies) and engagement (job engagement and organisation engagement) are typically complex and non-linear, and are influenced by experiences of stress and pressure. Second, findings indicate intra-person diversity concerning use of different parts of the overarching secure base system. That is findings indicate that workers might use different strategies related to different parts of the secure base use and provision system.

These findings confirm Tronick and Beeghly's (2011) model of messy interactions as typical, rather than atypical. That is, messy interpersonal factors as an organisational context are present and influence organisational outcomes, irrespective of whether we attend to them or not. Overall, there is utility in 
including the mess of interactions in our quest to further understand engagement behaviour.

\subsubsection{Jobs/tasks.}

While the focus of data collection was on the internal and the interpersonal dimensions, data from across the cases highlight features in the external dimension such as doing jobs and tasks as examples of engagement behaviour when under pressure and stress. Illustrating a positive experience, CS2E describes how doing her tasks and jobs had extended her and built her capacity to maintain engagement under pressure. In contrast, CS3E reports how a change in the job from being a 'sort of jack-of-all-trades' who could easily slot into different projects, to being now 'quite specialised', had made it difficult to share work. As a result, he had experienced increasing isolation at work. For CS3E, this experience did not typically affect his job engagement and organisation engagement, but when especially stressed at work, this isolation added another factor which made it difficult to seek help when he needed it.

The case studies also showed differences in how participants described the external dimension of their job. For example, participants that used connect-act strategies (the green segment) when under stress spontaneously described the external aspects of their jobs in ways that included the interpersonal dimension (e.g. CS1M, CS2M and CS4M). Participants that used the disconnect-act strategies (dark amber segment) when under pressure described the external dimension of their job in technical terms (CS3E, CS5E). Participants that experienced stress and who used the disconnect-immobilise strategy temporarily disconnected from doing their job. In addition, the use of pattern two strategies seemed to function as an anchor from which to re-engage with the external dimension of doing their job and the interpersonal dimension of re-engaging with colleagues.

\subsubsection{Mind states of engagement.}

In this framework, the commonly assessed variables such as perceived organisational support, job engagement, organisation engagement, organisational commitment and intention to quit/turnover are positioned on an outer circle. These 
constructs represent an employee's or manager's states of mind about themselves in relation to their job and their organisation, and the secure base system. From these mind states we can infer subsequent organisational behaviour on the proviso that we differentiate between an inference and an observation. Each coloured segment denotes the pattern of significant statistical associations between the corresponding manager-employee social engagement strategies. For example, in the green segment, the associated variables and their relationship with the connect-act strategy are denoted as follows: E + M: RQS, $\uparrow \mathrm{JE}, \uparrow \mathrm{OE}, \uparrow \mathrm{OC}, \downarrow$ ItQT M: $\downarrow$ POS. That is, from the employee and manager NZ MESE survey data, secure attachment, job engagement, organisation engagement and organisational commitment were significantly and positively associated with connect-act, and intention to quit/turnover was significantly and negatively associated. In the manager data, perceived organisational support was significantly and negatively associated with connect-act.

\subsubsection{Overarching patterns of social engagement and engagement.}

The outer circle represents the identified overarching patterns of engagement and interaction. These overarching patterns provide another window (albeit an open systems window) from which to map what we saw in the case studies. Managers and employees use a range of strategies that traverse both overarching patterns. In turn, the different strategies highlight a unique set of goals with unique engagement outcomes. Understanding these goals might inform pathways to increase engagement at both an individual and dyad level. For example as illustrated in case study 5 where CS5M shifted from strategy two, to strategy one use with self reported increases in engagement.

Furthermore, the two overarching patterns capture the theoretical interplay of the dimensions and the dissolution of the dimensions in practice.

Differentiating internal, interpersonal and external dimensions highlights the inclusion (and at times the exclusion) of social engagement strategies in association with states of mind and engagement behaviour. However, the case studies remind us that the practice of engagement is messy and non-linear with little regard for boundaries between the dimensions. For example, the participants 
simultaneously traversed boundaries in their narrative descriptions of their experiences of engagement with each other and their jobs.

\subsubsection{Theoretical framework: a summary.}

This theoretical framework highlights engagement as a dynamic system. Anchoring interpersonal engagement relationships at the framework hub suggests that engagement may operate as a meso-level organisational context. In turn, this suggests that further development of this framework would explore ways to view the multi-directional relationship between engagement and its social context.

\subsection{Implications}

The goal of this research was to increase our understanding of the interpersonal context of engagement. My hypothesis was that making connections between interpersonal manager-employee relationship, attachment, and mind states pertaining to engagement had the potential to provide insights into how to increase engagement. It was hoped that any new insights could be used to generate new practices and programmes aimed at increasing engagement. The framework developed by this research project has generated a new explanation for differences in engagement. It asserts that multidimensional engagement data is optimal for understanding engagement and informing engagement programmes. In turn, the framework offers a different route for increasing levels of engagement and provides a basis for implementing new types of engagement programmes.

\subsubsection{A new explanation for low engagement.}

Findings from this research suggest that we should not bypass the interpersonal dimension when explaining levels of engagement. This is because engagement intersects with the interpersonal manager-employee relationship, which is a mainstream aspect of organisational life. These findings complement current explanations for engagement that typically emphasise a connection between individual (internal) features such as management style and various mind states about engagement; and organisational (external) features, such as job characteristics, resources, rewards, and organisational outcomes like profit margins. The findings here highlight how workplace social engagement 
relationships traverse internal, interpersonal and external boundaries, irrespective of whether we attend to this or not.

In turn, the new framework developed by this research asserts, as Kahn (1990) did, that engagement can be more fully understood using a triadic dimensional lens that includes the interpersonal dimension. It also goes a step further by situating the interpersonal dimension as the hub of an engagement system. This approach shows that engagement can be explained in part as a system of relationships, where the focus of understanding is on how, when and why the parts of the system interact.

Explaining engagement as a system contextualises engagement knowledge within a dynamic process that includes the interplay of internal, external and interpersonal dimensions. However, including the interpersonal dimension undoubtedly complicates engagement research that has historically emphasised an internal and external boundary.

\subsubsection{An alternative route for increasing levels of engagement.}

The inclusion of social engagement strategies contributes to understanding changing levels of engagement behaviour. This suggests that engagement programmes could be more tailored to understanding employees' social engagement strategies when under pressure. It follows that future engagement programmes could be designed to include: (a) organisation specific activities to increase engagement; and (b) manager and employee specific activities to develop understandings about unique internal and interpersonal influences on their engagement.

This approach would entail a multidimensional approach to engagement, such as: (a) connecting first with the goals of the organisation (the external dimension); (b) connecting with staff mind states about engagement and attachment (internal dimension); and (c) providing a setting within which to understand the variety of manager-employee engagement strategies (interpersonal dimension) and their influence on engagement. Based on this data, an engagement action plan could be formulated that included a generic organisational approach, and a specific manager-employee approach. Such an approach, akin to a connectact strategy implemented at an organisational level, has the potential to increase 
the efficacy of future engagement programmes, and consequent higher engagement levels.

Moreover, the two overarching dynamic social engagement-engagement patterns also provide a possible map to changing levels of engagement behaviour. First, current engagement programmes that focus directly on the goal of increasing engagement match the engagement goals of workers who use pattern one strategies. However, for workers who use pattern two strategies when under pressure, the primary goal comprises the reduction of stress. Increasing engagement is a secondary goal. By implication, these workers might benefit more from engagement programmes that:

1. Explicitly demonstrate external and reliable secure base provision at a managerial and organisational level.

2. Provide repeated opportunities for workers to experience reliable secure base provision as a precursor to practicing secure base use.

3. Introduce new engagement goals after employees and managers demonstrate a capacity to maintain pattern one strategies of engagement when under stress.

\subsubsection{Management training and coaching.}

The framework developed here has the potential to inform management training and coaching with individual, dyads and with teams who work in direct relationship with each other on a shared goal. The framework provides a map for making sense of internal factors in an interpersonal context as a way to change features in the external dimension, such as engagement behaviour. As such the framework could inform management training that includes managers reviewing the interplay between aspects of their life history that have shaped how they think, work and relate to others at work when under pressure.

The framework could also inform workplace coaching where the coachee is the manager-employee relationship. The manager-employee interpersonal relationship is a central engagement context and could become the unit of training, in contrast to training for individual managers in isolation from their staff. Training programmes could focus on the multidimensional secure base system in conjunction with engagement. Such an approach acknowledges 
understanding the unique constellation of strategies and patterns of each individual in each relationship as a step in the process of developing and implementing engagement programmes.

For example, in support of the notion that the manager-employee relationship is a driver of engagement, the framework can be used to consider unique critical entry ports of change regarding engagement for managers and employees. For example, managers could be encouraged through training and coaching to identify and develop secure base use relationships as a way to support them in their role as a manager. This training/coaching could also entail identifying their preferred source of support when under pressure; and ascertaining if their current approach to secure base use is effective in helping them to support employees' engagement.

On the other hand employees could be encouraged with their supervisors, through dyadic/team coaching and training, to identify their unique use of manager-employee social engagement strategies along with their unconscious states of mind about attachment. This in turn could support the development of positive experiences of supervisor support, and in turn, positive experiences of organisational support; both of which were indicated as potential critical entry points of change in the good-fit employee models of engagement.

Moreover, the case studies illustrated the relative simplicity of the surveyinterview-dyad interview model. This model could be developed into a multidimensional coaching tool. Such a tool would focus on the interplay between experiences of stress and pressure, social relationships at work, secure base provision and use, and engagement behaviour. For example, the evolving feedback model in the case studies provided space for participants to connect with their findings across each dimension. That is the MESE survey provided a springboard to examine states of mind and dyadic interaction experiences of engagement when under pressure. In turn, making sense of the internal findings within the interpersonal dimension appeared to have an effect on the external dimension. This process was especially evident in case study 5 .

Finally, the research feedback model that evolved during the case studies paradoxically created an organisational space within which to talk about interpersonal engagement in a way that was not overly personal. However, case study 3 highlights the need for training and coaching approaches to be uniquely 
participant sensitive, and for trainers and coaches to develop assessment tools to guide the focus of the intervention before the training and or coaching begins. That is, for coaches and trainers to connect with managers and employees before implementing a coaching and or training programme.

For example, using the NZ MESE survey as an assessment tool, the relationship questionnaire score could guide the feedback approach. For example, if one or both parties indicate fearful-avoidant attachment in their survey, then this could be an indication that the multidimensional exploratory feedback model needs to be adapted. It is possible, with further refinement that the MESE survey findings may also be able to generate a global classification of pattern one and pattern two. Such a classification may guide the structure of coaching and or training in a way that optimises when needed opportunities to experience of support and use of support, in preparation for increasing engagement behaviour.

\subsubsection{Types of engagement data.}

The fourth implication from this study is a call to review how we typically collect engagement data (i.e. surveys) and who we collect engagement data from (individuals). The findings above remind us that surveys provide attitudinal data. They do not provide information about engagement behaviour. To collect information about engagement behaviour, organisational behaviour pertaining to engagement needs to be observed. The attachment theory informed secure base system provides a theoretical platform from which to extend the types of engagement data collected. It supports the collection of interpersonal data for the purposes of attending to the association between patterns of, and experiences of interaction at times of stress and pressure alongside self-reported levels of engagement.

This approach bridges: (a) the categorical and dimensional type approach to conceptualising and assessing attachment (typical in organisational science see Game, 2011) with; (b) the predominant use of interview and observation in the clinical use of attachment (Cassidy \& Shaver, 2008); and (c) the work on social engagement (Alfes et al., 2010; Gatenby et al., 2009) that introduced the notion of frequency and amount of social interaction to the broader picture of engagement. Further, as Ainsworth et al. (1978) have shown, observations of behaviour are 
best made when contextualised within the relevant relationship. By implication, for organisations to implement an optimal engagement programme, knowledge about the relationships within which the engagement programme is to be implemented is salient.

\subsection{Limitations and Strengths}

\subsubsection{Limitations.}

The reach of the survey study was NZ-based managers and employees who had internet access. Further, this study set out to research the manageremployee relationship as a driver of engagement. Given the complexity involved in researching this relationship, other socially oriented workplace relationships, such as relationships with peers, were not directly studied. Similarly, engagement involves the communication of organisational goals across dimensions and levels. The manager-employee relationship provided a window from which to view this communication, but it remains a constrained view.

In addition, the purposive sampling procedure used in the case studies was intentional and underpinned part of the study's ethics. However, in doing so it biased the sample towards the increased likelihood of cases illustrating connectact strategies. As a result, the social data in this study tells us more about this strategy than it does about the other strategies.

Concerning the process of scale development and construct validity, exploratory factor analysis provided preliminary data to support the ongoing process of construct validity. As I did not have the sample size to run exploratory and confirmatory factor analysis I infer that the manager-employee social engagement strategies show: (a) promise as valid constructs with high alpha scores (each above 0.70); and (b) practice utility in the case studies. However, the construct validation process is ongoing and requires a further study to be conducted with the same scales as in the manager-employee social engagement survey from which results can be analysed using confirmatory factor analysis.

Moreover, I conducted five manager-employee dyad case studies, but I did not continue to the point of theoretical saturation because:

1. The five case studies provided a rich source of data from which to make meaningful sense of the statistical data. 
2. The social case study data indicated a possible fourth manager-employee social engagement strategy: disconnect-immobilise. This socially generated strategy had theoretical links with attachment theory, but it had not yet been statistically tested.

3. Case study five highlighted an emerging development concerning how to feedback the survey data to participants in a way that made space for their active participation in the feedback process. This emerging process indicated a new direction in which to conduct subsequent studies. At this juncture, I took stock of the process and wanted to develop the feedback tool in conjunction with statistically validating the disconnect-immobilise strategy, before collecting further data.

Finally, while the overall design was experimental, the case studies were exploratory in nature. I did not design the studies to effect change in, nor evaluate changes in, levels of engagement. These studies generated rich descriptive social data from which an association between manager-employee social engagement strategies and changes in engagement behaviour could be made. However, the case studies did not provide data from which to prove a causal link between manager-employee social engagement strategies and levels of engagement.

\subsubsection{Strengths.}

The mixed methods design and theoretical framework were strengths within this study. First, findings from this study are the direct result of the mixed methods design. The survey findings showed that the manager-employee social engagement strategies of connect-act, disconnect-act, and stress-immobilise were reliable and had convergent validity with the relationship questionnaire attachment classification system. In addition they collectively contributed statistically to linear models of engagement and the case studies provided qualitative follow-up explanations to the statistical models.

In viewing the quantitative findings with a qualitative lens, I was able to explain something of why the statistics showed these results, which in turn illuminated nuances of manager-employee social engagement strategies. For example, the case studies highlighted the dynamic nature of manager-employee social engagement strategies. They showed how participants used the manager- 
employee social engagement strategies, and how they adapted them to suit the dynamic engagement dimensions, including the interpersonal manager-employee relationship. The participant stories socially connected the statistics with day-today experiences at work in ways that were unique and fluid, yet simultaneously recognisable.

Second, conceptualising engagement as a multidimensional concept, in conjunction with the use of attachment theory as a systems theory, provided a base from which to explore and explain the survey and case study findings. This theoretical base supported connections with the existing engagement literature, while maintaining focus on the interpersonal dimension of engagement within the social context of the manager-employee relationship. Similarly, the secure base phenomenon provided a map for case study participants to describe their experiences of engagement within their relationships at work in association with their engagement behaviour.

In summary, this approach supported a dynamic view of engagement and attachment. It illustrates the utility of attachment as a secure base system within organisational relationships. As a result, this study provides an alternative attachment theory lens to complement the personality-oriented lens which is dominant in attachment theory workplace research (Game, 2011; Neustadt et al., 2011).

\subsection{Future Research}

Further examination of the emergent theoretical framework suggests a future research agenda that shifts social engagement between managers and employees from the periphery of engagement research to its hub. Such an agenda might include (among many others) focusing on:

1. meso-level engagement research

2. the interpersonal manager-employee engagement relationship

3. finding out more about how we interact with each other when under pressure as a route to changing how much we are engaged

4. attachment theory as a social systems theory

5. issues of methodology in engagement research. 


\subsubsection{Meso-level engagement research.}

This study demonstrates the influence of manager-employee engagement strategies on engagement at the individual and the dyad level. However, to learn more about how these strategies function at an individual, dyad and potentially at a team level, a meso-level approach to research is required. This approach would focus on the complex interplay of social engagement strategies across dimensions. Such a lens complicates linear models of engagement that tend to bypass interpersonal engagement phenomena.

In turn, this research agenda may generate meso-level models of engagement. Such models would aim to conceptualise and operationalise engagement-related phenomena such as 'systems of emotional attachments and detachments' (Kahn, 1998, p. 70), and their association with engagement behaviour. In addition, these models may capture more of the 'messy' goaloriented social engagement interactions (Tronick \& Beeghly, 2011) that the case studies illustrated. Overall, meso-level models of engagement have the potential to capture the interactions between multidimensional descriptors of engagement.

\subsubsection{The manager-employee engagement relationship.}

Findings from this study highlight the utility of researching the manageremployee interpersonal relationship as a mainstream, organisational context. From the corporate boardroom to the busy open offices of community workers, there is much to learn about researching the interplay between internal, external and interpersonal dimensions of engagement at work.

For example, much remains to be explored regarding the manageremployee social engagement strategies in conjunction with constructs such as transactional and emotional engagement (Gourlay et al., 2012), as well measures of social engagement (Alfes et al., 2010; Gatenby et al., 2009). In addition, there remains much to understand about the various ways that managers and employees strategically adapt their interactions to maintain engagement, and or strategically adapt their levels of engagement to maintain a connection with each other, in turn supporting engagement.

Beyond the sample of this study, many workers are in some form of manager-employee relationship, and these relationships involve interactions as a 
part of communicating organisational goals, central to the practice of job and organisation engagement. Therefore, future research on the manager-employee engagement relationship has broad relevance as a research domain. Paradoxically, engaging in dynamic and systemic interpersonal workplace research is not a mainstream field in organisational research. However, findings from this study confirm the relevance of a future research agenda that places the manageremployee interpersonal relationship at the centre of engagement research. In addition and cited previously, support for person-to-person relationship research comes from both within the engagement field and within organisational science at large. For example it sits well within the research agendas of leader-member exchange theory.

\subsubsection{Keeping stress at bay and pressure in check.}

In keeping with the multidimensional theme, this study has highlighted that pressure and stress at work includes both the usual protagonists of internal personal factors and external organisational factors. However, it has also shown that the interpersonal dimension appears to affect both how and how much we engage, and the degree to which the interpersonal context contains pressure holding stress at bay. Future research on the experience of moving from pressure to stress and from stress to pressure would further develop a dynamic and systemic framework of engagement.

For example, there is the potential for a collaborative research approach to occur between: (a) attachment theory researchers who are examining the role and functions of close interpersonal relationships regarding associations between stress, social development and explorations (Lyons-Ruth \& Jacobvitz, 2008); and (b) organisational researchers who are studying the interplay of psychological and physiological stress and stressors in the workplace (Ganster \& Rosen, 2013).

\subsubsection{Attachment theory and engagement research.}

Attachment theory provided the theoretical underpinning which enabled a strategic and process-oriented view of social engagement in association with engagement - a hypothesised form of exploration. My goal here was to establish whether the model of engagement that emerged in a theoretical framework was 
useful for understanding the research problem (Patton, 2002b). Other frameworks, such as leader-member exchange theory, would undoubtedly have uncovered aspects of the data that this framework did not.

Therefore, future engagement research focusing on the interpersonal dimension would provide an avenue for the development of a theoretical relationship between Leader-member exchange and attachment theory to further an understanding of engagement. Collectively, both leader-member exchange theory and workplace attachment theory deal with everyday interpersonal issues in the workplace, such as asking for and offering help. Yet, as Richards and Hackett (2012) observed, there have been 'surprisingly ... no studies of LMX that have drawn from attachment theory' (p. 686). Researching engagement provides an opportunity for LMX and attachment theory to collaborate in an effort to further understandings about person-to-person relationships at work in association with organisational goals.

\subsubsection{Methodology.}

Future research into the multidimensional nature of engagement as a system invites a plethora of methodological considerations. First, continued validation of the manager-employee social engagement variables is needed using confirmatory factor analysis, sector specific studies and cross-cultural studies. At best, this ongoing linear research, which largely captures internal mind states of engagement, would occur in direct association with workplace conversations and observations of engagement behaviour.

Second, methodological approaches might include mixed methods design and longitudinal studies. In my research study, the benefits of mixed methods design are espoused and made use of, but the absence of observational longitudinal data is recognised. As a consequence, the statistics were generalisable to the sample, and the cases supported analytical generalisability (Yin, 2009); however, the findings here are not yet generalisable to populations (Stake, 1995; Yin, 2009). Future research could further operationalise the emergent theoretical framework to test its generalised applicability. In particular, investigation of the manager-employee social engagement strategies in conjunction with levels of engagement could suit a large-scale mixed methods design with matched pairs, or 
sets of workers within a team. In doing this, the proposed combinations of manager-employee social engagement strategies (and their potential link to measures of engagement) could be further explored.

It is acknowledged that mixed methods research is not a panacea to the challenges involved in quantifying and qualifying engagement phenomena. This is especially so as the practice of engagement encompasses the ever-elusive, unconscious and hard-to-capture social contexts. However, participants in the practice of research can teach us much about un-boundaried data as a pathway to understanding. For example, the case study participants seamlessly mixed their social and statistical data within the study. They mixed their data across time (past and present) and contexts (home and work) without concern for the theoretical debates about mixing qualitative and quantitative data. Further mixed methods engagement research would support increasing understandings about the interplay between linear descriptors and non-linear experiences of engagement.

Longitudinal studies are also suggested as a way to further explore engagement, as a system practised within diverse and dynamic social contexts within an organisation. While this study included cross-sectional survey alongside the individual and dyad interviews conducted across time, overall, the data in this study provides but a 'snapshot' of manager-employee social engagement. Future longitudinal research could increase understanding of engagement as a way to combine cross-sectional data and interview data while making a return to Kahn's (1990) original ethnographic participant observation studies. Longitudinal studies would greatly contribute to further developing a dynamic and people-oriented process understanding of engagement.

\subsection{Conclusion}

Engagement knowledge has grown, and increasing engagement has been identified as a central business issue, yet industry research continues to report low levels of engagement. Examining the literature to understand this anomaly, two issues were noted. First, engagement was originally conceptualised as a multidimensional construct, including the interpersonal dimension. Current engagement research emphasises the manager-employee relationship as central to the logic of engagement. Yet, the interpersonal manager-employee relationship is 
rarely studied as an engagement-related unit of analysis. Instead, engagement research has focused on internal and external dimensions of engagement.

Second, attachment has been frequently used to capture the amount of an employee's connection with their organisation, but attachment theory has been under-used to examine the manager-employee engagement relationship. For example, attachment theory research has typically researched attachment within an individual personality paradigm. As a result, models based on individual attachment styles and engagement have been developed (Hudson, 2010). Attachment theory as a social systems theory has been under-used for examining the social relationship between managers and employees, as a way to further understand levels of engagement.

To address this gap, I explored how managers and employees strategically managed their relationship to optimise their engagement at work. The study focused on the manager-employee relationship as a social engagement relationship. I developed an attachment theory-informed theoretical framework, which was designed to examine multiple dimensions of this relationship, including the interpersonal dimension. This framework was then used to explore the intersection of engagement and the MESE relationship.

Findings support a multidimensional view of engagement (Kahn, 1990), and they elaborate on recent engagement research that purposefully includes social engagement (Alfes et al., 2010; Gatenby et al., 2009) and attachment (Hudson, 2010). They show the utility of a multidimensional lens for understanding how social engagement strategies are related to engagement, and vice versa.

Collectively, these findings were used to develop a theoretical framework of manager-employee engagement that extends current attachment theory informed engagement research in three primary ways: conceptually, theoretically and methodologically. As a result, this study contributes: (a) the concept of manager-employee social engagement strategies and their respective scales; (b) a theoretical framework of manager-employee engagement; and (c) a possible new approach that includes both survey and interview techniques to examine engagement as a multidimensional organisational context.

These contributions advance understanding of the central question of this thesis: how do managers and employees strategically manage their relationship to 
optimise their engagement at work? Based on the premise that the manageremployee relationship is central to the logic of engagement, the interpersonal secure base system is central to the logic of attachment and the multidimensional manager-employee relationship is a driver of engagement, this study answered the question as follows. When under pressure, managers and employees use various combinations of social engagement strategies to engage with each other to optimise their capacity to maintain engagement with their job and their organisations. The quality of these social strategies appears to be influenced by the interplay of internal and external dimensions that includes perceptions and experiences about the nature of the current manager-employee, interpersonal secure base system. These social engagement strategies have a direct affect on engagement behaviour and vice versa. Finally, future research recommendations suggest a research agenda that anchors the manager-employee relationship as a multidimensional and perhaps a meso-level context at the centre of the swirling intersection of engagement. 


\section{References}

Agarwal, U., Datta, S., Blake-Beard, S. \& Bhargava, S. (2012). Linking LMX, innovative work behaviour and turnover intentions: The mediating role of work engagement. Career Development International, 17(3), 208-230.

Ainsworth, M. S. \& Wittig, B. (1969). Attachment and the exploratory behaviour of one-year-olds in a strange situation. In B. M. Foss (Ed.), Determinants of infant behaviour (Vol. 4., pp. 113-136). London: Methuen.

Ainsworth, M. S., Bell, S. \& Stayton, D. (1971). Infant-mother attachment and social development: Socialisation as a product of reciprocal responsiveness to signals. In M. Woodhead, R. Carr \& P. Light (Eds.), Becoming a person (pp. 30-55). London: Routledge.

Ainsworth, M. S., Blehar, M., Waters, E. \& Wall, S. (1978). Patterns of attachment: A psychological study of the strange situation. Hillsdale, NJ: Erlbaum.

Albrecht, S. (2010) (Ed.). Handbook of employee engagement: Perspectives, issues, research and practice. Cheltenham, UK: Edward Elgar Publishing.

Alfes, K., Truss, C., Soane, E. C., Rees, C. \& Gatenby, M. (2010). Creating an engaged workforce. London: Chartered Institute of Personnel and Development (CIPD).

Antonucci, T., Akiyama, H. \& Takahashi, K. (2004). Attachment and close relationships across the life span. Attachment and Human Development, 6(4), 353-370.

Aon Hewitt. (2011). Trends in global employee engagement. Retrieved January 5, 2011 from http://www.aonhewitt.com

Armstrong, J. (2007). Statistical significance tests are unnecessary even when properly done and properly interpreted: Reply to commentaries. International of Journal of Forecasting, 23, 335-336.

Aselage, J. \& Eisenberger, R. (2003). Perceived organizational support and psychological contracts: A theoretical integration, Journal of Organizational Behavior, 24(5), 491-509. 
Aspelmeier, J. \& Kerns, K. (2003). Love and school: Attachment/exploration dynamics in college. Journal of Social and Personal Relationships, 20, 530.

Bakker, A. B., Albrecht, S. \& Leiter, M. P. (2011). Key questions regarding work engagement. European Journal of Work and Organizational Psychology, 20(1), 4-28.

Bakker, A. B. \& Leiter, M. P. (2010). Where to go from here: Integration and future research on work engagement. In A. B. Bakker \& M. P. Leiter (Eds.), Work engagement: A handbook of essential theory and research (pp. 181-196). New York: Psychology Press.

Baron, R. \& Kenny, D. (1986). The moderator-mediator variable distinction in social psychological research: Conceptual, strategic, and statistical considerations. Journal of Personality and Social Psychology, 51(1), 1731,182 .

Bartholomew, K. (1990). Avoidance of intimacy: An attachment perspective. Journal of Social and Personal Relationships, 7, 147-178.

Bartholomew, K. \& Horowitz, L. (1991). Attachment styles among young adults: A test of a four-category model. Journal of Personality and Social Psychology, 61, 226-244.

Bates, S. (2004). Getting engaged. HR Magazine, 49(2), 44-51.

Baumruk, R. (2004). The missing link: The role of employee engagement in business success. Workspan, 47, 48-52.

Benson, G. (2006). Employee development, commitment, and intention to turnover: A test of 'employability' policies in action. Human Resource Management Journal, 16(2), 173-192.

Bentler, P. \& Chou, C. (1987). Practical issues in structural modeling. Sociological Methods and Research, 16, 78-117.

Betzner, A. (2008). Pragmatic and dialectic mixed methods approaches: An empirical comparison. Unpublished $\mathrm{PhD}$ thesis, University of Minnesota, USA.

Biwas, S. \& Bhatnagar, J. (2013). Mediator analysis of employee engagement: Role of perceived organizational support, P-O Fit, organizational commitment and job satisfaction. Vikalpa, 38(1), 27-40. 
Blessing White (2008). The state of employee engagement: North American overview white paper. Retrieved November 24, 2008, from www.blessingwhite.com

Bobko, P. (2001). Correlation and regression: Applications for industrial organizational psychology and management (2nd ed.). Thousand Oaks, CA: Sage Publications.

Bowlby, J. (1969). Attachment and loss Vol. 1: Attachment. London: The Hogarth Press.

Bowlby, J. (1973). Attachment and loss Vol. 2: Separation, anxiety and anger. London: The Hogarth Press.

Bowlby, J. (1980). Attachment and loss Vol. 3: Loss, sadness and depression. London: The Hogarth Press.

Bowlby, J. (1988). A secure base: Clinical applications of attachment theory. London: Routledge.

Bryant, F. \& Satorra, A. (2012). Principles and practice of scaled difference chisquare testing. Structural Equation Modeling, 19, 372-398.

Buckingham, M. \& Coffman, C. (1999). First break all the rules: What the world's greatest managers do differently. Sydney: Simon \& Schuster.

Buckner, S. (2005). Taking the debate on reflexivity further. Journal of Social Work Practice, 19(1), 59-72.

Cabrera-Nguyen, P. (2010). Author guidelines for reporting scale development and validation results. Journal of the Society for Social Work and Research, 1(2), 99-103.

Carnelley, K. \& Ruscher, J. (2000). Adult attachment and exploratory behavior in leisure. Journal of Social Behavior and Personality, 15, 153-165.

Cassidy, J. \& Shaver, P. (Eds.). (2008). Handbook of attachment: Theory research and clinical implications (2nd ed.). New York: Guilford Press.

Catteeuw, F., Flynn, E. \& Vonderhorst, J. (2007). Employee engagement: Boosting productivity in turbulent times. Organization Development Journal, 25(2), 151-157.

Chiu, C., Lin, C., Tsai, Y. \& Hsiao, C. (2005). Modelling turnover intentions and their antecedents using the locus of control as a moderator: A case of customer service employees. Human Resource Development Quarterly, 16(4), 481-499. 
Cohen, J. (1988). Statistical power analysis for the behavioral sciences (2nd ed.). Hillsdale, NJ: Erlbaum.

Cohn J. \& Tronick E. (1989). Specificity of infants' response to mothers' affective behavior. Journal of the American Academy of Child \& Adolescent Psychiatry, 28, 242-248.

Colaizzi, P. (1978). Psychological research as the phenomenologist views it. In R.Valle \& M. King (Eds.), Existential-phenomenological alternatives for psychology (5th ed., pp. 48-71). New York: Oxford University Press.

Colarelli, S. (1984). Methods of communication and mediating processes in realistic job previews. Journal of Applied Psychology, 69, 633-42.

Comrey, A. \& Lee, H. (1992). A first course in factor analysis. Hillsdale, NJ: Earlbaum Associates.

Corporate Leadership Council (2004). Employee engagement survey: Driving performance and retention through employee engagement. Retrieved May 6, 2010, from www.corporateleadershipcouncil.com

Costello, A. \& Osborne, J. (2005). Best practices in exploratory factor analysis: Four recommendations for getting the most from your analysis. Practical Assessment Research and Evaluation, 10(7), 1-9.

Coyle-Shapiro, J. A-M. \& Conway, N. (2004). The employment relationship through the lens of social exchange In: J. A-M. Coyle-Shapiro, L. Shore, S. Taylor \& L. Tetrick, (Eds.), The employment relationship: Examining psychological and contextual perspectives (pp. 5-28). Oxford, UK:

Oxford University Press.

Coyle-Shapiro, J. A-M., \& Kessler, I. (2000). Consequences of the psychological contract for the employment relationship: a large scale survey. Journal of Management Studies, 37(7), 903-930.

Coyle-Shapiro, J. A-M. \& Shore, L. (2007). The employee organization relationship: Where do we go from here? Human Resource Management Review, 17(2), 166-179.

Coyle-Shapiro, J. A-M., Shore, L., Taylor, S. \& Tetrick, L. (2004). The employment relationship: Examining psychological and contextual perspectives. Oxford, UK: Oxford University Press.

Crawford, S., Couper, M. \& Lamias, M. (2001). Web surveys: Perceptions of burden. Social Science Computer Review, 19, 146-162. 
Cresswell, J. \& Plano Clark, V. (2007). Designing and conducting mixed methods research. Thousand Oaks, California: Sage Publications.

Cronbach, L. (1951). Coefficient alpha and the internal structure of tests. Psychometrika, 16, 297-334.

Cropanzano, R. \& Mitchell, M. (2005). Social exchange theory: An interdisciplinary review. Journal of Management, 31, 874-900.

Cross, R., Gray, P., Gerbasi, A. \& Assimakopoulos, D. (2012). Building engagement from the ground up: How top organizations leverage networks to drive employee engagement. Organizational Dynamics, 41(3), 202211.

Crowell, J., \& Feldman, S. (1991). Mothers' working models of attachment relationships and mother and child behaviour during separation and reunion. Developmental Psychology, 27, 597-605.

Crowell, J., Fraley, R. \& Shaver, P. (2008). Measures of individual differences in adolescent and adult attachment. In J. Cassidy \& P. Shaver (Eds.), Handbook of attachment: Theory, research, and clinical applications (2nd ed., pp. 599-634). New York: Guilford Press.

Crowell, J., Pan, H., Gao, Y., Treboux, D., O'Connor, E. \& Waters, E. (1998). The secure base scoring system for adults. Retrieved May 5, 2011, from www.psychology.sunysb.edu/attachment/measures/content/SBSS_man ual_v2_1998.

Crowell, J. \& Treboux, D. (1995). A review of adult attachment measures: Implications for theory and research. Social Development, 4, 294-327.

Crowell, J., Treboux, D., Gao, Y., Fyffe, C., Pan, H. \& Waters, E. (2002). Assessing secure base behavior in adulthood: Development of a measure, links to adult attachment representations, and relations to couples' communication and reports of relationships. Developmental Psychology, 38, 679-693.

Crowell, J. \& Waters, E. (2005). Attachment representations, secure base behavior and the evolution of adult relationships: The Stony Brook Adult Relationship Project. In K. Grossman, K. Grossman \& E. Waters, (Eds.), Attachment from infancy to adulthood: The major longitudinal studies (pp. 223-245). London: The Guilford Press. 
Cullinane, N., \& Dundon, T. (2006). The psychological contract: A critical review. International Journal of Management Review, 8(2), 113 - 129.

Cunliffe, A. \& Eriksen, M. (2011). Relational leadership. Human Relations, 64(1), 1425-1449.

Czarnowsky, M. (2008). Learning's role in employee engagement. Alexandria, VA: An ASTD Research Study, American Society for Training and Development.

Dachler, H. \& Hosking, D. (1995). The primacy of relations in socially constructing organizational realities. In D. Hosking, H. Dachler, \& K. Gergen (Eds.), Management and organization: Relational alternatives to individualism (pp. 1-29). Aldershot: Avebury.

Dahl, F., Grotle, M., Benth, J. \& Natvig, B. (2008). Data splitting as a countermeasure against hypothesis fishing: With a case study of predictors for low back pain. European Journal of Epidemiology, 23(4), 237-242.

Dansereau, F., Jr., Graen, G., \& Haga, W. (1975). A vertical dyad linkage approach to leadership within formal organizations - a longitudinal investigation of the role making process. Organizational Behavior and Human Performance, 13, 46-78.

De Lange, A., De Witte, H. \& Notelaers, G. (2008). Should I stay or should I go? Examining longitudinal relations among job resources and work engagement for stayers versus movers. Work \& Stress, 22(3), 201-223.

de Vaus, D. (2002). Surveys in social research (5th ed.). London: Routledge. Denzin, N. (1989). The Research Act (3rd ed.). Englewood Cliffs: Prentice Hall. Dillman, D., Smyth, J. \& Christian, L. (2009). Internet, mail, and mixed-mode survey: The tailored design method. Hoboken, NJ: John Wiley \& Sons.

Dillman, D., Tortora, R. \& Bowker, D. (1999). Principles for constructing web surveys. Retrieved November 6, 2010, from http://survey.sesrc.wsu.edu/dillman/papers/websurveyppr.pdf

Dunning, H., Williams, A., Abonyi, S. \& Crooks, V. (2008). A mixed method approach to quality of life research: A case study approach. Social Indicators Research, 85, 145-158.

Eisenberger, R., Cummings, J., Armeli, S. \& Lynch, P. (1997). Perceived organizational support, discretionary treatment, and job satisfaction. Journal of Applied Psychology, 82, 812-820. 
Eisenberger, R., Huntington, R., Hutchison, S. \& Sowa, D. (1986). Perceived organizational support. Journal of Applied Psychology, 71, 500-507.

Eisenberger, R., Stinglhamber, F., Vandenberghe, C., Sucharski, I. \& Rhoades, L. (2002). Perceived supervisor support: Contributions to perceived organizational support and employee retention. Journal of Applied Psychology, 87(3), 565-573.

Eisenhardt, K. (1989). Building theories from case study research. Academy of Management Review, 14(4), 532-550.

Eisenhardt, K. (1991). Better stories and better constructs: The case for rigor and comparative logic. Academy of Management Review, 16(3), 620-627.

Eisenhardt, K. \& Graebner, M. (2007). Theory building from cases: Opportunities and challenges. Academy of Management Journal, 50(1), 25-32.

Ferris, G., Liden, R., Munyon, T., Summers, J., Basik, K. \& Buckley, M. (2009). Relationships at work: Toward a multidimensional conceptualization of dyadic work relationships. Journal of Management, 35(1), 1379-1403.

Field, A. (2009). Discovering statistics using SPSS. London: Sage.

Gallup Organization (2009). Employee engagement: What's your engagement ratio? Retrieved August 15, 2009, from http://www.gallup.com/consulting/121535/Employee-EngagementOverview-Brochure.aspx

Game, A. M. (2011). Leadership and attachment: Understanding interpersonal dynamics in leader-follower dyads. In A. Bryman, D. Collinson, K. Grint, B. Jackson \& M. Uhl-Bien (Eds.), SAGE handbook of leadership (pp. 916-947). London: Sage.

Ganster, D., \& Rosen, C. (2013). Work stress and employee health: A multidisciplinary review. Journal of Management, 39(5), 1085-1122.

Gatenby, M., Alfes, K., Truss, K., Rees, C. \& Soane, E. (2009). Harnessing employee engagement in UK public services. Paper presented at the Public Management Research Association Conference, Columbus, Ohio.

Gatenby, M., Rees, C., Soane, E., \& Truss, K. (2008). Employee engagement in context. London: Chartered Institute of Personnel and Development.

George, C., Kaplan, N. \& Main, M. (1985). Adult attachment interview protocol. Unpublished manuscript, University of California at Berkeley, USA. 
George, C. \& Solomon, J. (1999). Attachment and caregiving: The caregiving behavioral system. In J. Cassidy \& P. R. Shaver (Eds.), Handbook of attachment (pp. 649-670). New York, NY: Guilford.

George, C. \& West, M. (2001). The development and preliminary validation of a new measure of adult attachment: The adult attachment projective. Attachment and Human Development, 3, 30-61.

Gioia, D. \& Pitre, E. (1990). Multiparadigm perspective on theory building. The Academy of Management Review, 15(4), 584-602.

Gonzalez-Roma', V., Schaufeli, W. B., Bakker, A. B. \& Lloret, S. (2006). Burnout and work engagement: Independent factors or opposite poles? Journal of Vocational Behavior, 68, 165-174.

Gorsuch, R. (1983). Factor Analysis (2nd ed.). Hillsdale, NJ: Erlbaum.

Gourlay, S., Alfes, K., Bull, E., Baron, A., Petrov, G. \& Georgellis, Y. (2012). Emotional or transactional engagement — does it matter? Research Insight, May, London: CIPD.

Graen, G. \& Cashman, J. (1975). A role-making model of leadership in formal organizations: A development approach. In J. Hunt \& L. Larson (Eds.), Leadership frontiers (pp. 143-165). Kent, OH: Kent State University Press.

Green, S. (1991). How many subjects does it take to do a regression analysis? Multivariate Behavioral Research, 26, 449-510.

Greene, J. \& Caracelli, V. (2003). Making paradigmatic sense of mixed methods practice. In A. Tashakkori \& C. Teddlie, (Eds.), Handbook of mixed methods in social and behavioral research (pp. 91-110). Thousand Oaks, CA: Sage.

Griffin, D. \& Bartholomew, K. (1994a). Models of the self and other: Fundamental dimensions underlying measures of adult attachment. Journal of Personality and Social Psychology, 67(3), 430-445.

Griffin, D. \& Bartholomew, K. (1994b). Metaphysics of measurement: The case of adult attachment. In K. Bartholomew \& D. Perlman (Eds.), Advances in personal relationships, Vol. 5: Attachment processes in adulthood (pp. 1752). London: Jessica Kingsley. 
Grossmann, K. E. \& Grossmann, K. (1991). Attachment quality as an organizer of emotional and behavioral responses in a longitudinal perspective. In $\mathrm{C}$. Parkes, J. Stevenson-Hinde \& P. Marris (Eds.), Attachment across the life cycle (pp. 93-114). London/New York: Tavistock/Routledge.

Grossmann, K. E., Grossmann, K. \& Zimmermann, P. (1999). A wider view of attachment and exploration: Stability and change during the years of immaturity. In J. Cassidy \& P. Shaver (Eds.), Handbook of attachment: Theory, research, and clinical applications (pp. 760-786). New York: Guilford Press.

Grossmann, K., Grossmann, K. \& Waters, E. (Eds.). (2005). Attachment from infancy to adulthood: The major longitudinal studies. London: The Guilford Press.

Hallberg, U. \& Schaufeli, W. (2006). 'Same same' but different: Can work engagement be discriminated from job involvement and organizational commitment? European Psychologist, 11(2), 119-127.

Handy, C. (1989). The age of unreason. Boston, USA: Harvard Business School Press.

Handy, C. (1994). The age of paradox. Boston, USA: Harvard Business School Press.

Hardy, G. \& Barkham, M. (1994). The relationship between interpersonal attachment styles and work difficulties. Human Relations, 47(3), 263-282.

Harms, P. (2011). Adult attachment styles in the workplace. Human Resource Management Review, 21, 285-296.

Hart, C. (2005). Doing your masters dissertation. London: Sage Publications.

Harter, J., Schmidt, F., Killham, M. \& Agrawal, S. (2009). Q12 Meta-analysis:

The relationship between engagement at work and organizational outcomes. Omaha, NE: Gallup.

Hartley, J. (2004). Case study research. In C. Cassell \& G. Symon (Eds.), Essential guide to qualitative methods in organizational research (pp. 323-348). London: Sage.

Hazen, C. \& Shaver, P. (1987). Romantic love conceptualized as an attachment process. Journal of Personality and Social Psychology, 52, 511-524.

Hazen, C. \& Shaver, P. (1990). Love and work: An attachment theoretical perspective. Journal of Personality and Social Psychology, 59, 270-80. 
Hinkin, T. (1998). A brief tutorial on the development of measures for use in survey questionnaires. Organizational Research Methods, 1, 104-121.

Hinkle, D., Wiersma, W. \& Jurs, S. (2003). Applied statistics for the behavioural sciences (5th ed.). New York: Houghton Mifflin.

House, R., Rousseau, D. \& Thomas-Hunt, M. (1995). The meso paradigm: A framework for integration of micro and macro organizational. In L. L. Cummings \& B. Staw (Eds.), Research in organizational behavior (Vol. 17, pp. 71-114). Greenwich, CT: JAI Press.

Hu, L. \& Bentler, P. (1998). Fit indices in covariance structure modeling: Sensitivity to underparameterized model misspecification. Psychological Methods, 3(4), 424-453.

Hudson, D. (2010). Describing the relationship between workplace engagement and attachment theory. Unpublished PhD thesis, Phillips Graduate Institute, USA.

Hughes, B. (2009). In Macleod, D. and Clarke, N. (2009) Engaging for success: Enhancing performance through employee engagement: A report to government. London: Department for Business, Innovation and Skills.

Hussey, J. \& Hussey, R. (1997). Business research: A practical guide for undergraduate and post-graduate students. London: MacMillan Press Ltd.

Ivankova, N., Creswell, J. \& Stick, S. (2006). Using mixed-methods sequential explanatory design: From theory to practice. Field Methods, 18, 3-20.

John Robinson Associates (JRA) (2009). Building great organisations. Retrieved November, 2, 2009, from http://www.jra.co.nz

Johnson, S. (2008). Couple and family therapy: An attachment perspective. In J. Cassidy \& P. Shaver (Eds.), Handbook of attachment: Theory, research and clinical applications (2nd ed., pp. 811-832). New York: Guilford Press.

Johnson, R. \& Onwuegbuzie, A. (2004). Mixed methods research: a research paradigm whose time has come. Educational Researcher, 33(7), 14-26.

JÖreskog, K. (1993). Testing structural equation models. In K. Bollen \& Ö. Long (Eds.), Testing structural equation models (pp. 294-316). Newbury Park, CA: Sage. 
Jose, P. (2013). Moderation/Mediation Help Centre (Ver. 3.0). Victoria

University of Wellington, Wellington, New Zealand, School of

Psychology. Retrieved 5 August, 2013, from

http://www.victoria.ac.nz/psyc/paul-jose-

files/helpcentre/help7_mediation_example.php)

Juhdi, N., Pa'wan, F. \& Hansaram, R. (2013). HR practices and turnover intention:

The mediating roles of organizational commitment and organizational engagement in a selected region in Malaysia. The International Journal of Human Resource Management, 24(15), 3002-3019.

Kahn, W. (1990). Psychological conditions of personal engagement and disengagement at work. Academy of Management Journal, 33, 692-724.

Kahn, W. (1992). To be fully there: Psychological presence at work. Human Relations, 45, 321-349.

Kahn, W. (1993). Caring for the caregivers: Patterns of organizational caregiving. Administrative Science Quarterly, 38(4), 539-563.

Kahn, W. (1995). Organization change and the provision of a secure base:

Lessons from the field. Human Relations, 48(5), 485-514.

Kahn, W. (1996). Secure base relationships at work. In D. T. Hall and Associates, The career is dead-long live the career: A relational approach to careers (pp. 158-179). San Francisco: Jossey-Bass Publishers.

Kahn, W. (1998). Relational systems at work. Research in Organizational Behavior, 20, 39-76.

Kahn, W. (2002). Managing the paradox of self-reliance. Organizational Dynamics, 30(3), 239-256.

Kahn, W. (2003). The revelation of organizational trauma. Journal of Applied Behavioral Science, 39(4), 364-380.

Keller, T. (2003). Parental images as a guide to leadership sensemaking: An attachment perspective on implicit leadership theories. The Leadership Quarterly, 14, 141-160.

Kenny, D. (2012). Measuring model fit. Retrieved January 9, 2013, from http://davidakenny.net/cn/fit.htm

Kerlinger, F. N. \& Lee, H. B. (2000). Foundations of behavioral research (4th ed.). Holt, NY: Harcourt College Publishers. 
Keyton, J., Ford, D. \& Smith, F. (2008). A meso-level communicative model of interorganizational collaboration. Communication Theory, 18, 376-406.

Kiesler, S. \& Sproull, L. (1986). Response effects in the electronic survey. Public Opinion Quarterly, 50(3), 402-413.

Kobak, R., Cassidy, J., Lyons-Ruth, K. \& Ziv, Y. (2006). Attachment, stress, and psychopathology: a developmental pathways model. In D. Cicchetti, \& D. Cohen (Eds.), Developmental psychopathology (2nd ed., pp. 333-369). New York: Wiley.

Koch, T. (1996). Implementation of a hermeneutic inquiry in nursing: Philosophy, rigor and representation. Journal of Advanced Nursing, 24, 174-184.

Kottke, J. \& Sharafinski, C. (1988). Measuring perceived supervisory support and organizational support. Educational and Psychological Measurement, 48, 1075-1079.

Kular, S., Gatenby, M., Rees, C., Soane, E. \& Truss, K. (2008). Employee engagement: A literature review. Working paper series No 19, Kingston University, UK: Kingston Business School.

Kumar, D. \& Swetha, G. (2011). A prognostic examination of employee engagement from its historical roots. International Journal of Trade, Economics and Finance, 2(3), 232-240.

Lambdin, C. (2012). Significance tests as sorcery: Science is empiricalsignificance tests are not. Theory \& Psychology, 22, 67-90.

Lambert, E., Hogan, N. \& Barton, S. (2001). The impact of job satisfaction on turnover intent: A test of a structural measurement model using a national sample of workers. The Social Science Journal, 38, 233-250.

Langford, P. (2010). The nature and consequences of employee engagement: Searching for a measure that maximizes the prediction of organizational outcomes. In S. Albrecht (Ed.), Handbook of employee engagement (pp. 375-384). London: Edward Elgar Publishing.

Lather, P. (1986). Research as praxis. Harvard Educational Review, 56, 437-457.

Law, K., Chi-Sum, W. \& Mobley, W. (1998). Toward a taxonomy of multidimensional constructs. Academy of Management Review, 23, 74155. 
Lee, J. H. (2012). Antecedents and consequences of employee engagement: Empirical study of hotel employees and managers. $\mathrm{PhD}$ dissertation, Kansas State University, USA.

Lee, K. \& Allen, N. (2002). Organizational citizenship behavior and workplace deviance: The role of affect and cognitions. Journal of Applied Psychology, 87, 131-42.

Leiter, M. \& Bakker, A. (2010). Work engagement: An introduction. In A. B. Bakker and M. P. Leiter (Eds.), Work engagement: A handbook of essential theory and practice (pp. 1-9). London and New York: Psychology Press.

Leka, S., Griffiths, A. \& Cox, T. (2003). Work organization and stress. Protecting workers' health series, No. 3. UK: World Health Organization.

Leong, F. \& Austin, J. (2006). The psychology research handbook: A guide for graduate students and research assistants (2nd ed.). Thousand Oaks: Sage Publications.

Liden, R. \& Graen, G. (1980). Generalizability of the vertical dyad linkage model of leadership. Academy of Management Journal, 23, 451-465.

Liden, R. \& Maslyn, J. (1998). Multidimensionality of leader-member exchange: An empirical assessment through scale development. Journal of Management, 24, 43-72.

Liden, R., Sparrowe, R. \& Wayne, S. (1997). Leader-member exchange theory: The past and potential for the future. In G. Ferris (Ed.), Research in personnel and human resource management (Vol.15, pp. 47-120). Greenwich, CT: JAI Press.

Lin, C-P. (2010). Modeling corporate citizenship, organizational trust, and work engagement based on attachment theory. Journal of Business Ethics, 94, $517-531$.

Lincoln, Y. \& Guba, E. (1985). Naturalistic inquiry. Beverly Hills, CA: Sage.

Little, B. \& Little, P. (2006). Employee engagement: Conceptual issues. Journal of Organizational Culture, Communications and Conflict, 10(1), 111-120.

Lockhart, D. \& Russo, J. (1996). Mail and telephone surveys in marketing research: A perspective from the field. In P. Bagozzi (Ed.), Principles of marketing research (pp. 116-161). Cambridge, UK: Blackwell. 
Lyons-Ruth, K., \& Jacobvitz, D. (2008). Disorganized attachment: Genetic factors, parenting contexts, and developmental transformation from infancy to adulthood. In J. Cassidy \& P. Shaver (Eds.), Handbook of attachment: Theory, research, and clinical applications (2nd ed., pp. 666697). New York: Guilford.

Macey, W. \& Schneider, B. (2008). The meaning of employee engagement. Industrial and Organizational Psychology, 1(1), 3-30.

Macey, W., Schneider, B., Barbera, K. \& Young, S. (2009). Employee engagement: Tools for analysis, practice, and competitive advantage. West Sussex, UK: Wiley-Blackwell.

Macleod, D. \& Clarke, N. (2009). Engaging for success: Enhancing performance through employee engagement: a report to government. London:

Department for Business, Innovation and Skills.

Main, M. (2000). The organized categories of infant, child, and adult attachment: Flexible vs. inflexible attention under attachment-related stress. American Psychoanalytic Association, 48, 1055-1096.

Main, M., Kaplan, N. \& Cassidy, J. (1985). Security in infancy, childhood, and adulthood: A move to the level of representation. In I. Bretherton \& E. Waters (Eds.), Growing points of attachment theory and research. Monograph of the Society for Research in Child Development, 50(1-2), 66-104.

Main, M. \& Solomon, J. (1990). Procedures for identifying infants as disorganized/disoriented during the Ainsworth Strange Situation. In M. T. Greenberg, D. Cicchetti \& M. Cummings (Eds.), Attachment in the preschool years: Theory, research, and intervention (pp. 121-160). Chicago: University of Chicago Press.

Marsden, P., Kalleberg, A. \& Cook, C. (1993). Gender differences in organizational commitment: Influences of work positions and family roles. Work and Occupations, 20(3), 368-390.

Martin, R., Epitropaki, O., Thomas, G. \& Topakas, A. (2010). A review of leader member exchange research: Future prospects and directions. In G. Hodgkinson \& J. Ford (Eds.), International Review of Industrial and Organizational Psychology (Vol. 25, pp. 35-88). Chicheser, England: Wiley. 
Martin, J. \& Schmidt, C. (2010). How to Keep Your Top Talent. Harvard Business Review, May, 55-61.

Maslach, C., Schaufeli, W. \& Leiter, M. (2001). Job burnout. Annual Review of Psychology, 52, 397-422.

Mathieu, J., DeShon, R. \& Bergh, D. (2008). Mediational inferences in organizational research: Then, now, and beyond. Organizational Research Methods, 11(2), 203-223.

May, D., Gilson, R. \& Harter, L. (2004). The psychological conditions of meaningfulness, safety, and availability and the engagement of the human spirit at work. Journal of Occupational Psychology, 77, 11-37.

Meyer, J. \& Allen, N. (1997). Commitment in the workplace: Theory, research, and application. Thousand Oaks, CA: Sage.

Mikulincer, M. (1997). Adult attachment style and information processing: Individual differences in curiosity and cognitive closure. Journal of Personality and Social Psychology, 72, 1217-1230.

Mikulincer, M. (1998). Adult attachment style and affect regulation: Strategic variations in subjective self-other similarity. Journal of Personality and Social Psychology, 75(2), 420-435.

Mikulincer, M. \& Shaver, P. (2007). Attachment in adulthood: Structure, dynamics and change. London: The Guilford Press.

Mikulincer, M., Shaver, P., Sapir-Lavid, Y. \& Avihou-Kanza, N. (2009). What's inside the minds of securely and insecurely attached people? The securebase script and its associations with attachment-style dimensions. Journal of Personality and Social Psychology, 97, 615-633.

Miles, M. \& Huberman, A. (1994). Qualitative data analysis: An expanded sourcebook (2nd ed.). Thousand Oaks, CA: Sage.

Ministry of Business, Innovation \& Employment (2013). Employment relationships: From beginning to end. Retrieved January 7, 2013, from www.mbie.govt.nz

Misciagna, M. (2005). Measuring workplace attachment as the relationship between individuals and the social institutions for which they work. Unpublished $\mathrm{PhD}$ thesis, George Washington University, USA. 
Mobley, W., Horner, S. \& Hollingsworth, A. (1978). An evaluation of precursors of hospital employee turnover. Journal of Applied Psychology, 63(4), 408414.

Morgan, D. (1998). Practical strategies for combining qualitative and quantitative methods: applications to health research. Qualitative Health Research, $8(3), 362-376$.

Morse, J. (1991). Approaches to qualitative-quantitative methodological triangulation. Nursing Research, 40(2), 120-123.

Mowday, R., Porter, L. \& Steers, R. (1982). Employee-organization linkages: The psychology of commitment, absenteeism, and turnover. New York: Academic press.

Neustadt, E., Chamorro-Premuzic, T. \& Furnham, A. (2006). The relationship between personality traits, self-esteem, and attachment at work. Journal of Individual Differences, 27, 208-217.

Neustadt, E., Chamorro-Premuzic, T. \& Furnham, A. (2011). Attachment at work and performance. Attachment and Human Development, 13(5), 471-488.

Newman, D. \& Harrison, D. (2008). Been there, bottled that: Are state and behavioural work engagement new useful construct 'wines'? Industrial and Organisational Psychology, 1, 31-35.

Nokia Siemens Networks (2008). Employee engagement. Retrieved March 12, 2011, from www.nokiasiemensnetworks.com

Nunnally, J. (1978). Psychometric Theory. New York, NY: McGraw-Hill.

Obegi, J. \& Berant, E. (Eds.). (2009). Attachment theory and research in clinical work with adults. NY: The Guilford Press.

Padgett, D. (1998). Qualitative methods in social work research. London: Sage Publications.

Pallant, J. (2011). SPSS survival manual (4th ed.). NSW, Australia: Allen and Unwin.

Pang Tze Lin, K. (2009). Re-examining the leader-follower relationship and supportive leadership: the role of the leader as an attachment figure. Unpublished $\mathrm{PhD}$ thesis, National University of Singapore, Singapore.

Patton, M. (2002a). Two decades of developments in qualitative in inquiry: A personal experiential perspective. Qualitative Social Work, 1(3), 261-283. 
Patton, M. (2002b). Qualitative research and evaluation methods. Thousand Oaks, CA: Sage.

Pedhazur, E. \& Scmelkin, L. (1991). Measurement, design, and analysis: An integrated approach. Hillsdale, NY: Lawrence Erlbaum Associates Publishers.

Picard, R. \& Berk, K. (1990). Data splitting. The American Statistician, 44(2), 140-147.

Pines, A. (2004). Adult attachment styles and burnout. Work and Stress, 18(1), 66-80.

Popper, M. \& Mayseless, O. (2003). Back to basics: Applying a parenting perspective to transformational leadership. The Leadership Quarterly, 14, 41-65.

Porges, S. W. (2011). The polyvagal theory: Neurophysiological foundations of emotions, attachment, communication, and self-regulation. New York: Norton.

Porter, L., Steers, R., Mowday, R. \& Boulian, P. (1974). Organizational commitment, job satisfaction, and turnover among psychiatric technicians. Journal of Applied Psychology, 59(5), 603-609.

Qualtrics (2011). Qualtrics Research Suite. Copyright (C [2011] Qualtrics: Provo, UT, USA. Retrieved January 10, 2011, from http://www.qualtrics.com

Ragin, C. (1992). 'Casing' and the process of social inquiry. In C. Ragin \& H. Becker (Eds.). What is a case? Exploring the foundations of social inquiry (pp. 217-226). Cambridge: Cambridge University Press.

Redmond, B. (2004). Reflection in action: Developing reflective practice in health and social services. Aldershot, UK: Ashgate Publishing Ltd.

Reed, D. (2011). Leader-member exchange and employee engagement. Unpublished PhD thesis, Capella University, USA.

Rhoades, L. \& Eisenberger, R. (2002). Perceived organizational support: A review of the literature. Journal of Applied Psychology, 87, 698-714.

Rhoades, L., Eisenberger, R. \& Armeli, S. (2001). Affective commitment to the organization: The contribution of perceived organizational support. Journal of Applied Psychology, 86, 825-836. 
Rich, B., LePine, J. \& Crawford, E. (2010). Job engagement: Antecedents and effects on job performance. Academy of Management Journal, 53(3), 150 .

Richards, D. \& Hackett, R. (2012). Attachment and emotion regulation: Compensatory interactions and leader-member exchange. The Leadership Quarterly, 23(4), 686-701.

Richman, A. (2006). Everyone wants an engaged workforce how can you create it? Workspan, 49, 36-39.

Riggle, R., Edmondson, D. \& Hansen, J. (2009). A meta-analysis of the relationship between perceived organizational support and job outcomes: 20 years of research. Journal of Business Research, 62, 1027-1030.

Robertson-Smith, G. \& Markwick, C. (2009). Employee engagement: A review of current thinking. (Report 469). Institute for Employment Studies (IES). Retrieved from www.employment-studies.co.uk

Robinson, D., Perryman, S. \& Hayday, S. (2004). The drivers of employee engagement. (No. 405). Brighton: Institute for Employment Studies. Retrieved February 12, 2010, from www.employment-studies.co.uk Ronen, S. \& Mikulincer, M. (2009). Attachment orientations and work outcomes: The mediating roles of team cohesion and organizational fairness. Journal of Social and Personal Relationships, 26(4), 549-567.

Rothbard, N. (2001). Enriching or depleting? The dynamics of engagement in work and family roles. Administrative Science Quarterly, 46, 655-684.

Rousseau, D. M. \& House, R. J. (1994). Meso organizational behavior: Avoiding three fundamental biases. In C. L. Cooper \& D. M. Rousseau (Eds.), Trends in organizational behavior (Vol. 1, pp. 13-30). New York: Wiley.

Sager, J., Griffeth, R. \& Hom, P. (1998). A comparison of structural models representing turnover cognitions. Journal of Vocational Behavior, 53, 254-273.

Saks, A. M. (2006). Antecedents and consequences of employee engagement. Journal of Managerial Psychology, 21, 600-619.

Saks, A. M. \& Ashforth, B. (1997). A longitudinal investigation of the relationships between job information sources, applicant perceptions of fit, and work outcomes. Personnel Psychology, 50, 395-426. 
Sanders, P. (1982). Phenomenology: A new way of viewing organizational research. The Academy of Management Review, 7(3), 353-360.

Savolainen, R. (2005). From satisfaction to engaged. Boeing Frontiers, 4(2), 1-3.

Schaufeli, W. \& Bakker, A. (2004). Job demands, job resources, and their relationship with burnout and engagement: A multi-sample study. Journal of Organizational Behavior, 25, 293-315.

Schaufeli, W. \& Bakker, A. (2010). Defining and measuring work engagement: Bringing clarity to the concept. In A. Bakker \& M. Leiter, (Eds.), Work engagement: A handbook of essential theory and research (pp. 10-24). NY: Psychology Press.

Schaufeli, W., Bakker, A. \& Salanova, M. (2006). The measurement of work engagement with a short questionnaire. Educational and Psychological Measurement, 66, 701-716.

Schaufeli, W., Salanova, M., Gonzalez-Roma, V. \& Bakker, A. (2002). The measurement of engagement and burnout: A two sample confirmatory factor analytic approach. Journal of Happiness Studies, 3, 71-92.

Scherbaum, C., Putka, D., Naidoo, L. \& Youssefnia, D. (2010). Key driver analyses: Current trends, problems and alternative approaches. In S. Albrecht (Ed.). Handbook of employee engagement: Perspectives, issues, research and practice (pp. 182-196). UK: Edward Elgar Publishing Limited.

Schirmer, L. \& Lopez, F. (2001). Probing the social support-work strain relationship among adult workers: Contributions of adult attachment orientations. Journal of Vocational Behavior, 59, 17-33.

Schmuckler, M. (2001). What is ecological validity? A dimensional analysis. Infancy, 2(4), 419-436.

Schonlau, M., Fricker, R. \& Elliott, M. (2001). Conducting research surveys via email and the web. Retrieved April 5, 2008, from http://www.rand.org/publications/MR/MR1480/html.

Schwab, D. (1980). Construct validity in organizational behavior. In B. Staw \& L. Cummings (Eds.), Research in organizational behavior (Vol. 2, pp. 3-43). Greenwich, CT: JAI Press. 
Shore, L., Coyle-Shapiro, J. A-M. \& Tetrick, L. (Eds.) (2012). The employeeorganization relationship: Applications for the 21 st century. London, UK: Routledge Academic.

Shuck, B. (2010). Employee engagement: An examination of antecedent and outcome variables. Unpublished $\mathrm{PhD}$ thesis, Florida International University, USA.

Shuck, B. (2011). Four emerging perspectives of employee engagement: An integrative literature review. Human Resource Development Review, 10(3), 304-328.

Shuck, B., \& Reio, T. \& Rocco, T. (2011). Employee engagement: An antecedent and outcome approach to model development. Human Resource Development International, 14(4), 427-445.

Shuck, B. \& Wollard, K. (2010). Employee engagement and HRD: A seminal review of the foundations. Human Resource Development Review, 9(1), 911.

Simpson, M. (2009). Engagement at work: A review of the literature. International Journal of Nursing Studies, 46, 1020-1024.

Soane, E., Truss, K., Alfes, K., Shantz, A., Rees, C. \& Gatenby, M. (2012). Development and application of a new measure of employee engagement: The ISA engagement scale. Human Resource Development International, $15(5), 529-547$.

Society for Human Resource Management (SHRM) (2011). SHRM/Globoforce employee recognition tracker survey: Employee recognition programs. Alexandria, VA: The SHRM Foundation.

Sonnentag, S. (2003). Recovery, work engagement, and proactive behavior: A new look at the interface between non-work and work. Journal of Applied Psychology, 88, 518-528.

Sonnentag, S., Dormann, C. \& Demerouti, E. (2010). Not all days are created equal: The concept of state work engagement. In A. Bakker, \& M. Leiter (Eds.), Work engagement: Recent developments in theory and research (pp. 25-38). New York: Psychology Press.

Sonnentag, S., Mojza, E., Binnewies, C., \& Scholl, A. (2008). Being engaged at work and detached at home: A week-level study on work engagement, psychological detachment and affect. Work and Stress, 22(3), 257-276. 
Spall, S. (1998). Peer debriefing in qualitative research: Emerging operational models. Qualitative Inquiry, 4(2), 280-292.

Sroufe, L. (1988). The role of infant-caregiver attachment in adult development. In J. Belsky \& T. Nezworski (Eds.), Clinical implications of attachment (pp. 18-38). Hillsdale, NJ: Erlbaum.

Stake, R. (1995). The art of case study research. Thousand Oaks, CA: Sage.

Stake, R. (2000). The case study method in social inquiry. In R. Gomm, M. Hammersley \& P. Foster (Eds.), Case study method: Key issues, key texts (pp. 20-26). London: Sage.

Stake, R. (2005). Qualitative case studies. In N. K. Denzin \& Y. S. Lincoln (Eds.), The SAGE handbook of qualitative research (3rd ed., pp. 443-462). Thousand Oaks: Sage.

States, A. (2008). The rage to engage. Time. April 17. Retrieved April 17, 2010, from http://www.time.com/time/magazine/article/0,9171,1731893,00.html

Steel, R. \& Lounsbury, J. (2009). Turnover process models: Review and synthesis of a conceptual literature. Human Resource Management Review, 19(4), 271-282.

Steel, R. \& Ovalle, N. (1984). A review and meta-analysis of research on the relationship between behavioural intentions and employee turnover. Journal of Applied Psychology, 69, 673-686.

Stern, D. (2004). The present moment in psychotherapy and everyday life. London: W.W. Norton \& Company.

Tabachnick, B. \& Fidell, L. (2007). Using multivariate statistics (5th ed.). Boston: Pearson Education.

Tashakkori, A. \& Creswell, J. (2007). The new era of mixed methods. Journal of Mixed Methods, 1, 3-7.

Taylor, S. \& Bogdan, R. (1984). Introduction to qualitative research methods: The search for meanings. New York: John Wiley \& Sons.

Teddlie, C. \& Tashakkori, A. (2009). Foundations of mixed methods research: Integrating quantitative and qualitative approaches in the social and behavioral sciences. Los Angeles: Sage Publications, Inc.

Tett, R. \& Meyer, J. (1993). Job satisfaction, organizational commitment, turnover intention, and turnover: Path analyses based on meta-analytic findings. Personnel Psychology, 46, 259-293. 
The Ken Blanchard Companies (2009). 2009 Corporate issues Survey: A seven year look at the key issues organizations and leaders face. Retrieved March 1, 2010, from www.kenblanchard.com

Tjosvold, D., Hui, C. \& Law, K. (1998). Empowerment in the manager-employee relationship in Hong Kong: Interdependence and controversy. Journal of Social Psychology, 138, 624-637.

Towers Perrin (2006). Ten steps to creating an engaged workforce: Key European findings. Retrieved June 12, 2010, from www.towersperrin.com

Tronick, E. (1989). Emotions and emotional communication in infants. American Psychologist, 44, 112-119.

Tronick, E. \& Beeghly, M. (2011). Meaning making and infant mental health. American Psychologist, 66(2), 107-119.

Tsui, A., Egan, T. \& O’Reilly, C. (1992). Being different: Relational demography and organizational attachment. Administrative Science Quarterly, 37, 549579.

Ullman, J. (2007). Structural equation modeling. In B. Tabachnick \& L. Fidell (Eds.), Using multivariate statistics (5th ed., pp. 676-780). New York: Allyn Bacon.

Van Ijzendoorn, M. (1995). Adult attachments, representations, parental responsiveness and infant attachment: A meta-analysis on the predictive validity of the adult attachment interview. Psychological Bulletin, 117, 387-403.

Van Manen, M. (1990). Researching lived experience: Human science for an action sensitive pedagogy. Canada: The Althouse Press.

Van Manen, M. (2002). Writing in the dark: Phenomenological studies in interpretive inquiry. Canada: The Althouse Press.

Vance, R. (2006). Employee engagement and commitment: A guide to understanding, measuring, and increasing engagement in your organization. Alexandria, VA: The SHRM Foundation.

Vogt, W. P. (1999). Dictionary of statistics and methodology: A nontechnical guide for the social sciences. London: Sage.

Wagner, R. \& Harter, J. (2006). 12: The great elements of managing. Washington, DC: The Gallup Organization. 
Waters, E. \& Cummings, M. (2000). A secure base from which to explore relationships. Child Development, 71, 164-172.

Waters, E. \& Valenzuela, M. (1999). Explaining disorganized attachment: Clues from research on mild-to-moderately undernourished children in Chile. In J. Solomon \& C. George (Eds.), Attachment disorganization (pp. 265-287) New York: Guilford Press.

Waters, H. \& Waters, E. (2006). The attachment working models concept: Among other things, we build script-like representations of secure base experiences. Attachment \& Human Development, 8, 185-198.

Watkins, M. (2000). Monte Carlo PCA for parallel analysis [computer software]. State College, PA: Ed \& Psych Associates.

WatsonWyatt (2008-2009). Work survey report, continuous engagement: The key to unlocking the value of your people during rough times. Retrieved August 21, 2011, from www.watsonwyatt.com

Wefald, A. \& Downey, R. (2009). Construct dimensionality of engagement and its relation with satisfaction. Journal of Psychology, 143(1), 91-112.

Wellins, R., Bernthal, P. \& Phelps, M. (2005). Employee engagement: The key to realizing competitive advantage. Development Dimensions International, 1-30. Retrieved February, 7, 2011, from http://www.ddiworld.com/pdf/ddi_employeeengagement_mg.pdf

Wiley, J. (2010). Employee Engagement. Human Resources. Retrieved March 1, 2010, from www.allbusiness.com

WorldatWork (May 24, 2010). Managers not always held accountable for employee engagement. Retrieved July 17, 2010, from www.worldatwork.org

Yalabik, Z., Popaitoon, P. Chowne, J. \& Rayton, B. (2013).Work engagement as a mediator between employee attitudes and outcomes. The International Journal of Human Resource Management, 24(14), 2799-2823.

Yin, R. (2009). Case study research: Design and methods (4th ed.). Thousand Oakes, CA: Sage. 


\section{Appendices}

\section{Appendix A: Employee MESE Items}

\section{EMPLOYEE MESE Questionnaire}

Q1 MESE When you are under pressure, what kind of support do you usually seek from your manager?

Task oriented/information type support. (SEDA)
I like extra reassurance at this time and seek support to think through big and small
issues. (SESI)
$\begin{gathered}\text { I ask for information/resources and/or emotional support. It depends on what I need at } \\ \text { the time to keep me working. (SECA) }\end{gathered}$

Q2 When you are under pressure, what kind of support do you get from your manager?

Matter of fact, task oriented/information to help me do my job. (SEDA)

Support is often unreliable and I expect the unexpected. (SESI)

They show interest in how I am and are helpful in pointing me in the right direction towards new information/resources. (SECA)

Q3 When you are under pressure, how often would you seek support from your manager?

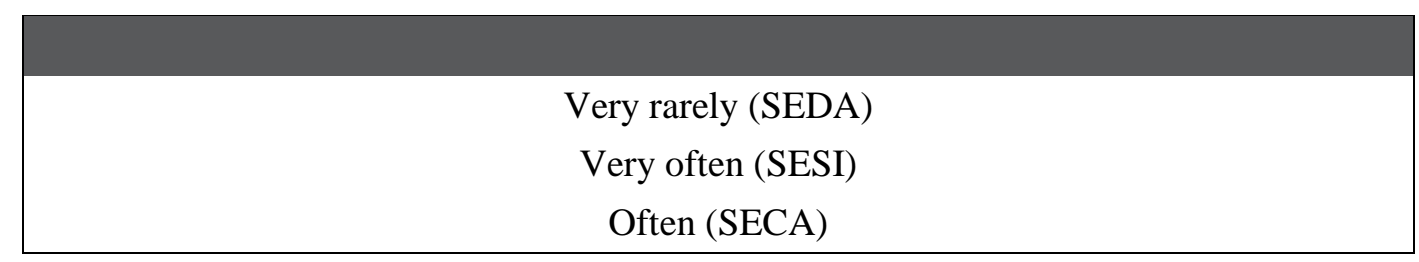

Q4 When you are under pressure, how do you deal with workplace conflict?

I keep the process short and focused by sticking with the facts and keeping emotions out of the process. (SEDA)

I often find myself in the middle of workplace conflict and I never know if it is going to get resolved. (SESI)

I see conflict as an inevitable part of working together. I give people space to say how they feel and work together with them to find a solution (SECA) 
Q5 When your manager is under pressure, how would you describe how you go about doing your job?

I try to keep focused on my own job and work as independently as I can. I rarely ask them for help or support during this time unless I really need to. (SEDA)

I find I often need their support at this time with my own work and I worry that they are not able to be available. It would be fair to say my work output at this time is reduced. (SESI)

I stay productive and am confident that I can ask for help or support if needed in a way that takes both my need for help and their situation into account. (SECA)

Q6 When you are under pressure, what kind of response do you expect to get from your manager?

They will provide matter of fact, task oriented/information to help me do my job. (SEDA)

They will be unreliable and mostly unavailable when I need to ask for support. (SESI)

They will show interest in how I am and will be helpful in pointing me in the right direction towards new information/ resources. (SECA)

Q7 When you are under pressure, what might your manager notice about how you seek support?

That I become increasingly independent and task focused. It would be unlikely I would ask directly for support. (SEDA)

That I increasingly seek and rely on their support to help me think through what I need to do to manage my day-to-day work load. If they are not available; and I seek support from my peers. (SESI)

That I ask information/resources or emotional support or understanding, based on what I most need at the time(SECA)

Q8 When you are under pressure, how do you prefer to deal with workplace conflict?

I prefer to avoid conflict. I deal with conflict by sticking with the facts and keeping emotions out of the process. (SEDA)

I prefer not to deal with conflict at all but I often find myself in the middle of workplace conflict and I never know if it is going to get resolved. (SESI)

I see conflict as an inevitable part of working together. I prefer to work it through by giving people space to say how they feel and then work together to find a solution.

(SECA) 
Q9 When other workers are under pressure, what kind of extra support do you prefer to offer?

I prefer a simple straight forward discussion regarding the task and the resources needed to complete the task. (SEDA)

I prefer to get emotionally close to workers to show them that I value them. (SESI)

I like to make space to hear what the issues are and then offer task oriented directions and/or personal support based help, depending on what's needed. (SECA)

Q10 When you are under pressure, what kind of support do you usually seek from within your organisation?

I don't ask for help much but when I do it is mostly about needing information about my job so I can do it better. (SEDA)

I find I ask for help a lot. I especially need emotional help and understanding about the pressures of my job. (SESI)

I am confident in asking my organisation for help. Sometimes it's about how I am and mostly about how I can do my job better. (SECA)

Q11 When you are under pressure at work, how does your organisation respond?

Information and technical support is more available than emotional support. (SEDA)

I never know how they are going to respond. I expect the unexpected. (SESI)

I am confident in asking my organisation for help. Sometimes it's about how I am and mostly about how I can do my job better. (SECA)

Q12 When you are under pressure at work, how would you describe your productivity in relationship to your organisation?

My mostly neutral relationship with my organisation does not affect my productivity in any way. (SEDA)

My sometimes negative relationship with my organisation makes it harder to stay productive. (SESI)

My mostly positive relationship with my organisation makes it easier to stay productive. (SECA) 
Q13 When you are under pressure at work, how do you usually show this to other people in your organisation?

I become increasingly work focused and keep my contact with others at work to a minimum. (SEDA)

I talk more to people at work about how I am feeling and I tend to do less work during these times. (SESI)

I talk more to just a few select people at work and this helps me to stay focused on my job. (SECA)

Q14 Thinking about your organisation overall, how closely do the following statements describe the goal-oriented partnership between managers and employees?

Managers and employees are mostly very task focused. There is sometimes a lot of conflict between them but this is not addressed. (SEDA)

Managers and employees are often in conflict with each other. The conflict rarely gets sorted out and nothing much changes long term about how we do our work (SESI)

Managers and employees share a mostly positive relationship with some conflict. Conflicts are worked through often resulting in good outcomes for managers and employees. (SECA) 


\section{Appendix B: Manager MESE Questions}

Manager MESE Questionnaire

Q1 When you are under pressure, what kind of support do you usually seek from senior colleagues?

Task oriented/information type support. (SEDA)

I like extra reassurance at this time and seek support to think through big and small issues. (SESI)

I ask for information/resources and/or emotional support. It depends on what I need at the time to keep me working. (SECA)

Q2 When you are under pressure, what kind of support do you get from your senior colleagues?

Matter of fact, task oriented/information to help me do my job. (SEDA)

Support is often unreliable and I expect the unexpected. (SESI)

They show interest in how I am and are helpful in pointing me in the right direction towards new information/resources. (SECA)

Q3 When you are under pressure, how often would you seek support from senior colleagues?

Very rarely (SEDA)

Very often (SESI)

Often (SECA) 
Q4 When you are under pressure, how do you deal with workplace conflict?

I keep the process short and focused by sticking with the facts and keeping emotions out of the process. (SEDA)

I often find myself in the middle of workplace conflict and I never know if it is going to get resolved. (SESI)

I see conflict as an inevitable part of working together. I give people space to say how they feel and work together with them to find a solution (SECA)

Q5 When your colleagues are under pressure, what kind of support do you offer to them?

Task oriented/information and instructions. (SEDA)

At best, emotional support and encouragement but when I am under pressure myself I am often not able to be as emotionally supportive as I would like to be. (SESI)

I try to create space to hear what the issue is and then offer task oriented direction and/or personal support based help. (SECA)

Q6 When you are under pressure, what might colleagues senior to you notice about how you seek support?

That I become increasingly independent and task focused. It would be very unlikely if I asked for direct support. (SEDA)

That I temporarily become more reliant on their support to think through the issues regarding my day-to-day work load. (SESI)

That I prefer to ask for what I most need at the time; sometimes it is for information/resources and other times emotional support and understanding. (SECA) 
Q7 When you are under pressure, what kind of response do you expect to get from your senior colleagues?

They will provide matter of fact, task oriented/information to help me do my job. (SEDA)

They will be unreliable and mostly unavailable when I need to ask for help. (SESI)

They will show interest in how I am and will be helpful in pointing me in the right direction towards new information/ resources. (SECA)

Q8 When you are under pressure, how do you prefer to deal with workplace conflict?

I prefer to avoid conflict. I deal with conflict by sticking with the facts and keeping emotions out of the process. (SEDA)

I prefer not to deal with conflict at all but I often find myself in the middle of workplace conflict and I never know if it is going to get resolved. (SESI)

I see conflict as an inevitable part of working together. I prefer to work it through by giving people space to say how they feel and then work together to find a solution.

(SECA)

Q9 When your employees are under pressure, what kind of extra support do you prefer to offer?

I prefer a simple straight forward discussion regarding the task and the resources needed to complete the task. (SEDA)

I prefer to get emotionally close to employees but it is not always possible as I have my own work to do as well. (SESI)

I like to make space to hear what the issues are and then offer task oriented directions and/or personal support, depending on what's needed. (SECA) 
Q10 When you are under pressure, what kind of support do you usually seek from within your organisation?

I don't ask for help much but when I do it is mostly about needing information about my job so I can do it better. (SEDA)

I find I ask for help a lot. I especially need emotional help and understanding about the pressures of my job. (SESI)

I am confident in asking my organisation for help. Sometimes it's about how I am and mostly about how I can do my job better. (SECA)

Q11 When you are under pressure at work, how does your organisation respond?

Information and technical support is more available than emotional support. (SEDA)

I never know how they are going to respond. I expect the unexpected. (SESI)

I am confident in asking my organisation for help. Sometimes it's about how I am and mostly about how I can do my job better. (SECA)

Q12 When you are under pressure at work, how would you describe your productivity in relationship to your organisation?

My mostly neutral relationship with my organisation does not affect my productivity in any way. (SEDA)

My sometimes negative relationship with my organisation makes it harder to stay productive. (SESI)

My mostly positive relationship with my organisation makes it easier to stay productive. (SECA) 
Q13 When you are under pressure at work, how do you usually show this to other people in your organisation?

I become increasingly work focused and keep my contact with others at work to a minimum. (SEDA)

I become increasingly people focused as I seek support to think through ways to deal with the many different challenges in my day-to-day job. (SESI)

I talk more to just a few select people at work and this helps me to stay focused on my job. (SECA)

Q14 Thinking about your organisation overall, how closely do the following statements describe the goal-oriented partnership between managers and employees?

Managers and employees are mostly very task focused. There is sometimes a lot of conflict between them but this is not addressed. (SEDA)

Managers and employees are often in conflict with each other. The conflict rarely gets sorted out and nothing much changes long term about how we do our work (SESI)

Managers and employees share a mostly positive relationship with some conflict. Conflicts are worked through often resulting in good outcomes for managers and employees. (SECA) 


\section{Appendix C: Pre-Validated Survey Study Variables}

Perceived Organisational Support (Eisenberger et al., 1997; Rhoades et al., 2001)

The organisation values my contribution to its wellbeing.

The organisation fails to appreciate any extra effort from me. (R)

The organisation would ignore any complaint from me. (R)

The organisation really cares about my wellbeing.

Even if I did the best job possible, the organisation would fail to notice. (R)

The organisation cares about my general satisfaction at work.

The organisation shows very little concern for me. (R)

The organisation takes pride in my accomplishments at work.

Perceived Supervisor Support (POS) (Kottke \& Sharafinski, 1988; Rhoades et al., 2001)

My supervisor values my contribution to its wellbeing.

My supervisor fails to appreciate any extra effort from me. (R)

My supervisor would ignore any complaint from me. (R)

My supervisor really cares about my wellbeing.

Even if I did the best job possible, my supervisor would fail to notice. (R)

My supervisor cares about my general satisfaction at work.

My supervisor shows very little concern for me. (R)

My supervisor takes pride in my accomplishments at work.

Job Engagement (Saks, 2006)

1. I really 'throw' myself into my job.

2. Sometimes I am so into my job that I lose track of time.

3. This job is all consuming; I am totally into it.

4. My mind often wanders and I think of other things when doing my job (R).

5. I am highly engaged in this job. 
Organization Engagement (Saks, 2006)

1. Being a member of this organisation is very captivating.

2. One of the most exciting things for me is getting involved with things happening in this organisation.

3. I am really not into the 'goings-on' in this organisation. (R).

4. Being a member of this organisation make me come 'alive'.

5. Being a member of this organisation is exhilarating for me.

6. I am highly engaged in this organisation.

Organisational Commitment (Marsden et al., 1993)

1. I am willing to work harder than I have in order to help this organisation succeed.

2. I feel very little loyalty to this organisation.

3. I would take almost any job to keep working for this organisation.

4. I find that my values and the organisation's are very similar.

5. I am proud to be working for this organisation.

6. I would turn down another job for more pay in order to stay with this organisation.

Intent to Quit/Turnover (Colarelli, 1984)

1. I frequently think of quitting my job.

2. I am planning to search for a new job during the next 12 months.

3. If I have my own way, I will be working for this organisation one year from now. (R). 
Relationship Questionnaire (Bartholomew \& Horowitz, 1991)

\begin{tabular}{cccccccc}
\hline Please rate each question according to the & Not at & Not & Not & Neutral & Somewhat & Like & Just \\
extent to which they correspond with your & all & like & much & (4) & like me (5) & me & like \\
general relationship style. & like & me & like & & & $(6)$ & me \\
& me & (2) & me (3) & & & & $(7)$ \\
& $(1)$ & & & & & & \\
\hline
\end{tabular}

It is relatively easy for me to be emotionally close to others. I am comfortable depending on others and having others depend on me. I don't worry about being alone or having others not accept me. (1)

I am comfortable without close emotional relationships. It is very important to me to feel independent and self-sufficient and I prefer not to depend on others or have others depend on me. (2)

I want to be completely emotionally intimate with others but I often feel that others are reluctant to get as close as I would like. I am uncomfortable being without close relationships but I sometimes worry that others don't value me as much as I value them. (3)

I am somewhat uncomfortable getting close to others. I want emotionally close relationships but I find it difficult to trust others completely or to depend on them. I sometimes worry that I will be hurt if I allow myself to become too close to others. (4)

\section{Which one of these statements best describes you in close relationships? It is relatively easy for me to be emotionally close to others.}

I am comfortable depending on others and having others depend on me. I don't worry about being alone or having others not accept me. (1)

I am comfortable without close emotional relationships. It is very important to me to feel independent and self- sufficient and I prefer not to depend on others or have others depend on me. (2)

I want to be completely emotionally intimate with others but I often feel that others are reluctant to get as close as I would like. I am uncomfortable being without close relationships but I sometimes worry that others don't value me as much as I value them. (3)

I am somewhat uncomfortable getting close to others. I want emotionally close relationships but I find it difficult to trust others completely or to depend on them. I sometimes worry that I will be hurt if I allow myself to become too close to others. (4)

\section{Classification codes:}
1. RQS Secure
2. RQDA Dismissing-avoidant
3. RQP Preoccupied
4. RQFA Dismissing-fearful 


\section{Appendix D: MESE Survey (Managers) 2011}

Thank you for taking the time to fill out this survey.

Your participation helps to explore the impact of day-to-day interactions between managers and employees on employee engagement.

This survey includes some demographic questions along with questions about your current job, workplace relationship style and relationship style generally.

This survey will take about 10 - 15 minutes to complete

Your participation is voluntary and anonymous.

Participation is understood as you giving consent for your answers to be used as information for this study.

This survey is being conducted as part of a $\mathrm{PhD}$ study at Victoria University Wellington and has the approval of the Victoria University of Wellington Human Ethics Committee.

Further information regarding this survey is available by clicking on this link: Manager and employee engagement study information sheet

The survey closes 13 May, 2011.

If you have any questions regarding this survey you can contact:

Maree Foley Email: Maree.Foley@vuw.ac.nz Phone:

Research Supervisors:

Dr Geoff Plimmer Email: Geoff.Plimmer@vuw.ac.nz, Phone:

Dr Jane Bryson Email: Jane.Bryson@vuw.ac.nz Phone: 
Q1 What is your age?

Under 21 years (1)

21 - 29 years (2)

30 - 39 years $(3)$

40 - 49 years $(4)$

50 - 59 years $(5)$

60 - 69 years $(6)$

70 - 79 years (7)

80 years and over (8)

Q2 What is your gender?

Female (1)

Male (2)

Q3 With which ethnic group do you most identify?

口 Maori (1)

New Zealand European (2)

$\square \quad$ Pacific Islander (3)

口 Asian (4)

$\square \quad$ Other European (5)

$\square$ Other (please specify) (6) 
Q4 Thinking about your current job and organisation please indicate your level of agreement with the following statements.

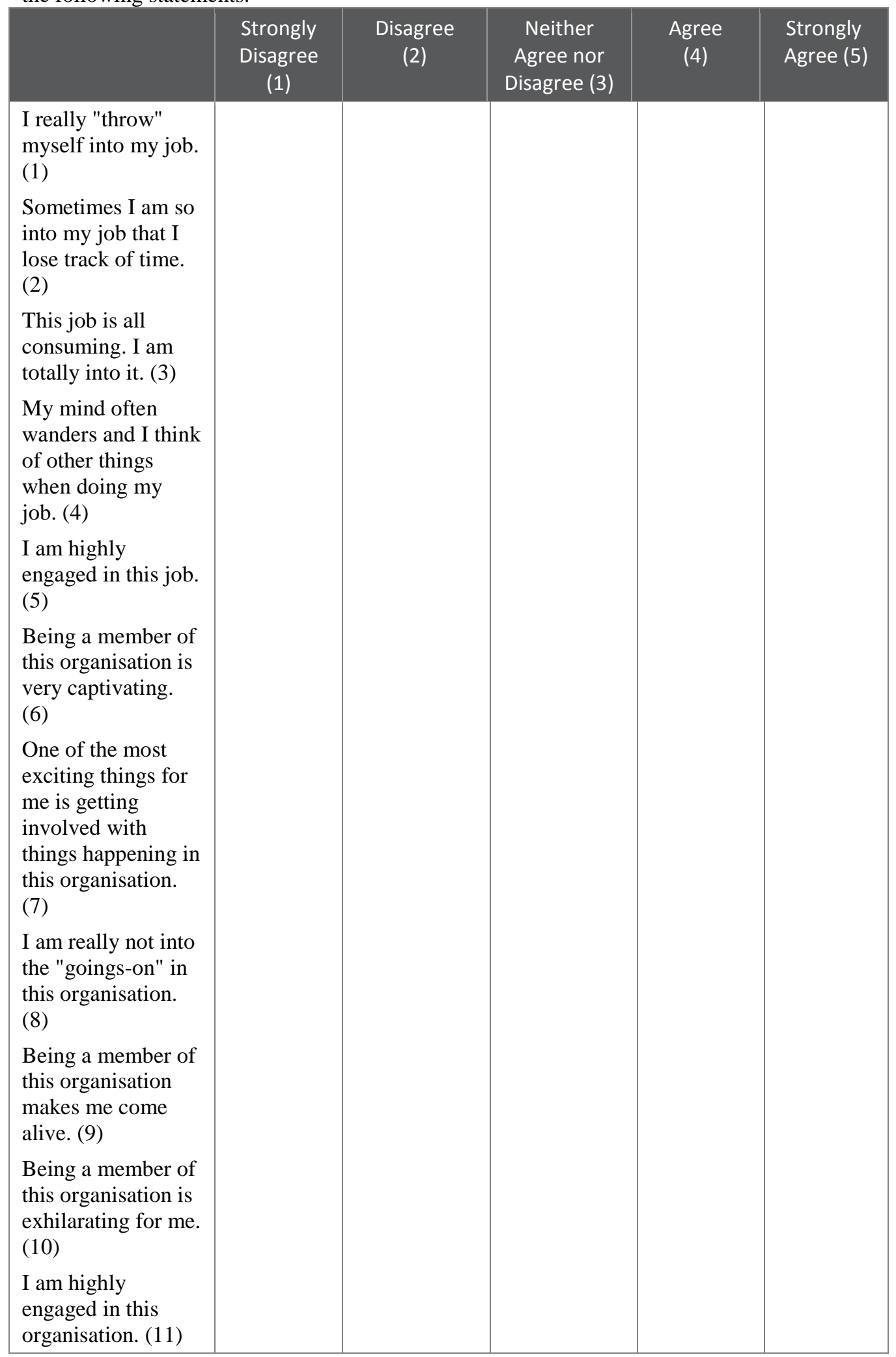


Q5 When you are under pressure, what kind of support do you usually seek from senior colleagues?

\begin{tabular}{|c|c|c|c|c|c|}
\hline & $\begin{array}{c}\text { Very } \\
\text { Unlikely (1) }\end{array}$ & Unlikely (2) & $\begin{array}{l}\text { Undecided } \\
\text { (3) }\end{array}$ & Likely (4) & $\begin{array}{l}\text { Very Likely } \\
\text { (5) }\end{array}$ \\
\hline $\begin{array}{l}\text { Task } \\
\text { oriented/information } \\
\text { type support. (1) } \\
\text { I like extra } \\
\text { reassurance at this } \\
\text { time and seek support } \\
\text { to think through big } \\
\text { and small issues. (2) } \\
\text { I ask for } \\
\text { information/resources } \\
\text { and/or emotional } \\
\text { support. It depends } \\
\text { on what I need at the } \\
\text { time to keep me } \\
\text { working. (3) }\end{array}$ & & & & & \\
\hline
\end{tabular}

Q6 When you are under pressure, what kind of support do you get from senior colleagues?

\begin{tabular}{|c|c|c|c|c|c|}
\hline & $\begin{array}{c}\text { Very } \\
\text { Unlikely (1) }\end{array}$ & Unlikely (2) & $\begin{array}{c}\text { Undecided } \\
\text { (3) }\end{array}$ & Likely (4) & $\begin{array}{l}\text { Very Likely } \\
\text { (5) }\end{array}$ \\
\hline $\begin{array}{l}\text { Matter of fact, task } \\
\text { oriented/information, } \\
\text { to support me to do } \\
\text { my job. (1) } \\
\text { Support is often } \\
\text { unreliable and I } \\
\text { expect the } \\
\text { unexpected. (2) } \\
\text { They show interest in } \\
\text { how I am and are } \\
\text { helpful in pointing me } \\
\text { in the right direction } \\
\text { towards new } \\
\text { information/resources. } \\
\text { (3) }\end{array}$ & & & & & \\
\hline
\end{tabular}

Q7 When you are under pressure, how often would you seek support from senior colleagues?

\begin{tabular}{|c|c|c|c|c|c|}
\hline & $\begin{array}{c}\text { Not at all like } \\
\text { me (1) }\end{array}$ & $\begin{array}{c}\text { Not like me } \\
\text { (2) }\end{array}$ & Neutral (3) & Like me (4) & $\begin{array}{c}\text { Just like me } \\
\text { Very rarely } \\
(1)\end{array}$ \\
& & & & \\
Very often (2) & & & & & \\
Often (3) & & & & \\
\hline
\end{tabular}


Q8 When you are under pressure, how do you deal with workplace conflict?

\begin{tabular}{|c|c|c|c|c|c|}
\hline & $\begin{array}{l}\text { Not at all } \\
\text { like me } \\
\text { (1) }\end{array}$ & $\begin{array}{l}\text { Not like me } \\
\text { (2) }\end{array}$ & $\begin{array}{c}\text { Neutral } \\
\text { (3) }\end{array}$ & $\begin{array}{l}\text { Like me } \\
\text { (4) }\end{array}$ & $\begin{array}{l}\text { Just like me } \\
\text { (5) }\end{array}$ \\
\hline $\begin{array}{l}\text { I keep the process } \\
\text { short and focused } \\
\text { by sticking with } \\
\text { the facts and } \\
\text { keeping emotions } \\
\text { out of the } \\
\text { process. (1) }\end{array}$ & & & & & \\
\hline $\begin{array}{l}\text { I often find } \\
\text { myself in the } \\
\text { middle of } \\
\text { workplace } \\
\text { conflict and I } \\
\text { never know if it } \\
\text { is going to get } \\
\text { resolved. (2) }\end{array}$ & & & & & \\
\hline $\begin{array}{l}\text { I see conflict as } \\
\text { an inevitable part } \\
\text { of working } \\
\text { together. I give } \\
\text { people space to } \\
\text { say how they feel } \\
\text { and work } \\
\text { together with } \\
\text { them to find a } \\
\text { solution. (3) }\end{array}$ & & & & & \\
\hline
\end{tabular}

Q 9 When your colleagues are under pressure, what kind of support do you offer to them?

\begin{tabular}{|c|c|c|c|c|c|}
\hline & $\begin{array}{l}\text { Very } \\
\text { Unlikely } \\
\text { (1) }\end{array}$ & $\begin{array}{l}\text { Unlikely } \\
\text { (2) }\end{array}$ & Undecided (3) & $\begin{array}{l}\text { Likely } \\
\text { (4) }\end{array}$ & $\begin{array}{c}\text { Very } \\
\text { Likely (5) }\end{array}$ \\
\hline $\begin{array}{l}\text { Task } \\
\text { oriented/information } \\
\text { and instructions. (1) } \\
\text { At best, emotional } \\
\text { support and } \\
\text { encouragement but } \\
\text { when I am under } \\
\text { pressure myself I am } \\
\text { often not able to be } \\
\text { as emotionally } \\
\text { supportive as I would } \\
\text { like to be. (2) } \\
\text { I try to create space } \\
\text { to hear what the } \\
\text { issue is and then } \\
\text { offer task oriented } \\
\text { direction and/or } \\
\text { personal support } \\
\text { based help. (3) }\end{array}$ & & & & & \\
\hline
\end{tabular}


Q10 Thinking about your current organisation, please indicate your level of agreement to the following statements.

\begin{tabular}{|c|c|c|c|c|c|c|c|}
\hline & $\begin{array}{c}\text { Strongly } \\
\text { Disagree } \\
\text { (1) }\end{array}$ & $\begin{array}{l}\text { Disagree } \\
\text { (2) }\end{array}$ & $\begin{array}{l}\text { Somewhat } \\
\text { Disagree } \\
\text { (3) }\end{array}$ & $\begin{array}{l}\text { Neither } \\
\text { Agree } \\
\text { nor } \\
\text { Disagree } \\
\text { (4) }\end{array}$ & $\begin{array}{c}\text { Somewhat } \\
\text { Agree (5) }\end{array}$ & $\begin{array}{l}\text { Agree } \\
\text { (6) }\end{array}$ & $\begin{array}{c}\text { Strongly } \\
\text { Agree (7) }\end{array}$ \\
\hline $\begin{array}{l}\text { The } \\
\text { organisation } \\
\text { values my } \\
\text { contribution } \\
\text { to its well- } \\
\text { being. (1) } \\
\text { The } \\
\text { organisation } \\
\text { fails to } \\
\text { appreciate any } \\
\text { extra effort } \\
\text { from me. (2) } \\
\text { The } \\
\text { organisation } \\
\text { would ignore } \\
\text { any complaint } \\
\text { from me. (3) } \\
\text { The } \\
\text { organisation } \\
\text { really cares } \\
\text { about my } \\
\text { well-being. } \\
\text { (4) } \\
\text { Even if I did } \\
\text { the best job } \\
\text { possible, the } \\
\text { organisation } \\
\text { would fail to } \\
\text { notice. (5) } \\
\text { The } \\
\text { organisation } \\
\text { cares about } \\
\text { my general } \\
\text { satisfaction at } \\
\text { work. (6) } \\
\text { The } \\
\text { organisation } \\
\text { shows very } \\
\text { little concern } \\
\text { for me. (7) } \\
\text { The } \\
\text { organisation } \\
\text { takes pride in } \\
\text { my } \\
\text { accomplishme } \\
\text { nts at work. } \\
\text { (8) }\end{array}$ & & & & & & & \\
\hline
\end{tabular}


Q11 Thinking about the person who you consider as your immediate manager (or senior mentor if you do not have a manager), please indicate your level of agreement to the following statements.

\begin{tabular}{|c|c|c|c|c|c|c|c|}
\hline & $\begin{array}{c}\text { Strongly } \\
\text { Disagree } \\
\text { (1) }\end{array}$ & $\begin{array}{c}\text { Disagree } \\
\text { (2) }\end{array}$ & $\begin{array}{c}\text { Somewhat } \\
\text { Disagree } \\
\text { (3) }\end{array}$ & $\begin{array}{c}\text { Neither } \\
\text { Agree } \\
\text { nor } \\
\text { Disagree } \\
\text { (4) }\end{array}$ & $\begin{array}{c}\text { Somewhat } \\
\text { Agree (5) }\end{array}$ & $\begin{array}{l}\text { Agree } \\
(6)\end{array}$ & $\begin{array}{c}\text { Strongly } \\
\text { Agree (7) }\end{array}$ \\
\hline
\end{tabular}

\section{My}

supervisor

values my contribution

to the organisation's well-being.

(1)

My

supervisor

fails to

appreciate any

extra effort from me. (2)

My

supervisor

would ignore any complaint from me. (3)

My

supervisor

really cares about my well-being.

(4)

Even if I did the best job possible, my supervisor would fail to notice. (5)

My

supervisor

cares about my general satisfaction at work. (6)

My

supervisor

shows very

little concern for me. (7)

My

supervisor

takes pride in my

accomplishme nts at work.

(8) 
Q12 When you are under pressure, what might colleagues senior to you notice about how you seek support?

\begin{tabular}{|c|c|c|c|c|c|}
\hline & $\begin{array}{c}\text { Not at all } \\
\text { like me (1) }\end{array}$ & $\begin{array}{l}\text { Not like me } \\
\text { (2) }\end{array}$ & Neutral (3) & Like me (4) & $\begin{array}{l}\text { Just like me } \\
\text { (5) }\end{array}$ \\
\hline $\begin{array}{l}\text { That I become } \\
\text { increasingly } \\
\text { independent and task } \\
\text { focused. It would be } \\
\text { very unlikely if I } \\
\text { asked for direct } \\
\text { support. (1) } \\
\text { That I temporarily } \\
\text { become more reliant } \\
\text { on their support to } \\
\text { think through the } \\
\text { issues regarding my } \\
\text { day-to-day work } \\
\text { load. (2) } \\
\text { That I prefer to ask } \\
\text { for what I most need } \\
\text { at the time; } \\
\text { sometimes it's for } \\
\text { information/resources } \\
\text { and other times for } \\
\text { emotional support } \\
\text { and understanding. } \\
\text { (3) }\end{array}$ & & & & & \\
\hline
\end{tabular}

Q13 When you are under pressure, what kind of response do you expect to get from your senior colleagues?

\begin{tabular}{|c|c|c|c|c|c|}
\hline & $\begin{array}{l}\text { Very Unlikely } \\
\text { (1) }\end{array}$ & $\begin{array}{c}\text { Unlikely } \\
\text { (2) }\end{array}$ & $\begin{array}{l}\text { Undecided } \\
\text { (3) }\end{array}$ & $\begin{array}{l}\text { Likely } \\
\text { (4) }\end{array}$ & $\begin{array}{c}\text { Very } \\
\text { Likely } \\
\text { (5) }\end{array}$ \\
\hline $\begin{array}{l}\text { They will provide matter } \\
\text { of fact, task } \\
\text { oriented/information to } \\
\text { help me do my job. (1) } \\
\text { They will be unreliable } \\
\text { and mostly unavailable } \\
\text { when I need to ask for } \\
\text { help. (2) } \\
\text { They will show interest } \\
\text { in how I am and will be } \\
\text { helpful in pointing me in } \\
\text { the right direction } \\
\text { towards new } \\
\text { information/ resources. } \\
\text { (3) }\end{array}$ & & & & & \\
\hline
\end{tabular}


Q14 When you are under pressure, how do you prefer to deal with workplace conflict?

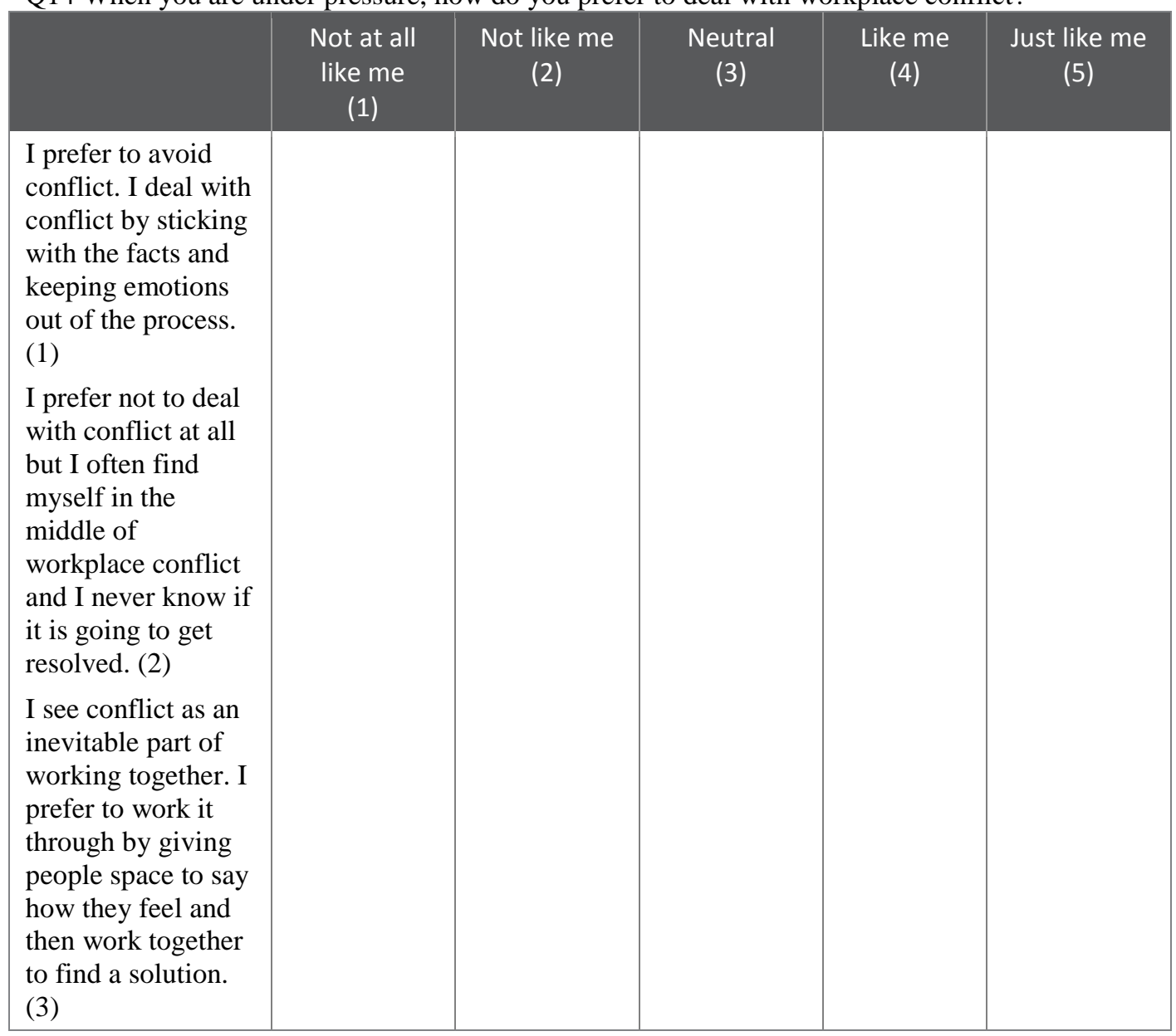

Q15 When your employees are under pressure, what kind of extra support do you prefer to offer?

\begin{tabular}{|c|c|c|c|c|c|}
\hline & $\begin{array}{l}\text { Not at all } \\
\text { like me } \\
\text { (1) }\end{array}$ & $\begin{array}{l}\text { Not like me } \\
\text { (2) }\end{array}$ & $\begin{array}{l}\text { Neutral } \\
\text { (3) }\end{array}$ & $\begin{array}{l}\text { Like me } \\
\text { (4) }\end{array}$ & $\begin{array}{c}\text { Just like } \\
\text { me (5) }\end{array}$ \\
\hline $\begin{array}{l}\text { I prefer a simple straight } \\
\text { forward discussion } \\
\text { regarding the task and the } \\
\text { resources needed to } \\
\text { complete the task. (1) } \\
\text { I prefer to get emotionally } \\
\text { close to employees but it is } \\
\text { not always possible as I } \\
\text { have my own work to do as } \\
\text { well. (2) } \\
\text { I like to make space to hear } \\
\text { what the issues are and then } \\
\text { offer task oriented } \\
\text { directions and/or personal } \\
\text { support, depending on } \\
\text { what's needed. (3) }\end{array}$ & & & & & \\
\hline
\end{tabular}


Q16 Please rate each question according to the extent to which they correspond with your general relationship style.

\begin{tabular}{|c|c|c|c|c|c|c|c|}
\hline Not at & Not like & Not & Neutral & Somewhat & Like & Just like \\
all like & me & much & $(4)$ & like & me & me (7) \\
me & $(2)$ & like me & & me (5) & (6) & \\
$(1)$ & & & $(3)$ & & & &
\end{tabular}

It is relatively easy for me to be emotionally close to others. I am comfortable depending on others and having others depend on me. I don't worry about being alone or having others not accept me. (1)

I am comfortable without close emotional relationships. It is very important to me to feel independent and selfsufficient and I prefer not to depend on others or have others depend on me. (2)

I want to be completely emotionally intimate with others but I often feel that others are reluctant to get as close as I would like. I am uncomfortable being without close relationships but I sometimes worry that others don't value me as much as I value them. (3)

I am somewhat uncomfortable getting close to others. I want emotionally close relationships but I find it difficult to trust others completely or to depend on them. I sometimes worry that I will be hurt if I allow myself to become too close to others. (4) 
Q17 Which one of these statements best describes you in close relationships?

It is relatively easy for me to be emotionally close to others. I am comfortable depending on others and having others depend on me. I don't worry about being alone or having others not accept me. (1)

I am comfortable without close emotional relationships. It is very important to me to feel independent and self- sufficient and I prefer not to depend on others or have others depend on me. (2)

I want to be completely emotionally intimate with others but I often feel that others are reluctant to get as close as I would like. I am uncomfortable being without close relationships but I sometimes worry that others don't value me as much as I value them. (3)

I am somewhat uncomfortable getting close to others. I want emotionally close relationships but I find it difficult to trust others completely or to depend on them. I sometimes worry that I will be hurt if I allow myself to become too close to others. (4)

Q18 Thinking about your workplace again, please indicate your level of agreement with the following statements.

\begin{tabular}{|c|c|c|c|c|}
\hline & $\begin{array}{c}\text { Strongly } \\
\text { Disagree } \\
\text { (1) }\end{array}$ & $\begin{array}{c}\text { Disagree } \\
\text { (2) }\end{array}$ & $\begin{array}{c}\text { Agree } \\
(3)\end{array}$ & $\begin{array}{c}\text { Strongly } \\
\text { Agree (4) }\end{array}$ \\
\hline $\begin{array}{l}\text { I am willing to work harder than I } \\
\text { have in order to help this } \\
\text { organisation succeed. (1) } \\
\text { I feel very little loyalty to this } \\
\text { organisation. (2) } \\
\text { I would take almost any job to keep } \\
\text { working for this organisation. (3) } \\
\text { I find that my values and the } \\
\text { organisation's, are very similar. (4) } \\
\text { I am proud to be working for this } \\
\text { organisation. (5) } \\
\text { I would turn down another job for } \\
\text { more pay in order to stay with this } \\
\text { organisation. (6) }\end{array}$ & & & & \\
\hline
\end{tabular}


Q19 You have nearly finished the survey. Please indicate your level of agreement with the following statements.

\begin{tabular}{|c|c|c|c|c|c|}
\hline $\begin{array}{c}\text { Strongly } \\
\text { Disagree }\end{array}$ & Disagree & Neither & Agree & $\begin{array}{c}\text { Strongly } \\
\text { Agree }\end{array}$ \\
& $(1)$ & & Agree & (4) & (5) \\
\hline
\end{tabular}

I frequently think of quitting my job. (1)

I am planning to search for a new job during the next 12 months. (2)

If I have my own way, I will be working for this organisation one year from now. (3)

Q20 When you are under pressure, what kind of support do you usually seek from within your organisation?

\begin{tabular}{|c|c|c|c|c|c|}
\hline & $\begin{array}{l}\text { Not at all } \\
\text { like me } \\
(1)\end{array}$ & $\begin{array}{c}\text { Not like } \\
\text { me (2) }\end{array}$ & $\begin{array}{c}\text { Neutral } \\
\text { (3) }\end{array}$ & $\begin{array}{c}\text { Like me } \\
\text { (4) }\end{array}$ & $\begin{array}{c}\text { Just like } \\
\text { me (5) }\end{array}$ \\
\hline $\begin{array}{l}\text { I don't ask for help } \\
\text { much but when I } \\
\text { do it is mostly } \\
\text { about needing } \\
\text { information about } \\
\text { my job so I can do } \\
\text { it better. (1) }\end{array}$ & & & & & \\
\hline $\begin{array}{l}\text { I find I ask for help } \\
\text { a lot. I especially } \\
\text { need emotional } \\
\text { help and } \\
\text { understanding } \\
\text { about the pressures } \\
\text { of my job. (2) }\end{array}$ & & & & & \\
\hline $\begin{array}{l}\text { I am confident in } \\
\text { asking my } \\
\text { organisation for } \\
\text { help. Sometimes } \\
\text { it's about how I am } \\
\text { and mostly about } \\
\text { how I can do my } \\
\text { job better. (3) }\end{array}$ & & & & & \\
\hline
\end{tabular}


Q21 When you are under pressure at work, how does your organisation respond?

\begin{tabular}{|c|c|c|c|c|c|}
\hline & $\begin{array}{c}\text { Very Unlikely } \\
\text { (1) }\end{array}$ & Unlikely (2) & Undecided (3) & Likely (4) & $\begin{array}{c}\text { Very Likely } \\
\text { (5) }\end{array}$ \\
\hline $\begin{array}{l}\text { Information } \\
\text { and technical } \\
\text { support is } \\
\text { more available } \\
\text { than emotional } \\
\text { support. (1) } \\
\text { I never know } \\
\text { how they are } \\
\text { going to } \\
\text { respond. I } \\
\text { expect the } \\
\text { unexpected. } \\
\text { (2) } \\
\text { I expect a } \\
\text { positive } \\
\text { response and } \\
\text { anticipate that } \\
\text { I will be } \\
\text { helped and } \\
\text { supported to } \\
\text { manage the } \\
\text { pressure. (3) }\end{array}$ & & & & & \\
\hline
\end{tabular}

Q22 When you are under pressure at work, how would you describe your productivity in relationship to your organisation?

\begin{tabular}{|c|c|c|c|c|c|}
\hline & $\begin{array}{c}\text { Not at all like } \\
\text { me (1) }\end{array}$ & $\begin{array}{c}\text { Not like me } \\
\text { (2) }\end{array}$ & Neutral (3) & Like me (4) & $\begin{array}{l}\text { Just like me } \\
\text { (5) }\end{array}$ \\
\hline $\begin{array}{l}\text { My mostly } \\
\text { neutral } \\
\text { relationship } \\
\text { with my } \\
\text { organisation } \\
\text { does not affect } \\
\text { my } \\
\text { productivity in } \\
\text { any way. (1) }\end{array}$ & & & & & \\
\hline $\begin{array}{l}\text { My sometimes } \\
\text { negative } \\
\text { relationship } \\
\text { with my } \\
\text { organisation } \\
\text { makes it harder } \\
\text { to stay } \\
\text { productive. (2) }\end{array}$ & & & & & \\
\hline $\begin{array}{l}\text { My mostly } \\
\text { positive } \\
\text { relationship } \\
\text { with my } \\
\text { organisation } \\
\text { makes it easier } \\
\text { to stay } \\
\text { productive. (3) }\end{array}$ & & & & & \\
\hline
\end{tabular}


Q23 When you are under pressure at work, how do you usually show this to other people in your organisation?

\begin{tabular}{|c|c|c|c|c|c|}
\hline & $\begin{array}{l}\text { Not at all } \\
\text { like me (1) }\end{array}$ & $\begin{array}{l}\text { Not like me } \\
\text { (2) }\end{array}$ & Neutral (3) & Like me (4) & $\begin{array}{c}\text { Just like } \\
\text { me (5) }\end{array}$ \\
\hline $\begin{array}{l}\text { I become increasingly } \\
\text { work focused and keep } \\
\text { my contact with others } \\
\text { at work to a minimum. } \\
\text { (1) } \\
\text { I become increasingly } \\
\text { people focused as I seek } \\
\text { support to think through } \\
\text { ways to deal with the } \\
\text { many different } \\
\text { challenges in my day-to- } \\
\text { day job. (2) } \\
\text { I talk more to just a few } \\
\text { select people at work } \\
\text { and this helps me to stay } \\
\text { focused on my job. (3) }\end{array}$ & & & & & \\
\hline
\end{tabular}

Q24 Two more questions to go. How closely do the following statements describe the goal oriented partnership between managers and employees in your organisation?

\begin{tabular}{|c|c|c|c|c|c|}
\hline & $\begin{array}{c}\text { Very } \\
\text { Unlikely } \\
\text { (1) }\end{array}$ & $\begin{array}{c}\text { Unlikely } \\
\text { (2) }\end{array}$ & $\begin{array}{c}\text { Undecided } \\
\text { (3) }\end{array}$ & Likely (4) & Very Likely (5) \\
\hline $\begin{array}{l}\text { Managers and } \\
\text { employees are mostly } \\
\text { very task focused. } \\
\text { There is sometimes a } \\
\text { lot of conflict between } \\
\text { them but this is not } \\
\text { addressed. (1) } \\
\text { Managers and } \\
\text { employees are often in } \\
\text { conflict with each } \\
\text { other. The conflict } \\
\text { rarely gets sorted out } \\
\text { and nothing much } \\
\text { changes long term } \\
\text { about how we do our } \\
\text { work (2) } \\
\text { Managers and } \\
\text { employees share a } \\
\text { mostly positive } \\
\text { relationship with some } \\
\text { conflict. Conflicts are } \\
\text { worked through often } \\
\text { resulting in good } \\
\text { outcomes for managers } \\
\text { and employees. ( } 3 \text { ) }\end{array}$ & & & & & \\
\hline
\end{tabular}

Q25 In which industry are you currently employed? 


\section{Appendix E: MESE Survey (Employees) 2011}

Thank you for taking the time to fill out this survey.

Your participation helps to explore the impact of day-to-day interactions between employees and managers on employee engagement.

This survey includes some demographic questions along with questions about your current job, workplace relationship style and relationship style generally.

This survey will take about 10 - 15 minutes to complete. Your participation is voluntary and anonymous. Participation is understood as you giving consent for your answers to be used as information for this study.

This survey is being conducted as part of a $\mathrm{PhD}$ study at Victoria University Wellington and has the approval of the Victoria University of Wellington Human Ethics Committee.

Further information regarding this survey is available by clicking on this link: Manager and employee engagement study information sheet

The survey closes 13 May, 2011.

If you have any questions regarding this survey you can contact:

Maree Foley Email: Maree.Foley@vuw.ac.nz Phone:

Research Supervisors:

Dr Geoff Plimmer. Email: Geoff.Plimmer@vuw.ac.nz Phone:

Dr Jane Bryson. Email: Jane.Bryson@vuw.ac.nz_Phone: 
Q1 What is your age?

Under 21 years (1)

21 - 29 years (2)

30 - 39 years $(3)$

40 - 49 years $(4)$

50 - 59 years $(5)$

60 - 69 years $(6)$

70 - 79 years (7)

80 years and over (8)

Q2 What is your gender?

Female (1)

Male (2)

Q3 With which ethnic group do you most identify?

口 Maori (1)

- New Zealand European (2)

- Pacific Islander (3)

口 Asian (4)

$\square \quad$ Other European (5)

$\square$ Other (please specify) (6) 
Q4 Thinking about your current job and organisation please indicate your level of agreement with the following statements.

\begin{tabular}{|c|c|c|c|c|c|}
\hline & $\begin{array}{l}\text { Strongly } \\
\text { Disagree } \\
\text { (1) }\end{array}$ & $\begin{array}{l}\text { Disagree } \\
\text { (2) }\end{array}$ & $\begin{array}{l}\text { Neither Agree } \\
\text { nor Disagree } \\
\text { (3) }\end{array}$ & $\begin{array}{l}\text { Agree } \\
\text { (4) }\end{array}$ & $\begin{array}{l}\text { Strongly } \\
\text { Agree } \\
\text { (5) }\end{array}$ \\
\hline $\begin{array}{l}\text { I really "throw" myself } \\
\text { into my job. (1) }\end{array}$ & & & & & \\
\hline $\begin{array}{l}\text { Sometimes I am so into } \\
\text { my job that I lose track } \\
\text { of time. (2) }\end{array}$ & & & & & \\
\hline $\begin{array}{l}\text { This job is all } \\
\text { consuming. I am totally } \\
\text { into it. (3) }\end{array}$ & & & & & \\
\hline $\begin{array}{l}\text { My mind often wanders } \\
\text { and I think of other } \\
\text { things when doing my } \\
\text { job. (4) }\end{array}$ & & & & & \\
\hline $\begin{array}{l}\text { I am highly engaged in } \\
\text { this job. (5) }\end{array}$ & & & & & \\
\hline $\begin{array}{l}\text { Being a member of this } \\
\text { organisation is very } \\
\text { captivating. (6) }\end{array}$ & & & & & \\
\hline $\begin{array}{l}\text { One of the most exciting } \\
\text { things for me is getting } \\
\text { involved with things } \\
\text { happening in this } \\
\text { organisation. (7) }\end{array}$ & & & & & \\
\hline $\begin{array}{l}\text { I am really not into the } \\
\text { "goings-on" in this } \\
\text { organisation. (8) }\end{array}$ & & & & & \\
\hline $\begin{array}{l}\text { Being a member of this } \\
\text { organisation makes me } \\
\text { come alive. (9) }\end{array}$ & & & & & \\
\hline $\begin{array}{l}\text { Being a member of this } \\
\text { organisation is } \\
\text { exhilarating for me. (10) }\end{array}$ & & & & & \\
\hline $\begin{array}{l}\text { I am highly engaged in } \\
\text { this organisation. (11) }\end{array}$ & & & & & \\
\hline
\end{tabular}


Q5 When you are under pressure, what kind of support do you usually seek from your manager?

\begin{tabular}{|l|l|l|l|l|l|} 
& \multicolumn{1}{|c|}{$\begin{array}{c}\text { Very } \\
\text { Unlikely (1) }\end{array}$} & Unlikely (2) & $\begin{array}{c}\text { Undecided } \\
\text { (3) }\end{array}$ & Likely (4) & $\begin{array}{c}\text { Very Likely } \\
\text { (5) }\end{array}$ \\
\hline $\begin{array}{l}\text { Task } \\
\text { oriented/information } \\
\text { type support. (1) }\end{array}$ & & & & \\
$\begin{array}{l}\text { I like extra } \\
\text { reassurance at this } \\
\text { time and seek support } \\
\text { to think through big } \\
\text { and small issues. (2) }\end{array}$ & & & & \\
$\begin{array}{l}\text { I ask for } \\
\text { information/resources } \\
\text { and/or emotional } \\
\text { support. It depends } \\
\text { on what I need at the } \\
\text { time to keep me } \\
\text { working. (3) }\end{array}$ & & & & \\
\hline
\end{tabular}


Q6 When you are under pressure, what kind of support do you get from your manager?

\begin{tabular}{|c|c|c|c|c|c|}
\hline & $\begin{array}{c}\text { Very } \\
\text { Unlikely (1) }\end{array}$ & Unlikely (2) & $\begin{array}{c}\text { Undecided } \\
\text { (3) }\end{array}$ & Likely (4) & $\begin{array}{l}\text { Very Likely } \\
\text { (5) }\end{array}$ \\
\hline $\begin{array}{l}\text { Matter of fact, task } \\
\text { oriented/information } \\
\text { to help me do my job. } \\
\text { (1) } \\
\text { Support is often } \\
\text { unreliable and I } \\
\text { expect the } \\
\text { unexpected. (2) } \\
\text { They show interest in } \\
\text { how I am and are } \\
\text { helpful in pointing me } \\
\text { in the right direction } \\
\text { towards new } \\
\text { information/resources. } \\
\text { (3) }\end{array}$ & & & & & \\
\hline
\end{tabular}

Q7 When you are under pressure, how often would you seek support from your manager?

\begin{tabular}{|c|c|c|c|c|c|}
\hline & $\begin{array}{c}\text { Not at all like } \\
\text { me (1) }\end{array}$ & $\begin{array}{c}\text { Not like me } \\
(2)\end{array}$ & Neutral (3) & Like me (4) & Just like me \\
\hline $\begin{array}{c}\text { Very rarely } \\
\text { (1) }\end{array}$ & & & & & \\
Very often (2) & & & & \\
Often (3) & & & & \\
\hline
\end{tabular}


Q8 When you are under pressure, how do you deal with workplace conflict?

\begin{tabular}{|c|c|c|c|c|c|}
\hline & $\begin{array}{l}\text { Not at all like } \\
\text { me (1) }\end{array}$ & $\begin{array}{l}\text { Not like me } \\
\text { (2) }\end{array}$ & Neutral (3) & Like me (4) & $\begin{array}{l}\text { Just like me } \\
\text { (5) }\end{array}$ \\
\hline $\begin{array}{l}\text { I keep the } \\
\text { process short } \\
\text { and focused by } \\
\text { sticking with } \\
\text { the facts and } \\
\text { keeping } \\
\text { emotions out } \\
\text { of the process. } \\
\text { (1) } \\
\text { I often find } \\
\text { myself in the } \\
\text { middle of } \\
\text { workplace } \\
\text { conflict and I } \\
\text { never know if } \\
\text { it is going to } \\
\text { get resolved. } \\
\text { (2) } \\
\text { I see conflict } \\
\text { as an } \\
\text { inevitable part } \\
\text { of working } \\
\text { together. I give } \\
\text { people space } \\
\text { to say how } \\
\text { they feel and } \\
\text { work together } \\
\text { with them to } \\
\text { find a } \\
\text { solution. (3) }\end{array}$ & & & & & \\
\hline
\end{tabular}


Q9 When your manager is under pressure, how would you describe how you go about doing your job?

\begin{tabular}{c|c|c|c|c|}
$\begin{array}{c}\text { Not at all like } \\
\text { me (1) }\end{array}$ & $\begin{array}{c}\text { Not like me } \\
(2)\end{array}$ & Neutral (3) & Like me (4) & Just like me \\
& & & $(5)$
\end{tabular}

I try to keep

focused on my own job and

work as

independently

as I can. I rarely

ask them for

help or support

during this time

unless I really

need to. (1)

I find I often need their

support at this

time with my

own work and I

worry that they

are not able to

be available. It

would be fair to

say my work

output at this

time is

reduced. (2)

I stay

productive and

am confident

that I can ask

for help or

support if

needed in a way

that takes both

my need for

help and their

situation into

account. (3) 
Q10 Thinking about your current organisation, please indicate your level of agreement to the following statements.

\begin{tabular}{|c|c|c|c|c|c|c|c|}
\hline & $\begin{array}{c}\text { Strongly } \\
\text { Disagree } \\
\text { (1) }\end{array}$ & $\begin{array}{l}\text { Disagree } \\
\text { (2) }\end{array}$ & $\begin{array}{l}\text { Somewhat } \\
\text { Disagree } \\
\text { (3) }\end{array}$ & $\begin{array}{l}\text { Neither } \\
\text { Agree nor } \\
\text { Disagree } \\
\text { (4) }\end{array}$ & $\begin{array}{l}\text { Somewhat } \\
\text { Agree } \\
\text { (5) }\end{array}$ & $\begin{array}{l}\text { Agree } \\
\text { (6) }\end{array}$ & $\begin{array}{l}\text { Strongly } \\
\text { Agree (7) }\end{array}$ \\
\hline $\begin{array}{l}\text { The organisation } \\
\text { values my } \\
\text { contribution to its } \\
\text { well-being. (1) } \\
\text { The organisation } \\
\text { fails to appreciate } \\
\text { any extra effort } \\
\text { from me. (2) } \\
\text { The organisation } \\
\text { would ignore any } \\
\text { complaint from me. } \\
\text { (3) } \\
\text { The organisation } \\
\text { really cares about } \\
\text { my well-being. (4) } \\
\text { Even if I did the } \\
\text { best job possible, } \\
\text { the organisation } \\
\text { would fail to } \\
\text { notice. (5) } \\
\text { The organisation } \\
\text { cares about my } \\
\text { general satisfaction } \\
\text { at work. (6) } \\
\text { The organisation } \\
\text { shows very little } \\
\text { concern for me. (7) } \\
\text { The organisation } \\
\text { takes pride in my } \\
\text { accomplishments at } \\
\text { work. (8) }\end{array}$ & & & & & & & \\
\hline
\end{tabular}


Q11 Thinking about the person at work who you consider as your immediate manager, please indicate your level of agreement to the following statements.

\begin{tabular}{|c|c|c|c|c|c|c|c|}
\hline & $\begin{array}{c}\text { Strongly } \\
\text { Disagree } \\
\text { (1) }\end{array}$ & $\begin{array}{c}\text { Disagree } \\
\text { (2) }\end{array}$ & $\begin{array}{l}\text { Somewh } \\
\text { at } \\
\text { Disagree } \\
\text { (3) }\end{array}$ & $\begin{array}{c}\text { Neither } \\
\text { Agree } \\
\text { nor } \\
\text { Disagree } \\
\text { (4) }\end{array}$ & $\begin{array}{c}\text { Somewhat } \\
\text { Agree (5) }\end{array}$ & $\begin{array}{l}\text { Agree } \\
(6)\end{array}$ & $\begin{array}{l}\text { Strongly } \\
\text { Agree (7) }\end{array}$ \\
\hline
\end{tabular}

My
supervisor
values my
contribution
to the
organisation's
well-being.

(1)

My supervisor

fails to

appreciate any

extra effort

from me. (2)

My

supervisor

would ignore

any complaint

from me. (3)

My

supervisor

really cares

about my

well-being.

(4)

Even if I did

the best job

possible, my

supervisor

would fail to notice. (5)

My

supervisor

cares about

my general

satisfaction at

work. (6)

My

supervisor

shows very

little concern

for me. (7)

My

supervisor

takes pride in

my

accomplishme

nts at work.

(8) 
Q12 When you are under pressure, what might your manager notice about how you seek support?

\begin{tabular}{|c|c|c|c|c|c|}
\hline & $\begin{array}{c}\text { Not at all } \\
\text { like me (1) }\end{array}$ & $\begin{array}{l}\text { Not like me } \\
\text { (2) }\end{array}$ & Neutral (3) & Like me (4) & $\begin{array}{c}\text { Just like me } \\
\text { (5) }\end{array}$ \\
\hline $\begin{array}{l}\text { That I become } \\
\text { increasingly } \\
\text { independent and task } \\
\text { focused. It would be } \\
\text { unlikely if I asked } \\
\text { directly for support. } \\
\text { (1) } \\
\text { That I increasingly } \\
\text { seek and rely on their } \\
\text { support to help me } \\
\text { think through what I } \\
\text { can best do to } \\
\text { manage my day-to- } \\
\text { day workload and if } \\
\text { they are not } \\
\text { available, I seek the } \\
\text { same from my peers. } \\
\text { (2) } \\
\text { That I ask for } \\
\text { information/resources } \\
\text { or emotional support } \\
\text { and understanding, } \\
\text { based on what I most } \\
\text { need at the time. (3) }\end{array}$ & & & & & \\
\hline
\end{tabular}

Q13 When you are under pressure, what kind of response do you expect to get from your manager?

\begin{tabular}{|c|c|c|c|c|c|}
\hline & $\begin{array}{c}\text { Very } \\
\text { Unlikely (1) }\end{array}$ & Unlikely (2) & $\begin{array}{l}\text { Undecided } \\
\text { (3) }\end{array}$ & Likely (4) & $\begin{array}{l}\text { Very Likely } \\
\text { (5) }\end{array}$ \\
\hline $\begin{array}{l}\text { They will provide } \\
\text { matter of fact, task } \\
\text { oriented/information } \\
\text { to help me do my } \\
\text { job. (1) } \\
\text { They will be } \\
\text { unreliable and } \\
\text { mostly unavailable } \\
\text { when I need to ask } \\
\text { for support. (2) } \\
\text { They will show } \\
\text { interest in how I am } \\
\text { and will be helpful } \\
\text { in pointing me in } \\
\text { the right direction } \\
\text { towards new } \\
\text { information/ } \\
\text { resources. (3) }\end{array}$ & & & & & \\
\hline
\end{tabular}


Q14 When you are under pressure, how do you prefer to deal with workplace conflict?

\begin{tabular}{|c|c|c|c|c|c|}
\hline & $\begin{array}{c}\text { Not at all like } \\
\text { me (1) }\end{array}$ & $\begin{array}{c}\text { Not like me } \\
\text { (2) }\end{array}$ & Neutral (3) & Like me (4) & $\begin{array}{l}\text { Just like me } \\
\text { (5) }\end{array}$ \\
\hline $\begin{array}{l}\text { I prefer to } \\
\text { avoid conflict. } \\
\text { I deal with } \\
\text { conflict by } \\
\text { sticking with } \\
\text { the facts and } \\
\text { keeping } \\
\text { emotions out } \\
\text { of the process. } \\
\text { (1) } \\
\text { I prefer not to } \\
\text { deal with } \\
\text { conflict at all } \\
\text { but I often find } \\
\text { myself in the } \\
\text { middle of } \\
\text { workplace } \\
\text { conflict and I } \\
\text { never know if } \\
\text { it is going to } \\
\text { get resolved. } \\
\text { (2) } \\
\text { I see conflict } \\
\text { as an } \\
\text { inevitable part } \\
\text { of working } \\
\text { together. I } \\
\text { prefer to work } \\
\text { it through by } \\
\text { giving people } \\
\text { space to say } \\
\text { how they feel } \\
\text { and then work } \\
\text { together to } \\
\text { find a solution. } \\
\text { (3) }\end{array}$ & & & & & \\
\hline
\end{tabular}


Q15 When other workers are under pressure, what kind of extra support do you prefer to offer?

\begin{tabular}{|c|c|c|c|c|c|}
\hline & $\begin{array}{c}\text { Not at all like } \\
\text { me (1) }\end{array}$ & $\begin{array}{c}\text { Not like me } \\
\text { (2) }\end{array}$ & Neutral (3) & Like me (4) & $\begin{array}{l}\text { Just like me } \\
\text { (5) }\end{array}$ \\
\hline $\begin{array}{l}\text { I prefer a } \\
\text { simple straight } \\
\text { forward } \\
\text { discussion } \\
\text { regarding the } \\
\text { task and the } \\
\text { resources } \\
\text { needed to } \\
\text { complete the } \\
\text { task. (1) } \\
\text { I prefer to get } \\
\text { emotionally } \\
\text { close to } \\
\text { workers to } \\
\text { show them that } \\
\text { I value them. } \\
\text { (2) } \\
\text { I like to make } \\
\text { space to hear } \\
\text { what the issues } \\
\text { are and then } \\
\text { offer task } \\
\text { oriented } \\
\text { directions } \\
\text { and/or personal } \\
\text { support based } \\
\text { help, } \\
\text { depending on } \\
\text { what's needed. } \\
\text { (3) }\end{array}$ & & & & & \\
\hline
\end{tabular}


Q16 Please rate each question according to the extent to which they correspond with your general relationship style.

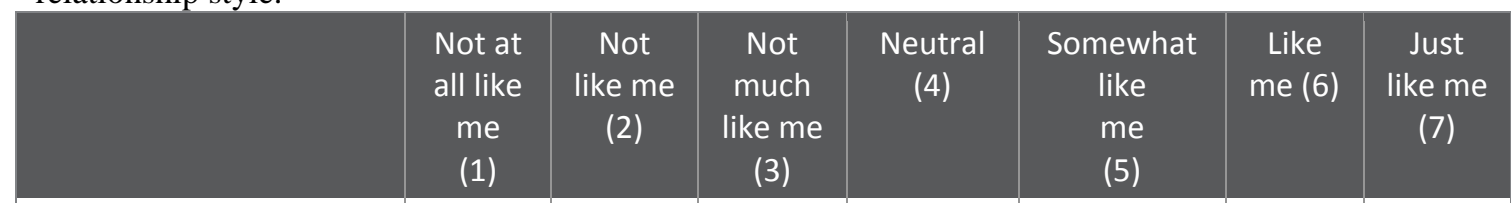

It is relatively easy for me to be emotionally close to others. I am comfortable depending on others and having others depend on me. I don't worry about being alone or having others not accept me. (1)

I am comfortable without close emotional relationships. It is very important to me to feel independent and selfsufficient and I prefer not to depend on others or have others depend on me. (2)

I want to be completely emotionally intimate with others but I often feel that others are reluctant to get as close as I would like. I am uncomfortable being without close relationships but I sometimes worry that others don't value me as much as I value them.

(3)

I am somewhat uncomfortable getting close to others. I want emotionally close relationships but I find it difficult to trust others completely or to depend on them. I sometimes worry that I will be hurt if I allow myself to become too close to others. (4) 
Q17 Which statement best describes you in close relationships?

It is relatively easy for me to be emotionally close to others. I am comfortable depending on others and having others depend on me. I don't worry about being alone or having others not accept me. (1)

I am comfortable without close emotional relationships. It is very important to me to feel independent and self- sufficient and I prefer not to depend on others or have others depend on me. (2)

I want to be completely emotionally intimate with others but I often feel that others are reluctant to get as close as I would like. I am uncomfortable being without close relationships but I sometimes worry that others don't value me as much as I value them. (3)

I am somewhat uncomfortable getting close to others. I want emotionally close relationships but I find it difficult to trust others completely or to depend on them. I sometimes worry that I will be hurt if I allow myself to become too close to others. (4)

Q18 Thinking about your workplace again, please indicate your level of agreement with the following statements.

\begin{tabular}{|c|c|c|c|c|}
\hline & $\begin{array}{c}\text { Strongly } \\
\text { Disagree (1) }\end{array}$ & Disagree (2) & Agree (3) & $\begin{array}{c}\text { Strongly Agree } \\
\text { (4) }\end{array}$ \\
\hline $\begin{array}{l}\text { I am willing to } \\
\text { work harder than I } \\
\text { have in order to } \\
\text { help this } \\
\text { organisation } \\
\text { succeed. (1) } \\
\text { I feel very little } \\
\text { loyalty to this } \\
\text { organisation. (2) } \\
\text { I would take } \\
\text { almost any job to } \\
\text { keep working for } \\
\text { this organisation. } \\
\text { (3) } \\
\text { I find that my } \\
\text { values and the } \\
\text { organisation's are } \\
\text { very similar. (4) } \\
\text { I am proud to be } \\
\text { working for this } \\
\text { organisation. (5) } \\
\text { I would turn down } \\
\text { another job for } \\
\text { more pay in order } \\
\text { to stay with this } \\
\text { organisation. (6) }\end{array}$ & & & & \\
\hline
\end{tabular}


Q19 You have nearly finished the survey. Please indicate your level of agreement with the following statements.

\begin{tabular}{|c|c|c|c|c|c|}
\hline & $\begin{array}{c}\text { Strongly } \\
\text { Disagree (1) }\end{array}$ & Disagree (2) & $\begin{array}{c}\text { Neither } \\
\text { Agree nor } \\
\text { Disagree (3) }\end{array}$ & Agree (4) & $\begin{array}{c}\text { Strongly } \\
\text { Agree (5) }\end{array}$ \\
\hline $\begin{array}{l}\text { I frequently } \\
\text { think of } \\
\text { quitting my } \\
\text { job. (1) } \\
\text { I am planning } \\
\text { to search for a } \\
\text { new job during } \\
\text { the next } 12 \\
\text { months. (2) } \\
\text { If I have my } \\
\text { own way, I } \\
\text { will be } \\
\text { working for } \\
\text { this } \\
\text { organisation } \\
\text { one year from } \\
\text { now. (3) }\end{array}$ & & & & & \\
\hline
\end{tabular}

Q20 When you are under pressure, what kind of support do you usually seek from within your organisation?

\begin{tabular}{|c|c|c|c|c|c|}
\hline & $\begin{array}{c}\text { Not at all like } \\
\text { me (1) }\end{array}$ & $\begin{array}{l}\text { Not like me } \\
\text { (2) }\end{array}$ & Neutral (3) & Like me (4) & $\begin{array}{l}\text { Just like me } \\
\text { (5) }\end{array}$ \\
\hline $\begin{array}{l}\text { I don't ask for } \\
\text { help much but } \\
\text { when I do it is } \\
\text { mostly about } \\
\text { needing } \\
\text { information } \\
\text { about my job so } \\
\text { I can do it } \\
\text { better. (1) } \\
\text { I find I ask for } \\
\text { help a lot. I } \\
\text { especially need } \\
\text { emotional help } \\
\text { and } \\
\text { understanding } \\
\text { about the } \\
\text { pressures of my } \\
\text { job. (2) } \\
\text { I am confident } \\
\text { in asking my } \\
\text { organisation for } \\
\text { help. } \\
\text { Sometimes it's } \\
\text { about how I am } \\
\text { and mostly } \\
\text { about how I can } \\
\text { do my job } \\
\text { better. ( } 3 \text { ) }\end{array}$ & & & & & \\
\hline
\end{tabular}


Q21 When you are under pressure at work, how does your organisation respond?

\begin{tabular}{|c|c|c|c|c|c|}
\hline & $\begin{array}{c}\text { Very } \\
\text { Unlikely (1) }\end{array}$ & Unlikely (2) & $\begin{array}{c}\text { Undecided } \\
\text { (3) }\end{array}$ & Likely (4) & $\begin{array}{l}\text { Very Likely } \\
\text { (5) }\end{array}$ \\
\hline $\begin{array}{l}\text { Information and } \\
\text { technical support } \\
\text { is more available } \\
\text { than emotional } \\
\text { support. (1) } \\
\text { I never know } \\
\text { how they are } \\
\text { going to respond. } \\
\text { I expect the } \\
\text { unexpected. (2) } \\
\text { I expect a } \\
\text { positive response } \\
\text { and anticipate } \\
\text { that I will be } \\
\text { helped and } \\
\text { supported to } \\
\text { manage the } \\
\text { pressure. (3) }\end{array}$ & & & & & \\
\hline
\end{tabular}

Q22 When you are under pressure at work, how would you describe your productivity in relationship to your organisation?

\begin{tabular}{|c|c|c|c|c|c|}
\hline & $\begin{array}{l}\text { Not at all like } \\
\text { me (1) }\end{array}$ & $\begin{array}{c}\text { Not like me } \\
\text { (2) }\end{array}$ & Neutral (3) & Like me (4) & $\begin{array}{l}\text { Just like me } \\
\text { (5) }\end{array}$ \\
\hline $\begin{array}{l}\text { My mostly } \\
\text { neutral } \\
\text { relationship } \\
\text { with my } \\
\text { organisation } \\
\text { does not affect } \\
\text { my } \\
\text { productivity in } \\
\text { any way. (1) } \\
\text { My sometimes } \\
\text { negative } \\
\text { relationship } \\
\text { with my } \\
\text { organisation } \\
\text { makes it harder } \\
\text { to stay } \\
\text { productive. (2) } \\
\text { My mostly } \\
\text { positive } \\
\text { relationship } \\
\text { with my } \\
\text { organisation } \\
\text { makes it easier } \\
\text { to stay } \\
\text { productive. (3) }\end{array}$ & & & & & \\
\hline
\end{tabular}


Q23 When you are under pressure at work, how do you usually show this to other people in your organisation?

\begin{tabular}{|c|c|c|c|c|c|}
\hline & $\begin{array}{c}\text { Not at all like } \\
\text { me (1) }\end{array}$ & $\begin{array}{l}\text { Not like me } \\
\text { (2) }\end{array}$ & Neutral (3) & Like me (4) & $\begin{array}{l}\text { Just like me } \\
\text { (5) }\end{array}$ \\
\hline $\begin{array}{l}\text { I become } \\
\text { increasingly } \\
\text { work focused } \\
\text { and keep my } \\
\text { contact with } \\
\text { others at work } \\
\text { to a minimum. } \\
\text { (1) } \\
\text { I talk more to } \\
\text { people at work } \\
\text { about how I am } \\
\text { feeling and I } \\
\text { tend to do less } \\
\text { work during } \\
\text { these times. } \\
\text { (2) } \\
\text { I talk more to } \\
\text { just a few } \\
\text { select people at } \\
\text { work and this } \\
\text { helps me to } \\
\text { stay focused on } \\
\text { my job. (3) }\end{array}$ & & & & & \\
\hline
\end{tabular}


Q24 Two more questions to go. How closely do the following statements describe the goal oriented partnership between managers and employees in your organisation?

\begin{tabular}{|c|c|c|c|c|c|}
\hline & $\begin{array}{c}\text { Very } \\
\text { Unlikely } \\
\text { (1) }\end{array}$ & $\begin{array}{c}\text { Unlikely } \\
\text { (2) }\end{array}$ & $\begin{array}{c}\text { Undecided } \\
\text { (3) }\end{array}$ & $\begin{array}{l}\text { Likely } \\
(4)\end{array}$ & $\begin{array}{l}\text { Very } \\
\text { Likely } \\
\text { (5) }\end{array}$ \\
\hline $\begin{array}{l}\text { Managers and } \\
\text { employees are } \\
\text { mostly very task } \\
\text { focused. There is } \\
\text { sometimes a lot of } \\
\text { conflict between } \\
\text { them but this is not } \\
\text { addressed. (1) } \\
\text { Managers and } \\
\text { employees are } \\
\text { often in conflict } \\
\text { with each other. } \\
\text { The conflict rarely } \\
\text { gets sorted out and } \\
\text { nothing much } \\
\text { changes long term } \\
\text { about how we do } \\
\text { our work. (2) } \\
\text { Managers and } \\
\text { employees share a } \\
\text { mostly positive } \\
\text { relationship with } \\
\text { some conflict. } \\
\text { Conflicts are } \\
\text { worked through } \\
\text { often resulting in } \\
\text { good outcomes for } \\
\text { managers and } \\
\text { employees. (3) }\end{array}$ & & & & & \\
\hline
\end{tabular}

Q25 In which industry are you currently employed? 


\section{Appendix F: Survey Information Sheet}

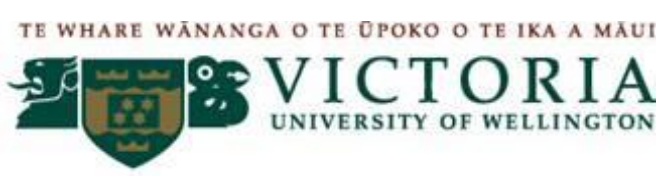

\section{Employee and Manager Engagement Study: Information Sheet}

A key influence on employee engagement is the manager-employee relationship. However, little is known about this relationship as an engagement relationship. To understand more about this engagement relationship this study is exploring workplace interaction styles between managers and employees.

Your input into this study will be used to increase understanding of both employee and manager engagement. These understandings will then be developed into an engagement practice framework to be used by managers and employees.

This study is part of the requirements of a $\mathrm{PhD}$ study, conducted through the Victoria Management School, Victoria University of Wellington. The study has been granted ethical approval by Victoria University of Wellington.

\section{The questions}

The questions do not require you to identify yourself, your organisation or anybody else.

What will happen to your data?

$>$ The survey is anonymous and has been set up to record only your responses. There is no way to track you as a respondent. You and your organisation are not identifiable.

$>$ Access to this anonymous data will be restricted to the student researcher and her two supervisors at Victoria University.

$>$ It is anticipated that findings will be used in this $\mathrm{PhD}$ thesis, presented at a conference and published in an academic journal. Key participating organisations and professional bodies will also receive summaries that can then be made available to members.

$>$ The time frame for participation is: February and March, 2011.

$>$ If you are personally interested in receiving your own copy of the survey results, email Maree Foley and she will forward a copy of these to you when they are available.

Yours sincerely,

Maree Foley

PhD Candidate, Victoria Management School, Victoria University of Wellington.

Email: Maree.Foley@vuw.ac.nz

Student Researcher Supervisors:

Associate Professor Jane Bryson

Victoria Management School

Dr Geoff Plimmer

Victoria University of Wellington

Email: Jane.Bryson@vuw.ac.nz

Victoria Management School

Victoria University of Wellington

Email: Geoff.Plimmer@vuw.ac.nz 


\title{
Appendix G: Case Study Participant Information Sheet
}

\author{
VICTORIA UNIVERSITY OF WELLINGTON \\ Te Whare Wananga o te Upoko o te Ika a Maui
}

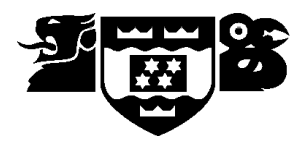

VICTORIA

MANAGEMENT SCHOOL

Te Kura Whakahaere

\section{Manager-Employee Engagement Study CASE STUDY PARTICIPANT INFORMATION SHEET Researcher: Maree Foley}

\section{Project description}

This study tests out a brief engagement programme designed for managers and employees who work together. This programme is not a trouble-shooting programme. Instead, this programme aims to: 1 . Understand more about the different ways that managers and employees communicate with each other on a day-to-day basis about the work/job that they are doing; and 2. Explore the efficacy of communication within each unique manager-employee relationship/work context in relation to getting the tasks of the job done.

\section{Researcher introduction}

Maree Foley is the primary researcher of this study. Maree is currently a full time Doctoral student in the Victoria Management School, at Victoria University of Wellington (VUW) and her work is being supervised by Associate Professor Jane Bryson and Dr Geoff Plimmer from the Victoria Management School. Previous to this study Maree has had fifteen years practice as a trainer in both the public and private sector, with individuals, dyads and groups. She is a member of the NZ Coaching Psychology Steering Committee. During the course of this study she will also be receiving coaching psychology supervision from a registered psychologist.

\section{Selection to participate}

To participate, each manager and employee unit needs to:

1. Currently work directly together, and to have done so for at least six months;

2. Be happy enough with their own individual communication style at work;

3. Be interested in exploring communication skills that are unique to the job and the organisation;

4. Agree to voluntarily participate;

5. Agree to keep the identity of each other confidential; and 
6. Have clearance where necessary from your organisation to participate.

\begin{abstract}
About the Study
This project will begin in the latter part of 2011 and run into the early part of 2012. The following steps for part one and part two are outlined below. Participating in part one will involve about 2 hours of each participant's time across a two to three week period; and participating in part two will involve about 3 hours across a two to three week period.
\end{abstract}

\title{
PART ONE: Individual Engagement
}

Step 1: Introduction to the researcher and the programme

The researcher will meet with manager and employee separately and then together to:

(i) Address any further questions regarding the study;

(ii) Sign consent forms; and

(iii) Create an interview timetable to fit around your schedules.

Step 2: Online survey

This survey will take approximately 10 to 15 minutes. The survey is confidential. Full results will be available only to you, and will be discussed with you in a confidential feedback session.

\section{Step 3: Individual feedback session (Audio recorded)}

The session (I hour) goals:

(i) Identify communication styles that are most effective for you in getting your job done as well as identifying any styles that are less effective to getting your job done;

(ii) Explore skills to optimise your communication style; and

(iii) Develop a plan for on-the-job skill building practice.

Your full interview will be transcribed and then summarised. You will receive the written summary. At the end of this summary you will be invited to consider participating in part two as a manager-employee dyad.

\section{PART TWO: Manager-Employee Engagement}

Step 1: Programme overview and establishing the ground-rules.

(i) The researcher will meet with you both as a dyad to talk about the interview process, to establish ground-rules, and to go over the details in the consent form. To add extra safety for you as participants, the ground-rules we establish will also be reviewed by my Victoria University supervisors. Once we (that is you, me and my Victoria University supervisors) are all happy with the ground-rules we then prepare for the manager-employee dyad coaching sessions.

(ii) At this point, the researcher will meet with each individual participant in the dyad to clarify and obtain verbal (audio recorded) consent 
to use their information from part one for this part of the programme. It is important for you to know that only the agreed upon information will be used in this part of the programme.

(iii) Then, based on the agreed upon aspects, a summary will be developed. The summary is considered a confidential document. Only you, the other person that you are doing this programme with, and possibly my supervisors, will have access to this summary.

Step 2: Manager-Employee dyad feedback engagement session (Audio recorded)

The goals of this manager-employee led session (I hour) include:

(i) Exploring how each of your communication styles influences how you go about getting your work done.

(ii) Examining practice skills to optimise the communication styles that you are both using; and

(iii) Developing a plan for on-the-job practice of any new skills.

The audio recording will be transcribed and a summary will be made available to you both as a confidential document. You will be invited to comment on this if you choose.

Step 3: Manager-Employee dyad follow-up session on engagement and communication styles (Audio-recorded)

The goals of this manager-employee led session ( 1 hour) are to explore any questions or queries arising from the previous session; and respond to any possible coaching requests. In this situation, the researcher will recommend coaching colleagues who you can contact.

As above, the audio recording will be transcribed and a summary of this will be made available to you both as a confidential document. You will be invited to comment on this if you choose.

\section{Information and Confidentiality}

Information that is collected forms the basis of my doctoral research study. It will be used in the writing of my thesis and in other related publications.

All the information that you provide, will be treated confidentially. Your name will not be used in any research report or in any presentation of the findings/publication. You will be asked to provide a pseudonym. Your identity will be protected at all times with your information identifiable only by code and pseudonym.

\section{Data storage/retention/destruction/future use}

All the data you provide will be stored in a locked cabinet on the Victoria University of Wellington campus. Data that is held on digital file will be password protected. Your Consent Form/s will be stored separately from your data. At the end of this study, the audio file of your individual interviews will be returned to you and or deleted by the researcher. Dyad interview recordings will be deleted at the close of the study. All other data will be destroyed after three years from the time of the case studies. 


\section{Benefits to you participating and access to results}

As a participant you will:

a) Be part of a manager-employee engagement programme; and

b) Receive a written summary of the study findings.

\section{Potential Risks?}

It is not anticipated that there are any risks to you as person, the other person participating with you, or to your organisation. This study is focused on exploring day-to-day communication activities that occur at work. This is not a clinical or diagnostic trial. It is a programme designed for managers and employees to conduct together. However, given the ordinary role differences between managers and employees, all efforts will be made by the researcher to provide a safe working space for both the manager and employee.

\section{Right to withdraw from participation}

You may withdraw yourself from this project (before data collection and analysis is complete) without having to give reasons or without penalty of any sort. The researcher will let you know at the beginning of the study what the last date for withdrawal will be.

\section{Ethics Approval}

Ethics approval for this study from Victoria University has been granted.

\section{Any further queries?}

If you have any questions or would like to receive further information about the project, please contact me at: Maree.Foley@vuw.ac.nz.

Or if you prefer you can contact my primary supervisor, Associate Professor Jane Bryson, at the Victoria Management School, Victoria University of Wellington, P.0. Box 600, Wellington. Email:Jane.Bryson@vuw.ac.nz 


\title{
Appendix H: Case Study Consent Form (part one).
}

\author{
VICTORIA UNIVERSITY OF WELLINGTON \\ Te Whare Wananga o te Upoko o te Ika a Maui
}

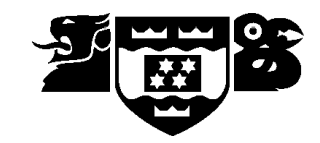

VICTORIA

MANAGEMENT SCHOOL

Te Kura Whakahaere

\section{Manager-Employee Engagement Study CASE STUDY PARTICIPANT CONSENT FORM PART ONE Researcher: Maree Foley \\ CONSENT TO PARTICIPATE}

* I have been given and have understood an explanation of this research project. I have had the opportunity to ask any questions related to this study and have received satisfactory answers to my questions.

* I understand that any information I provide will be kept confidential to the researcher, the supervisors and the person who transcribes the audio recordings of my interview.

* I understand that the identity of the other person who is participating with me in this study is to remain confidential.

* I understand that all comments made by the other person who is participating with me in this study are to remain confidential.

* I understand the published results will not use my name, and that no opinions will be attributed to me in any way that will identify me.

* I understand that the audio recordings of individual interviews will be electronically wiped at the end of the project unless I indicate that I would like them returned to me.

* I understand that I may withdraw myself from this project (before data collection and analysis is complete) without having to give reasons or without penalty of any sort.

* I understand that ethics approval for this study from Victoria University has been granted.

I agree to participate in the research. I understand that I may withdraw myself from this project without giving reasons.

I agree to keep the identity of the other person in this study confidential and I agree to keep all comments made by them confidential. 
Participant Name: (Please print)

Participant Signature:

Length of time, you have worked with this colleague in the role of manager and direct report

Type of Organisation:

Type of work:

How much contact do you have with this person on an average week?

Any organisational processes to undergo before proceeding?

Preferred pseudonym?:

Email:

Phone:

Research code for the online survey:

Signed:

Date:

Name of Participant: 


\section{Appendix I: Individual Manager Feedback Session (Schedule)}

\section{Session Purpose}

1. Work through survey findings, identifying and exploring the participant's day-to-day communication styles, specific to their work setting.

2. Identify communication styles the participant wishes to develop.

3. Take time to explore skills and identify every-day workplace situations to practice the skills.

\section{Pre-session preparation}

1. Send manager a summary of their survey with a suggested exploratory question.

2. Print copies of the written summary material to have available at the session.

\section{The session structure}

A 60 minute, digitally audio recorded session.

a) Go over the plan for the hour (5 mins).

b) Go over the survey findings - take time to explore any aspects of interest to the participant. Note any observations or queries from the participant (10 mins).

c) Explore the semi-planned question/s (if required) - employee to choose which ones to begin with (15 mins).

d) Identify communication styles the participant wishes to develop (5 mins). Explore skills and identify every-day workplace situations to practice the skills (20 mins).

e) At the end, identify and verbally consent to what of the survey findings will be shared in the dyad; and identify any aspects of the exploratory interview questions they do not want shared in the dyad (5 mins).

Potential questions to facilitate exploration of communication styles and engagement. The specific question to explore will be finalised following the survey analysis but will be very similar to one of the following:

A. Think of a time over the past three months when there was conflict of some kind that you needed to, or wished you could address with this employee.

B. Think of a time over the past three months, when you needed to ask this employee to help you with a workplace issue. For example, an unexpected extra job or a project that had run over time.

C. Think of a time over the past three months, when your employee needed extra support with a workplace issue. For example, an unexpected extra job, a project that had run over time etc,

For each scenario: say a little about the situation; how you approached the situation; and what you thought the outcome was for you in terms of how engaged you were about your work and with your organisation.

The interview method will be guided by the principles of in-depth research semi-structured interviews (Kvale, 1996) and "person-centred coaching psychology" (Joseph, 2006). To support my research role I will also be receiving weekly coaching psychology supervision from a registered psychologist (who is also bound re a code of ethics which includes confidentiality). These sessions will not include the research content from participants but will be process focused are about my own professional development. 


\section{Appendix J: Individual Employee Feedback Session (Schedule)}

\section{Session Purpose}

1. Work through survey findings, identifying and exploring this participant's day-today communication styles, specific to their work setting.

2. Identify communication styles the participant wishes to develop.

3. Take time to explore skills and identify every-day workplace situations to practice the skills.

\section{Pre-session preparation}

1. Send employee a summary of their survey with a suggested exploratory question.

2. Print copies of the written summary material to have available at the session.

\section{The session structure}

A 60 minute, digitally audio recorded session.

a) Go over the plan for the hour (5 mins).

b) Go over the survey findings - take time to explore any aspects of interest to the participant. Note any observations or queries from the participant (10 mins).

c) Explore the semi-planned question/s (if required) - employee to choose which ones to begin with (15 mins).

d) Identify communication styles the participant wishes to develop (5 mins). Explore skills and identify every-day workplace situations to practice the skills (20 mins).

e) At the end, identify and verbally consent to what of the survey findings will be shared in the dyad; and identify any aspects of the exploratory interview questions they do not want shared in the dyad (5 mins).

Potential questions to facilitate exploration of communication styles and engagement. The specific question to explore will be finalised following the survey analysis but will be very similar to one of the following:

A. Think of a time over the past three months when there was conflict of some kind that you needed to (or wished you could) address with this manager.

B. Think of a time over the past three months, when you needed to ask this manager to help you with a workplace issue. For example, an unexpected extra job or a project that had run over time etc.

C. Think of a time over the past three months, when your manager needed extra support with a workplace issue. For example, an unexpected extra job or a project that had run over time etc.

For each scenario: say a little about the situation; how you approached the situation; and what you thought the outcome was for you in terms of how engaged you were about your work and with your organisation.

The interview method will be guided by the principles of in-depth research semi-structured interviews (Kvale, 1996) and "person-centred coaching psychology" (Joseph, 2006). To support my research role I will also be receiving weekly coaching psychology supervision from a registered psychologist (who is also bound re a code of ethics which includes confidentiality). These sessions will not include the research content from participants but will be process focused are about my own professional development. 


\title{
Appendix K: Case Study Consent Form (part two).
}

\author{
VICTORIA UNIVERSITY OF WELLINGTON \\ Te Whare Wananga o te Upoko o te Ika a Maui
}

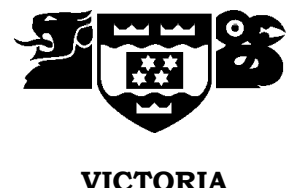

MANAGEMENT SCHOOL

Te Kura Whakahaere

\section{Manager-Employee Engagement Study CASE STUDY PARTICIPANT CONSENT FORM: PART TWO Researcher: Maree Foley}

\section{CONSENT TO PARTICIPATE}

* I have been given and have understood an explanation of this research project. I have had the opportunity to ask any questions related to this study and have received satisfactory answers to my questions.

* I understand that any information I provide will be kept confidential to the researcher, the supervisors and the person who transcribes the audio recordings of my interview.

* I understand that the identity of the other person who is participating with me in this study is to remain confidential.

* I understand that all comments made by the other person who is participating with me in this study are to remain confidential.

* I understand the published results will not use my name, and that no opinions will be attributed to me in any way that will identify me.

* I understand that the audio recordings of the dyad interviews will be electronically wiped at the end of the project.

* I understand that I may withdraw myself from this project (before data collection and analysis is complete) without having to give reasons or without penalty of any sort.

* I understand that ethics approval for this study from Victoria University has been granted.

* I agree to participate in the research. I understand that I may withdraw myself from this project without giving reasons.

I agree to the following ground-rules:

Participant Name: (Please print)

Participant Signature: 


\section{Appendix L: Manager- Employee Dyad Feedback Session (Schedule)}

\section{Manager-Employee dyad feedback session on engagement}

\section{Session Purpose}

1. Work through the agreed information to be shared and explore the participant's day-to-day communication styles with each other, specific to their work setting.

2. Identify communication styles that work best for them within their work context that optimise both the manager's and the employee's performance.

3. Take time to identify every-day workplace situations for the dyad to practice any changes in their communication styles that they may wish to make.

\section{Pre-session preparation}

1. Send employee and manager a summary of their survey and the suggested questions to be asked in the interview.

2. Print copies of the written summary material to have available at the session.

\section{The session structure}

A 60 minute, digitally audio recorded coaching session.

a) Go over the plan for the hour (5 mins).

b) Go over the agreed shared findings - take time to explore any aspects of interest to the participants. (25 mins).

c) Identify communication styles the dyad wishes to develop (5 mins). Explore every-day workplace situations to practice any communication style changes (20 mins).

d) Any closing remarks, confirm time of the next session (5 mins). 


\section{Appendix M: Manager-Employee Dyad Follow-Up Session (optional) (Schedule)}

\section{Manager-employee Dyad Follow Up Session on Engagement}

\section{Session Purpose}

The objective of the interview is to:

1. Hear from participants about how their on-site communication practice has gone.

2. Explore any further questions or queries.

3. Invite reflections on the experience of what it has been like to be part of the programme. If participants are seeking further coaching, the researcher will recommend that they contact the NZ Coaching Psychology Group and enquire about coaching possibilities.

\section{Pre-session preparation}

1. Send employee and manager a summary of their survey and the suggested questions to be asked in the interview.

2. Print copies of the written summary material to have available at the session.

\section{The session structure}

A 60 minute, digitally audio recorded session.

a) Go over the plan for the hour (5 mins).

b) Hear from participants about how their on-site communication practice has gone (15 mins)

c) Explore any further questions or queries (15 mins).

d) Invite reflections on the experience of what it has been like to be part of the programme (20 mins)

- What has it been like to be part of this study?

- What ideas/thoughts do you have about the approach that this study has used as a way to explore communication styles and engagement?

- Were there any aspects of participating that you think have been useful to you and if so, in what ways?

- Were there any aspects of participating that you think have been unhelpful to you and if so, in what ways?

- What do you think the benefits, and or challenges have been of meeting as dyad?

- If you were to summarise briefly your experience of participating what might you say?

e) Close with thank-you's and talk about the summary they will receive. Also if participants are seeking further coaching, either or both participants can contact the researcher who will recommend that they contact the NZ Coaching Psychology Group and enquire about coaching possibilities (5 mins). 
Appendix N: Manager Initial Factor Analysis with 42 Items

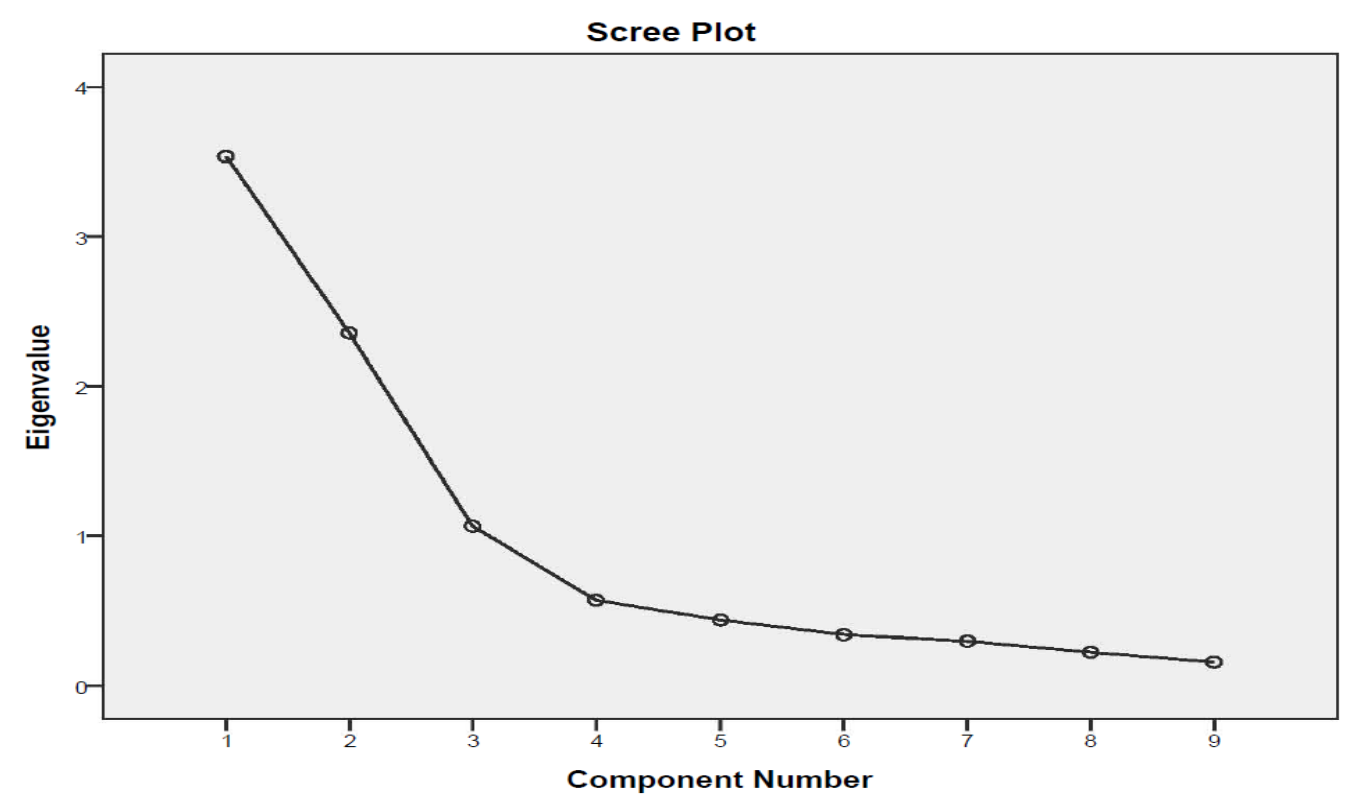

Manager 42 Item Scree plot 
Manager 42 Item Component Matrix ${ }^{\mathrm{a}}$

\begin{tabular}{|c|c|c|c|}
\hline & \multicolumn{3}{|c|}{ Components } \\
\hline & SESI & SECA & $S E D A$ \\
\hline 11SESI & .774 & & \\
\hline 11SECA & -.764 & & \\
\hline 7 SECA & -.721 & & \\
\hline 7 SESI & .692 & & \\
\hline 14 SESI & .677 & & \\
\hline 12 SESI & .657 & & \\
\hline $12 S E C A$ & -.642 & & \\
\hline $2 S$ SECA & -.621 & & \\
\hline 14 SEDA & .606 & & \\
\hline 8 SESI & .583 & & \\
\hline 14 SECA & -.541 & & \\
\hline 2 SESI & .536 & & \\
\hline 4 SESI & .487 & .372 & \\
\hline $12 S E D A$ & .470 & & \\
\hline $5 S E C A$ & -.468 & & \\
\hline 8 SECA & -.390 & & -.321 \\
\hline $10 S E C A$ & -.380 & & \\
\hline 9 SECA & -.334 & & \\
\hline 3 SESI & & .678 & \\
\hline 3 SECA & & -.650 & \\
\hline $1 S E C A$ & & .608 & \\
\hline 1 SESI & & .605 & \\
\hline 3 SEDA & & -.592 & \\
\hline 10 SESI & & .529 & \\
\hline 6 SESI & & .527 & \\
\hline 6 SEDA & & -.457 & \\
\hline 5 SESI & & .442 & \\
\hline 6 SECA & -.321 & .421 & \\
\hline 9 SESI & & .420 & \\
\hline $13 S E C A$ & & .367 & \\
\hline 13 SESI & & -.320 & \\
\hline $7 S E D A$ & & & .703 \\
\hline $2 S E D A$ & & & .637 \\
\hline 9 SEDA & & & .572 \\
\hline $1 S E D A$ & & & .535 \\
\hline 10 SEDA & & & .503 \\
\hline 5 SEDA & & & .500 \\
\hline 8 SEDA & .336 & & .463 \\
\hline 11 SEDA & & & .460 \\
\hline 4 SEDA & & & .440 \\
\hline 4 SECA & & & -.397 \\
\hline 13 SEDA & & & .397 \\
\hline
\end{tabular}

Extraction Methods: Principal Components Analysis.

a. 3 components extracted. 
Appendix O: Employee Initial Factor Analysis with 42 Items

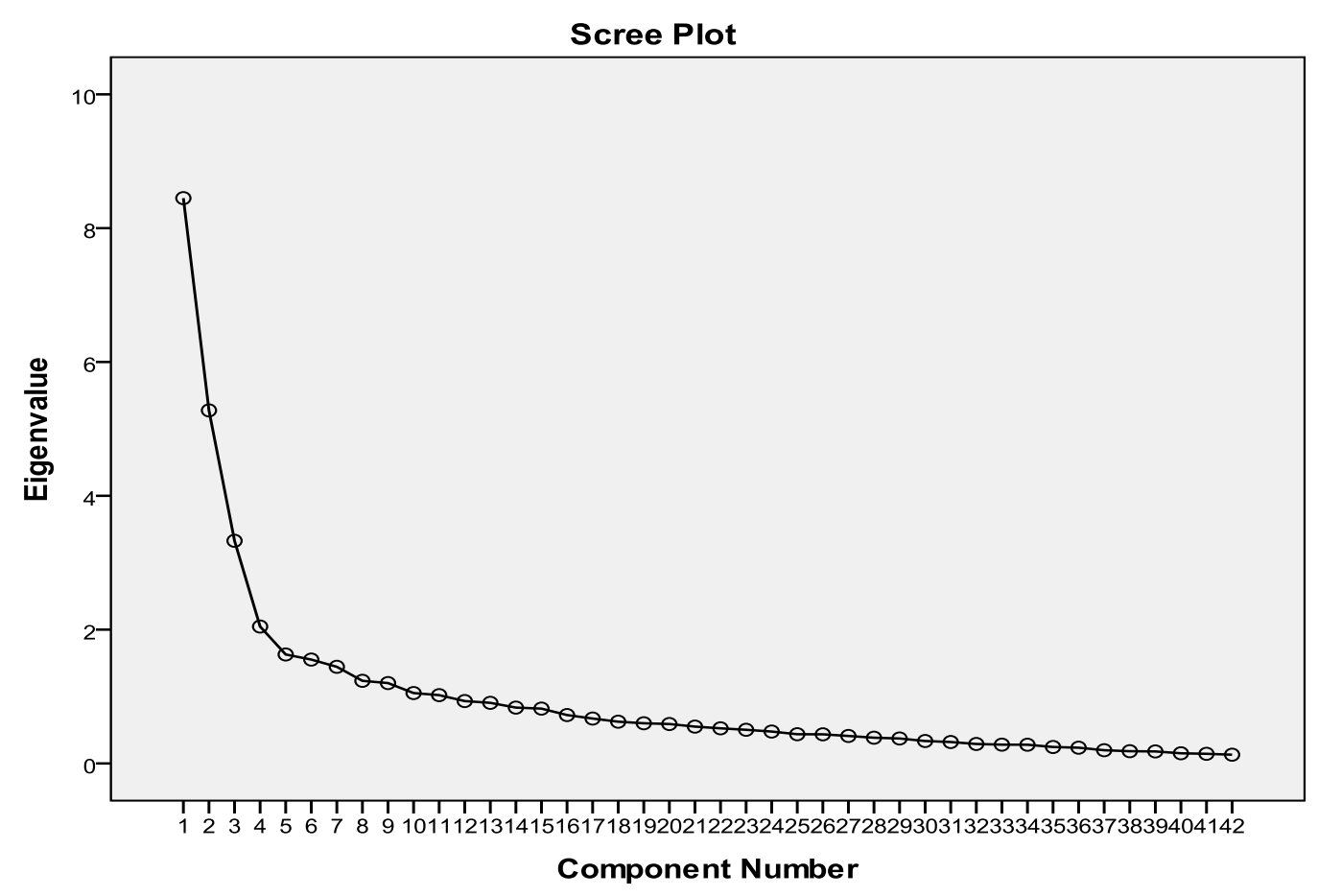


Employee Component Matrix ${ }^{a}$

\begin{tabular}{|c|c|c|c|c|c|c|}
\hline \multirow{2}{*}{ ITEM } & \multicolumn{6}{|c|}{ Component } \\
\hline & SECA & SESI & $\begin{array}{l}\text { SEDA } \\
\end{array}$ & SECA & SEDA & SESI \\
\hline 11 SECA & .778 & & & & & \\
\hline 6 SECA & .747 & & & & & \\
\hline 2 SECA & .709 & & & & & \\
\hline 14 SECA & .682 & & & & & \\
\hline 14 SESI & -.667 & & & & & \\
\hline 1 SESI & -.665 & & & & & \\
\hline 6 SESI & -.665 & & & & & \\
\hline 11 SESI & -.663 & & & & & \\
\hline 5 SECA & .647 & & & & & \\
\hline 12 SECA & .645 & & & & & \\
\hline 10 SECA & .628 & & & & & \\
\hline 14 SEDA & -.566 & & & & & \\
\hline 7 SECA & .546 & & & & & \\
\hline 1 SECA & .539 & & & & & \\
\hline 12 SESI & -.517 & .443 & & & & \\
\hline 8 SESI & -.502 & .379 & & & & .455 \\
\hline 9 SECA & .483 & & -.365 & .322 & & \\
\hline 8 SECA & .463 & & -.425 & .440 & & \\
\hline 4 SESI & -.453 & .378 & & & & .413 \\
\hline 13 SECA & .396 & & & .330 & & \\
\hline 10 SECA & & 688 & & & & \\
\hline 3 SESI & & .620 & & & & \\
\hline 5 SESI & -.313 & .600 & & & & \\
\hline 7 SESI & & .591 & & & & \\
\hline 13 SESI & & .585 & & & & \\
\hline 5 SEDA & & -.571 & & & & \\
\hline 1 SESI & & .563 & & & & \\
\hline 7 SEDA & & -.562 & & & & \\
\hline 3 SEDA & -.323 & -.544 & & & .412 & \\
\hline 10 SEDA & & -.513 & & & & \\
\hline 3 SECA & .375 & .511 & & & .313 & \\
\hline 9 SESI & & .405 & & & & .339 \\
\hline 9 SEDA & & -.339 & .583 & & .332 & \\
\hline 6 SEDA & & & .577 & 421 & & \\
\hline 8 SEDA & & & .537 & & & \\
\hline 4 SEDA & & & .527 & & & \\
\hline 12 SEDA & & & .455 & & & \\
\hline 1 SEDA & & & . 448 & & & \\
\hline 13 SEDA & & -.360 & .442 & & & \\
\hline 4 SECA & .402 & & -.310 & .531 & & \\
\hline 2 SEDA & & & .494 & .512 & -.341 & \\
\hline 11 SEDA & & & . 366 & .394 & & \\
\hline
\end{tabular}

Extraction Method: Principal Components Analysis.

a. 6 components extracted. 


\section{Appendix P: Manager Scree Plots and Pattern Matrix (SESI and SEDA)}

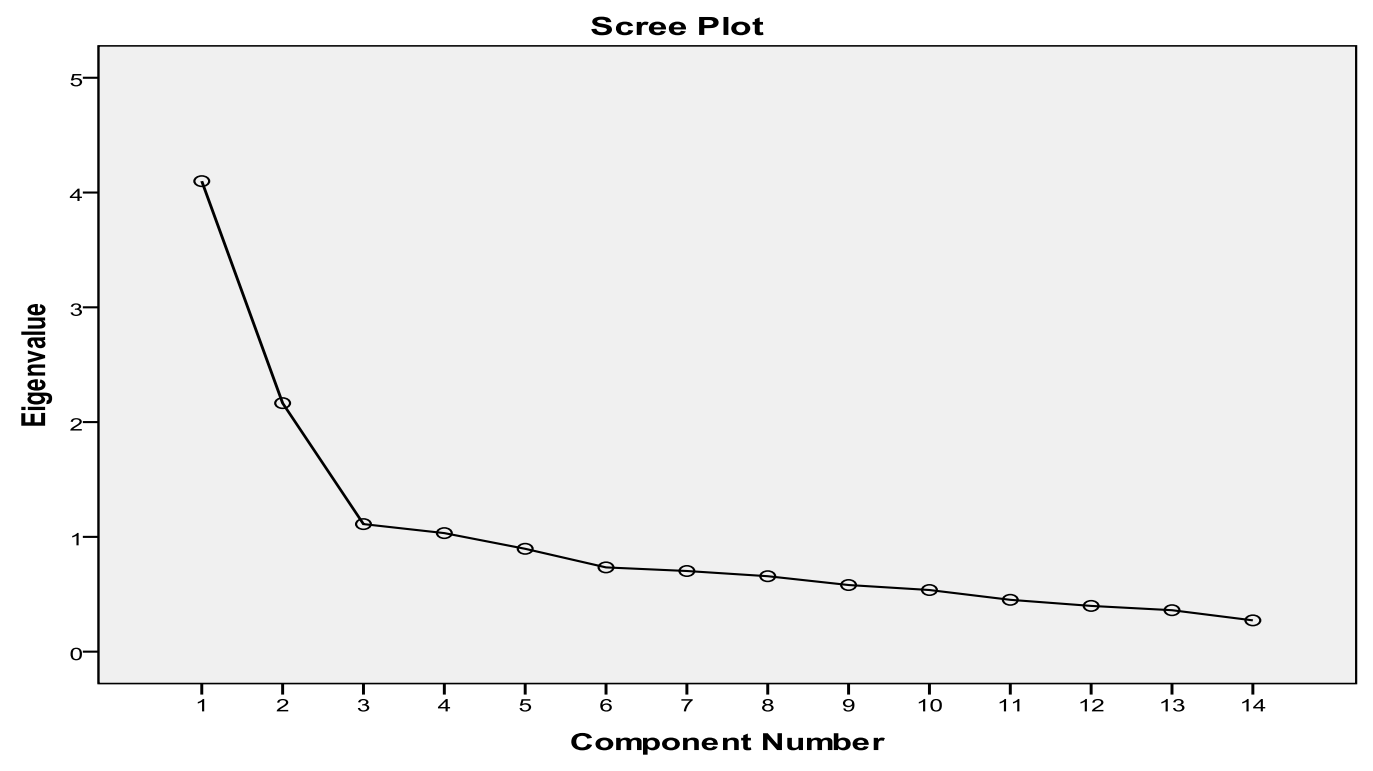

Manager SESI Scree Plot

Manager SESI Pattern Matrix

\begin{tabular}{lccc}
\hline \multicolumn{1}{c}{ Manager MESE Items } & \multicolumn{3}{c}{ Stress-immobilise (SESI) } \\
& $\begin{array}{c}1 \\
\text { Conflict }\end{array}$ & & Support \\
\hline Q1: Secure base seeking & .028 & $\mathbf{. 6 7 7}$ \\
Q2: Support received & $\mathbf{. 6 5 1}$ & -.153 \\
Q3: Support seeking frequency & .018 & $\mathbf{. 6 4 2}$ \\
Q4: Conflict response & $\mathbf{. 4 9 0}$ & .392 \\
Q5: Support to others & .332 & .408 \\
Q6: Support seeking behaviour & -.193 & $\mathbf{. 6 8 8}$ \\
Q7: Expected support & $\mathbf{. 7 7 5}$ & -.103 \\
Q8: Preferred conflict response & $\mathbf{. 5 9 5}$ & .281 \\
Q9: Support to others & .172 & $\mathbf{. 5 2 2}$ \\
Q10: Support organisation & .234 & $\mathbf{. 5 1 3}$ \\
Q11: Organisation response & $\mathbf{. 8 5 0}$ & -.103 \\
Q12: Doing the job & $\mathbf{. 7 0 8}$ & .066 \\
Q13: Stress behaviour & -.261 & .408 \\
Q14: Goal sharing & $\mathbf{. 6 6 2}$ & .057
\end{tabular}

Notes: Extraction method: PCA. Rotation method: Oblimin with kaiser normalization Rotation converged in 8 iterations. Major loadings are bolded 


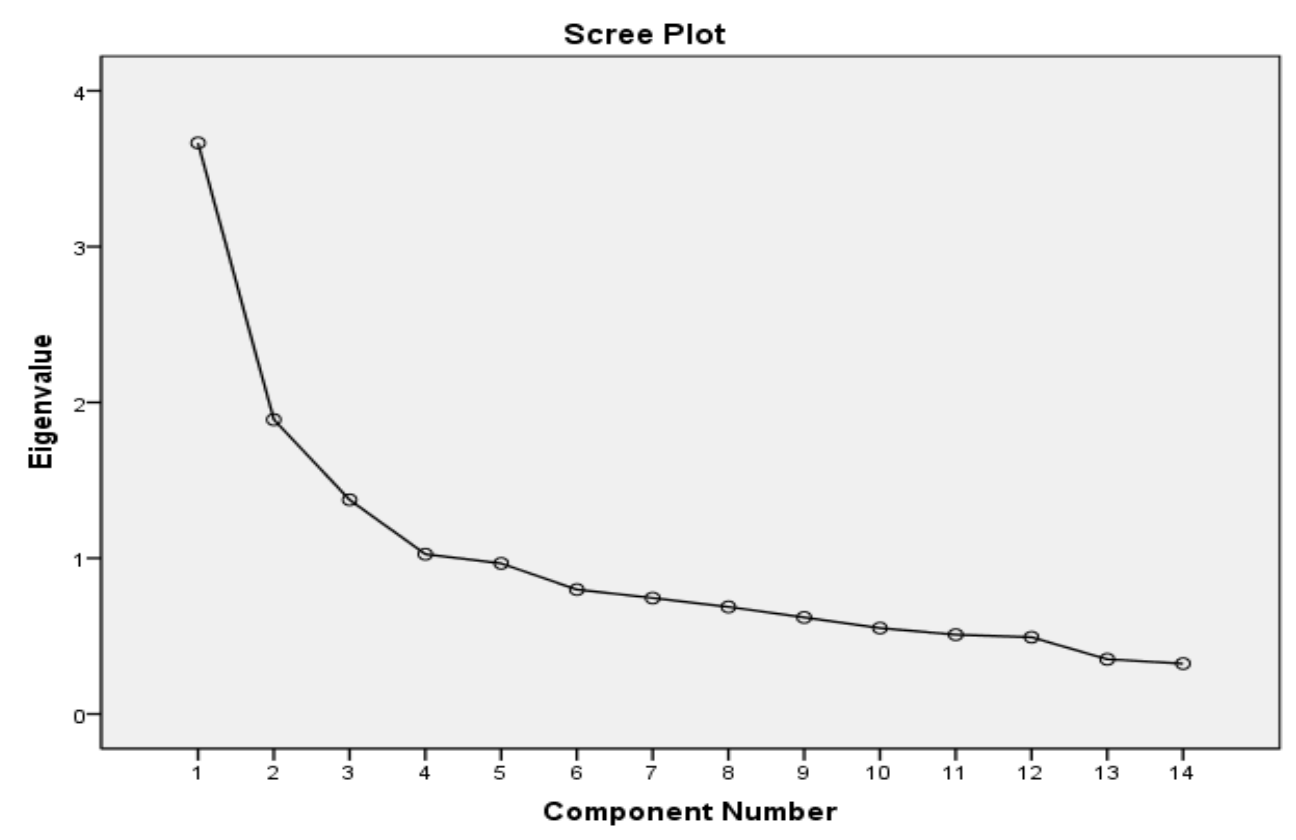

Manager SEDA Scree Plot

Manager SEDA Pattern Matrix

\begin{tabular}{|c|c|c|c|}
\hline & \multicolumn{3}{|c|}{ Disconnect-act (SEDA) } \\
\hline & $\begin{array}{c}1 \\
\text { Disconnection }\end{array}$ & $\begin{array}{c}2 \\
\text { Support }\end{array}$ & $\begin{array}{c}3 \\
\text { Conflict }\end{array}$ \\
\hline Q1: Secure base seeking & .088 & -.830 & .201 \\
\hline Q2: Support received & -.046 & -.867 & .048 \\
\hline Q3: Support seeking frequency & .664 & .246 & -.018 \\
\hline Q4: Conflict response & -.083 & .061 & -.802 \\
\hline Q5: Support to others & .020 & -.374 & -.417 \\
\hline Q6: Support seeking behaviour & .628 & -.039 & .120 \\
\hline Q7: Expected support & -.189 & -.674 & -.304 \\
\hline Q8: Preferred conflict response & .233 & .089 & -.595 \\
\hline Q9: Support to others & .010 & -.001 & -.851 \\
\hline Q10: Support organisation & .424 & -.357 & -.109 \\
\hline Q11: Organisation response & .436 & -.324 & -.092 \\
\hline Q12: Doing the job & .641 & -.036 & -.069 \\
\hline Q13: Stress behaviour & .370 & -.220 & -.184 \\
\hline Q14: Goal sharing & .604 & .080 & -.032 \\
\hline
\end{tabular}

Notes: Extraction Method:PCA. Rotation Method: Oblimin with Kaiser normaliSation. erged in 11 iterations. Major loadings for each item are bolded. 


\section{Appendix Q: Employee Scree Plots and Pattern Matrix (SESI and SEDA)}

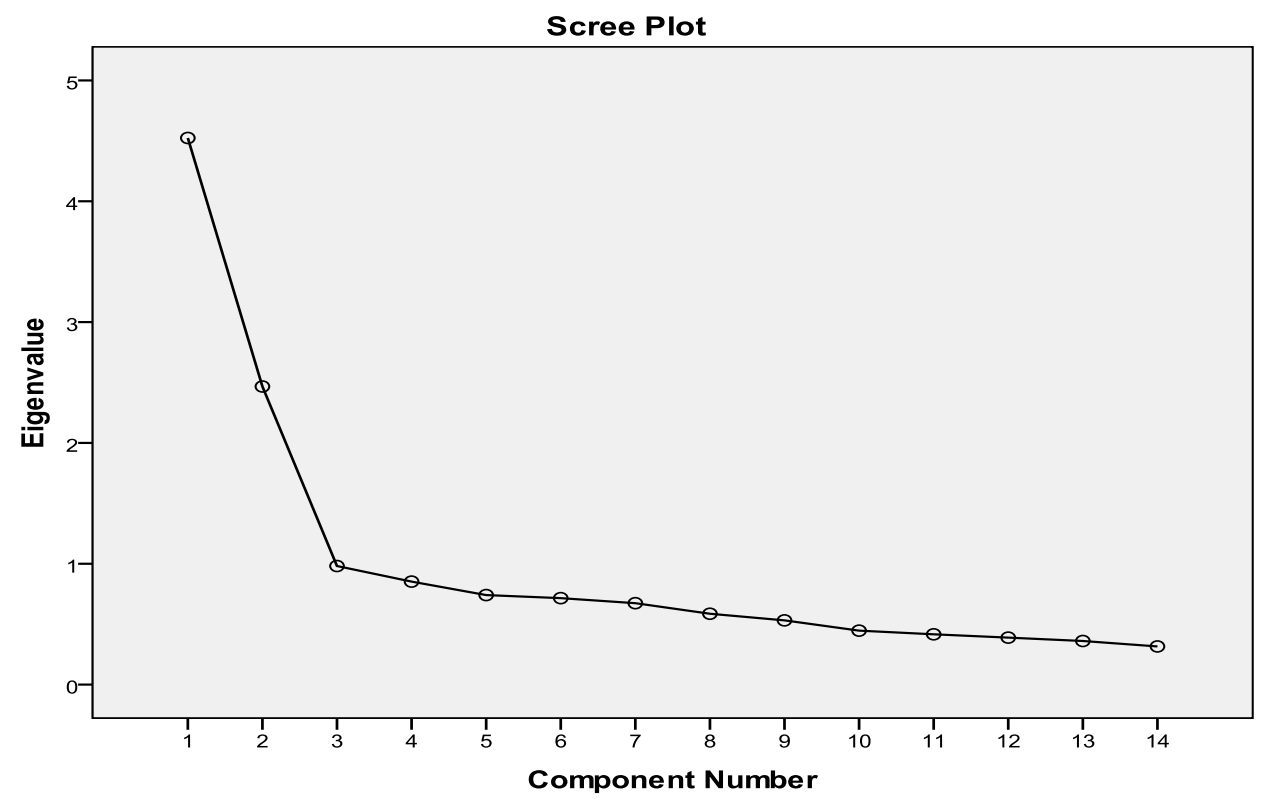

Employee SESI Scree Plot

Employee SESI Pattern Matrix

\begin{tabular}{lcc}
\hline \multicolumn{1}{c}{ Employee MESE Items } & \multicolumn{2}{c}{ Stress-immobilise (SESI) } \\
& Conflict & \multicolumn{2}{c}{ Support } \\
\hline Q1: Secure base seeking & .267 & $\mathbf{7 1 0}$ \\
Q2: Support received & $\mathbf{. 7 6 6}$ & -.209 \\
Q3: Support seeking frequency & .124 & $\mathbf{. 6 6 3}$ \\
Q4: Conflict response & $\mathbf{. 5 9 6}$ & .272 \\
Q5: Support to others & .400 & $\mathbf{. 5 2 5}$ \\
Q6: Expected support & -190 & $\mathbf{7 4 8}$ \\
Q7: Support seeking behaviour & $\mathbf{. 7 5 1}$ & -.202 \\
Q8: Preferred conflict response & $\mathbf{. 5 7 3}$ & .320 \\
Q9: Support to others & .127 & .433 \\
Q10: Support organisation & .261 & $\mathbf{. 6 7 2}$ \\
Q11: Organisation response & $\mathbf{. 7 5 2}$ & -.040 \\
Q12: Doing the job & $\mathbf{. 5 8 8}$ & .335 \\
Q13: Stress behaviour & .310 & $\mathbf{. 5 2 7}$ \\
Q14: Goal sharing & $\mathbf{. 7 6 5}$ & -.056 \\
Extraction Method: Principal Component Analysis. Rotation Method: Oblimin with Kaiser \\
Normalisation. Rotation occurred in 12 iterations. Major loadings for each item are bolded
\end{tabular}




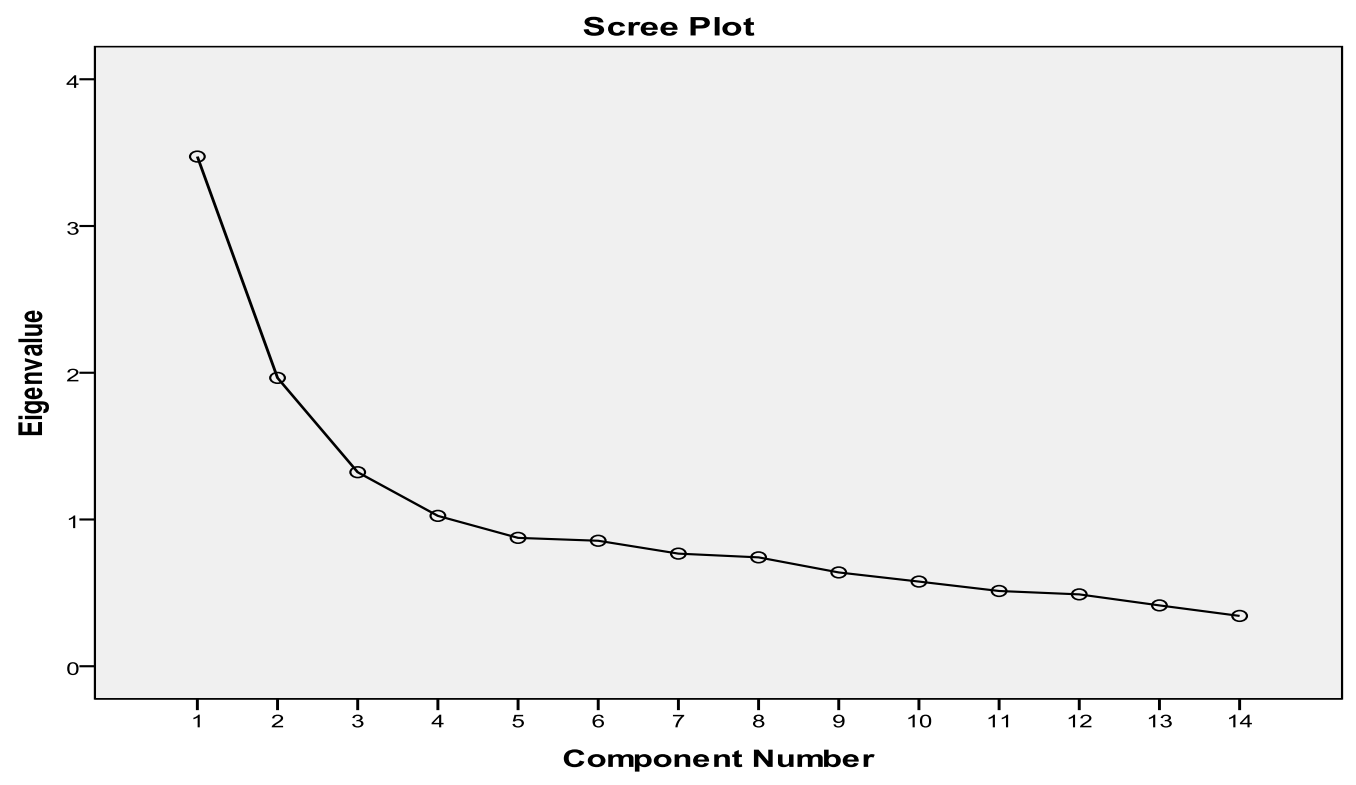

Employee SEDA Scree Plot

Employee SEDA Pattern matrix

\begin{tabular}{|c|c|c|}
\hline \multirow[b]{2}{*}{ Employee MESE Items } & \multicolumn{2}{|c|}{ Disconnect-act (SEDA) } \\
\hline & $\begin{array}{c}1 \\
\text { Disconnection }\end{array}$ & $\begin{array}{c}2 \\
\text { Support }\end{array}$ \\
\hline Q1: Secure base seeking & -.108 & .661 \\
\hline Q2: Support received & -.051 & .815 \\
\hline Q3: Support seeking frequency & .490 & -.250 \\
\hline Q4: Conflict response & .466 & .351 \\
\hline Q5: Support to others & .659 & -.031 \\
\hline Q6: Expected support & .646 & -.030 \\
\hline Q7: Support seeking behaviour & .040 & .777 \\
\hline Q8: Preferred conflict response & .532 & .167 \\
\hline Q9: Support to others & .573 & .267 \\
\hline Q10: Support organisation & .681 & -.048 \\
\hline Q11: Organisation response & .314 & .353 \\
\hline Q12: Doing the job & .555 & .007 \\
\hline Q13: Stress behaviour & .587 & .041 \\
\hline Q14: Goal sharing & .317 & -.135 \\
\hline
\end{tabular}




\section{Appendix R: Manager and Employee MESE Component Correlations}

\begin{tabular}{|c|c|c|c|c|c|c|c|c|c|c|}
\hline \multicolumn{11}{|c|}{ Employee MESE Correlations } \\
\hline MESE Variables & SESI & $\begin{array}{c}\text { SESI- } \\
\text { Conflict }\end{array}$ & $\begin{array}{l}\text { SESI- } \\
\text { Support }\end{array}$ & SECA & $\begin{array}{c}\text { SECA } \\
\text { Support } \\
\text { received }\end{array}$ & $\begin{array}{c}\text { SECA } \\
\text { Connecti } \\
\text { on }\end{array}$ & $\begin{array}{c}\text { SECA } \\
\text { Secure base } \\
\text { use }\end{array}$ & SEDA & $\begin{array}{c}\text { SEDA- } \\
\text { Disconnecti } \\
\text { on }\end{array}$ & $\begin{array}{l}\text { SEDA- } \\
\text { Conflict }\end{array}$ \\
\hline SESI & 1 & $.96 * *$ & $.71 * *$ & $-.61 * *$ & $-.67^{* *}$ & $-.39^{* *}$ & $-.32^{* *}$ & $-.16 *$ & .01 & -.12 \\
\hline $\begin{array}{l}\text { SESI } \\
\text { Conflict }\end{array}$ & $.96 * *$ & 1 & $.50 * *$ & $-.66^{* *}$ & $-.72^{* *}$ & $-.37^{* *}$ & $-.42^{* *}$ & -.10 & .13 & $-.22^{* *}$ \\
\hline $\begin{array}{l}\text { SESI } \\
\text { Support }\end{array}$ & $.71 * *$ & $.50 * *$ & 1 & $-.23^{* *}$ & $-.27^{* * *}$ & $-.31^{* *}$ & .06 & $-.26^{* *}$ & $-.27^{* *}$ & .13 \\
\hline SECA & $-.615^{* *}$ & $-.66^{* *}$ & $-.23^{* *}$ & 1 & $.90 * *$ & $.65 * *$ & $.83 * *$ & -.12 & $-.33^{* *}$ & $.18^{*}$ \\
\hline $\begin{array}{l}\text { SECA- } \\
\text { Support } \\
\text { received }\end{array}$ & $-.67^{* *}$ & $-.72^{* *}$ & $-.27^{* *}$ & $.90 * *$ & 1 & $.39 * *$ & $.59 * *$ & -.04 & $-.28^{* *}$ & $.18^{*}$ \\
\hline $\begin{array}{l}\text { SECA- } \\
\text { Connection }\end{array}$ & $-.39^{* *}$ & $-.37^{* * *}$ & $-.31^{* *}$ & $.65 * *$ & $.39 * *$ & 1 & $.36 * *$ & -.15 & $-.21^{* *}$ & -.04 \\
\hline $\begin{array}{l}\text { SECA-Secure } \\
\text { base use }\end{array}$ & $-.32^{* *}$ & $-.42^{* * *}$ & .06 & $.83 * *$ & $.59 * *$ & $.36 * *$ & 1 & -.12 & $-.32^{* *}$ & $.27^{* *}$ \\
\hline SEDA & $-.16^{*}$ & -.10 & $-.26^{* *}$ & -.12 & -.04 & -.15 & -.12 & 1 & $.85 * *$ & $.57 * *$ \\
\hline $\begin{array}{l}\text { SEDA- } \\
\text { Disconnection }\end{array}$ & .01 & .13 & $-.27^{* *}$ & $-.33^{* *}$ & $-.28^{* *}$ & $-.21^{* * *}$ & $-.32^{* *}$ & $.85 * *$ & 1 & .14 \\
\hline $\begin{array}{l}\text { SEDA- } \\
\text { Support }\end{array}$ & -.12 & $-.22^{* * *}$ & .13 & $.18^{*}$ & $.18^{*}$ & -.04 & $.27^{* *}$ & $.57 * *$ & .14 & 1 \\
\hline
\end{tabular}




\begin{tabular}{|c|c|c|c|c|c|c|c|c|c|c|c|}
\hline \multicolumn{12}{|c|}{ Manager MESE Correlations } \\
\hline $\begin{array}{c}\text { MESE } \\
\text { Variables }\end{array}$ & SESI & $\begin{array}{c}\text { SESI- } \\
\text { Conflict }\end{array}$ & $\begin{array}{c}\text { SESI- } \\
\text { Support }\end{array}$ & SECA & $\begin{array}{c}\text { SECA } \\
\text { Support } \\
\text { received }\end{array}$ & $\begin{array}{c}\text { SECA } \\
\text { Connectio } \\
\mathrm{n}\end{array}$ & $\begin{array}{c}\text { SECA } \\
\text { Secure } \\
\text { base use }\end{array}$ & SEDA & $\begin{array}{c}\text { SEDA- } \\
\text { Disconnectio } \\
n\end{array}$ & $\begin{array}{l}\text { SEDA- } \\
\text { Support }\end{array}$ & $\begin{array}{c}\text { SEDA } \\
\text { Conflict }\end{array}$ \\
\hline SESI & 1 & $.91 * *$ & $.74 * *$ & $-.28 * *$ & $-.53 * *$ & $-.17^{*}$ & .04 & .13 & $.27^{* *}$ & -.07 & .06 \\
\hline $\begin{array}{l}\text { SESI } \\
\text { Conflict }\end{array}$ & $.91 * *$ & 1 & $.39 * *$ & $-.49^{* * *}$ & $-.73^{* *}$ & $-.21^{* *}$ & -.14 & .11 & $.30^{* *}$ & $-.17^{*}$ & .08 \\
\hline $\begin{array}{l}\text { SESI } \\
\text { Support }\end{array}$ & $.74 * *$ & $.39 * *$ & 1 & .13 & -.01 & -.04 & $.30^{* *}$ & .10 & .10 & .12 & .03 \\
\hline SECA & $-.28^{* *}$ & $-.49^{* *}$ & .13 & 1 & $.75^{* *}$ & $.69 * *$ & $.77 * *$ & $-.23^{* *}$ & $-.34^{* *}$ & .08 & $-.25^{* *}$ \\
\hline $\begin{array}{l}\text { SECA } \\
\text { Support } \\
\text { Received }\end{array}$ & $-.53^{* *}$ & $-.73^{* *}$ & -.01 & $.75^{* *}$ & 1 & $.27 * *$ & $.39 * *$ & -.06 & $-.28^{* *}$ & $.25^{* *}$ & -.09 \\
\hline $\begin{array}{l}\text { SECA } \\
\text { Connection }\end{array}$ & $-.17^{*}$ & $-.21^{* *}$ & -.04 & $.69 * *$ & $.27 * *$ & 1 & $.35 * *$ & $-.32^{* *}$ & $-.25^{* *}$ & $-.15^{*}$ & $-.26^{* *}$ \\
\hline $\begin{array}{l}\text { SECA } \\
\text { Secure base } \\
\text { use }\end{array}$ & .04 & -.14 & $.30^{* *}$ & $.77 * *$ & $.39 * *$ & $.35 * *$ & 1 & -.12 & $-.18^{*}$ & .06 & $-.16^{*}$ \\
\hline SEDA & .13 & .11 & .10 & $-.23 * *$ & -.06 & $-.32^{* *}$ & -.12 & 1 & $.80 * *$ & $.71 * *$ & $.78 * *$ \\
\hline $\begin{array}{l}\text { SEDA } \\
\text { Disconnectio } \\
\mathrm{n}\end{array}$ & $.26^{* *}$ & $.30^{* *}$ & .10 & $-.34^{* * *}$ & $-.28^{* *}$ & $-.25^{* *}$ & $-.18^{*}$ & $.80 * *$ & 1 & $.35 * *$ & $.47 * *$ \\
\hline $\begin{array}{l}\text { SEDA } \\
\text { Support }\end{array}$ & -.07 & $-.17^{*}$ & .12 & .08 & $.25^{* *}$ & $-.15^{*}$ & .06 & $.71 * *$ & $.35 * *$ & 1 & $.29 * *$ \\
\hline $\begin{array}{l}\text { SEDA } \\
\text { Conflict }\end{array}$ & .06 & .08 & .03 & $-.25^{* *}$ & -.09 & $-.26^{* *}$ & $-.16^{*}$ & $.78 * *$ & $.47 * *$ & $.29 * *$ & 1 \\
\hline
\end{tabular}




\section{Appendix S: Manager and Employee MESE components and Variables of Interest Correlations: Zero order Tables}

Table I

Manager SECA and POS, PSS

\begin{tabular}{|c|c|c|c|c|c|c|c|c|}
\hline Variable & M & SD & POS & PSS & SECA & SECA-Support & SECA-Connection & SECA-Secure base \\
\hline POS & 3.99 & 0.36 & $(.75)$ & & & & & \\
\hline PSS & 3.96 & 0.32 & $.44 * * *$ & $(.84)$ & & & & \\
\hline SECA & 3.25 & 0.42 & $-.16^{*}$ & -.12 & $(.80)$ & & & \\
\hline SECA-Support & 3.84 & 0.69 & $-.16^{*}$ & -.13 & $.75 * * *$ & $(.81)$ & & \\
\hline SECA-Connection & 4.05 & 0.59 & -.11 & .003 & $.69 * * *$ & $.27 * * *$ & $(.75)$ & \\
\hline SECA-Secure base use & 3.46 & 0.71 & -.05 & -.02 & $.77 * * *$ & $.39 * * *$ & $.35 * * *$ & $(.55)$ \\
\hline
\end{tabular}

Notes. $* p<0.05 ; * * p<0.01 ; * * * P<0.001$; and reliabilities are in parentheses.

Table II

Manager SECA and JE, OE, OC, ItQT

\begin{tabular}{|c|c|c|c|c|c|c|c|c|c|c|}
\hline Variable & M & SD & $\mathrm{JE}$ & $\mathrm{OE}$ & $\mathrm{OC}$ & ItQT & SECA & $\begin{array}{l}\text { SECA- } \\
\text { Support }\end{array}$ & $\begin{array}{c}\text { SECA- } \\
\text { Connection }\end{array}$ & $\begin{array}{c}\text { SECA-Secure } \\
\text { base use }\end{array}$ \\
\hline $\mathrm{JE}$ & 3.89 & 0.62 & $(.81)$ & & & & & & & \\
\hline $\mathrm{OE}$ & 3.824 & 0.72 & $.54 * * *$ & $(.83)$ & & & & & & \\
\hline $\mathrm{OC}$ & 2.64 & 0.35 & $.29 * * *$ & $.64 * * *$ & $(.73)$ & & & & & \\
\hline ItQT & 2.25 & 1.12 & $-.26 * * *$ & $-.58 * * *$ & $-.55 * * *$ & $(.87)$ & & & & \\
\hline SECA & 3.25 & 0.42 & $.23 * *$ & $.34 * * *$ & $.37 * * *$ & $-.44 * * *$ & $(.80)$ & & & \\
\hline SECA-Support & 3.84 & 0.69 & $.19 *$ & $.47 * * *$ & $.54 * * *$ & $-.63 * * *$ & $.75 * * *$ & $(\quad .81)$ & & \\
\hline SECA-Connection & 4.05 & 0.59 & $.21 * *$ & $.16^{*}$ & $.16^{*}$ & $-.17 *$ & $.69 * * *$ & $.27 * * *$ & $(\quad .75)$ & \\
\hline SECA-Secure base & 3.46 & 0.71 & .10 & .13 & .12 & $-.17 *$ & $.77 * * *$ & $.39 * * *$ & $.35 * * *$ & $(.55)$ \\
\hline
\end{tabular}

Notes. $* p<0.05 ; * * p<0.01 ; * * * P<0.001$; and reliabilities are in parentheses. 
Table III

Manager SEDA and POS, PSS

\begin{tabular}{|c|c|c|c|c|c|c|c|c|}
\hline Variable & M & SD & POS & PSS & SEDA & $\begin{array}{c}\text { SEDA- } \\
\text { Disconnection }\end{array}$ & $\begin{array}{c}\text { SEDA } \\
\text { Support }\end{array}$ & $\begin{array}{c}\text { SEDA } \\
\text { Conflict }\end{array}$ \\
\hline POS & 3.99 & 0.36 & $(.75)$ & & & & & \\
\hline PSS & 3.96 & 0.32 & $.44 * * *$ & $(.84)$ & & & & \\
\hline SEDA & 3.46 & 0.55 & $.18 *$ & .06 & $(.78)$ & & & \\
\hline SEDA Disconnection & 3.33 & 0.67 & $.14 *$ & .07 & $.80 * * *$ & $(.60)$ & & \\
\hline SEDA-Support & 3.54 & 0.82 & .09 & -.03 & $.71 * * *$ & $.35 * * *$ & $(.75)$ & \\
\hline SEDA-Conflict & 3.57 & 0.69 & .14 & .05 & $.78 * * *$ & $.47 * * *$ & $.29 * * *$ & $(.68)$ \\
\hline
\end{tabular}

Notes. $* p<0.05 ; * * p<0.01 ; * * * P<0.001$; and reliabilities are in parentheses. 
Table IV

Manager SEDA and JE, OE, OC, ItQT

\begin{tabular}{|c|c|c|c|c|c|c|c|c|c|c|}
\hline Variable & M & SD & JE & $\mathrm{OE}$ & $\mathrm{OC}$ & ITQT & SEDA & $\begin{array}{c}\text { SEDA } \\
\text { Disconnection }\end{array}$ & $\begin{array}{l}\text { SEDA } \\
\text { Support }\end{array}$ & $\begin{array}{l}\text { SEDA- } \\
\text { Conflict }\end{array}$ \\
\hline $\mathrm{JE}$ & 3.89 & 0.62 & $(.81)$ & & & & & & & \\
\hline $\mathrm{OE}$ & 3.824 & 0.72 & $.54 * * *$ & $(.83)$ & & & & & & \\
\hline $\mathrm{OC}$ & 2.64 & 0.35 & $.29 * * *$ & $.64 * * *$ & $(.73)$ & & & & & \\
\hline ItQT & 2.25 & 1.12 & $-.26 * * *$ & $-.58 * * *$ & $-.56^{* * *}$ & (.87) & & & & \\
\hline SEDA & 3.46 & 0.55 & -.03 & $-.17 *$ & -.13 & 0.46 & $(.78)$ & & & \\
\hline SEDA-Disconnection & 3.33 & 0.67 & .04 & $-.21 * *$ & $-.19 * *$ & $.16^{*}$ & $.80^{* * *}$ & $(.60)$ & & \\
\hline SEDA Support & 3.54 & 0.82 & $-.15 *$ & -.05 & 0.27 & $-.16^{*}$ & $.71 * * *$ & $.35 * * *$ & $(.75)$ & \\
\hline SEDA-Conflict & 3.57 & 0.69 & .06 & -.08 & -.12 & .07 & $.78 * * *$ & $.47 * * *$ & $.29 * * *$ & (.68) \\
\hline
\end{tabular}

Notes. $* \mathrm{p}<0.05 ; * * p<0.01 ; * * * p<0.001 ;$ and reliabilities are in parentheses. 
Table V

Manager SESI and POS, PSS

\begin{tabular}{|c|c|c|c|c|c|c|c|}
\hline Variable & M & SD & POS & PSS & SESI & $\begin{array}{c}\text { SESI } \\
\text { Conflict }\end{array}$ & $\begin{array}{r}\text { SESI } \\
\text { Support }\end{array}$ \\
\hline 1. POS & 3.99 & 0.36 & $(.75)$ & & & & \\
\hline 2. PSS & 3.96 & 0.32 & $.44 * * *$ & $(.84)$ & & & \\
\hline 3. SESI & 2.25 & 0.56 & $.21 * *$ & $.18^{*}$ & $(.80)$ & & \\
\hline 4. SESI-Conflict & 2.10 & 0.69 & $.24 * *$ & $.19 * *$ & $.91 * * *$ & $(.82)$ & \\
\hline 5. SESI-Support & 2.44 & 0.61 & .14 & .08 & $.74 * * *$ & $.39 * * *$ & $(.64)$ \\
\hline
\end{tabular}

Notes. $* p<0.05 ; * *<<0.01 ; * * * p<0.001$; and reliabilities are in parentheses. Statistically it was assumed that SESI and SESI-1 were measuring the same construct.

\section{Table VI}

Manager SESI and JE, OE, OC and ItQT

\begin{tabular}{|c|c|c|c|c|c|c|c|c|c|}
\hline Variable & M & SD & $\mathrm{JE}$ & $\mathrm{OE}$ & $\mathrm{OC}$ & ItQT & SESI & SESI-Conflict & SESI-Support \\
\hline JE & 3.89 & 0.62 & $(.81)$ & & & & & & \\
\hline $\mathrm{OE}$ & 3.824 & 0.72 & $.54 * * *$ & $(.83)$ & & & & & \\
\hline $\mathrm{OC}$ & 2.64 & 0.35 & $.29 * * *$ & $.64 * * *$ & $(.73)$ & & & & \\
\hline ItQT & 2.25 & 1.12 & $-.26 * * *$ & $-.58 * * *$ & $-.55 * * *$ & $(.87)$ & & & \\
\hline SESI & 2.25 & 0.56 & $-.20 * *$ & $-.38 * * *$ & $-.33 * * *$ & $.55 * * *$ & $(.80)$ & & \\
\hline SESI-Conflict & 2.10 & 0.69 & $-.21 * *$ & $-.47 * * *$ & $-.48 * * *$ & $.63 * * *$ & $.91 * * *$ & $(.82)$ & \\
\hline SESI-Support & 2.44 & 0.61 & -.08 & -.08 & .03 & $.21 * *$ & $.74 * * *$ & $.39 * * *$ & $(.64)$ \\
\hline
\end{tabular}

Notes. $* p<0.05 ; * * p<0.01$; *** $p<0.001$; and reliabilities are in parentheses. Statistically it was assumed that SESI and SESI-Conflict were measuring the same construct. 
Table I

Employee SECA and POS, PSS

\begin{tabular}{|c|c|c|c|c|c|c|c|c|}
\hline Variable & M & SD & POS & PSS & SECA & $\begin{array}{l}\text { SECA- } \\
\text { Support }\end{array}$ & $\begin{array}{c}\text { SECA- } \\
\text { Connection }\end{array}$ & $\begin{array}{c}\text { SECA-Secure } \\
\text { base }\end{array}$ \\
\hline POS & 4.06 & 0.41 & $(.50)$ & & & & & \\
\hline PSS & 3.96 & 0.34 & $.48 * * *$ & $(.77)$ & & & & \\
\hline SECA & 3.51 & 0.61 & -.09 & -.09 & $(.88)$ & & & \\
\hline SECA-Support & 3.63 & 0.78 & -.09 & -.08 & $.90 * * *$ & $(.87)$ & & \\
\hline SECA-Connection & 3.78 & 0.64 & -.02 & -.01 & $.65^{* * *}$ & $.39 * * *$ & $(.77)$ & \\
\hline SECA-Secure base use & 3.13 & 0.80 & -.00 & -.01 & $.83 * * *$ & $.59 * * *$ & $.36 * * *$ & $(.73)$ \\
\hline
\end{tabular}

Notes. ${ }^{*} p<0.05 ; * * p<0.01 ; * * * P<0.001$; and reliabilities are in parentheses. 
Table II

Employee SECA and JE, OE, OC ItQT

\begin{tabular}{|c|c|c|c|c|c|c|c|c|c|c|}
\hline Variable & M & SD & $\mathrm{JE}$ & OE & OC & ItQT & SECA & $\begin{array}{l}\text { SECA- } \\
\text { Support }\end{array}$ & $\begin{array}{c}\text { SECA- } \\
\text { Connection }\end{array}$ & $\begin{array}{l}\text { SECA- } \\
\text { Secure } \\
\text { base use }\end{array}$ \\
\hline $\mathrm{JE}$ & 3.69 & 0.70 & $(.77)$ & & & & & & & \\
\hline $\mathrm{OE}$ & 3.32 & 0.82 & $.63 * * *$ & $(.92)$ & & & & & & \\
\hline $\mathrm{OC}$ & 2.58 & 0.46 & $.32 * * *$ & $.67 * * *$ & $(.72)$ & & & & & \\
\hline ItQT & 2.41 & 0.95 & $-.33 * * *$ & $-.41 * * *$ & $-.31 * * *$ & (.64) & & & & \\
\hline SECA & 3.51 & 0.61 & $.28 * * *$ & $.47 * * *$ & $.55 * * *$ & $-.19 *$ & $(.88)$ & & & \\
\hline SECA-Support & 3.63 & 0.78 & $.24 * *$ & $.44 * * *$ & $.61 * * *$ & $-.22 * *$ & $.90 * * *$ & $(.87)$ & & \\
\hline SECA-Connection & 3.78 & 0.64 & $.27 * * *$ & $.29 * * *$ & $.26 * * *$ & -.13 & $.65 * * *$ & $.39 * * *$ & $(.77)$ & \\
\hline SECA-Secure base & 3.13 & 0.80 & $.17 *$ & $.31 * * *$ & $.35 * * *$ & -.11 & $.83 * * *$ & $.59 * * *$ & $.36 * * *$ & $(.73)$ \\
\hline
\end{tabular}

Notes. $* p<0.05 ; * * p<0.01 ; * * * P<0.001$; and reliabilities are in parentheses. 
Table III

Employee SEDA and POS, PSS

\begin{tabular}{|c|c|c|c|c|c|c|c|}
\hline Variable & M & SD & POS & PSS & SEDA & $\begin{array}{c}\text { SEDA- } \\
\text { Disconnection }\end{array}$ & $\begin{array}{l}\text { SEDA } \\
\text { Support }\end{array}$ \\
\hline POS & 4.06 & 0.41 & $(.50)$ & & & & \\
\hline SEDA & 3.60 & 0.51 & .15 & .06 & $(.73)$ & & \\
\hline SEDA Disconnection & 3.52 & 0.57 & $.19 * *$ & .03 & $.85 * * *$ & $(.78)$ & \\
\hline
\end{tabular}

Notes. $* p<0.05$; ** $p<0.01$; *** $P<0.001$; and reliabilities are in parentheses.

Table IV

Employee SEDA and JE, $O E, O C$ and ItQT

\begin{tabular}{|c|c|c|c|c|c|c|c|c|c|}
\hline Variable & M & SD & $\mathrm{JE}$ & $\mathrm{OE}$ & $\mathrm{OC}$ & ItQT & SEDA & $\begin{array}{c}\text { SEDA- } \\
\text { Disconnection }\end{array}$ & $\begin{array}{l}\text { SEDA } \\
\text { Support }\end{array}$ \\
\hline $\mathrm{JE}$ & 3.89 & 0.62 & $(.81)$ & & & & & & \\
\hline $\mathrm{OE}$ & 3.824 & 0.72 & $.63 * * *$ & $(.83)$ & & & & & \\
\hline $\mathrm{OC}$ & 2.64 & 0.35 & $.32 * * *$ & $.67 * * *$ & $(.73)$ & & & & \\
\hline ItQT & 2.25 & 1.12 & $-.33 * * *$ & $-.41 * * *$ & $-.31 * * *$ & (.64) & & & \\
\hline SEDA & 3.60 & 0.51 & -.05 & $-.17 *$ & $-.17 *$ & -.02 & $(.73)$ & & \\
\hline SEDA-Disconnection & 3.52 & 0.57 & -.06 & $-.23 * *$ & $-.26 * *$ & .05 & $.85 * * *$ & $(.78)$ & \\
\hline SEDA-Support & 3.62 & 0.83 & .007 & -.008 & -.05 & -.04 & $.57 * * *$ & .14 & $(.69)$ \\
\hline
\end{tabular}

Notes. $* p<0.05 ; * * p<0.01$; *** $P<0.001$; and reliabilities are in parentheses. 
Table V

Employee SESI and POS, PSS

\begin{tabular}{|c|c|c|c|c|c|c|c|}
\hline Variable & M & SD & POS & PSS & SESI & $\begin{array}{l}\text { SESI- } \\
\text { Conflict }\end{array}$ & SESI-Support \\
\hline POS & 4.06 & 0.41 & $(.50)$ & & & & \\
\hline PSS & 3.96 & 0.34 & $.48 * * *$ & $(.77)$ & & & \\
\hline SESI & 2.11 & 0.67 & $.27 * * *$ & $.24 * *$ & $(.85)$ & & \\
\hline SESI-Conflict & 2.41 & 0.78 & $.28 * * *$ & $.20 * *$ & $.97 * * *$ & $(.84)$ & \\
\hline SESI-Support & 2.11 & 0.68 & .11 & .14 & $.71 * * *$ & $.50 * * *$ & $(.70)$ \\
\hline
\end{tabular}

Notes. $* p<0.05 ; * * p<0.01$; *** $P<0.001$; and reliabilities are in parentheses. Statistically it was assumed that SESI and SESI-Conflict were measuring the same construct.

Table VI

Employee SESI and JE, OE, OC and ItQT

\begin{tabular}{|ccccccccc|}
\hline Variable & M & SD & JE & OE & OC & ItQT & $\begin{array}{c}\text { SESI } \\
\text { SESI- } \\
\text { Conflict } \\
\text { Support }\end{array}$ \\
\hline JE & 3.89 & 0.62 & $(.81)$ & & & & \\
\hline OE & 3.824 & 0.72 & $.63 * * *$ & $(.83)$ & & & \\
\hline OC & 2.64 & 0.35 & $.32 * * *$ & $.67 * * *$ & $(.73)$ & & \\
\hline ItQT & 2.25 & 1.12 & $-.33 * * *$ & $-.41 * * *$ & $-.31 * * *$ & $(.64)$ & $(.85)$ \\
\hline SESI & 2.11 & 0.67 & $\mathbf{- . 2 4 * *}$ & $\mathbf{- . 2 9 * * *}$ & $\mathbf{- . 4 3 * * *}$ & $.25 * *$ & $.95 * * *$ & $(.84)$ \\
\hline SESI-Conflict & 2.41 & 0.78 & $\mathbf{- . 2 2 * *}$ & $\mathbf{- . 3 1 * * *}$ & $\mathbf{- . 4 5 * * *}$ & $.21 * *$ & $.71 * * *$ & $.50 * * *$ \\
\hline SESI-Support & 2.11 & 0.68 & $\mathbf{- . 1 7 *}$ & $\mathbf{- . 0 7}$ & $\mathbf{- . 1 7 *}$ & $.20 * *$ & $(.70)$ \\
\hline
\end{tabular}

Notes. $* p<0.05 ; * * p<0.01 ; * * * P<0.001$; and reliabilities are in parentheses. Statistically it was assumed that SESI and SESI-Conflict were measuring the same construct. 